\title{
Implementation of a Building Sustainability Rating Tool: A Survey of the New Zealand Building Industry
}

Jonathan Smith

February 2008

A thesis submitted to the School of Architecture, Victoria University of Wellington in fulfilment of the requirements for the degree of Master of Building Science. 



\section{Acknowledgements}

Many thanks to the Primary Supervisor of this research project Professor George Baird, who was always available to give valuable feedback and guidance, and to Michael Donn, who as Administrative Supervisor helped secure additional funding for this research.

Acknowledgement to the Building Research Levy who provided financial assistance for this project.

Also acknowledgement to the National Energy Research Institute who provided additional financial assistance for this project.

Thanks also to the New Zealand Green Building Council Chief Executive Officer Jane Henley, who also assisted in securing funding for this project and her continued support and feedback.

Many thanks to those who made this study possible, through their interest willingness to provide helpful information and support. I would especially like to thank those who took the time to participate in the Project Advisory Group: Wayne Sharman from Building Research, Patrick Arnold and Quentin Jackson from eCubed Building Workshop, Chris Wood from the Ministry for the Environment, Michael Warwick from Stephenson and Turner, Peter Thorby from the Department of Building and Housing, Rachel Hargreaves from BRANZ and Michael Field from URS New Zealand.

Also many thanks to the nineteen building industry related organisations which assisted with the distribution of the survey; Concrete and Cement Association of New Zealand, Design Institute of New Zealand, Earth Building Association of New Zealand, Energy Management Association of New Zealand, Illuminating Engineering Society of Australia and New Zealand, Institute of Professional Engineers New Zealand, Institute of Refrigeration Heating and Air Conditioning Engineers of New Zealand, New Zealand Building Industry Subcontractors Federation, New Zealand Green Building Council, New Zealand Institute of Quantity Surveyors, New Zealand Metal Roofing Manufacturers, New Zealand Planning Institute, New Zealand Property Investors Federation, New Zealand Timber Design Society, Property Council of New Zealand, Property Institute of New Zealand, Roofing Association of New Zealand, Registered Master Builders Federation, Window Association of New Zealand. 
I would like to acknowledge the 476 participants of the survey. Without their willing and thorough responses, this study would not have been possible.

Thanks to all my family and friends who provided insightful feedback through the duration of this research.

Finally, I would like to make special acknowledgement of Jen Wittig, whose love, support and feedback made this research possible. 


\section{Preface}

This thesis was submitted as part of the requirements for the degree of Master of Building Science at School of Architecture, Victoria University of Wellington.

Author:

Jonathan Smith

School of Architecture

Victoria University of Wellington

Email: jonathan.ian.smith@gmail.com

Primary Supervisor:

Dr. George Baird

Professor of Building Science

School of Architecture

Victoria University of Wellington

Email: george.baird@vuw.ac.nz 


\section{Table of Contents}

Acknowledgements iii

Preface $\mathbf{v}$

List of Tables xv

List of Figures xix

Abstract 1

1 Introduction 5

1.1 Background __ 5

1.1.1 Current Definitions of Sustainable Development and Sustainability____ 5

1.1.2 The New Zealand Context___ 10

1.1.2.1 The New Zealand Building Industry ___ 15

1.1.2.2 Sustainable Buildings: Identification of a Gap ___ 17

1.1.3 Professional Background to Building Sustainability Rating Tools__ 20

1.1.3.1 Green Building Councils__ 20

1.1.3.2 New Zealand Green Building Council___ 20

1.1.3.3 Building Sustainability Rating Tools__ 21

1.1.3.4 Green Star New Zealand ___ 23

1.1.3.5 Research Background _ 26

1.2 Problem Statement _ 26

1.2.1 Aims and Objectives _ 27

1.3 Methodology Overview __ 28

1.4 Professional Significance ___ 28

1.5 Project Advisory Group and Ethics___ 30

1.6 Key Definitions _ 30

1.7 Organisation of Thesis__ 31

2 Literature Review _ 33

2.1 Overview__ 33

2.1.1 Implementation-Specific Research___ 33

2.1.1.1 Communication__ 35

2.1.1.2 Targets__ 37

2.1.1.3 Marketing __ 38

2.1.1.4 Flexibility and Adaptability of Building Sustainability Rating Tools __ 39

$2.2 \quad$ Non-implementation Specific Research _ 40

2.2.1.1 BSRT Reviews__ 40

2.2.1.2 Environmental Assessment Criteria and Weighting ___ 42 
2.2.1.3 Voluntary or Compulsory Tool __ 45

2.2.1.4 Potential or Actual Performance __ 46

2.2.1.5 Regional Variation __ 47

2.3 Summary _ 48

3 Research Design ___ 51

3.1 The General Method ___ 51

3.1.1 Context and Access _ 51

3.1.2 Sample Frame and Target Population _ـ 52

3.1.3 Sample Selection __ 53

3.1.4 Sample Size _ 55

3.2 Survey Design Limitations ___ 56

3.2.1 Non-response _ 56

3.2.1.1 Techniques to Reduce Non-response Bias__ 56

3.2.1.2 Accounting for Non-response _ 57

3.2.2 Other Sources of Bias _ـ 59

3.3 Survey Instrument _ 59

3.3.1 Web-survey Interface__ 60

3.3.2 Survey Procedure__ 61

3.3.3 Questionnaire Design _ 62

3.3.3.1 Section Classification___ 62

3.3.3.2 Survey Questions__ 64

3.3.3.3 Question Type and Development ___ 64

3.4 Data collection__ 66

3.5 Analyses__ 67

3.6 Summary of Method __ 68

4 Results __ 69

4.1 Statistical Significance __ 69

4.1.1 Total Response __ 69

4.1.2 Confidence Interval and Margin of Error__ 70

4.1.3 Response Rate _ 71

4.1.4 Non-response - t-tests__ 71

4.2 Survey Results _ 73

4.2.1 Section 1: Background __ 73

4.2.1.1 Level of Interest _ 73

4.2.1.2 Level of Involvement__ 78

4.2.1.3 Interest versus Involvement___ 83

4.2.1.4 Discussion___ 84 
4.2.2 Section 2: Building Sustainability Rating Tools

4.2.2.1 Purpose of a Building Sustainability Rating Tool __ 85

4.2.2.2 New Zealand Specific Building Sustainability Rating Tool ___ 86

4.2.2.3 Awareness of Existing Building Sustainability Rating Tools ____ 87

4.2.2.4 Experience with Existing Building Sustainability Rating Tools ____ _ 89

4.2.2.5 Discussion___ 90

4.2.3 Section 3: Green Star New Zealand ___ 91

4.2.3.1 Green Star New Zealand Awareness ___ 91

4.2.3.2 New Zealand Equivalent of Green Star____ 92

4.2.3.3 Green Star New Zealand Influence ___ 94

4.2.3.4 Use of Green Star New Zealand ___ 95

4.2.3.5 Intended Use of Green Star New Zealand ____ 96

4.2.3.6 Green Star New Zealand Training ___ 99

4.2.3.7 Green Star New Zealand Certification ___ 100

4.2.3.8 Reasons for Using Green Star New Zealand __ 100

4.2.3.9 Discussion___ 102

4.2.4 Section 4: The New Zealand Green Building Council ___ 104

4.2.4.1 New Zealand Green Building Council Awareness ___ 104

4.2.4.2 New Zealand Green Building Council Approach___ 104

4.2.4.3 New Zealand Green Building Council Influence ___ 106

4.2.4.4 Discussion__ 107

4.2.5 Section 5: Triggers, Drivers, Obstacles and Reasons for Sustainable Building__ 108

4.2.5.1 Trigger Person of Sustainable Building___ 108

4.2.5.2 Main Driver for Sustainable Building ___ 110

4.2.5.3 Trigger Stage for Sustainable Building ___ 111

4.2.5.4 Drivers for Sustainable Building_________ 112

4.2.5.5 Obstacles for Sustainable Building___ 114

4.2.5.6 Reasons for Involvement in Sustainable Building___ 115

4.2.5.7 Economic Reasons for Sustainable Building ___ 116

4.2.5.8 Environmental Reasons for Sustainable Building___ 117

4.2.5.9 Social Reasons for Sustainable Building ___ 118

4.2.5.10 Discussion____ 119

4.2.6 Section 6: Sustainable Building Information____ 120

4.2.6.1 Sustainable Building Information Requirements___ 120

4.2.6.2 Sustainable Building Information Satisfaction ___ 122

4.2.6.3 Discussion _ 124

4.3 Methodology Issues___ 124 
4.3.1 Random Sample__ 124

4.3.2 Incentives — 125

4.3.3 Survey Design _ 125

4.3.4 Web-Survey Instrument__ 126

5 Comparative Analyses and Results _ 129

5.1 International Comparison _ 129

5.1.1 Trigger Stage for Sustainable Building _ 130

5.1.2 Drivers for Sustainable Building__ 131

5.1.3 Obstacles for Sustainable Building___ 133

5.1.4 Reasons for Involvement in Sustainable Building____ 134

5.1.5 Economic Reasons for Sustainable Building _ 136

5.1.6 Environmental Reasons for Sustainable Building__ 137

5.1.7 Social Reasons for Sustainable Building __ 138

5.1.8 Sustainable Building Information Requirements___ 139

5.2 Discussion __ 141

6 Conclusions and Recommendations __ 143

6.1 Conclusions___ 144

6.1.1 Awareness and Involvement _ 144

6.1.2 Building Sustainability Rating Tools___ 144

6.1.3 Green Star New Zealand ___ 145

6.1.4 The New Zealand Green Building Council ___ 146

6.1.5 Drivers, Triggers, Obstacles and Reasons for Sustainable Building____ 146

6.1.6 Sustainable Building Information___ 147

6.1.7 International Comparison __ 147

6.2 Implications for Future Research__ 148

List of Works Cited ___ 151

Additional References___ 159

Appendix A: Background __ 167

A.1 The Zealand Context___ 167

A.1.1 Annex 1 Parties _ 167

A.1.2 Emission Summaries _ 169

A.1.2.1 New Zealand Emissions __ 169

A.1.2.2 Australia Emissions _ 170

A.1.2.3 United States Emissions___ 171

A.1.2.4 National Emissions per Capita___ 172

A.1.3 Ecological Footprint and Biocapacity___ 174 
A.1.3.1 Ecological Footprint and Biocapacity 2003 174

A.1.3.2 Ecological Footprint and Biocapacity 1999 176

A.1.4 The New Zealand Building Industry ___ 178

A.1.4.1 The New Zealand Energy Market ___ 179

A.1.4.2 Office Building - Twenty Year Present Values _ 180

A.2 Professional Background __ 180

A.2.1 Green Building Councils___ 180

A.2.2 Building Sustainability Rating Tools___ 181

A.2.3 Green Star New Zealand ____ 181

A.2.3.1 Environmental Impact Categories ___ 181

A.2.3.2 Category Score___ 182

A.2.3.3 Weighted Category Score___ 182

A.2.3.4 Single Score ___ 183

A.2.3.5 Ratings___ 184

A.2.3.6 Green Star Certification___ 184

A.2.3.7 Eligibility _ 185

A.2.3.8 Green Star NZ Office Design v1 __ 185

Appendix B: Research Design___ 187

B.1 Sample Frame and Target Population ___ 187

B.1.1 Contacted Building Industry professionals____ 187

B.1.1.1 Conservative Population Estimate ___ 187

B.1.2 Desired Sample Size___ 190

B.2 Questionnaire Design ___ 190

B.2.1 Question List___ 190

B.2.2 Web-survey Questionnaire___ 193

Appendix C: Results ___ 223

C.1 Statistical Significance ___ 223

C.1.1 Actual Margin of Error ___ 223

C.1.2 Non-response ___ 224

C.2 Survey Results __ 238

C.2.1 Background ___ 238

C.2.1.1 Level of Interest ___ 238

C.2.1.2 Level of Involvement___ 242

C.2.1.3 Interest versus Involvement___ 245

C.2.2 Building Sustainability Rating Tools___ 246

C.2.2.1 Purpose of a Building Sustainability Rating Tool ___ 246

C.2.2.2 New Zealand Specific Building Sustainability Rating Tool ___ 247 
C.2.2.3 Awareness of Existing Building Sustainability Rating Tools 248

C.2.2.4 Experience with Existing Building Sustainability Rating Tools 250

C.2.2.5 Existing Accreditation __ 251

C.2.3 Green Star New Zealand __ 252

C.2.3.1 Green Star New Zealand Awareness ___ 252

C.2.3.2 New Zealand Equivalent of Green Star __ 252

C.2.3.3 Green Star New Zealand Influence ___ 254

C.2.3.4 Use of Green Star New Zealand _ـ 255

C.2.3.5 Intended Use of Green Star New Zealand ___ 257

C.2.3.6 Green Star New Zealand Training ___ 259

C.2.3.7 Green Star New Zealand Certification __ 260

C.2.3.8 Reasons for Using Green Star New Zealand ___ 262

C.2.4 The New Zealand Green Building Council ___ 264

C.2.4.1 New Zealand Green Building Council Awareness ___ 264

C.2.4.2 New Zealand Green Building Council Approach____ 264

C.2.4.3 New Zealand Green Building Council Influence ___ 266

C.2.5 Drivers, Triggers, Obstacles and Reasons for Sustainable Building___ 268

C.2.5.1 Trigger Person of Sustainable Building____ 268

C.2.5.2 Main Driver of Sustainable Building _ 270

C.2.5.3 Trigger Stage for Sustainable Building __ 272

C.2.5.4 Drivers for Sustainable Building ___ 274

C.2.5.5 Obstacles for Sustainable Building___ 277

C.2.5.6 Reasons for Involvement in Sustainable Building___ 279

C.2.5.7 Economic Reasons for Sustainable Building ___ 281

C.2.5.8 Environmental Reasons for Sustainable Building___ 283

C.2.5.9 Social Reasons for Sustainable Building __ 285

C.2.6 Sustainable Building Information____ 287

C.2.6.1 Sustainable Building Information Requirements___ 287

C.2.6.2 Sustainable Building Information Satisfaction _ 290

C.3 Collated Data___ 307

Appendix D: Comparative Analyses and Results __ 309

D.1 International Comparison __ 309

D.1.1 Trigger Stage for Sustainable Building ___ 309

D.1.1.1 United States Results ___ 310

D.1.1.2 Australian Results __ 311

D.1.2 Drivers for Sustainable Building____ 312

D.1.2.1 United States Results ___ 313 
D.1.2.2 Australian Results __ 314

D.1.3 Obstacles for Sustainable Building___ 315

D.1.3.1 United States Results ___ 316

D.1.3.2 Australian Results __ 317

D.1.4 Reasons for Involvement in Sustainable Building___ 318

D.1.4.1 United States Results ___ 319

D.1.4.2 Australian Results _ 320

D.1.5 Economic Reasons for Sustainable Building __ 321

D.1.5.1 United States Results ___ 322

D.1.5.2 Australian Results __ 323

D.1.6 Environmental Reasons for Sustainable Building___ 324

D.1.6.1 United States Results ___ 325

D.1.6.2 Australian Results _ 326

D.1.7 Social Reasons for Sustainable Building ___ 327

D.1.7.1 United States Results ___ 328

D.1.7.2 Australian Results _ 329

D.1.8 Sustainable Building Information___ 330

D.1.8.1 United States Results___ 331

D.1.8.2 Australian Results __ 332 


\section{List of Tables}

Table 1-1: Greenhouse gas emissions without land use, land use change and forestry 11

Table 1-2: Greenhouse gas net emissions/removals with land use, land use change and forestry 12

Table 1-3: Ecological Footprint comparison 13

Table 1-4: Industry makeup according to 2006 New Zealand Census 15

Table 1-5: Green Star NZ rating tool scores 25

Table 1-6: Weighted Categories 25

Table 2-1: Rating Tool Workshop environmental aspect weighting 44

Table 2-2: Environmental weightings of each Australian State 48

Table 4-1: Building industry categories 69

Table 4-2: Example of statistical information of survey questions 72

Table 4-3: Example of independent samples t-test procedure 72

Table 4-4: Key of options choices for difference between level of interest and level of involvement 83

Table 4-5: Top six interpretations to the purpose of a BSRT 85

Table 4-6: Definitions of option choices for how Green Star NZ is likely to be used 97

Table 4-7: Definitions of option choices to reasons for using Green Star NZ 101

Table 4-8: Definitions of option choices to who triggers sustainable building 108

Table 4-9: Definitions of option choices of who should drive sustainable building 110

Table 4-10: Definitions of option choices to when sustainable building is most likely triggered 111

Table 4-11: Definitions of option choices to drivers for sustainable buildings 112

Table 4-12: Definitions of option choices to obstacles for sustainable building 114

Table 4-13: Definitions of option choices to reasons for being involved in sustainable building 115

Table 4-14: Definitions of option choices to economic reasons/benefits for sustainable building 116

Table 4-15: Definitions of option choices to environmental reasons/benefits for sustainable building (in order asked in survey) 117

Table 4-16: Definitions of option choices to social reasons/benefits for sustainable building_ 118

Table 4-17: Definitions of option choices to information requirements 121

Table 4-18: Definitions of option choices to information requirements with colour key 123

Table 5-1: Definition of answer choices to reasons for involvement in sustainable building to when sustainable is most likely triggered 130

Table 5-2: Definition of answer choices to drivers for sustainable building 132

Table 5-3: Definition of answer choices to obstacles for sustainable building 133

Table 5-4: Definition of answer choices to reasons for involvement in sustainable building 134 
Table 5-5: Definition of answer choices to economic reasons/benefits for sustainable building 136

Table 5-6: Definition of answer choices to environmental reasons/benefits for sustainable buildings 137

Table 5-7: Definition of answer choices to social reasons/benefits for sustainable buildings _ 138

Table 5-8: Definition of answer choices to information requirements regarding sustainable buildings 140

Table A-1: Emissions summary for New Zealand 169

Table A-2: Emissions summary for Australia 170

Table A-3: Emissions summary for the United States 171

Table A-4: National equivalent carbon dioxide emissions per capita 172

Table A-5: Ecological Footprint 2003 174

Table A-6: Biocapacity 2003 175

Table A-7: Ecological Footprint 1999 176

Table A-8: Biocapacity 1999 177

Table A-9: 2006 New Zealand Census building industry make-up 178

Table A-10: Green Star NZ rating tool scores 184

Table A-11: Credit summary table 185

Table B-1: Number of professionals in each participating organisation 187

Table B-2: Respondents number of affiliations with building industry related organisations 188

Table B-3: Conservative population estimate calculation 189

Table C-1: Statistical information of survey questions 224

Table C-2: Results of the independent samples T-test procedure 230

Table C-1: Key of options choices for difference between level of interest and level of involvement 245

Table C-2: Participant interpretations to the purpose of a BSRT 246

Table C-3: Overall participant level of professional accreditation for existing BSRTs 251

Table C-4: Overall awareness of Green Star NZ 252

Table C-5: Definitions of option choices for how Green Star NZ is likely to be used 257

Table C-6: Definitions of option choices to reasons for using Green Star NZ 262

Table C-7: Overall awareness of the NZGBC 264

Table C-8: Definitions of option choices to who triggers sustainable building 268

Table C-9: Definitions of option choices to who should drive sustainable building 270

Table C-10: Definitions of option choices to when sustainable building is most likely triggered

Table C-11: Definitions of option choices to drivers for sustainable buildings 272

Table C-12: Definitions of option choices to obstacles for sustainable building 274 277 
Table C-13: Definitions of option choices to reasons for being involved in sustainable building 279

Table C-14: Definitions of option choices to economic reasons/benefits for sustainable building 281

Table C-15: Definitions of option choices to environmental reasons/benefits for sustainable building 283

Table C-16: Definitions of option choices to social reasons/benefits for sustainable building 285

Table C-17: Definitions of option choices to information requirements 287

Table C-18: Definitions of option choices to information requirements with colour key 291

Table D-1: Definition of answer choices to reasons to when sustainable is most likely triggered 309

Table D-2: Definition of answer choices to reasons to when sustainable is most likely triggered in the United States 310

Table D-3: Definition of answer choices to reasons to when sustainable is most likely triggered in Australia 311

Table D-4: Definition of answer choices to drivers for sustainable building 312

Table D-5: Definition of answer choices to drivers for sustainable building in the United States

Table D-6: Definition of answer choices to drivers for sustainable building in Australia 313

Table D-7: Definition of answer choices to obstacles for sustainable building 314

Table D-8: Definition of answer choices to obstacles for sustainable building in the United States 316

Table D-9: Definition of answer choices to obstacles for sustainable building in Australia 317

Table D-10: Definition of answer choices to reasons for involvement in sustainable building 318 Table D-11: Definition of answer choices to reasons for involvement in sustainable building in the United States 319

Table D-12: Definition of answer choices to reasons for involvement in sustainable building in Australia 320

Table D-13: Definition of answer choices to economic reasons/benefits for sustainable building 321

Table D-14: Definition of answer choices to economic reasons/benefits for sustainable building in the United States 322

Table D-15: Definition of answer choices to economic reasons/benefits for sustainable building in Australia 323

Table D-16: Definition of answer choices to environmental reasons/benefits for sustainable buildings 324 
Table D-17: Definition of answer choices to environmental reasons/benefits for sustainable buildings in the United States 325

Table D-18: Definition of answer choices to environmental reasons/benefits for sustainable buildings in Australia 326

Table D-19: Definition of answer choices to social reasons/benefits for sustainable buildings 327 Table D-20: Definition of answer choices to social reasons/benefits for sustainable buildings in the United States 328

Table D-21: Definition of answer choices to social reasons/benefits for sustainable buildings in Australia 329

Table D-22: Definition of answer choices to information requirements regarding sustainable buildings 330

Table D-23: Definition of answer choices to information requirements regarding sustainable buildings in the United States 331

Table D-24: Definition of answer choices to information requirements regarding sustainable buildings in Australia 332 


\section{List of Figures}

Figure 1-1: Weak Sustainability

Figure 1-2: Strong Sustainability

Figure 1-3: 2005 net consumer energy ___ 16

Figure 1-4: Percentage increase in energy use by sector from 1996 to $2005 \_17$

Figure 1-5: Basic structure of Green Star NZ__ 24

Figure 1-6: Green Star NZ building process coverage __ 24

Figure 2-1: Comparison of environmental aspect weightings for a New Zealand based BSRT

against other existing systems __ 43

Figure 3-1: Survey timeline__ 52

Figure 3-2: Example of scalar formatted question __ 65

Figure 3-3: Example of tick all which apply formatted question___ 65

Figure 3-4: Example of single yes or no formatted question___ 65

Figure 4-1: Makeup of survey participants _ 70

Figure 4-2: Overall participant interest in sustainability, sustainable building and BSRTs __ 73

Figure 4-3: Overall interest in sustainability by industry sector___ 74

Figure 4-4: Overall interest in sustainable building by industry sector___ 74

Figure 4-5: Overall interest in BSRTs by industry sector __ 75

Figure 4-6: Overall interest in sustainability by NZGBC vs. non-NZGBC__ 76

Figure 4-7: Overall interest in sustainable buildings by NZGBC vs. non-NZGBC__ 76

Figure 4-8: Overall interest in BSRTs by NZGBC vs. non-NZGBC _ 77

Figure 4-9: Overall participant involvement in sustainability, sustainable building and BSRTs _ 78

Figure 4-10: Overall involvement in sustainability by industry sector __ 79

Figure 4-11: Overall involvement in sustainable buildings by industry sector ___ 80

Figure 4-12: Overall involvement in BSRTs by industry sector___ 80

Figure 4-13: Overall involvement in sustainability by NZGBC vs. non-NZGBC ___ 81

Figure 4-14: Overall involvement in sustainable buildings by NZGBC vs. non-NZGBC___ 82

Figure 4-15: Overall involvement in BSRTs by NZGBC vs. non-NZGBC

Figure 4-16: Overall difference between level of interest and level of involvement____ 83

Figure 4-17: Overall importance for New Zealand to have a specific BSRT ___ 86

Figure 4-18: Overall awareness of the current existing BSRTs __ 87

Figure 4-19: Overall awareness of the current existing BSRTs by industry sector___ 88

Figure 4-20: Overall current experience with existing BSRTs ___ 89

Figure 4-21: Overall importance for Green Star NZ to be a New Zealand equivalent of the Australian Green Star system____ 92 
Figure 4-22: Overall importance for Green Star NZ to be a New Zealand equivalent of the Australian Green Star system by industry sector 93

Figure 4-23: Overall perceived extent that Green Star NZ will influence the building industry in a shift towards more sustainable building development in New Zealand

Figure 4-24: Overall likelihood that participants will use Green Star NZ once it is officially released 95

Figure 4-25: Overall anticipation how Green Star NZ will be used, if participant are likely to use it

Figure 4-26: Overall anticipation how Green Star NZ will be used, if participants are likely to use it by NZGBC vs. non-NZGBC 98

Figure 4-27: Overall likelihood that participants will seek training to become a Green Star NZ accredited professional 99

Figure 4-28: Overall importance that New Zealand buildings seek full Green Star NZ certification 100

Figure 4-29: Overall reasons for using Green Star NZ 101

Figure 4-30: Overall appropriateness of the approach of the NZGBC in the establishment of a New Zealand specific BSRT 105

Figure 4-31: Overall perceived extent that the NZGBC will influence the building industry in a shift towards more sustainable building development 106

Figure 4-32: Overall participant experience of who triggers sustainable building in the first place 109

Figure 4-33: Overall participant experience of who triggers sustainable building in the first place by industry sector 109

Figure 4-34: Overall opinion of who should be the main driver for sustainable building 110

Figure 4-35: Overall stage of the building process that sustainable building most likely triggered - 111

Figure 4-36: Overall drivers for sustainable building 113

Figure 4-37: Overall obstacles to sustainable buildings 114

Figure 4-38: Overall reasons for being involved with sustainable building 115

Figure 4-39: Overall economic reasons/benefits of sustainable building 116

Figure 4-40: Overall perception of the environmental reasons/benefits of sustainable building 117

Figure 4-41: Overall perceived social reasons/benefits of sustainable building 118

Figure 4-42: Overall requirements for information about sustainable building 121

Figure 4-43: Overall level of satisfaction with the current information available about sustainable building 122 
Figure 4-44: Overall level of satisfaction with the current information available about sustainable building according to option choices 123

Figure 5-1: Overall international comparison of when sustainable building is most likely triggered 130

Figure 5-2: Overall international comparison of drivers for sustainable building 132

Figure 5-3: Overall international comparison of obstacles for sustainable building 133

Figure 5-4: Overall international comparison of reasons for involvement in sustainable building 135

Figure 5-5: Overall international comparison of the economic reasons/benefits of sustainable building 136

Figure 5-6: Overall international comparison of the environmental reasons/benefits of sustainable building 137

Figure 5-7: Overall international comparison of the social reasons/benefits for sustainable building

Figure 5-8: Overall international comparison of information requirements regarding sustainable building 140

Figure A-1: National equivalent carbon dioxide emissions per capita 173

Figure A-2: International compartitive electricity prices in 2005 179

Figure A-3: Total primary energy supply by fuel type in 2005 179

Figure A-4: Office building - 20 year present values 180

Figure A-5: Environmental weightings of the Green Star NZ categories 183

Figure C-1: Overall participant interest in sustainability, sustainable building and BSRTs 238

Figure C-2: Overall interest in sustainability by industry sector 239

Figure C-3: Overall interest in sustainable building by industry sector 239

Figure C-4: Overall interest in BSRTs by industry sector 240

Figure C-5: Overall interest in sustainability by NZGBC vs. non-NZGBC 240

Figure C-6: Overall interest in sustainable buildings by NZGBC vs. non-NZGBC 241

Figure C-7: Overall interest in BSRTs by NZGBC vs. non-NZGBC 241

Figure C-8: Overall participant involvement in sustainability, sustainable building and BSRTs 242

Figure C-9: Overall involvement in sustainable buildings by industry sector 242

Figure C-10: Overall involvement in BSRTs by industry sector 243

Figure C-11: Overall involvement in sustainability by NZGBC vs. non-NZGBC 243

Figure C-12: Overall involvement in sustainable buildings by NZGBC vs. non-NZGBC 244

Figure C-13: Overall involvement in BSRTs by NZGBC vs. non-NZGBC 244

Figure C-14: Overall difference between level of interest and level of involvement 245

Figure C-15: Overall importance for New Zealand to have a specific BSRT 247

Figure C-16: Overall importance for New Zealand to have a specific BSRT by industry sector 247 
Figure C-17: Overall importance for New Zealand to have a specific BSRT by NZGBC vs. non-

NZGBC 248

Figure C-18: Overall awareness of the current existing BSRTs 248

Figure C-19: Overall awareness of the current existing BSRTs by industry sector 249

Figure C-20: Overall awareness of the current existing BSRTs by NZGBC vs. non-NZGBC 249

Figure C-21: Overall current experience with existing BSRTs 250

Figure C-22: Overall current experience with existing BSRTs by NZGBC vs. non-NZGBC _ 250

Figure C-23: Overall importance for Green Star NZ to be a New Zealand equivalent of the Australian Green Star system 252

Figure C-24: Overall importance for Green Star NZ to be a New Zealand equivalent of the Australian Green Star system by industry sector 253

Figure C-25: Overall importance for Green Star NZ to be a New Zealand equivalent of the Australian Green Star system by NZGBC vs. non-NZGBC 253

Figure C-26: Overall perceived extent that Green Star NZ will influence the building industry in a shift towards more sustainable building development in New Zealand 254 Figure C-27: Overall perceived extent that Green Star NZ will influence the building industry in a shift towards more sustainable building development in New Zealand by industry sector 254 Figure C-28: Overall perceived extent that Green Star NZ will influence the building industry in a shift towards more sustainable building development in New Zealand by NZGBC vs. nonNZGBC

Figure C-29: Overall likelihood that participants will use Green Star NZ once it is officially released 255

Figure C-30: Overall likelihood that participants will use Green Star NZ once it is officially released by industry sector 256 Figure C-31: Overall likelihood that participants will use Green Star NZ once it is officially released by NZGBC vs. non-NZGBC 256 Figure C-32: Overall anticipation how Green Star NZ will be used, if participants are likely to use it 257

Figure C-33: Overall anticipation how Green Star NZ will be used, if participants are likely to use it by industry sector 258

Figure C-34: Overall anticipation how Green Star NZ will be used, if participants are likely to use it by NZGBC vs. non-NZGBC 258

Figure C-35: Overall likelihood that participants will seek training to become a Green Star NZ accredited professional

Figure C-36: Overall likelihood that participants will seek training to become a Green Star NZ accredited professional by industry sector 259 
Figure C-37: Overall likelihood that participants will seek training to become a Green Star NZ accredited professional by NZGBC vs. non-NZGBC 260

Figure C-38: Overall importance that New Zealand buildings seek full Green Star NZ accreditation

Figure C-39: Overall importance that New Zealand buildings seek full Green Star NZ accreditation by industry sector

Figure C-40: Overall importance that New Zealand buildings seek full Green Star NZ accreditation by NZGBC vs. non NZGBC 261

Figure C-41: Overall reasons for using Green Star NZ 262

Figure C-42: Overall reasons for using Green Star NZ by industry sector 263

Figure C-43: Overall reasons for using Green Star NZ by NZGBC vs. non-NZGBC 263

Figure C-44: Overall appropriateness of the approach of the NZGBC in the establishment of a New Zealand specific BSRT 264

Figure C-45: Overall appropriateness of the approach of the NZGBC in the establishment of a New Zealand specific BSRT by industry sector 265

Figure C-46: Overall appropriateness of the approach of the NZGBC in the establishment of a New Zealand specific BSRT by NZGBC vs. non-NZGBC 265

Figure C-47: Overall perceived extent that the NZGBC will influence the building industry in a shift towards more sustainable building development 266

Figure C-48: Overall perceived extent that the NZGBC will influence the building industry in a shift towards more sustainable building development by industry sector 267 Figure C-49: Overall perceived extent that the NZGBC will influence the building industry in a shift towards more sustainable building development by NZGBC vs. non-NZGBC 267 Figure C-50: Overall participant experience of who triggers sustainable building in the first place (in order from highest to lowest 268

Figure C-51: Overall participant experience of who triggers sustainable building in the first place by industry sector 269

Figure C-52: Overall participant experience of who triggers sustainable building in the first place by NZGBC vs. non-NZGBC 269

Figure C-53: Overall opinion of who should be the main driver for sustainable building 270

Figure C-54: Overall opinion of who should be the main driver for sustainable building by industry sector 271

Figure C-55: Overall opinion of who should be the main driver for sustainable building by NZGBC vs. non-NZGBC 271

Figure C-56: Overall stage of the building process that sustainable building most likely triggered 
Figure C-57: Overall stage of the building process that sustainable building most likely triggered by industry sector 273

Figure C-58: Overall stage of the building process that sustainable building most likely triggered by NZGBC and non-NZGBC 273

Figure C-59: Overall drivers for sustainable building 274

Figure C-60: Overall drivers for sustainable building by industry sectors 275

Figure C-61: Overall drivers for sustainable building by industry sector ___ 275

Figure C-62: Overall drivers for sustainable building by NZGBC vs. non-NZGBC___ 276

Figure C-63: Overall obstacles to sustainable buildings __ 277

Figure C-64: Overall obstacles to sustainable buildings by industry sector __ 278

Figure C-65: Overall obstacles to sustainable buildings by NZGBC vs. non-NZGBC __ 278

Figure C-66: Overall reasons for being involved with sustainable building___ 279

Figure C-67: Overall reasons for being involved with sustainable building by industry sector_ 280

Figure C-68: Overall reasons for being involved with sustainable building by NZGBC vs. non-

NZGBC —_ 280

Figure C-69: Overall economic reasons/benefits of sustainable building ___ 281

Figure C-70: Overall economic reasons/benefits of sustainable building by industry sector _ 282

Figure C-71: Overall economic reasons/benefits of sustainable building by NZGBC vs. nonNZGBC

Figure C-72: Overall perceived of the environmental reasons/benefits of sustainable building 283

Figure C-73: Overall perceived of the environmental reasons/benefits of sustainable building by industry sector 284

Figure C-74: Overall perceived of the environmental reasons/benefits of sustainable building by

NZGBC vs. non-NZGBC 284

Figure C-75: Overall perceived social reasons/benefits of sustainable building 285

Figure C-76: Overall perceived social reasons/benefits of sustainable building by industry sector 286

Figure C-77: Overall perceived social reasons/benefits of sustainable building by NZGBC vs. non-NZGBC 286

Figure C-78: Overall requirements for information about sustainable building 287

Figure C-79: Overall requirements for information about sustainable building by industry sector 288

Figure C-80: Overall requirements for information about sustainable building by industry sector 288

Figure C-81: Overall requirements for information about sustainable building by NZGBC vs. non-NZGBC 289 
Figure C-82: Overall level of satisfaction with the current information available about sustainable building 290

Figure C-83: Overall level of satisfaction with the current information available about sustainable building according to option choices

Figure C-84: Overall level of satisfaction with the current information available about green products by industry sector

Figure C-85: Overall level of satisfaction with the current information available about green products by NZGBC vs. non-NZGBC

Figure C-86: Overall level of satisfaction with the current information available about environmental and economic cost benefit case studies by industry sector

Figure C-87: Overall level of satisfaction with the current information available about environmental and economic cost benefit case studies by NZGBC vs. non-NZGBC

Figure C-88: Overall level of satisfaction with the current information available about green building emerging trends by industry sector

Figure C-89: Overall level of satisfaction with the current information available about green building emerging trends by NZGBC vs. non-NZGBC

Figure C-90: Overall level of satisfaction with the current information available about green projects by industry sector 295

Figure C-91: Overall level of satisfaction with the current information available about green projects NZGBC vs. non-NZGBC

Figure C-92: Overall level of satisfaction with the current information available about how-to design a 'green' building by industry sector 296

Figure C-93: Overall level of satisfaction with the current information available about how-to design a 'green' building by NZGBC vs. non-NZGBC 296

Figure C-94: Overall level of satisfaction with the current information available about reviews and profiles of Green Star NZ buildings by industry sector

Figure C-95: Overall level of satisfaction with the current information available about reviews and profiles of Green Star NZ buildings by NZGBC vs. non-NZGBC

Figure C-96: Overall level of satisfaction with the current information available about how-to market a 'green' building by industry sector 298

Figure C-97: Overall level of satisfaction with the current information available about how-to market a 'green' building by NZGBC vs. non-NZGBC 298

Figure C-98: Overall level of satisfaction with the current information available about engineering or scientific information by industry sector 299

Figure C-99: Overall level of satisfaction with the current information available about engineering or scientific information by NZGBZ vs. non-NZGBC 299 
Figure C-100: Overall level of satisfaction with the current information available about Green Star NZ accreditation course by industry sector 300

Figure C-101: Overall level of satisfaction with the current information available about Green Star NZ accreditation course by NZGBC vs. non-NZGBC 300

Figure C-102: Overall level of satisfaction with the current information available about how-to manage a 'green' building by industry sector 301

Figure C-103: Overall level of satisfaction with the current information available about how-to manage a 'green' building by NZGBC vs. non-NZGBC 301

Figure C-104: Overall level of satisfaction with the current information available about green players by industry sector 302

Figure C-105: Overall level of satisfaction with the current information available about green players NZGBC vs. non-NZGBC 302

Figure C-106: Overall level of satisfaction with the current information available about Green Star NZ players by industry sector 303

Figure C-107: Overall level of satisfaction with the current information available about Green Star NZ players by NZGBC vs. non-NZGBC 303

Figure C-108: Overall level of satisfaction with the current information available about business management information by industry sector 304

Figure C-109: Overall level of satisfaction with the current information available about business management by NZGBC vs. non-NZGBC

Figure C-110: Overall level of satisfaction with the current information available about curriculum for senior executives by industry sector 305

Figure C-111: Overall level of satisfaction with the current information available about curriculum for senior executives by NZGBC vs. non-NZGBC 305

Figure C-112: Overall level of satisfaction with the current information available about curriculum for line staff by industry sector 306

Figure C-113: Overall level of satisfaction with the current information available about curriculum for line staff by NZGBC vs. non-NZGBC 306

Figure D-1: Overall international comparison of when sustainable building is most likely triggered

$\longrightarrow 309$

Figure D-2: When sustainable building is most likely triggered in the United States __ 310

Figure D-3: When sustainable building is most likely triggered in Australia __ 311

Figure D-4: Overall international comparison of drivers for sustainable building____ 312

Figure D-5: Drivers for sustainable building in the United States___ 313

Figure D-6: Drivers for sustainable building in Australia ___ 314

Figure D-7: Overall international comparison of obstacles for sustainable building ___ 315

Figure D-8: Obstacles for sustainable building in the United States __ 316 
Figure D-9: Obstacles for sustainable building in Australia

Figure D-10: Overall international comparison of reasons for involvement in sustainable building 318

Figure D-11: Reasons for involvement in sustainable building in the United States 319

Figure D-12: Reasons for involvement in sustainable building in Australia 320

Figure D-13: Overall international comparison of the economic reasons/benefits of sustainable building 321

Figure D-14: Economic reasons/benefits for sustainable building in the United States 322

Figure D-15: Economic reasons/benefits for sustainable building in Australia 323

Figure D-16: Overall international comparison of the environmental reasons/benefits of sustainable building

Figure D-17: Environmental reasons/benefits for sustainable buildings in the United States _ 325

Figure D-18: Environmental reasons/benefits for sustainable buildings in Australia 326

Figure D-19: Overall international comparison of the social reasons/benefits for sustainable building 327

Figure D-20: social reasons/benefits for sustainable buildings in the United States 328

Figure D-21: Social reasons/benefits for sustainable buildings in Australia 329

Figure D-22: Overall international comparison of information requirements regarding sustainable building 330

Figure D-23: Information requirements regarding sustainable buildings in the United States _ 331

Figure D-24: Information requirements regarding sustainable buildings in Australia 332 


\begin{abstract}
Building Sustainability Rating Tools (BSRTs) are being developed worldwide with considerable success. As a result their implementation has created the awareness necessary to cement their role in creating positive change. With the release of New Zealand's own BSRT, Green Star New Zealand (Green Star NZ), and the establishment of the New Zealand Green Building Council (NZGBC) this awareness was expected to strengthen.
\end{abstract}

The NZGBC has stated that the implementation of Green Star NZ can only be successful if the selected tool is widely accepted, and meets the requirements of the building industry. To date, little research has been carried out into the correct implementation of a BSRT despite this being a fundamental part of a tool's overall success.

Therefore, the overall aim of this research was to investigate the requirements of stakeholders and end-users including their understanding of sustainability, BSRT's and the NZGBC. The research also intended to provide a 'sustainability snapshot' of the New Zealand building industry and of the current New Zealand market, establishing a base point for future measurement.

The specific objectives of the research were to investigate:

- The building industry's level of awareness and the level of involvement regarding sustainability, sustainable building and BSRTs

- The building industry's existing knowledge and experience with BSRTs

- How different groups within the building industry anticipate using Green Star NZ and if they are likely to seek formal certification

- The building industry's understanding of the NZGBC, and its likely impact in the production of more sustainable buildings in New Zealand

- The drivers, triggers, obstacles and reasons for sustainable building

- The requirement for sustainable building information and the corresponding level of satisfaction regarding this information

- How international research compared with the current study, allowing trends, differences and similarities to be discussed

To meet these aims and objectives a survey was developed in collaboration with the NZGBC, with the intention of acquiring a wide building industry response (e.g. property developers, building contractors, and architects). The participants were canvassed from several associated building organisations which agreed to assist in the distribution of the survey. The survey was conducted between 19 February and 12 March 2007 and ultimately received 476 responses which 
approximated to a response rate of 3\% with a confidence interval of $95 \%$ and margin of error of $\pm 4 \%$.

Significantly, the analyses identified a substantial difference between the level of interest and level of involvement regarding sustainability, sustainable buildings and BSRTs. This result emphasised that the building industry is much more willing to participate, and be part of a sustainable building community than may be currently perceived.

Anecdotal evidence suggests BSRTs are often used primarily as 'design guides', with no intention to seek a formal rating. According to the results, using Green Star NZ as a 'design guide' was still reasonably high, however a good proportion of the industry anticipated seeking a certified rating for both 'design' and 'performance'.

According to experience of the respondents, the client was considered the single most important person to drive sustainable building. Clearly, as the main financial source, the client has the final say on any proposed design, although they may not have the necessary knowledge to propose sustainable design options or even be aware of them. For this reason, a further question explored who rather 'should' be the main driver for sustainable building. The results showed rather than a single person being responsible for driving sustainable building, it should be 'an integrated process where responsibility is shared'.

The main reason for sustainable building was 'rising energy costs' and emphasised the importance and increasing demand on energy production. The biggest obstacle for sustainable building was 'perceived higher upfront costs', which indicated confusion and the requirement for better information and the need for organisations such as the NZGBC to be a 'vehicle' to provide the building industry with direct and reliable information.

Even though, at the time of the survey the NZGBC and Green Star NZ were in their infancy, there was a significant demand for Green Star NZ related material, such as Green Star NZ certified case study buildings, accreditation procedures and building professionals.

In terms of satisfaction, the participants were clearly not content with the current level of information regarding sustainable building. Again, this lack of information reinforced the requirements for more sustainable building information, and the need for better education procedures. 
While aspiring to assist in the facilitation of more successful BSRT for New Zealand, the results from the research could serve to enhance the potential of Green Star NZ's success and smooth the period of transition for implementation. Furthermore the results could reinforce the relationship between the NZGBC and the wider building industry, encouraging dialogue to help develop the tool and ultimately lead to the construction of more sustainable buildings in New Zealand. 
Abstract 


\section{Introduction}

The introductory chapter discusses the background, rationale and the specific context in which this research project was undertaken, leading on to the problem statement, including the aim and objectives.

\subsection{Background}

Literature shows a considerable amount of research effort has been directed at the 'product' aspect of BSRTs, their technical features and weightings, however the implementation phase of a BSRT is often overlooked, but fundamental for their overall success.

Therefore the overall aim of the study was to investigate the requirements of stakeholders and end-users including their understanding of sustainability, the NZGBC and BSRTs. The research also intended to provide a 'snapshot' of the New Zealand building industry and of the current New Zealand market, establishing a base point for future measurement.

\subsubsection{Current Definitions of Sustainable Development and Sustainability}

To investigate the above aspects of sustainability, it was necessary to consider the meaning of sustainable development and sustainability, and the interpretations currently offered from the building industry.

Although the notion (or practice) of sustainable development and sustainability existed previously in some capacity the most famous, most quoted, yet somewhat ambiguous definition of sustainable development originates from the 1987 World Commission on Sustainable Development (WCSD) report, which states $\{55\}$ :

"Sustainable development is the development that meets the needs of the present without compromising the ability of future generations to meet their own needs".

This definition contains two key concepts \{World Commission on Sustainable Development $55\}$ :

- The concept of 'needs', in particular the essential needs of the world's poor, to which overriding priority should be given

- The idea of limitations imposed by the state of technology and social organisation on the environment's ability to meet present and future needs 
Albert Bartlett argues in his discussion of sustainability that the WCSD definition is both optimistic and vague $\{6\}$ :

“...they (WCSD) probably felt that the discussion had to be optimistic, but given the facts, it was necessary to be vague and contradictory in order not to appear to be pessimistic".

The term can also be oxymoronic, for example 'sustainable growth', which is often used by political leaders, has several underlying meanings $\{$ Bartlett 5-6\}:

"At one end of the spectrum, the term is used with precision by people who are introducing new concepts as a consequence of thinking profoundly about the long-term future of the human race. In the middle of the spectrum, the term is simply added as a modifier to the names and titles of very beneficial studies in efficiency, etc. that have been in progress for years. Near the other end of the spectrum, the term is used as a placebo. In some cases the term may be used mindlessly (or possibly with the intent to deceive) in order to try to shed a favourable light on continuing activities that may or may not be capable of continuing for long periods of time. At the very far end of the spectrum, we see the term used in a way that is oxymoronic".

Cole offers his interpretation of Robinson's review on sustainable development, stating \{Building Environmental Assessment Methods: Redefining Intentions and Roles 460-1\}:
"Sustainable development maintains an anthropocentric view and favours incremental change that does not challenge any existing entrenched powers or privileges, institutional reforms and technological advance. Sustainability, by contrast, promotes a biocentric view that places the human presence within a larger natural context, and focuses on constraints and on fundamental value and behavioural change".

Whereas government and the private sector tend to favour the definition of 'sustainable development', the application of 'sustainable' and 'sustainability' has become more prevalent, which Robinson suggests as being used increasingly more by academics, environmentalists and non-governmental organisations \{qtd. in Cole, Building Environmental Assessment Methods: Redefining Intentions and Roles 460-1\}. 
It has been suggested the definition proposed by Viederman is more accurate. It states \{qtd. in Munier 10$\}$

"...sustainability is a vision of the future that provides us with a road map and helps us to focus our attention on a set of values and ethical and moral principles by which to guide our actions".

Fricker reinforces this argument, that sustainability is not a methodology, but a will for change \{qtd. in Munier 13\}:

"The challenge of sustainability is neither wholly technical nor rational. It is one of change in attitude and behaviour. Sustainability therefore must include the social discourse where the fundamental issues are explored collaboratively within the groups of community concerned. We do not do that very well, partly because of increasing populations, complexity, distractions, and mobility, but more because of certain characteristics of the dominant paradigm that are seen as desirable".

The dilemma for the definition of sustainability is it can be interpreted in a myriad of ways, each with a different meaning and outcome. The Government of Western Australia suggests sustainability is much like 'love', 'hope' or 'freedom', and tends to remain vague until applied in a specific context \{qtd. in Pope, Annandale and Morrison-Saunders 598; New Zealand, Parliamentary Commissioner for the Environment 31$\}$. 
From the various interpretations, two main theories have been developed to illustrate the principles of sustainable development, integrating the dimensions of the environment, society and economy. The report 'Creating Our Future: Sustainable Development for New Zealand' defines the first model as 'weak sustainability' (refer Figure 1-1). This theory describes the economy, society and the environment as competing interests \{New Zealand, Parliamentary Commissioner for the Environment 34$\}$.

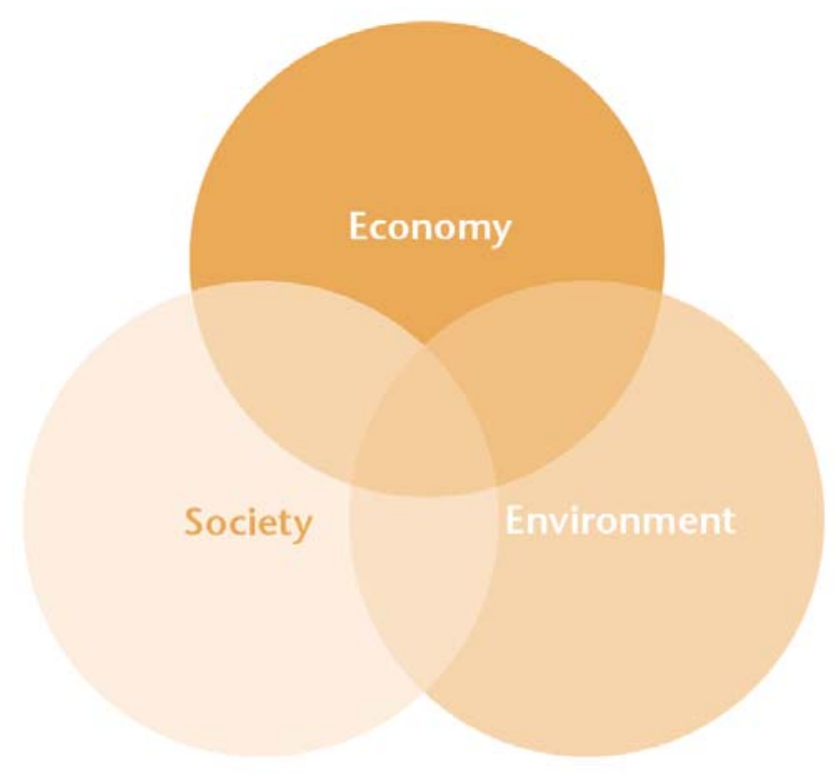

Figure 1-1: Weak Sustainability $\{$ New Zealand, Parliamentary Commissioner for the Environment $34\}$

The Pacific Rim Institute of Sustainable Management (PRISM) and Knight suggest that while there is some common ground where each of the circles overlap, the main priority in this model is the health of the economy. Weak sustainability assumes that deterioration of one dimension (environmental, social or economic) can be compensated for by improvement in another. One of the problems is 'weak sustainability' fails to acknowledge the ecological constraints humans, markets, policies and developments must operate within \{qtd. in New Zealand, Parliamentary Commissioner for the Environment 34-5\}. Furthermore Armstrong points out that the 'sustainable management' approach of the 1991 New Zealand Resource Management Act has been criticised for this very reason \{qtd. in New Zealand, Parliamentary Commissioner for the Environment 35$\}$. 
Additionally PRISM and Knight argue \{qtd. in New Zealand, Parliamentary Commissioner for the Environment 35\}:

“...sustainable development based on the pursuit of economic efficiency and ecological pragmatism only slows down ecological and social degradation rather than reverses it".

The second model, referred to as 'strong sustainability' represents the limits within which the economy and society must operate to function in a sustainable way (refer to Figure 1-2) $\{$ New Zealand, Parliamentary Commissioner for the Environment 7\}.

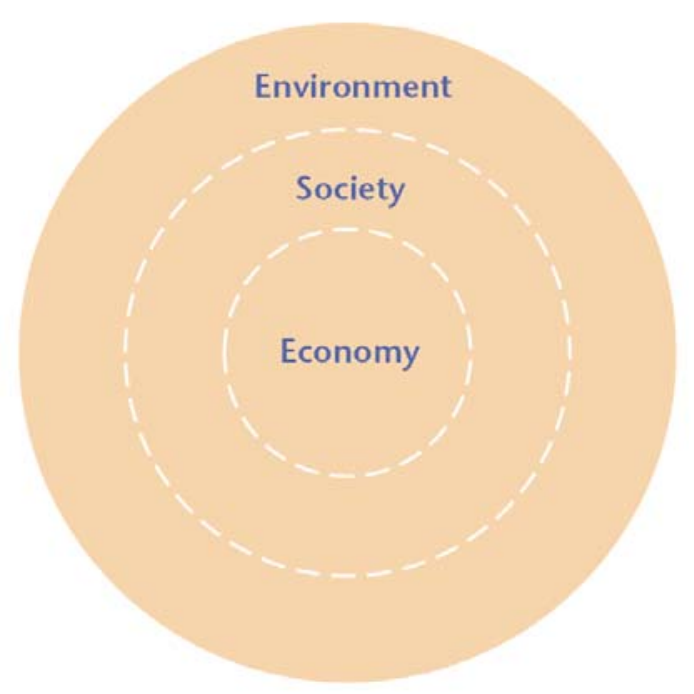

Figure 1-2: Strong Sustainability \{New Zealand, Parliamentary Commissioner for the Environment 7\}

The interpretation offered in the 'Creating Our Future' report states that strong sustainability $\{$ New Zealand, Parliamentary Commissioner for the Environment 7$\}$ :

"...recognises that the economy is a sub-set of society..., and that many important aspects of society do not involve economic activity. Similarly, human society and the economic activity within it are totally constrained by the natural systems of our planet. The economy may expand or contract, and society's expectations and values may change overtime, but to function in a sustainable way we must not exceed the capacity of the biosphere to absorb the effects of human activities". 
Munier discusses these two theories, suggesting 'weak sustainability' is utilitarian, and natural resources are there to support humankind, but are seen as another commodity. 'Strong sustainability' on the other hand is not utilitarian; resources should be used in a more rational and restrained way, respecting their intrinsic qualities and enjoying the biodiversity they offer $\{$ Munier 15$\}$.

While 'sustainable development' and 'sustainability' are and will likely remain vague and undefined, it has fuelled the debate, bringing concepts of sustainability into the mainstream through politics, media coverage and better public awareness. Uncontrolled this constructive debate can quickly deteriorate into a discussion of meaningless semantics, where the question remains, if there was a precise definition of sustainable development or sustainability, would it actually provide a resolution to the problem \{Cole, Building Environment Assessment Methods: Clarifying Intentions 232$\}$ ? Robinson sums this up $\{374\}$ :

“...the need to leave such terms as sustainable development undefined, to profit from what he describes as 'constructive ambiguity', where any attempt to define the concept precisely, even if it were possible, would have the effect of excluding those whose views were not expressed in that definition".

\subsubsection{The New Zealand Context}

New Zealand is generally promoted as a 'clean and green' country and this is evident in overseas marketing campaigns such as $100 \%$ Pure New Zealand. To a degree, our small population perpetuates this image, yet in reality we are not as 'green' as we are led to believe. Of a total of forty-one countries in 2004, New Zealand's total greenhouse gas emissions were only $0.28 \%$ (Annex 1 Parties, refer to Appendix A.1.1) \{United Nations Framework Convention on Climate Change, Annex 1 Parties GHG Total with LULUCF\}. While this is small on a global scale, what is significant is New Zealand's equivalent carbon dioxide emissions have increased $21.3 \%$, from base levels recorded in 1990 (refer to Table 1-1) \{United Nations Framework Convention on Climate Change, Party Emissions Summaries\}. 
Table 1-1: Greenhouse gas emissions without land use, land use change and forestry \{United Nations Framework Convention on Climate Change, Party Emissions Summaries\}

\begin{tabular}{|c|c|c|c|}
\hline Country & \multicolumn{3}{|c|}{ Emissions, in Gigagrams carbon dioxide equivalent } \\
\hline & 1990 & 2000 & 2004 \\
\hline New Zealand & $61,893.0$ & $70,314.7$ & $75,088.0$ \\
\hline Australia & $418,274.5$ & $497,774.3$ & $525,914.4$ \\
\hline United States & $6,103,283.3$ & $6,975,928.7$ & $7,067,569.6$ \\
\hline $\begin{array}{ll}\text { Annex } & 1 \\
\text { Parties } & \\
\end{array}$ & $19,652,726.2$ & $19,678,023.6$ & $20,135,360.5$ \\
\hline Country & \multicolumn{3}{|c|}{ Changes in emissions, in per cent } \\
\hline & From 1990 to 2000 & From 1990 year to 2004 & From 2000 to 2004 \\
\hline New Zealand & $13.6 \%$ & $21.3 \%$ & $6.8 \%$ \\
\hline Australia & $19.0 \%$ & $25.7 \%$ & $5.7 \%$ \\
\hline United States & $14.3 \%$ & $15.8 \%$ & $1.3 \%$ \\
\hline $\begin{array}{ll}\text { Annex } & 1 \\
\text { Parties } & \end{array}$ & $0.13 \%$ & $2.4 \%$ & $2.3 \%$ \\
\hline Country & \multicolumn{3}{|c|}{ Average annual growth rates, in per cent per year } \\
\hline & From 1990 to 2000 & From 1990 year to 2004 & From 2000 to 2004 \\
\hline New Zealand & $1.3 \%$ & $1.4 \%$ & $1.7 \%$ \\
\hline Australia & $1.8 \%$ & $1.7 \%$ & $1.4 \%$ \\
\hline United States & $1.4 \%$ & $1.1 \%$ & $0.3 \%$ \\
\hline $\begin{array}{ll}\text { Annex } & 1 \\
\text { Parties } & \\
\end{array}$ & $0.01 \%$ & $0.16 \%$ & $0.46 \%$ \\
\hline
\end{tabular}

Even if Land Use, Land Use Change and Forestry ${ }^{1}$ (LULUCF) are accounted for New Zealand's emissions still increased 17.9\% (refer to Table 1-2, Appendix A.1.2.1, and to Appendix A.1.2.2 and A.1.2.3 for Australian and United States Emissions Summaries respectively) \{United Nations Framework Convention on Climate Change, Party Emissions Summaries\}.

\footnotetext{
${ }^{1}$ Human activities, through LULUCF activities, affect changes in carbon stocks between the carbon pools of the terrestrial ecosystem and between the terrestrial ecosystem and the atmosphere \{Land use, land-use change and forestry\}. Accounting for LULUCF has the potential to either add or remove carbon dioxide from the atmosphere which contributes to climate change.
} 
Table 1-2: Greenhouse gas net emissions/removals with land use, land use change and forestry \{United Nations Framework Convention on Climate Change, Party Emissions Summaries\}

\begin{tabular}{|c|c|c|c|}
\hline Country & \multicolumn{3}{|c|}{ Emissions, in Gigagrams carbon dioxide equivalent } \\
\hline & 1990 & 2000 & 2004 \\
\hline New Zealand & $42,915.1$ & $50,099.0$ & $50,605.8$ \\
\hline Australia & $499,903.3$ & $510,363.2$ & $525,674.6$ \\
\hline United States & $5,198,587.5$ & $6,222,795.9$ & $6,294,315.0$ \\
\hline Country & \multicolumn{3}{|c|}{ Changes in emissions, in per cent } \\
\hline & From 1990 to 2000 & From 1990 year to 2004 & From 2000 to 2004 \\
\hline New Zealand & $16.7 \%$ & $17.9 \%$ & $1.0 \%$ \\
\hline Australia & $2.1 \%$ & $5.2 \%$ & $3.0 \%$ \\
\hline United States & $19.7 \%$ & $21.1 \%$ & $1.1 \%$ \\
\hline Country & \multicolumn{3}{|c|}{ Average annual growth rates, in per cent per year } \\
\hline & From 1990 to 2000 & From 1990 year to 2004 & From 2000 to 2004 \\
\hline New Zealand & $1.6 \%$ & $1.2 \%$ & $0.3 \%$ \\
\hline Australia & $0.2 \%$ & $0.4 \%$ & $0.8 \%$ \\
\hline United States & $1.8 \%$ & $1.4 \%$ & $0.3 \%$ \\
\hline
\end{tabular}

In comparison with other countries, New Zealand is unique environmentally, particularly in the high ratio of non-carbon dioxide emissions of the total greenhouse gas emissions. For example the ratio of non-carbon dioxide emissions (i.e. methane, nitrous oxide, hydrofluorocarbons, perfluorocarbons, and sulphur hexafluoride) was 58.9\% in 1990, and 53.9\% in 2003, much higher than other Annex 1 Parties \{New Zealand, Ministry for the Environment, New Zealand's Fourth National Communication 44\}. Australia's ratio of non-carbon dioxide emissions on the other hand were $27.9 \%$ and $28.2 \%$ in 1990 and 2003 respectively \{Australia, Department of the Environment and Heritage 3$\}$.

On a global scale New Zealand produced the equivalent of 19.44 tonnes of greenhouse emissions (2003). This resulted in New Zealand being ranked 32nd out of a total 36 countries ( 1 = lowest emitter, 36 = highest emitter), ahead of only the USA, Canada, Luxembourg and Australia2 $^{2}$ (refer to Appendix A.1.2.4) \{qtd. in Myers and Bannon 2\}.

Figures from World Wild Life Fund for Nature suggest on a global scale New Zealand has an ecological footprint of 8.68 global hectares per person in 1999 and more recently 5.9 global hectares per person in 2003 (refer to Table 1-3) \{Living Planet Report 2002 26; Living Planet Report 2006 32\}. While this shows a significant decrease in ecological footprint, the differences may be explained through greater values that make up the total footprint and not through changes/improvements in lifestyle. For example, differences in cropland footprint, grazing land footprint and additional changes in the calculation method (refer to Appendix A.1.3.1 and A.1.3.2).

\footnotetext{
2 Original source - Globalis. "Indicator: greenhouse gas emissions per capita - 2003." 28 June 2007 $<$ http://globalis.gvu.edu/indicator.cfm?IndicatorID=199>.
} 
Table 1-3: Ecological Footprint comparison (global hectares per person in 2003) \{World Wild Life Fund for Nature, Living Planet Report 2006 28-35\}

\begin{tabular}{|l|r|r|r|}
\hline & \multicolumn{1}{|c|}{$\begin{array}{c}\text { Population 2003 } \\
\text { (millions) }\end{array}$} & \multicolumn{1}{c|}{$\begin{array}{c}\text { Total ecological } \\
\text { footprint 2003 }\end{array}$} & \multicolumn{1}{c|}{$\begin{array}{c}\text { Footprint change per } \\
\text { person (\%) 1975-2003 }\end{array}$} \\
\hline World & 6301.5 & 2.23 & $14 \%$ \\
\hline $\begin{array}{l}\text { High income } \\
\text { countries }\end{array}$ & 955.6 & 6.4 & $40 \%$ \\
\hline $\begin{array}{l}\text { Middle } \\
\text { income } \\
\text { counties }\end{array}$ & 3011.7 & 1.9 & $14 \%$ \\
\hline $\begin{array}{l}\text { Low income } \\
\text { countries }\end{array}$ & 2303.1 & 0.8 & $8 \%$ \\
\hline & & & \\
\hline New Zealand & 3.9 & 5.9 & \\
\hline Australia & 19.7 & 6.6 & $-7 \%$ \\
\hline United States & 294 & 9.6 & $38 \%$ \\
\hline
\end{tabular}

Central, local and other public bodies are realising the impact of human actions and the need to be environmentally, socially and economically sustainable. In a recent interview the New Zealand Prime Minister, Helen Clark provided a Government vision of a sustainable New Zealand $\{$ Crosfield 9\}:

"Being sustainable means living and working in a way which meets the needs of our community without compromising the wellbeing of future generations...environmentally this means protecting the quality of our air, our water and the land. It means reducing our waste and managing better the waste we do have. It means we must tackle the very serious issue of climate change...most New Zealanders can see the sense in living sustainably and we know that most people believe they need to make lifestyle choices to reduce the effects of climate change. Our clean green image is already part of our national identity. Sustainability is rapidly becoming a core value in many countries around the world - it is an imperative, environmentally, socially, and economically - and there are compelling reasons why New Zealand should be in the vanguard of making it happen. In time, being truly sustainable and carbon neutral will become as important to us as being nuclear free". 
As the Prime Minister suggests the Government is becoming more aware of sustainability, and this change is being reflected in a greater volume of legislation, statutes and reports. The report 'Creating Our Future: Sustainable Development of New Zealand' recognises sustainable development and the shift towards sustainability and states \{New Zealand, Parliamentary Commissioner for the Environment 6\}:

- The finite reserves of non-renewable resources and the importance of using them wisely and, where possible, substituting them with renewable resources

- The limits of natural life-supporting systems (ecosystems) to absorb the effects of human activities that produce pollution and waste

- The linkages and interactions between environmental, social and economic factors when making decisions, emphasising that all three factors must be taken into consideration if we are to achieve sustainable outcomes, particularly in the long term

- The well-being of current and future generations as a key consideration.

Other examples of sustainability in Government are \{New Zealand, Parliamentary Commissioner for the Environment 9\}:

- Environment Act (1986)

- Resource Management Act (1991)

- Kyoto Protocol (1997)

- Energy Efficiency and Conservation Act (2000)

- National Energy Efficiency and Conservation Strategy (2001)

- New Zealand Waste Management Strategy (2002)

- New Zealand Transport Strategy (2002)

- National Rail Strategy (2004)

Likewise many building and building related documents and initiatives are incorporating sustainability, some of these are:

- New Zealand Building Code

- Various building standards

- MfE's Govt3 Programme

- Energy Wise Home Grants

- EECA's Home Energy Rating Scheme (HERS) 


\subsubsection{The New Zealand Building Industry}

From 2006 New Zealand Census data, the New Zealand building industry is made up of several sectors and components (refer to Table 1-4 and to Appendix A.1.4).

Table 1-4: Industry makeup according to 2006 New Zealand Census ${ }^{3}$ \{New Zealand, Statistics New Zealand, Table Builder\}

\begin{tabular}{|l|r|r|}
\hline Industry Sectors & $\begin{array}{c}\text { Number of } \\
\text { Businesses }\end{array}$ & $\begin{array}{c}\text { Percentage of Total } \\
\text { Industry }\end{array}$ \\
\hline $\begin{array}{l}\text { Commercial Property Developers, Investors Owners } \\
\text { and Property Managers }\end{array}$ & 52128 & $41 \%$ \\
\hline Building Contractors & 44383 & $35 \%$ \\
\hline Property and Construction Professionals & 13908 & $11 \%$ \\
\hline Residential Developers and Major Portfolio Owners & 4824 & $4 \%$ \\
\hline Building Product Manufacturers and Distributors & 4484 & $3 \%$ \\
\hline Engineers & 3842 & $2 \%$ \\
\hline Architects and Draftpersons & 2437 & $0 \%$ \\
\hline Research and Non Government Organisations & 415 & $100 \%$ \\
\hline Total & 126421 & \\
\hline
\end{tabular}

Cole describes the building industry as a large, multifaceted organisation made up of several components, but is often slow to adopt change. Technical innovations and advances in building design for instance are often constrained by economic possibilities and social expectations $\{$ Cost and Value 305$\}$. Much like Government, the building industry also incorporates sustainability into documents and practice; but anecdotal evidence suggests they (the building industry) are not doing enough to embrace sustainability. Cole believes there needs to be an attitudinal shift for industry to embrace these new environmental concerns. Although Cole acknowledges while individuals can drive change, there will always be barriers in the industry which hinder both the extent and rate of progress for sustainability $\{$ Cost and Value 305\}.

Larsson further illustrates this barrier; in such a market-oriented economy developers and investors build to suit what they believe the market is willing to pay for. He emphasises developers and investors would be more willing to design sustainable buildings, if only there was a greater market demand for it. \{Larsson 333\}. Bartlett and Howard reinforce this, that \{qtd. 315\}:

"Value has traditionally been judged in terms of location, quality, function and aesthetics".

${ }^{3}$ Not included in the above analysis are Owners Occupiers, Major Corporate Tenants and Retailers, and Related Interests. This inclusion was not possible due to the limitations of the Census data and therefore no assumption could be made of the makeup of these sectors. 
As Cole states, buildings represent significant capital investment, both financial and ecological \{Cost and Value 304\}. Currently New Zealand's built environment represents a national investment valued at over $\$ 300$ billion $\{$ Best Practice in Procurement\}, and in the year ended September 2006 the value of building work put in place was $\$ 12.7$ billion. This was an increase of $4.7 \%$ from the previous year (New Zealand, Statistics New Zealand, Value of Building Work Put in Place\}.

While the built environment represents considerable investment, it is also a significant consumer of energy. The New Zealand Ministry of Economic Development reported in 2005, commercial and residential buildings consumed 24\% (111PJ) of the total National energy supply, this was an increase of $32 \%$ and $22 \%$ for commercial and residential buildings respectively (refer to Figure 1-3 and 1-4) \{Draft New Zealand Energy Efficiency and Conservation Strategy 8-9\}.

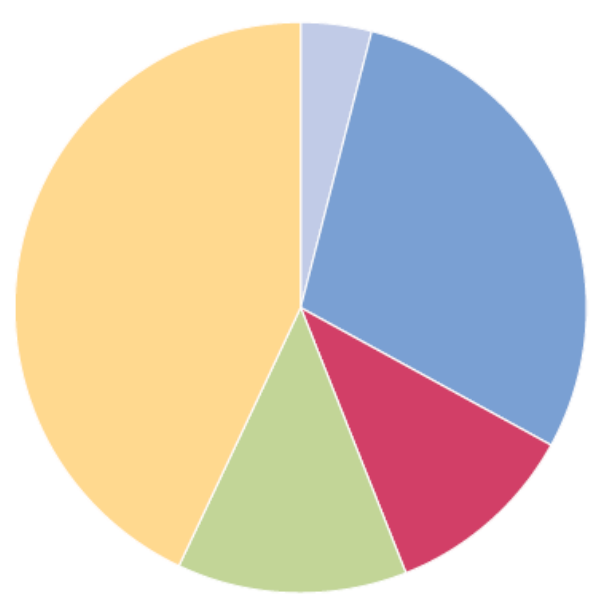

\author{
$4 \%$ Agriculture (20 PJ) \\ $29 \%$ Industrial (136 PJ) \\ $11 \%$ commercial (49 PJ) \\ $13 \%$ Residential (62 PJ) \\ $43 \%$ National transport (198 PJ)
}

Figure 1-3: 2005 net consumer energy (total 465PJ) \{New Zealand, Ministry for Economic Development, Draft New Zealand Energy and Efficiency and Conservation Strategy 8$\}$ 


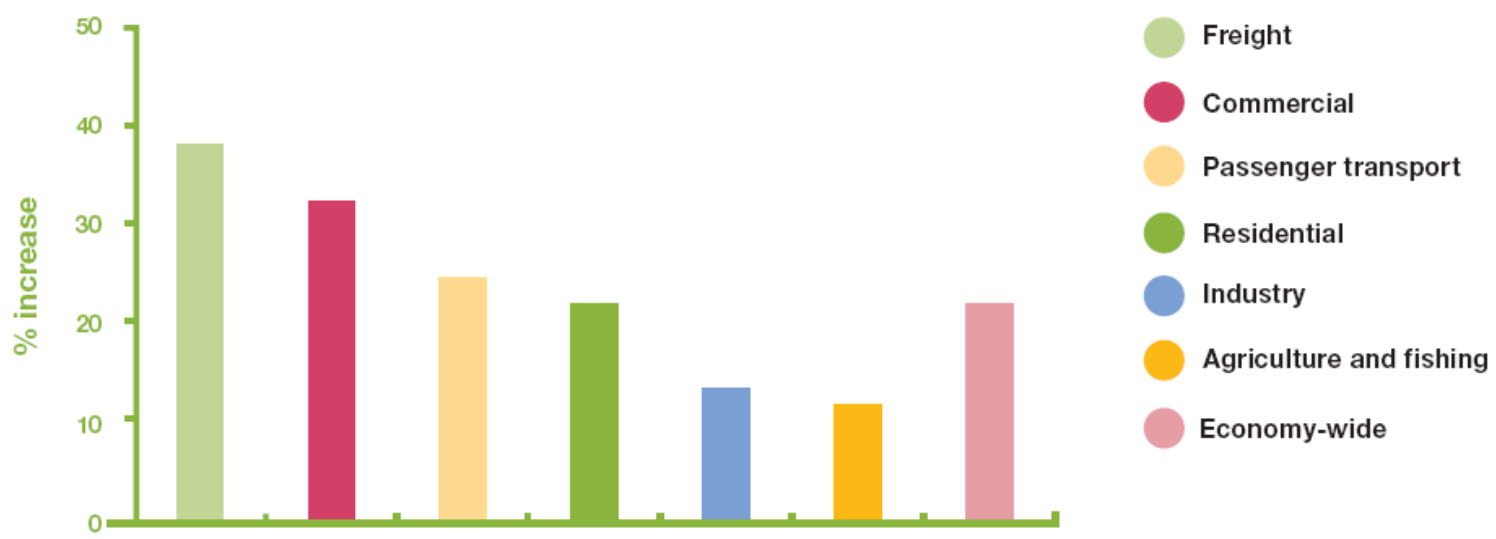

Figure 1-4: Percentage increase in energy use by sector from 1996 to 2005 \{New Zealand, Ministry for Economic Development, Draft New Zealand Energy and Efficiency and Conservation Strategy 9\}

The New Zealand, Ministry for the Environment has also estimated that over eight million tonnes of carbon dioxide was expelled into the atmosphere in 2005 (refer to Appendix A.1.4.1) \{Draft-Powering Our Future 22\}. In addition, three million tonnes of construction and demolition debris were sent to landfills by New Zealand industry and households \{New Zealand, Ministry for the Environment, Valuing New Zealand's Clean Green Image 3:8\}.

\subsubsection{Sustainable Buildings: Identification of a Gap}

Sustainable building has a high marketing value and there are few people who actually oppose it, except based on the assumption that sustainable buildings are more expensive. Although Kohler explains it is a mystery as to how people could assume sustainable building is more expensive than conventional building without an agreed definition of what a sustainable building is $\{317\}$. Kohler further suggests sustainable buildings are supposed to have something additional to conventional buildings and as a result, this additional quality justifies a supplement in cost $\{317\}$.

'Green' buildings comprise approximately $2 \%$ of new non-residential buildings in the United States. This equates to a figure of US $\$ 3.3$ billion. By 2010 this figure is estimated to grow to $5-10 \%$, and places a value between $\$ 10.2$ and $\$ 20.5$ billion on the US green building market \{McGraw Hill Construction 4\}. Appling these figures to the New Zealand non-residential market, this translates to a potential sustainable building market ranging from $\$ 102$ million ( $2 \%$ of $\$ 5.143$ billion) to $\$ 257$ million ( $5 \%$ of $\$ 5.143$ billion) and $\$ 514$ million (10\% of $\$ 5.413$ ) \{New Zealand, Statistics New Zealand, Value of Building Work Put in place: September 2006 quarter\}.

The 'Value Case for Sustainable Buildings in New Zealand' report suggests both Government and the public sector can play a leading role in initially driving sustainable building, but realise any 
long term success depends on the adoption of sustainability in the private sector $\{\mathrm{New}$ Zealand, Ministry for the Environment vii\}.

Cole suggests for projects where sustainable building initiatives are an option, are often dismissed by clients and designers without serious exploration, due to the perception that sustainable buildings are more expensive (between 5\% and 15\% from the outset) \{Cost and Value 305\}. Corresponding New Zealand case studies show this figure could even vary from 15\% less to 11.5\% more \{New Zealand, Ministry for the Environment, Value Case vii\}.

Another barrier for any building project is capital cost, and the instinctive desire to save money and minimise construction costs. According to the New Zealand Ministry for the Environment report initial capital costs are only a fraction of other building associated costs. That 20 -year present value salaries are approximately 18 times the value of the initial cost of the building, yet salary costs and productivity are rarely considered during the design process (refer to Appendix A.1.4.2) \{Value Case 45\}.

If the aim for a design project is to build sustainably, it is extremely important the right ideology is integrated from the outset. Romm and Browning suggest by the time the design is completed, $80-90 \%$ of the buildings life-cycle economic and environmental costs will have already become predetermined. More importantly, when just $1 \%$ of a development's up-front costs have been spent, up to $70 \%$ of its whole-of-life costs may already be committed \{qtd. in New Zealand, Ministry for the Environment, Value Case 41\}. Furthermore decisions made during design stage gives the project direction, and integrated building design is critical for developing sustainable buildings \{New Zealand Green Building Council, Green Star NZ Office Design v1: Technical Manual xi\}.

The report further concluded \{New Zealand, Ministry for the Environment, Value Case vii\}:

- "For owner occupiers, a 20-year whole-of-life cost view indicates the marginal cost increase of sustainable building is likely to be repaid between five or six times by operating cost savings alone.

- For tenants, the probable 20-year rental premium for sustainable buildings is likely to be repaid by a factor of approximately three from operating cost savings only

- For owner occupiers, developers and investment funders, a residual land value analysis shows a sustainable office building may have a land value of $40 \%$ more than that of a conventional building. Its true worth is nearly $40 \%$ more than a conventional building

- A set of case study buildings have shown that that energy costs are 35-50\% of those for similar conventional buildings $\{6\} "$ 
The report continues, the benefits of sustainable buildings are clear $\{\mathrm{New}$ Zealand, Ministry for the Environment, Value Case vii\}:

“...sustainable buildings are intrinsically more economic to run over their whole lifetime. They reduce waste and are much more efficient in their use of key resources such as land, energy, water and materials. They can also be healthier and more comfortable, and support greater productivity, with improved levels of natural light, cleaner air and a higher degree of personal control. They are also adaptable and durable enough to meet the requirements for flexibility and needs of future generations of building occupiers".

Bartlett and Howard also suggest a sustainable building tends to be more passive and simpler to operate, more energy and water efficient, requiring a more integrated but less sophisticated building system. As a result they are often more robust to alternative uses, are more flexible and durable, ensuring a longer life \{321; qtd. in Cole, Cost and Value 306; New Zealand, Ministry for the Environment, Value Case 43\}.

The Property Council of Australia highlighted several key benefits for sustainable building. These were \{qtd. in New Zealand, Ministry for the Environment, Value Case 41\}:

- Tenant benefits

- Lower operating costs for energy, water and waste

- Higher levels of occupancy satisfaction, health and productivity benefits

- Identification with corporate environmental responsibility investor benefits

- Marketing advantages due to point of difference

- A faster lease-up period

- Marginal increases in rental

- Higher tenant retention rates due to enhanced user satisfaction, health, comfort and productivity

- Higher loan value and lower equity requirements

- Higher building value on sale and appraisal

- Asset protection

- Overall greater return on investment 


\subsubsection{Professional Background to Building Sustainability Rating Tools}

\subsubsection{Green Building Councils}

Buildings have a significant impact on the environment, consuming $32 \%$ of the world's resources, including $12 \%$ of its water and up to $40 \%$ of its energy. Buildings are also responsible for $40 \%$ of the waste which ends up in the landfills and $40 \%$ of the greenhouse gas emissions in the developed world \{New Zealand Green Building Council, Green Star NZ Office Design v1: Technical Manual iv; World Green Building Council\}.

As a result many national bodies have emerged to establish Green Building Councils (GBCs) as a legitimate means to improve and reduce the environmental impact of buildings by driving the adoption of sustainable building practices. These non-government organisations are made up of industry leaders who are committed to developing healthier innovative buildings \{Green Building Council Australia; New Zealand Green Building Council\}.

Providing a supervisory role for these national organisations is the World Green Building Council (WorldGBC) which provides an international forum for the national GBCs. The main mission of the WorldGBC is to accelerate the transformation of the global property industry towards sustainability and define several key aims. These are \{World Green Building Council\}:

- Establish common principals for GBCs

- Serve as a global voice on behalf of GBCs

- Support and promote individual GBCs

- Establish a clearing for 'knowledge' transfer between GBCs

- Encourage development of market based environmental rating systems

- Recognise global green building leadership

For a list of current members (as of September 2007) refer to Appendix A.2.1.

\subsubsection{New Zealand Green Building Council}

The NZGBC formed in July 2005 and was granted formal organisational status on 1 February 2006, with the appointment of a twelve-member board reflecting the twelve sections of the building industry in July 2006. These twelve sections are \{New Zealand Green Building Council\}:

- Commercial Property Developers

- Investors, Owners and Property Managers

- Residential Developers and Major Portfolio Owners 
- Owner Occupiers (education, central and local government, defence, corporate, etc)

- Major Corporate Tenants and Retailers

- Building Contractors

- Building Product Manufacturers and Distributors

- Architects and Draftpersons

- Engineers

- Property and Construction Professionals (surveyors, consultants, project managers, etc)

- Research and Non-Government Organisations

- Related Interests (utilities, financial, legal, insurance, etc)

Like other national GBCs, the purpose of the NZGBC is to promote the mainstream adoption of sustainable building principles, policies, practices, standards and tools, by accelerating the development and adoption of market based sustainable building practices. Their main focus is to \{New Zealand Green Building Council\}:

- Develop Building Rating Tools for New Zealand

- Increase the level of knowledge and expertise through education and training

- Provide information and resources that will enable the industry to deliver tangible building performance improvements.

Additionally the NZGBC developed their own BSRT, Green Star NZ to stimulate market demand for high-performing, sustainable buildings. Additionally the aim is to provide the 'branding' to transform the skills and knowledge of the building industry as a whole \{World Green Building Council\}.

\subsubsection{Building Sustainability Rating Tools}

BSRTs are being used internationally and have emerged as a legitimate means to evaluate the performance of buildings across a broad range of environmental considerations \{Cole and Larsson 18; Cole, Building Environment Assessment Methods: Clarifying Intentions 231\}. Cole also suggests BSRTs have contributed considerably to furthering the promotion of higher environmental expectations and are directly and indirectly influencing the performance of buildings \{Cole, Building Environment Assessment Methods: Redefining Intentions and Roles $457\}$. These assessment techniques and rating tools are seen to be necessary to enable the environmental effects of urban or building schemes to be demonstrated and/or compared. They allow owners, architects, building professionals, authorities to select options, set targets and establish goals, enabling sustainable development to take place in a more measured and accurate way $\{$ Pitts 85$\}$. 
BSRTs were initially conceived, and still largely function, as voluntary, market place mechanisms to evaluate specific environmental aspects (e.g. energy, water, indoor environment quality) or specific building types (offices, homes, etc). Most existing BSRTs evaluate 'green' performance through either assigned points or weightings (refer to Appendix A.2.2 for a list of general characteristics) \{Cole, Building Environment Assessment Methods: Redefining Intentions and Roles 457-8\}.

The following list is by no means exhaustive but illustrates the variety of tool that have been developed \{United States, Dept. of Energy 41-3\}. Some of these are:

- BASIX (Australia)

- Green Star (Australia)

- NABERS (Australia)

- NatHERS (Australia)

- Green Globes (Canada)

- LEED Canada (Canada)

- GOBAS (China)

- PromisE (Finland)

- HK-BEAM (Hong Kong)

- TERI-GRIHA (India)

- GBTool (International)

- CASBEE (Japan)

- BRANZ Green Home Scheme (New Zealand)

- BRANZ Green Office Scheme (New Zealand)

- Green Star NZ (New Zealand)

- HERS (New Zealand)

- SBAT (South Africa)

- BREEAM (United Kingdom

- EcoHomes (United Kingdom)

- LEED (United States)

- HERS (United States)

Cole emphasises the most significant contribution of BSRTs has been to acknowledge and institutionalise the importance of assessing buildings across a broad range of considerations beyond just a single performance criterion (e.g. energy) \{Building Environment Assessment Methods: Clarifying Intentions 231\}. The result of the range of issues assessed by these assessments has required greater communication and interaction between the design team and 
various sectors of the building industry \{Building Environment Assessment Methods: Clarifying Intentions 231; Cole and Larsson18\}.

This is reinforced by Kaatz, who states BSRTs facilitate the integration of stakeholders' values, needs, and preferences into the design, delivery and operation of a building. They offer the means to potentially enhance the quality of decision-making in the building process by incorporating a variety of views and backgrounds to create a whole building process, allowing sustainable development to take place $\{$ Kaatz $316-18\}$

Furthermore, BSRTs can form part of a broader context for creating change within the building industry. Specifically, assessments can \{Cole, Emerging Trends 5\}:

- Provide a common and verifiable set of criteria and targets

- Gather and organise detailed information about a building, assisting management to lower operating, financing and insurance costs

- Be used by building owners to identify priorities for future administration measures, building retrofits, etc

- Provide building owners a means to communicate to prospective tenants the inherent environmental qualities of the building they are leasing

- Offer a means of structuring environmental information of a building design, providing a reference by which building owners and design teams can formulate effective environmental design strategies

- Assist in the creation of knowledge and expertise within the building industry, facilitating the assimilation of environmental issues into building practice

\subsubsection{Green Star New Zealand}

For a New Zealand context the NZGBC created Green Star NZ, the country's first comprehensive BSRT. It was created to $\{\mathrm{New}$ Zealand Green Building Council\}:

- Establish a common language and standard of measurement for green buildings

- Promote integrated, whole-building design

- Raise awareness of green building benefits

- Recognise environmental leadership

- Reduce the environmental impact of development

Green Star NZ evaluates building projects against eight environmental impact categories, including a separate innovation section. Within each category, points are awarded for initiatives which demonstrate a project has met the overall objectives of Green Star NZ and the specific 
criteria of the relevant rating tool credits. Points are then weighted and an overall score is calculated, determining the project's Green Star NZ rating (refer to Figure 1-5).

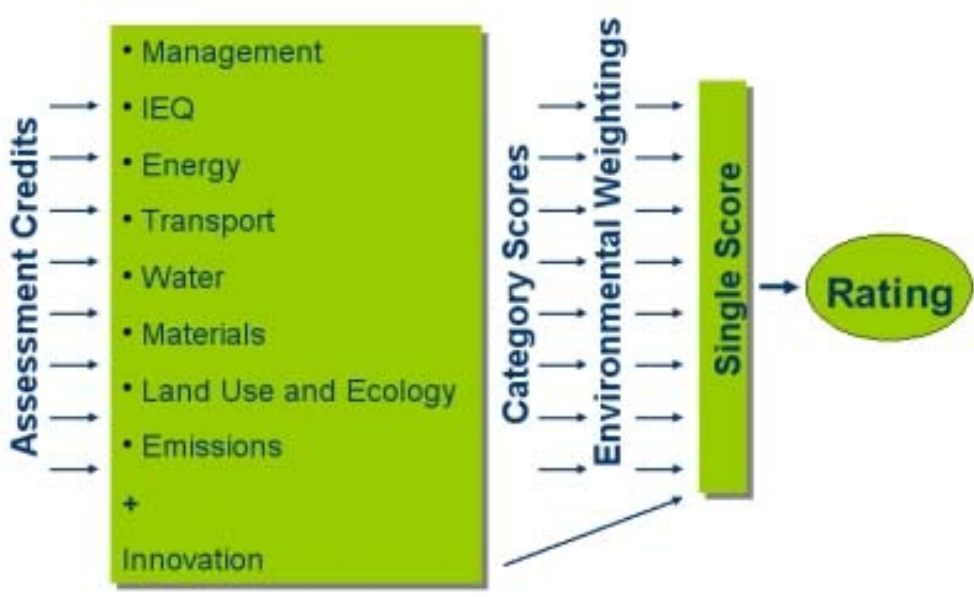

Figure 1-5: Basic structure of Green Star NZ \{New Zealand Green Building Council, Green Star NZ Office Design v1: Technical Manual vi\}

Green Star NZ was designed as a voluntary, performance based, graduated system to rate a building's attributes (not operations), and reward best building practice. As of August 2007 the only available version of the tool is Green Star NZ: Office Design v1, but once developed, it is intended to assess all phases of a building's development (i.e. design, as built, fit-out and performance - refer to Figure 1-6) and also different building types (e.g. office, retail, health, education, residential, industrial, etc). The order at which these rating tools will be developed and released is dependent on market demand.

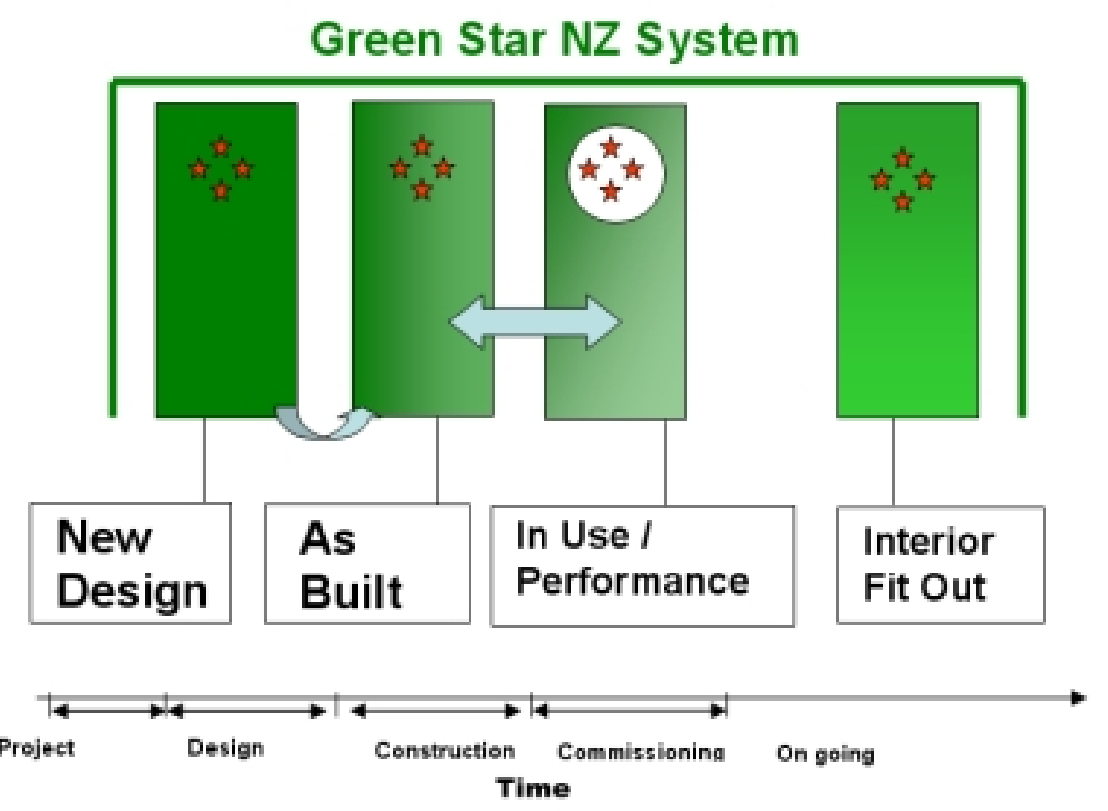

Figure 1-6: Green Star NZ building process coverage \{New Zealand Green Building Council\} 
The aim of Green Star NZ: Office Design v1 was to \{New Zealand Green Building Council, Green Star NZ Office Design v1: Technical Manual xi\}:

- Encourage development of new and emerging technologies

- Reduce the environmental impact through direct and indirect initiatives

- Encourage a new approach to designing buildings by rewarding best practice and excellence

- Ensure that effective design strategies are accounted for without the overlay of operational management and user behaviour

- Allow different designs to have their environmental initiatives fairly benchmarked

The system awards an overall score out of 100 , which is determined by adding together the entire weighted category scores (refer to Table 1-5 and 1-6), plus the innovation points \{New Zealand Green Building Council, Green Star NZ Office Design v1: Technical Manual ix\}.

Table 1-5: Green Star NZ rating tool scores \{Green Star NZ Office Design v1: Technical Manual xi; Green Star Level 1 Training\}

\begin{tabular}{|l|l|l|}
\hline Single Score (Overall) & Rating & Outcome \\
\hline $0-19$ & One Star & $\begin{array}{l}\text { Not eligible for formal certification, signifies 'Minimum } \\
\text { Practice' }\end{array}$ \\
\hline $20-29$ & Two Star & $\begin{array}{l}\text { Not eligible for formal certification, signifies 'Average } \\
\text { Practice' }\end{array}$ \\
\hline $30-44$ & Three Star & $\begin{array}{l}\text { Not eligible for formal certification, signifies 'Good } \\
\text { Practice' }\end{array}$ \\
\hline $45-59$ & Four Star & $\begin{array}{l}\text { Eligible for Four Star Green Star NZ certification, } \\
\text { signifies 'Best Practice' }\end{array}$ \\
\hline $60-74$ & Five Star & $\begin{array}{l}\text { Eligible for Five Star Green Star NZ certification, signifies } \\
\text { 'New Zealand Excellence' }\end{array}$ \\
\hline $75+$ & Six Star & $\begin{array}{l}\text { Eligible for Six Star Green Star NZ certification, signifies } \\
\text { 'World Leader }\end{array}$ \\
\hline
\end{tabular}

Table 1-6: Weighted Categories \{New Zealand Green Building Council; New Zealand Green Building Council, Green Star NZ Office Design v1: Technical Manual viii\}

\begin{tabular}{|l|r|}
\hline Environmental Category & NZ Weightings \\
\hline Management & $10 \%$ \\
\hline Indoor Environment Quality & $20 \%$ \\
\hline Energy & $25 \%$ \\
\hline Transport & $10 \%$ \\
\hline Water & $10 \%$ \\
\hline Materials & $10 \%$ \\
\hline Land Use and Ecology & $10 \%$ \\
\hline Emissions & $5 \%$ \\
\hline Total & $100 \%$ \\
\hline
\end{tabular}

For more detail about Green Star NZ Assessment process refer to Appendix A.2.3. 


\subsubsection{Research Background}

Literature shows a considerable amount of research effort has been directed at the 'product' aspect of BSRTs; their technical features such as weightings (more detail in Section 2). Conversely relatively little consideration has been given to how the structure of BSRTs facilitates dialogue between different stakeholders in formulating and pursuing a design project \{Cole, Building Environment Assessment Methods: Redefining Intentions and Roles 466\}.

Cole suggests a building project involves many individuals, all with different agendas, expectations, interests and influences. Therefore it is critical for good communication between those involved in a project, to prevent problems arising from miscommunication in both building design and construction \{Cole, Cost and Value 308\}. As a result BSRTs have a distinct opportunity to facilitate this dialogue, bringing members together from the outset of a project, improving the quality of communication, thus creating better, more integrated sustainable buildings \{Cole, Cost and Value 306-7\}.

An article in the NZGBC Newsletter (March 2006) highlighted the need for New Zealand to accelerate the introduction of a BSRT, and having the scheme up and running was the most important need at the time, as the tool will evolve with use \{Sustainable Building Assessment Scheme Project\}. While it is important the tool be operational, there still is a requirement for its implementation to be well researched; once it is received by the building industry, any negativity could adversely influence the overall success of the tool and its infiltration of the market. As Ray Cole emphasised in a presentation for the NZGBC (2006), the implementation phase is often overlooked, but is fundamental for the overall success of the tool.

\subsection{Problem Statement}

BSRTs have enjoyed considerable success and Cole states that awareness of these tools has created the mass of interest necessary to cement their role in creating positive change. While BSRTs have been successful in entering the jargon of the building industry, the number of actual assessed and certified building projects remains relatively low (more detail in Section 2.1.1) \{Cole, Building Environment Assessment Methods: Redefining Intentions and Roles 456\}. The NZGBC has stated the implementation of a BSRT can only be successful if the selected tool is widely accepted and adopted by members of the building industry. If these key stakeholders are reluctant to adopt the tool, voluntary uptake will not occur and implementation will be slow \{New Zealand, Ministry for the Environment, Green Building Assessment Tool Research Project: Draft Report 7:5\}. 
This asks the question; how can a BSRT become more successful in its implementation phase, and be well received by the New Zealand building industry?

\subsubsection{Aims and Objectives}

The overall aim of the study was to investigate the requirements of stakeholders and end-users including their understanding of sustainability, the NZGBC and BSRTs, ensuring potential barriers were identified and addressed in the early stages of Green Star NZ implementation. The research also intended to provide a 'sustainability snapshot' of the New Zealand building industry and of the current New Zealand market, establishing a base point for future measurement.

The specific objectives of the research were to investigate:

- The building industry's level of awareness and the level of involvement regarding sustainability, sustainable building and BSRTs

- The building industry's existing knowledge and experience with BSRTs

- How different groups within the building industry anticipate using Green Star NZ and if they are likely to seek formal certification

- The building industry's understanding of the NZGBC, and its likely impact in the production of more sustainable buildings in New Zealand

- The drivers, triggers, obstacles and reasons for sustainable building

- The requirement for sustainable building information and the corresponding level of satisfaction regarding this information

- How international research compared with the current study, allowing trends, differences and similarities to be discussed

Additionally the results from the research could serve to enhance and improve:

- The identification of possible issues regarding the BSRT, to help smooth the period of transition for implementation and make it more New Zealand specific

- The potential for a more successful BSRT, including, penetration of the market and widespread application

- The relationship between the NZGBC and industry, encouraging dialogue to help develop the tool

- Ultimately the chance for the development of more sustainable buildings in New Zealand, through increasing education and awareness

While this research focussed on the New Zealand context, it was anticipated the methodology could also find application internationally. 


\subsection{Methodology Overview}

In overview, a quantitative survey was employed to ascertain the New Zealand building industry's understanding of sustainability, sustainable building and BSRTs. The survey was conducted through a questionnaire over the three-week period from the 19 February 2007 to the 12 March 2007. In total an estimated 17,350 building industry professionals were contacted, with an ultimate response of 476. The resulting data was inserted into Microsoft Excel, which organised and performed the initial analyses. To test the reliability of the results, statistical analyses (t-tests) were performed through the software package SPSS 14.0 to investigate the significance of non-response.

\subsection{Professional Significance}

It was anticipated the results from this research would allow the building industry to identify possible information gaps, and to use the results to lobby Government to direct extra funding into these areas, whilst identifying future avenues for research. The research also intended to assist the NZGBC and other non-governmental organisations to educate the building industry, creating more demand for sustainable buildings and Green Star NZ certification. Potentially this 'education' could accelerate the market, contributing to more innovative and economical advances in building technology.

With support from the NZGBC and its CEO Jane Henley, a number of outcomes were identified to be of direct benefit to the Council. In particular it was pointed out this research could provide the necessary snapshot of the current New Zealand market and the industry's awareness of sustainability, sustainable buildings and BSRTs. It would also provide a base point from which the NZGBC would be able to measure their continuing impact and the success of Green Star NZ. For instance in two or three years time a similar study could be conducted to investigate how far they have come and if the NZGBC have fulfilled their original aims or if these aims have changed. This research also intended to help ascertain how well the expectations of the building industry were being met by the NZGBC, enabling them to develop their training and education procedures to better meet these expectations.

The American BSRT, LEED is considered to be a success, even though it has a small uptake (around 5\%) relative to the number of new and existing commercial buildings which have the opportunity to use it. This research aimed to propose solutions to the obstacles and barriers to the uptake of Green Star NZ, allowing the NZGBC to aim for a much higher percentage of uptake, having a more significant effect on the market. To increase the possibility for even greater uptake, the research will attempt to understand how end-users might use and apply the tool. There is anecdotal evidence from the building industry that existing BSRTs are being used 
only as a design guideline. It is therefore important to investigate what barriers could be inhibiting full certification of Green Star NZ.

From a NZGBC perspective, it was important to make comparisons at an international level. Two reports from Australia and the United States allowed some comparison; the 2006 'Green Building Market Report', and the 2005 'Green Building SmartMarket Report' (analyses in Section 5). While both studies were completed with each of their respective BSRTs already well established, Green Star NZ was yet to be officially released; the study would allow the NZGBC to gauge where they are in terms of their own development and at an international level.

An outcome of having a better more successful BSRT is the development of more sustainable buildings. The report for the New Zealand Ministry for the Environment states the benefits New Zealand's buildings are of increased performance, as BSRT can help determine how sustainable the building sector is in relation to benchmarking standards, to easily communicate the relative level of sustainability to clients and the market $\{$ Value Case 56$\}$.

The additional benefits of the BSRT were seen to be:

- Promoting industry awareness

- Transforming the market

- Raising awareness and benefits of sustainable buildings, including non-financial benefits (e.g. productivity, health, and well-being)

- Establishing a common language

- Setting a standard for measurement of sustainable buildings

- Reduction of building impact on the environment

- Waste reduction/minimisation

- Increase in energy efficiency

- Reduction of water use

- Reduction of carbon dioxide

- Reduction of resource use

While these are only some of the benefits, it emphasises the need for a BSRT and in conjunction with good validation processes, research of this nature can assuredly assist in the implementation of a New Zealand specific BSRT. 


\subsection{Project Advisory Group and Ethics}

The notion of industry participation and involvement was vital for this research and key to establishing a 'real world' focus to the research (i.e. meeting the requirements of industry). Therefore selected industry members were invited to join a Project Advisory Group (PAG) for duration of the research, and were consulted collectively and individually through either presentations or meetings, where the progress of the research could be discussed. This process allowed the PAG to help mould and develop the research, while helping the study keep its integrity with industry.

The following people have contributed to the PAG:

Patrick Arnold - eCubed Building Workshop

Michael Field - URSCorp

Rachel Hargreaves - BRANZ

Quentin Jackson - eCubed Building Workshop

Wayne Sharman - Building Research and NZGBC Board member

Peter Thorby - Department of Building and Housing

Michael Warwick - Stephenson and Turner

Chris Wood - Ministry for the Environment

In addition NZGBC CEO, Jane Henley was closely consulted throughout.

Due to the use of the survey methodology ethical consent was obtained from the Victoria University of Wellington's Human Ethics Committee, and followed their strict protocols and guidelines.

\subsection{Key Definitions}

There are many different combinations of adjectives to describe BSRTs, for example:

- Building rating tools

- Sustainable building assessment

- Building sustainability assessment

- Environmental rating tools

- Environmental assessment

- Environmental impact assessment

- Building assessment methods 
In terms of this research, these assessments have been defined as 'Building Sustainability Rating Tools'. It is also important to justify the use of the term sustainability, for it is not the tool that is sustainable but a tool which measures sustainability hence the sustainability of a building. Kaatz also emphasises the term sustainability is preferable, as 'sustainable' may imply the building is sustainable to begin with $\{311\}$.

\subsection{Organisation of Thesis}

This thesis is divided into six main sections, with the current introduction section providing the background, rationale and the specific context in which this research project was undertaken, leading up to the problem statement and the aim and objectives.

Section 2 reviews and discusses literature regarding BSRTs, citing specific evidence, and how it relates to the current research project. The chapter first discusses implementation-specific research and then non-implementation-specific related literature.

Section 3 describes the methodology employed in this research to determine the conditions needed for the successful implementation of a New Zealand BSRT. It includes the survey design, and the procedures for conducting the study, including details about how the data was gathered, the participants, and statistical analyses.

The results of the survey are presented in Section 4. Firstly, the chapter examines the statistical significance of the data, including total response, confidence intervals and margin of error, response rate, and the issue of non-response. Then the chapter describes the results of the web-based survey, providing a summary discussion at the end of each section. Finally it presents the methodological issues encountered and recommendations for further improvement.

Section 5 discusses the differences and similarities of the results found in this study and the results from similar studies done in the United States and Australia.

Conclusions are made in Section 6, highlighting the key findings of the research. The chapter concludes by suggesting future implications and research avenues.

The Appendices are found in the rear of this document and within an attached CD, providing additional information to support the rationale, assumptions and findings of this research project. 
Introduction 


\section{Literature Review}

\subsection{Overview}

The following chapter reviews and discusses literature regarding BSRTs, citing specific evidence, and how it relates to the current research project. The chapter is divided into two main parts. The first discusses in detail implementation-specific research such as communication, targets, marketing, and the flexibility and adaptability of BSRTs. The second discusses nonimplementation-specific literature including BSRT reviews, environmental assessment criteria and weighting, voluntary assessment against compulsory assessment, potential performance versus actual performance, and regional variation. Finally the whole chapter is concluded with a summary discussion, highlighting key evidence to support the approach taken to this research.

\subsubsection{Implementation-Specific Research}

Sustainability has become a part of the vernacular of the 21 st century, as human impact on the environment is increasingly being realised and understood (e.g. pollution and global warming). The questions nevertheless are why are we not seeing the creation of more sustainable buildings in practice, and what are the barriers limiting their adoption \{Cole, Cost and Value 307\}? Bordass argues $\{350$; qtd. in Cole, Cost and Value 307\}:

\footnotetext{
"It is not surprising that people find it difficult to know if they really want sustainable buildings and how much they should be paying for them, given the current situation of poor information, market lock-in, uncertain risk, mixed motives, confusing government leadership and contradictory price signals".
}

While BSRTs have enjoyed considerable success, the overall awareness of BSRTs has created a significant mass of interest in creating positive change, even though the number of actual assessed and certified projects are still relatively low \{Cole, Redefining Intentions and Roles 456\}. In Australia for example (as of December 2007), there have only been 38 Green Star certified projects, even though these tools have been available since 2003 \{Green Building Council Australia\}.

There is a potential role for a BSRT to be a driver for the creation of sustainable buildings, yet current and past literature has presented several fundamental questions. Firstly, whether BSRTs that focus on sustainability will find favour with the business community; secondly, if greater engagement by stakeholders is required to establish a more positive influence; and thirdly, how 
can stakeholders and end-users be better engaged in the development of a BSRT without undermining the overall process \{Cole Redefining Intentions 465 \}.

The application of a BSRT provides an opportunity to facilitate dialogue between the various parties of a building project, bringing these individuals together from the outset, improving the quality of communication, and thus creating more integrated sustainable buildings \{Cole, Cost and Value 306-7\}. Little research exists regarding the implementation phase of BSRTs. As one of the main contributors in this field, Professor Raymond Cole identifies a considerable amount of past research has been directed at the product aspect of BSRTs, with little consideration for its implementation. Rather he asks how the structure of a BSRT can facilitate dialogue between different stakeholders in formulating and pursuing a design project \{Redefining Intentions and Roles 466$\}$. He further emphasised this in a presentation for the NZGBC in 2006, that the implementation phase of BSRTs is often overlooked, but is fundamental for its overall success.

A further report commissioned for the Ministry for the Environment concluded, the implementation of a BSRT can only be successful if the selected tool is widely accepted and adopted by its members of industry. If these key stakeholders are reluctant to adopt the tool, voluntary uptake will not occur and implementation will be slow \{Green Building Assessment Tool Research Project: Draft Report 7:5\}. This is reflected in the attitude of the building industry, which has been generally slow to adopt change. For example technical innovations (e.g. photovoltaics) and advances in building design have been constrained by economic possibilities and social expectations (i.e. their cost and perceived value). Therefore to accommodate these innovations and advances, building design must challenge many of the underlying premises and fundamentals that determine its direction, to create the shift in attitude to embrace sustainability \{Cole, Cost and Value 305\}. Cole expresses with time these innovations may become standard and assimilated within a BSRT, but it is in this transitional period of implementation where the issues of specification and interpretation are less well defined, where conflict and resistance are most evident.

Part of this conflict clearly arises from the numerous interests of stakeholders and end-users, as interests from those involved can constrain both the extent and rate of progress of a BSRT \{Cost and Value 305\}. A building project for instance involves many different individuals, from clients, tenants, and developers, to architects, engineers and contractors, even though their agendas, expectations, interests and influences can be very different (e.g. differences between who pays and who derives value from a sustainable building) \{Cole, Cost and Value 308\}. Larsson further identifies this conflict; that the conservative nature of owner and operator associations can dilute the requirements of a BSRT being established, to the point where significant environmental 
advantages cannot be gained \{Larsson 335\}. Consequently, with the range and number people involved in the building process, good communication is critical \{Cole, Cost and Value 308\}.

Cole also recognises a primary future role of BSRTs to transform the culture of the building industry, accommodating sustainability as a common, consistent and integral part of the decision-making process \{Building Environmental Assessment Methods: Redefining Intentions and Roles 464; qtd. in Kaatz 311\}. The question therefore posed is, how can a BSRT be more successful in creating better dialogue between stakeholders and end-users?

\subsubsection{Communication}

The development of BSRTs has largely been driven by the scoping and structuring of the performance criteria, i.e. the environmental assessment categories, such as Management, Indoor Environmental Quality, Energy, Transport, Water, Materials, Land Use and Ecology, and Emissions. While the environmental assessment criteria of a BSRT are an important component, there is also a requirement for the result of a BSRT to be organised in a way that facilitates meaningful dialogue between stakeholders and end-users.

Cole states it is during this result or output phase the complete performance profile of the building is evident and where the result must be presented in a coherent and informative way to a variety of users \{Building Environmental Assessment Methods: Clarifying Intentions 240; Cole, Building Environmental Assessment Methods: Redefining Intentions and Roles 464\}. With the wide range of assessment criteria, BSRTs also need their results presented in a manner which communicates overall performance of a building clearly and succinctly without compromising detail. He further states, while broadly defined environmental categories are the least restrictive, they have a tendency to generalise the value of an assessment. In contrast, if these categories are too detailed, the assessment can become complex, prohibiting execution, presentation and interpretation \{Cole, Building Environmental Assessment Methods: Redefining Intentions and Roles 464$\}$.

Tufte suggests the ways in which results are illustrated can have a direct bearing on how they are used and understood \{qtd. in Gann, Salter and Whyte 322, qtd. in Cole, Building Environmental Assessment Methods: Redefining Intentions and Roles 464\}. The Japanese BSRT, CASBEE for instance, explicitly distinguishes between how the performance information is organised during the assessment process and how it is then transformed to communicate for a variety of different outputs, including an overall performance profile as well as detailed descriptions \{Cole, Building Environmental Assessment Methods: Redefining Intentions and Roles 464\}. 
Increased use of BSRTs has also identified a host of new potential roles. Such roles relate primarily to the facilitation of communication between stakeholders and end-users, as the culture of the building industry changes to address sustainability. Cole states BSRTs remain constrained by a lack of clarity regarding their emerging roles \{Building Environmental Assessment Methods: Redefining Intentions and Roles 465$\}$. Furthermore he stresses a number of fundamental issues lie at the heart of the debate, in particular the need for clarity and distinction between the roles of a BSRT as an assessment, as a measure of performance and progress, and as a catalyst for market transformation \{Cole, Building Environmental Assessment Methods: Redefining Intentions and Roles 465$\}$.

While there is a strong temptation to opt for a system that is simple and permits rapid assessment, the danger is simplistic assessments may lack long-term credibility \{Larsson 336\}. Pope, Annandale and Morrison-Saunders also identified the concern BSRTs are not being formed by proper critical debate, and there appears to be a view that any move towards establishing a BSRT will automatically be a good thing $\{597\}$.

Current international BSRTs generally only measure a building in the design phase, it has been suggested future developments should allow a BSRT assessment to be described or measured in successively and logically connected detailed levels (e.g. different stages of the building process design, as built, performance). This would open-up the BSRT framework and not only offer the potential for greater transparency, but also allow a better understanding of the basis upon which assessments have been made. Moreover, it would provide stakeholders and end-users with the ability to revisit and adjust performance criteria as the BSRT matures while maintaining an understanding of the linkages between the various performance issues \{Cole, Emerging Trends 8$\}$.

Any new development (e.g. scheme, innovation or tool) can often create a level of uncertainty, and stakeholders and end-users can be cautious about moving into unfamiliar areas. Hydes advocates for incremental advances, small, but innovative, steps to build stakeholder confidence \{qtd. in Cole, Cost and Value 307\}. Bordass suggests a marketing approach be taken, that reliable, robust information is needed to smooth the transition for more sustainable buildings, reassuring stakeholders and end-users both short and long-term risks can/are being effectively managed \{350; qtd. in Cole, Cost and Value 307\}.

By improving communication between end-users, a BSRT can have profound implications on education and training, and also the responsibilities of building professionals to create and assess sustainable buildings. As Bordass suggests, greater visibility of intentions and outcomes of a 
BSRT, will inherently create better information, benchmarking, and feedback \{350; qtd in Cole, Cost and Value 308$\}$.

While communication of results is important at the end of an assessment, it just as vital that communication between stakeholders and end-users is created in the implementation phase of a BSRT. With the integration of stakeholder and end-user values in the implementation phase it enhances the ability of a tool's overall success and greater awareness of the BSRT, before it is introduced to the building industry.

\subsection{Integration of Stakeholder and End-user Values}

Kaatz states the process of social and collaborative learning is fundamental for any interdisciplinary activity. That it is vital for a BSRT to facilitate the integration of stakeholder and end-user values, needs and preferences into the design, delivery and operation of a sustainable building $\{316-7\}$. For this reason it is crucial the results of a BSRT assessment are fed back into the building process, in order to increase the relevance of the results and outputs \{Kaatz 316$\}$.

Kaatz further emphasises the importance of broader stakeholder participation to generate and permit the transfer of knowledge, and that the application of a BSRT should be a collaborative process requiring the participation of all stakeholders of the building industry $\{316\}$. Through better communication a BSRT could then provide an opportunity to develop a better understanding of the issues regarding sustainable building, leading to more active involvement from the building industry $\{$ Kaatz 316$\}$.

In terms of the BSRT process itself, research during the implementation phase would allow better transparency and enable validity of the verification process and allow better understanding of stakeholder and end-user expectations $\{$ Kaatz 316$\}$.

\subsubsection{Targets}

As already stated, BSRTs have been relatively successful overseas, but the number of actual assessed and certified projects is still relatively low \{Cole and Larsson 18; Cole, Building Environmental Assessment Methods: Clarifying Intentions 231; Cole, Building Environmental Assessment Methods: Redefining Intentions and Roles 456\}. As already stated the Australian BSRT, Green Star for instance is considered a success, even though it has a small number of certified projects (38 projects as of December 2007) relative to the number of new and existing buildings which have the opportunity to use it \{Green Building Council Australia\}. The question then is what is the appropriate and realistic level of uptake for Green Star NZ? 
Cole emphasises that defining a target level for uptake and operation misses the point. Instead, the building industry needs to set a target for maximum engagement of stakeholders and then develop approaches to achieve that goal. Furthermore, settling for small targets of 5-10\% will not have the desired impact to push the development of more sustainable buildings \{Cole, Re: Masters Research\}. In correspondence with the NZGBC it was stated no exact figure had been defined, and emphasise rather, what would it take to have $50 \%$ of new buildings achieving a four Green Star NZ rating or higher \{Henley, Re: Rating Tool\}.

With any targeted level of uptake and operation it is very much dependent on the size of the market the BSRT is implemented in. While a larger market might create more opportunities for sustainable design and the use of a BSRT, it may in fact be more difficult to infiltrate and to achieve a good level of awareness. Due to New Zealand's smaller market size, it might actually have an advantage over other nations and achieving a greater level of awareness may in fact be easier and quicker.

\subsubsection{Marketing}

Marketing is an important factor for the success of a BSRT and should be directed at all appropriate areas of the building industry, from the experienced user to the complete novice. Larsson states there are two factors which are necessary to persuade investors and tenants to adopt a BSRT, the availability of a coherent, robust and thoroughly tested system, and the development of industry values that favour high performance and quality $\{338\}$. He further suggests no matter how good the design of the tool or the capabilities of the assessors, it will certainly fail unless there is a massive and continued marketing effort to convince the building industry of the long-term benefits of the BSRT \{Larsson 338$\}$.

With the proliferation of BSRTs available, it is not surprising competing systems can slow the widespread adoption of sustainable building practices and lead to market confusion \{Cole, Shared Markets 368; Wilson and Tagazza 8\}. Ervin states that building industries possess an excess of labelling and rating programs, fragmenting the market and impeding information \{qtd. in Cole, Shared Markets 368\}. Cole reinforces this, by offering a consistent industry-wide definition of best environmental practice and performance targets, the result of a BSRT can focus attention on clarity and debate of sustainable building practice \{Shared Markets 368$\}$.

The competition between different BSRTs can also create confusion, sending mixed messages to stakeholders and end-users, creating uncertainty to which system will best suit their requirements \{Cole, Shared Markets 368.\} In Australia, about 27 systems co-exist (e.g. Green Star, AGBR, BASIX, NatHERS, NABERS) and while each is slightly different, they can create confusion in 
the market place \{Rating CIBSE's Night of Stars 12\}. Again due to the small nature and its inherent limitations (i.e. market size) of New Zealand's building industry it has a distinct advantage, as there is less chance competing systems will be developed, thus reducing confusion. To make it more user friendly it would also be preferable any subsequent BSRTs be part of the NZGBC Green Star NZ suite of rating tools.

\subsubsection{Flexibility and Adaptability of Building Sustainability Rating Tools}

It is an important component for BSRTs to remain flexible, allowing them to evolve towards differing outlooks, and changes in the importance of environmental concerns and criteria, and methods of calculation. Therefore there is a necessity for BSRTs to incorporate new sustainable design techniques as old ones become industry norm. In New Zealand for instance, it would be expected that overtime Green Star NZ would influence sustainable building at the ground level, and these advances and innovations in sustainable design would filter down through the New Zealand Building Code \{New Zealand Green Building Council, Green Star NZ: Accredited Professional Level 2 Training\}.

For that reason BSRTs should aspire to be robust, simple but also comprehensive. Although, it is not necessarily easy to capture all the possible scenarios of a sustainable building project into one defined set of assessment criteria \{Kaatz 312\}. Kaatz states it is then crucial to provide mechanisms that allow for flexibility and adaptability of the assessment methodology $\{313\}$.

Cole identifies existing BSRTs have a limited shelf life, that with such a dynamic range of environmental issues and a rapidly increasing knowledge base they do not have an explicit method of dealing with the evolution in performance standards. Apart from updated versions, there has been no indication further building assessments will be made after the initial. \{Cole, Emerging Trends 10\}. Many existing BSRTs focus on buildings in only the design phase, with a rating being applied indefinitely, even though the actual performance of the building may differ significantly. For this reason Green Star NZ has specifically been designed as a graduated system, with versions to assess the design, as built, and performance phases of a building project. That is, any rating achieved in the design phase is only applicable to that stage and does not subsequently carry over to another phase.

The NZGBC has stated preliminary certification (i.e. Design) will initially be granted in the design phase, but once the building has been constructed, it can be certified through verification that the design was delivered to the same standard (i.e. As built). A final commission period of around one to two years will be required before any performance certification is issued 
(i.e. Performance) \{New Zealand Ministry for the Environment, Green Building Assessment Tool Research Project: Final Report 7:8\}.

At this stage, the NZGBC expects a performance rating will be valid for five years and after this point as the BSRT and new environmental concerns evolve a new rating will be required for the buildings current performance. The purpose of this approach is designed to avoid the problem many international tools now face, in giving buildings a rating and keeping this rating indefinitely, irrespective of its actual performance or evolution or building design. Again, this could create market confusion when comparing two similarly rated buildings with one being constructed five to ten years prior, where the requirements to meet a 'high' standard will be harder to achieve and as a result the efficiencies expected would be greater (New Zealand Ministry for the Environment, Green Building Assessment Tool Research Project: Final Report 7:8\}.

\subsection{Non-implementation Specific Research}

Discussed above was the implementation specific research, and the opportunity for a BSRT to facilitate dialogue between stakeholders of a building project. The following section explores the non-implementation specific research, which as Cole describes, has been directed at the product aspect of BSRTs. This discussion was necessary in establishing the outcomes of past research, and why it was important for this research to focus on the specific issues related to the implementation of a BSRT.

\subsubsection{BSRT Reviews}

Research has frequently been dedicated to reviews of current BSRTs, and the need to determine a 'best' tool for adoption. While reviews of this nature can be helpful to provide insightful discussion as to the benefits and success of BSRTs, the limiting factor of such literature is no tool should be regarded as 'perfect' or the 'best' as each will have its own specific issues and characteristics. In New Zealand two reports have evaluated current available BSRTs; the 2005 BRANZ report 'Compendium and Evaluation of Building Environmental Impact Schemes being used in Australasia' and the 2007 collaborative report for the New Zealand Ministry for the Environment, 'Green Building Assessment Tool Research Project: Final Report'.

The goal of the BRANZ report was to compile and evaluate current Australasian based BSRTs (nine BSRTs were examined), with a view to recommending a scheme for use in New Zealand office buildings \{Hargreaves 1\}. Smith and Donn emphasised whether one examines only tools currently used in Australasia or widens the purview to all available tools, the more important concept is any tool will need to be adapted to a New Zealand context before use $\{2\}$. Hargreaves also reinforces this, that no tool is exactly the same and all methods differ slightly 
depending on which markets they cater for, what type of buildings they apply to, what environmental issues are included, and whether the evaluation is undertaken at the design stage or retrospectively $\{i i i\}$. This strengthens the argument any BSRT will need to be adapted to the New Zealand context before use.

The purpose of the second report for the Ministry for the Environment was to present a solution for the development of a BSRT for new office buildings in New Zealand. This report outlined a set of criteria to evaluate each tool based on the needs of the New Zealand market. The criteria were $\{$ New Zealand Ministry for the Environment, Green Building Assessment Tool Research Project: Final Report 6:5\}:

- "Applicability to New Zealand conditions

- Any barriers with legislation frameworks

- Simple interface

- Ability to adapt the tool for NZ conditions

- What characteristic does the tool measure; does it cover a broad enough range of social, environmental and economic issues?

- How is performance of the building measured?

- Other considerations that could be important?"

Overall, fourteen BSRTs were evaluated; though it is not clear from the discussion why the unsuccessful BSRTs that did not meet the above criteria were discarded from further investigation.

Both reports recommended the Australian system Green Star be adapted for New Zealand office buildings \{Hargreaves iv, 33; New Zealand Ministry for the Environment, Green Building Assessment Tool Research Project: Final Report 6:6\}. While it is not explicitly stated, there is certain speculation the recommendation had some political basis. That stakeholders and investors in the New Zealand building market are based on both sides of the Tasman and to gain funding and support, the tool needed to be well recognised \{Smith and Donn 3\}. Furthermore, the Ministry report states Green Star (Australia) is already widely used by sustainable building professionals in New Zealand and consequently was seen to be the most logical solution for adoption $\{7: 7\}$.

The most important factor for any review is to understand no tool should be seen to be the best; that they are all designed with specific contexts in mind and as an industry we should be learning from all the various possibilities. Likewise, any recommendation should only be made based on a 
clearly defined framework with specified criteria, because no matter what tool(s) are chosen they will have to be modified to a specific New Zealand context before use.

\subsubsection{Environmental Assessment Criteria and Weighting}

The range of environmental criteria that are relevant to buildings is potentially limitless, and any attempt to generate design guidelines or undertake a comprehensive assessment should be preceded by a declaration and characterisation of this range. Although it is relatively straightforward to list the environmental criteria, organising them into useful, related categories and prioritising them for either design or assessment is far more problematic \{Cole, Emerging Trends 5\}. Cole emphasises the number, organisation of criteria and rigour applied to the formulation in assessment methods are influenced by \{Cole, Emerging Trends 5-6\}:

- "The practicality and cost of making an assessment - the greater the number of criteria, the greater the effort required to collect and analyse the results

- The ability to make assessments repeatedly and reliably by trained assessors or through self-assessment. The credibility of an assessment method within the market-place is, in part, dependent on the consistency of the results, i.e. different assessors of the same building should produce essentially the same performance evaluation. Greater differences can be expected if the assessment methods includes a large number of qualitative criteria involving personal judgement on the part of the assessor

- Whether there is general agreement over the criteria, and therefore confidence, as to their significance. Although some aspects of building performance are widely accepted as critical environmental concerns and have clearly defined performance indicators, e.g. greenhouse gas emissions, others such as embodied energy or design for deconstruction are less well understood at this time

- The ability of users to fully comprehend to the results of the assessment. Clearly the comprehensiveness of an assessment is improved by increasing the number of assessment criteria which are included. However, the ability of building owners, users and the public to interpret the results of an assessment diminishes with each additional criterion. Creating summaries of a wide range of criteria to make the results understandable becomes an increasingly important requirement but at the expense of making the overall process less transparent"

Likewise, different aspects of the output can hold greater interest for different users and it is necessary for the output to allow detailed scrutiny of each aspect of performance. This would allow a more objective interpretation of the criteria and results, improving the confidence of the overall rating. 
As stated earlier considerable research has been directed at the product aspect of BSRTs, with little consideration for its implementation \{Building Environmental Assessment Methods: Redefining Intentions and Roles 466\}. A previous research project, 'A Sustainability Rating Tool for New Zealand Commercial Buildings' was directed towards this product aspect. This research was based upon the assumption when choosing a tool in a new country or ecological situation, it is best to select the most relevant performance indicators from a variety of tools and combine them in a manner that has been customised (weighted) for the local environment.

The hypothesis was that a BSRT for New Zealand will of necessity have different weightings of importance between the different constituent aspects of 'sustainability' and would also have some dimensions which are not accounted for internationally in other BSRTs but specifically related to New Zealand (i.e. cultural/treaty related issues).

A survey of building industry BSRT experts produced a set of draft weightings for aspects of sustainability in New Zealand and as a final check on the process, these weightings were compared to existing international tools LEED, BREEAM, and Green Star (refer to Figure 2-1). According to the results, none of the existing tools examined fitted the sustainability model defined by the surveyed industry experts $\{$ Smith 6-7; Smith and Donn 1$\}$.

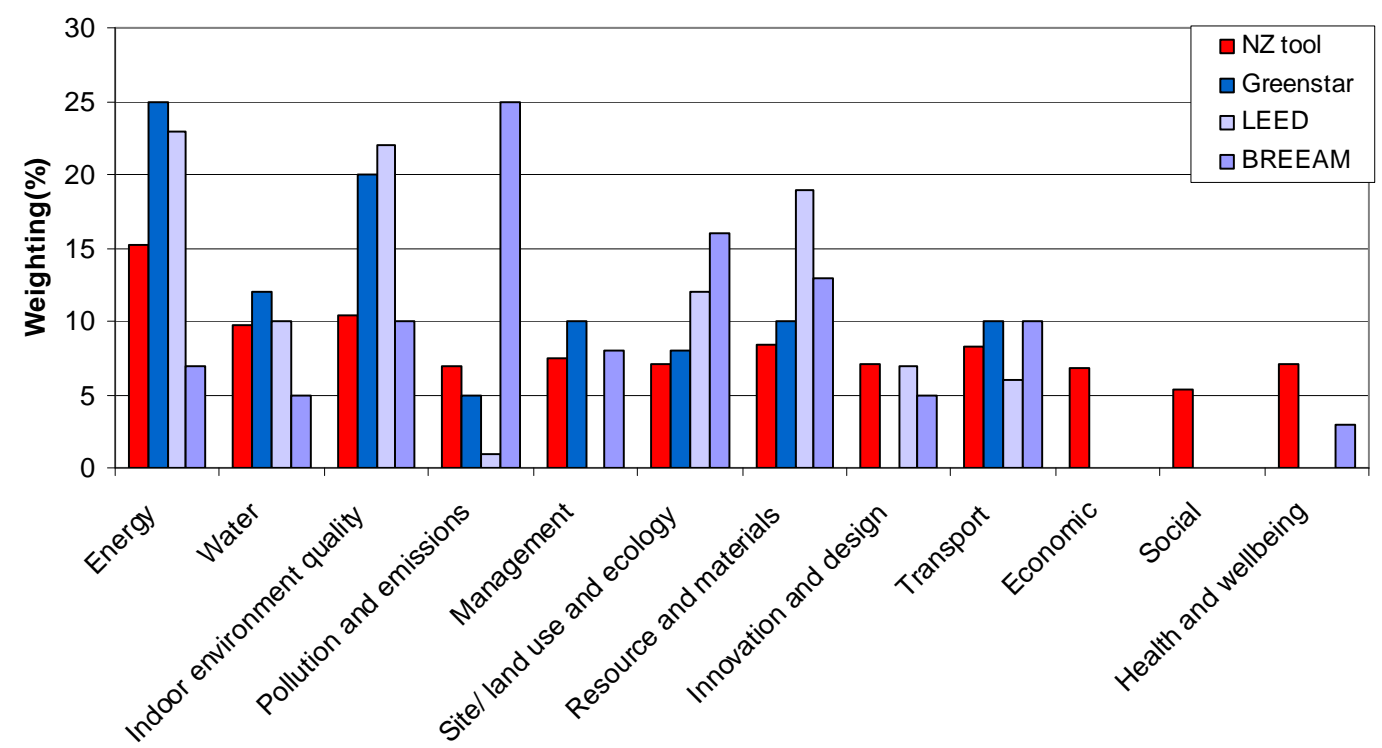

Figure 2-1: Comparison of environmental aspect weightings for a New Zealand based BSRT against other existing systems $\{$ Smith 30; Smith and Donn 6\}

Additionally this research demonstrated the methodology was a means by which a consensus might be developed as to appropriate weightings for sustainability aspects in a New Zealand based BSRT. It also showed these consensus weightings might be used as a general means of 
evaluation of the suitability of a BSRT to New Zealand. That is, they could be used as a new set of weightings to adjust an internationally developed tool to New Zealand conditions \{Smith and Donn 1$\}$.

Further research was also conducted by the NZGBC in a range of industry workshops, where more than 200 building professionals evaluated and discussed the makeup of a BSRT for New Zealand and what were the important aspects for its specific context. In groups, the attendees were asked to rank typical environmental aspects and their categories from one to ten. Seen in Table 2-1 is the overall priority of the environmental aspects that were perceived by the industry and across the three main centres of New Zealand (i.e. Auckland, Wellington and Christchurch) \{New Zealand Green Building Council, Building Assessment Scheme Project 2\}.

Table 2-1: Rating Tool Workshop environmental aspect weighting \{New Zealand Green Building Council, Building Assessment Scheme Project 2\}

\begin{tabular}{|l|r|r|r|r|}
\hline $\begin{array}{l}\text { Environmental aspects of typical } \\
\text { existing BSRT }\end{array}$ & Overall & Auckland & Wellington & Christchurch \\
\hline Energy efficiency & 1 & 1 & 1 & 1 \\
\hline Environmental quality within the building & 2 & 2 & 2 & 5 \\
\hline Transport & 3 & 3 & 6 & 8 \\
\hline Materials & 4 & 5 & 6 & 6 \\
\hline $\begin{array}{l}\text { Management systems, procedures and } \\
\text { plans }\end{array}$ & 5 & 6 & 4 & 3 \\
\hline Land use and ecology & 6 & 4 & 3 & 3 \\
\hline Water efficiency & 7 & 8 & 9 & 9 \\
\hline Flexibility and adaptability & 8 & 9 & 5 & 2 \\
\hline Emissions, effluent and pollution & 9 & 7 & 8 & 6 \\
\hline Quality, service and risk & 10 & 10 & 10 & 10 \\
\hline
\end{tabular}

Cole identifies two critical issues for weighting; the basis for deriving the weightings and the manner in which the weighting process affects the interpretation of the aggregated result \{Building Environmental Assessment Methods: Clarifying Intentions 242\}. The question as Cole states should not be whether air pollution is more important than water pollution, but instead whether air pollution or water pollution exerts a greater specific potential impact on the endpoints of concern \{Cole, Building Environmental Assessment Methods: Clarifying Intentions $242\}$.

Cole goes on to say; very few existing BSRTs use an explicit weighting system to acknowledge the relative significance of the environmental performance criteria in deriving an overall score. Such weighting remains a controversial aspect of a BSRT, with the primary concerns being the absence of an agreed theoretical and non-subjective basis for deriving an appropriate weighting \{Cole, Emerging Trends 9\}. Levin proposes the following criteria be used for developing weightings of a BSRT \{qtd in. Cole, Emerging Trends 9\}: 
- "Spatial scale of impact (where a global impact would be worse than a local one)

- Severity of hazard (where a more toxic, damaging hazard would be worse)

- Degree of exposure (where well-sequestered substances would be less of a concern than readily mobilized substances)

- Penalty of being wrong (where longer remediation time would be of greater concern) status of affected sinks"

The weightings for Green Star NZ are yet to be finalised as the current version uses the environmental weightings from Tasmania with variations to water and energy, due to differences on the importance placed on each aspect (refer to Section 1.1.3.4 and Appendix A.2.3.3).

\subsubsection{Voluntary or Compulsory Tool}

The majority of existing BSRTs are voluntary in their application and serve the primary objective of stimulating market demand for sustainable buildings \{Cole, Building Environmental Assessment Methods: Redefining Intentions and Roles 464\}. The underlying premise is key groups (i.e. stakeholders and end-users) will adopt these voluntary assessments, incorporating environmental responsibility into the building industry, and as a result others will follow suit to remain competitive. However, Cole states voluntary BSRTs must serve two conflicting requirements \{Cole, Building Environmental Assessment Methods: Clarifying Intentions 9 \}:

"...they must function as an objective and sufficiently demanding metric to have credibility within the environmental community, while simultaneously being attractive to building owners who wish to have something positive to show for any effort that they have placed on environmental performance. To satisfy these twin requirements invariably compromises both the number of criteria that are assessed and the level at which benchmarks are set".

A compulsory tool on the other hand will have a different set of difficulties. Due to the compulsory nature they cannot be as rigorous as a voluntary tool, so, are ideally suited to the low-mid range market rather than the high end market. A compulsory tool would function similarly to the New Zealand Building Code, defining minimum standards for achievement and be relatively easy to attain. Anecdotally a compulsory BSRT may be seen to be a hindrance for the adoption of sustainable building, as it could be viewed by the market as more government interference and more red tape for owners and clients. In turn this could lead to less enthusiasm for the BSRT and less market acceptance, resulting in less well performing sustainable buildings.

While further research could investigate the difference of a compulsory tool and voluntary based BSRT, the approach for New Zealand has already been decided by the NZGBC in developing a 
voluntary BSRT, and is obliged to do so to fulfil the requirements of the WorldGBC in establishing a GBC \{World Green Building Council\}.

A possible option for the future could lie in the approach of local authorities defining mandatory requirements for buildings to achieve a minimum Green Star NZ rating. The New South Wales Government for example has a mandatory requirement for any new office building in Sydney's Central Business District to achieve a minimum Green Star rating of five \{New Zealand Green Building Council, Green Star NZ: Accredited Professional Level 1 Training\}.

\title{
2.2.1.4 Potential or Actual Performance
}

\begin{abstract}
"A significant issue arising from the analysis of some of the existing building rating tools is that of design certification versus certification of existing building stock, and the problem of fully accredited building designs that either fail to function as sustainably as desired, or that are not built to design specifications".
\end{abstract}

The issue outlined in the statement above, is one of considerable concern to those who design and manage rating tool systems \{Ministry for the Environment, Green Building Assessment Tool Research Project: Final Report 7:7\}. Evidence suggests a building's actual performance profile is often significantly different from its predicted performance, due to changes in construction, materials and operation. Portcullis House in London for instance, in its first year of the operation, used around four times the $90 \mathrm{kWh} / \mathrm{m}^{2} / \mathrm{yr}$ of energy predicted by the project's engineers \{United Kingdom Parliament; qtd. in Smith 14\}.

The advantage of actual performance is it captures what resources have been consumed, the ecological loadings and the actual indoor environment qualities. Beyond external factors such as specific weather conditions, actual performance depends largely on occupant behaviour and the actions of building operators. On the other hand potential performance (i.e. design) is based on assumed schedules of occupant behaviour and building operation, but makes it easier to distinguish between improvements in the physical features of buildings and improved efficiencies in operation \{Cole, Building Environmental Assessment Methods: Clarifying Intentions 237; Zimmerman 3$\}$.

Bordass and Leaman describe although potential performance is less 'real', it can still produce useful information for developers, owners, and designers of buildings \{Future Buildings and Their Services 195; qtd. in Cole, Building Environmental Assessment Methods: Clarifying Intentions 237$\}$. Cole reiterates this, there needs to be a recognisable relationship between any strategic design and the ease with which a building can be managed and operated, thus making 
the design of the building's management and operational systems part of the overall building design and procurement process \{Building Environmental Assessment Methods: Clarifying Intentions 238$\}$.

Zimmerman also discusses the differences between potential and actual performance; that a newly constructed building may differ significantly from its original design, that equipment, plant type and behaviour of management techniques can change from those assumed by the designers or clients. Furthermore an operational building may allow benchmarking and comparisons to be made against other similar buildings, while potential performance allows opportunities for review of the design concepts and assumptions, correcting deficiencies, and improving performance in operation $\{1\}$.

Again this reinforces the structure of Green Star NZ to assess both potential and actual performance (i.e. design, as built, and performance phases of a building project) (New Zealand Ministry for the Environment, Green Building Assessment Tool Research Project: Final Report $7: 9\}$.

\subsubsection{Regional Variation}

The NZGBC Rating Tool Workshops (refer to Section 2.2.1.2) also identified key differences between New Zealand's three main centres (i.e. Auckland, Wellington and Christchurch) in determining the weightings for a New Zealand BSRT. The environmental category 'Flexibility and adaptability' for example was ranked 9th in Auckland, 5th in Wellington, and 2nd in Christchurch.

As Larsson reinforces, environmental issues are regional in nature and for any potential BSRT the framework would need to handle regionally specific issues in relation to a common-core set of considerations \{336; Cole, Emerging Trends 6\}. For such an approach to be successful the BSRT would require an explicit declaration of environmental criteria and its intentions, to provide a common basis for developing customised regionally specific criteria \{Cole, Emerging Trends 9$\}$. 
In Australia, Green Star has different weightings for each particular State (refer to Table 2-2).

Table 2-2: Environmental weightings of each Australian State \{Green Building Council of Australia. Green Star: Design v2 Technical Manual viii\}

\begin{tabular}{|l|r|r|r|r|r|r|r|r|}
\hline Environmental Category & \multicolumn{9}{|c|}{ State } \\
\hline & ACT & NSW & NT & QLD & SA & TAS & VIC & WA \\
\hline Management & 10 & 10 & 10 & 10 & 10 & 10 & 10 & 10 \\
\hline Indoor Environment Quality & 20 & 20 & 20 & 20 & 20 & 20 & 20 & 20 \\
\hline Energy & 25 & 25 & 25 & 25 & 25 & 20 & 25 & 25 \\
\hline Transport & 10 & 10 & 10 & 10 & 10 & 10 & 10 & 10 \\
\hline Water & 12 & 12 & 10 & 10 & 15 & 15 & 15 & 12 \\
\hline Materials & 10 & 10 & 10 & 10 & 10 & 10 & 10 & 10 \\
\hline Land Use and Ecology & 8 & 8 & 10 & 10 & 5 & 5 & 5 & 8 \\
\hline Emissions & 5 & 5 & 5 & 5 & 5 & 5 & 5 & 5 \\
\hline Total & 100 & 100 & 100 & 100 & 100 & 100 & 100 & 100 \\
\hline
\end{tabular}

Defining a regional set of weightings may prove to be difficult, as was identified in the report 'A Sustainability Rating Tool for New Zealand Commercial Buildings'. To be successful, a clearly defined framework would be required to derive the weightings. A survey for example could be developed to ask experts from the building industry what regionally specific weightings they would apply to a New Zealand BSRT. However this would have to take into consideration the bias created from several influencing factors before any assumption could be made (i.e. the influence created by a respondents background, such as place of education and place of occupation) $\{$ Smith 39$\}$.

While the NZGBC at this stage states it is more important to establish Green Star NZ nationally, it has not yet ruled out regionally specific weightings in the future $\{\mathrm{New}$ Zealand Green Building Council, Green Star NZ: Accredited Professional Level 2 Training\}.

\subsection{Summary}

In summary the literature showed an enormous amount of research effort has been directed at the 'product' aspect of BSRTs, whereas relatively little consideration has been given to how the structure of BSRTs facilitates dialogue between different stakeholders in formulating and pursuing a design project \{Cole, Building Environmental Assessment Methods: Redefining Intentions and Roles 466$\}$. From the outset the creation of this dialogue brings together various parties of a building project \{Cole, Cost and Value 306-7\}. The result of improving the communication can have profound implications on education and training of a BSRT, and also the responsibilities of building professionals to create and assess sustainable buildings. As explained communication of BSRT results is important at the end of an assessment, it just as vital that communication between stakeholders and end-users is created in the implementation phase of a BSRT. As the integration of stakeholder and end-user values in the implementation phase 
enhances the ability of a BSRTs overall success. Therefore it is crucial information gained in the implementation phase is fed back into the BSRT process, in order to increase the relevance of its results, allowing better transparency and validity of the verification process $\{$ Kaatz 316$\}$. 
Literature Review 


\section{Research Design}

The following chapter describes the methodology employed in this research. It describes the design of the survey and questionnaire, and the procedures for conducting the study, including details about the participants, how the data was gathered, and the statistical analyses undertaken.

\subsection{The General Method}

This research was quantitative in nature and made use of a survey to fulfil the aim to investigate the requirements of stakeholders and end-users, including their understanding of sustainability, the NZGBC and BSRTs.

\subsubsection{Context and Access}

The NZGBC was granted formal organisational status in February 2006 and due to this new status the Council was beginning to have an influence on the immediate sectors of the building industry. This influence was also expected to strengthen and with the impending release of Green Star NZ.

The survey was conducted through a questionnaire over the three-week period from the 19 February 2007 to the 12 March 2007. This relatively short time period was critical for the study as it was important to capture the desired data set before the release of Green Star NZ. While a longitudinal study lasting several months may have resulted in a greater number of responses, it would have increased the potential for bias, as new events motivated change and/or new information updated the knowledge base of the targeted population frame \{Särndal and Lundström 10$\}$.

Additionally the survey was designed to pre-empt the public release of Green Star NZ: Office Design v1 (released on the 20 March 2007) and to coincide with the closing date for comments on the pilot version of Green Star NZ midway through the survey period (1 March 2007) (refer to Figure 3-1). 
Pre Survey

Survey

Post survey

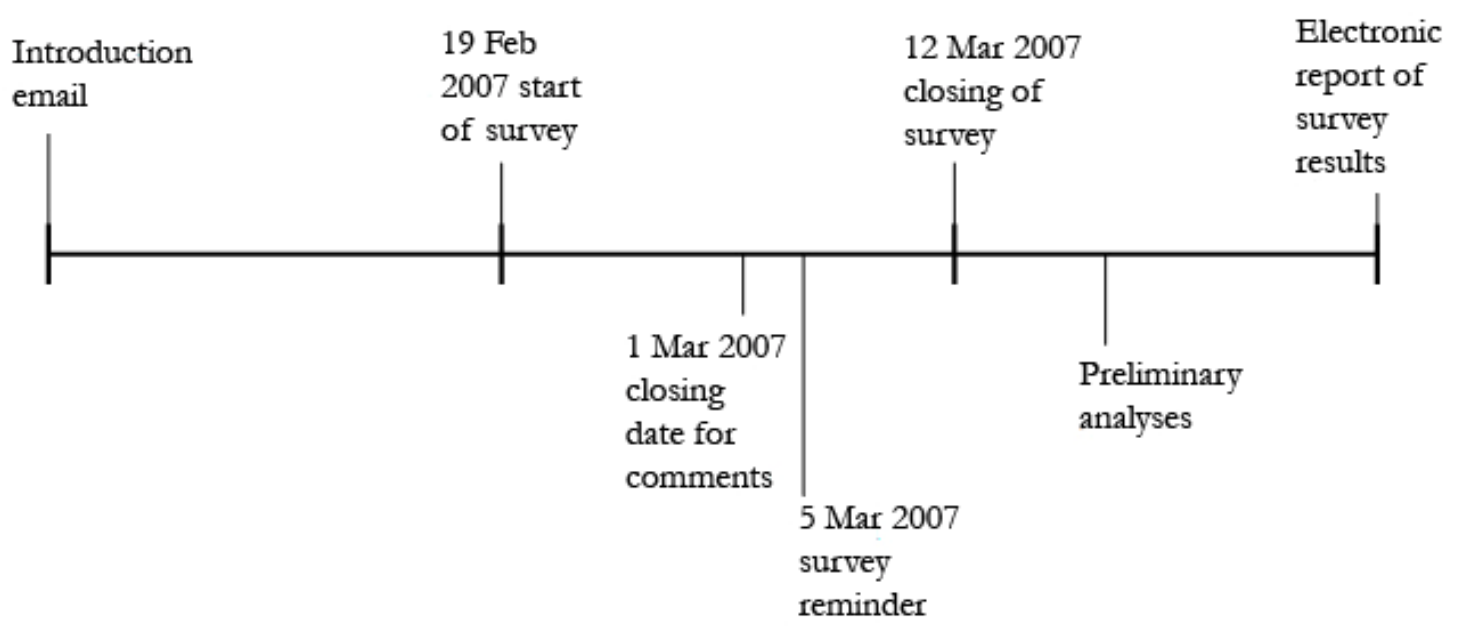

Figure 3-1: Survey timeline

As a result this study was also seen to create a snapshot of the New Zealand commercial market and its building industry, providing a base point from which the NZGBC could measure their continued influence and the success of Green Star NZ.

\subsubsection{Sample Frame and Target Population}

The targeted population for the survey was the New Zealand building industry, in particular end-users and stakeholders of the NZGBC BSRT, Green Star NZ. For this reason, it was important to define both a stakeholder and an end-user in the context of this research as the survey aimed to distinguish between these groups.

Stakeholders were defined as individuals who have an interest and/or an involvement in the outcome of the Green Star NZ process, but were not directly involved with the application of the tool. As defined by the NZGBC, stakeholders include \{New Zealand Green Building Council\}:

- Commercial property developers

- Investors, owners and property managers

- Residential developers and major portfolio owners

- Owner occupiers

- Major corporate tenants and retailers

- Building contractors

- Building product manufacturers and distributors

- Architects and Draftpersons

- Engineers

- Property and construction professionals 
- Research and non-government organisations

- Related interests (utilities, financial institutions, insurance companies, etc)

End-users on the other hand, were defined as individuals who are directly involved in the application of the BSRT and in this context, someone who is likely to aspire to accreditation. End-users include:

- Assessors

- Consultants

- Particular stakeholders (architects, designers, engineers)

According to data from the 2006 New Zealand Census, the size of the targeted population (the building industry) was estimated to be made up of 126,421 businesses ${ }^{4}$ (refer to Appendix A.1.4.) \{Statistics New Zealand, Table Builder\}. However, there was a level of ambiguity in relation to this figure, due to the difficulty in defining the businesses within 'Owner Occupiers', 'Major Corporate Tenants and Retailers', and 'Related Interests'. 'Related Interests' for instance could be seen to be very broad, encompassing many different sections of the building industry not already associated with the other eleven building industry categories. Likewise, 'Major Corporate Tenants and Retailers' was rather an ambiguous term, and trying to determine from the Census Data who were associated within this group was difficult, as this specific type of information was not available. For this reason the figure of 126,421, 'Owner Occupiers', 'Major Corporate Tenants and Retailers', and 'Related Interests' have not been accounted for, and as a result the actual population is likely to be larger.

\subsubsection{Sample Selection}

As the survey was aimed at the New Zealand building industry, the first step was to contact relevant building industry related organisations to assist in the distribution of the survey. An email outlined the research and the intended study, and the assistance each organisation could provide in helping to administer the survey. Those organisations which agreed to participate were asked to forward an email including a link to the survey onto their email contacts once the survey was open to response. For purposes of calculating response rates each participating organisation was asked to provide the number of contacts within their respective database(s).

\footnotetext{
${ }^{4}$ In the 2006 New Zealand Census the term 'Enterprises' is used, to reduce confusion, the term business' was substituted instead to describe each separate company in New Zealand
} 
In total nineteen organisations agreed to provide their assistance in disseminating the survey 5 . These organisations were:

- Concrete and Cement Association of New Zealand

- Design Institute of New Zealand

- Earth Building Association of New Zealand

- Energy Management Association of New Zealand

- Illuminating Engineering Society of Australia and New Zealand

- Institute of Professional Engineers New Zealand

- Institute of Refrigeration, Heating and Air Conditioning Engineers of New Zealand

- New Zealand Building Industry Subcontractors Federation

- New Zealand Green Building Council

- New Zealand Institute of Quantity Surveyors

- New Zealand Metal Roofing Manufacturers

- New Zealand Planning Institute

- New Zealand Property Investors Federation

- New Zealand Timber Design Society

- Property Council of New Zealand

- Property Institute of New Zealand

- Roofing Association of New Zealand

- Registered Master Builders Federation

- Window Association of New Zealand

Disappointingly, the New Zealand Institute of Architects declined to disseminate the survey. This was stated to be due to the nature of the intended research (i.e. BSRTs) and the timing of the survey was deemed to be inappropriate for their members. Given this group was seen to be a key component of both end-users and stakeholders, it was crucial the architectural and design sector was involved. The NZIA annually publish a list of registered architectural firms in New Zealand (Architecture New Zealand), but because the NZIA declined to participate, the use of this list was seen to be inappropriate. Therefore because NZIA members could not be contacted, a list of architectural firms was sourced from the website www.architecturenz.net ${ }^{6}$. As a result, 576 architectural firms and individuals were contacted directly by the researcher.

\footnotetext{
5 A total of 71 building industry related organisations were contacted. Of these nineteen agreed to participate, five asked for a draft of the survey but did not confirm their participation, nine declined to participate and the remaining 38 did not reply.

${ }^{6}$ www.architecturenz.net is a web-based client source for NZIA member practices.
} 
Organisations such as BRANZ, the Ministry for the Environment, and the Energy Efficiency and Conservation Authority were not asked to participate in administering the survey. These and other similar organisations were seen to be separate enterprises rather than organisations where individuals joined up as members or as part of an emailing list (e.g. monthly newsletters). The assumption being these organisations could take the survey beyond the intended scope of the study, where individuals not part of the identified end-user and stakeholder groups could have responded and created a source of bias (e.g. administration staff). Furthermore these separate enterprises (e.g. BRANZ) were assumed to have individuals associated with other surveyed building industry related organisations.

\subsubsection{Sample Size}

The voluntary technique used to sample the target population meant in relative terms, the survey was a sample within a sample. From the organisations which were initially contacted only a selection of these agreed to participate, and likewise, only a selection of the industry professionals who were contacted through their association with the participating organisations volunteered to provide a response to the survey. Due to this reliance of organisations on whether or not to involve their contact databases, an opportunity for bias was created from non-response, which increased the possibility the results were not representative of the population.

Based on the figures provided by each participating organisation and the 576 NZIA associated architectural firms, the total number of professionals contacted was 22,208 (refer to Appendix B.1.1). The likelihood though was this figure was significantly less, due to the probability a number of those contacted were in several organisational databases. To account for this discrepancy a conservative figure of 17,350 was determined to be more accurate. This figure was calculated based on the actual response to the survey and the respondents' number of associated affiliations with building industry related organisations (refer to Appendix B.1.1.1).

While 126,421 businesses were identified to be associated with the building industry, the number of individuals that made up these businesses was not known, the population was assumed to be infinite. Therefore to achieve a confidence interval of $95 \%$ and margin of error of $\pm 5 \%$, the survey required a sample of 384 participants to ensure an overall representative population (refer to Appendix B.1.2) \{Sample Size Formulas\}. Furthermore if the whole population was known the likelihood is the required sample size would not change, as the greater the population size the less influence it has on sample size. 


\subsection{Survey Design Limitations}

\subsubsection{Non-response}

Non-response and the associated bias it introduces is a major concern and a central issue in any survey methodology, especially if the respondents differ significantly from the non-respondents. It is suggested non-response can severely harm the quality and statistical significance of a survey and as a result, it requires either an estimate or extracted data from the non-respondents \{Burkell $240\}$. While it is likely some form of non-response will occur, by using good design and survey techniques it can be substantially reduced and prevented \{Burkell 240-244; Särndal and Lundström 1$\}$.

There are two main identified types of non-response. These are \{Survey Sample 88\}:

- Item non-response - where part of a response is missing from a units data (e.g. participant either refused or did not know, etc)

- Unit non-response - where no data are collected from a particular unit (e.g. participant does not respond at all)

In this study unit non-response was more likely to occur and to potentially have a greater influence on the results than item non-response. Of the 17,350 professionals contacted it is likely more will choose not to respond to the survey, rather than a participant not responding to a particular question in the survey.

\subsubsection{Techniques to Reduce Non-response Bias}

To reduce the bias created by non-response the following techniques were used \{Survey Sample $87-88\}$ :

- Modification of objectives

o In this instance the objective was to survey the building industry rather than the whole population of New Zealand, as the topics involved in the survey required a distinct level of knowledge and hence the building industry was more likely to respond

- Increasing awareness

o In addition to assisting the distribution of the survey the NZGBC, IPENZ and IRHACE all dedicated a portion of their respective newsletters to an article outlining the research and the intended survey, thus further informing their contacts and increasing the chances for a greater response 
- Pre-notification

o An introduction email well before the survey was set to commence was sent to the building industry related organisations, outlining the intentions of the survey and when it was set to commence. Organisation newsletters also provided a form of pre-notification

- Incentives

o To increase participation the NZGBC offered a $\$ 200$ incentive for one of its members to attend NZGBC related events

- Giving the population a compulsion to respond

o To increase the potential for greater response the targeted building industry was informed of the distinct opportunity they had to influence the design and structure Green Star NZ

While the above examples reduce non-response, it is also important to minimise it through the design of the survey. Some of the techniques used to prevent bias were to:

- Provide clear information, explaining the purpose of the survey, the use of the results and assurance about confidentiality and privacy

- Ensure questions elicited the intended response

\subsubsection{Accounting for Non-response}

Non-response presents two problems for the interpretation of any results. Firstly, it reduces the sample size, thus decreasing the precision with which results can be assessed. Secondly, and more importantly, it introduces error into the sampling process by excluding a subset of the population. If the excluded subset is different from those who responded to the survey, there is a distinct possibility for bias \{Burkell 242\}. The problem here, as Burkell points out, is there is no way to know whether non-response affects the results. Specifically, to know if non-response affected the results, it would require information about the differences between respondents and non-respondents $\{245\}$.

Burkell describes several methods to account for non-response. For instance, if subgroup differences occur, it is possible to estimate the degree to which such differences are affected by non-response, using analysis of variance, i.e. t-tests ${ }^{7}$ \{qtd. in Burkell 247\}. Unless response rates are extremely high, these methods effectively reduce the precision of survey results, due to the compensation made for sampling bias from non-response. As such, t-tests can be overly

\footnotetext{
${ }^{7}$ T-tests are used to evaluate the statistical significance between means of two groups
} 
conservative and can increase the likelihood for underestimation, reducing the significance of the results $\{$ Burkell 247\}.

A more conventional approach to account for non-response is to determine whether non-response has introduced sampling bias, and correcting that bias if it has occurred. The most commonly used strategy compares the respondents to a second group, either including or representing non-respondents. If a significant difference between the two subgroups has occurred, suggesting the presence of sampling bias, the data can be corrected by re-weighting \{Burkell 247\}. This method was deemed inappropriate in this research, as the survey participants and the targeted population were anonymous, and consequently there was no reliable method to determine who the non-respondents were. Furthermore, if the non-respondents were known and were able to be surveyed, the problem of non-response would still exist. To be exact, there could still be non-response from the original non-respondents.

Another alternative solution for accounting for non-response is to compare the resulting data with similar historical data. Due to the research being the first instance of a survey of this nature in New Zealand, there was no data to make a reliable comparison. Existing data from the United States and Australia could allow some comparison, but using this data to account for survey non-response was seen to be inappropriate. This was due to the unique contexts and circumstances of each study, as each study surveyed different demographics and different timeframes. Most significantly, the United States and Australian studies were conducted with their respective BSRTs (LEED and Green Star) already well established, whereas in New Zealand Green Star NZ had yet to be officially launched. Due to the described limitations of each method (analysis of variance, subgroup differences, historical data), the most appropriate solution was the first, to account for non-response by using t-tests to investigate the differences between two unique subgroups.

As stated previously, due to a low response rate the analysis of variance technique can be overly conservative and can increase the likelihood for underestimation of survey results. However, research indicates non-respondents are more like late respondents in both expressed attitudes and demographics \{qtd. in Burkell 247\}. Hence, the technique to account for survey non-response was to divide the data into two select subgroups; those before and those after the reminder email. Between these two groups t-tests were used to investigate the differences (if any) that existed. 


\subsubsection{Other Sources of Bias}

A source of bias was there was no clear means to account for additional responses from participants forwarding the survey and taking it beyond the intended scope of the study. While an additional request to the participants in the introduction email may have helped prevent this bias, it is not a guarantee participants will necessarily follow the instructions and can often be ignored.

Invalid email addresses were also a concern, however it was assumed most contact lists were updated on an annual basis. The potential of this bias was not known as the participating organisations were responsible for forwarding the survey onto their contacts, and as such, the contacts were anonymous. Likewise, individuals who do not have access to the internet during the three week survey period were another source for bias.

A potential source for bias was also derived from how the respondents answered the survey. For instance certain terms and concepts (e.g. sustainability) could be seen to be socially desirable, and respondents might be inclined to elevate their response even though they may not be consciously aware of it. An example is participants may perceive themselves to be more interested or more involved in sustainability than they actually are. While there is no comprehensive solution to resolve this bias, the anonymity of the participants decreased its potential of occurring e.g. because personal details were not known, and there was no direct competition between participants. Furthermore because there is no way to measure for elevated responses, the conservative assumption was if it was occurring, it was done across the entire building industry, thus balancing itself out.

In terms of the scope and coverage of the building industry, an additional source of bias was the exclusion of professionals associated with the building industry, but not through direct association with the participating building industry related organisations. That according to the 2006 New Zealand Census, 126,421 businesses were identified as being associated with building industry, however only an estimated 17,350 building industry professionals were contacted in the survey. While it is not known to what degree this bias could affect the results, it was seen to be more practical to survey a representative sample rather than the entire building industry.

\subsection{Survey Instrument}

The specific aim of this research was to investigate the requirements of end-users and stakeholders, and their understanding of sustainability, the NZGBC and BSRTs, ensuring any potential barriers were identified and addressed in the early stages of Green Star NZ's implementation. 
According to literature and industry discussion, it was anticipated Green Star NZ would require some form of testing before it was officially implemented. This view is reflected in the report commissioned for the Ministry for the Environment that if the selected scheme (i.e. Green Star NZ) is to be implemented successfully it would require continuous support with dedicated training, marketing and validation processes, i.e. 3rd party certification \{Green Building Assessment Tool Research Project: Draft Report 9:1\}. It was also suggested to achieve market acceptance, the BSRT will need to be developed in consultation with those which will be using it on a regular basis to ensure their needs are addressed, i.e. stakeholders \{Green Building Assessment Tool Research Project: Draft Report 7:5\}. While it is important to consider the needs of NZGBC stakeholders, it is just as important to consider the needs of the general building industry. As these are the specific individuals who need more persuasion about the function, purpose and benefits of a BSRT.

\subsubsection{Web-survey Interface}

The survey methodology was regarded as an appropriate technique to investigate the aims of this research and gave several advantages. These advantages were $\{$ Gillham 5-9\}:

- Respondent anonymity

- Lack of interviewer bias

- Efficiency in collecting information from a large number of respondents

- Possibility for very large samples

- Flexibility of information, a wide range of data can be collected and can be used to study attitudes, values, beliefs, and past behaviours

- Ease of application

Furthermore, by using a web-based survey with an email for the administration side over other techniques was it was seen to be the most effective and efficient way to contact the building industry with the limited resources and time available. The assumption was the large majority of the building industry had an email address and regular access to it. As a result, the web-based technique was more likely to achieve higher response rate as opposed to a postal survey which can be seen by respondents to be more laborious and time consuming, i.e. they have to fill it out and return it.

Other surveying techniques such as face to face and telephone interviews were not considered as options. To understand processes and influences behind sustainable design decisions of home owners, Christie discovered even as a pilot study, the level of interaction and organisation 
required to interview both clients and architects was substantial \{Sustainable Design Decisions: Processes, influences, values of the homebuilder\}.

Using a web-based programme also collected the results into an immediately usable format, reducing time and potential error from manual data entry. The web-based programme also allowed for a clear layout to be achieved, allowing good readability and understanding, contributing to reducing item non-response error.

Early in the design of the survey the problem of multiple responses was identified as a potential source of bias. Specifically, participants could respond more than once to the survey. The solution in this instance was using the web-survey instrument to collect each respondent's computer IP address, and to store cookie files within the participating computer, preventing them from providing more than one set of answers.

The web programme used for the web-survey interface was Zapsurveys and was based on several of the factors. These were:

- The programme recorded dates and times of when and how long respondents took to respond to the survey

- It recorded the I.P. address and stored cookies within each respondents computer, preventing multiple responses

- The layout, how data was collected and stored within the web-survey interface

- The compatibility of the web-survey instrument with analysis software such as Microsoft Excel and SPSS for Windows

\subsubsection{Survey Procedure}

The survey was conducted through a questionnaire over the three week period from the 19 February 2007 to the 12 March 2007. To encourage response the survey adhered to the following steps (refer to Figure 3-1)

- Introduction email requesting assistance from building industry organisations to administer the survey to their contacts

- Distribution of survey to participating building organisations, including an information sheet describing the intended research and purpose of the survey for the participants

- Reminder email of closing of survey, sent with one week remaining

- Closing of survey 
Additionally two steps were conducted post survey. These were:

- Collation of data and performance of preliminary analyses

- A short electronic report was made available to the respondents

\subsubsection{Questionnaire Design}

The survey questions were directly tailored to investigate end-users and stakeholders understanding of sustainability, the NZGBC, BSRTs and sustainable buildings. Initially it was proposed only the NZGBC contacts would be surveyed, the PAG however reinforced the importance of surveying all sectors of the building industry. That is, rather than just preaching to the already converted, by surveying those outside the NZGBC, it would provide a better overall indication of what the building industry perceived sustainability to be, and what the benefits of a New Zealand BSRT were. This would also provide an opportunity for separate analyses of those directly associated with the NZGBC and those not associated with the NZGBC.

Much of this research methodology was designed to expand on from both the Australian and the United States green building reports (i.e. 'Building and Construction Interchange 2006' and 'McGraw-Hill Construction 2005'). The Australian report drew from a sample of 212 architects, by surveying a total of 3200 randomly selected building professionals, contractors and building owners from the Building and Construction Interchange research database \{Building and Construction Interchange 35\}. At its conclusion, the study achieved a response rate of 5.3\%, although there was no suggestion of a confidence interval or margin of error. More importantly, there was no allowance or mention of bias created by non-response. The United States report did provide a confidence interval of $95 \%$ and a margin of error of $\pm 5 \%$. The research also surveyed 417 building industry professionals, which was stated to be representative of $0.1 \%$ of the building industry population, i.e. 400,000 professionals \{McGraw-Hill Construction 25\}. As in the Australian report, there was no allowance for bias created by non-response.

Therefore it was important in this research to expand the survey beyond only one organisational database and to make allowances for any bias created by non-response.

\subsubsection{Section Classification}

The survey was structured in such a manner which asked the most important questions first. An educated assumption was made that as the survey progressed participants might withdraw and not complete the survey. In the event a participant did not complete the survey, the survey instrument (Zapsurvey) was designed to collect all the respondent's answers up until they either finally completed it or decided to pull out. This was seen to be crucial as some other survey instruments only record a response once a participant has finished and submitted the survey. 
The survey was made up of seven key sections. These were:

1. Industry Information

Section 1 gathered knowledge of the respondent population, the appropriate sector of the building industry they represented and their associated affiliations within the industry. This would allow the data to be broken down into the different industry sectors, enabling comparisons to be made, enabling a discussion of their differences and similarities.

2. Background

Section 2 contained two key questions and investigated the respondent's level of interest and involvement in sustainability, sustainable buildings and BSRTs. The importance of this question was to give an understanding of what the building industry believes in relation to how it behaves.

3. Building Sustainability Rating Tools

Section 3 was specifically directed at BSRTs and investigated the respondent's perceived purpose of BSRTs, and their awareness and experience with current tools.

4. Green Star New Zealand

Section 4 was structured similarly to Section 3, but specifically investigating Green Star NZ. Questions asked how a participant anticipated they would use Green Star NZ (e.g. as a design guideline or to achieve Design certification), the importance that Green Star NZ is an equivalent of the Australian system (Green Star), the importance for New Zealand buildings to achieve certification, and the likelihood the participants would use Green Star once it was available.

5. The New Zealand Green Building Council

Again Section 5 was structured similarly to the previous two sections, but investigated the NZGBC, gathering an understanding of how it is portrayed within the building industry. Some example questions were the impact of the NZGBC in the production of more sustainable buildings, the appropriateness of the NZGBC in the establishment of a New Zealand specific BSRT.

6. Triggers, Drivers, Obstacles and Reasons for Sustainable Building

Section 6 sought to develop an understanding of what the participants perceived to be the triggers, barriers, obstacles and reasons for sustainable building. Several of the questions in this section were directly developed from those used in the Australian and United States 'green building market reports'. The aim here was to develop an understanding of why the building industry would want to create sustainable buildings, what was driving them to do so, and if not which barriers were preventing them. 
7. Information Requirements

The final section contained two questions aimed at gathering and providing an overview of what the building industry required in regards to sustainable building. To make better more informed choices about sustainable building. To reinforce this, participants were then asked to evaluate their current level of satisfaction regarding this sustainable building information.

\subsubsection{Survey Questions}

Although the survey aimed to establish the wants and needs of end-users/stakeholders, it was important to develop the level of understanding in the industry of both BSRTs and sustainability. Therefore the survey questions were directed at two key areas. These were:

- General field questions - providing a background to the level of knowledge and understanding of BSRTs, the NZGBC, sustainability, and also the drivers that are pushing industry to build sustainably

- Implementation-specific questions - seeking responses regarding the implementation of the BSRT such as output type, training, accreditation, value (e.g. economic and environmental)

For a full list of the questions please refer to Appendix B.2.1 and to Appendix B.2.2 for the complete survey.

Industry involvement was regarded as an important factor in this research. For this reason the questionnaire was developed with the assistance of a PAG and the help of the NZGBC CEO, Jane Henley. The involvement of these professionals helped with the design of the survey questions, and gave it a more industry-focused outlook. To ensure the web-survey instrument was correctly working and the questionnaire elicited the intended response, the survey was thoroughly tested on a sample audience of ten research colleagues before it was implemented and released to the building industry.

\subsubsection{Question Type and Development}

The design of the questions in the survey was extremely important, because a participant could be influenced and directed towards a predetermined answer, depending on how the questions were arranged and asked. The result of such influence can create an unwanted source for bias, though through good survey design, it can be easily negated. In the design of the closed ended question for example, where answers were provided in a scalar format with ordered response categories, the scale was expanded to a 7 point scale as opposed to 5 points (refer to Figure 3-2). 
The reason for expanding the scale to accommodate 7 points was it was important to have a large variation between the responses, allowing better comprehension and assessment of the data.

Question 4: How important is it to have a New Zealand specific Build ing Sustainability Rating Tool?
\begin{tabular}{|l|c|c|c|c|c|c|c|c|c|}
\hline & I don't know & $\begin{array}{c}\text { Not } \\
\text { important }\end{array}$ & $\begin{array}{c}\text { Hardly } \\
\text { important }\end{array}$ & $\begin{array}{c}\text { Slightly } \\
\text { important }\end{array}$ & $\begin{array}{c}\text { Moderately } \\
\text { important }\end{array}$ & $\begin{array}{c}\text { Considerably } \\
\text { important }\end{array}$ & $\begin{array}{c}\text { Very } \\
\text { important }\end{array}$ & $\begin{array}{c}\text { Extremely } \\
\text { important }\end{array}$ \\
\hline \hline Level of importance & C & C & C & C & C & C & C & C \\
\hline
\end{tabular}

Figure 3-2: Example of scalar formatted question

Other closed type ended questions consisted of 'tick all which apply' categories or single 'yes' or 'no' answers (refer to Figure 3-3 and 3-4).

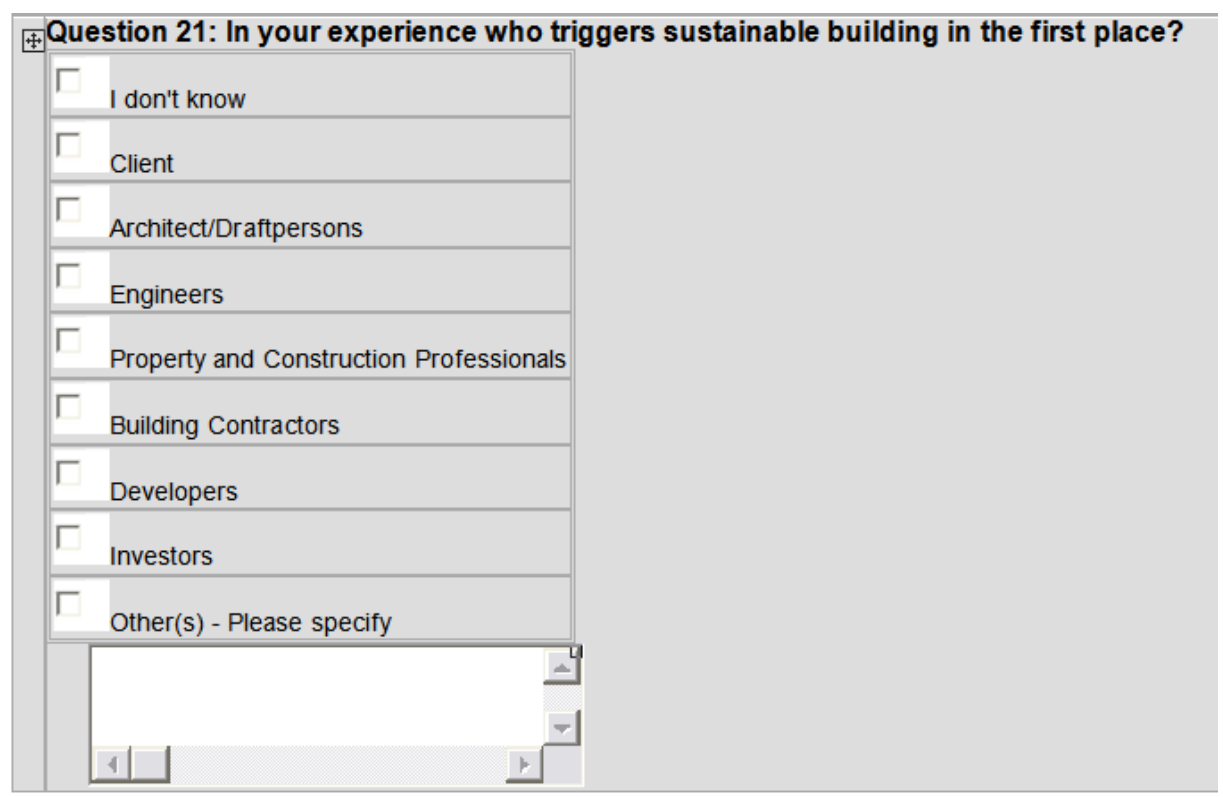

Figure 3-3: Example of tick all which apply formatted question

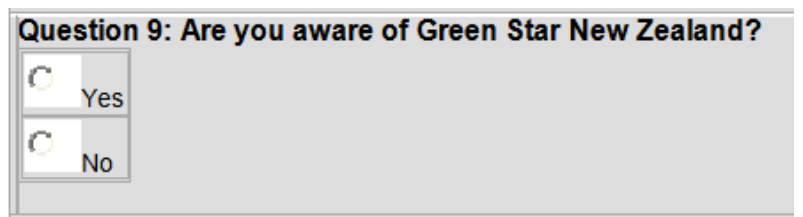

Figure 3-4: Example of single yes or no formatted question

While the information provided from a closed type question is less 'rich' in information, i.e. answers are already predetermined and hence do not allow for variation in respondent answers. The data is also easier to analyse and interpret, and where the answer is factual and predictable this method is recommended. However due to the nature of the intended survey and the topics involved, it was likely opinions, beliefs and judgements would be sought and an open ended question would be required. Also due to the difficulty and time required to analyse an open ended question, their use was limited in this particular study to only one specific question: 
'What do you see as the purpose of a Building Sustainability Rating Tool'? The question did not want to direct the participants towards a predetermined answer but rather have the participants provide their own interpretation of the purpose of a BSRT. The result would allow an understanding to be established of whether the respondents actually knew the purpose of a BSRT, and if further information was required to educate the building industry.

The only other instance where an open ended question was used, was at the end of each section in the questionnaire, where participants were able to provide 'additional comments', to either provoke further question(s) or as justification of a previous answer they had just given.

It was important questions in the survey were structured in a manner that allowed comparative analyses. One such example was to make a comparison between the participant's level of interest and their level of involvement regarding sustainability, sustainable building, and BSRTs. Christie, in her own research showed an attitudinal and behavioural gap of New Zealand homeowners. Described as a 'value-action' gap, sustainability was valued highly by the homeowners, but in actuality it was not a motivating factor behind their building design decisions $\{46\}$.

\subsection{Data collection}

The data was stored securely within the web-survey instrument, and collated into several formats. The most useful formats were:

- Summary reports

- Data file with exact text of respondents' answers

- Data file with an appropriate numerical value representing respondents' answers

In regards to the numerical results, the file from the survey instrument had several errors and subsequently had to be manually altered in a text editor. Respondents complete answer sets for example were listed repeatedly, and it was necessary to delete the numerous duplicates. The data and results were then compared to one another and to the respondent exact test answers to ensure accuracy. Zapsurvey could not explain the reason for this error and it could only be assumed to be a problem with the web-survey instrument and how the answers were recorded.

The files from the web-survey instrument were stored as comma separated values files, and were compatible with Microsoft Excel and SPSS for Windows. In this instance Microsoft Excel was used to organise and perform the initial analyses. 
The survey data once collated was stored electronically in a password protected folder until the conclusion of the research.

\subsection{Analyses}

Once the survey was completed, the data was downloaded and organised into each of the 31 questions for analyses. Then for each question the data was organised by industry type (i.e. the 12 defined building industry sectors, refer to Section 3.3), to allow greater understanding of the data and the New Zealand building industry, but also differences between building industry sectors.

Participants associated with the NZGBC and participants not associated with the NZGBC were also analysed. These two groups were organised on the basis of the participant's answers to their associated affiliations with building industry related organisations (i.e. if they identified an association with the NZGBC). A comment made in the survey pointed out that involving the NZGBC in the survey might create bias. It was suggested those involved with the NZGBC had a greater understanding of the issues introduced in the survey, and thus could be more likely to respond. This source of bias was also identified in the Australian report (Green Building Market Report 2006) of the 3200 professionals contacted, 200 of those were from the Green Building Council of Australia (GBCA). This equated to a response rate from the GBCA of $26.5 \%$, significantly higher the overall response rate of $5.3 \%$ \{Building and Construction Interchange $35\}$. Therefore it was important to analyse these two distinct groups separately.

The data was also organised by the week of the survey period, which each participant responded (i.e. week 1, week 2, week 3). The purpose of this arrangement was to provide additional information to support the results of the t-tests, and the significance of non-response.

The purpose of the t-test analyses was to evaluate the differences between two select groups, in this case the differences of the respondents before and after the survey reminder. If the two groups were significantly different from one another it could be assumed non-response was a problem, and if the differences were minimal, non-response was not a problem. The t-test analyses were performed using SPSS (version 14.0 for Windows). In this instance the critical value was one greater than 0.05 , meaning non-response was not a significant issue in the survey and did not create a source for bias (refer to Section 4.1.4). The questions which were analysed in this manner were only those where participants were asked to provide a single answer to a predetermined scale set of answers (e.g. scalar formatted questions). 
Initially because building industry representation was important it was necessary to re-weight the data based on the actual building industry. However under scrutiny this was seen to be unreliable due to the level of ambiguity related to the 2006 New Zealand Census data (e.g. refer to Section 1.1.2.1). More importantly re-weighting the data could have created a source for bias, due to some sectors of the building industry being under represented in the survey. For instance, only ten participants identified themselves as Commercial Property Developers when as a whole they represented 52,128 separate businesses. To re-weight this data based on only ten professionals would have placed a much greater emphasis on those who answered, and because of the low response, no assumption could be made if these ten professionals were representative of all Commercial Property Developers.

\subsection{Summary of Method}

To summarise, a quantitative survey was employed to ascertain the New Zealand building industry's understanding of sustainability, sustainable building and BSRTs. The survey was conducted through a questionnaire over the three-week period from the 19 February 2007 to the 12 March 2007. In total nineteen organisations agreed to provide their assistance in disseminating the survey. Based on the figures provided by each participating organisation and the 576 NZIA associated architectural firms, the total number of professionals contacted was calculated to be 17,350 .

The survey comprised of 31 questions and investigated the following seven key sections:

1. Industry Information

2. Background

3. Building Sustainability Rating Tools

4. Green Star New Zealand

5. The New Zealand Green Building Council

6. Triggers, Drivers, Obstacles and Reasons for Sustainable Building

7. Information Requirements

The resulting data was inserted into Microsoft Excel, and was organised to perform the initial analyses. To test the reliability of the results, statistical analyses (t-tests) were performed through the software package SPSS 14.0 to investigate the significance of non-response. 


\section{Results}

The following chapter describes the results of this research. Firstly it examines the statistical significance of the data, including total response, confidence intervals and margin of error, response rate, and non-response. Secondly the chapter describes the results of the web-based survey and provides a summary discussion at the end of each section.

For all graphed results refer to Appendix C.2.

\subsection{Statistical Significance}

\subsubsection{Total Response}

The survey received a total 476 responses, made up from the twelve predetermined building industry categories (refer to Table 4-1).

Table 4-1: Building industry categories

\begin{tabular}{|l|l|l|}
\hline Building Industry Sector & Abbreviation & Key \\
\hline Commercial Property Developers & CPD & \\
\hline Investors, Owners and Property Managers & IO\&PM & \\
\hline Residential Developers and Major Portfolio Owners & RD\&MPO & \\
\hline Owner Occupiers & OO & \\
\hline Major Corporate Tenants and Retailers & MCT\&R & \\
\hline Building Contractors & BC & \\
\hline Building Product Manufacturers and Distributors & BPM\&D & \\
\hline Architects and Draftpersons & A\&D & \\
\hline Engineers & E & \\
\hline Property and Construction Professionals & P\&CP & \\
\hline Research and Non Government Organisations & R\&NGO & \\
\hline Related Interests & RI & \\
\hline
\end{tabular}


As is seen in Figure 4-1 four groups made up almost 70\% of the responses, 'Architects and Draftpersons' represented 32\%, 'Building Product Manufacturers and Distributors' 15\%, 'Engineers' $12 \%$, and 'Property and Construction Professionals' 10\%. This was expected to a certain degree as 'Architects and Draftpersons', 'Engineers', and 'Property and Construction Professionals' are more likely to seek Green Star NZ accreditation, while 'Building Product Manufacturers and Distributors' have a particular interest in ensuring their products contribute and comply with sustainable building.

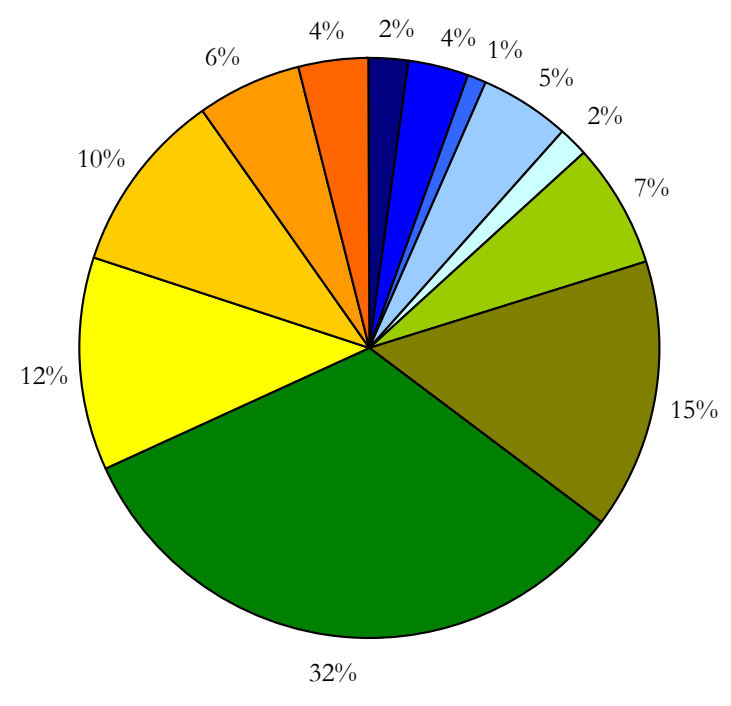

$\square$ CPD $\square$ IO\&PM $\square$ RD\&MPO $\square$ OO $\square$ MCT\&R $\square$ BC $\square$ BPM\&D $\square$ A\&D $\square$ E $\square$ PCP $\square$ R\&NGO $\square$ RI

Figure 4-1: Makeup of survey participants

This level of response corresponds extremely well to other similar surveys that were conducted in the United States and Australia, which achieved 417 and 212 responses respectively.

\subsubsection{Confidence Interval and Margin of Error}

From the estimated 17,350 professionals contacted the aim was to acquire a minimum return response of 384 to achieve a confidence interval of $95 \%$ with a margin of error of $\pm 5 \%$. At its conclusion the survey received a total of 476 responses, an additional 92 responses more than required. This result maintained a confidence interval of 95\%, but improved the margin of error to $\pm 4 \%$ (refer to Appendix C.1.1). This meant there was a $95 \%$ level of confidence the results were representative of the population (i.e. 126,421 businesses) with a margin of error of $\pm 4 \%$. 


\subsubsection{Response Rate}

Based on the figures provided by each participating organisation and those contacted through the NZIA associated list, the total number of professionals contacted was 17,350. According to the calculation below, this produced a response rate of $2.74 \%$.

$$
\frac{476}{17350}=2.74 \%
$$

While the response rate could be considered to be low when compared to other surveys like television polls, this level of response is mainly due to the volunteer technique used to select the participants from the New Zealand building industry (i.e. a sample within a sample - refer to Section 3.3.2). As stated previously, it was not possible to achieve the high response rate of a randomly selected representative sample. To achieve this, this study would have required only a random 384 participants to be contacted and surveyed, and not the 17,350 professionals contacted in this study (refer to Appendix B.1.2).

To acquire a representative sample of 382 in the context of this research would have required the collation of a single database of building industry contacts to ensure the selection was random and representative of the population. The question nevertheless would be how to assemble this database. The most likely solution to acquire this information would be from building industry organisations and businesses, yet it would be a fair assumption due privacy and confidentiality, most organisations would be unwilling and unable to give out information of this nature.

\subsubsection{Non-response - t-tests}

As stated in the methodology, non-response was considered a potential hazard, negatively influencing the results of the survey. The technique used in this research to account for non-response in the survey was to divide the data into two select subgroups; those before and those after the reminder email.

Using the software package SPSS 14.0 for Windows, analyses were performed using the Independent Sample T-test procedure to compare the means of the two subgroups. The result of the analyses produced a table demonstrating the significance of the survey data (refer to Table 4-2 and 4-3). According to the 'Levene's Test for Equality of Variances (Sig.)', a figure of greater than 0.05 it was safe to assume equal variances for both early and late respondents, and if the significance value was less than 0.05 then the assumption was for unequal variances \{SPSS for Windows $\}$. Likewise, if the corresponding figure for the 't-test for Equality of Means (Sig. 2 tailed)' was less than 0.05 it indicated there was a significant difference between early and 
late respondents \{SPSS for Windows $\}$. Therefore the desired value for the t-test was one greater than 0.05 .

Table 4-2: Example of statistical information of survey questions

\begin{tabular}{|c|c|c|c|c|c|}
\hline \multicolumn{6}{|c|}{$\begin{array}{l}\text { Question 10: How important is it for Green Star New Zealand to be a New Zealand } \\
\text { equivalent of the Australian Green Star system? }\end{array}$} \\
\hline $\begin{array}{l}\text { Early respondents versus late } \\
\text { respondents }\end{array}$ & Number & Mean & Std. Deviation & $\begin{array}{l}\text { Std. } \\
\text { Mean }\end{array}$ & Error \\
\hline Early & 298 & 5.453 & 2.2307 & 0.1292 & \\
\hline Late & 87 & 5.2644 & 2.3941 & 0.2567 & \\
\hline
\end{tabular}

Table 4-3: Example of independent samples t-test procedure

\begin{tabular}{|c|c|c|c|c|c|c|c|c|c|}
\hline \multicolumn{10}{|c|}{$\begin{array}{l}\text { Question 10: How important is it for Green Star New Zealand to be a New Zealand equivalent of the } \\
\text { Australian Green Star system? }\end{array}$} \\
\hline \multirow[t]{3}{*}{$\begin{array}{l}\text { Equal or } \\
\text { unequal } \\
\text { variances }\end{array}$} & \multicolumn{2}{|c|}{$\begin{array}{l}\text { Levene's Test for } \\
\text { Equality of } \\
\text { Variances }\end{array}$} & \multicolumn{7}{|c|}{ t-test for Equality of Means } \\
\hline & F & Sig. & $\mathrm{T}$ & df & $\begin{array}{l}\text { Sig. }(2- \\
\text { tailed) }\end{array}$ & $\begin{array}{l}\text { Mean } \\
\text { Difference }\end{array}$ & $\begin{array}{l}\text { Std. Error } \\
\text { Difference }\end{array}$ & $\begin{array}{l}95 \% \quad C \\
\text { Interval } \\
\text { Differen }\end{array}$ & $\begin{array}{l}\text { nfidence } \\
\text { of the } \\
\text { e }\end{array}$ \\
\hline & & & & & & & & Lower & Upper \\
\hline $\begin{array}{l}\text { Equal } \\
\text { variances } \\
\text { assumed }\end{array}$ & 1.2258 & 0.2689 & 0.6825 & 383.000 & 0.4954 & 0.1887 & 0.2764 & -0.3549 & 0.7322 \\
\hline $\begin{array}{l}\text { Equal } \\
\text { variances } \\
\text { not } \\
\text { assumed }\end{array}$ & & & 0.6565 & 132.651 & 0.5126 & 0.1887 & 0.2874 & -0.3798 & 0.7571 \\
\hline
\end{tabular}

In only one instance was the significance of the 'Levene's Test and Equality of Variances' less than 0.05. This was for the data related to the level of satisfaction regarding the Green Star NZ accreditation course, which produced significance figure of 0.0317 for the Levene's Test and a corresponding Equality of means significance of 0.0318 . This result implied in this particular part of Question 31 non-response could have influenced the data and may not have been representative of the population. This was the only instance of a total of thirty-three data sets analysed in this manner and overall the data can be interpreted with a certain level of confidence. This meant, according to the analyses performed in SPSS, non-response was not an influencing factor for bias in the survey and the results of the survey can be applied to the building industry (refer to Appendix C.1.2). 


\subsection{Survey Results}

\subsubsection{Section 1: Background}

The following section investigated the background regarding the building industry's interest and involvement in sustainability, sustainable building, and BSRTs (refer to Appendix C.2.1).

\subsubsection{Level of Interest}

\section{Question: To what extent would you describe your level of interest in?}

Overall, the results showed an increasing trend regarding the level of interest in sustainability, sustainable building and BSRTs. According to Figure 4-2, there was a good level of interest in all three areas (sustainability, sustainable building and BSRTs), with 29-33\% of the respondents stating they were 'very interested'. This figure increases to $43 \%$ and $44 \%$ at the 'extremely interested' level regarding sustainability and sustainable building, though the increase in interest level for BSRTs is much less, at 33\%.

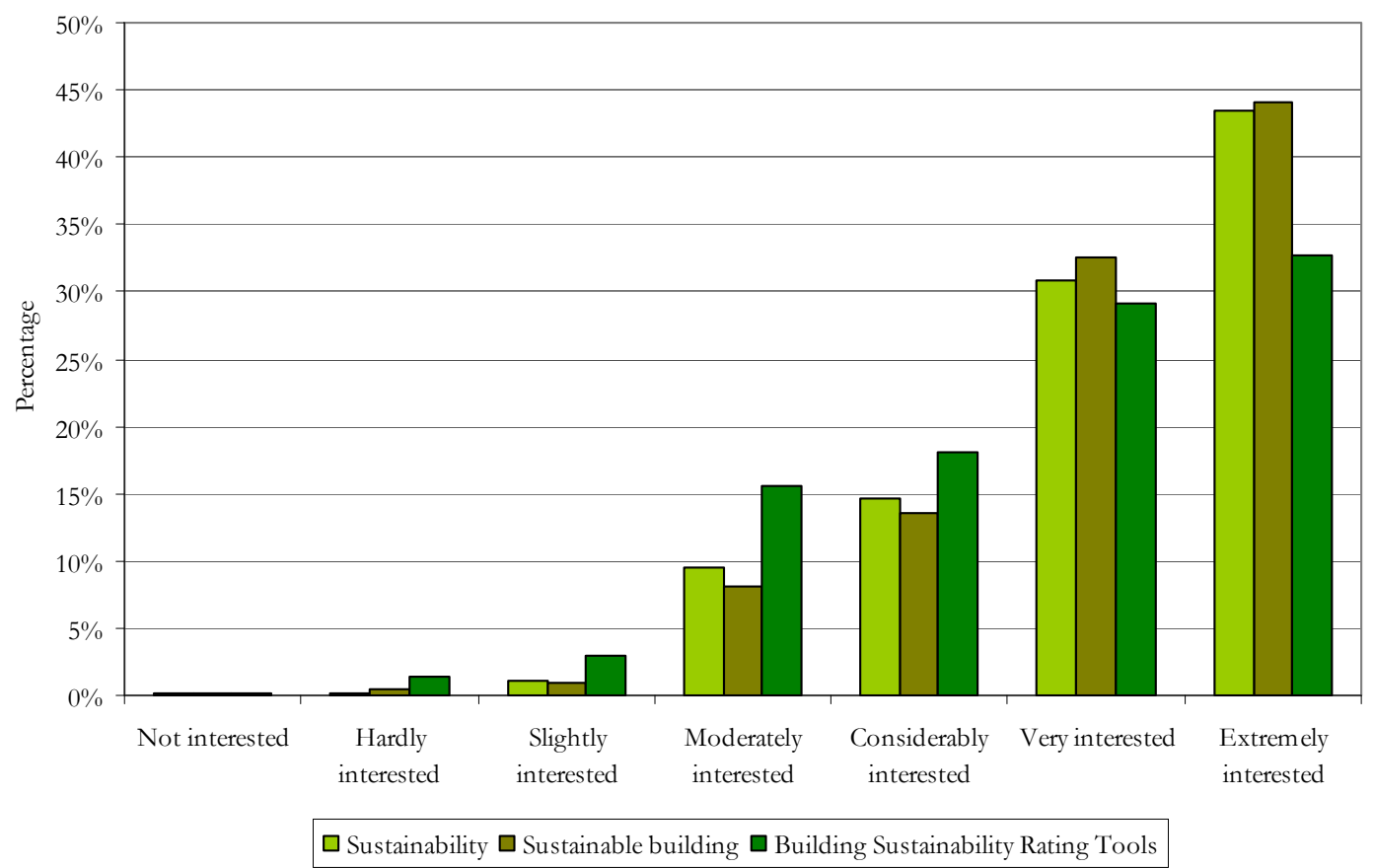

Figure 4-2: Overall participant interest in sustainability, sustainable building and BSRTs

As seen in Figures 4-3, 4-4 and 4-5 'Investors, Owners and Property Managers' have an extremely high level of interest in sustainability, sustainable building and BSRTs, 89\%, 71\% and $60 \%$ respectively. However any conclusions about this stakeholder group should be made with caution, due to the low level of response (i.e. 'Investors, Owners and Property Managers' represent $4 \%$ of the total response). Other sectors, such as 'Architects and Draftpersons' can be 
interpreted with a high level of confidence (i.e. 'Architects and Draftpersons' represent 32\% of the total responses). According to the results $47 \%$ of 'Architects and Draftpersons' were extremely interested in sustainability, $48 \%$ in sustainable building, but only $30 \%$ were extremely interested in BSRTs.

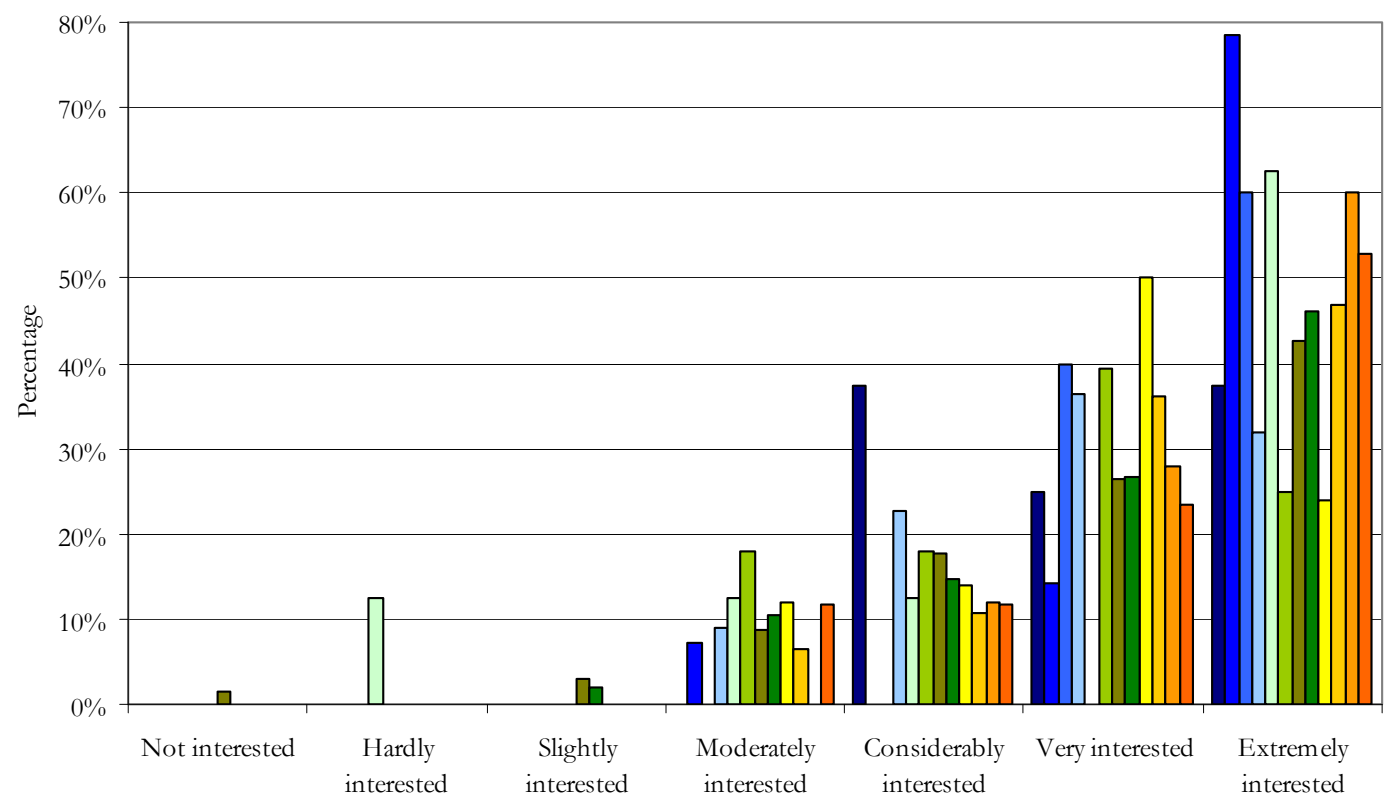

$\square$ CPD $\square$ IO\&PM $\square$ RD\&MPO $\square$ OO $\square$ MCT\&R $\square$ BC $\square$ BPM\&D $\square$ A\&D $\square$ E $\square$ P\&CP $\square$ R\&NGO $\square$ RI

Figure 4-3: Overall interest in sustainability by industry sector

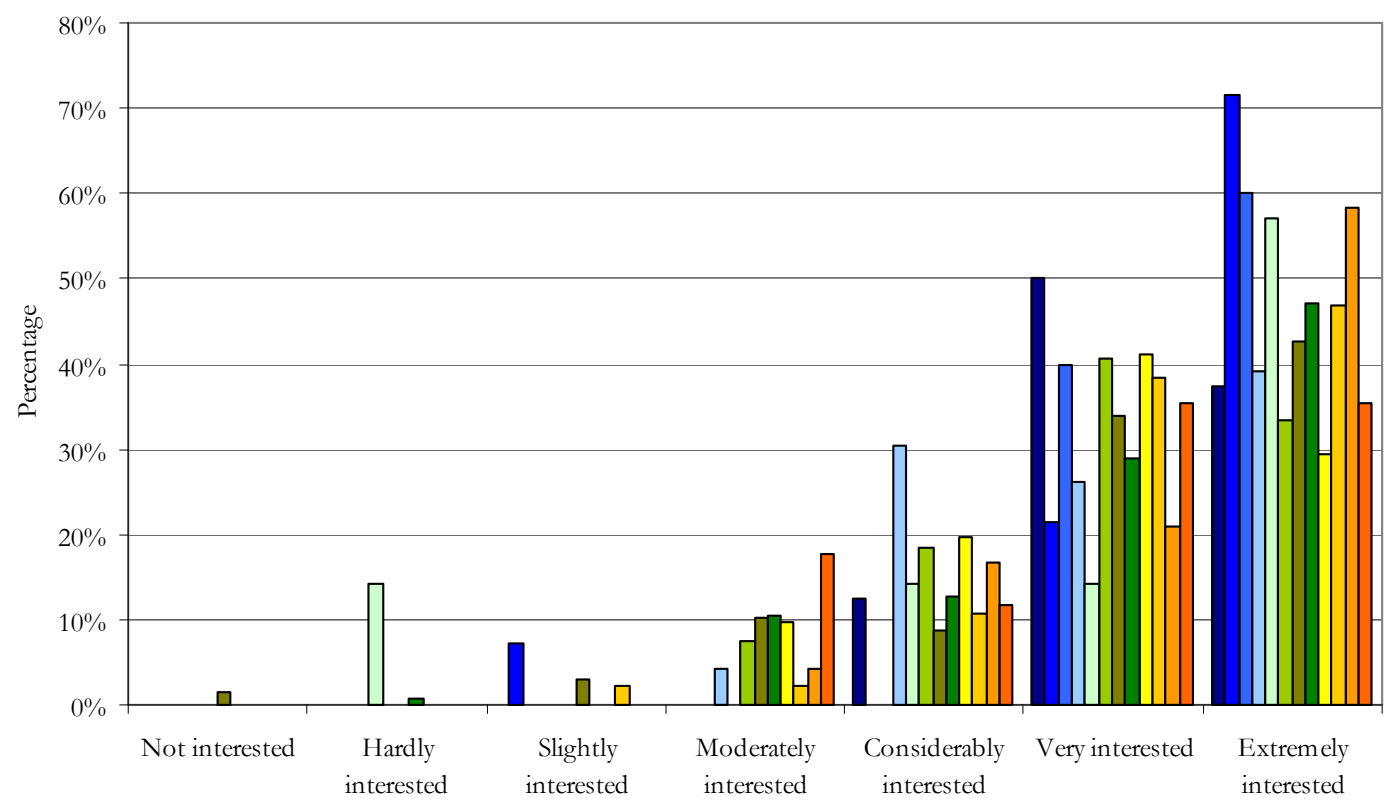

CPD $\square$ IO\&PM $\square$ RD\&MPO $\square$ OO $\square$ MCT\&R $\square$ BC $\square$ BPM\&D $\square$ A\&D $\square$ E P\&CP $\square$ R\&NGO $\square$ RI

Figure 4-4: Overall interest in sustainable building by industry sector 


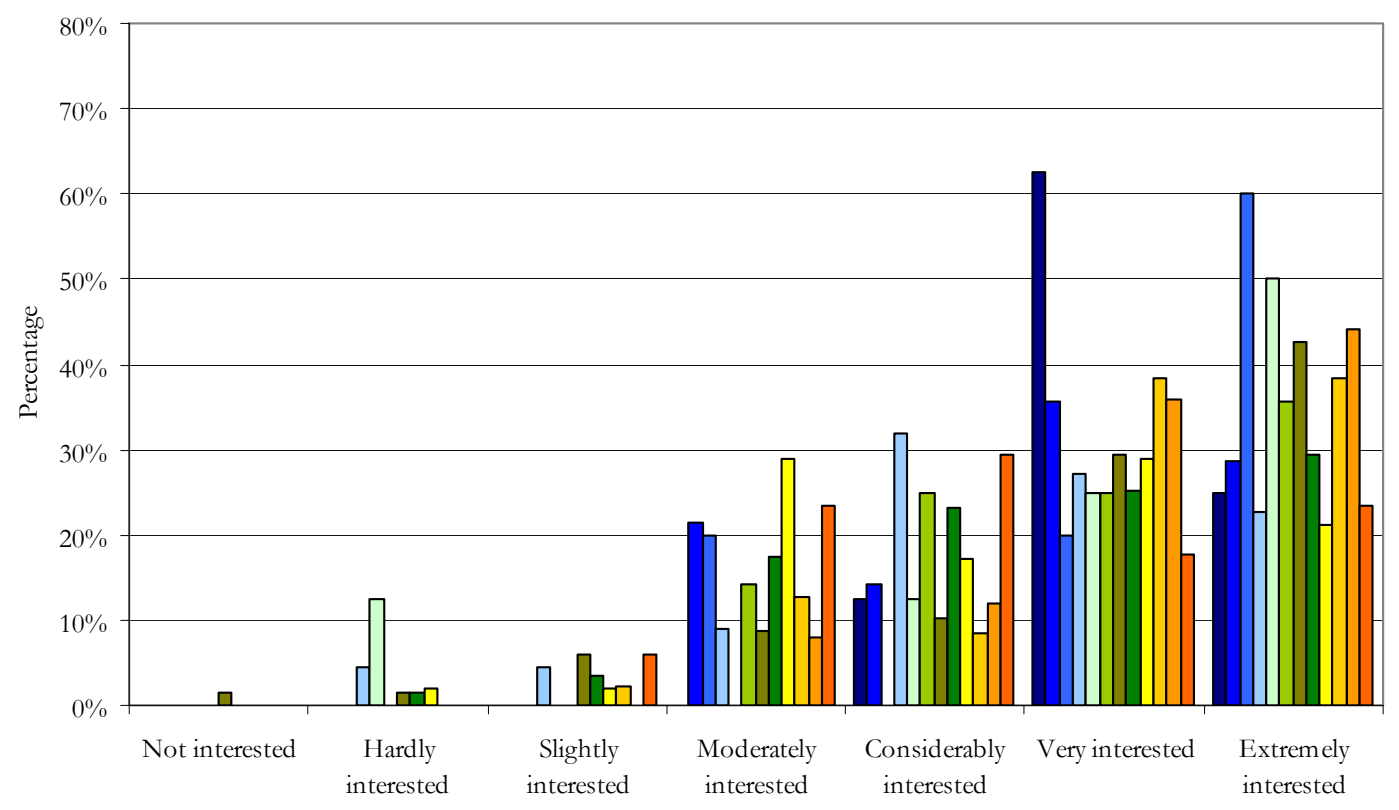

- CPD $\square$ IO\&PM $\square$ RD\&MPO $\square$ OO $\square$ MCT\&R $\square$ BC $\square$ BPM\&D $\square$ A\&D $\square$ E $\square$ P\&CP $\square$ R\&NGO $\square$ RI

Figure 4-5: Overall interest in BSRTs by industry sector

Also analysed were the views of industry members associated with the NZGBC and in contrast to those not associated with the NZGBC. The expectation was there would be a higher, more positive response from the NZGBC members, because these professionals already had an established interest in the surveyed topics. In Figures 4-6, 4-7 and 4-8, only this more positive response is demonstrated at the 'extremely interested' level with a difference of $19 \%$ between NZGBC and non-NZGBC associates. 


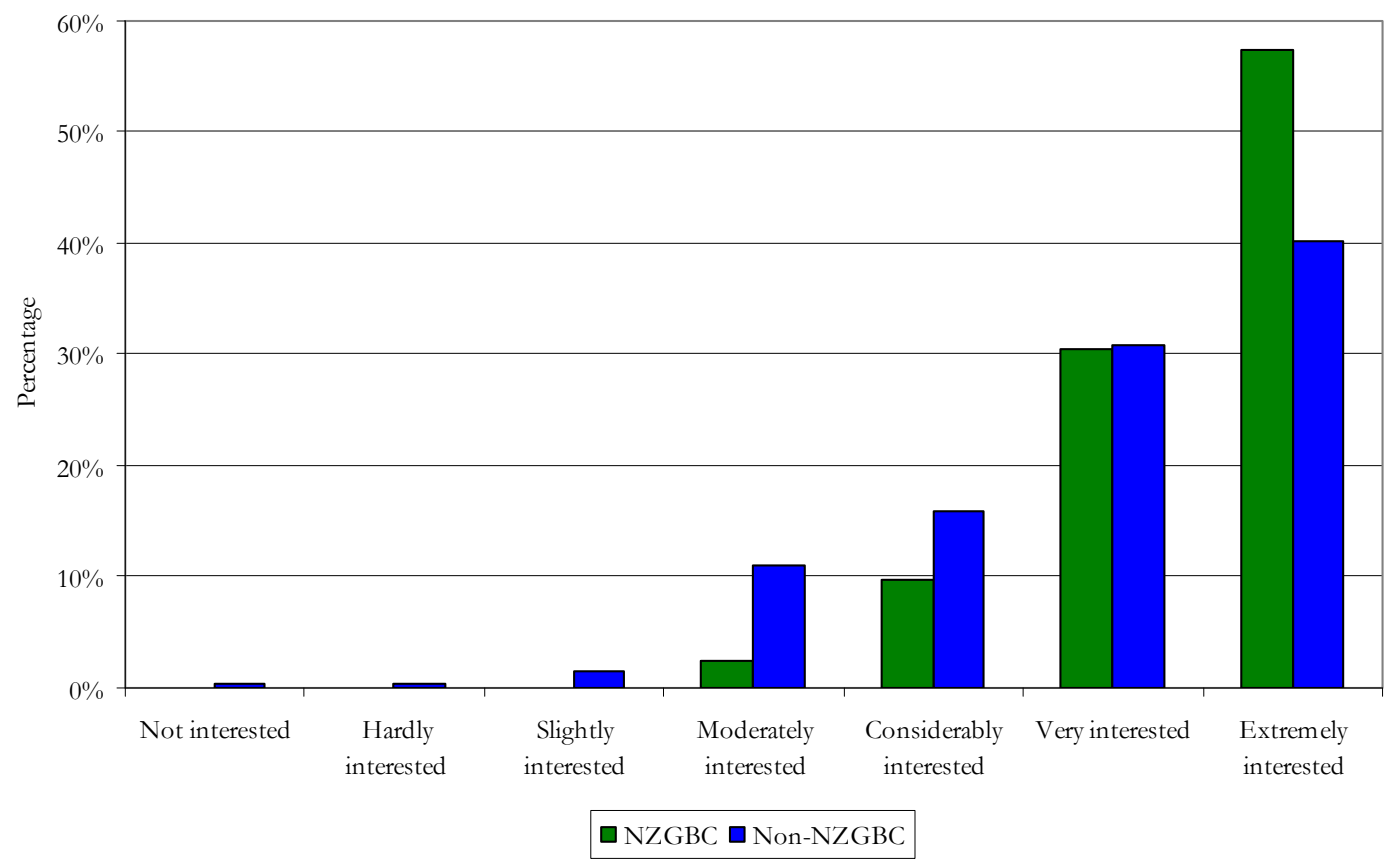

Figure 4-6: Overall interest in sustainability by NZGBC vs. non-NZGBC

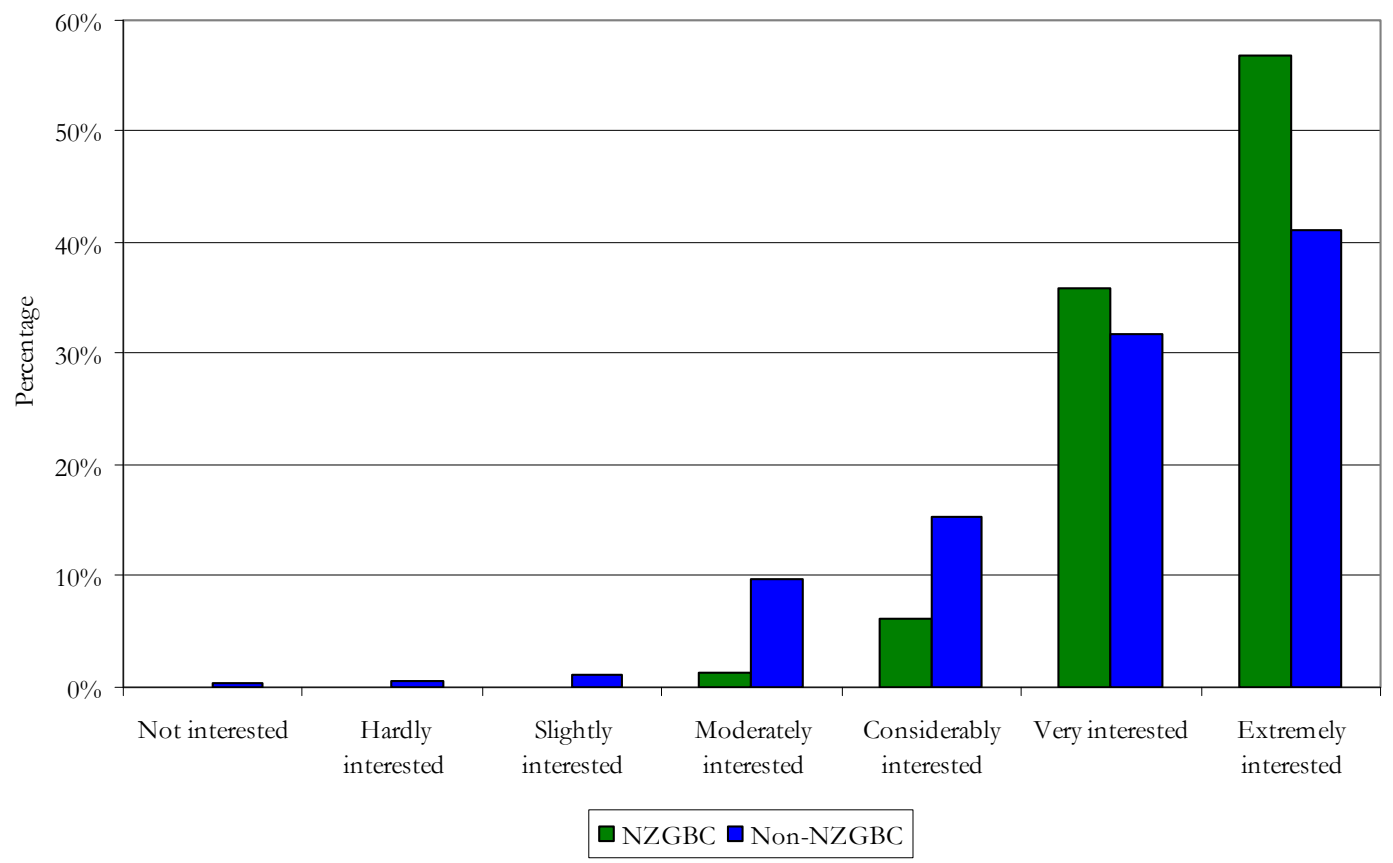

Figure 4-7: Overall interest in sustainable buildings by NZGBC vs. non-NZGBC 


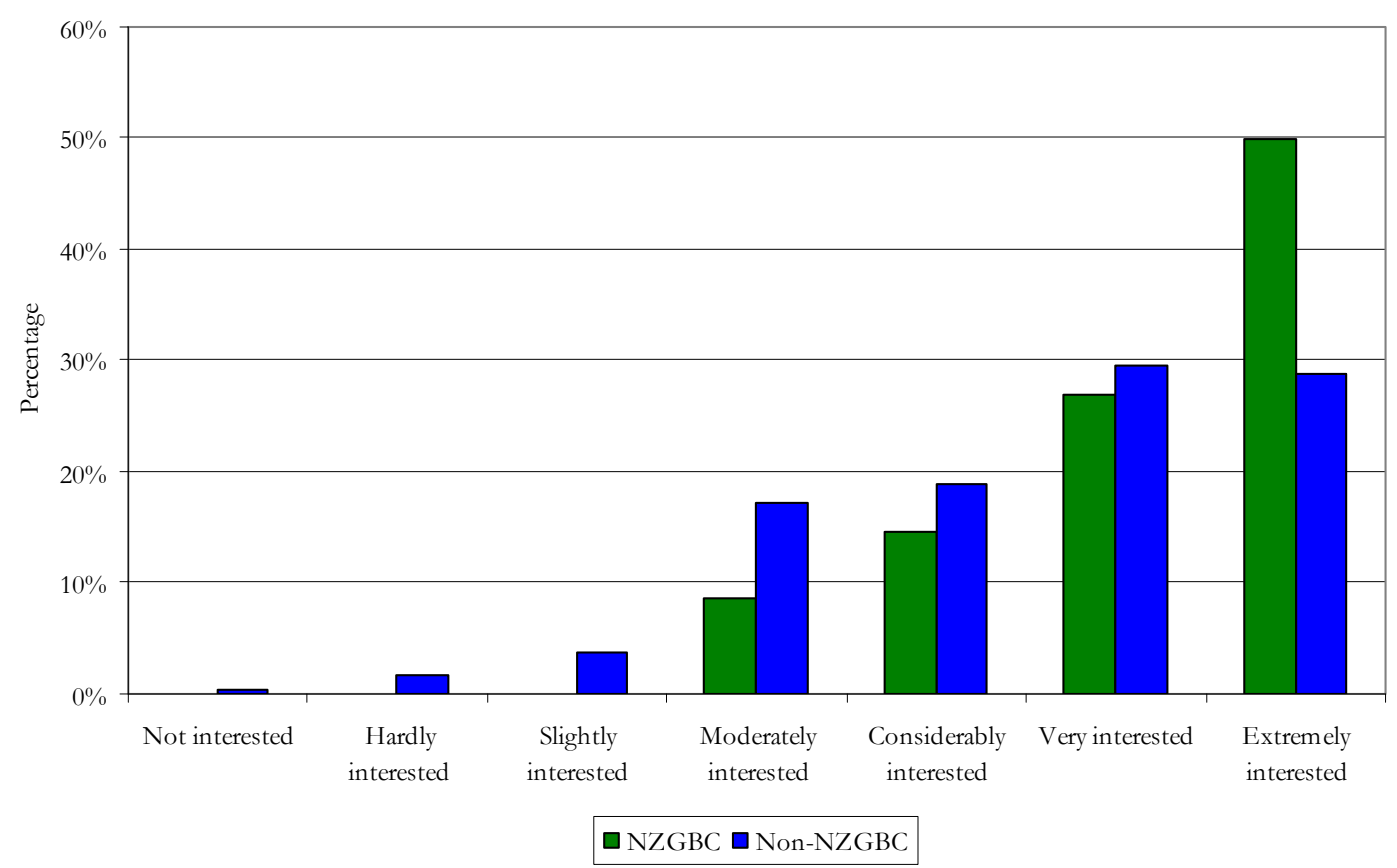

Figure 4-8: Overall interest in BSRTs by NZGBC vs. non-NZGBC 


\subsubsection{Level of Involvement}

\section{Question: What best describes your level of involvement?}

The level of involvement in sustainability, sustainable building and BSRTs is quite different to the level of interest, and in the case of BSRTs shows a negative trend (refer to Figure 4-9). According the results sustainability and sustainable building peak with $26 \%$ and $25 \%$ respectively at the 'moderately involved' level, whereas $24 \%$ of the respondents were not involved with BSRTs.

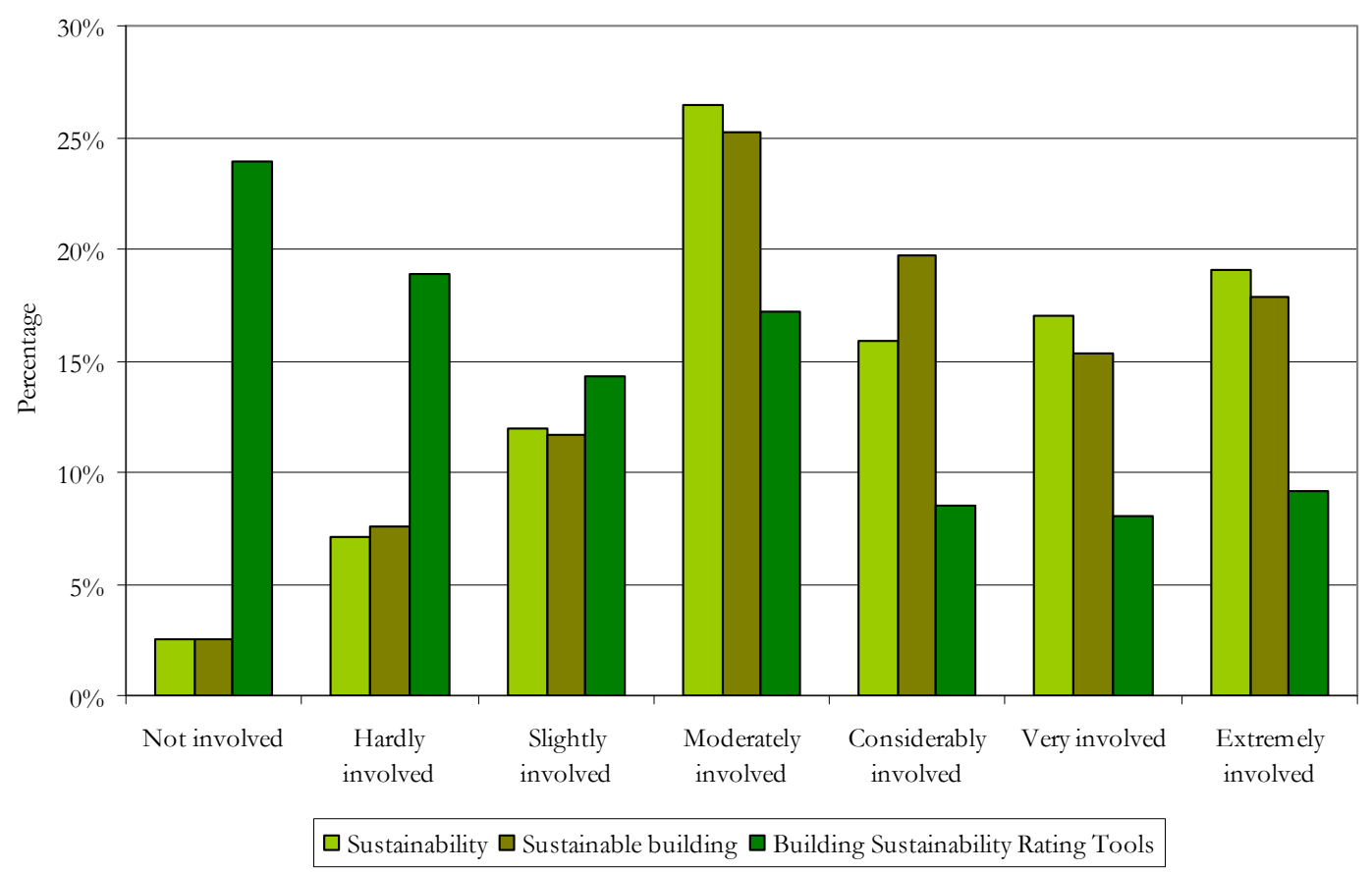

Figure 4-9: Overall participant involvement in sustainability, sustainable building and BSRTs

Overall participant interest was found to be far greater than participant involvement in sustainability, sustainable building and BSRTs (refer to Figures 4-2 and 4-9 for a comparison). According to the results over $40 \%$ of the participants said they were 'extremely interested' in sustainability and sustainable building, whereas less than $20 \%$ were 'extremely involved'. 
As seen in Figure 4-10, 50\% of 'Major Corporate Tenants and Retailers' saw themselves having an extreme involvement in sustainability and sustainable building, but only $26 \%$ were involved with BSRTs. It is important to note this group only makes up $2 \%$ of the total response, and may not reflect the majority of 'Major Corporate Tenants and Retailers'. This is also applicable to 'Residential Developers and Major Portfolio Owners' (who represent 1\% of the total response), 'Investors Owners and Property Managers' (who represent 4\% of the total response), and 'Commercial Property Developers' (who represent $2 \%$ of the total response).

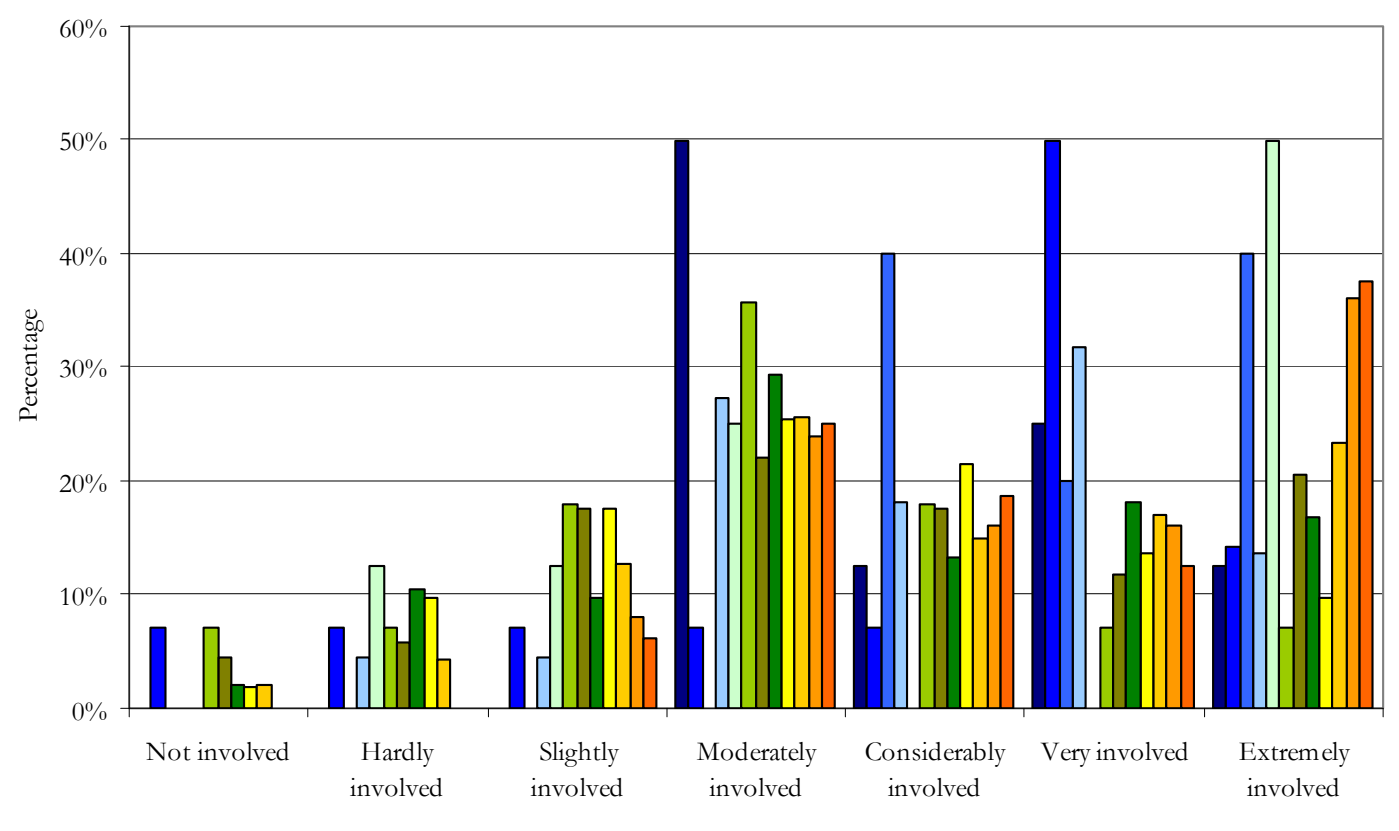

- CPD $\square$ IO\&PM $\square$ RD\&MPO $\square$ OO $\square$ MCT\&R $\square$ BC $\square$ BPM\&D $\square$ A\&D $\square$ E P\&CP $\square$ R\&NGO $\square$ RI

Figure 4-10: Overall involvement in sustainability by industry sector 


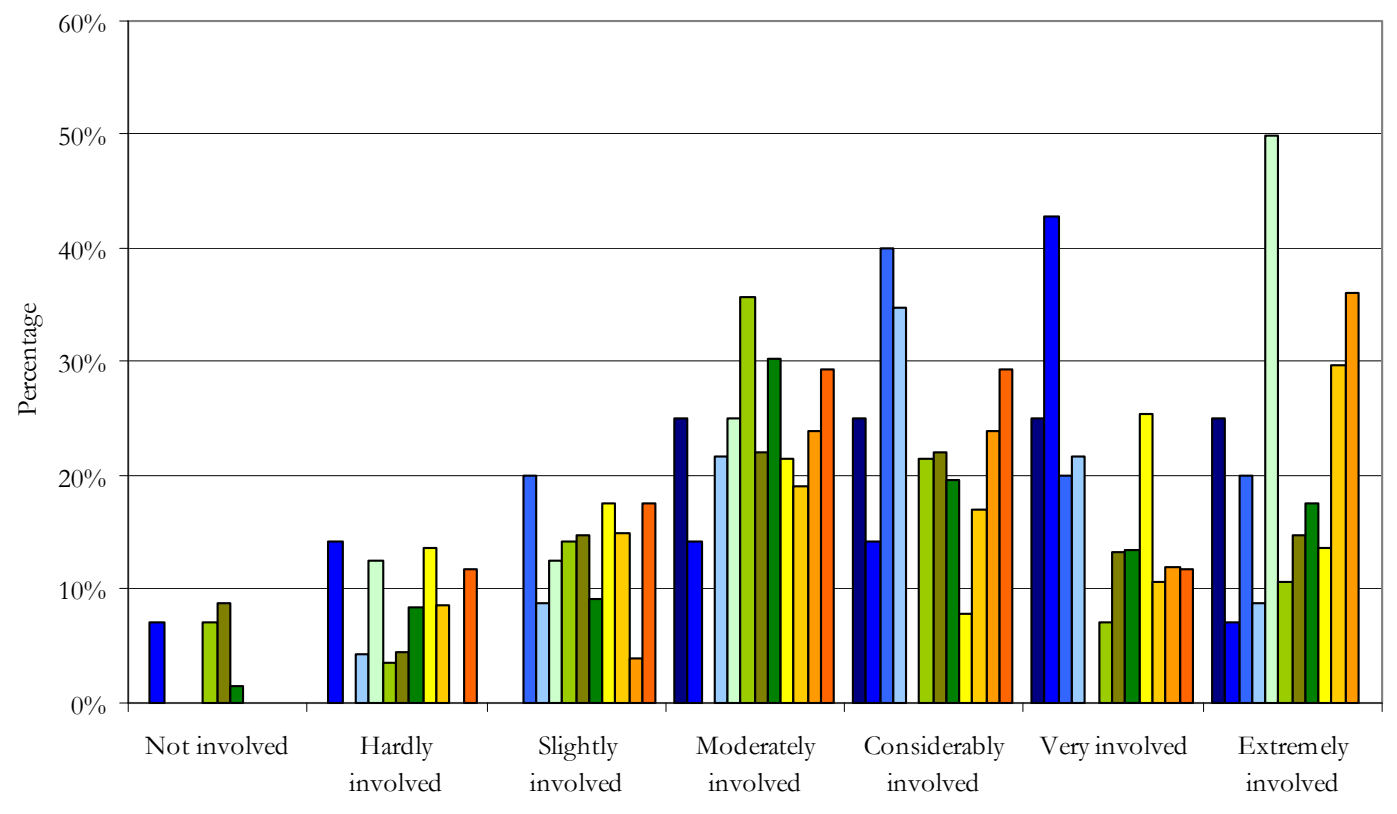

— CPD $\square$ IO\&PM $\square$ RD\&MPO $\square$ OO $\square$ MCT\&R $\square$ BC $\square$ BPM\&D $\square$ A\&D $\square$ E $\square$ P\&CP $\square$ R\&NGO $\square$ RI

Figure 4-11: Overall involvement in sustainable buildings by industry sector

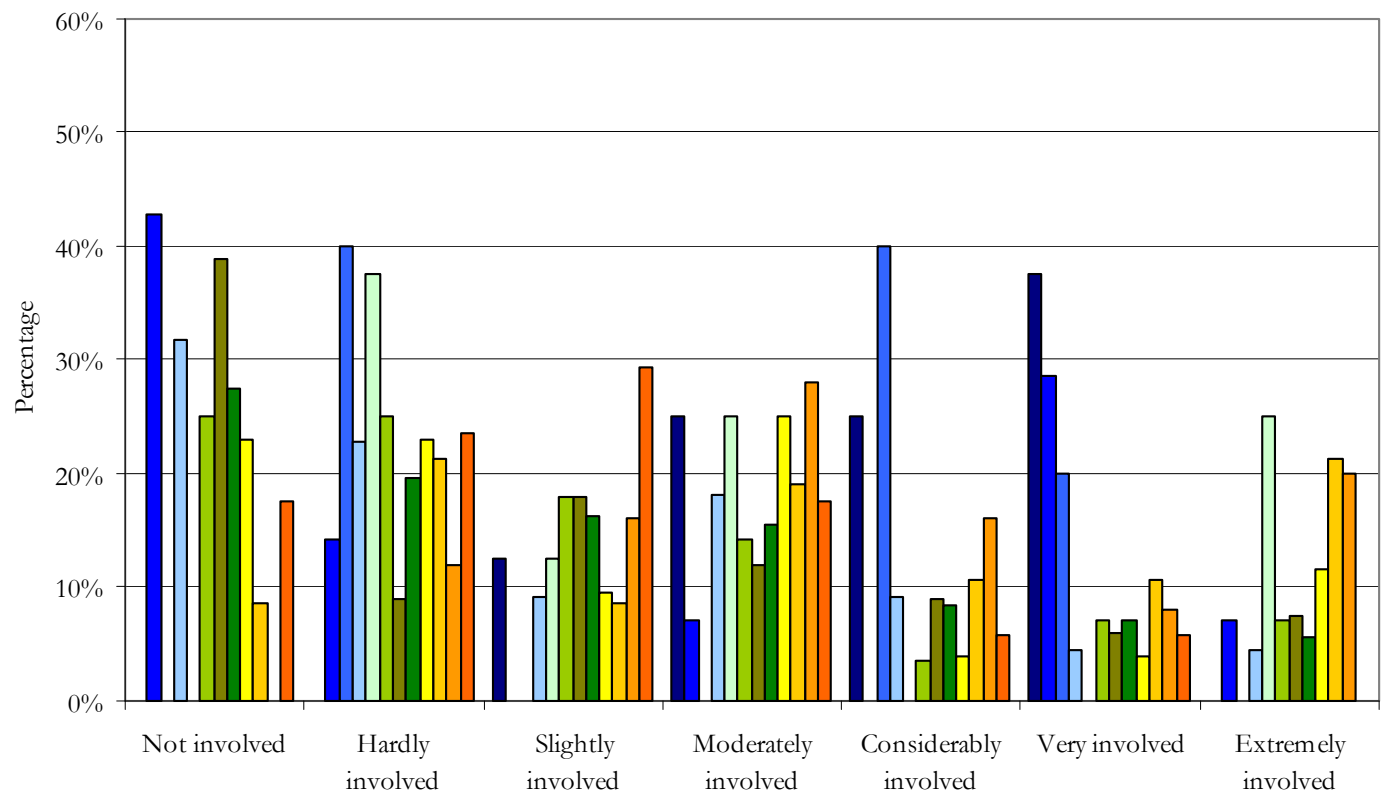

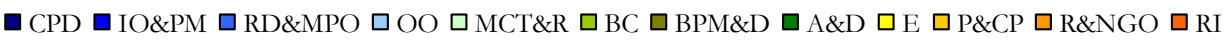

Figure 4-12: Overall involvement in BSRTs by industry sector 
Again, the response of industry members associated with the NZGBC and those not associated with the NZGBC were analysed. According to Figures 4-13 and 4-14 NZGBC associates saw an increasing trend in the level of involvement regarding sustainability and sustainable building, whereas non-NZGBC associates peaked at the moderately involved level. Whereas, Figure 4-15 shows involvement in BSRTs was significantly different where NZGBC associates had quite an even distribution, while non-NZGBC associates saw a decreasing trend in the level of involvement.

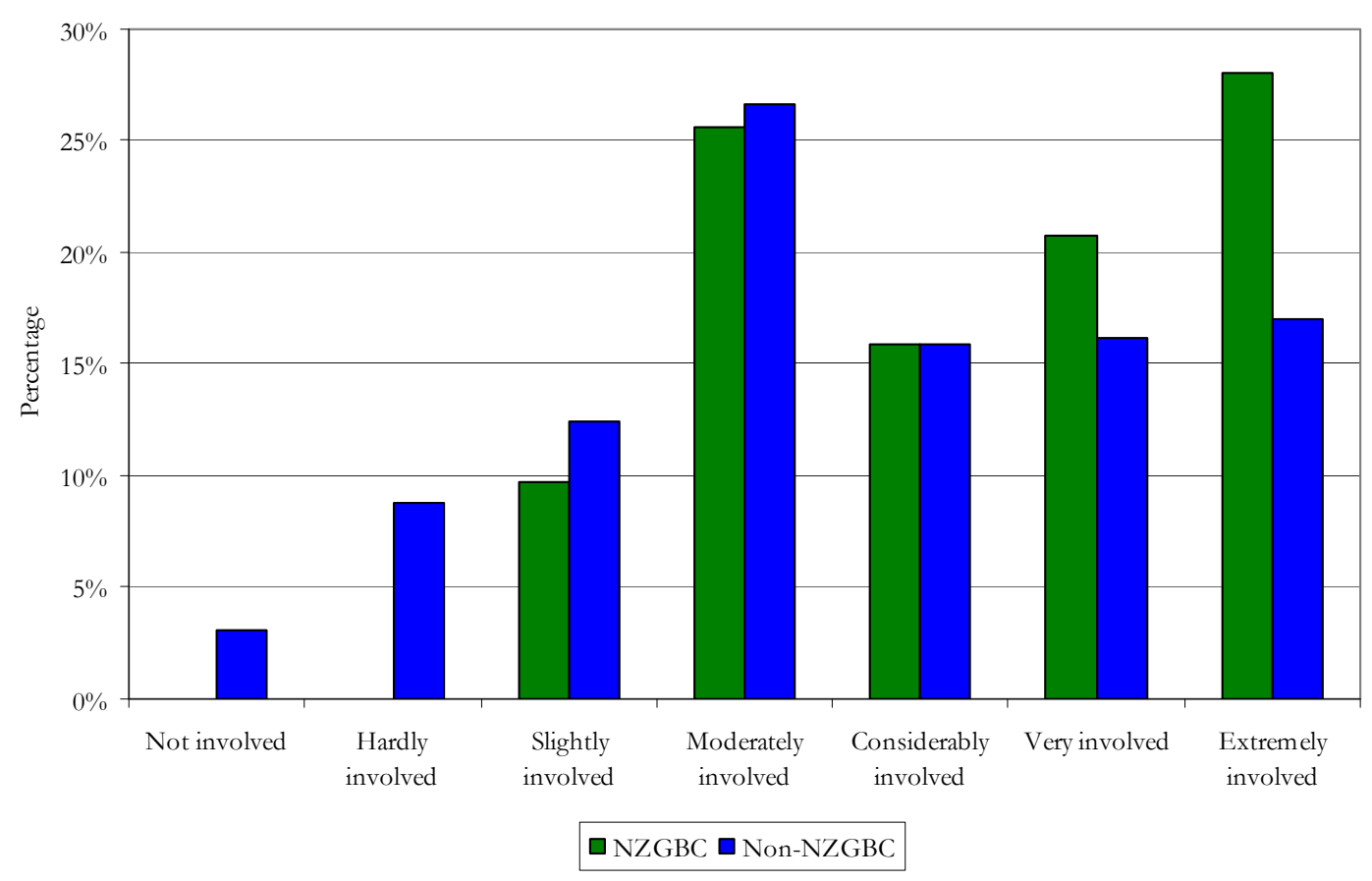

Figure 4-13: Overall involvement in sustainability by NZGBC vs. non-NZGBC 


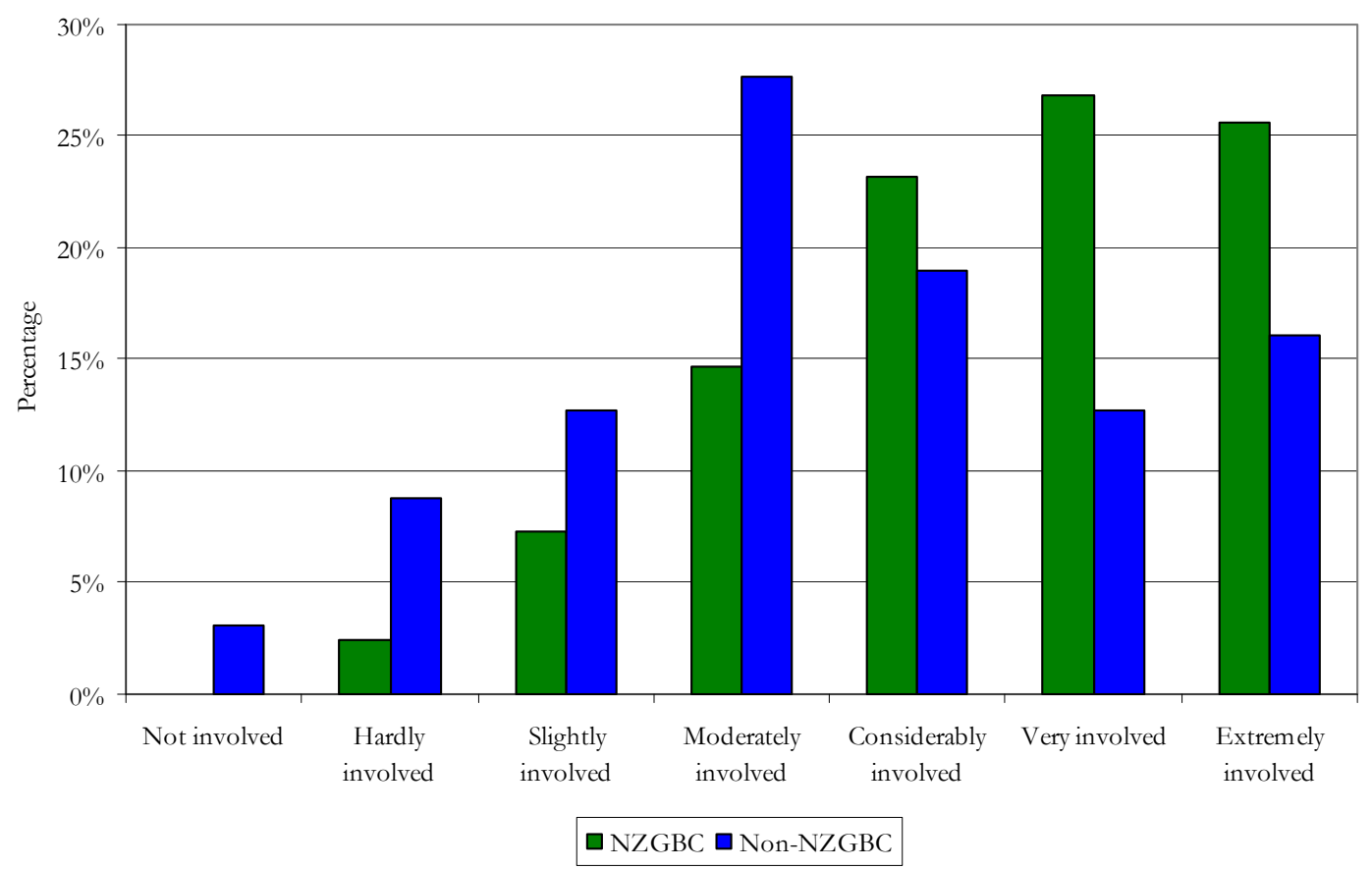

Figure 4-14: Overall involvement in sustainable buildings by NZGBC vs. non-NZGBC

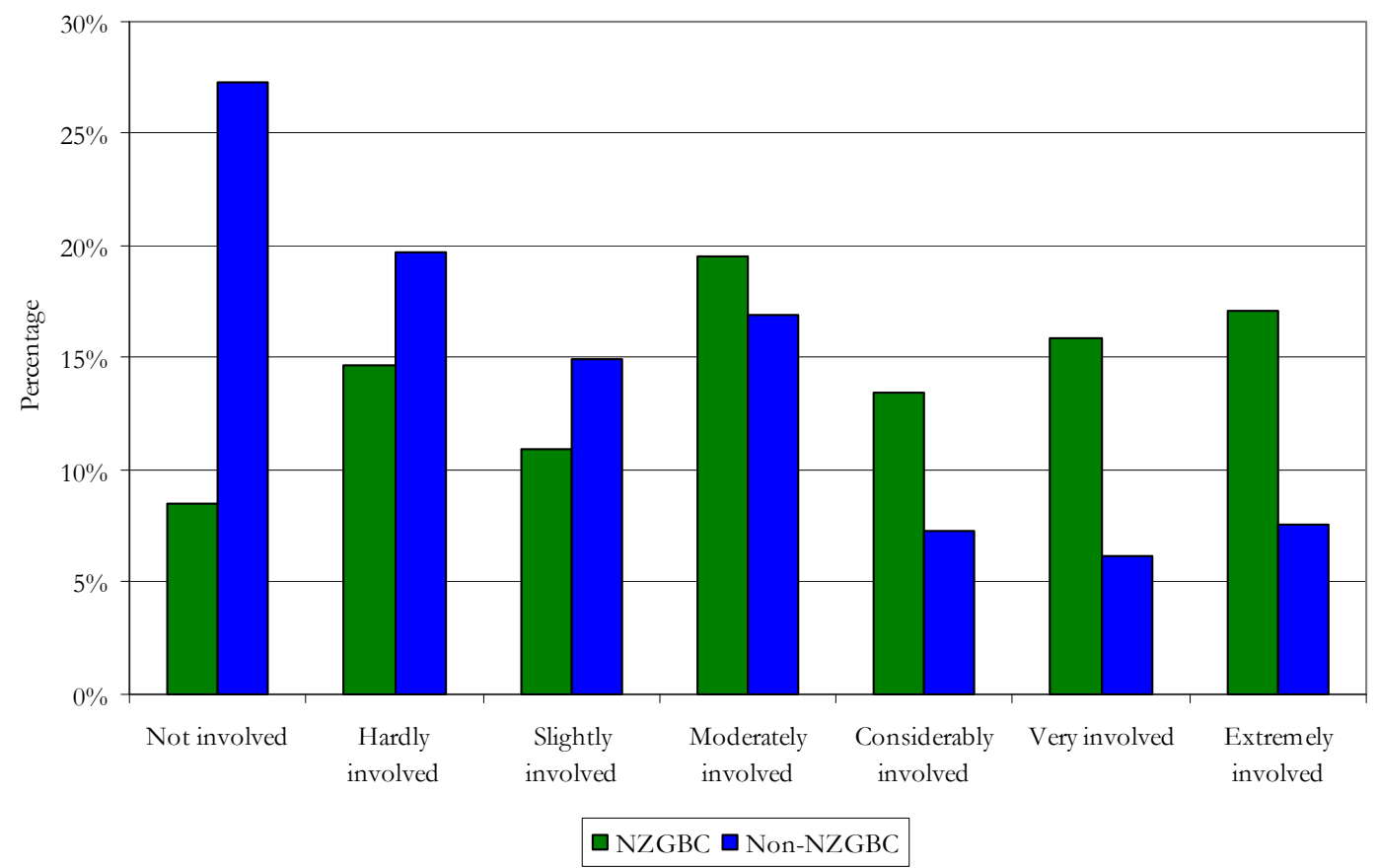

Figure 4-15: Overall involvement in BSRTs by NZGBC vs. non-NZGBC 


\subsubsection{Interest versus Involvement}

Highlighted in the above results was the difference between the level of interest and level of involvement regarding sustainability, sustainable buildings and BSRTs. Figure 4-16 details this relationship. The figure shows there is an average decrease of $25 \%$ from those who are 'extremely interested' to 'extremely involved'. Likewise 'very interested' to 'very involved' had an average decrease of $17 \%$. The smallest change occurs for those who are 'considerably interested' and 'considerably involved' with an average difference of 3\%, and those below this level all see an increase in involvement when compared to interest level, clearly due to the decreasing involvement at higher levels. In addition, a considerable increase is seen with the level of non-involvement of BSRTs with a $24 \%$ of respondents 'not involved'.

Table 4-4: Key of options choices for difference between level of interest and level of involvement

\begin{tabular}{|l|l|}
\hline Number & Definition \\
\hline 1 & Not interested and not involved \\
\hline 2 & Hardly interested and hardly involved \\
\hline 3 & Slightly interested and slightly involved \\
\hline 4 & Moderately interested and moderately involved \\
\hline 5 & Considerably interested and considerably involved \\
\hline 6 & Very interested and very involved \\
\hline 7 & Extremely interested and extremely involved \\
\hline
\end{tabular}

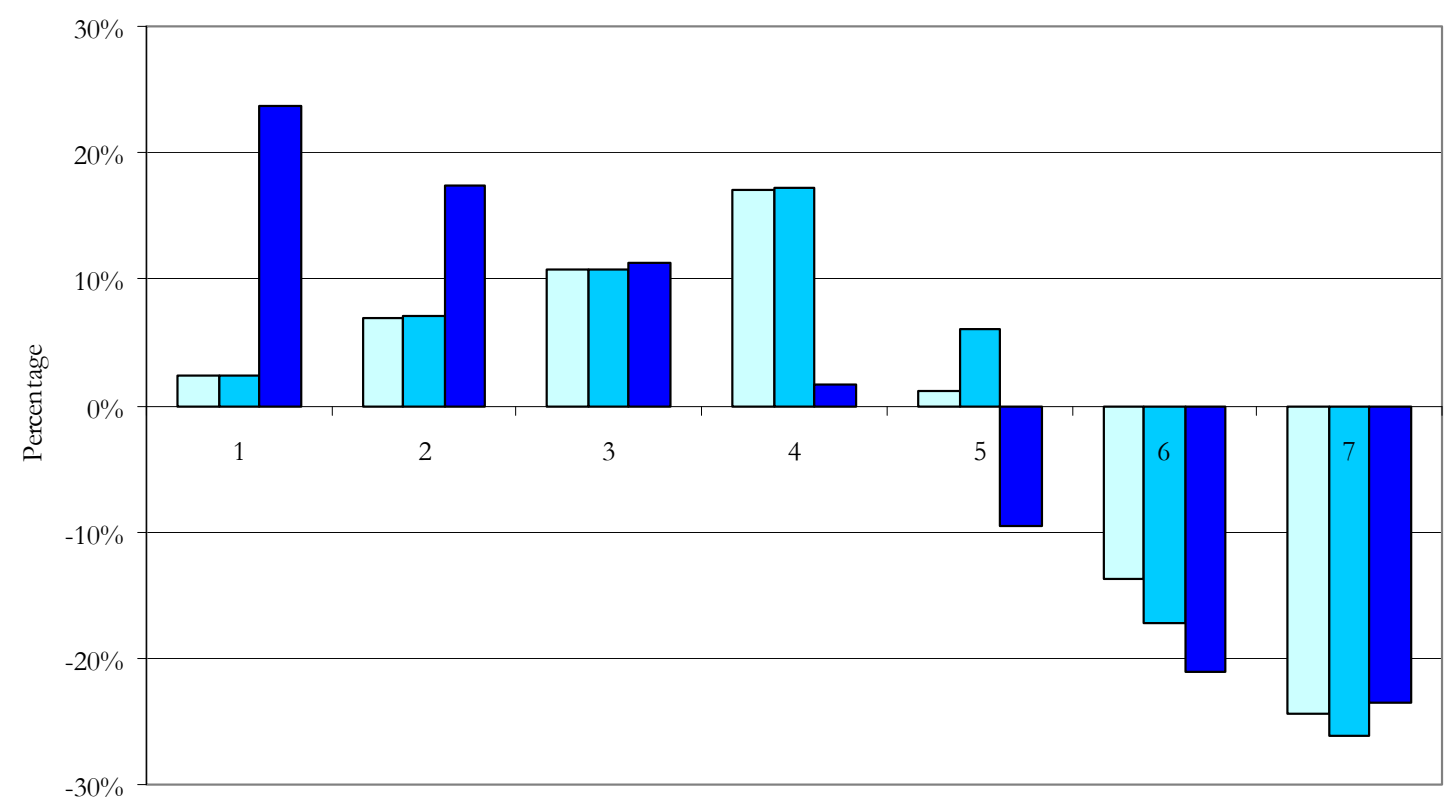

$\square$ Sustainability $\square$ Sustainable building $\boldsymbol{\square}$ Building Sustainability Rating Tools

Figure 4-16: Overall difference between level of interest and level of involvement 


\subsubsection{Discussion}

Overall, the results showed there was a high level of interest regarding sustainability, sustainable building and BSRTs. However, the level of involvement from the participants was significantly lower in each of these three areas. This result emphasised the gap between level of interest and level of involvement of the building industry, and perhaps the building industry are much more willing to participate, and be part of a sustainable building than is currently perceived. Consequently, there is a requirement for more and better sustainable building information (e.g. email, newsletters reports) from either the NZGBC and/or other similar organisations. This in turn could lead to a higher uptake of Green Star NZ and more sustainable buildings.

Additionally the results showed there was a greater level of interest and involvement in sustainability and sustainable building than BSRTs. This result emphasised since both sustainability and sustainable building have been part of the building industry for a longer period and are better understood. Whereas BSRTs are relatively new in comparison, especially in New Zealand, and are yet to create the necessary level of interest to cement their role in the New Zealand building industry. Although it would be expected that over time as Green Star NZ evolves, it will achieve greater awareness from the building industry, hence greater market acceptance. 


\subsubsection{Section 2: Building Sustainability Rating Tools}

This section was specifically directed at BSRTs and investigated the respondent's perceptions of the purpose of BSRTs, and their awareness and experience with current tools (refer to Appendix C.2.2).

\subsubsection{Purpose of a Building Sustainability Rating Tool}

\section{Question: What do you see as the purpose of a Building Sustainability Rating Tool?}

The rationale for this question was to investigate the respondent's interpretation of what is the purpose of a BSRT, rather than what it is or does. According to the NZGBC the purpose of a BSRT is to (New Zealand Green Building Council\}:

- "Establish a common language and standard of measurement for green buildings

- Promote integrated, whole-building design

- Raise awareness of green building benefits

- Recognise environmental leadership

- Reduce the environmental impact of development"

According to the results (refer to Table 4-5) the respondents recognised the ability of a BSRT to 'standardise and set benchmarks'. Still, these answers could have several meanings; for instance benchmarks could refer to minimum building standards (i.e. Building Code) and not the demanding high-end performance benchmark wanted by the NZGBC to recognise environmental leadership.

In addition to standardisation, assisting in the decision making process and the ability to make comparisons were seen as important purposes of a BSRT. The ability for comparison as described earlier could allow similar buildings to be compared at a national level and/or international level, and as a result create competition to advance the development of sustainable buildings.

Table 4-5: Top six interpretations to the purpose of a BSRT

\begin{tabular}{|l|r|}
\hline Purpose & Number \\
\hline To standardize/set benchmarks & 59 \\
\hline To assist in the decision making process & 31 \\
\hline To enable comparisons & 30 \\
\hline To assist with education, creating better awareness & 23 \\
\hline To quantify the sustainability of buildings & 20 \\
\hline To protect the environment/reduce buildings environmental impact & 20 \\
\hline
\end{tabular}


Other interesting comments from the survey include a negative interpretation of the purpose of a BSRT, 'to add more bureaucracy and government interference' which acquired five votes. While this may seem a cynical response to the question, this interpretation achieved a surprisingly similar level of response to the interpretation 'creation of best practice'. It also reinforces some of the potential barriers the NZGBC and Green Star NZ have to overcome and the negativity of some parts of the building industry (refer to Appendix C.2.2.1 for full list of answers).

\subsubsection{New Zealand Specific Building Sustainability Rating Tool}

Question: How important is it to have a New Zealand specific Building Sustainability Rating Tool?

According to the results having a New Zealand specific BSRT was important, with 30\% of the participants rating it as 'extremely important', 28\% 'very important', 19\% 'considerably important' and 15\% 'moderately important' (refer to Figure 4-17). Only $2 \%$ of the respondents said it was 'not important'.

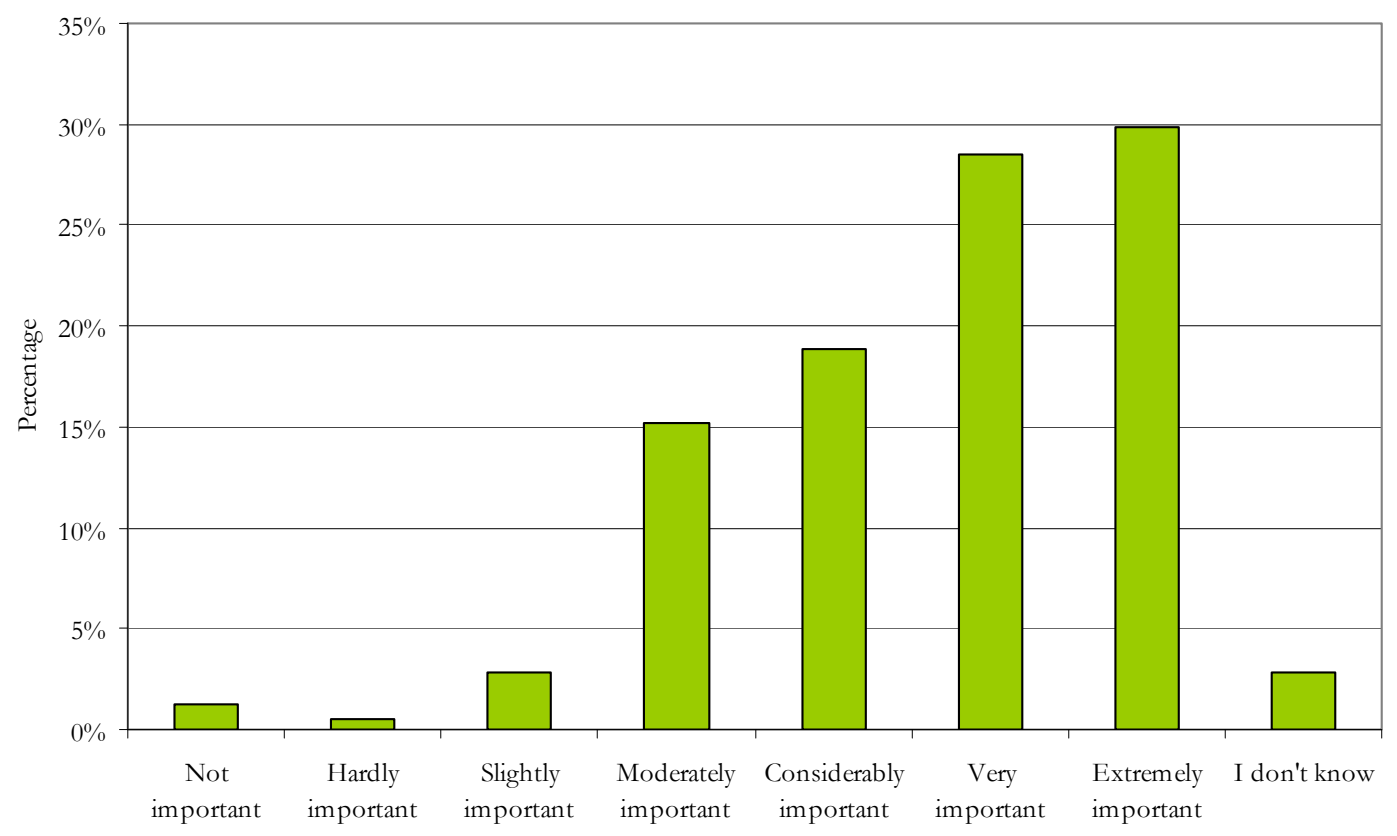

Figure 4-17: Overall importance for New Zealand to have a specific BSRT 


\subsubsection{Awareness of Existing Building Sustainability Rating Tools}

Question: Of the current existing Building Sustainability Rating Tools which are you aware of?

As expected the Australian system Green Star recorded the greatest level of awareness (57\%) from the participants (refer to Figure 4-18). The United States BSRT, LEED achieved an awareness level of $36 \%$ and the United Kingdom BSRT BREEAM a 32\% level of awareness. This is not surprising considering these tools have been in existence for quite some time.

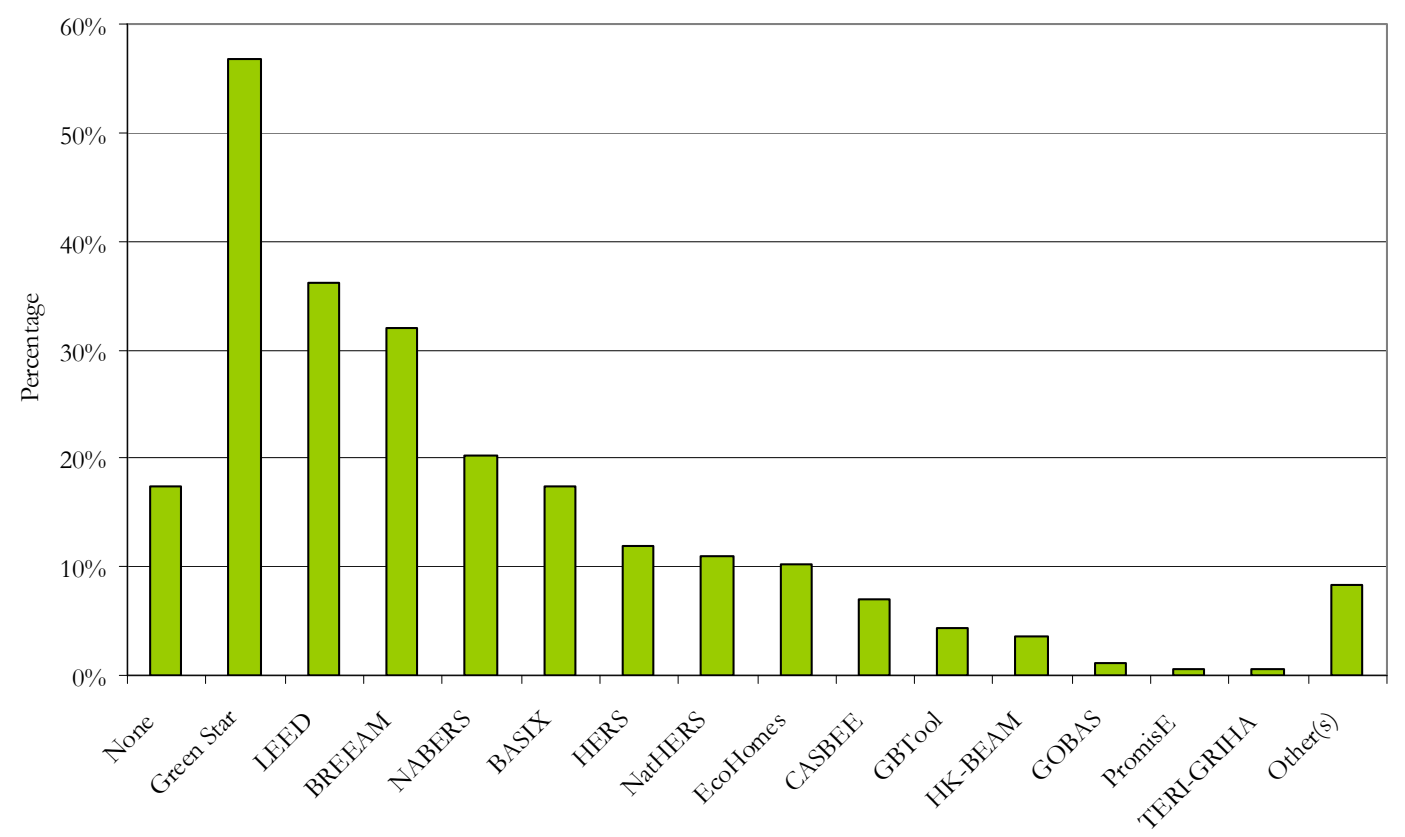

Figure 4-18: Overall awareness of the current existing BSRTs (in order of highest to lowest) 
Likewise, Green Star achieved a higher level of awareness across the building industry than LEED and BREEAM, and certainly emphasises the decision by the NGBC to adopt the Australian tool (refer to Figure 4-19). 'Building Contractors' could also be interpreted to have a lower overall awareness of the existing BSRTs, which might reflect that while 'Building Contractors' may be involved in the creation of a sustainable building, they may not be necessarily involved its design, and hence do not see the indirect benefits such as a higher resale value to that of a building owner.

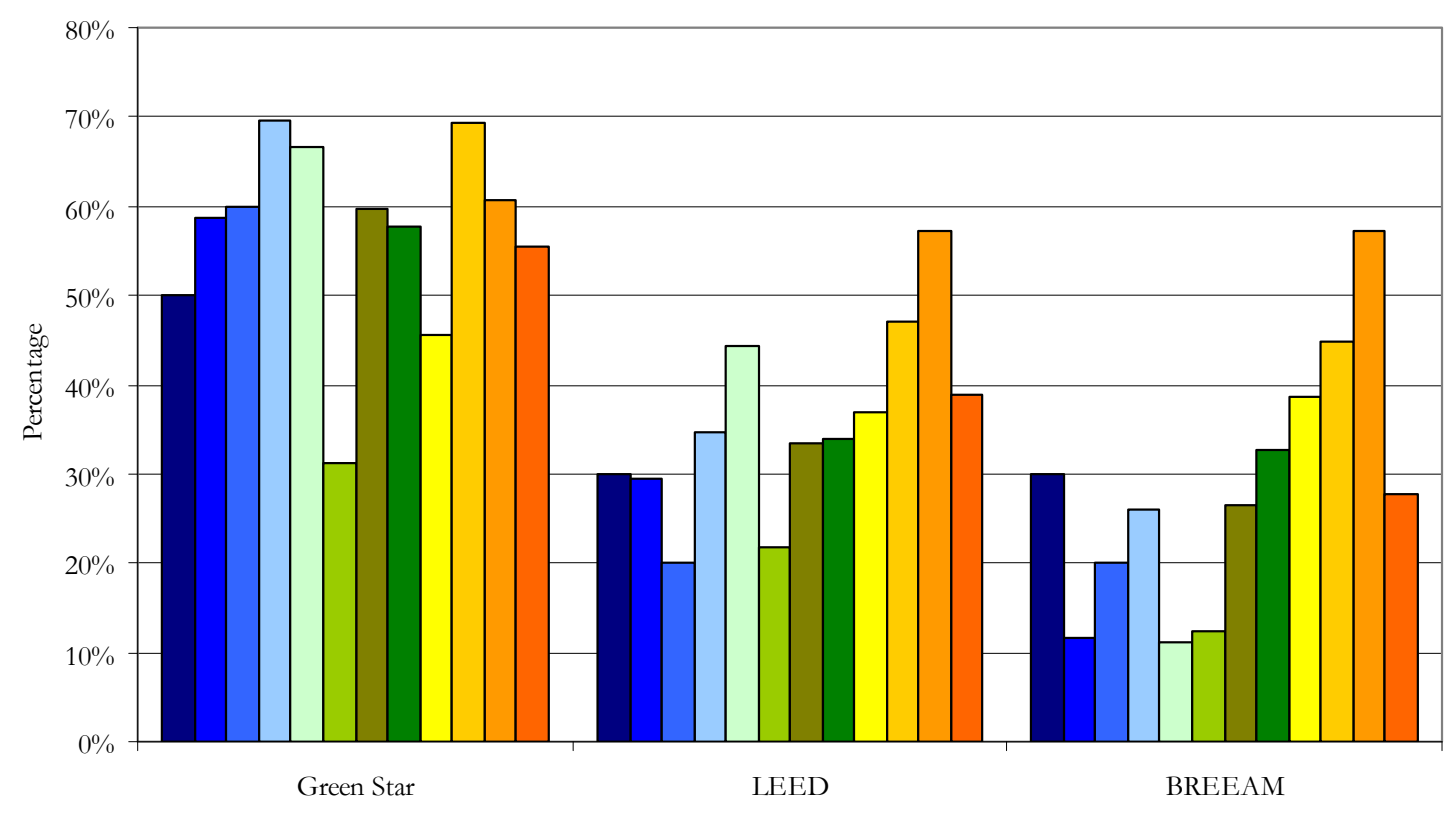

$\square \mathrm{CPD} \square \mathrm{IO \& PM} \square \mathrm{RD \& MPO} \square \mathrm{OO} \square \mathrm{MCT \& R} \square \mathrm{BC} \square \mathrm{BPM} \& \mathrm{~A}$ A\&D $\square \square \mathrm{P} \& \mathrm{CP} \square \mathrm{R} \& N G \mathrm{R} \mathrm{RI}$

Figure 4-19: Overall awareness of the current existing BSRTs by industry sector (top three results) 


\subsubsection{Experience with Existing Building Sustainability Rating Tools}

Question: Of the current existing Building Sustainability Rating Tools which do you have experience with?

When it came to experience with existing BSRTs, the majority of the industry's experience was much lower than its awareness, with over $50 \%$ of the respondents having had no experience with any existing tool (refer to Figure 4-20). While not as substantial as the level of awareness, Green Star (Australia) still achieved the highest level of experience from the participants with $18 \%$. This low level of experience is also supported by the fact only $8 \%$ of the all responses said they had completed training to become an accredited professional of another currently available BSRT.

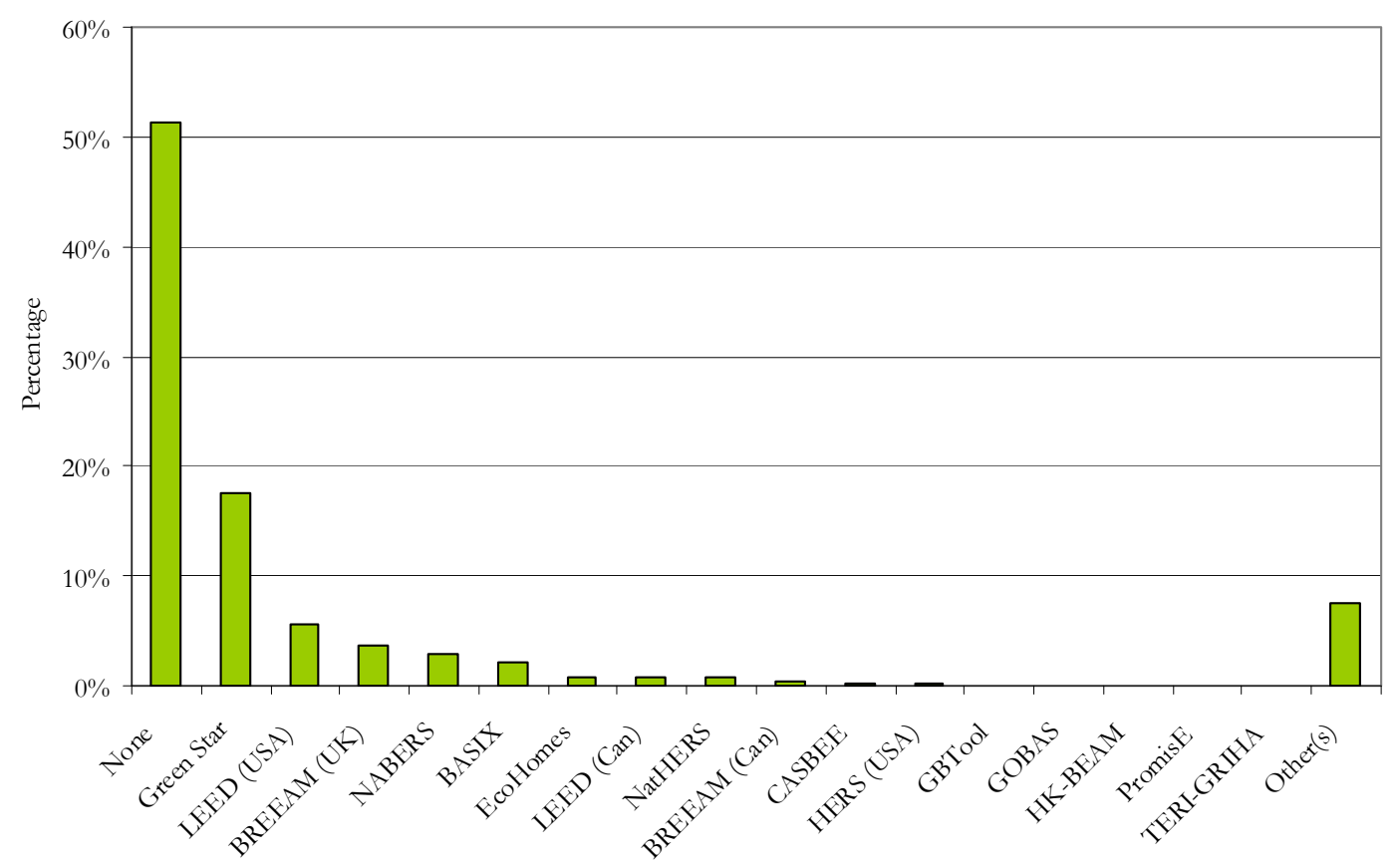

Figure 4-20: Overall current experience with existing BSRTs (in order of highest to lowest) 


\subsubsection{Discussion}

According to the results, there was a good level of awareness from the respondents regarding BSRTs. The participants reinforced the approach of the NZGBC in establishing a BSRT for New Zealand, as $58 \%$ of the respondents rated it between 'very' and 'extremely important' in having a New Zealand specific BSRT. This result suggested having a New Zealand specific BSRT is an important component in driving the New Zealand building industry towards more sustainable building practice and the use of Green Star NZ. In the past building owners have used other existing international BSRTs as a guideline for creating sustainable buildings (e.g. the Australian system Green Star), which in some cases buildings have been informally rated, and as the assessment is for an Australian context any subsequent rating is interpreted with a degree of cynicism.

The analyses compared the respondents associated with the NZGBC and those not associated with the NZGBC, with the subsequent results identifying a difference of those 'extremely interested' in sustainability, sustainable building and BSRTs. This result suggests due to the lack of awareness there is a degree of apprehension from the non-NZGBC associates to fully embracing the sustainable building attitude.

Identified in the results was also the lack of involvement in BSRTs; this was expected, as at the time of the survey's distribution Green Star NZ had not been officially launched into the New Zealand market and as a result, use of Green Star NZ outside the NZGBC was almost non-existent. The gap between interest and involvement emphasised that the building industry is far more willing to participate in the production of sustainable buildings. The interpretation here is while there seems to be a high level of interest from the building industry, its involvement is much lower. More importantly, a potential gap was identified, where the NZGBC and other organisations can direct information and/or events to get industry more involved.

The building industry recognised the need of a BSRT to allow standardisation and setting of sustainable building benchmarks. Furthermore a BSRT can assist in the decision making process and create the ability for comparison of similar building types to be compared at a national level and/or international level.

As for existing BSRTs, the Australian Green Star system was clearly the most recognised existing BSRT. Again this result justifies the decision by the NZGBC to develop Green Star, and a high level of awareness is critical for market penetration and overall success. 


\subsubsection{Section 3: Green Star New Zealand}

The following section investigated Green Star NZ, including how the building industry anticipates they will use the tool and if they were likely to seek formal certification (refer to Appendix C.2.3).

\subsubsection{Green Star New Zealand Awareness}

Question: Are you aware of Green Star New Zealand?

As with awareness of existing BSRTs there is a good level of awareness of Green Star NZ, with $78 \%$ of the respondents aware of its existence. Even $74 \%$ of those not associated with the NZGBC were aware of Green Star NZ. 


\subsubsection{New Zealand Equivalent of Green Star}

Question: How important is it for Green Star New Zealand to be an equivalent of the Australian Green Star system?

With importance already placed on the relationship between Green Star and Green Star NZ (i.e. the NZGBC has adapted Green Star to a New Zealand context), participants were asked how important it was for Green Star NZ to be an actual equivalent of the Australian system. According to the results, $26 \%$ of the respondents saw it as 'very important', with $21 \%$ 'considerably important', 15\% 'moderately important', and 14\% 'extremely important' (refer to Figure 4-21).

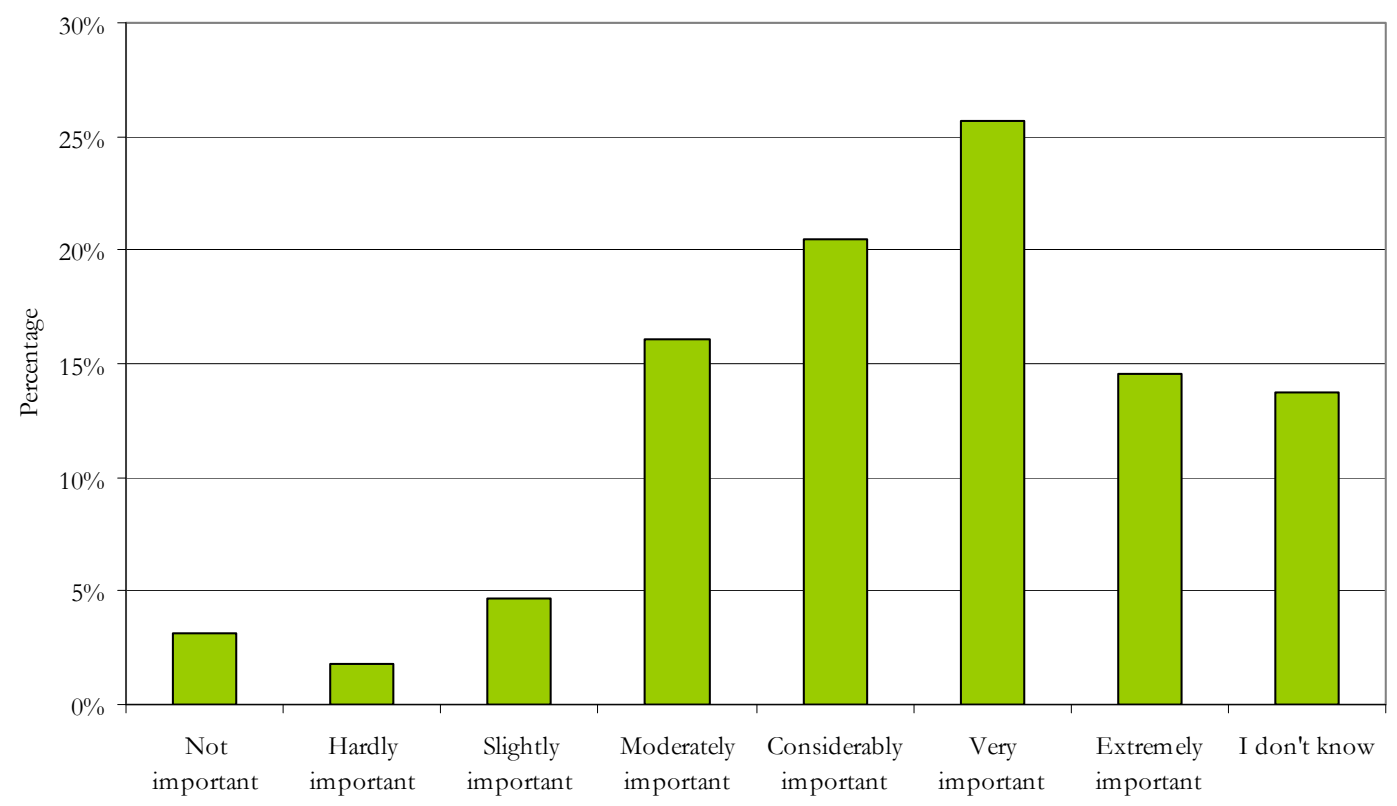

Figure 4-21: Overall importance for Green Star NZ to be a New Zealand equivalent of the Australian Green Star system 
At an industry sector level the results show a similar pattern. What is most evident is the large deviation from the average by 'Residential Developers and Major Portfolio Owners', with 60\% answering it as 'extremely important' for Green Star NZ to be equivalent to the Australian tool (refer to Figure 4-22). Again, it should be noted this equates to only $1 \%$ of the total response and may not represent all 'Residential Developers and Major Portfolio Owners'. Likewise $50 \%$ of 'Commercial Property Developers' saw it to be 'considerably important', but again this only equates to $2 \%$ of the total response.

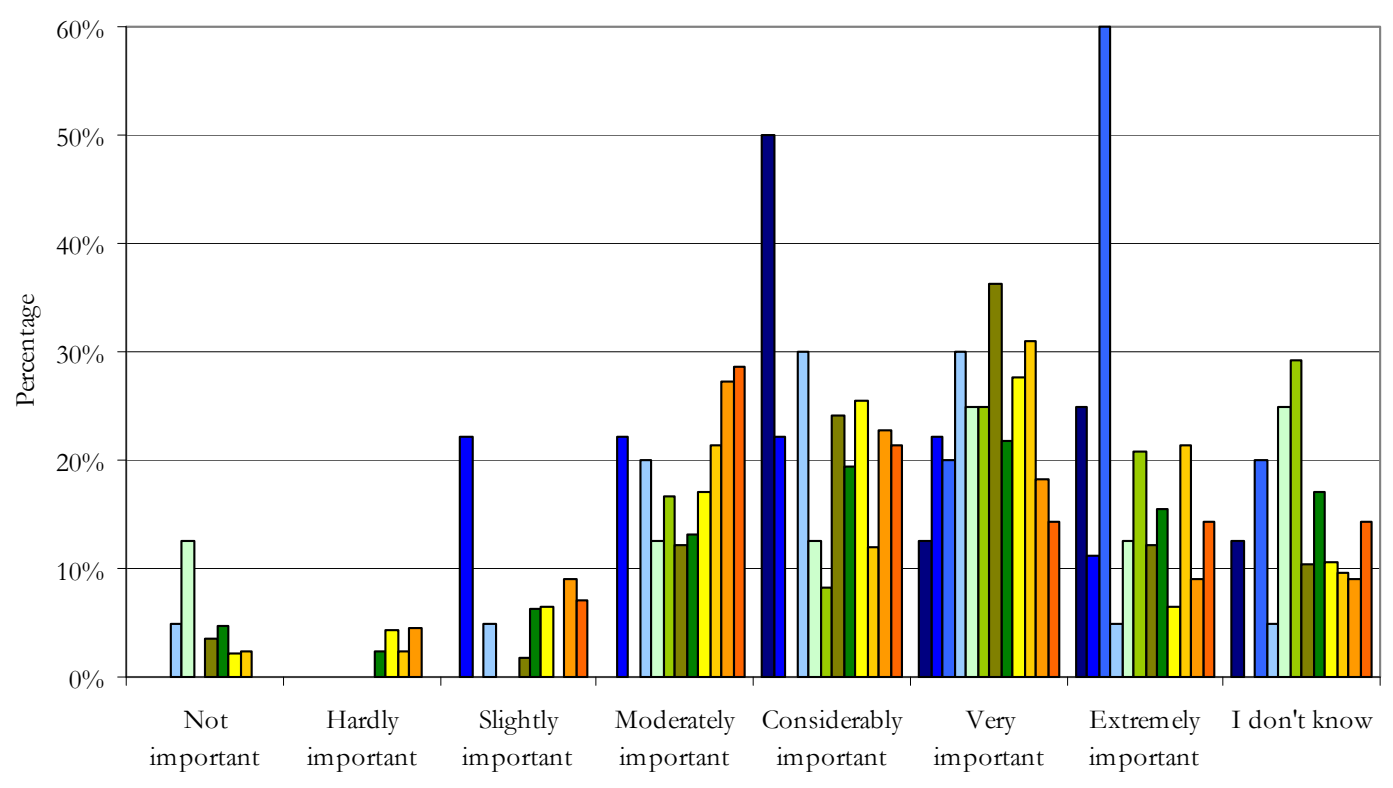

CPD $\square$ IO\&PM $\square$ RD\&MPO $\square$ OO $\square$ MCT\&R $\square$ BC $\square$ BPM\&D $\square$ A\&D $\square$ E $\square$ P\&P $\square$ R\&NGO $\square$ RI

Figure 4-22: Overall importance for Green Star NZ to be a New Zealand equivalent of the Australian Green Star system by industry sector 


\subsubsection{Green Star New Zealand Influence}

To what extent do you think Green Star New Zealand will influence the building industry in a shift towards more sustainable building development in New Zealand?

According to the results, $35 \%$ of the respondents perceived Green Star NZ to have a 'considerable influence' on the building industry in the creation of sustainable building, with a further $40 \%$ selecting either a 'moderate influence' or a 'great influence' (refer to Figure 4-23).

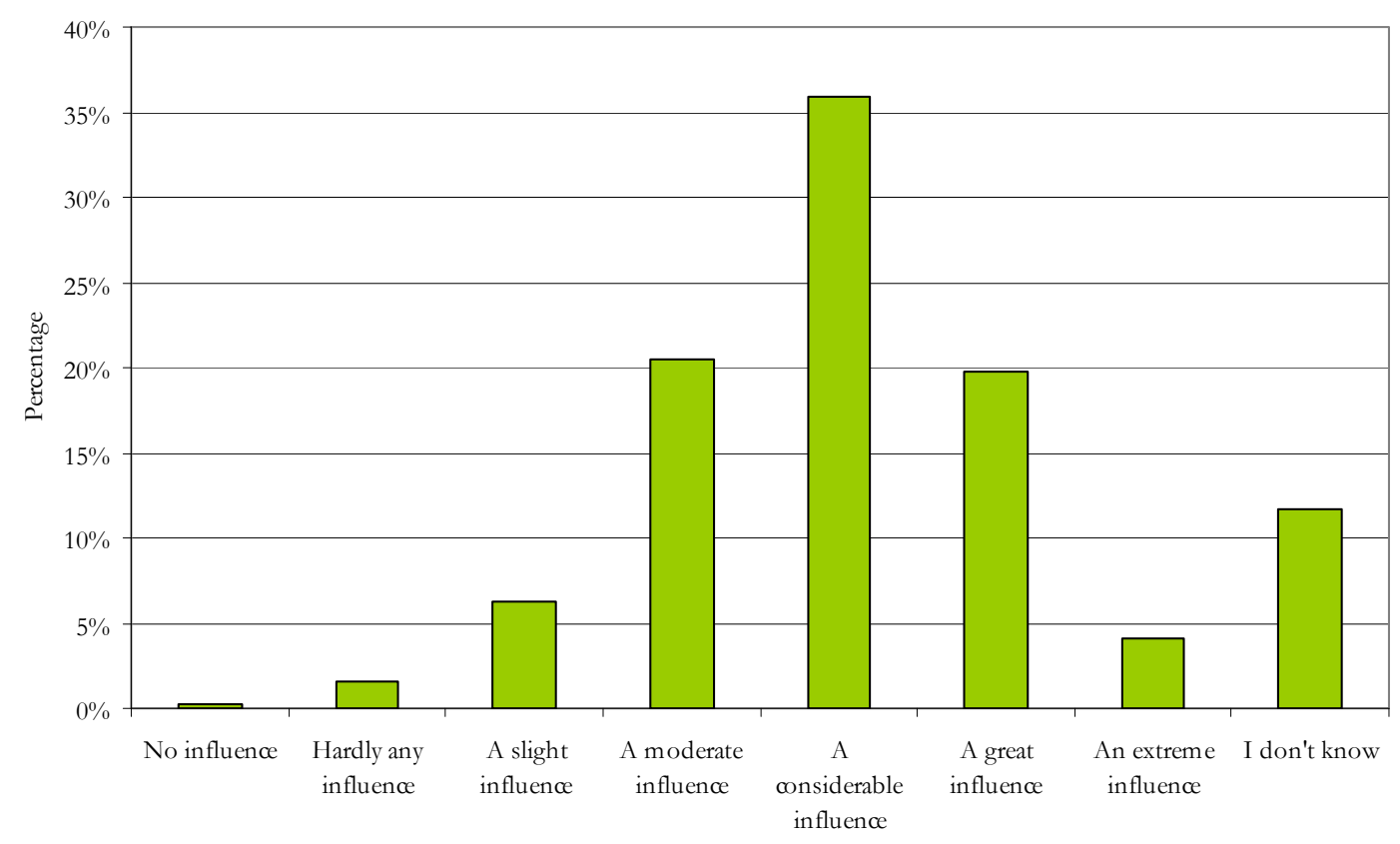

Figure 4-23: Overall perceived extent that Green Star NZ will influence the building industry in a shift towards more sustainable building development in New Zealand 


\subsubsection{Use of Green Star New Zealand}

Question: How likely is it that you will use Green Star New Zealand once it is officially released?

According to the results, the respondents were likely use Green Star NZ, with 27\% selecting 'extremely likely', 26\% 'very likely', 20\% 'considerably likely' and 15\% 'moderately likely (refer to Figure 4-24). Only 4\% said they were 'not likely' and 2\% 'hardly likely' to use Green Star NZ

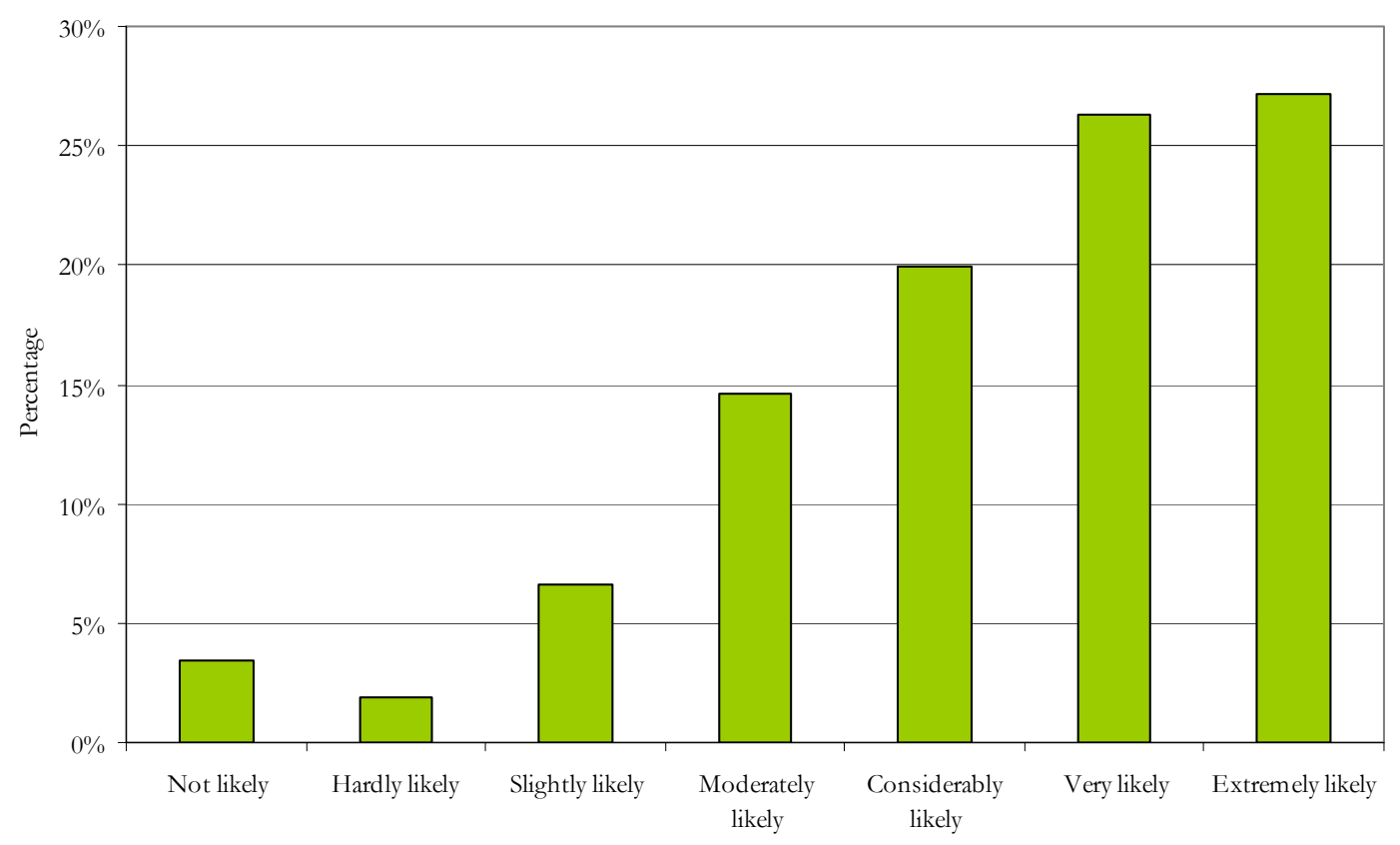

Figure 4-24: Overall likelihood that participants will use Green Star NZ once it is officially released 


\subsubsection{Intended Use of Green Star New Zealand}

Question: If you are likely to use Green Star New Zealand, how do you anticipate using it?

From the NZGBC perspective, it was important to gather an understanding of how the building industry intends to use Green Star NZ. Colloquially it has been suggested BSRTs are often used primarily as design guides, with no intention to seek a formal rating. Furthermore, those who do achieve a 'design rating' do not seek to attain an 'as built' or a 'performance' rating. The NGZBC have discussed various measures for applicants to seek not only a 'design rating' but to go through the complete rating process from start to finish (e.g. tax incentives).

According to the results show in Figure 4-25, a good proportion of the industry anticipates they will seek certification for both design (33\%) and performance (29\%). Using Green Star NZ as a design guideline was still high at $27 \%$, but it is important to note not all commercial office buildings will be eligible to obtain an official rating, and the important factor is getting those who are eligible to take the next steps for formal certification. 
Table 4-6: Definitions of option choices for how Green Star NZ is likely to be used (in order asked in survey)

\begin{tabular}{|l|l|}
\hline Option & Definition \\
\hline Option A & Design guideline \\
\hline Option B & Design Certification \\
\hline Option C & As Built Certification \\
\hline Option D & Guideline for fit-out \\
\hline Option E & Fit-out Certification \\
\hline Option F & Understanding building performance \\
\hline Option G & Performance Certification \\
\hline Option H & Other(s) \\
\hline
\end{tabular}

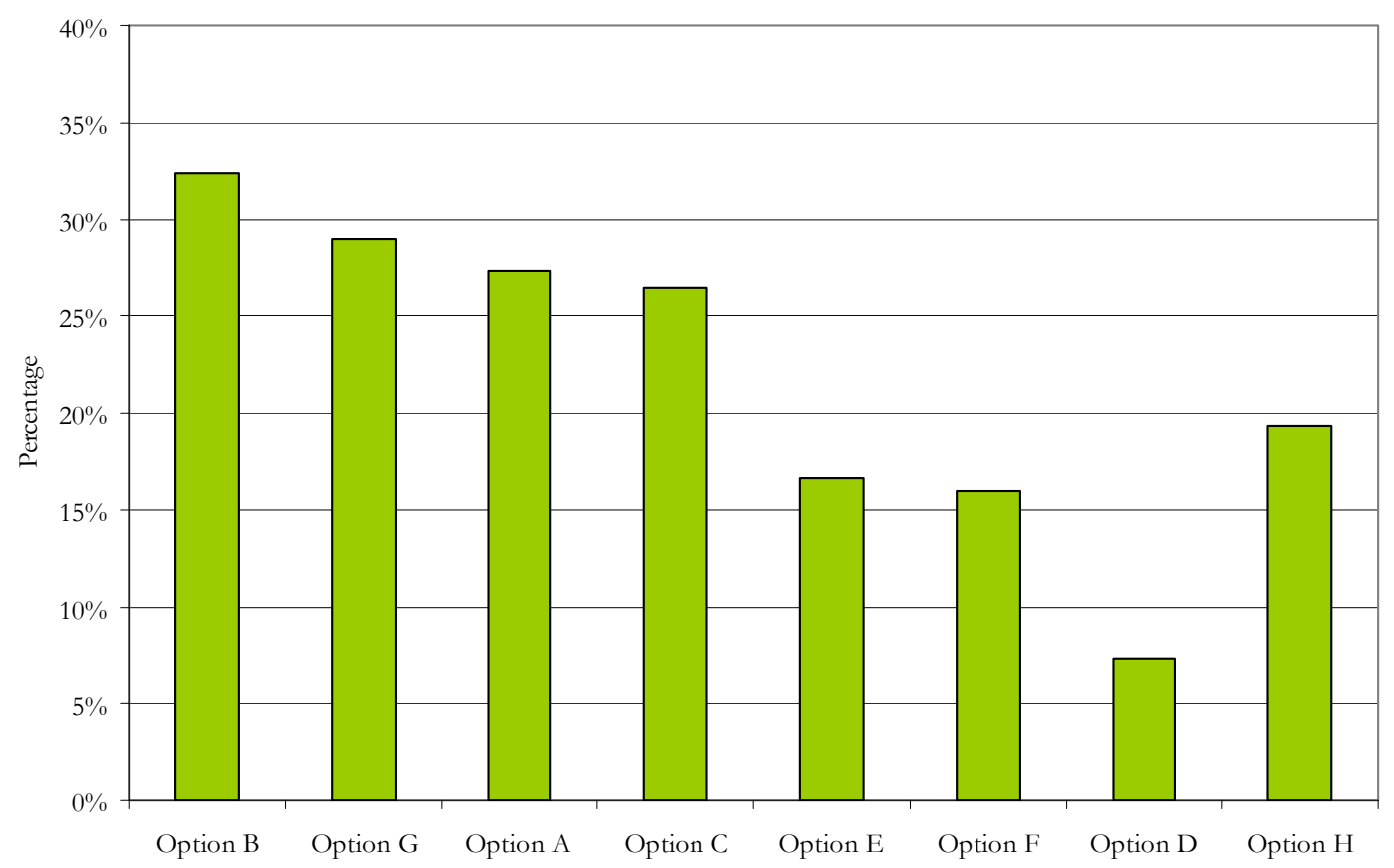

Figure 4-25: Overall anticipation how Green Star NZ will be used, if participant are likely to use it (in order of highest to lowest) 
For this particular question, responses from NZGBC and non-NZGBC affiliations did not follow a similar pattern/trend to earlier questions (refer to previous NZGC/non-NZGC comparisons in Appendix C.2). The NZGBC responses clearly saw the benefit of certification; whereas non-NZGBC respondents were more likely to use Green Star NZ as a design tool when compared to NZGBC affiliates (refer to Figure 4-26).

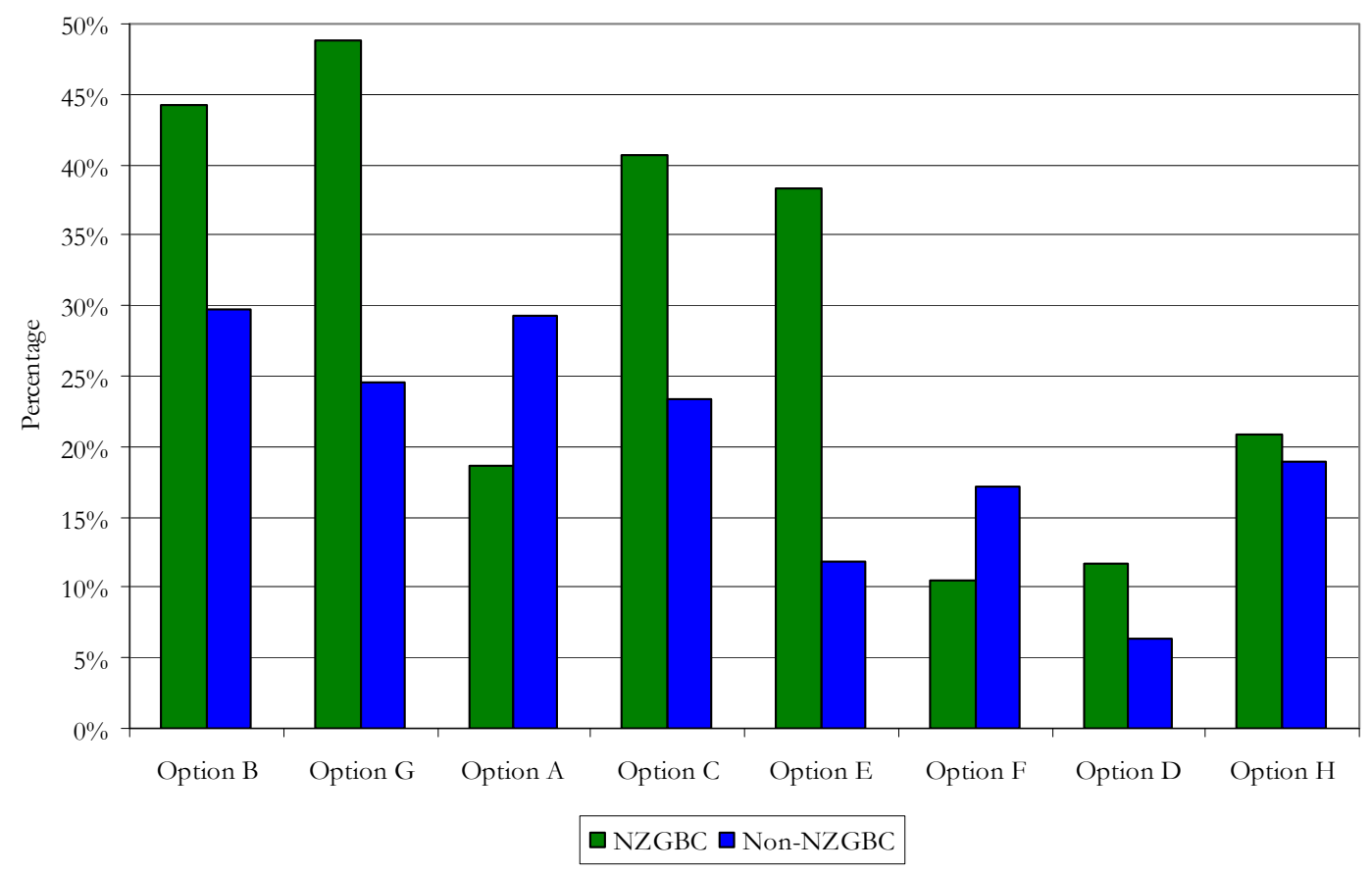

Figure 4-26: Overall anticipation how Green Star NZ will be used, if participants are likely to use it by NZGBC vs. non-NZGBC 


\subsubsection{Green Star New Zealand Training}

Question: How likely is it that you will seek training to become a Green Star New Zealand accredited professional?

From the results, less is known about those seeking to acquire Green Star NZ training to become an accredited professional. Overall, no definitive conclusion can be made about the respondents and the requirement for Green Star NZ training. The option 'not likely' acquired the highest response of $18 \%$, with the remaining categories ranging from $11 \%$ to $16 \%$ (refer to Figure 4-27).

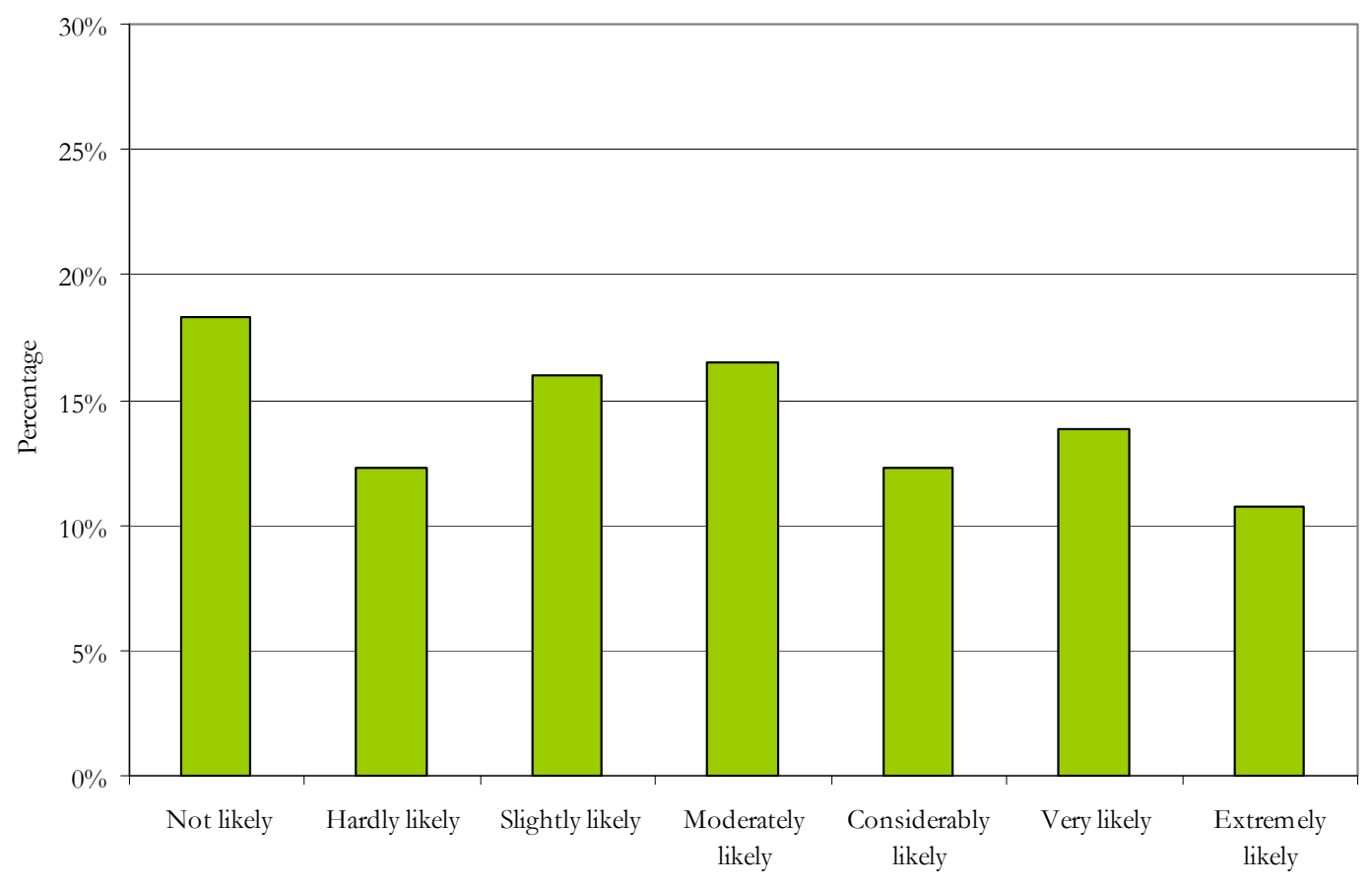

Figure 4-27: Overall likelihood that participants will seek training to become a Green Star NZ accredited professional

Making a comparison to the recent Green Star NZ training courses (as of 26 October 2007), of the twelve courses run in Auckland, Wellington and Christchurch, 342 building professionals have attended the Level 2 training and are now eligible to sit the accreditation exam. 


\subsubsection{Green Star New Zealand Certification}

Question: How important is it that New Zealand buildings seek Green Star New Zealand certification?

According to the results, a distinct majority of the respondents saw it important for New Zealand buildings to acquire Green Star NZ certification, with 20\% selecting 'moderately important', $23 \%$ 'considerably important' and 29\% 'very important' (refer to Figure 4-28).

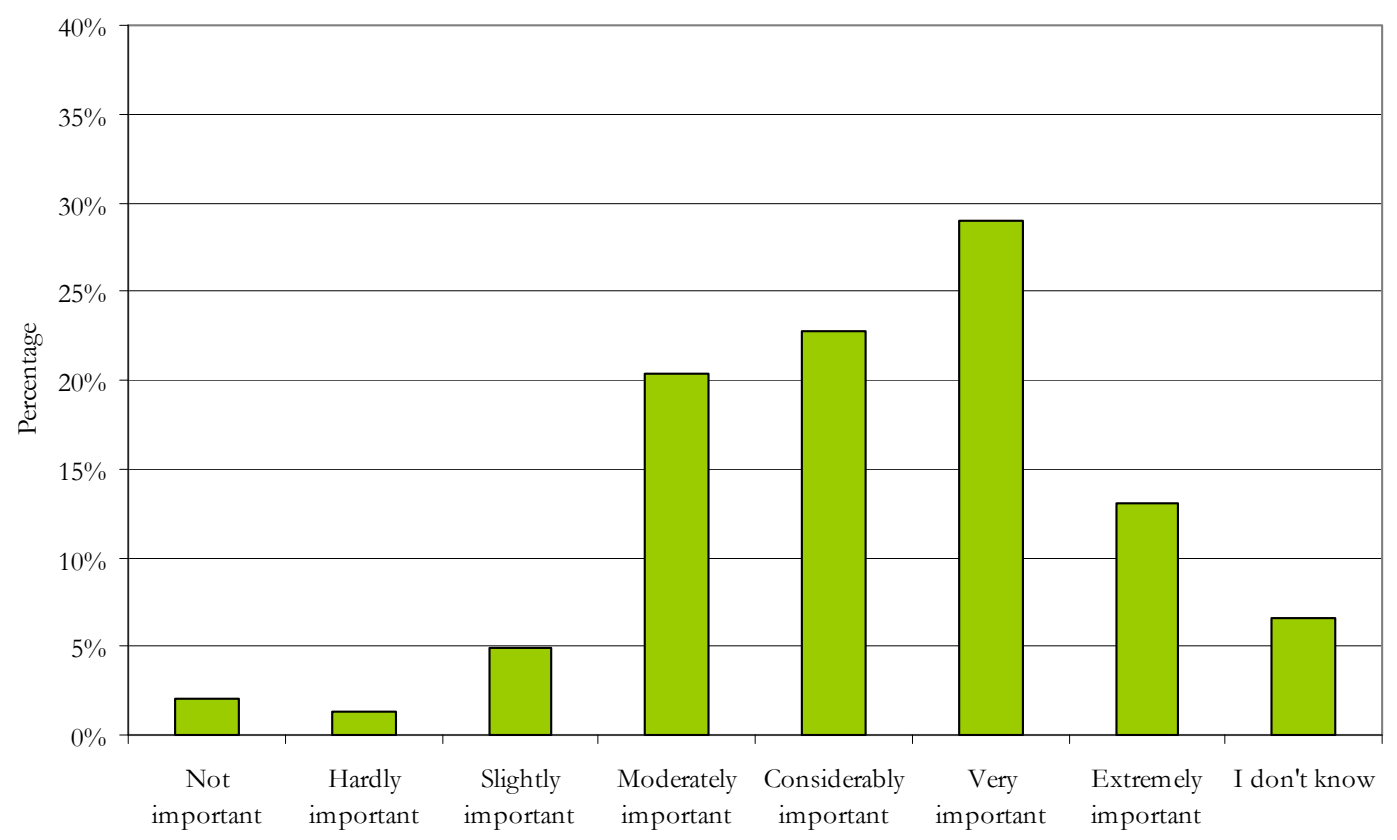

Figure 4-28: Overall importance that New Zealand buildings seek full Green Star NZ certification

\subsubsection{Reasons for Using Green Star New Zealand}

Question: What would be your reasons for using Green Star New Zealand?

According to Figure 4-29 the most popular reasons for using Green Star NZ was the ability to assess the environmental impact of buildings, and environmental responsibility to create 'green' buildings recording $57 \%$ and $54 \%$ of the respondents selecting these answers. This demonstrated to a certain extent a moral emphasis is placed on sustainable building by the New Zealand building industry. Additionally, this moral emphasis is accompanied by an economic value, with promotional purposes acquiring 38\%. Least important was the 'to attract tenants' with 15\%, 'to use the information for company sustainability reporting' with $23 \%$, and 'building comparisons at an international level' with $24 \%$. 
Table 4-7: Definitions of option choices to reasons for using Green Star NZ (in order asked in survey)

\begin{tabular}{|l|l|}
\hline Option & Definition \\
\hline Option A & Being able to assess the environmental impact of buildings \\
\hline Option B & Building comparisons at a national level \\
\hline Option C & Building comparisons at an international level \\
\hline Option D & Promotional purposes \\
\hline Option E & To use the information for company sustainability reporting \\
\hline Option F & Social and environmental responsibility to create 'green' buildings \\
\hline Option G & To attract tenants \\
\hline Option H & To compete in New Zealand's growing market \\
\hline Option I & Other(s) - Please specify \\
\hline
\end{tabular}

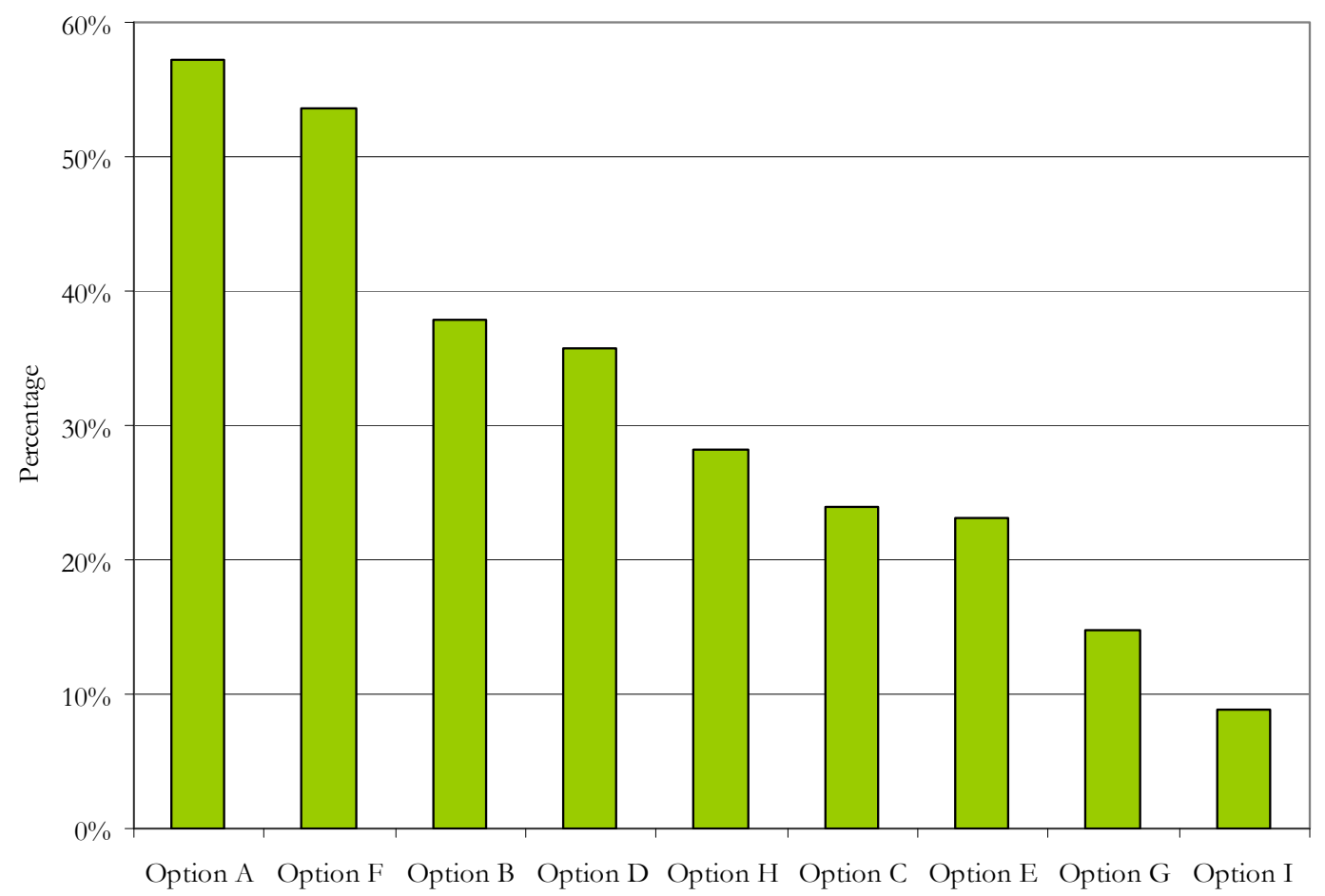

Figure 4-29: Overall reasons for using Green Star NZ (in order of highest to lowest) 


\subsubsection{Discussion}

Green Star NZ received an encouraging level of awareness from the participants and even those not directly associated with the NZGBC. It was evident the respondents saw the importance of Green Star NZ being an equivalent of the Australian Green Star system, with $76 \%$ of the respondents rating it between 'moderately important' and 'extremely important', however the question is why. It would seem having an equivalent tool would enable further comparisons, not only between similar building types, but also internationally between New Zealand and Australia. With an already existing relationship with Australia's building industry, through shared building standards and practices, the decision by the NZGBC to develop of Green Star into a New Zealand specific tool seems to be logical.

The participants also indicated Green Star NZ is not the only tool, development or initiative that will be required to assist the shift towards sustainable building. That it will need supplementary assistance, such as guidance and information from the NZGBC, the building industry and Government to increase the development of sustainable building.

A majority (72\%) of the respondents also regarded it as important for New Zealand buildings to acquire Green Star NZ certification. This was reiterated by the responses to the reasons for using Green Star NZ, the most popular being the ability to assess the environmental impact of buildings, and the environmental responsibility to create 'green' buildings. This result identified an increasing social/moral emphasis placed on sustainable building by the New Zealand building industry.

According to how the respondents anticipated using Green Star NZ, the responses from NZGBC and non-NZGBC affiliations were quite different. The interpretation was the NZGBC associated responses clearly saw the benefit of certification, whereas the non-NZGBC respondents were more likely to use Green Star NZ as a design tool when compared to NZGBC affiliates. This emphasised a key difference between the two groups, those associated with the NZGBC are better informed than their counterparts and those not associated with the NZGBC are perhaps more cautious about Green Star NZ.

The results further indicated while the awareness of Green Star is relatively high, there is still apprehension from the industry towards the new BSRT and being an accredited professional is not appropriate for everyone. Although through continued education of accreditation procedures and benefits of Green Star NZ this apprehension should lessen. 
A distinct majority also saw the importance for New Zealand buildings to acquire Green Star NZ certification, with $20 \%$ selecting 'moderately important', 23\% 'considerably important' and 29\% 'very important'. While this may not be the levels at which the NZGBC would want, with continued education, the importance of Green Star NZ certified building should increase overtime as its 'real value' is understood (e.g. productivity and return on investment).

According to the results, the respondents are likely use Green Star NZ, with 53\% selecting either 'extremely likely' or 'very likely'. Also at an industry sector level there were encouraging signs from 'Commercial Property Developers', 'Residential Developers and Major Portfolio Owners', and 'Major Corporate Tenants and Retailers', who initially may not have been as likely to use Green Star NZ. This suggests already these key stakeholders appreciate the potential benefit of a Green Star NZ rated building. 


\subsubsection{Section 4: The New Zealand Green Building Council}

This section investigated the NZGBC and gathered an understanding of how the NZGBC is portrayed within the building industry and its perceived impact in the production of more sustainable buildings in New Zealand (refer to Appendix C.2.4).

\subsubsection{New Zealand Green Building Council Awareness}

Question: Are you aware of the New Zealand Green Building Council?

The participants showed the building industry has a good level of awareness of the NZGBC, with $82 \%$ of those who answered aware of its existence. At a NZGBC versus non-NZGBC comparison, those not associated with the NZGBC are marginally less aware of their existence at $78 \%$.

\subsubsection{New Zealand Green Building Council Approach}

Question: How appropriate is the approach of the New Zealand Green Building Council in the establishment of a New Zealand specific Building Sustainability Rating Tool?

Less understanding was evident from the participants in the approach of the NZGBC in establishing a New Zealand specific BSRT, with a $26 \%$ of the respondents selecting 'I don't know', and another $26 \%$ selecting 'considerably appropriate' (refer to 4-30). However, the question in itself may have created a level of confusion as those with little experience with sustainable buildings or BSRTs may have wondered what else could the NZGBC do or have done. 
Results

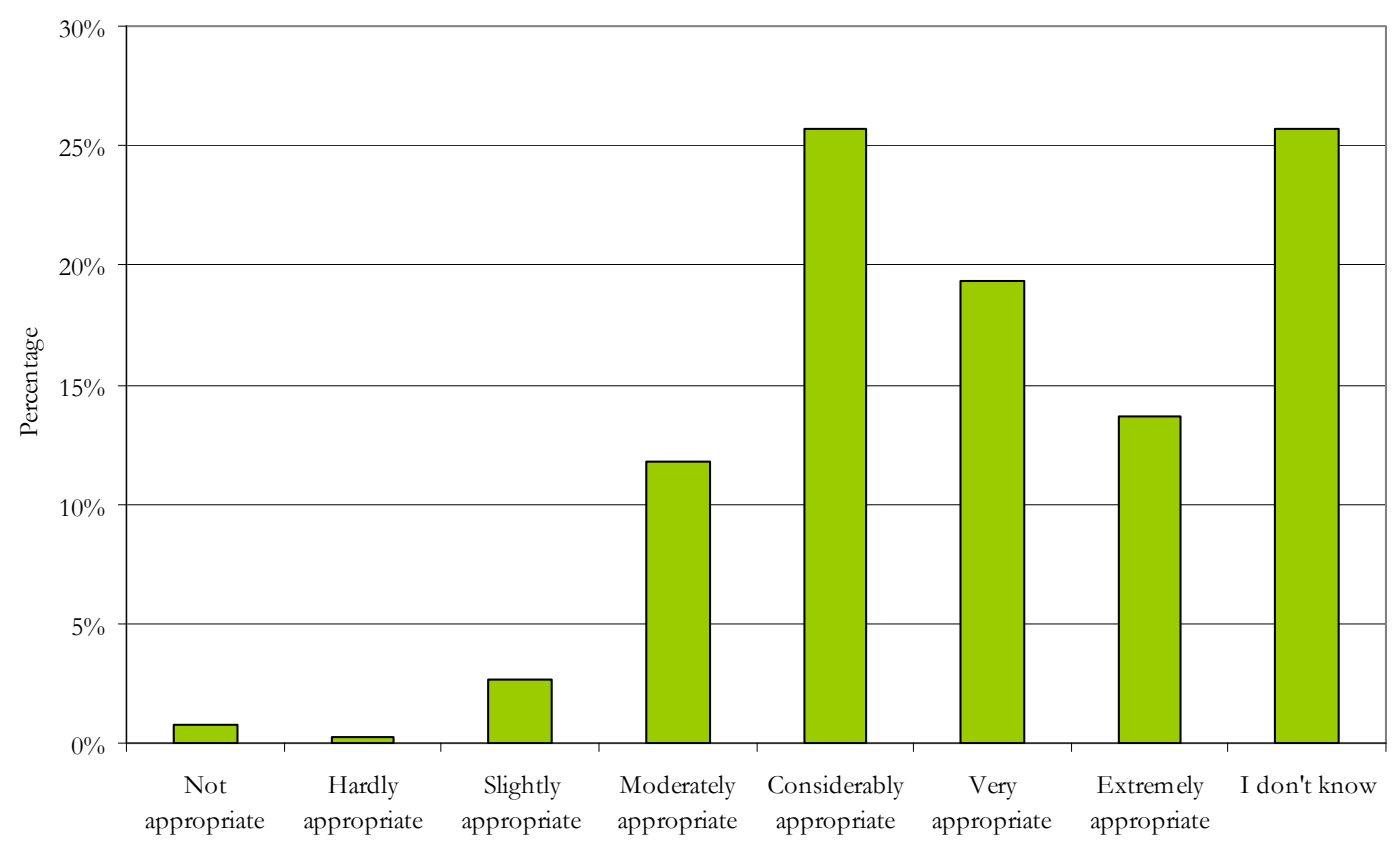

Figure 4-30: Overall appropriateness of the approach of the NZGBC in the establishment of a New Zealand specific BSRT 


\subsubsection{New Zealand Green Building Council Influence}

Question: To what extent do you think the New Zealand Green Building Council will influence the building industry in a shift towards more sustainable building development?

According to the results, Green Star NZ was earlier perceived by 33\% of the respondents to have a 'considerable influence' in a shift towards more sustainable buildings (refer to 4-23). Interestingly the respondents were not as optimistic that the NZGBC would influence sustainable building (refer to Figure 4-31). For example, those who saw the NZGBC to be a 'considerable influence' decreased 3\% to 33\% and those who saw it as a 'great influence' from $20 \%$ to $14 \%$, whereas a 'moderate influence' increased' from $21 \%$ to $26 \%$. The only positive increase was those who saw the NZGBC as an 'extreme influence', up from $4 \%$ to $7 \%$.

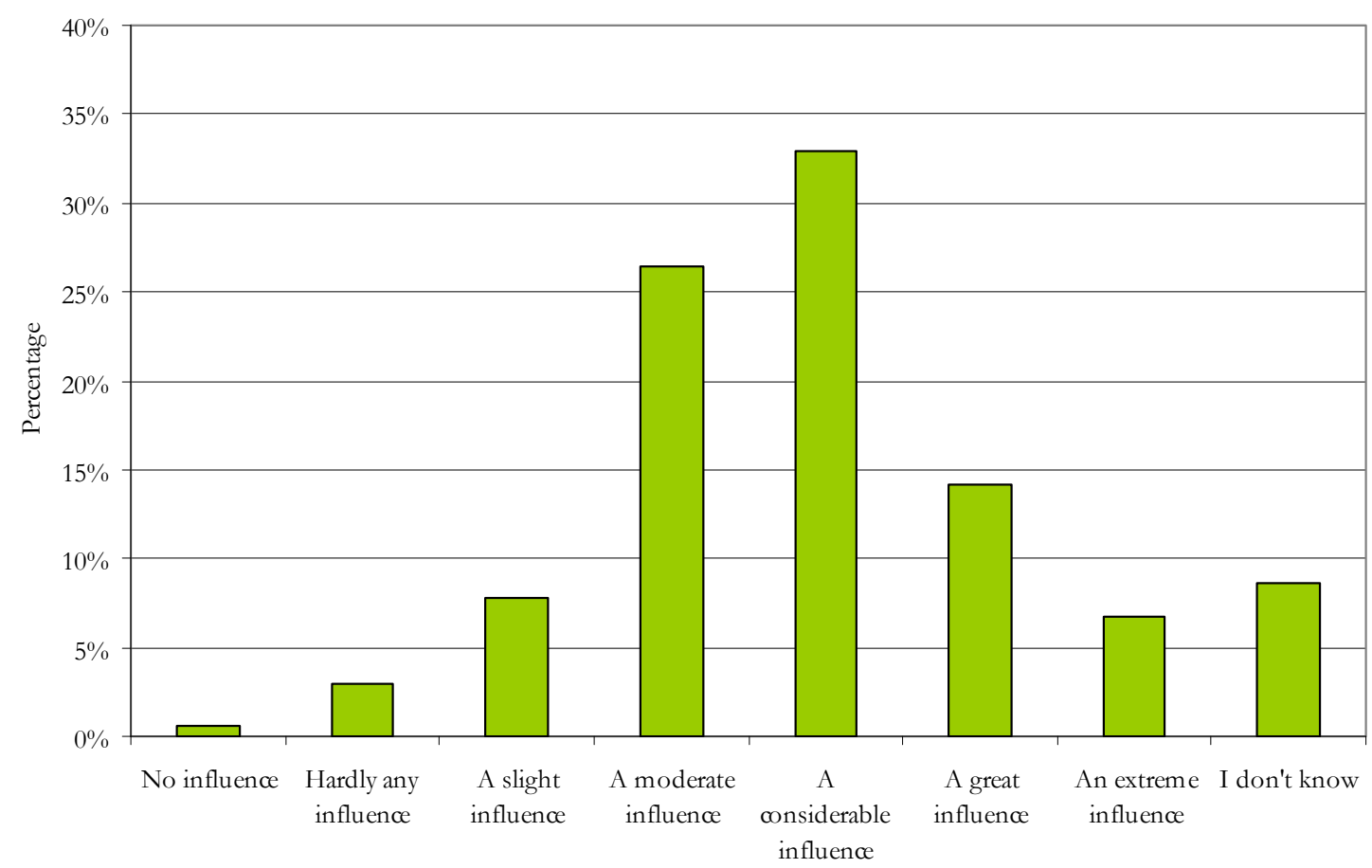

Figure 4-31: Overall perceived extent that the NZGBC will influence the building industry in a shift towards more sustainable building development 


\subsubsection{Discussion}

The participants showed the building industry has a good level of awareness of the NZGBC, with $82 \%$ of those who answered aware of its existence. Although, less understanding was evident in the approach of the NZGBC in establishing a New Zealand specific BSRT, with a 26\% of the response selecting 'I don't know'. As was identified, the question itself may have created confusion as those with little experience with BSRTs may have wondered what else could the NZGBC do or have done. The participants also perceived the NZGBC to have a 'considerable influence' in a shift towards more sustainable buildings. Again, this indicated not only will the NZGBC be required in the development of sustainable buildings, but it will need support from the whole building industry.

At a industry sector level those sectors who saw the influence of the NZGBC in a more positive respect (i.e. 'great influence' to an 'extreme influence') were stakeholders such as 'Commercial Property Developers', 'Investors, Owners and Property Managers', 'Residential Developers and Major Portfolio Owners', and 'Major Corporate Tenants and Retailers'. Consequently, what then are the barriers to end-users fully embracing the NZGBC and Green Star NZ? Perhaps this is an indication end-users are more apprehensive and realise assistance/development is required than just the NZGBC if we are to see the development of more sustainable buildings in New Zealand (e.g. Government initiatives and financial assistance). 


\subsubsection{Section 5: Triggers, Drivers, Obstacles and Reasons for Sustainable Building}

The following section sought to understand what the participants perceived to be the triggers, barriers, obstacles and reasons for sustainable building (refer to Appendix C.2.5).

\subsubsection{Trigger Person of Sustainable Building}

Question: In your experience who triggers sustainable building in the first place?

From the results (Figure 4-32) the 'Client' was seen to be the main driver for sustainable building, accounting for $55 \%$ of the responses. Next important was the role of the 'Architect/Draftperson' with 38\%. This result emphasised the influence both the client and architect have on the design of a sustainable building.

Table 4-8: Definitions of option choices to who triggers sustainable building (in order asked in survey)

\begin{tabular}{|l|l|}
\hline Option & Definition \\
\hline Option A & I don't know \\
\hline Option B & Client \\
\hline Option C & Architect/Draftpersons \\
\hline Option D & Engineers \\
\hline Option E & Property and Construction Professionals \\
\hline Option F & Building Contractors \\
\hline Option G & Developers \\
\hline Option H & Investors \\
\hline Option I & Other(s) \\
\hline
\end{tabular}




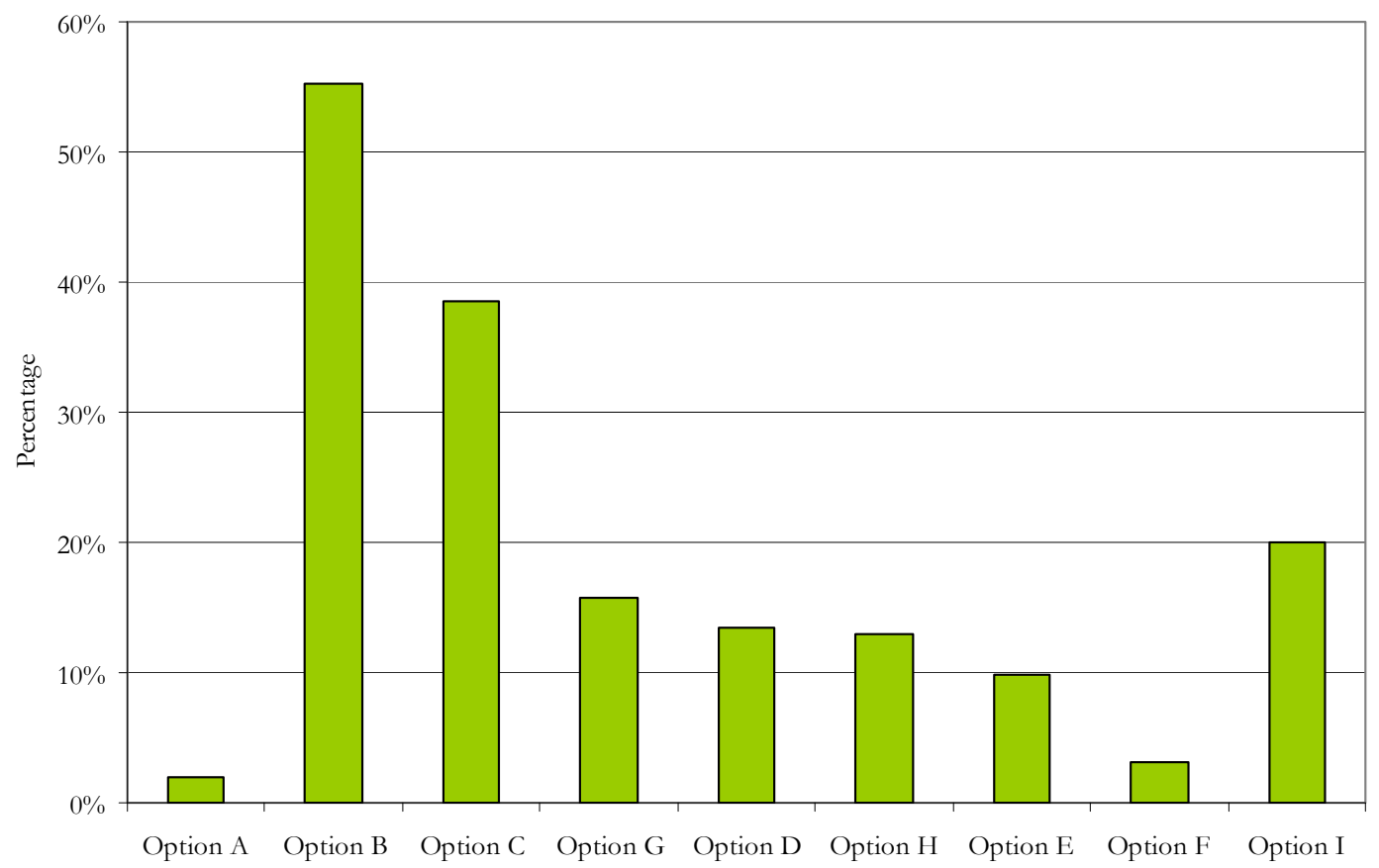

Figure 4-32: Overall participant experience of who triggers sustainable building in the first place (in order of highest to lowest)

The majority of industry also saw the 'Client' as the main driver and taking the initiative for a sustainable building project. Interestingly, 'Architects/Draftpersons' identified themselves with a slightly greater influence than that of the client (refer to Figure 4-33).

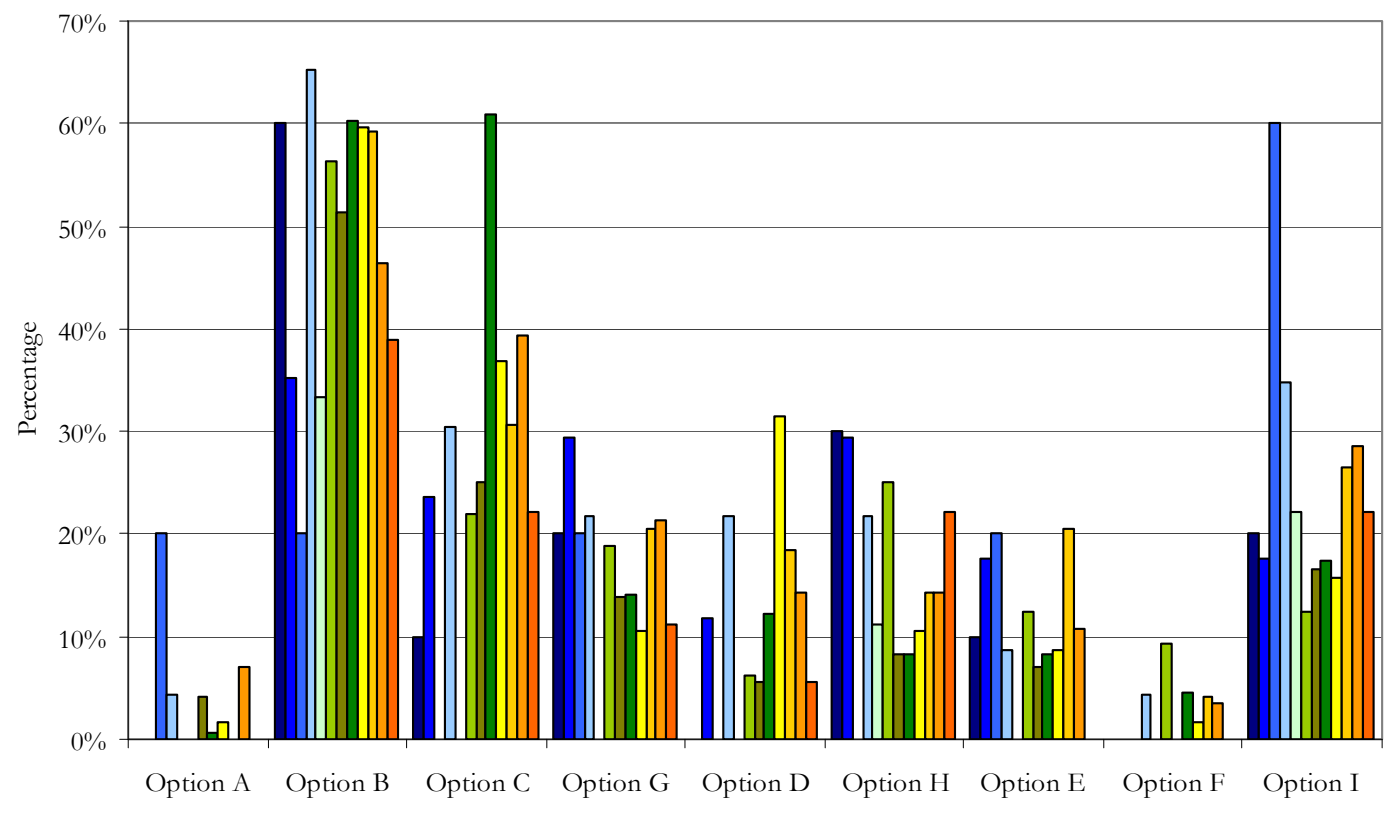

CPD $\square$ IO\&PM $\square$ RD\&MPO $\square$ OO $\square$ MCT\&R $\square$ BC $\square$ BPM\&D $\square$ A\&D $\square$ E $\square$ PCP $\square$ R\&NO $\square$ RI

Figure 4-33: Overall participant experience of who triggers sustainable building in the first place by industry sector 


\subsubsection{Main Driver for Sustainable Building}

Question: In your opinion who should be the main driver for sustainable building?

To make a comparison to the above question, the following question sought rather to understand who should be the main driver for a sustainable building. As previously, 'Clients' and 'Architects/Draftpersons' were seen to be significant drivers; but the most important driver in this case was to have 'an integrated process where responsibility is shared' (refer to Figure 4-34). This result emphasises the respondents realise good sustainable building design has to involve all parties in the building process.

Table 4-9: Definitions of option choices of who should drive sustainable building (in order asked in survey)

\begin{tabular}{|l|l|}
\hline Option & Definition \\
\hline Option A & I don't know \\
\hline Option B & Client \\
\hline Option C & Architect/Draftpersons \\
\hline Option D & Engineers \\
\hline Option E & Property and Construction Professionals \\
\hline Option F & Building Contractors \\
\hline Option G & Developers \\
\hline Option H & Investors \\
\hline Option I & An integrated process where responsibility is shared \\
\hline Option J & Other(s) \\
\hline
\end{tabular}

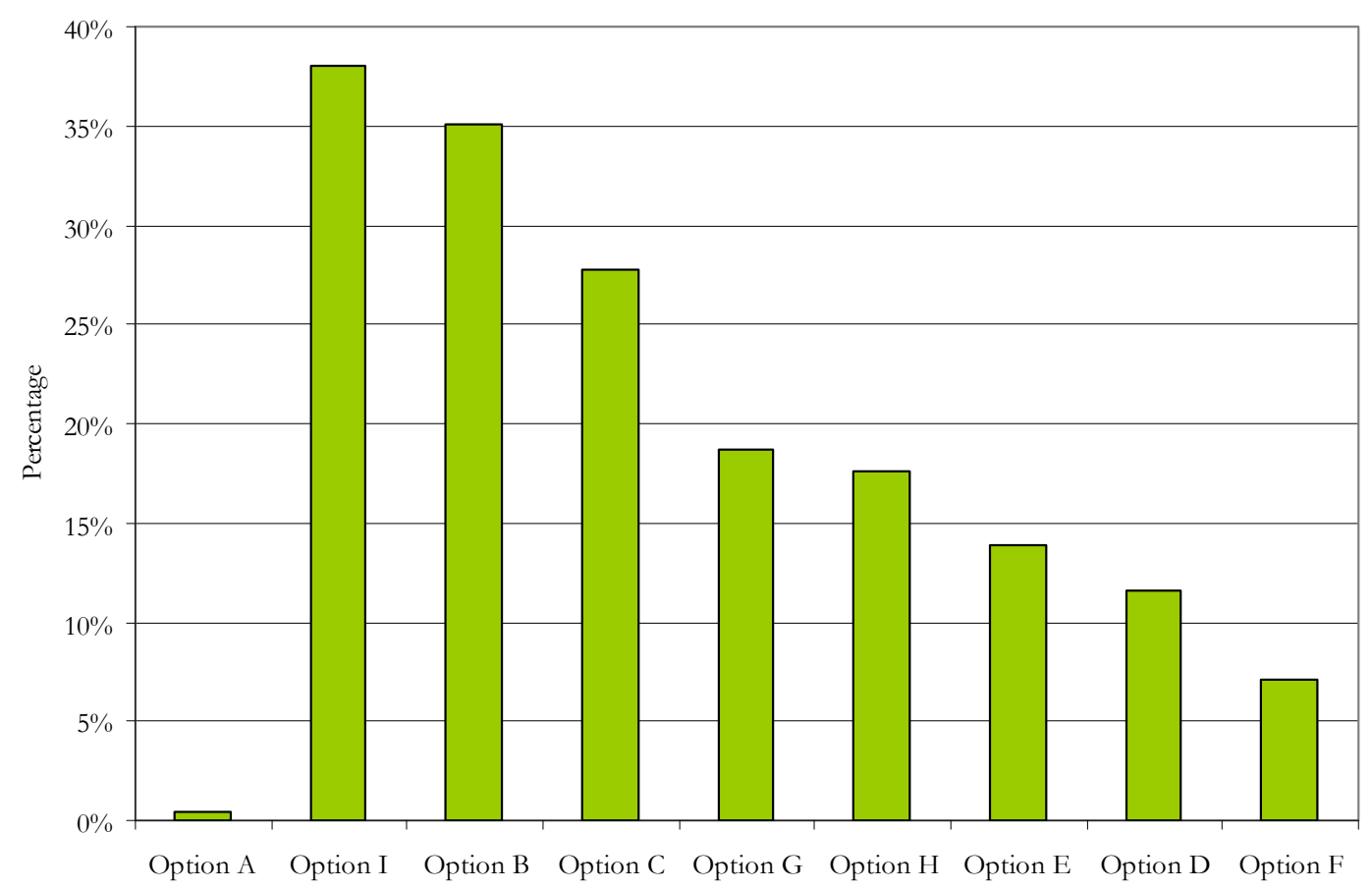

Figure 4-34: Overall opinion of who should be the main driver for sustainable building (in order from highest to lowest) 


\subsubsection{Trigger Stage for Sustainable Building}

Question: At what stage of the building process is sustainable building most likely triggered?

Participants understood the importance to introduce sustainable design into the building process as early as possible, with $49 \%$ selecting sustainable building is most likely triggered in the 'pre-design' stage, and 37\% in the 'design development' stage (refer to Figure 4-35). Evidence also supports this, that the earlier sustainable building is triggered the more likely it is to succeed and to even reduce the long-term construction costs $\{\mathrm{New}$ Zealand, Ministry for the Environment, Value Case 54-55\}.

Table 4-10: Definitions of option choices to when sustainable building is most likely triggered (in order asked in survey)

\begin{tabular}{|l|l|}
\hline Option & Definition \\
\hline Option A & I don't know \\
\hline Option B & Preliminary inquiries \\
\hline Option C & Pre-design \\
\hline Option D & Design development \\
\hline Option E & Construction development process \\
\hline Option F & Commissioning \\
\hline Option G & Construction \\
\hline Option H & Other(s) \\
\hline
\end{tabular}

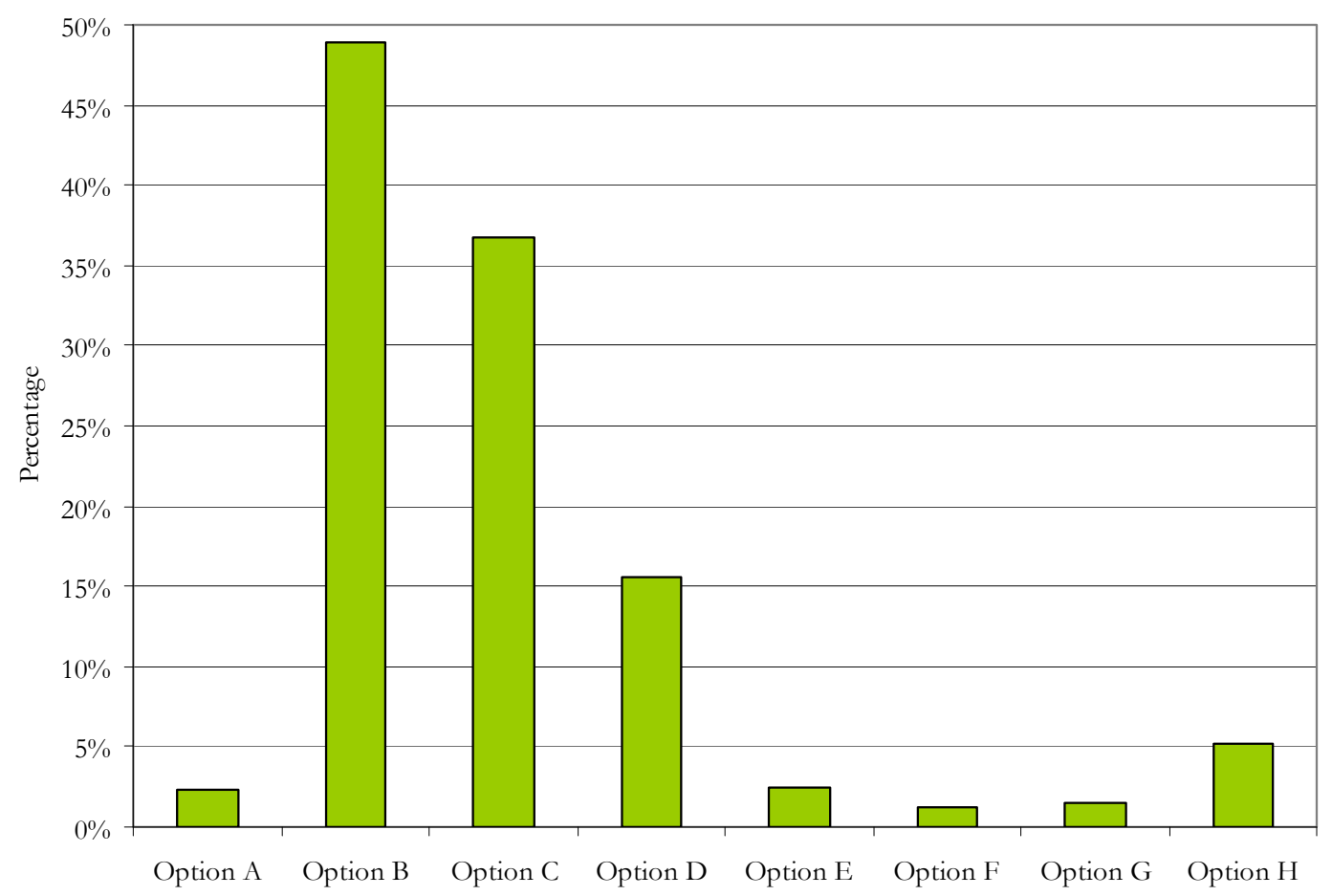

Figure 4-35: Overall stage of the building process that sustainable building most likely triggered (in order from highest to lowest) 
It must be noted some bias may have been created due to when particular sectors are introduced into the building process. As those who enter the building process later may perceive this point to be when sustainable building is triggered.

\subsubsection{Drivers for Sustainable Building}

Question: What do you think are the main drivers for sustainable building?

According to Figure 4-36, Option A 'rising energy costs' was seen to be the main driver for sustainable buildings (49\% of the responses). This result is in accordance with both Australia and the United States which weighted rising energy costs as the most important. Likewise 'client demand' and 'environmental conditions' were also deemed highly important in driving sustainable buildings. Least important was 'disruptive/enabling technology' with $2 \%$, 'Government rating systems' with $7 \%$ and 'increased emphasis on productivity' with $8 \%$.

Table 4-11: Definitions of option choices to drivers for sustainable buildings (in order asked in survey)

\begin{tabular}{|l|l|}
\hline Option & Definition \\
\hline Option A & Rising energy costs \\
\hline Option B & Government regulation \\
\hline Option C & Lower life-cycle costs \\
\hline Option D & Client demand \\
\hline Option E & Independent rating system \\
\hline Option F & Government rating systems \\
\hline Option G & Competitive advantage \\
\hline Option H & Superior performance \\
\hline Option I & Increased education \\
\hline Option J & Environmental conditions \\
\hline Option K & Attraction and retention of staff \\
\hline Option L & Increased emphasis on productivity \\
\hline Option M & International trends show it is smart business \\
\hline Option N & Disruptive/enabling technology \\
\hline Option O & Other(s) \\
\hline
\end{tabular}




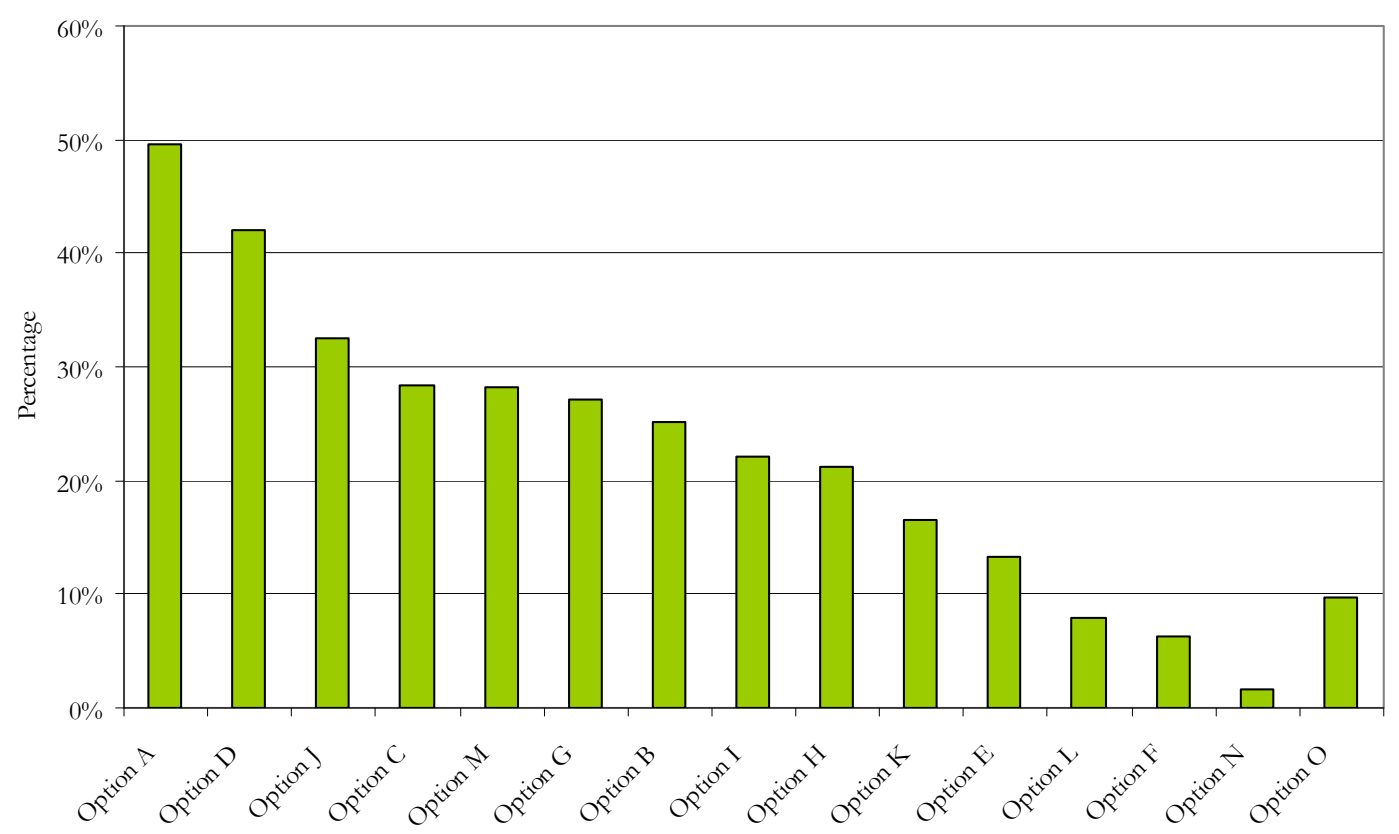

Figure 4-36: Overall drivers for sustainable building (in order from highest to lowest) 


\subsubsection{Obstacles for Sustainable Building}

\section{Question: What are the obstacles to sustainable building?}

Participants were also asked about the obstacles to sustainable building. The results show $65 \%$ of the participants selected 'perceived higher upfront costs' (refer to Figure 4-37). Additionally, 'lack of education' and 'lack of awareness' were also seen as strong barriers to sustainable building. The least important barriers were 'different accounting methods', and 'politics'.

Table 4-12: Definitions of option choices to obstacles for sustainable building (in order asked in survey)

\begin{tabular}{|l|l|}
\hline Option & Definition \\
\hline Option A & Perceived higher upfront costs \\
\hline Option B & Lack of education \\
\hline Option C & Lack of awareness \\
\hline Option D & No fiscal incentive \\
\hline Option E & Different accounting methods \\
\hline Option F & No coordination or consistency \\
\hline Option G & Politics \\
\hline Option H & Payback periods \\
\hline Option I & Education of non 'green' people \\
\hline Option J & Other(s) \\
\hline
\end{tabular}

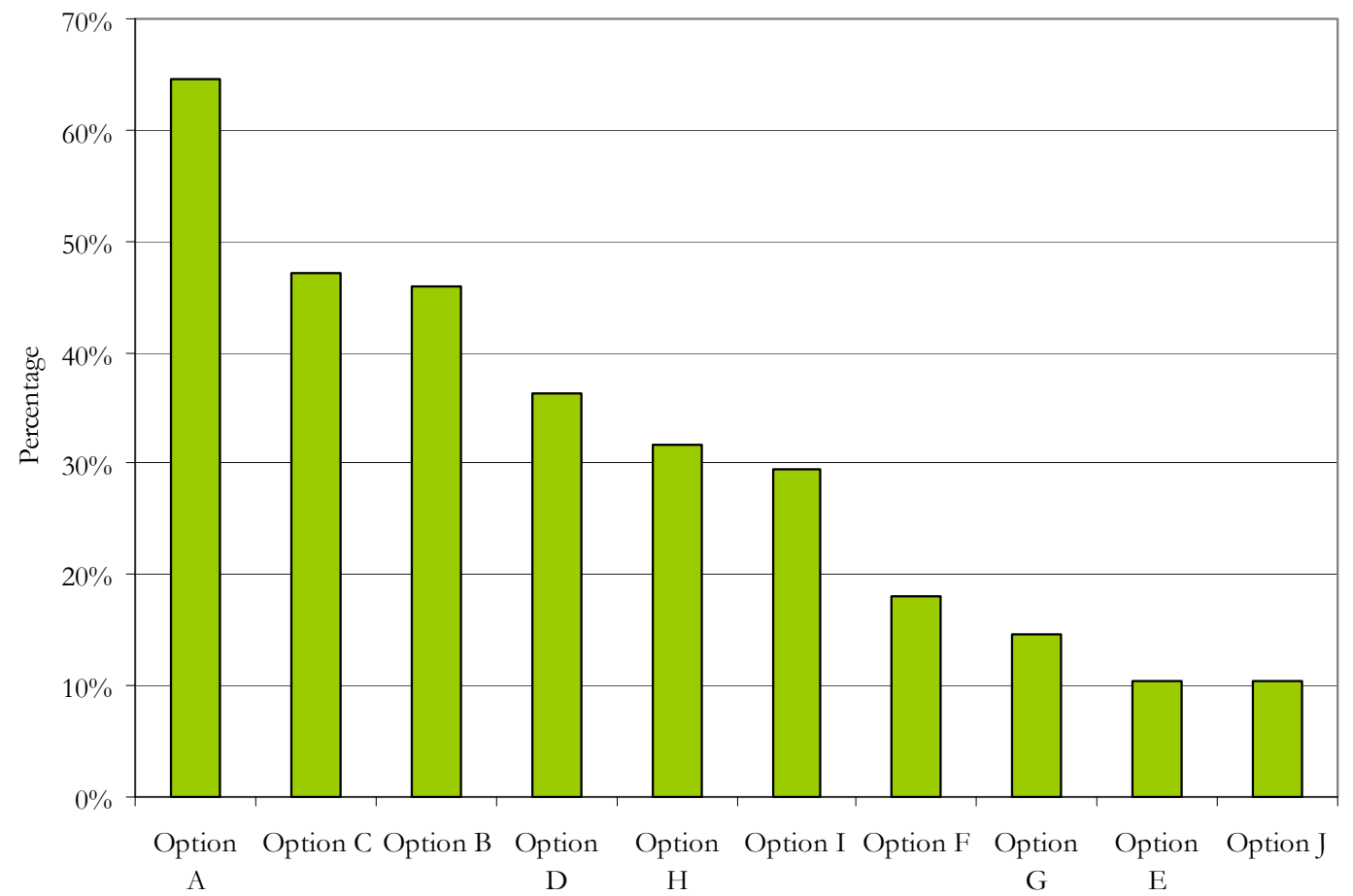

Figure 4-37: Overall obstacles to sustainable buildings (in order from highest to lowest) 


\subsubsection{Reasons for Involvement in Sustainable Building}

Question: What are your reasons for being involved in sustainable building?

The most important reason for sustainable building was 'being part of an industry that values the environment' (refer to Figure 4-38). This result though does not account for the level of involvement shown previously, where involvement can vary substantially (refer to Section 4.2.1). This also raises the question; if there are so many professionals involved why are we not seeing the creation of more sustainable buildings?

Table 4-13: Definitions of option choices to reasons for being involved in sustainable building (in order asked in survey)

\begin{tabular}{|l|l|}
\hline Option & Definition \\
\hline Option A & I am not involved \\
\hline Option B & Being part of an industry that values the environment \\
\hline Option C & Achieving lower life-cycle costs \\
\hline Option D & Contract requirement (e.g. Government tenders) \\
\hline Option E & Expanding my business with 'green' building clients \\
\hline Option F & Benefit from publicity \\
\hline Option G & Triple bottom line reporting \\
\hline Option H & Attraction an retention of talent \\
\hline Option I & Green product information \\
\hline Option J & Awards for green building \\
\hline Option K & Higher return on investment on resale \\
\hline Option L & Other(s) \\
\hline
\end{tabular}

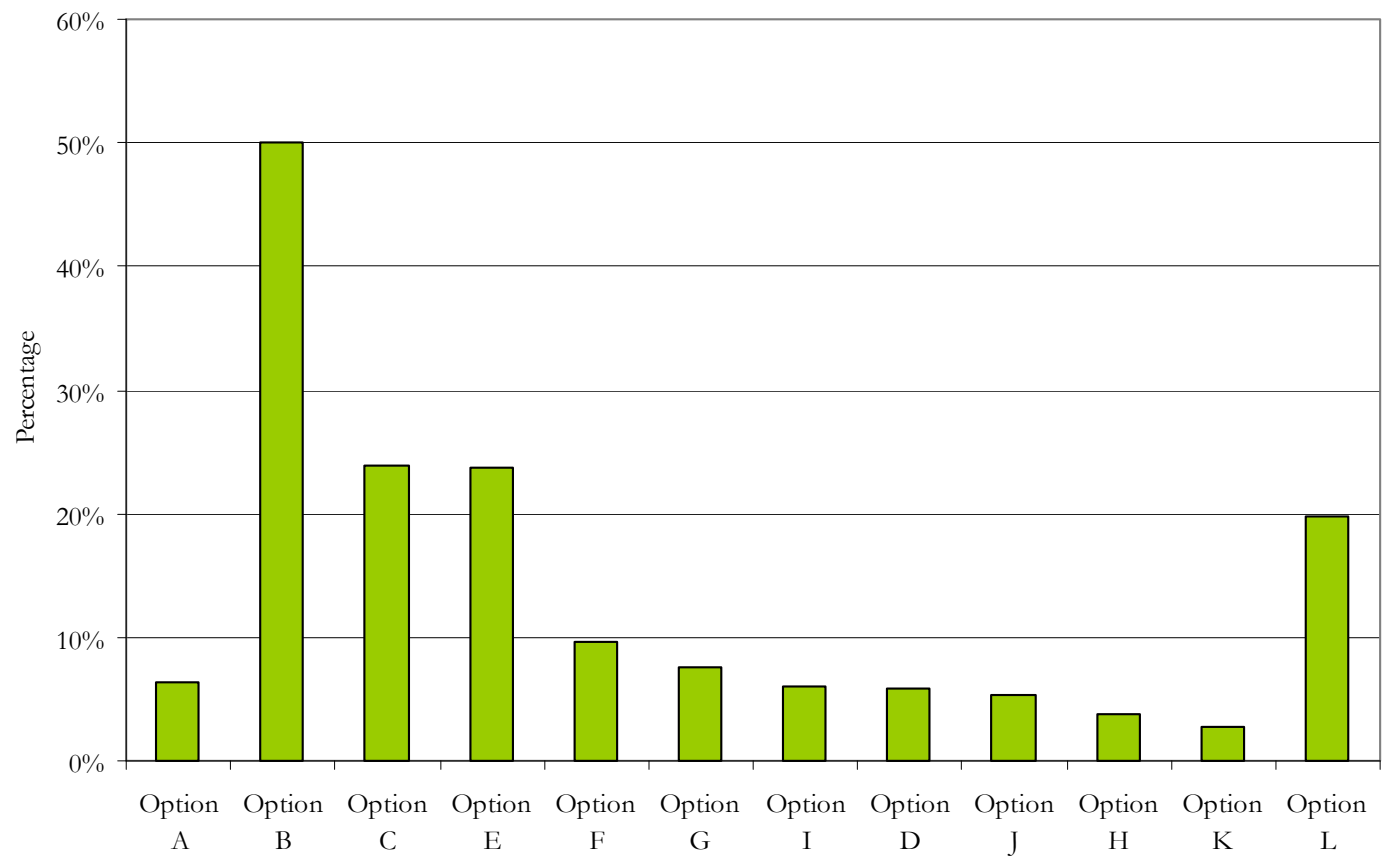

Figure 4-38: Overall reasons for being involved with sustainable building (in order from highest to lowest) 


\subsubsection{Economic Reasons for Sustainable Building}

Question: What do you believe are the economic reasons/benefits of sustainable building?

At a deeper level participants were asked specifically about their economic, environmental and social reasons/benefits of sustainable building. According to the respondents 'lower lifetime costs' were identified to be the most important economic reason with $58 \%$ (refer to Figure 4-39). 'Lower operating costs' achieved 56\%, 'enhanced marketability' $44 \%$ and 'higher building value' $40 \%$. The least important economic reason for sustainable building was 'reduced liability and risk' with $13 \%$.

Table 4-14: Definitions of option choices to economic reasons/benefits for sustainable building (in order asked in survey)

\begin{tabular}{|l|l|}
\hline Option & Definition \\
\hline Option A & Lower operating costs \\
\hline Option B & Lower lifetime costs \\
\hline Option C & Higher building value \\
\hline Option D & Enhanced marketability \\
\hline Option E & Helping to transform the market \\
\hline Option F & Increase staff productivity and retention \\
\hline Option G & Higher return on investment \\
\hline Option H & Reduced liability and risk \\
\hline Option I & Other(s) \\
\hline
\end{tabular}

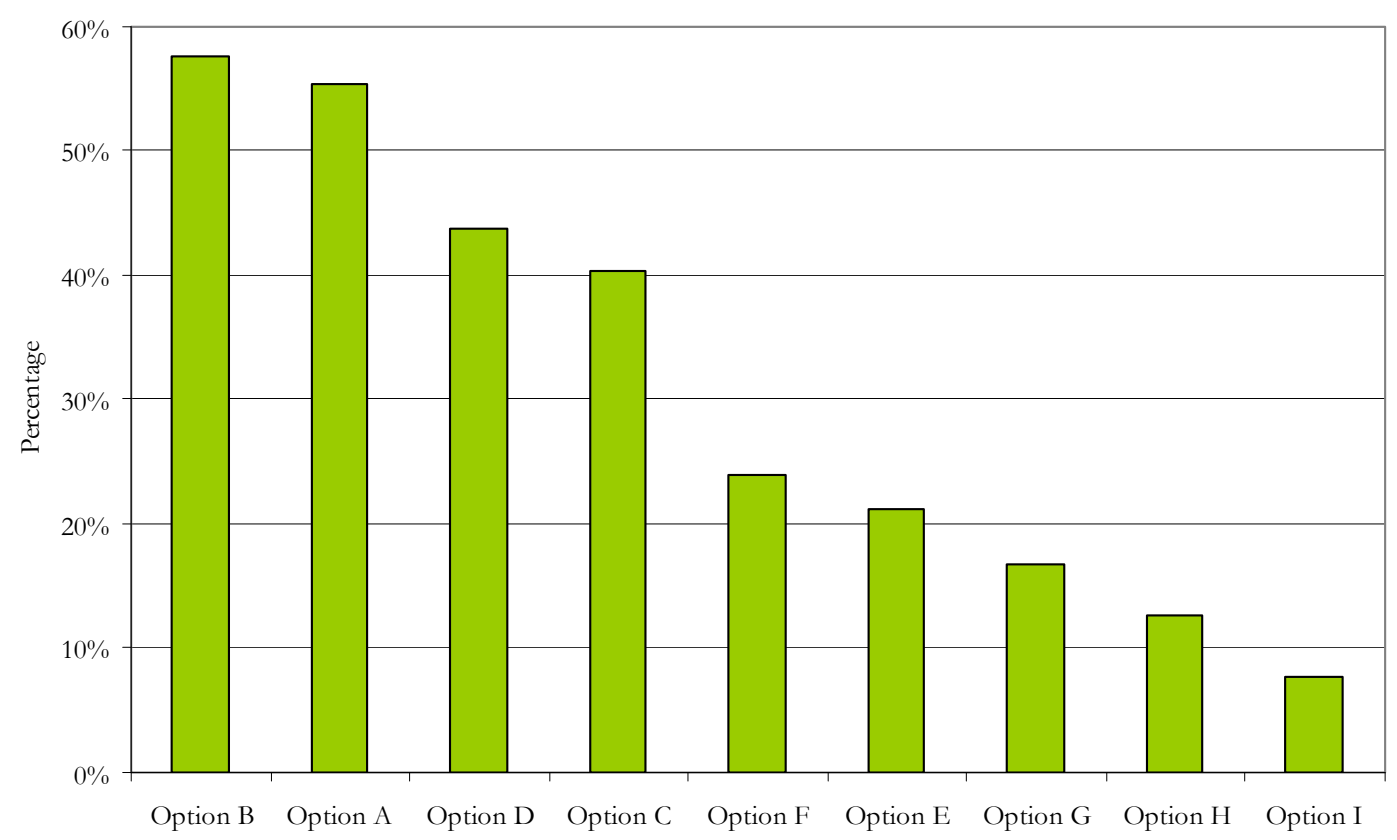

Figure 4-39: Overall economic reasons/benefits of sustainable building (in order from highest to lowest) 


\subsubsection{Environmental Reasons for Sustainable Building}

Question: What do you believe are the environmental reasons/benefits of sustainable building?

The most important environmental reasons/benefits of sustainable building was 'minimising ecological impact of buildings accounting' with $61 \%$. Below this 'reducing climate change and emissions', 'protection of the environment', and 'waste reduction' were also important at over 50\% (refer to Figure 4-40).

Table 4-15: Definitions of option choices to environmental reasons/benefits for sustainable building (in order asked in survey)

\begin{tabular}{|l|l|}
\hline Option & Definition \\
\hline Option A & Protection of the environment \\
\hline Option B & Reducing climate change and emissions \\
\hline Option C & Minimising ecological impact of buildings \\
\hline Option D & Scarcity of natural resources \\
\hline Option E & Improving indoor environment quality \\
\hline Option F & Waste reduction \\
\hline Option G & Other(s) \\
\hline
\end{tabular}

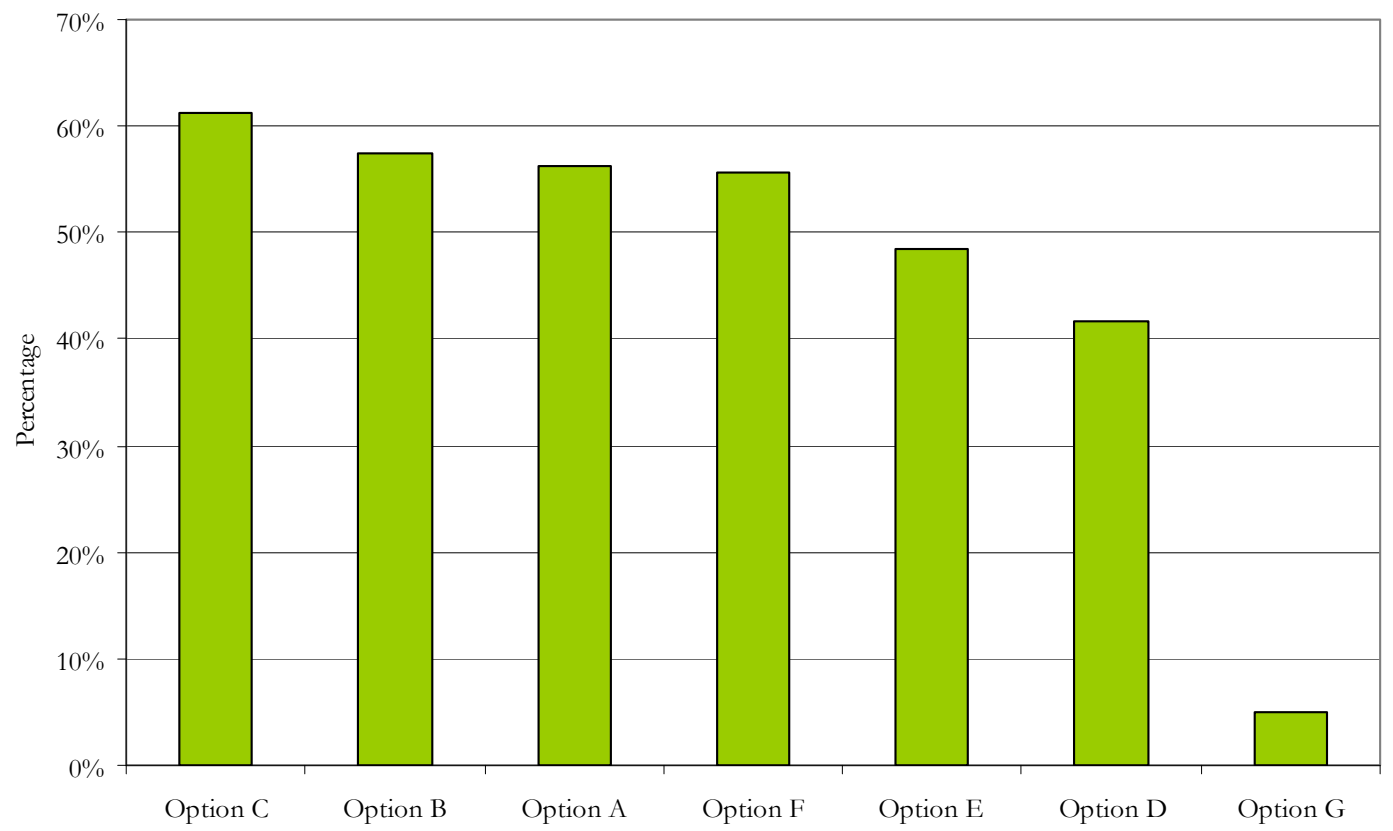

Figure 4-40: Overall perception of the environmental reasons/benefits of sustainable building (in order from highest to lowest) 


\subsubsection{Social Reasons for Sustainable Building}

Question: What do you believe are the social reasons/benefits of sustainable building?

Harder to quantify were the intangible social reasons/benefits of sustainable buildings. According to the results 'greater health and well-being' were identified as most important, attracting 59\% of the responses (refer to Figure 4-41). The respondents also showed a good proportion have a moral imperative for sustainable building, and look beyond just financial gain. Least important was for a building to be 'aesthetically pleasing' with $16 \%$.

Table 4-16: Definitions of option choices to social reasons/benefits for sustainable building (in order asked in survey)

\begin{tabular}{|l|l|}
\hline Option & Definition \\
\hline Option A & Greater health and well-being \\
\hline Option B & Improved learning and healing environments \\
\hline Option C & Tenant productivity \\
\hline Option D & Support for New Zealand economy \\
\hline Option E & Moral imperative of being 'green' \\
\hline Option F & Aesthetically pleasing \\
\hline Option G & Other(s) \\
\hline
\end{tabular}

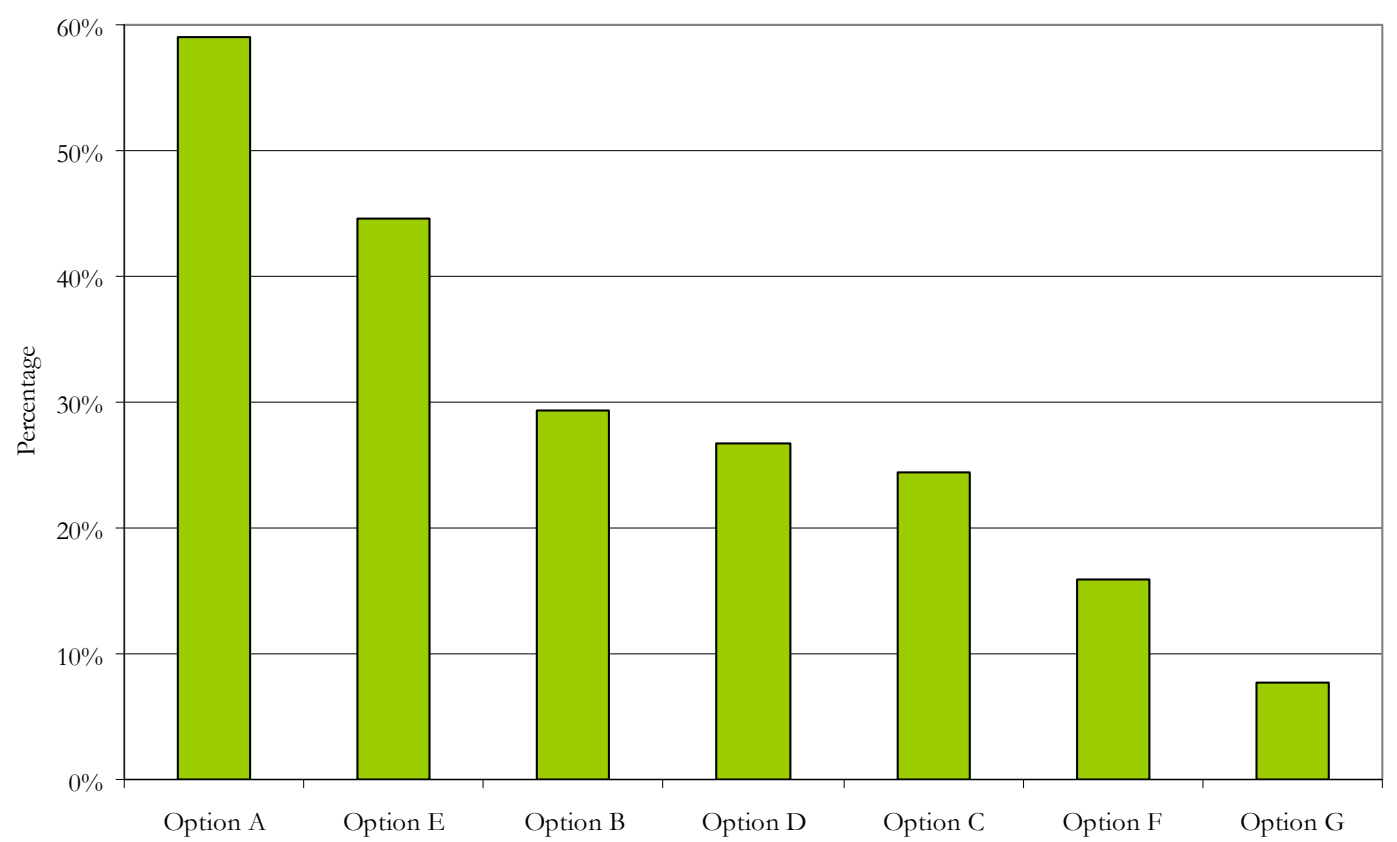

Figure 4-41: Overall perceived social reasons/benefits of sustainable building (in order from highest to lowest) 


\subsubsection{Discussion}

According to experience of the respondents, the client was considered to be the single most important person to drive sustainable building. Clearly, as the financial source, they have the final say of any proposed design, but while a building should be built to the clients requirements they may not have the necessary knowledge to propose sustainable options or even be aware of them. To investigate this, a further question asked the participants who 'should' be the main driver for sustainable building, in which 'an integrated process where responsibility is shared' was considered to be the most important. This result emphasised the respondents realised good sustainable building design has to have involvement from all parties in the building process.

The participants understood the importance of introducing sustainable design into the building process as early as possible, with $49 \%$ selecting sustainable building is most likely triggered in the 'pre-design' stage, and 37\% in the 'design development' stage.

'Rising energy costs' were seen to be one of the main drivers for sustainable buildings ( $49 \%$ of the responses). Likewise, 'environmental conditions' and 'client demand' and were also deemed highly important in driving sustainable buildings. 'Environmental conditions' certainly emphasises the importance placed on energy, and the increasing demand from the public and industry. Whereas 'client demand' reiterates the importance the building industry places on the client in the production of sustainable building.

The results showed 'perceived higher upfront costs' were the biggest obstacle to sustainable building, with additional barriers of 'lack of education' and 'lack of awareness'. The latter two results reinforced the need for organisation such as the NZGBC to be a 'vehicle' to provide the building industry with direct and reliable information.

The most important reason for sustainable building was 'being part of an industry that values the environment'. Specific economic reasons suggested the economic value of sustainable building is better understood than may be currently perceived, that long-term ownership of buildings may become more frequent as short-term leases do not see the greater economic benefits over the life of a building. The options for the environmental reasons/benefits of sustainable building were all considered to be reasonably important by the participants. This result emphasised the building industry's better understanding of the environmental benefits of sustainable building and perhaps New Zealand's identity of 'being clean and green'. Socially the respondents showed a good portion have a moral imperative for sustainable building, and look beyond just financial gain. 


\subsubsection{Section 6: Sustainable Building Information}

This section investigated the New Zealand building industry's sustainable building information requirements and their corresponding level of satisfaction regarding this information (refer to Appendix C.2.6).

\subsubsection{Sustainable Building Information Requirements}

Question: What information do you require in regards to sustainable building?

'Environmental and economic cost benefit case studies' were identified as the most required piece of information by the respondents, accounting for 57\% (refer to Figure 4-42). Supporting this was the requirement for 'reviews and profiles of Green Star NZ buildings, even though Green Star NZ was not yet fully operational.

Important also, was the requirement for information regarding 'green products', which has already been identified with the development of the system, 'GreenBuild', designed to tackle this information in New Zealand. Furthermore majority of information required is related to the design phase of building, which shows the building industry realises the importance of early intervention of sustainable design in a building project. 
Table 4-17: Definitions of option choices to information requirements (in order asked in survey)

\begin{tabular}{|l|l|}
\hline Option & Definition \\
\hline Option A & Green products \\
\hline Option B & Environmental and economic cost benefit case studies \\
\hline Option C & Green building emerging trends \\
\hline Option D & Green projects \\
\hline Option E & How-to design a 'green' building \\
\hline Option F & Reviews and profiles of Green Star New Zealand buildings \\
\hline Option G & Engineering or scientific information \\
\hline Option H & How-to market a 'green' building \\
\hline Option I & Green Star New Zealand accreditation course \\
\hline Option J & How-to manage a 'green' building \\
\hline Option K & 'Green' players (services guide) \\
\hline Option L & Green Star New Zealand players \\
\hline Option M & Business management information \\
\hline Option N & Curriculum for senior executives \\
\hline Option O & Curriculum for line staff \\
\hline Option P & Other(s) \\
\hline
\end{tabular}

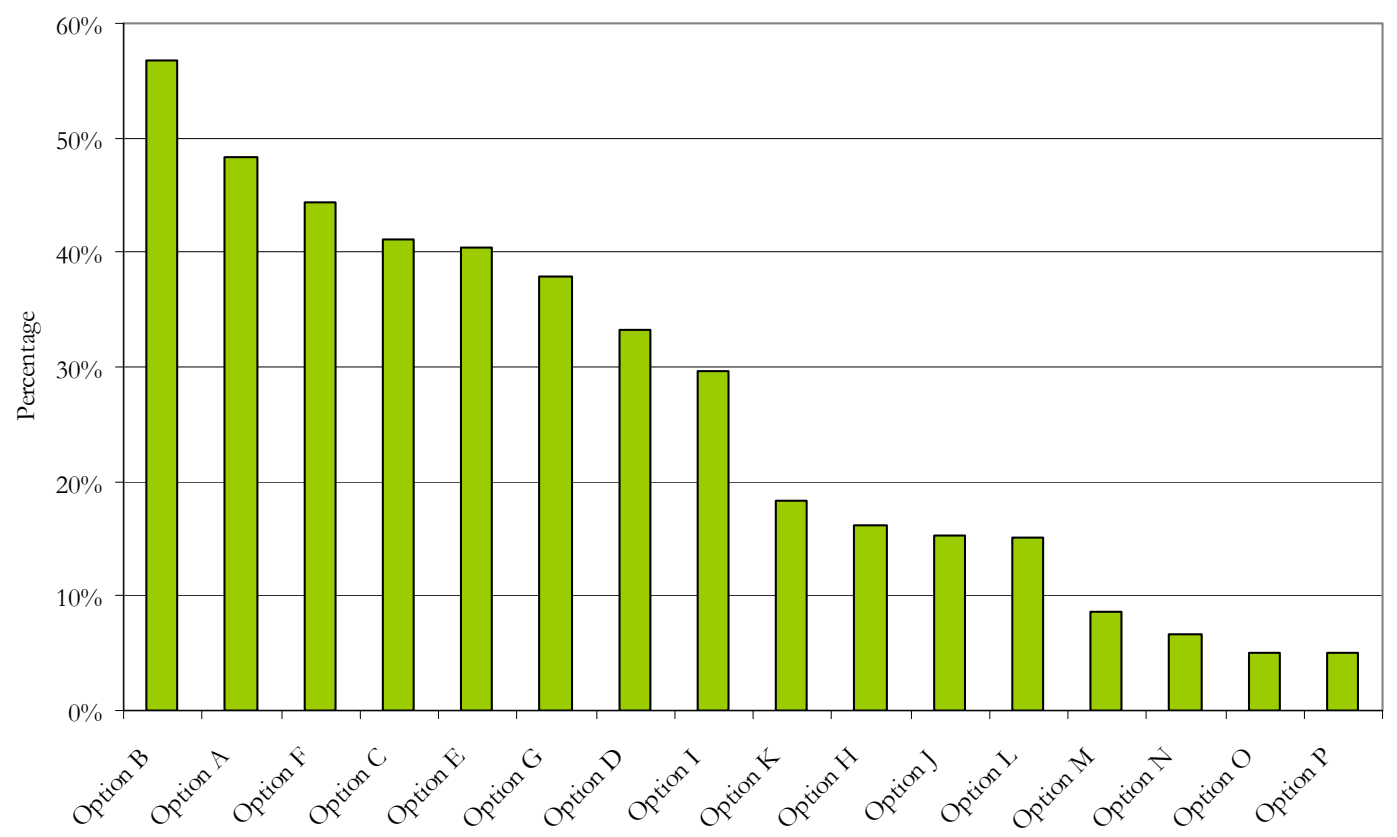

Figure 4-42: Overall requirements for information about sustainable building 


\subsubsection{Sustainable Building Information Satisfaction}

Question: What is your level of satisfaction with current information about sustainable building?

Overall the response shows participants were not overly satisfied with the current level of information, with 31\% not satisfied and 30\% hardly satisfied (refer to Figure 4-43). This reinforces the previous question of the requirements for sustainable building information, and emphasises the gap between requirements and satisfaction regarding this information and the need for better education procedures.

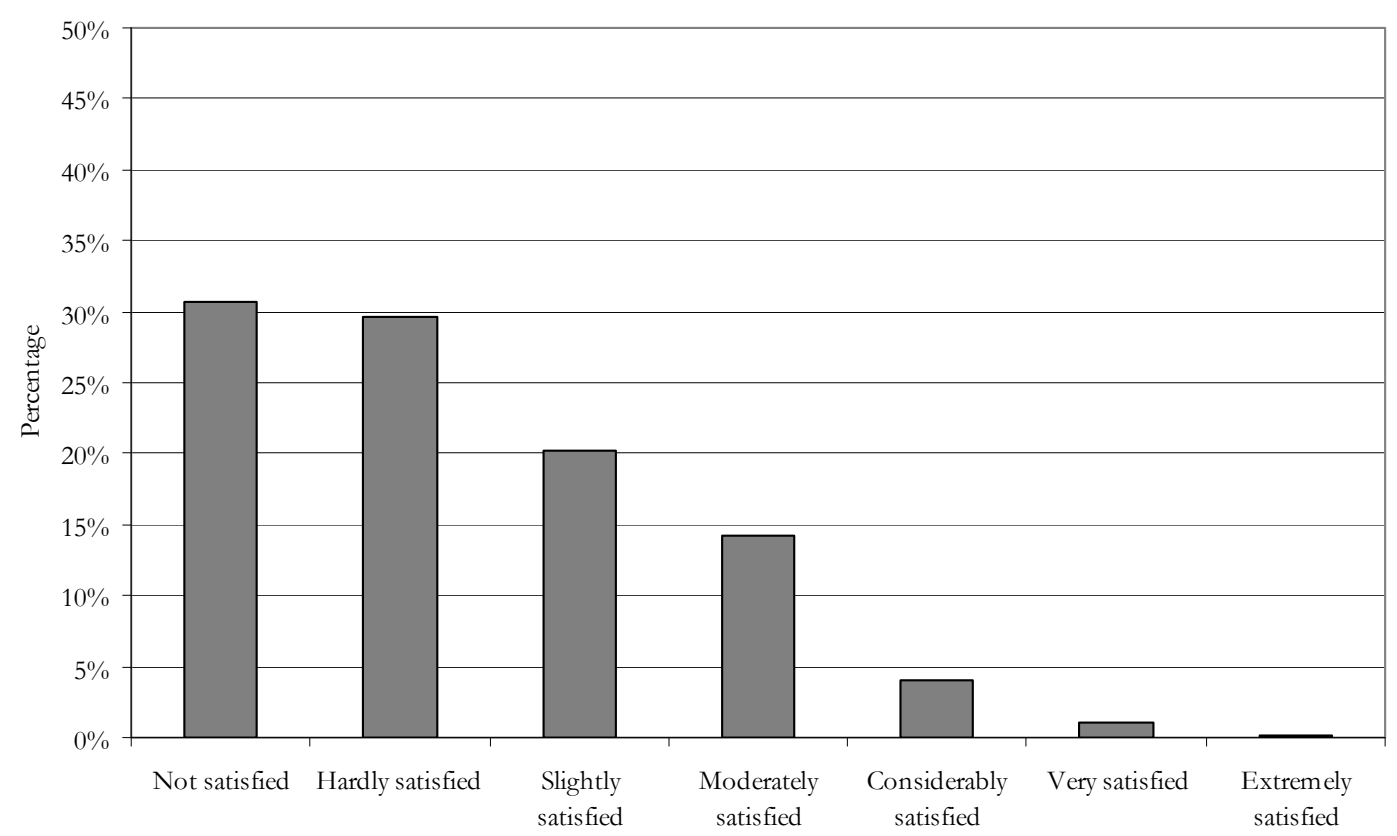

Figure 4-43: Overall level of satisfaction with the current information available about sustainable building

Seen in Figure 4-44 are some surprising results. For example 'reviews and profiles of Green Star New Zealand buildings' (Option F), 'Green Star New Zealand accreditation course’ (Option I), and 'Green Star New Zealand players' (Option L), it would be expected the level of satisfaction would be low, as Green Star had yet to be officially released. Yet surprisingly at the 'moderately satisfied' level, these options achieved $10 \%, 12 \%$ and $15 \%$ respectively. 
Table 4-18: Definitions of option choices to information requirements with colour key

\begin{tabular}{|l|l|l|}
\hline Answer Choice & Definition & Key \\
\hline Option A & Green products & \\
\hline Option B & Environmental and economic cost benefit case studies & \\
\hline Option C & Green building emerging trends & \\
\hline Option D & Green projects & \\
\hline Option E & How-to design a 'green' building & \\
\hline Option F & Reviews and profiles of Green Star New Zealand buildings & \\
\hline Option G & Engineering or scientific information & \\
\hline Option H & How-to market a 'green' building & \\
\hline Option I & Green Star New Zealand accreditation course & \\
\hline Option J & How-to manage a 'green' building & \\
\hline Option K & 'Green' players (services guide) & \\
\hline Option L & Green Star New Zealand players & \\
\hline Option M & Business management information & \\
\hline Option N & Curriculum for senior executives & \\
\hline Option O & Curriculum for line staff & \\
\hline
\end{tabular}

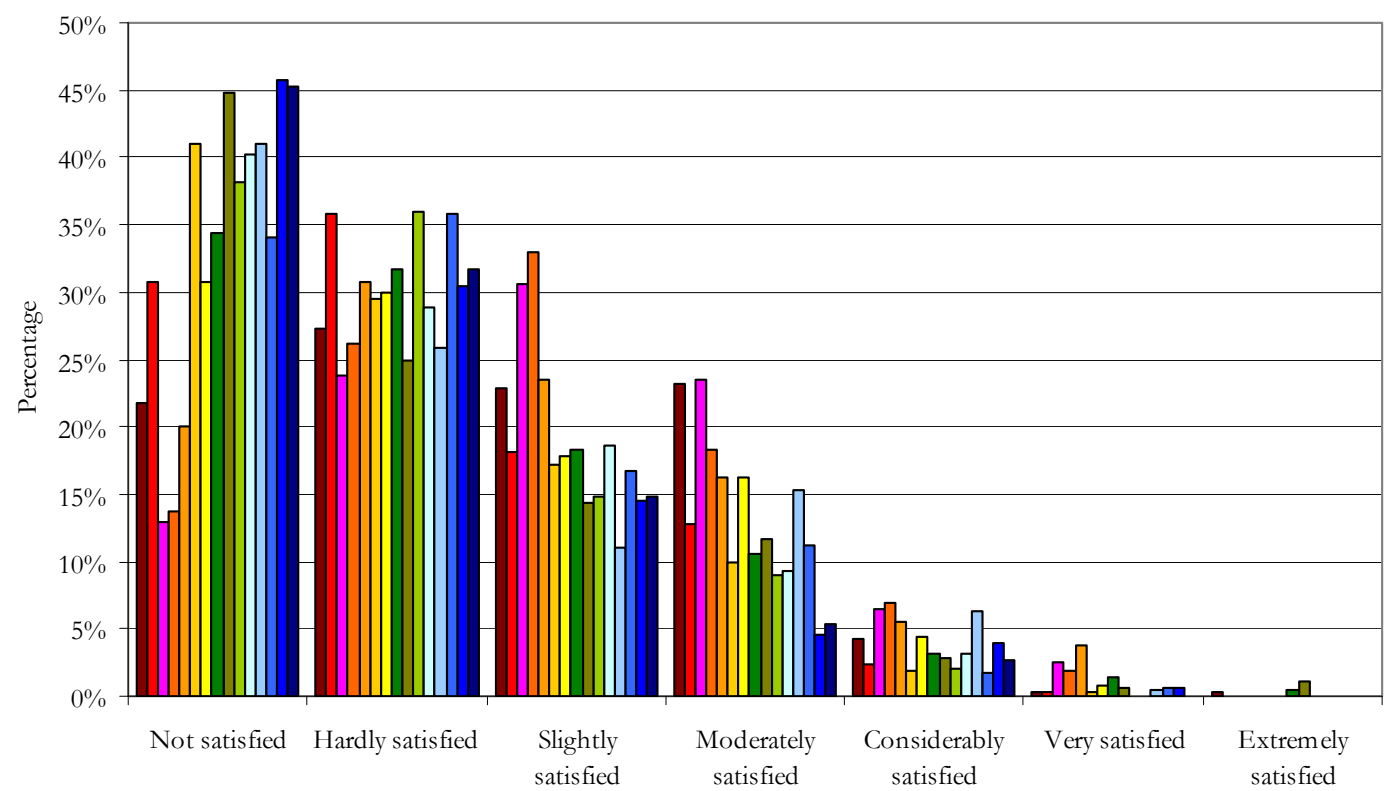

$\square$ Option A $\square$ Option B $\square$ Option C $\square$ Option D $\square$ Option E $\square$ Option F $\square$ Option G $\square$ Option H

$\square$ Option I $\quad \square$ Option J $\quad \square$ Option K $\square$ Option L $\quad \square$ Option M $\square$ Option N $\square$ Option O

Figure 4-44: Overall level of satisfaction with the current information available about sustainable building according to option choices 


\subsubsection{Discussion}

Even though the NZGBC and Green Star NZ are in their infancy there was a significant demand for Green Star NZ related material, such as 'Green Star NZ certified buildings', 'Green Star NZ accreditation course' and 'Green Star NZ professionals', even though Green Star was yet to be officially launched. The results showed the most important piece of information sought by the respondents to be 'environmental and economic cost benefit case studies'. The requirement for information regarding 'green products' was also important. This result emphasises the appropriateness of the web based green product system GreenBuild, which has been specifically designed for the New Zealand market to tackle this area of green product information. Nevertheless, both the United States and Australia have green product rating systems in place, and from the results it was identified 'green products' were still the most important piece of information required in these countries. As a result, GreenBuild cannot be expected to completely fill this gap, and like Green Star NZ will require additional support from the building industry.

In terms of satisfaction, the participants identified they were not overly satisfied with the current level of information, with 31\% not satisfied and 30\% hardly satisfied. This result reinforced the requirement for sustainable building information, and the gap between requirements and satisfaction regarding this information and the need for better education procedures.

\subsection{Methodology Issues}

The following discussion identifies some of the methodological problems encountered in this research and suggests improvements and adjustments for future study.

\subsubsection{Random Sample}

As already described, the survey relied on organisations to forward an email with web link onto the respective contacts, and as a result, there was an associated level of trust in relying on outside groups to assist in the distribution of the survey. On this basis, the survey was not entirely random, but selectively random. In the future, it would be recommended that instead of contacting as many individuals as possible, the survey would only survey a random representative sample of the population (i.e. the building industry). This would mean instead of the 17,350 building industry professionals contacted in this survey, only a sample of 384 would be required to be contacted and surveyed.

While this may increase the level of precision at which the results could be stated, the difficulty would be acquiring the representative sample, as it would required specific information about the 
building industry and its members to be collected, much of it confidential. To do this the methodology would have to accommodate for the outcome that if a randomly chosen participant refused to respond, a substitute participant would be required to replace the refusal, thus ensuring a representative sample.

While a survey was implemented in this research, it is still recommended that any future survey canvas or sample from the whole building industry, rather than one select database like both the United States and Australian research, which only contacted their own respective email contacts. The result of this reduces the chance of non-response bias, hence the results can be interpreted as representative of the whole building industry.

\subsubsection{Incentives}

It would be important for any future study to accommodate for the provision of an award or an incentive. In this study to increase survey participation, the NZGBC offered a $\$ 200$ incentive for one of its members to attend NZGBC related events. In retrospect, an incentive for all the participants of the survey would have been beneficial. The likely outcome would increase the chances for a greater response, improving the confidence interval, and reducing the margin of error.

\subsubsection{Survey Design}

At the conclusion of the survey, two questions were determined to be unnecessary. These questions were:

- Question 7: In your experience with existing Building Sustainability Rating Tools what have been the highest achieved ratings/scores?

- Question 19: Do you have any reason for your selection of the appropriateness of the New Zealand Green Building Council in the establishment of a New Zealand specific Buildings Sustainability Rating Tool?

The first question was thought to have gained further knowledge about the building industry and allow comparison against usage of existing BSRTs. The question however excluded answers from the respondents who may have used an existing BSRT but who had not carried out an assessment. Furthermore, for a future survey, it is likely that Green Star NZ would be more widely used by the industry, and this type of question would then become redundant.

The second question sought to gain knowledge about the reasons for a previous answer: What is appropriateness of the New Zealand Green Building Council in the establishment of a New Zealand specific Buildings Sustainability Rating Tool??. The majority of respondents 
however did not have a reason or did not know, and thus the question did not add any real value to the results. For instance many of the answers from those that did respond were related to BSRTs or Green Star NZ rather than the required NZGBC.

Likewise it may also be beneficial to alter the wording of the question; 'Please list your associated affiliations with building industry related organisations'. The word, 'affiliation' implies a form of membership, and not just an association of being on an email contact database. For that reason, the question needed to be more clearly defined, incorporating and quantifying the level of appropriate association.

\subsubsection{Web-Survey Instrument}

Even though the survey was thoroughly tested, at its conclusion several concerns were raised about the survey instrument used in the study. On three reported occasions, the URL did not correctly link to the survey. The main cause in this instance was that various email clients treated the link differently, and some email clients actually truncated the URL and split it onto two lines. The portion on the second line was not attached to the first, and as a result when opened, the link appeared to be broken. Additionally this may have also been created by an overloaded website, where the survey was not able to manage an excess of participants trying to access the website at one particular moment.

On one occasion, it was reported that on completion of the survey all a respondent's answers were deleted and they were taken back to the beginning of the survey. The survey-hosting website (Zapsurvey) was unable to provide an exact answer other than that the survey possibly timed out after 60 minutes. However, this should have not been an issue as the survey was designed to take only 20 minutes to complete, and the 60 minute time out feature resets after each new section.

The last problem with the survey instrument was when one participant was required to provide an answer, where an answer was not actually required to proceed. Again, Zapsurvey could not provide a reason, and in the end had to be put down to a fault in the survey instrument.

\subsection{Multiple response}

A reason for choosing Zapsurvey to host the survey was that it collected the I.P. address of the participant's computer and stored cookies within each participant's computer. As a result it prevented multiple responses from a single individual. Though in essence this only prevented the same computer being used to make the response, not the same participant. In actuality, this may have prevented a legitimate participant responding from an already accessed computer. 
A possible solution could be for participants to log on to the survey with a password. However this method could deter possible respondents from answering, by adding another level of complexity. It should also be noted that due to the length and specialised topics in the survey the occurrence of multiple responses was low and any prevention techniques have to be weighed up against the prevention of legitimate response.

In the survey, it was not clear why a respondent did not answer a question. Either, the respondent did not know the answer, or there was no appropriate option for their answer, or simply they did not want to provide an answer. Therefore to improve the distinction between why a participant did not respond the provision of an 'I don't know' and/or 'none' option would have assisted in the analyses. As a result the 'I don't know' answers could be rescaled or removed from further analyses. Also requiring a response to each question would have helped to eliminate the occurrence of unit non-response (i.e. missing answers), thus improving statistical significance. 
Results 


\section{Comparative Analyses and Results}

This section discusses the United States and Australian studies and compares it to the results found in this New Zealand study. The importance of this was to gauge where the New Zealand building industry is in comparison to other international contexts.

\subsection{International Comparison}

As a form of comparison, the results from this survey were compared with existing data from existing international research from McGraw Hill Construction (United States) and Building Construction Interchange (Australia). However due to the significant differences between the contexts of each study the results should only be interpreted as a precursor for New Zealand's future. For example, the United States and Australian studies for example were conducted with their respective BSRT already well established in the industry, whereas in New Zealand, Green Star NZ had yet to be officially launched. Furthermore, due to these differences some criteria did not fit the New Zealand model, and was either modified to allow comparison or removed completely from the analyses (refer to Appendix D for all comparative results, including individual results from the United States and Australia).

The questions which allowed this comparison were:

- At what stage of the building process is sustainable building most likely triggered?

- What do you think are the main drivers for sustainable building?

- What are the obstacles to sustainable building?

- What are your reasons for being involved in sustainable building?

- What do you believe are the economic reasons/benefits of sustainable building?

- What do you believe are the environmental reasons/benefits of sustainable building?

- What do you believe are the social reasons/benefits of sustainable building?

- What is your level of satisfaction with current information about sustainable building? 


\subsubsection{Trigger Stage for Sustainable Building}

Question: At what stage of the building process is sustainable building most likely triggered?

From Figure 5-1, it can be seen in New Zealand sustainable building is more likely to be considered earlier in the design sequence (refer to Appendix D.1.1). Almost 50\% of the respondents expressed sustainable building is most likely triggered during the 'preliminary inquiries'. In comparison, $36 \%$ of the United States, and $43 \%$ of the Australian respondents believed sustainable building was triggered at this stage.

Table 5-1: Definition of answer choices to reasons for involvement in sustainable building to when sustainable is most likely triggered (in order asked in New Zealand survey)

\begin{tabular}{|l|l|}
\hline Option & Definition \\
\hline Option A & I don't know \\
\hline Option B & Preliminary inquiries \\
\hline Option C & Pre-design \\
\hline Option D & Design development \\
\hline Option E & Construction development process \\
\hline Option F & Commissioning \\
\hline Option G & Construction \\
\hline
\end{tabular}

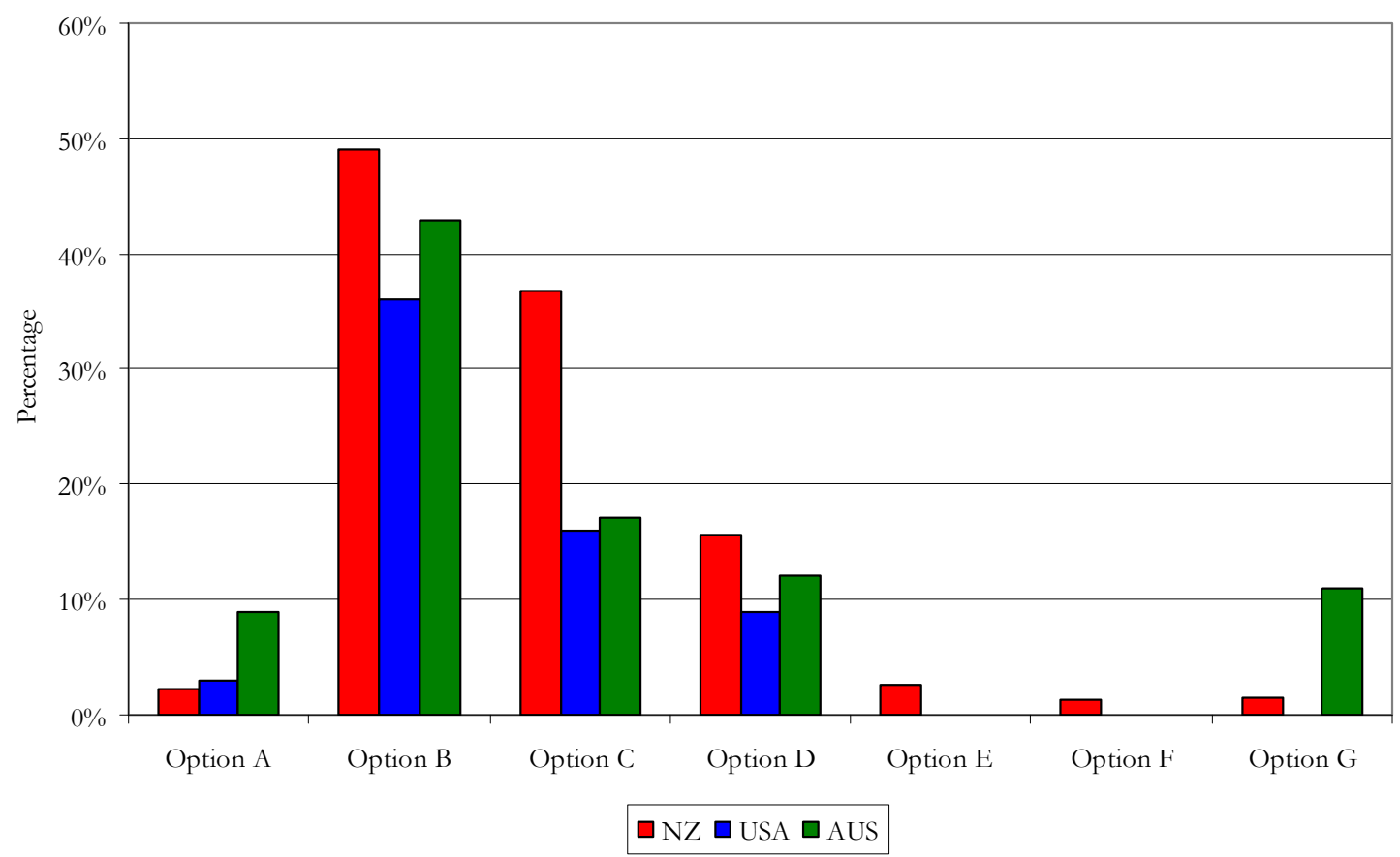

Figure 5-1: Overall international comparison of when sustainable building is most likely triggered (in order of highest to lowest in New Zealand) 
The results show there is a difference at the 'pre-design' stage, with $37 \%$ of the New Zealand respondents said this was when sustainable building was most likely triggered, whereas it only achieved 16\% in the United States and 17\% in Australia. It should be noted though that in both Australia and United States several other options were available but not included in this research (refer to Appendix D.1.1.1 and D.1.1.2). While this could explain some of the differences between the countries, the emphasis in the design stage for New Zealand is certainly encouraging and reinforces the perception of the client as a main driver for sustainable building.

\subsubsection{Drivers for Sustainable Building}

\section{Question: What do you think are the main drivers for sustainable building?}

In most cases the level of importance placed on the drivers (refer Table 5-2) to sustainable building by the New Zealand building industry were lower than those perceived by the United States and Australia (refer to Figure 5-2 and Appendix D.1.2). For example Option E, 'independent rating system' only accounts for $13 \%$ of the New Zealand respondents, whereas in the United States and Australia records figures of 58\% and 53\%. This result emphasises the differences between the studies, but more importantly, how with experience and application of Green Star NZ the perceptions of the New Zealand building industry may elevate in the future. That is, continued use of Green Star NZ should create greater demand for sustainable building. 
Table 5-2: Definition of answer choices to drivers for sustainable building (in order asked in New Zealand survey)

\begin{tabular}{|l|l|}
\hline Option & Definition \\
\hline Option A & Rising energy costs \\
\hline Option B & Government regulation \\
\hline Option C & Lower life-cycle costs \\
\hline Option D & Client demand \\
\hline Option E & Independent rating system \\
\hline Option F & Government rating systems \\
\hline Option G & Competitive advantage \\
\hline Option H & Superior performance \\
\hline Option I & Increased education \\
\hline Option J & Environmental conditions \\
\hline Option $\mathrm{K}$ & Attraction and retention of staff \\
\hline Option L & Increased emphasis on productivity \\
\hline Option M & International trends show it is smart business \\
\hline Option N & Disruptive/enabling technology \\
\hline
\end{tabular}

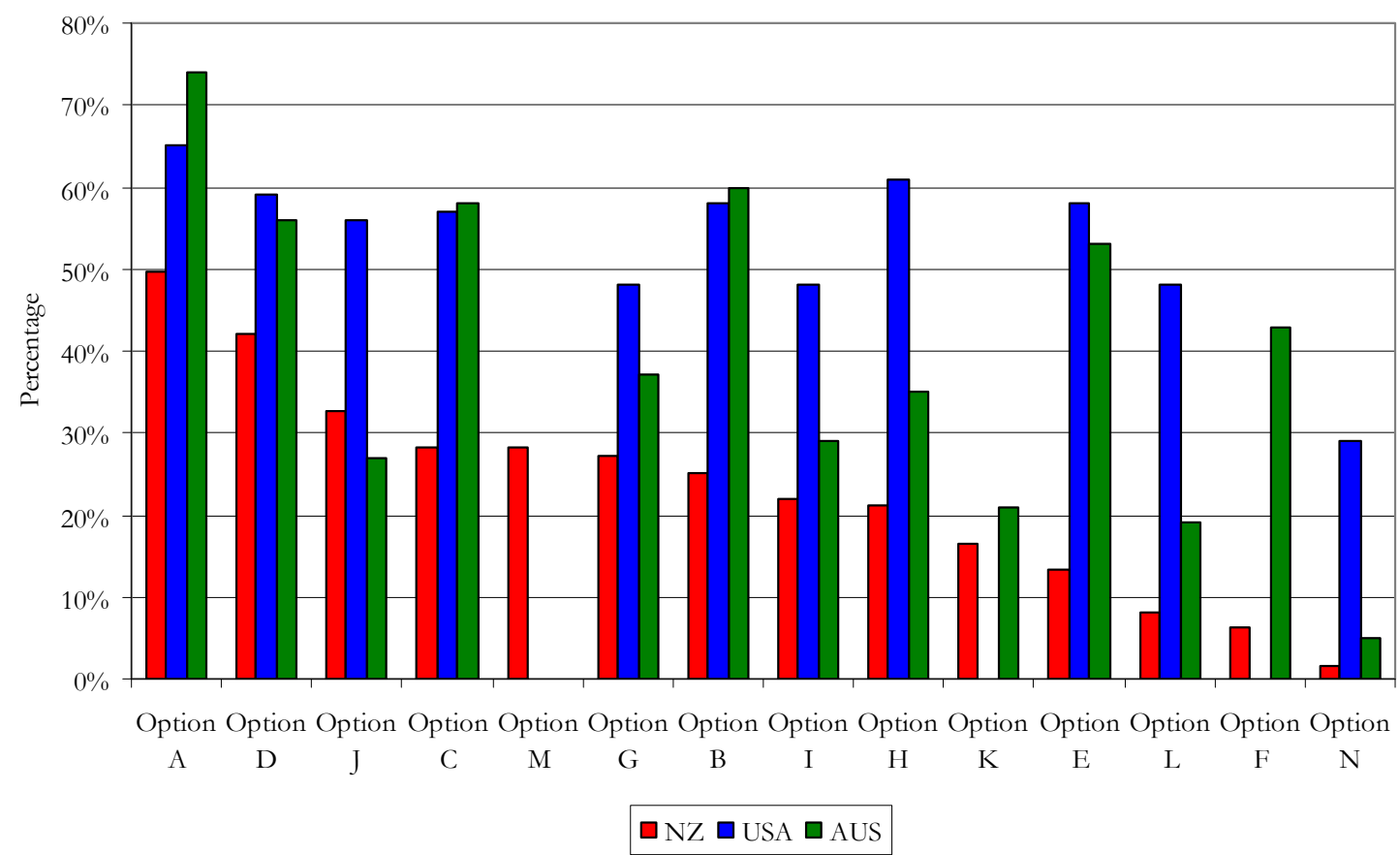

Figure 5-2: Overall international comparison of drivers for sustainable building (in order of highest to lowest in New Zealand) 


\subsubsection{Obstacles for Sustainable Building}

Question: What are the obstacles to sustainable building?

In all three studies 'perceived higher upfront costs' were seen to be the main obstacle for sustainable building, with New Zealand having an almost identical figure to the United States of 64\% (refer to Figure 5-3 and to Appendix D.1.3). Likewise, 'lack of awareness' and lack of education' provided similar numbers. At the lower end, 'different accounting methods' was seen to be the least important from a New Zealand perspective, whereas in the United States and Australia it recorded figures of $45 \%$ and $38 \%$ respectively.

Table 5-3: Definition of answer choices to obstacles for sustainable building (in order asked in survey New Zealand)

\begin{tabular}{|l|l|}
\hline Option & Definition \\
\hline Option A & Perceived higher upfront costs \\
\hline Option B & Lack of education \\
\hline Option C & Lack of awareness \\
\hline Option D & No fiscal incentive \\
\hline Option E & Different accounting methods \\
\hline Option F & No coordination or consistency \\
\hline Option G & Politics \\
\hline Option H & Payback periods \\
\hline Option I & Education of non 'green' people \\
\hline
\end{tabular}

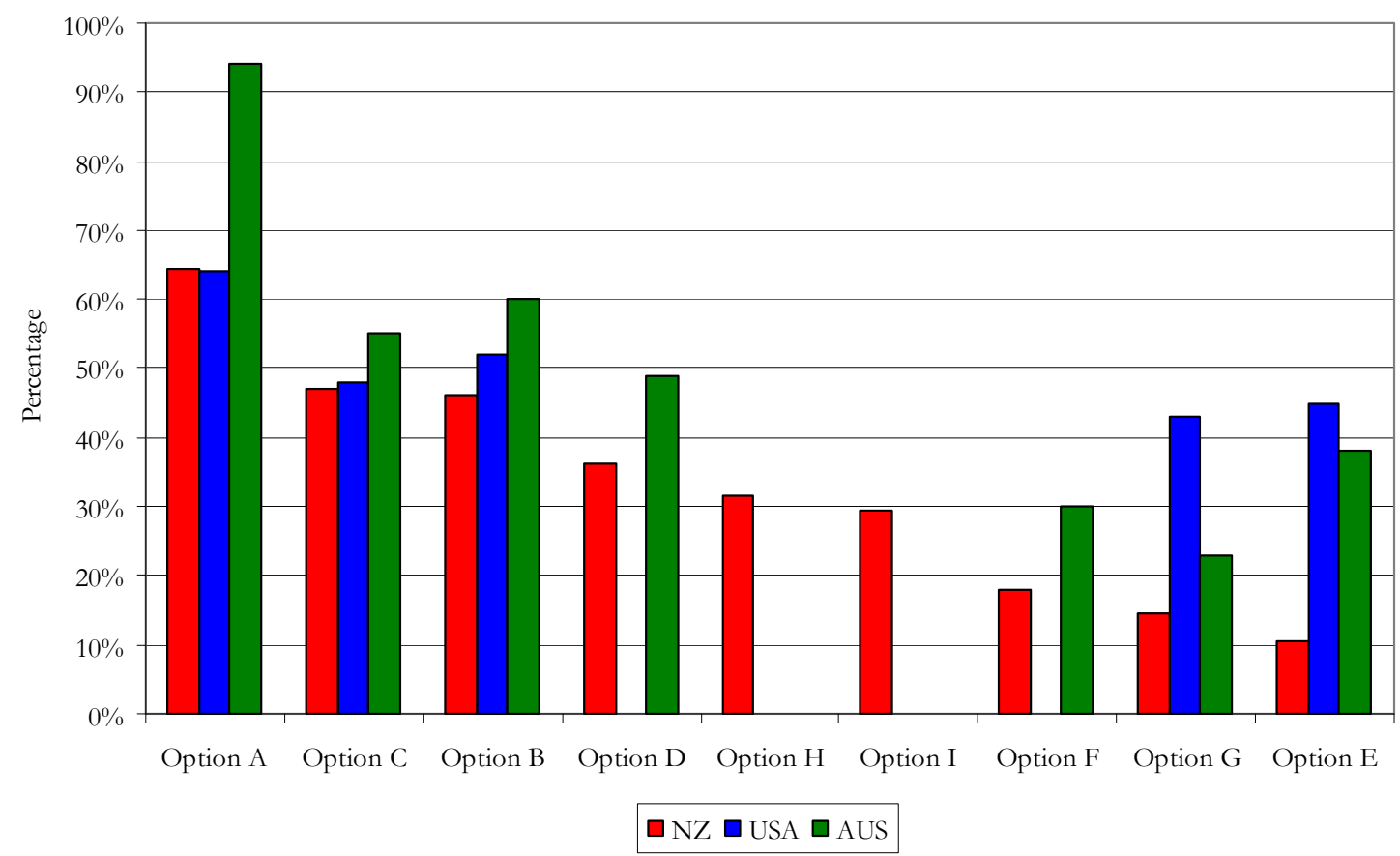

Figure 5-3: Overall international comparison of obstacles for sustainable building (in order of highest to lowest in New Zealand) 
This result suggests while New Zealand understands the more basic elements of sustainable building, its comprehension of more complex theories may be limited due to the lack of knowledge and experience of sustainable building in the industry. Again, this may become more evident over time as sustainable building development evolves in New Zealand.

\subsubsection{Reasons for Involvement in Sustainable Building}

Question: What are your reasons for being involved in sustainable building?

According to Figure 5-4, 73\% of the United States respondents perceived 'achieving lower life cycle costs' and $72 \%$ of the Australia respondents perceived 'being part of an industry the values the environment' and as the most important reason for being involved in sustainable building (refer to Appendix D.1.4). Again, due to the context of the New Zealand study it would seem the reasons for sustainable building are yet to be fully realised. Although as the New Zealand building industry evolves, adapts and adapts Green Star NZ, the reasons for sustainable building should become clearer.

Table 5-4: Definition of answer choices to reasons for involvement in sustainable building (in order asked in New Zealand survey)

\begin{tabular}{|l|l|}
\hline Option & Definition \\
\hline Option A & I am not involved \\
\hline Option B & Being part of an industry that values the environment \\
\hline Option C & Achieving lower life-cycle costs \\
\hline Option D & Contract requirement (e.g. Government tenders) \\
\hline Option E & Expanding my business with 'green' building clients \\
\hline Option F & Benefit from publicity \\
\hline Option G & Triple bottom line reporting \\
\hline Option H & Attraction and retention of talent \\
\hline Option I & Green product information \\
\hline Option J & Awards for green building \\
\hline Option K & Higher return on investment on resale \\
\hline
\end{tabular}




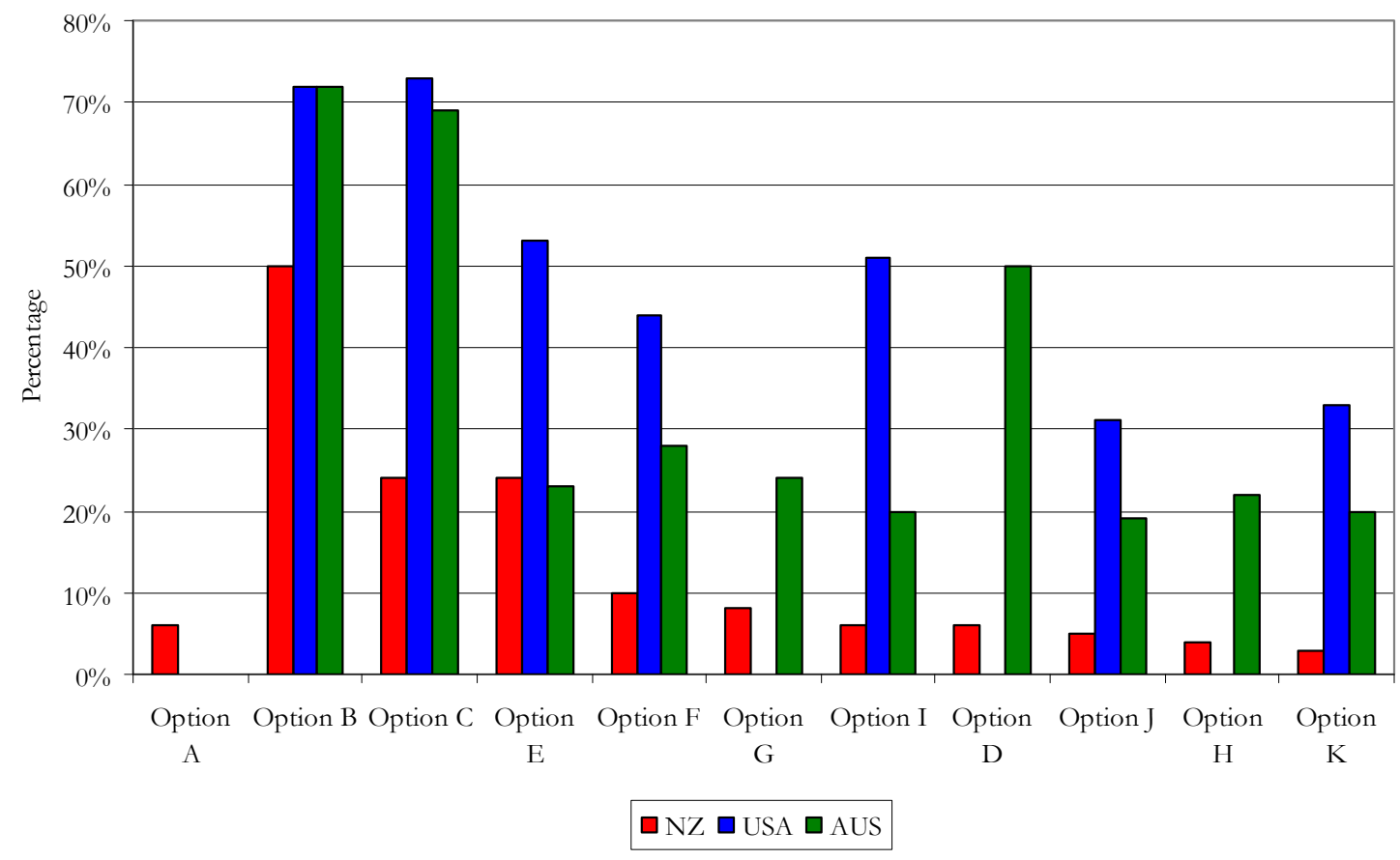

Figure 5-4: Overall international comparison of reasons for involvement in sustainable building (in order of highest to lowest in New Zealand) 


\subsubsection{Economic Reasons for Sustainable Building}

Question: What do you believe are the economic reasons/benefits of sustainable building?

Overall New Zealand's perceptions of the economic reasons for sustainable building compare well against the United States and Australia, even though these countries had their respective BSRTs already well established. According to Figure 5-5, New Zealand views 'lower operating costs' just as important as 'lower lifetime costs', yet in the United States and Australia 'lower operating costs' are valued higher (refer to Appendix D.1.5).

Table 5-5: Definition of answer choices to economic reasons/benefits for sustainable building (in order asked in New Zealand survey)

\begin{tabular}{|l|l|}
\hline Option & Definition \\
\hline Option A & Lower operating costs \\
\hline Option B & Lower lifetime costs \\
\hline Option C & Higher building value \\
\hline Option D & Enhanced marketability \\
\hline Option E & Helping to transform the market \\
\hline Option F & Increase staff productivity and retention \\
\hline Option G & Higher return on investment \\
\hline Option H & Reduced liability and risk \\
\hline
\end{tabular}

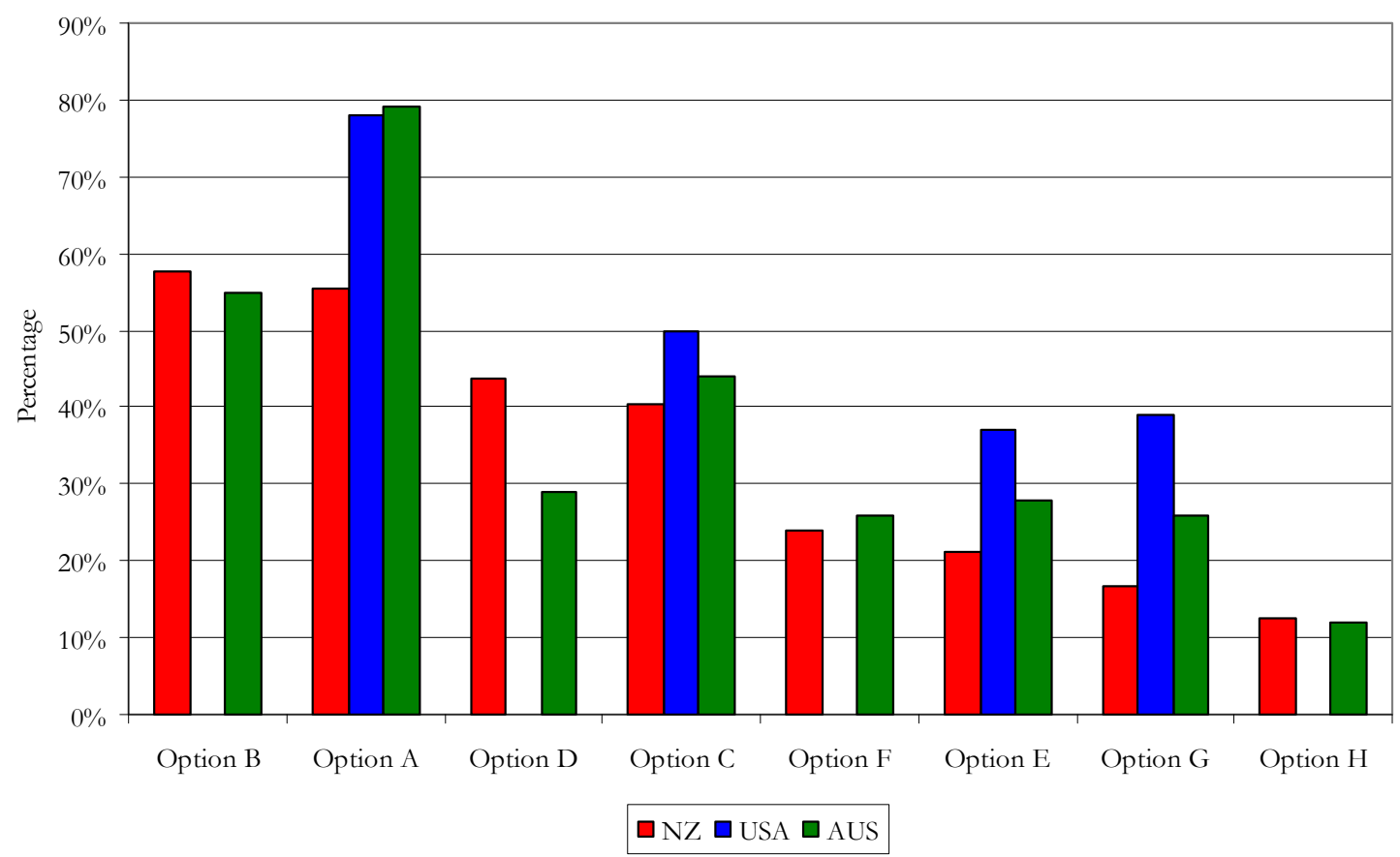

Figure 5-5: Overall international comparison of the economic reasons/benefits of sustainable building (in order of highest to lowest in New Zealand) 


\subsubsection{Environmental Reasons for Sustainable Building}

Question: What do you believe are the environmental reasons/benefits of sustainable building?

According to the results, environmental reasons are more clearly understood by the building industry, with a similar level of response for each environmental option in New Zealand and Australian findings (refer to Figure 5-6 and Appendix D.1.6). Evident is also the lack of comparison to the United States. The reason for this lack of comparison were the options given by the United States research, which in this case were determined not to be environmental reasons but rather economic and social reasons (refer to Appendix D.1.6.1). Overall New Zealand understanding is certainly encouraging, and is perhaps an emphasis on our own perceptions of being a ‘clean and green' country.

Table 5-6: Definition of answer choices to environmental reasons/benefits for sustainable buildings (in order asked in New Zealand survey)

\begin{tabular}{|l|l|}
\hline Option & Definition \\
\hline Option A & Protection of the environment \\
\hline Option B & Reducing climate change and emissions \\
\hline Option C & Minimising ecological impact of buildings \\
\hline Option D & Scarcity of natural resources \\
\hline Option E & Improving indoor environment quality \\
\hline Option F & Waste reduction \\
\hline
\end{tabular}

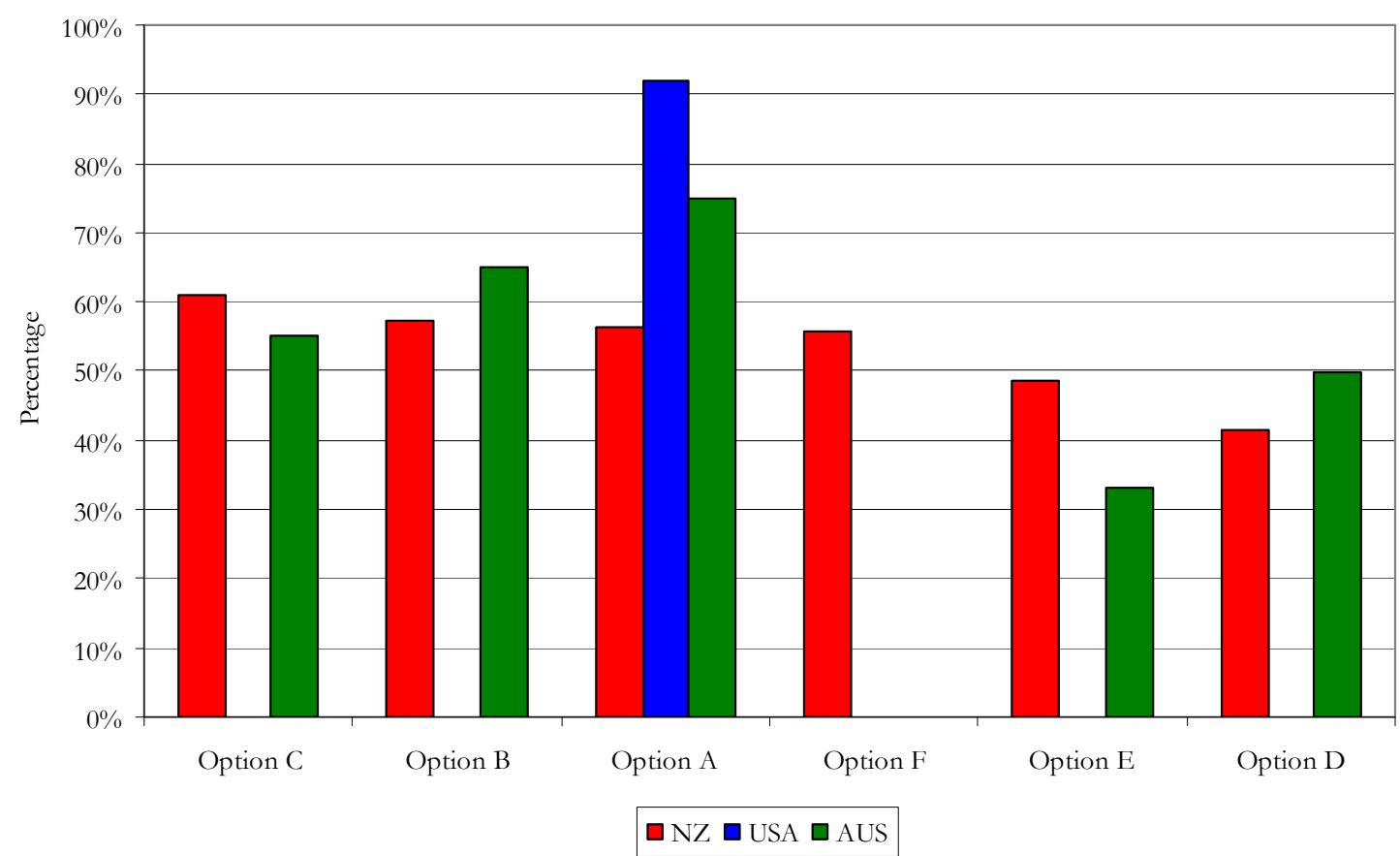

Figure 5-6: Overall international comparison of the environmental reasons/benefits of sustainable building (in order of highest to lowest in New Zealand) 


\subsubsection{Social Reasons for Sustainable Building}

Question: What do you believe are the social reasons/benefits of sustainable building?

Harder to measure are the intangible, social reasons/benefits of sustainable building. In all three contexts, 'greater health and well-being' was seen to be the most important issue, however corresponding figures from the United States and Australia are significantly higher. As stated previously the differences between New Zealand the United States and Australia were the periods of each study and most significantly with the New Zealand study Green Star NZ was yet to be officially launched (refer to Figure 5-7 and Appendix D.1.7). Again, as experience with Green Star NZ develops and matures these societal reasons should increase with our greater understanding of sustainable building.

Table 5-7: Definition of answer choices to social reasons/benefits for sustainable buildings (in order asked in New Zealand survey)

\begin{tabular}{|l|l|}
\hline Option & Definition \\
\hline Option A & Greater health and well-being \\
\hline Option B & Improved learning and healing environments \\
\hline Option C & Tenant productivity \\
\hline Option D & Support for applicable economy (NZ, USA, AUS) \\
\hline Option E & Moral imperative of being 'green' \\
\hline Option F & Aesthetically pleasing \\
\hline
\end{tabular}

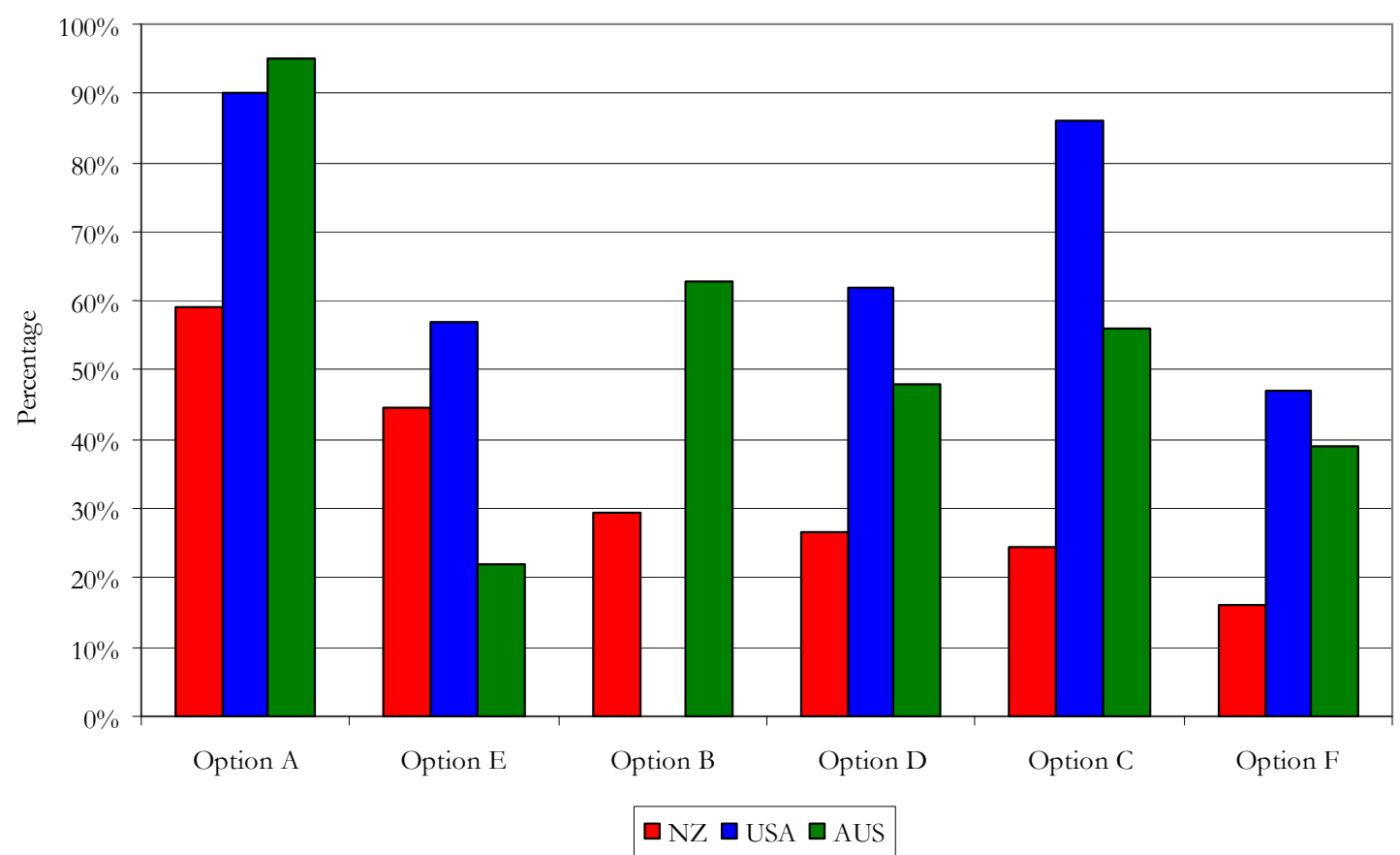

Figure 5-7: Overall international comparison of the social reasons/benefits for sustainable building (in order of highest to lowest in New Zealand) 


\subsubsection{Sustainable Building Information Requirements}

Question: What is your level of satisfaction with current information about sustainable building?

Surprisingly the United States and Australian information requirements were still substantially high, even though these countries have had BSRTs available and created more sustainable buildings, the demand for information has not decreased (refer to Figure 5-8 and Appendix D.1.8). Although, it is not necessarily the responsibility of a BSRT to fulfil this demand for more information, rather these results should be used in a way to propose further research and the employment of techniques to satisfy these information gaps. 
Table 5-8: Definition of answer choices to information requirements regarding sustainable buildings (in order asked in New Zealand survey)

\begin{tabular}{|l|l|}
\hline Option & Definition \\
\hline Option A & Green products \\
\hline Option B & Environmental and economic cost benefit case studies \\
\hline Option C & Green building emerging trends \\
\hline Option D & Green projects \\
\hline Option E & How-to design a 'green' building \\
\hline Option F & Reviews and profiles of applicable BSRT buildings \\
\hline Option G & Engineering or scientific information \\
\hline Option H & How-to market a 'green' building \\
\hline Option I & Applicable BSRT accreditation course \\
\hline Option J & How-to manage a 'green' building \\
\hline Option K & 'Green' players (services guide) \\
\hline Option L & Applicable BSRT players \\
\hline Option M & Business management information \\
\hline Option N & Curriculum for senior executives \\
\hline Option O & Curriculum for line staff \\
\hline
\end{tabular}

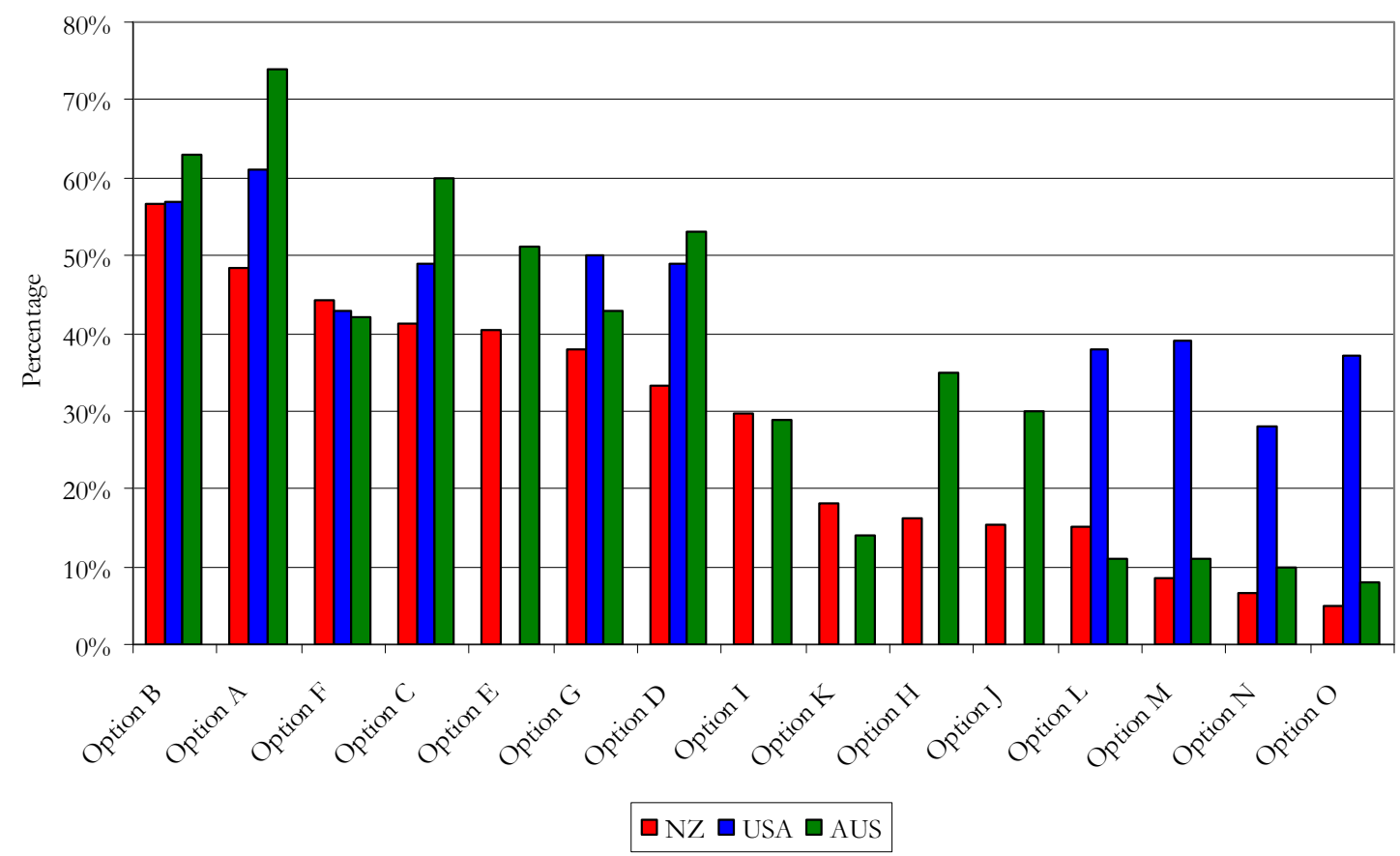

Figure 5-8: Overall international comparison of information requirements regarding sustainable building (in order of highest to lowest in New Zealand) 


\subsection{Discussion}

The purpose of the comparative analyses was to investigate the differences and similarities of the results found in this study, against findings from the United States and Australia. For example when compared to the United States (36\%) and Australia (43\%), almost 50\% of the respondents in this survey expressed sustainable building was more likely to be considered during the 'preliminary inquiries'.

Again in comparison, the importances placed on the drivers to sustainable building by the New Zealand building industry were lower than those of the United States and Australia studies. For example 'independent rating system' accounted for 13\% of the New Zealand respondents, whereas in the United States and Australia it recorded 58\% and 53\% respectively.

In all three studies 'perceived higher upfront costs' were seen to be the main obstacle for sustainable building, with New Zealand having an almost identical figure to the United States of $64 \%$. While in other instances the New Zealand survey recorded similar levels of response, New Zealand's views were often seen to be less important. For example 'different accounting methods' recorded a response of 10\%, whereas in the United States and Australia it recorded figures of $45 \%$ and $38 \%$ respectively. Likewise in respect to the reason for sustainable building, 'being part of an industry the values the environment' recorded $72 \%$ in both the United States and Australia, but in New Zealand acquired a figure of $50 \%$.

New Zealand's demand for sustainable building information was significant, yet in both the United States and Australia the demand for this information doesn't seem to have decreased, even though these countries have had BSRTs available and created more sustainable buildings. However this could be a result of the longer availability and use of LEED and Green Star (Australia) in their respective markets, hence they have created a greater demand for sustainable building information.

While the comparative analyses identified both similarities and differences between the three countries, the results should be interpreted as a precursor for New Zealand's future and not as an identical comparison. That the United States and Australian research were conducted with their respective BSRT already well established in the industry, whereas in New Zealand, Green Star NZ was yet to be officially launched. 
Comparative Analyses and Results 


\section{Conclusions and Recommendations}

The overall aim of the study was to investigate the requirements of stakeholders and end-users including their understanding of sustainability, the NZGBC and BSRTs, ensuring that potential barriers were identified and addressed in the early stages of Green Star NZ implementation. The research also intended to provide a 'sustainability snapshot' of the New Zealand building industry and of the current New Zealand market, establishing a base point for future measurement.

The specific objectives of the research were to investigate:

- The building industry's level of awareness and the level of involvement regarding sustainability, sustainable building and BSRTs

- The building industry's existing knowledge and experience with BSRTs

- How different groups within the building industry anticipate using Green Star NZ and if they are likely to seek formal certification

- The building industry's understanding of the NZGBC, and its likely impact in the production of more sustainable buildings in New Zealand

- The drivers, triggers, obstacles and reasons for sustainable building

- The requirement for sustainable building information and the corresponding level of satisfaction regarding this information

- How international research compared with the current study, allowing trends, differences and similarities to be discussed

Additionally the results from the research could serve to enhance and improve:

- The identification of possible issues regarding the BSRT and therefore help smooth the period of transition for implementation and make it more New Zealand specific

- The potential for a more successful BSRT, including, penetration of the market and widespread application

- The relationship between the NZGBC and industry, encouraging dialogue to help develop the tool

- Ultimately the chances for the development of more sustainable buildings in New Zealand, through increasing education and awareness

To investigate these aims and objectives a quantitative survey was employed to ascertain the New Zealand building industry's understanding of sustainability, sustainable building and BSRTs. The results of the survey gave insight into the New Zealand commercial building market and how sustainability and sustainable building was being perceived and approached, thus establishing a base point for future investigation. 
Overall, this research methodology could be deemed to be successful and valuable in investigating the current New Zealand building market, with 476 responses the survey achieved a confidence interval of $95 \%$ and a margin of error of \pm 4 percent. Also identified in the design of this research methodology was the problem of non-response, and its bias and influence on results. Through analysis of early and late respondents, non-response was shown not to have the influence that was originally perceived, and consequently the results could be interpreted with a high degree of confidence.

\subsection{Conclusions}

The following conclusions identify the key findings of the research in relation to the specific objectives outlined above.

\subsubsection{Awareness and Involvement}

Overall, the results identified a significant difference between the level of interest and level of involvement regarding sustainability, sustainable buildings and BSRTs. For example there was an average decrease of $25 \%$ from those who are 'extremely interested' to 'extremely involved'. This result implied the building industry was much more willing to participate in the creation of sustainable building than is currently perceived. However, due to this lack of involvement there is a need for more and better sustainable building information, which in turn could lead to a higher uptake of Green Star NZ and more sustainable buildings.

The result also showed a lack of interest and involvement regarding BSRTs in comparison to sustainability and sustainable building. This lack of interest and involvement inferred that BSRTs are relatively new developments, especially in New Zealand, and are yet to create the necessary level of interest to cement their role in the New Zealand building industry. Whereas sustainability and sustainable building have been part of the building industry for a longer period, hence they have greater acceptance. Although it would be expected that over time as Green Star NZ evolves, its awareness will increase, along with its interest and involvement.

\subsubsection{Building Sustainability Rating Tools}

The participants reinforced the approach of the NZGBC to establish a specific BSRT for New Zealand, with 58\% rating it between 'very' and extremely important. This level of awareness suggested that having a New Zealand specific BSRT is an important component in driving the New Zealand building industry towards more sustainable building practice and the use of Green Star NZ. 
The most popular purpose of a BSRT was to allow standardisation and setting of sustainable building benchmarks. Other important purposes of a BSRT were to assist in the decision making process and create an ability for comparison of similar building types at a national level and international level.

The respondents largely showed a good level of awareness of existing BSRTs, with the Australian Green Star system the most recognised and most used by the building industry. Again, this is only one reason, but it approves the decision by the NZGBC to develop Green Star NZ, and that a high level of awareness is critical for market penetration and overall success.

\subsubsection{Green Star New Zealand}

According to the results, the respondents saw the importance of Green Star NZ being an equivalent to the Australian Green Star system. The obvious reason for an equivalent tool would be to enable comparisons, not only between similar building types, but also internationally between New Zealand and Australia.

The participants indicated that Green Star NZ will not be the only tool, development or initiative that will be required to assist the shift towards sustainable building. That Green Star NZ will need further support, guidance and information from both the NZGBC, and the wider building community to increase the development of sustainable building. The results further indicated that while the awareness of Green Star NZ is relatively high, there is still apprehension from the industry towards the new BSRT and being an accredited professional is not appropriate for everyone.

Colloquially evidence suggests, BSRTs are often used primarily as design guides, with no intention to seek formal certification. Furthermore, those who do achieve a 'design rating' do not seek to an 'as built' or 'performance' rating. The results showed that a good proportion of the industry anticipates that they will seek certification for both design and performance. While using Green Star NZ as a design guide was still reasonably high, it is important to note that not all buildings will be eligible to obtain an official rating, but the important factor is getting those who are eligible to take the next steps for formal certification.

Overall the respondents stated that they were likely to use Green Star NZ. Even at an industry sector level there were encouraging signs from 'Commercial Property Developers', 'Residential Developers and Major Portfolio Owners', and 'Major Corporate Tenants and Retailers', who initially may not have been perceived likely to use Green Star NZ. This suggests that already these key stakeholders appreciate the potential benefit of a Green Star NZ rated building. 


\subsubsection{The New Zealand Green Building Council}

Less understanding was evident in the appropriateness of the NZGBC in establishing a New Zealand specific BSRT. Those with little experience of BSRTs, expressed confusion and wondered what else the NZGBC could have done, with a $26 \%$ of the respondents selecting 'I don't know'.

Like Green Star NZ, the participants also perceived the NZGBC to have a 'considerable influence' in a shift towards more sustainable buildings. Again, this indicated that not only will the NZGBC be required to help develop sustainable buildings, but it will need support and assistance from the whole building industry.

At a base industry sector level those sectors who saw the influence of the NZGBC in a more positive respect (i.e. 'great influence' to an 'extreme influence') were stakeholders such as 'Commercial Property Developers', 'Investors, Owners and Property Managers', 'Residential Developers and Major Portfolio Owners', and 'Major Corporate Tenants and Retailers'. Consequently this raised the question: 'What are the barriers to end-users fully embracing the NZGBC and Green Star NZ?' Perhaps it indicated end-users are more apprehensive and realise assistance/development is required than just the NZGBC if we are to see the development of more sustainable buildings in New Zealand (e.g. Government initiatives and financial assistance).

\subsubsection{Drivers, Triggers, Obstacles and Reasons for Sustainable Building}

According to experience of the respondents, the client was considered to be the single most important person to drive sustainable building. Clearly, as the main financial source, they have the final say of any proposed design, although they may not have the necessary knowledge to propose sustainable design options or even be aware of them. A follow up question was posed, asking who rather 'should' be the main driver for sustainable building. The results showed that 'an integrated process where responsibility is shared' was considered to be the most important.

It was identified that the participants understood the importance of introducing sustainable design into the building process as early as possible, with a majority stating that sustainable building is most likely triggered in the 'pre-design' stage and 'design development' stage.

The main driver for sustainable building was 'rising energy costs'. This result emphasised the importance and increasing demand placed on energy supply and production. In contrast 
'perceived higher upfront costs' was the biggest obstacle to sustainable building. This indicated the requirement for better information and the need for organisations such as the NZGBC to be a 'vehicle' to provide the building industry with direct and reliable information. The most important reason for sustainable building was described as 'being part of an industry that values the environment', which emphasised the earlier level of interest shown from the respondents in being involved in sustainable building.

\subsubsection{Sustainable Building Information}

Even though, at the time of the survey the NZGBC and Green Star NZ were in their early stages of development there was a significant demand for Green Star NZ related material, such as 'Green Star NZ certified buildings', 'Green Star NZ accreditation' and 'Green Star NZ professionals'. The results showed the most desired piece of information sought by the respondents was 'environmental and economic cost benefit case studies'. The requirement for information regarding 'green products' was also important, emphasising the appropriateness of the web based green product system GreenBuild, which has been specifically designed for the New Zealand market to tackle this area of green product information.

In terms of satisfaction, the participants were clearly not content with the current level of information regarding sustainable building, with 31\% not satisfied and 30\% hardly satisfied. This tended to reinforce the requirement for more sustainable building information, and the need for better education procedures.

\subsubsection{International Comparison}

According to the results, sustainable building in New Zealand is more likely to be considered earlier in the design sequence, when compared to the United States and Australia. Even though the importance placed on the drivers to sustainable building was lower in New Zealand, it still suggested that with experience and application of Green Star NZ the perceptions of the New Zealand building industry may elevate in the future, that continued use will lead to greater demand.

In all three studies 'perceived higher upfront costs' were seen to be the main obstacle for sustainable building, with New Zealand having an almost identical figure to the United States. While 'different accounting methods' were the least important from a New Zealand perspective, they were significantly higher in the United States and Australia. This result suggests that while New Zealand understands the more basic elements of sustainable building, its comprehension of more complex theories may be limited due to the lack of experience with sustainable building in the industry. 
Both in the United States and Australia, respondents perceived 'being part of an industry that values the environment' as very important. Whilst this was very important in New Zealand, it was not at the levels of the other nations. Furthermore, all other options were significantly lower, which suggested the reasons for sustainable building have not been realised yet to the same extent in New Zealand. As building industry matures the reasons for sustainable building should become clearer with time.

Surprisingly the United States (61\%) and Australian (73\%) information requirements are still substantially high (New Zealand 49\%). Even though these countries have had a BSRT available for a number of years, the demand for information has not decreased. For example GreenBuild has been specifically designed to target green product information in New Zealand, both the United States and Australia have green product rating systems in place, yet this was still identified as the most important piece of required information. Therefore, GreenBuild cannot be expected to completely fill this gap, and like Green Star NZ will require additional support from the building industry.

\subsection{Implications for Future Research}

New Zealand is in the unique position where it is able to learn from existing GBCs and BSRTs, and because of our relatively small and well connected building industry there is a great potential for New Zealand to become a world leader in sustainability and sustainable building.

Currently the New Zealand built environment represents a national investment valued at over $\$ 300$ billion \{Building Research, Best Practice in Procurement\}, and in the year ended September 2006 the value of building work put in place was $\$ 12.7$ billion, which was an increase of $4.7 \%$ from the previous year \{New Zealand Statistics New Zealand, Value of Building Work Put in Place\}. 'Green' building comprises approximately $2 \%$ of new non-residential buildings in the United States, this equates to a figure of US $\$ 3.3$ billion. By 2010 this figure is estimated to grow to $5-10 \%$, and places a value between $\$ 10.2$ and $\$ 20.5$ billion on the US green building market $\{$ McGraw Hill Construction 4\}.

Appling these figures to the New Zealand non-residential market, this translates to a potential sustainable building market ranging from $\$ 102$ million ( $2 \%$ of $\$ 5.143$ billion) to $\$ 257$ million (5\% of 5.143 billion) and $\$ 514$ million (10\% of $\$ 5.413)$ \{ New Zealand Statistics New Zealand, Value of Building Work Put in Place: September 2006 Quarter\}. 
A report found that in contrast with current practice, New Zealand Ministry for the Environment, Value Case vii\}:

\begin{abstract}
"Sustainable buildings are intrinsically more economic to run over their whole lifetime. They reduce waste and are much more efficient in their use of key resources such as land, energy, water and materials. They can also be healthier and more comfortable, and support greater productivity, with improved levels of natural light, cleaner air and a higher degree of personal control. They are also adaptable and durable enough to meet the requirements for flexibility and needs of future generations of building occupiers".
\end{abstract}

In particular, this research provided a 'snapshot' of the current New Zealand market and the industry's awareness of sustainability, sustainable buildings and BSRTs, thus creating a base point from which the NZGBC can measure their continuing impact and success of Green Star NZ. A similar research project could be undertaken in three years for example, allowing comparisons to be made between the two data sets, exploring the differences, similarities and even predicting possible future trends. Likewise a three year period between the surveys would allow direct comparison with the Australian research, which surveyed its industry three years after its respective BSRT was implemented into the industry.

This would also allow some quality control, to ascertain how well the expectations of the building industry were being met, enabling the NZGBC to develop their training and education procedures to better meet these expectations. Furthermore, a future study could help to measure and determine that the results from this research actually assisted in facilitating a better more successful BSRT.

These results in this research could be of value to the wider building industry to identify possible information gaps, to lobby Government and other agency's to direct extra funding into these areas and also make recommendations for future research (e.g. tax incentives). 'Green products' for example were a key information requirement by the New Zealand building industry, and although GreenBuild has been designed in an attempt to fill this information gap, the building industry should not get complacent. As shown in the United States and Australia both have various 'green products' systems and tools available, yet clearly more of this information is still required.

Furthermore, it could assist the NZGBC and other research organisations to better educate the building industry, creating more demand for sustainable buildings and Green Star NZ 
certification. Additionally this could accelerate the market and contribute to more innovative and economical advances in building technology. 


\section{List of Works Cited}

Australia. Department of the Environmental and Heritage. Australian Green House Office. Australia's Fourth national Communication on Climate Change: A report under the United Nations Framework Convention on Climate Change. Nov. 2005. 28 November $2007<$ http://unfccc.int/resource/docs/natc/ausnc4.pdf> .

Bartlett, Albert A. "Just the Facts - Debunking Myths: Reflections of Sustainability, Population Growth, and the Environment - Revisited." Renewable Resources Journal. 15.4 (19978): 6-23. 15 May 2007 <http://www.capsweb.org/facts/bartlettreflections.pdf>.

"Best Practice in Procurement". Building Research. 13 February 2007 $<$ http://www.buildingresearch.org.nz/best-practice-in-procurement/>.

Bordass, W. and A. Leaman. "Future Buildings and Their Services: Strategic Considerations for Designers and Clients." Building Research and Information. 25.4 (1997): 190-05. Journal Finder. Victoria U of Wellington, New Zealand, The Lib. 30 June 2006. $<$ http://www.vuw.ac.nz/library/>.

Building Construction Interchange. Green Building Market Report 2006. Green Building Council Australia. Australia. 2006.

Burkell, Jacquelyn. "The dilemma of survey nonresponse." Library and Information Science and Research. 25 (2003): 239-63. SCOPUS. Databases. Victoria U of Wellington, New Zealand, The Lib. 29 October $2006<$ http://www.vuw.ac.nz/library/>.

Christie, Lauren H. "Sustainable Design Decisions: Processes, influences, values of the homebuilder.” Diss. Victoria U of Wellington, 2005.

Cole, Raymond J. "Building Environmental Assessment Methods: Clarifying Intentions." Building Research and Information. 27.4-5 (1999): 230-46. Journal Finder. Victoria U of Wellington, New Zealand, The Lib. 29 April $2006<$ http://www.vuw.ac.nz/library/>.

---. "Building Environmental Assessment Methods: Redefining Intentions and Roles.” Building Research and Information. 35.5 (2005): 455-67. Journal Finder. Victoria U of Wellington, New Zealand, The Lib. 30 April $2006<$ http://www.vuw.ac.nz/library/>. 
---, ed. "Cost and Value in Building Green." Building Research and Information. 28.5-6 (2000): 304-9. Journal Finder. Victoria U of Wellington, New Zealand, The Lib. 29 April 2006 $<$ http://www.vuw.ac.nz/library/>.

---. "Emerging Trends in Building Environmental Assessment Methods." Building Research and Information. 26.1 (1998): 3-16. Journal Finder. Victoria U of Wellington, New Zealand, The Lib. 30 April 2006 <http://www.vuw.ac.nz/library/>.

---. Lecture. New Zealand Green Building Council. Quest on Willis, Wellington, New Zealand. 2 Mar. 2006.

---. "Shared markets: Coexisting Building Environmental Assessment Methods." Building Research and Information. 34.4 (2006): 357-71. Journal Finder. Victoria U of Wellington, New Zealand, The Lib. 26 July $2006<$ http://www.vuw.ac.nz/library/>.

---. "Re: Masters Research: Preconditions to the Implementation of a SRT". Email to the author. Raymond Cole, 26 Apr. 2006.

Cole, Raymond. J. and Nils Larsson. "Preliminary assessment of the GBC assessment process." Green Building Challenge 98: Conference Retrospective. CD-ROM. Ottawa: Minister of Natural Resources, 1999.

Crosfield, Julia. Interview with the Prime Minister, Helen Clark. "A Sustainable New Zealand." ENVIRONZ: Magazine of the Ministry for the Environment. Feb. (2007): 8-10. 11 May 2007 <http://www.mfe.govt.nz/publications/about/environz/environz-apr-2007.pdf>.

"Land use, land-use change and forestry." United Nations. Framework Convention on Climate Change. $\quad 31 \quad$ December $2007 \quad<$ http://unfccc.int/methods_and _science/lulucf/items/4122.php>.

Gann, David M., Ammon J, Salter and Jennifer K. Whyte. "The Design Quality Indicator as a Tool for Thinking." Building Research and Information. 31.5 (2003): 318-33. Journal Finder. Victoria U of Wellington, New Zealand, The Lib. 30 June 2006. $<$ http://www.vuw.ac.nz/library/>.

Gillham, Bill. Developing a Questionnaire. London: Continiuum, 2000. 
Green Building Council Australia. 23 Jun. 2006. 26 June 2006. <http://www.gbcaus.org>.

Green Building Council of Australia. Green Star: Design v2 Technical Manual.

Hargreaves, Rachel. Compendium and Evaluation of Building Environmental Impact Schemes being used in Australasia. Building Research Association of New Zealand. May. 2005.

Henley, Jane and Rachel Hargreaves. "Building Assessment Scheme Project. Workshop Two." New Zealand Green Building Council and Building Research. Westpac Stadium, Wellington, New Zealand. 21 Jun. 2006.

Henley Jane. "Re: Rating Tools". Email to the author 20 Jul. 2007.

Larsson, Nils. K. "Development of a Building Performance Rating and Labelling System in Canada." Building Research and Information. 27.4-5 (1999): 332-41. Journal Finder. Victoria $U$ of Wellington, New Zealand, The Lib. 3 May 2006 $<$ http://www.vuw.ac.nz/library/>

Kaatz, Ewelina, et al. "Advancing Key Outcomes of Sustainability Building Assessment." Building Research and Information. 34.4 (2006): 308-20. Journal Finder. Victoria U of Wellington, New Zealand, The Lib. 26 July 2006 <http://www.vuw.ac.nz/library/>.

Kohler, Niklaus "The Relevance of Green Building Challenge: An Observers Perspective." Building Research and Information. 27.4-5 (1999): 309-20. Journal Finder. Victoria U of Wellington, New Zealand, The Lib. 10 May 2006 <http://www.vuw.ac.nz/library/>.

McGraw Hill Construction. Green Building SmartMarket Report. New York. 2005.

Mebratu, Desta. "Sustainability and Sustainable Development: Historical and Conceptual review.” Environmental Impact Assessment Review. 18.6 (1998): 493 - 520. ScienceDirect. Databases. Victoria U of Wellington, New Zealand, The Lib. 3 July 2006 $<$ http://www.vuw.ac.nz/library/>.

Munier, Nolberto. Introduction to Sustainability: Road to a Better Future. Dordecht, The Nethrlands: Springer, 2005. 
Myers, Georgia and Kim Bannon. Future-Proofing New Zealand's Commercial property for a Sustainable Tomorrow. Jones Lang LaSalle. New Zealand. Jul. 2006. 14 March 2007 <http://www.joneslanglasalle.co.nz/en-gb/>. Path: Research, New Zealand Research.

New Zealand Green Building Council. 2006. 26 June 2006. < http://www.nzgbc.org.nz>.

New Zealand Green Building Council. "Green Star NZ: Accredited Professional Level 1 Training." Michael Fowler Wellington Convention Centre. Wellington. New Zealand. 31 May. 2007.

New Zealand Green Building Council. "Green Star NZ: Accredited Professional Level 2 Training." Michael Fowler Wellington Convention Centre. Wellington. New Zealand. 31 May. 2007.

New Zealand Green Building Council.. Green Star NZ Office Design v1: Technical Manual. May/June 2007.

New Zealand. Ministry for the Environment. Environmental Reporting - Technical Paper: Ecological Footprints of New Zealand and its Regions. Gary McDonald and Dr. Murray $\begin{array}{llllll}\text { Patterson. Wellington. } & \text { Sep. 2003. } & \text { February } & \end{array}$ $<$ http://www.mfe.govt.nz/publications/ser/eco-footprint-sep03/eco-footprintsep03.pdf $>$.

New Zealand. Ministry for the Environment. Green Building Assessment Tool Research Project: Draft Report. New Zealand Green Building Council. 26. Jun. 2006.

New Zealand. Ministry for the Environment. Green Building Assessment Tool Research Project: Final Report. New Zealand Green Building Council. 28 Jun. 2006.

New Zealand. Ministry for the Environment. New Zealand's Fourth National Communication Under the United Nations Framework Convention on Climate Change. Mar. 2006. 28 November $2007<$ http://unfccc.int/resource/docs/natc/nzlc4.pdf>.

New Zealand. Ministry for the Environment. Value Case for Sustainable Building in New Zealand. D. Fullbrook, Q. Jackson and G. Finlay. Feb. 2006. 31 March 2006 $<$ http://www.mfe.govt.nz/publications/sus-dev/value-case-sustainable-buildingfeb06/value-case-sustainable-building-feb06.pdf $>$. 
New Zealand. Ministry for the Environment. Valuing New Zealand's Clean Green Image. Aug. 2001. 8 September 2007 <http://www.mfe.govt.nz/publications/sus-dev/clean-greenimage-value-aug01/index.html>.

New Zealand. Ministry of Economic Development. Draft New Zealand Energy Efficiency and Conservation Strategy. Dec. 2006. 9 February 2007. <http://www.eeca.govt.nz/eecalibrary/eeca-reports/neecs/report/draft-nzeecs-06.pdf $>$.

New Zealand. Ministry of Economic Development. Draft - Powering Our Future: Draft New Zealand Energy Strategy to 2050. Dec. 2006. 8 February 2007 $<$ http://www.med.govt.nz/upload/43136/draft-energy-strategy.pdf $>$.

New Zealand. Parliamentary Commissioner for the Environment. Creating Our Future: Sustainable Development for New Zealand. Wellington. Jun. 2002. 9 June 2006 $<$ http://www.pce.govt.nz/reports/allreports/1_877274_03_8.pdf >.

New Zealand. Statistics New Zealand. “Table Builder”. Beyond 20/20 Web Data Server. Version 7.4. 2006. 8 Dec 2006. <www.stats.govt.nz>. Path: Products and Services; Table Builder; Business Statistics; Detailed industry by area.

New Zealand. Statistics New Zealand. Value of Building Work Put in place: September 2006 $\begin{array}{llllll}\text { quarter.. } & 8 & \text { Dec. } & 2006 . & 13 & \text { February }\end{array}$ <http://www.stats.govt.nz/NR/rdonlyres/A42F6686-677E-4C35-857728586278E4B7/17269/vbwSep2006alltables.xls>.

New Zealand. Statistics New Zealand. "Value of Building Work Put in Place". 8 Dec. 2006. 13 February 2007. <http://www.stats.govt.nz/products-and-services/hot-off-thepress/value-of-building/value-building-work-sep06qtr-hotp.htm>.

Pacific Rim Institute of Sustainable Development and Stephen Knight. Sustainable Development in New Zealand: Here Today, Where Tomorrow? 5 July 2007 <www.pce.govt.nz/reports/allreports/0_473_07338_2.pdf>. 
Pezzoli, Keith. "Sustainable Development: A Transdisciplinary Overview of the Literature." Journal of Environmental Planning and Management. 40.5 (1997): 549-574. SCOPUS. Databases. Victoria U of Wellington, New Zealand, The Lib. 3 July 2006 $<$ http://www.vuw.ac.nz/library/>.

Pitts, Adrian. Planning and Design Strategies for Sustainability and Profit: Pragmatic Sustainable Design on Building and Urban Scales. Oxford: Architectural Press, 2004.

Pope, Jenny, David Annandale and Angus Morrison-Saunders. "Conceptualising Sustainability Assessment." Environmental Impact Assessment Review. 24.6 (2004): 595-616.

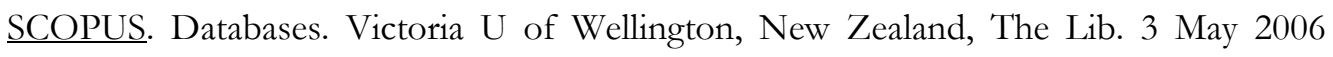
$<$ http://www.vuw.ac.nz/library/>.

“Rating CIBSE's night of the stars". Climate Control News. Oct. (2004): 12.

Robinson, John. "Squaring the Circle? Some Thoughts on the Idea of Sustainable Development." Ecological Economics. 48.4 (2004): 369-84. ScienceDirect. Databases. Victoria U of Wellington, New Zealand, The Lib. 10 May 2006 <http://www.vuw.ac.nz/library/>.

"Sample Size Formuals". The Survey System. 2003. Creative Research Systems. 9 August 2007 $<$ http://www.survey system.com/ssformu.htm>.

Särndal, C. and Lundström, S. 2005. "Estimation in Surveys with Nonresponse." John Wiley and Sons. West Sussex, England.

Smith, Jonathan. "A Sustainability Rating Tool for New Zealand Commercial Buildings.” Diss. Victoria U of Wellington, 2005.

Smith, Jonathan and Michael Donn "A Methodology for Developing a Sustainability Rating Tool for New Zealand Commercial Buildings." Fabricating Sustainability: 39th Annual Conference of the Architectural Science Association. Wellington, New Zealand, 2005.

"Survey Sample". STATS392. School of Mathematics, Victoria University of Wellington. 2007.

"Sustainable Building Assessment Scheme Project." New Zealand Green Building Council. Newsletter. March 06. 
United Kingdom Parliament. Select Committee on Public Accounts: Sixty-Third Report: Use of $\begin{array}{llll}\text { Competition. } & \text { London. } & 2002 & 20\end{array}$ $<$ http://www.publications.parliament.uk/pa/cm200102/cmselect/cmpubacc/861/8610 4.htm>.

United Nations. Framework Convention on Climate Change. Annex 1 Parties GHG Total with LULUCF. 26 June 2006 $<$ http://www.unfcc.int/files/ghg_emissions_data/application/x-zipcompressed/ai_total_wlulucf.zip>.

United Nations. Framework Convention on Climate Change. Annex 1 Parties GHG Total without LULUCF. 26 June 2006 $<$ http://www.unfcc.int/files/ghg_emissions_data/application/x-zipcompressed/ai_total_wolulucf.zip>.

United Nations. Framework Convention on Climate Change. Party Emissions Summary for Australia. 26 June 2006 $<$ http://www.unfcc.int/files/ghg_emissions_data/application/x-zipcompressed/aus_ghg_profile.zip>.

United Nations. Framework Convention on Climate Change. Party Emissions Summary for New Zealand. 26 June $2006<$ http://www.unfcc.int/files/ghg_emissions_data/application/xzip-compressed/nzl_ghg_profile.zip>.

United Nations. Framework Convention on Climate Change. Party Emissions Summary for United States of America. 26 June 2006 $<$ http://www.unfcc.int/files/ghg_emissions_data/application/x-zipcompressed/usa_ghg_profile.zip>.

United States. Dept. of Energy. Pacific Northwest National Laboratory. Sustainable Building Rating Systems Summary. K.M. Fowler and E.M. Rauch. Jul. 2006. 24 November 2006 <https://www.usgbc.org/ShowFile.aspx?DocumentID=1915>.

World Commission on Environment and Development. Our Common Future. Oxford: Oxford $\begin{array}{lllll}\text { UP, } & 1987 . & 10 & \text { May }\end{array}$ $<$ http://www.are.admin.ch/imperia/md/content/are/nachhaltigeentwicklung/brundtla nd_bericht.pdf?PHPSESSID $=$ accbdc3076b4622f23ad37fef5885667>. 
World Green Building Council. 2006. 26 June 2006. <http://www.worldgbc.org>.

World Wide Fund for Nature. Living Planet Report 2002. United Nations Environment Programme World Conservation Monitoring Centre and Redefining Progress. Jun.2002. 29 June 2007 <http://assets.panda.org/downloads/lpr2002.pdf>.

World Wide Fund for Nature. Living Planet Report 2006. Zoological Society of London and Global Footprint Network. Oct. 2006. 27 June 2007 $<$ http://assets.panda.org/downloads/lpr2002.pdf >.

Zimmerman, Alex, et al. "Proposed Framework for Environmental Assessment of Existing Buildings." Sustainable Building Conference 2002: Proceedings. CD-ROM. Oslo, Norway, 2002. 


\section{Additional References}

Bakens, Wim, Greg Foliente and Mansi Jasuja. "Engaging Stakeholders in Performance-based Building: Lessons From the Performance-Based Building (PeBBu) Network.” Building Research and Information. 33.2 (2005): 149-58. Journal Finder. Victoria U of Wellington, New Zealand, The Lib. 30 April $2006<$ http://www.vuw.ac.nz/library/>.

Bartlett, Ed and Nigel Howard. "Informing the Decision Makers on the Csot and vaue of Green Building." Building Research and Information. 28.5 (2000): 315-24. Journal Finder. Victoria U of Wellington, New Zealand, The Lib. 18 May 2007 $<$ http://www.vuw.ac.nz/library/>.

Beacon Pathway Limited. PR 101 Regulatory Framework Development: Understanding Current Sustainability Regulations and Policy. Mike O'Connell. Building Research Association of New Zealand. Auckland. Jan. 2005. 8 February 2007 $<$ http://www.beaconpathway.co.nz/Portals/5/PR101-

RegulatoryFrameworkDevelopment.pdf $>$.

Beacon Pathway Limited. PR 107 Regulatory Framework Development: Understanding Current Sustainability Regulations and Policy. Auckland. Sep. 2006. 8 February 2007 $<$ http://www.beaconpathway.co.nz/Portals/5/PR107-

UnderstandingCurrentSustainabilityRegulationsandPolicy.pdf $>$.

Beacon Pathway Limited. PR 200 Local Council Sustainable Barriers and Incentives - Auckland $\begin{array}{lllllll}\text { City Case Study. Auckland. Jul. 2006. } 8 \text { February } 2007 & \end{array}$ <http://www.beaconpathway.co.nz/Portals/5/PR200SustainableBuildingBarriers.pdf > .

Beaudoin, Marc and Lyse Tremblay. "Specifying Green Buildings: The Owner-occupant's Perspective." Sustainable Building Conference 2002: Proceedings. CD-ROM. Oslo, Norway, 2002.

BRE Environmental Assessment Method. 2006. Building Research Establishment. 26 June 2006 $<$ http://www.breeam.org $>$. 
Burnett, John. "Assessing the Performance of Buildings: Only the Final Product Counts." Action for Sustainability: The 2005 World Sustainable Building Conference. CD-ROM. Tokyo: The National Conference Board SB05Tokyo, 2005. 1621-28.

CASBEE - Comprehensive Assessment System for Building Environmental Efficiency. 2005. Japanese Sustainable Building Consortium. 28 June 2006. $<$ http://www.ibec.or.jp/CASBEE/english/index.htm>.

Chandra, Shailja, Deo Prasad and Steve King. "Investigation of Risks of Uncertainty in Building Environmental Assessment Tools." Action for Sustainability: The 2005 World Sustainable Building Conference. CD-ROM. Tokyo: The National Conference Board SB05Tokyo, 2005. 2071-2078.

Cohen, Steven B. "Integrated survey designs: A framework for nonresponse bias reduction." Journal of Economic Development and Social Measurement. 30 (2005) 101-14. Journal Finder. Victoria U of Wellington, New Zealand, The Lib. 03 November 2006. $<$ http://www.vuw.ac.nz/library/>.

Cole, Raymond J. "Changing Context for Environmental Knowledge." Building Research and Information. 32.2 (2004): 91-109. Journal Finder. Victoria U of Wellington, New Zealand, The Lib. 30 April 2006 <http://www.vuw.ac.nz/library/>.

---, ed. "Building Environmental Assessment Methods: Changing the Culture of Practice." Building Research and Information. 34.4 (2006): 303-07. Journal Finder. Victoria U of Wellington, New Zealand, The Lib. 26 July 2006. <http://www.vuw.ac.nz/library/>.

---. "Lessons Learned, Future Directions and Issues for GBC." Building Research and Information. 29.5 (2001): 355-73. Journal Finder. Victoria U of Wellington, New Zealand, The Lib. 29 April 2006 <http://www.vuw.ac.nz/library/>.

Commonwealth of Australia. Australian Green House Office. Australian Commercial Building Sector Greenhouse Gas Emissios 1900-2010. Comp. EMET Consutlants Pty Ltd and Solarch Group. Canberra. Dec. 1999. 13 July 2006 <http://www.greenhouse.gov.au/buildings/publications/pubs/commbuild.pdf>. 
Comprehensive Assessment System for Building Environmental Efficiency Assessment Software: CASBEE for New Construction. Vers. 1.02. 28 March 2006 $<$ http://www.ibec.or.jp/CASBEE/english/download/CASBEE-NCe2004v1.02.XLS>.

Cooper, Ian. "Which Focus for Building Assessment Methods - Environmental Performance or Sustainability?" Building Research and Information. 27.4-5 (1999): 321-31. SCOPUS. Databases. Victoria U of Wellington, New Zealand, The Lib. 3 May 2006 $<$ http://www.vuw.ac.nz/library/>.

Dillman, Don A. Mail and Internet Surveys: The Tailored Design Method. Toronto: John Wiley and Sons, 2000.

Dresner, Simon. The Principles of Sustainability. United Kingdom: Earthscan Publications, 2002.

Endo, Junko, et al. "Extended Framework of CASBEE: Designing and Assessment System of Buildings for All Lifecycle Stages Based on the Concept of Eco-efficiency.” Action for Sustainability: The 2005 World Sustainable Building Conference. CD-ROM. Tokyo: The National Conference Board SB05Tokyo, 2005. 1856-1863.

Green Building Council of Australia. Green Star: As Built v2 Technical Manual.

Hassall, James and Lucie Drummond. "Green Wash or green to the core? Pushing the business world to take sustainability seriously." Proceedings of the $2^{\text {nd }}$ International Conference on Sustainability Engineering and Science, February 21-23, 2007. The New Zealand Society for Sustainability Engineering and Science. Auckland: Faculty of Engineering, U $\begin{array}{llll}\text { of } & \text { Auckland. } & 13 & \text { March }\end{array}$ <http://nzsses.auckland.ac.nz/conference/2007/papers/HASSALL-GreenWash.pdf>.

Howard, Nigel. "Building Environmental Assessment Methods: In Practice." Action for Sustainability: The 2005 World Sustainable Building Conference. CD-ROM. Tokyo: The National Conference Board SB05Tokyo, 2005. 2008-15.

Larsson, Nils. K. "Development of a Building Performance Rating and Labelling System in Canada." Building Research and Information. 27.4-5 (1999): 332-41. Journal Finder. Victoria $U$ of Wellington, New Zealand, The Lib. 3 May 2006 $<$ http://www.vuw.ac.nz/library/>. 
Lechner, Norbert. Heating, Cooling, Lighting: Design Methods for Architects. New York: Wiley Interscience, 2004.

Lockwood, Charles. "Building the Green Way." Harvard Business Review. 86.6 (2006): 129-36. SCOPUS. Databases. Victoria U of Wellington, New Zealand, The Lib. 19 March 2007 $<$ http://www.vuw.ac.nz/library/>.

Lorenz, David and Thomas Luetzkendorf. "Towards Sustainable Development in Property ad Construction: A Survey of Drivers, Trends, Strategies and Instruments." Action for Sustainability: The 2005 World Sustainable Building Conference. CD-ROM. Tokyo: The National Conference Board SB05Tokyo, 2005. 4445-52.

Japanese Sustainable Building Consortium, ed. Comprehensive Assessment System for Building Environmental Efficiency (CASBEE). Institute for Building Environment and Energy Conservation, 2005.

Kats, Greg, et al. The Costs and Financial Benefits of Green Buildings. Sustainable Building Taskforce. California. Oct. 2003. 9 January $2007<$ http://www.cape.com/ewebeditpro/items/O59F3259.pdf>.

Kawazu, Yukihiro, et al. "Comparison of the Assessment Results of BREEAM, LEED, GBTool and CASBEE." Action for Sustainability: The 2005 World Sustainable Building Conference. CD-ROM. Tokyo: The National Conference Board SB05Tokyo, 2005. 1700-05.

Kimmins, James Peter. The Ethics of Energy: A Framework for Action. United Nations Education, Scientific and Cultural Organisation. World Commission on the Ethics of Scientific Knowledge and Technology. 2001. 6 July 2007. <http://unesdoc.unesco.org/images/0012/001235/123511eo.pdf>.

Korinek, Anton, Johan A. Mistian and Martin Ravallion. "An Econometric Method of Correcting Unit Nonresponse Bias in Surveys.” Journal of Econometrics. 136 (2007): 213-35. ScienceDirect. Databases. Victoria U of Wellington, New Zealand, The Lib. 3 May 2006 <http://www.vuw.ac.nz/library/>. 
Madew, Romilly. The Dollars and Sense of Green Buildings 2006: Building the Business Case for Green Commercial Buildings in Australia. Green Building Council Australia. 2006. 27 July

$<$ http: / / www.gbcaus.org/download.asp?file $=\% 5$ CDocuments $\% 5$ CDollars + and + Sense + of + Green + Buildings $\% 2$ Epdf $>$.

McKibben, Bill. “Worried? Us?” GRANTA: The Magazine of New Writing. 83 (2003): 7-12.

National Australian Built Environmental Rating System. 2006. Department of Energy Utilities and Sustainability New South Wales Government. 6 June 2006 . < http://www.nabers.com.au/>

Nelms, Cheryl, Alan D. Russell, and Barbara J. Lence. "Assessing the Performance of Sustainable Technologies for Building Projects." Canadian Journal of Civil Engineering. 32.1 (2005): 114-28. SCOPUS. Databases. Victoria U of Wellington, New Zealand, The Lib. 3 May $2006<$ http://www.vuw.ac.nz/library/>.

New Zealand. Energy Efficiency and Conservation Authority and the Ministry for the Environment. National Energy Efficiency and Conservation Strategy: Towards a Sustainable Energy Future. Sep. 2001. 14 July 2006 <http://www.eeca.govt.nz/eecalibrary/eeca-reports/neecs/report/national-energy-efficiency-and-conservation-strategy01.pdf $>$.

New Zealand. Energy Efficiency and Conservation Authority. The Challenge of New Zealand's Energy Efficiency Strategy: EECA and the Year Three Report on the National Energy Efficiency and Conservation Strategy. 2004. 17 October 2005 $<$ http://www.eeca.govt.nz/eeca-library/eeca-reports/neecs/report/neecs-three-yearon-report-05.pdf $>$

New Zealand. Ministry for the Environment. Govt ${ }^{3}$. Walking the talk to sustainability. Wellington. Oct. 2006. 8 February 2006 <http://www.mfe.govt.nz/publications/susdev/walk-talk-sustainability-oct06/walk-talk-sustainability-oct06.pdf $>$.

New Zealand. Ministry for the Environment. Headline indicators for tracking progress to sustainability in New Zealand. Dr. Murray Patterson. Wellington. Mar. 2002. 8 February $2007<$ http://www.mfe.govt.nz/publications/ser/tech-report-71-sustainabilitymar02.pdf $>$. 
New Zealand. Ministry for the Environment. Our clean green image: What's it Worth? Wellington. Aug. 2002. 8 February 2007 <http://www.mfe.govt.nz/publications/sus$\mathrm{dev} /$ clean-green-image-value-aug01/summary-leaflet-aug01.pdf $>$.

New Zealand. Ministry for the Environment. Simply Sustainable: A straightforward guide to sustainable business practices. Wellington. Jun. 2005. 8 February 2007 <http://www.mfe.govt.nz/publications/sus-dev/simply-jun05/simply-jun05.pdf>.

New Zealand. Ministry of Economic Development. Dept. of Prime Minister and Cabinet. Sustainable Development for New Zealand: Programme of Action. Jan. 2003. 12 February $\quad 2007 \quad<$ http://www.beehive.govt.nz/hobbs/30199-med-susineddevelopm.pdf $>$.

New Zealand. Ministry of Economic Development. Revised New Zealand Energy Greenhouse Gas Emissions 1990-2005. Dec.2006. 29 June 2007 <http://www.med.govt.nz/upload/38637/GHG\%20report.pdf>.

New Zealand. Treasury, The, Crown Financial Statements. New Zealand's Liability under the $\begin{array}{lllllll}\text { Kyoto } & \text { Protocol. } & 8 & \text { Jul. } & 2005 . & 20 & \text { October }\end{array}$ $<$ http://www.treasury.govt.nz/release/kyoto

"Rating Tool Workshop Two." New Zealand Green Building Council and Building Research. Westpac Stadium, Wellington, New Zealand. 21 Jun. 2006.

Sinou, Maria and Stella Kyvelou. "Present and future of building performance assessment tools." Management of Environmental Quality: An International Journal. 17.5 (2006): 570-86. Journal Finder. Victoria U of Wellington, New Zealand, The Lib. 03 November 2006. $<$ http://www.vuw.ac.nz/library/>.

Theaker, Ian. G. and Raymond J. Cole. "The Role of Local Governments in Fostering Green Buildings: A Case Study.” Building Research and Information. 29.5 (2001): 394-408. Journal Finder. Victoria U of Wellington, New Zealand, The Lib. 30 April 2006. $<$ http://www.vuw.ac.nz/library/>.

United Nations. Framework Convention on Climate Change. Report of the centralized in-depth review of the fourth national communication of New Zealand. 18 Jan. 2007. 26 June 2007 <http://www.unfccc.int/resorce/docs/2007/idr/nz104.pdf>. 
United Nations. Intergovernmental Panel on Climate Change. Climate Change 2007: The Physical Science Basis. Feb. 2007. 6 June 2007 <www.ipcc.ch/SPM2feb07.pdf>.

United Nations. Intergovernmental Panel on Climate Change. IPCC Second Assessment Climate Change 1995. 5 July $2007<$ www.ipcc.ch/pub/sa(E).pdf>.

United States. Dept. of Commerce. National Oceanic and Atmospheric Administration. National Weather Service. Service Assessment: Hurricane Katrina August 23-31, 2005. Jun. 2006. 29 June 2006 <http://www.weather.gov/om/assessments/pdfs/Katrina.pdf>.

United States Green Building Council. 2006. 26 June 2006. <http://www.usgbc.org>.

United States. National Hurricane Center. Tropical Cyclone Report: Hurricane Katrina. Richard D. Knabb, Jamie R. Rhome and Daniel P. Brown. 10 Aug. 2006. 29 June 2007 <http://www.nhc.noaa.gov/pdf/TCR-AL122005_Katrina.pdf >.

United States. The Office of the Federal Environmental Executive. The Federal Commitment to Green Building: Experiences and Expectations. 2003. 29 February 2007 $<$ http://www.ofee.gov/sb/fgb_report.pdf>.

Vidal, John and David Adam. "China overtakes US as world's biggest CO2 emitter.” Guardian $\begin{array}{llllll}\text { Unlimited. } & 19 & \text { Jun. } & 2007 . & 5 & \text { July }\end{array}$ $<$ http://environment.guardian.co.uk/climatechange/story/0,2106689,00.html>.

Vijayan, Abhilash and Ashok Kumar. "A Review of Tools to Assess the Sustainability in Building Construction." Environmental Progress. 24.2 (2005): 125- 32. SCOPUS. Databases. Victoria U of Wellington, New Zealand, The Lib. 19 March 2007 $<$ http://www.vuw.ac.nz/library/>.

Voogt, Robert J.J. "An alternative approach to correcting response and nonresponse bias in election research." Proceedings of the Statistical Methods for Attrition and Nonresponse in Social Surveys Conference, 28 May 2004. Economic and Social Research Council. London: Royal Statistical Society. 03 November 2006 <http://www.ccsr.ac.uk/methods/events/attrition/documents/Voogt_000.pdf>. 
Wackernagel, Mathis and David Yount. "Footprints For Sustainability: The Next Steps." Environment, Development and Sustainability. 2.1 (2000): 21-42. SCOPUS. Databases. Victoria U of Wellington, New Zealand, The Lib. 19 March 2007 $<$ http://www.vuw.ac.nz/library/>.

Watt, Emily. "Towns may have to move - PM". The Dominion Post [Wellington] 12 Jul. 2007: $\mathrm{A} 1+$.

Wilson, J.L. and E. Tagazza. Green Buildings in Australia: Drivers and Barriers. Building $\begin{array}{lllll}\text { Commission } & \text { Victoria. } & 2004 & 29 & \text { April }\end{array}$ <http://businessoutlook.com.au/site/archives/Green\%20building\%20$\% 20 \% 20$ barriers $\% 20$ and $\% 20$ drivers.pdf $>$. 


\section{Appendix A: Background}

\section{A.1 The Zealand Context}

\section{A.1.1 Annex 1 Parties}

The following list is of the Annex 1 Parties to the Convention ${ }^{8}$ \{United Nations Framework Convention on Climate Change\}:

- Australia

- $\quad$ Austria

- Belarus **

- Belgium

- Bulgaria

- Canada

- Croatia **

- Czech Republic **

- Denmark

- Estonia

- European Community

- Finland

- France

- Germany

- Greece

- Hungary

- Iceland

- Ireland

- $\quad$ Italy **

- Japan

- Latvia

- Liechtenstein **

- Lithuania

- Luxembourg

- $\quad$ Monaco **

- Netherlands

- New Zealand

$8 *$ Observer State; ** Party for which there is a specific COP and/or CMP decision 
Appendix A

- Norway

- Poland

- Portugal

- Romania

- $\quad$ Russian Federation **

- $\quad$ Slovakia **

- $\quad$ Slovenia **

- Spain

- Sweden

- Switzerland

- Turkey **

- $\quad$ Ukraine **

- United Kingdom of Great Britain and Northern Ireland

- United States of America 


\section{A.1.2 Emission Summaries}

\section{A.1.2.1 New Zealand Emissions}

Table A-1: Emissions summary for New Zealand \{United Nations Framework Convention on Climate Change, Party Emissions for New Zealand\}

\begin{tabular}{|c|c|c|c|}
\hline & \multicolumn{3}{|c|}{ Emissions, in $\mathrm{Gg} \mathrm{CO} 2$ equivalent } \\
\hline & Base year & 2000 & 2004 \\
\hline CO2 emissions without LULUCF & $25,373.4$ & $31,036.8$ & $34,038.9$ \\
\hline CO2 net emissions/removals by LULUCF & $-19,080.9$ & $-20,322.3$ & $-24,565.4$ \\
\hline CO2 net emissions/removals with LULUCF & $6,292.4$ & $10,714.5$ & $9,473.5$ \\
\hline GHG emissions without LULUCF & $61,893.0$ & $70,314.7$ & $75,088.4$ \\
\hline GHG net emissions/removals by LULUCF & $-18,977.9$ & $-20,215.7$ & $-24,482.6$ \\
\hline \multirow[t]{3}{*}{ GHG net emissions/removals with LULUCF } & $42,915.1$ & $50,099.0$ & $50,605.8$ \\
\hline & \multicolumn{3}{|c|}{ Changes in emissions, in per cent } \\
\hline & $\begin{array}{c}\text { From base } \\
\text { year to } 2000\end{array}$ & $\begin{array}{c}\text { From base } \\
\text { year to } 2004\end{array}$ & $\begin{array}{l}\text { From } 2000 \text { to } \\
2004\end{array}$ \\
\hline CO2 emissions without LULUCF & 22.3 & 34.2 & 9.7 \\
\hline CO2 net emissions/removals by LULUCF & 6.5 & 28.7 & 20.9 \\
\hline CO2 net emissions/removals with LULUCF & 70.3 & 50.6 & -11.6 \\
\hline GHG emissions without LULUCF & 13.6 & 21.3 & 6.8 \\
\hline GHG net emissions/removals by LULUCF & 6.5 & 29.0 & 21.1 \\
\hline \multirow[t]{3}{*}{ GHG net emissions/removals with LULUCF } & 16.7 & 17.9 & 1.0 \\
\hline & \multicolumn{3}{|c|}{$\begin{array}{c}\text { Average annual growth rates, in per cent } \\
\text { per year }\end{array}$} \\
\hline & $\begin{array}{c}\text { From base } \\
\text { year to } 2000\end{array}$ & $\begin{array}{l}\text { From base } \\
\text { year to } 2004\end{array}$ & $\begin{array}{l}\text { From } 2000 \text { to } \\
2004\end{array}$ \\
\hline CO2 emissions without LULUCF & 2.1 & 2.2 & 2.4 \\
\hline CO2 net emissions/removals by LULUCF & 0.9 & 2.0 & 4.9 \\
\hline CO2 net emissions/removals with LULUCF & 7.0 & 4.4 & -2.2 \\
\hline GHG emissions without LULUCF & 1.3 & 1.4 & 1.7 \\
\hline GHG net emissions/removals by LULUCF & 0.9 & 2.1 & 4.9 \\
\hline GHG net emissions/removals with LULUCF & 1.6 & 1.2 & 0.3 \\
\hline
\end{tabular}

The base year under the Climate Change Convention is 1990 except for Bulgaria (1988), Hungary (average of 1985 to 1987), Poland (1988), Romania (1989) and Slovenia (1986), as defined by decisions 9/CP.2 and 11/CP.4. 


\section{A.1.2.2 Australia Emissions}

Table A-2: Emissions summary for Australia \{United Nations Framework Convention on Climate Change, Party Emissions for Australia\}

\begin{tabular}{|c|c|c|c|}
\hline & \multicolumn{3}{|c|}{ Emissions, in Gg CO2 equivalent } \\
\hline & Base year & 2000 & 2004 \\
\hline CO2 emissions without LULUCF & $279,763.7$ & $352,582.9$ & $383,884.5$ \\
\hline $\mathrm{CO} 2$ net emissions/removals by LULUCF & $75,370.9$ & $9,055.2$ & $-6,993.5$ \\
\hline CO2 net emissions/removals with LULUCF & $355,134.6$ & $361,638.1$ & $376,891.0$ \\
\hline GHG emissions without LULUCF & $418,274.5$ & $497,774.3$ & $525,914.4$ \\
\hline GHG net emissions/removals by LULUCF & $81,628.8$ & $12,588.9$ & -239.8 \\
\hline \multirow[t]{3}{*}{ GHG net emissions/removals with LULUCF } & $499,903.3$ & $510,363.2$ & $525,674.6$ \\
\hline & \multicolumn{3}{|c|}{ Changes in emissions, in per cent } \\
\hline & $\begin{array}{c}\text { From base } \\
\text { year to } 2000\end{array}$ & $\begin{array}{c}\text { From base } \\
\text { year to } 2004\end{array}$ & $\begin{array}{c}\text { From } 2000 \text { to } \\
2004\end{array}$ \\
\hline CO2 emissions without LULUCF & 26.0 & 37.2 & 8.9 \\
\hline CO2 net emissions/removals by LULUCF & -88.0 & -109.3 & -177.2 \\
\hline CO2 net emissions/removals with LULUCF & 1.8 & 6.1 & 4.2 \\
\hline GHG emissions without LULUCF & 19.0 & 25.7 & 5.7 \\
\hline GHG net emissions/removals by LULUCF & -84.6 & -100.3 & -101.9 \\
\hline \multirow[t]{3}{*}{ GHG net emissions/removals with LULUCF } & 2.1 & 5.2 & 3.0 \\
\hline & \multicolumn{3}{|c|}{$\begin{array}{l}\text { Average annual growth rates, in per cent } \\
\text { per year }\end{array}$} \\
\hline & $\begin{array}{c}\text { From base } \\
\text { year to } 2000\end{array}$ & $\begin{array}{c}\text { From base } \\
\text { year to } 2004\end{array}$ & $\begin{array}{l}\text { From } 2000 \text { to } \\
2004 \\
\end{array}$ \\
\hline CO2 emissions without LULUCF & 2.3 & 2.3 & 2.2 \\
\hline CO2 net emissions/removals by LULUCF & -5.7 & -33.6 & -103.2 \\
\hline CO2 net emissions/removals with LULUCF & 0.2 & 0.5 & 1.1 \\
\hline GHG emissions without LULUCF & 1.8 & 1.7 & 1.4 \\
\hline GHG net emissions/removals by LULUCF & -10.7 & -24.4 & -58.4 \\
\hline GHG net emissions/removals with LULUCF & 0.2 & 0.4 & 0.8 \\
\hline
\end{tabular}

The base year under the Climate Change Convention is 1990 except for Bulgaria (1988), Hungary (average of 1985 to 1987), Poland (1988), Romania (1989) and Slovenia (1986), as defined by decisions 9/CP.2 and 11/CP.4. 


\section{A.1.2.3 United States Emissions}

Table A-3: Emissions summary for the United States \{United Nations Framework Convention on Climate Change, Party Emissions for the United States\}

\begin{tabular}{|c|c|c|c|}
\hline & \multicolumn{3}{|c|}{ Emissions, in Gg CO2 equivalent } \\
\hline & Base year & 2000 & 2004 \\
\hline CO2 emissions without LULUCF & $5,005,254.9$ & $5,864,464.9$ & $5,987,984.4$ \\
\hline CO2 net emissions/removals by LULUCF & $-910,373.1$ & $-759,506.7$ & $-780,094.2$ \\
\hline CO2 net emissions/removals with LULUCF & $4,094,881.8$ & $5,104,958.2$ & $5,207,890.2$ \\
\hline GHG emissions without LULUCF & $6,103,283.3$ & $6,975,928.7$ & $7,067,569.6$ \\
\hline GHG net emissions/removals by LULUCF & $-904,695.8$ & $-753,132.8$ & $-773,254.5$ \\
\hline \multirow[t]{3}{*}{ GHG net emissions/removals with LULUCF } & $5,198,587.5$ & $6,222,795.9$ & $6,294,315.0$ \\
\hline & \multicolumn{3}{|c|}{ Changes in emissions, in per cent } \\
\hline & $\begin{array}{l}\text { From base } \\
\text { year to } 2000\end{array}$ & $\begin{array}{l}\text { From base } \\
\text { year to } 2004\end{array}$ & $\begin{array}{l}\text { From } 2000 \text { to } \\
2004\end{array}$ \\
\hline CO2 emissions without LULUCF & 17.2 & 19.6 & 2.1 \\
\hline CO2 net emissions/removals by LULUCF & -16.6 & -14.3 & 2.7 \\
\hline CO2 net emissions/removals with LULUCF & 24.7 & 27.2 & 2.0 \\
\hline GHG emissions without LULUCF & 14.3 & 15.8 & 1.3 \\
\hline GHG net emissions/removals by LULUCF & -16.8 & -14.5 & 2.7 \\
\hline \multirow[t]{3}{*}{ GHG net emissions/removals with LULUCF } & 19.7 & 21.1 & 1.1 \\
\hline & \multicolumn{3}{|c|}{$\begin{array}{l}\text { Average annual growth rates, in per cent } \\
\text { per year }\end{array}$} \\
\hline & $\begin{array}{l}\text { From base } \\
\text { year to } 2000\end{array}$ & $\begin{array}{l}\text { From base } \\
\text { year to } 2004\end{array}$ & $\begin{array}{l}\text { From } 2000 \text { to } \\
2004\end{array}$ \\
\hline CO2 emissions without LULUCF & 1.6 & 1.3 & 0.5 \\
\hline CO2 net emissions/removals by LULUCF & -1.4 & -0.8 & 0.7 \\
\hline CO2 net emissions/removals with LULUCF & 2.3 & 1.8 & 0.5 \\
\hline GHG emissions without LULUCF & 1.4 & 1.1 & 0.3 \\
\hline GHG net emissions/removals by LULUCF & -1.4 & -0.8 & 0.7 \\
\hline GHG net emissions/removals with LULUCF & 1.8 & 1.4 & 0.3 \\
\hline
\end{tabular}

The base year under the Climate Change Convention is 1990 except for Bulgaria (1988), Hungary (average of 1985 to 1987), Poland (1988), Romania (1989) and Slovenia (1986), as defined by decisions 9/CP.2 and 11/CP.4. 


\section{A.1.2.4 National Emissions per Capita}

Table A-4: National equivalent carbon dioxide emissions per capita \{Globalis\}

\begin{tabular}{|c|c|c|}
\hline Rank & Country & CO2 equivalent (tonnes) \\
\hline 1 & Monaco & 3.82 \\
\hline 2 & Latvia & 4.56 \\
\hline 3 & Lithuania & 4.99 \\
\hline 4 & Romania & 6.4 \\
\hline 5 & Croatia & 6.75 \\
\hline 6 & Belarus & 7.27 \\
\hline 7 & Switzerland & 7.29 \\
\hline 8 & Liechtenstien & 7.65 \\
\hline 9 & Sweden & 7.95 \\
\hline 10 & Portugal & 8.07 \\
\hline 11 & Hungary & 8.43 \\
\hline 12 & Bulgaria & 8.76 \\
\hline 13 & France & 9.26 \\
\hline 14 & Slovakia & 9.57 \\
\hline 15 & Spain & 9.8 \\
\hline 16 & Italy & 9.92 \\
\hline 17 & Slovenia & 9.98 \\
\hline 18 & Iceland & 10.38 \\
\hline 19 & Japan & 10.49 \\
\hline 20 & Ukraine & 10.86 \\
\hline 21 & Austria & 11.28 \\
\hline 22 & Norway & 12.08 \\
\hline 23 & Germany & 12.34 \\
\hline 24 & Greece & 12.54 \\
\hline 25 & Netherlands & 13.3 \\
\hline 26 & Denmark & 14.07 \\
\hline 27 & Czech Republic & 14.21 \\
\hline 28 & Belgium & 14.3 \\
\hline 29 & Estonia & 16.17 \\
\hline 30 & Finland & 16.43 \\
\hline 31 & Ireland & 17.07 \\
\hline 32 & New Zealand & 19.44 \\
\hline 33 & United States & 23.44 \\
\hline 34 & Canada & 23.49 \\
\hline 35 & Luxembourg & 24.9 \\
\hline 36 & Australia & 26.11 \\
\hline
\end{tabular}


Appendix A

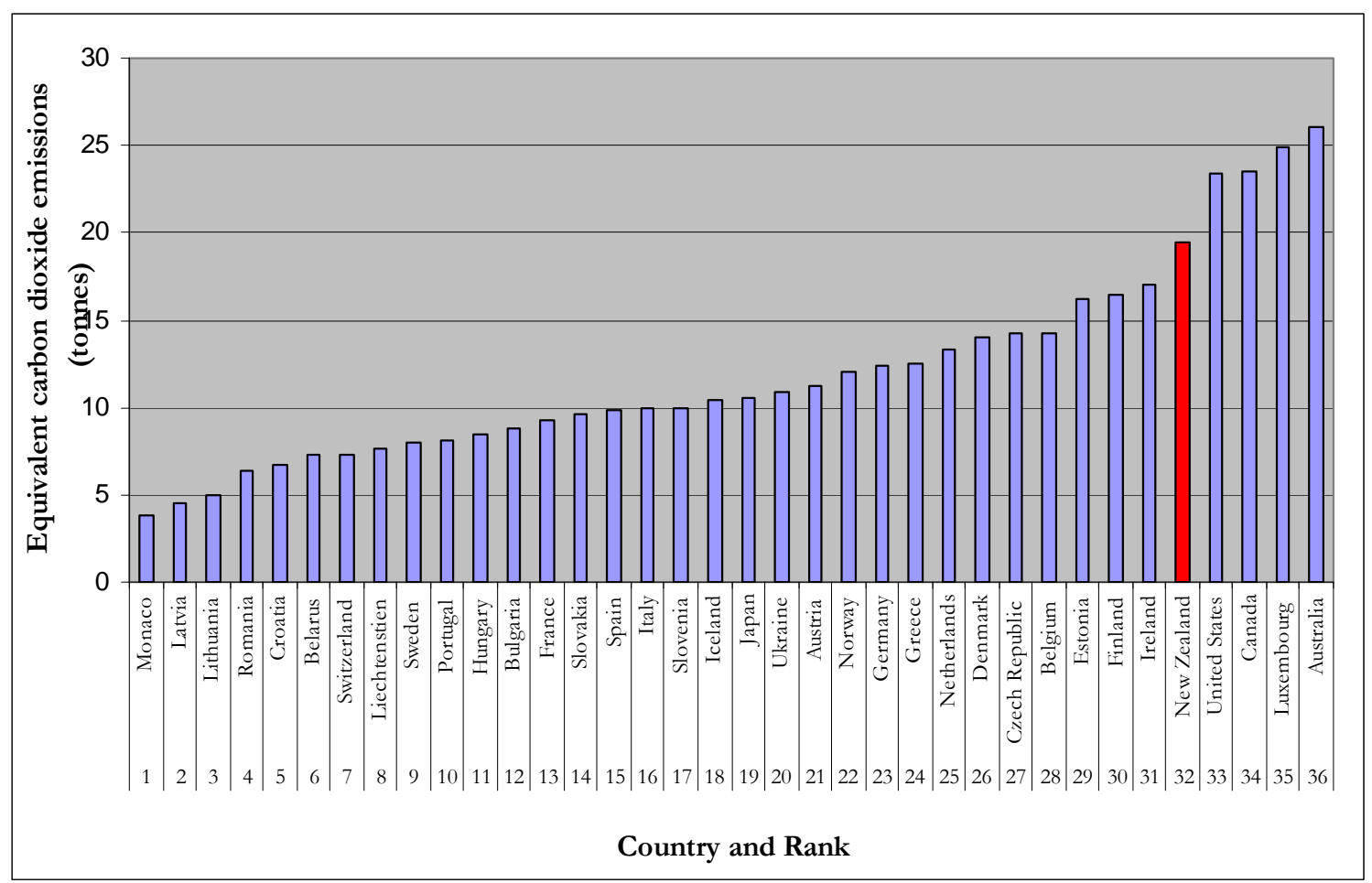

Figure A-1: National equivalent carbon dioxide emissions per capita \{Globalis\} 


\section{A.1.3 Ecological Footprint and Biocapacity}

\section{A.1.3.1 Ecological Footprint and Biocapacity 2003}

Table A-5: Ecological Footprint 2003 \{World Wild Life Fund International, Living Planet Report 2006 28-35\}

\begin{tabular}{|c|c|c|c|c|c|c|c|c|c|c|c|}
\hline \multirow[b]{2}{*}{ Country/region } & \multirow[b]{2}{*}{$\begin{array}{l}\text { population } \\
\text { (millions) }\end{array}$} & \multicolumn{10}{|c|}{ Ecological Footprint (global hectares per person in 2003 gha) } \\
\hline & & $\begin{array}{l}\text { Total } \\
\text { ecological } \\
\text { footprint }\end{array}$ & Cropland & $\begin{array}{l}\text { Grazing } \\
\text { Land }\end{array}$ & $\begin{array}{l}\text { Forest: } \\
\text { timber, } \\
\text { pulp and } \\
\text { paper }\end{array}$ & $\begin{array}{l}\text { Forest: } \\
\text { fuelwood }\end{array}$ & $\begin{array}{l}\text { Fishing } \\
\text { ground }\end{array}$ & $\begin{array}{l}\mathrm{CO} 2 \\
\text { from } \\
\text { fossil } \\
\text { fuels }\end{array}$ & Nuclear & $\begin{array}{l}\text { Built } \\
\text { up } \\
\text { land }\end{array}$ & $\begin{array}{l}\text { Water } \\
\text { withdrawals } \\
\text { per person } \\
\text { ('000 } \\
\mathrm{m}^{3} / \text { year) }\end{array}$ \\
\hline World & 6301.5 & 2.23 & 0.49 & 0.14 & 0.17 & 0.06 & 0.15 & 1.06 & 0.08 & 0.08 & 618 \\
\hline Middle-income countries & 3011.7 & 1.9 & 0.47 & 0.17 & 0.11 & 0.05 & 0.15 & 0.85 & 0.03 & 0.07 & 552 \\
\hline Low-income countries & 2303.1 & 0.8 & 0.34 & 0.04 & 0.02 & 0.08 & 0.04 & 0.21 & 0 & 0.05 & 550 \\
\hline New Zealand & 3.9 & 5.9 & 0.68 & 1.01 & 1.3 & 0 & 1.19 & 1.6 & 0 & 0.16 & 549 \\
\hline Australia & 19.7 & 6.6 & 1.17 & 0.87 & 0.53 & 0.03 & 0.28 & 3.41 & 0 & 0.28 & 1224 \\
\hline United States & 294 & 9.6 & 0.98 & 0.46 & 1.21 & 0.03 & 0.23 & 5.66 & 0.56 & 0.47 & 1647 \\
\hline
\end{tabular}


Table A-6: Biocapacity 2003 \{World Wild Life Fund International, Living Planet Report 2006 28-35\}

\begin{tabular}{|c|c|c|c|c|c|c|c|c|c|c|c|c|}
\hline \multirow[b]{2}{*}{ Country/region } & \multirow[b]{2}{*}{$\begin{array}{l}\text { populati } \\
\text { on } \\
\text { (millions } \\
\text { ) }\end{array}$} & \multicolumn{11}{|c|}{ Biocapacity (global hectares per person, in 2003 gha) } \\
\hline & & $\begin{array}{l}\text { Total } \\
\text { biocapaci } \\
\text { ty }\end{array}$ & $\begin{array}{l}\text { Croplan } \\
\text { d }\end{array}$ & $\begin{array}{l}\text { Grazin } \\
\text { g Land }\end{array}$ & $\begin{array}{l}\text { Fore } \\
\text { st }\end{array}$ & $\begin{array}{l}\text { Fishin } \\
\text { g } \\
\text { groun } \\
\text { d }\end{array}$ & $\begin{array}{l}\text { Ecological } \\
\text { reserve or } \\
\text { deficit (-) } \\
\text { (gha/perso } \\
\text { n) }\end{array}$ & $\begin{array}{l}\text { Footpri } \\
\text { nt } \\
\text { change } \\
\text { per } \\
\text { person } \\
(\%) \\
1975 \quad- \\
2003 \\
\end{array}$ & $\begin{array}{l}\text { Biocapaci } \\
\text { ty change } \\
\text { per } \\
\text { person } \\
(\%) 1975- \\
2003\end{array}$ & $\begin{array}{l}\text { Human } \\
\text { developme } \\
\mathrm{nt} \text { index } \\
2003\end{array}$ & $\begin{array}{l}\text { Chang } \\
\text { e in } \\
\text { HDI } \\
(\%) \\
1975- \\
2003 \\
\end{array}$ & $\begin{array}{l}\text { Water } \\
\text { withdraw } \\
\text { ls } \% \text { of } \\
\text { total } \\
\text { resource } \\
\text { s }\end{array}$ \\
\hline World & 6301.5 & 1.78 & 0.53 & 0.27 & 0.78 & 0.14 & -0.45 & 14 & -25 & 0.74 & - & 10 \\
\hline $\begin{array}{l}\text { High-income } \\
\text { countries }\end{array}$ & 955.6 & 3.3 & 1.1 & 0.19 & 1.48 & 0.31 & -3.12 & 40 & -14 & 0.91 & - & 10 \\
\hline $\begin{array}{l}\text { Middle-income } \\
\text { countries }\end{array}$ & 3011.7 & 2.1 & 0.5 & 0.31 & 1.05 & 0.15 & 0.18 & 14 & -11 & 0.77 & - & 5 \\
\hline $\begin{array}{l}\text { Low-income } \\
\text { countries }\end{array}$ & 2303.1 & 0.7 & 0.31 & 0.17 & 0.12 & 0.06 & -0.09 & 8 & -48 & 0.59 & - & 10 \\
\hline New Zealand & 3.9 & 14.9 & 3.34 & 4.4 & 6.59 & 0.45 & 9 & 28 & -9 & 0.93 & 10 & 1 \\
\hline Australia & 19.7 & 12.4 & 4.26 & 1.83 & 3.34 & 2.73 & 5.9 & -7 & -28 & 0.96 & 13 & 5 \\
\hline United States & 294 & 4.7 & 1.71 & 0.28 & 1.93 & 0.36 & -4.8 & 38 & -20 & 0.94 & 9 & 16 \\
\hline
\end{tabular}




\section{A.1.3.2 Ecological Footprint and Biocapacity 1999}

Table A-7: Ecological Footprint 1999 \{World Wild Life Fund International, Living Planet Report 2002 22-29\}

\begin{tabular}{|c|c|c|c|c|c|c|c|c|c|c|c|c|}
\hline \multirow[b]{2}{*}{ Country/region } & \multirow[b]{2}{*}{$\begin{array}{l}\text { Population } \\
\text { (millions) }\end{array}$} & \multicolumn{11}{|c|}{ Ecological Footprint (global hectares per person in 1999 gha) } \\
\hline & & $\begin{array}{l}\text { Total } \\
\text { ecological } \\
\text { footprint }\end{array}$ & Cropland & $\begin{array}{l}\text { Grazing } \\
\text { Land }\end{array}$ & $\begin{array}{l}\text { Forest (ex. } \\
\text { Fuelwood) }\end{array}$ & $\begin{array}{l}\text { Fishing } \\
\text { ground }\end{array}$ & $\begin{array}{l}\text { Total } \\
\text { energy }\end{array}$ & $\begin{array}{l}\text { CO2 } \\
\text { from } \\
\text { fossil } \\
\text { fuels }\end{array}$ & Fuelwood & Nuclear & Hydro & $\begin{array}{l}\text { Built- } \\
\text { ip } \\
\text { land }\end{array}$ \\
\hline World & 5978.7 & 2.28 & 0.53 & 0.12 & 0.27 & 0.14 & 1.12 & 0.99 & 0.06 & 0.08 & 0 & 0.1 \\
\hline & & 6.48 & & & & & & & & & & \\
\hline High-income countries & 906.5 & 1.99 & 1.04 & 0.23 & 0.7 & 0.41 & 3.86 & 3.4 & 0.03 & 0.42 & 0.01 & 0.25 \\
\hline Middle-income countries & 2941 & 0.83 & 0.49 & 0.13 & 0.2 & 0.13 & 0.94 & 0.86 & 0.06 & 0.02 & 0 & 0.09 \\
\hline Low-income countries & 2114 & & 0.3 & 0.03 & 0.16 & 0.03 & 0.25 & 0.17 & 0.06 & 0 & 0 & 0.06 \\
\hline New Zealand & 3.7 & 8.68 & 3.03 & 1.6 & 1.09 & 0.71 & 2.03 & 1.92 & id & 0.06 & 0.05 & 0.22 \\
\hline Australia & 18.9 & 7.58 & 1.64 & 0.62 & 0.6 & 0.25 & 4.35 & 4.31 & 0.02 & 0 & 0.01 & 0.11 \\
\hline United States & 280.4 & 9.7 & 1.48 & 0.32 & 1.28 & 0.31 & 5.94 & 5.38 & 0.06 & 0.5 & 0.01 & 0.37 \\
\hline
\end{tabular}


Appendix A

Table A-8: Biocapacity 1999 \{World Wild Life Fund International, Living Planet Report 2002 22-29\}

\begin{tabular}{|c|c|c|c|c|c|c|c|c|c|c|}
\hline \multirow[b]{2}{*}{ Country/region } & \multicolumn{8}{|c|}{ Biocapacity (global hectares per person, in 2003 gha) } & \multirow[b]{2}{*}{$\begin{array}{l}\text { Water } \\
\text { withdrawls } \\
2000 \quad \text { est. } \\
\text { (thousand } \\
\mathrm{m}^{3} / \text { person/yea } \\
\text { r) }\end{array}$} & \multirow[b]{2}{*}{$\begin{array}{l}\text { Water resources } \\
2000 \text { est. } \\
\text { (thousand } \\
\mathrm{m}^{3} / \text { person/yea } \\
\mathrm{r} \text { ) }\end{array}$} \\
\hline & $\begin{array}{l}\text { Total } \\
\text { biocapacit } \\
\text { y }\end{array}$ & $\begin{array}{l}\text { Croplan } \\
\text { d }\end{array}$ & $\begin{array}{l}\text { Grazin } \\
\text { g Land }\end{array}$ & $\begin{array}{l}\text { Fores } \\
t\end{array}$ & $\begin{array}{l}\text { Fishin } \\
\mathrm{g} \\
\text { groun } \\
\mathrm{d}\end{array}$ & $\begin{array}{l}\text { Ecological } \\
\text { reserve or } \\
\text { deficit (-) } \\
\text { (gha/person } \\
\text { ) }\end{array}$ & $\begin{array}{l}\text { Ecologica } \\
1 \\
\text { footprint } \\
1996\end{array}$ & $\begin{array}{l}\text { Biocapacit } \\
\text { y } 1996\end{array}$ & & \\
\hline World & 1.9 & 0.53 & 0.27 & 0.86 & 0.14 & 0.38 & 2.39 & 1.98 & 0.55 & 8.89 \\
\hline High-income countries & 3.55 & 1.13 & 0.71 & 1.1 & 0.37 & 2.93 & 6.49 & 3.66 & 0.98 & 9.65 \\
\hline $\begin{array}{l}\text { Middle-income } \\
\text { countries }\end{array}$ & 1.89 & 0.47 & 0.35 & 0.84 & 0.12 & 0.1 & 2.11 & 1.93 & 0.52 & 11.1 \\
\hline Low-income countries & 0.95 & 0.3 & 0.08 & 0.44 & 0.06 & -0.11 & 0.89 & 0.98 & 0.42 & 5.55 \\
\hline New Zealand & 22.95 & 3.05 & 13.68 & 5.51 & 0.44 & -14.28 & 8.08 & 23.34 & 0.53 & 105.59 \\
\hline Australia & 14.61 & 4.38 & 4.94 & 2.3 & 2.86 & -7.03 & 8.57 & 16.21 & 0.94 & 21.13 \\
\hline United States & 5.27 & 1.77 & 1.26 & 1.42 & 0.44 & 4.43 & 9.62 & 5.35 & 1.69 & 8.92 \\
\hline
\end{tabular}




\section{A.1.4 The New Zealand Building Industry}

Table A-9: 2006 New Zealand Census building industry make-up \{Statistics New Zealand, Table Builder\}

\begin{tabular}{|c|c|c|}
\hline Industry Sectors & $\begin{array}{l}\text { Number of } \\
\text { businesses }\end{array}$ & $\begin{array}{l}\text { Percentage of } \\
\text { Total Industry }\end{array}$ \\
\hline 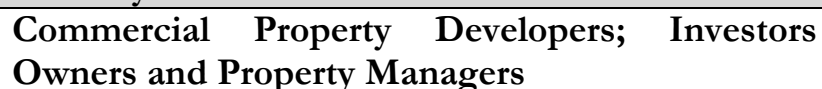 & 52128 & $41 \%$ \\
\hline Commercial Property Operators and Developers & 52128 & $41 \%$ \\
\hline Building Contractors & 44383 & $35 \%$ \\
\hline Construction & 44383 & $35 \%$ \\
\hline Property and Construction Professionals & 13908 & $11 \%$ \\
\hline Real Estate Agents & 10095 & $8 \%$ \\
\hline Legal Services & 2710 & $2 \%$ \\
\hline Technical Services & 664 & $1 \%$ \\
\hline Surveying & 439 & $0 \%$ \\
\hline $\begin{array}{l}\text { Residential Developers and Major Portfolio } \\
\text { Owners }\end{array}$ & 4824 & $4 \%$ \\
\hline Residential Property Operators & 4484 & $4 \%$ \\
\hline Building Product Manufacturers and Distributors & 4484 & $4 \%$ \\
\hline Other Wood Product Manufacturing & 1631 & $1 \%$ \\
\hline Builders Supplies Wholesaling & 1382 & $1 \%$ \\
\hline Structural Metal Product Manufacturing & 1023 & $1 \%$ \\
\hline $\begin{array}{l}\text { Cement, Lime, Plaster and Concrete Product } \\
\text { Manufacturing }\end{array}$ & 321 & $0 \%$ \\
\hline Electrical Equipment Manufacturing nec & 226 & $0 \%$ \\
\hline Prefabricated Building Manufacturing & 117 & $0 \%$ \\
\hline Mining and Construction Machinery Manufacturing & 43 & $0 \%$ \\
\hline Commercial Space Heating and Cooling Equipment & 31 & $0 \%$ \\
\hline Ceramic Tile and Pipe Manufacturing & 13 & $0 \%$ \\
\hline Clay Brick Manufacturing & 11 & $0 \%$ \\
\hline Electrical Cable and Wire Manufacturing & 7 & $0 \%$ \\
\hline Engineers & 3842 & $3 \%$ \\
\hline Consultant Engineers Services & 3842 & $3 \%$ \\
\hline Architects and Draftpersons & 2437 & $2 \%$ \\
\hline Architectural Services & 2437 & $2 \%$ \\
\hline Research and Non Government Organisations & 415 & $0 \%$ \\
\hline Scientific Research & 415 & $0 \%$ \\
\hline Total & 126421 & $100 \%$ \\
\hline
\end{tabular}




\section{A.1.4.1 The New Zealand Energy Market}

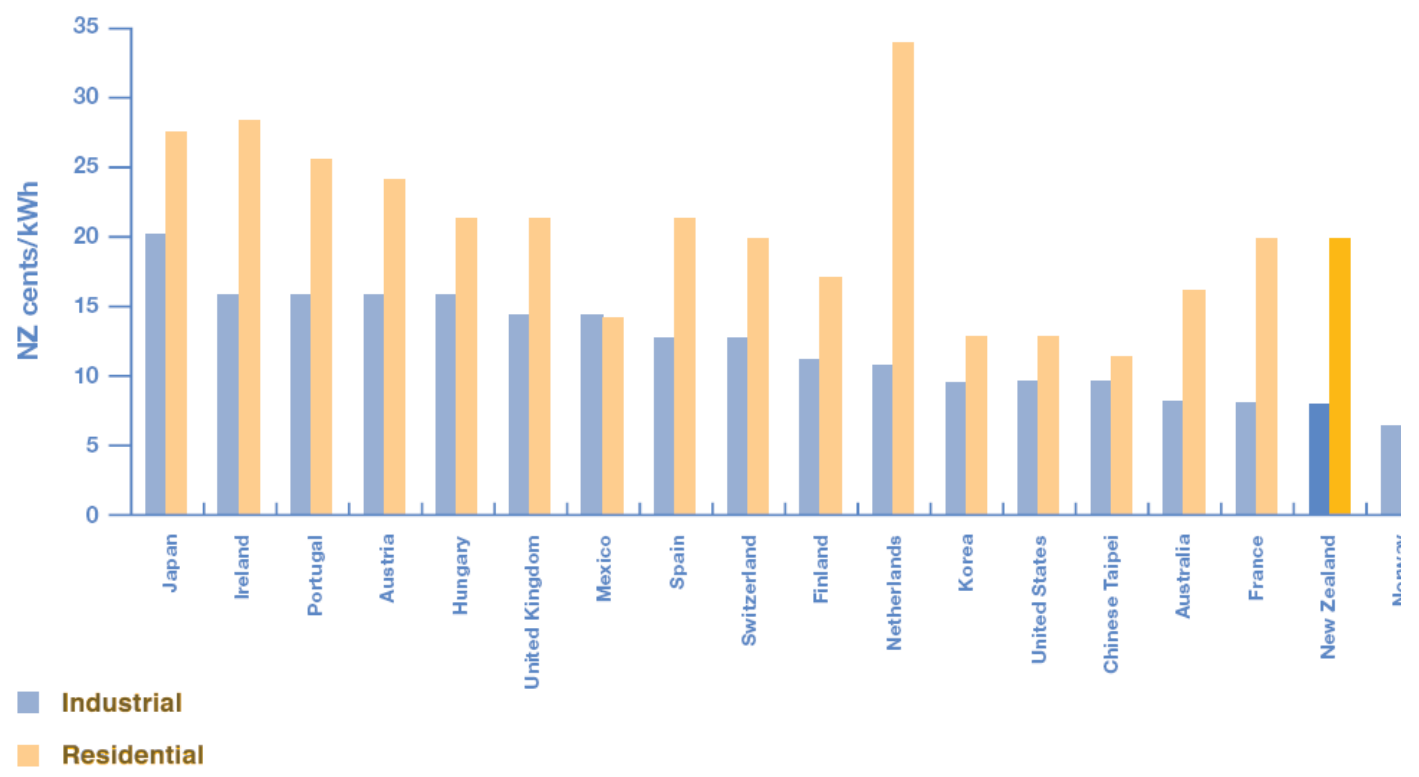

Figure A-2: International compartitive electricity prices in 2005 (including applicable country/regional taxes \{qtd. in Ministry of Economic Development, Powering Our Future 7\}

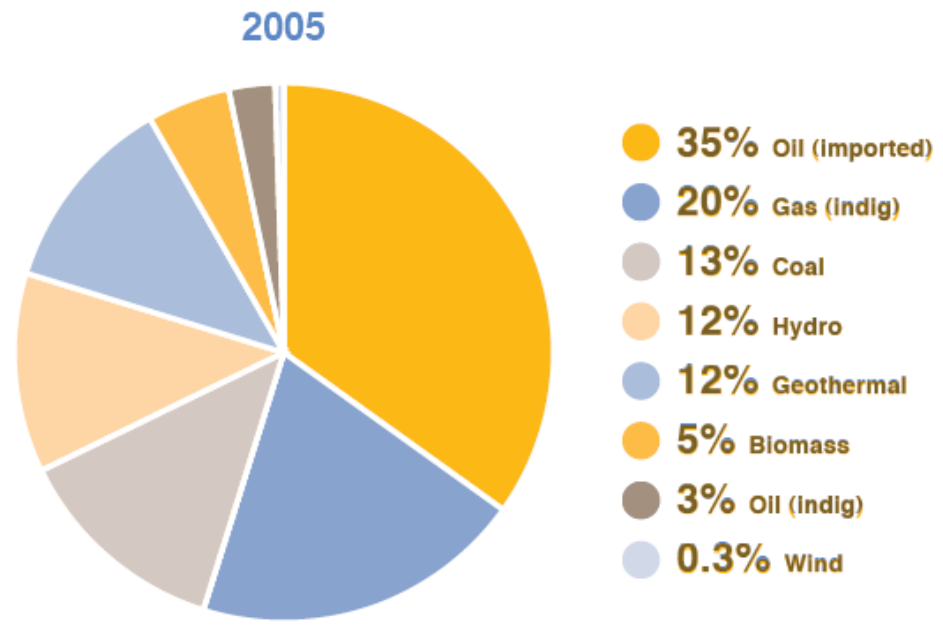

Figure A-3: Total primary energy supply by fuel type in 2005 \{qtd. in Ministry for Economic Development, Powering Our Future 24\} 


\section{A.1.4.2 Office Building - Twenty Year Present Values}

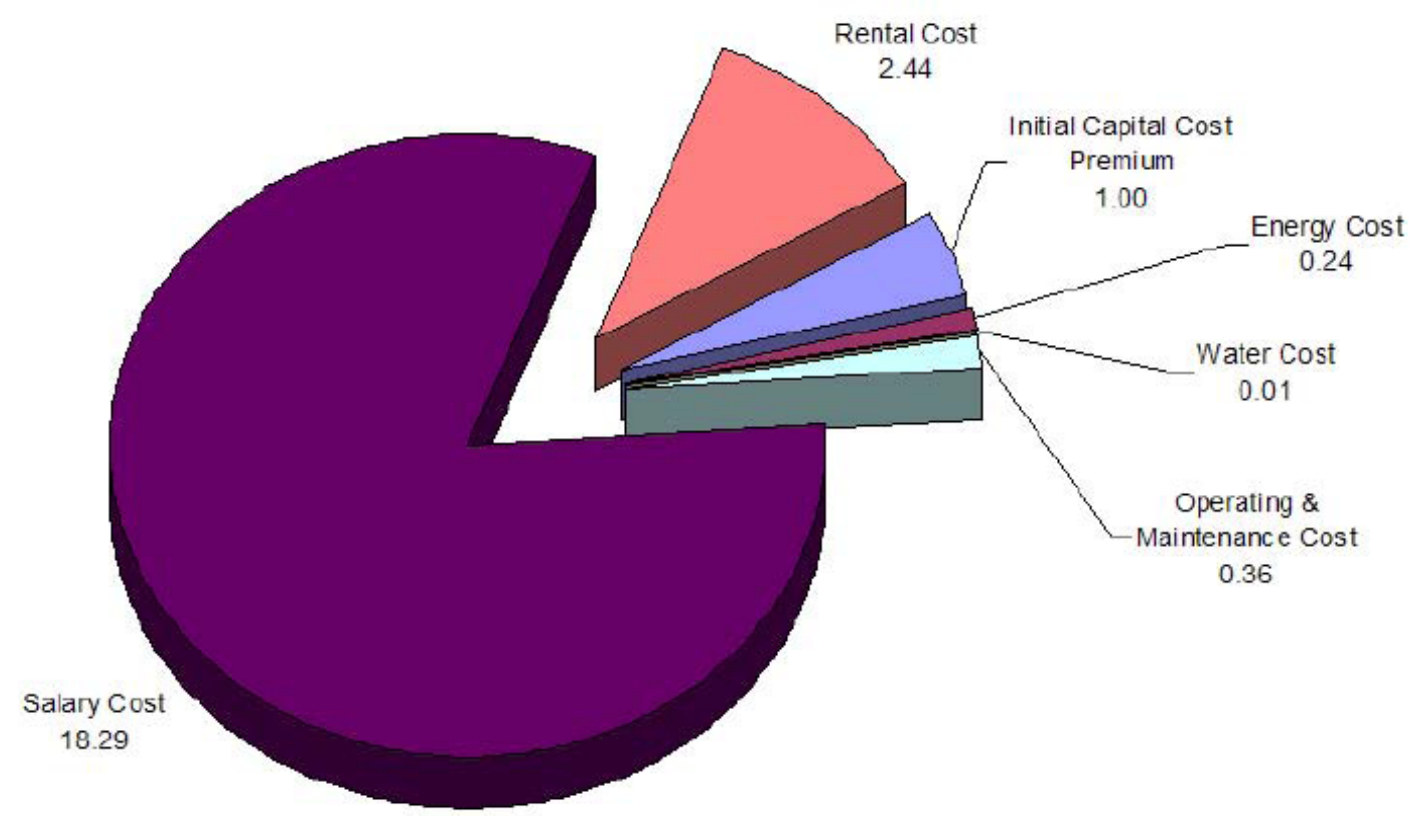

Figure A-4: Office building - 20 year present values (relative to the initial capital cost premium) \{Ministry for the Environment, Value Case 45\}

\section{A.2 Professional Background}

\section{A.2.1 Green Building Councils}

Current members of the World GBC are as (of December 2007):

- Australia

- Brazil

- India

- Japan

- Mexico

- New Zealand

- Taiwan

- United Arab Emirates

- United Kingdom

- United States 


\section{A.2.2 Building Sustainability Rating Tools}

Cole states that the majority of existing BSRTs evaluate 'green' performance through either assigned points or weightings. They have the following general characteristics \{qtd. in Redefining Intentions and Roles 457\}:

- "Technically framed and emphasize the assessment of resource use, ecological loadings, health and comfort in individual buildings

- Primarily concerned with mitigation: reducing stresses on natural systems by improving the environmental performance of buildings

- Assess performance relative to explicitly declared or implicit benchmarks and, as such, measure the extent of improvement rather than proximity to a defined, desired goal

- Assess design intentions and potential as determined through prediction rather than actual real world performance

- Structure performance scoring as a simple additive process and use explicitly declared or implicit weightings to denote priority

- Offer a performance summary, certificate or label that can be part of leasing documents and promotional documents

- Operate primarily through the use of 'hard' copies of performance requirements in the form of published manuals and 'hard' copies of submittal requirements"

\section{A.2.3 Green Star New Zealand}

Please refer to NZGBC, Green Star NZ Office Design v1: Technical Manual for more information.

\section{A.2.3.1 Environmental Impact Categories}

The environmental considerations of a building project are assessed within nine Environmental Impact Categories:

\footnotetext{
- Management

- Indoor Environment Quality

- Energy

- Transport

- Water

- Materials

- Land Use and Ecology

- Missions

- Innovation
} 
In order to encourage the development and spread of innovative technologies, designs and processes that could improve building projects' environmental performance, an 'Innovation' category is included in each Green Star rating tool.

The categories are further divided into credits. Each credit addresses an initiative that improves, or has the potential to improve, a building project's environmental performance.

For example in the Transport category, credits exist for a building project's provision of cyclist facilities, and for its proximity to public transport networks.

Points are awarded in each credit for actions that demonstrate that the project has met the overall objectives of Green Star NZ, as well as the specific aims of the relevant tool.

Once a building project has been assessed for all the credits in each category, a percentage score for the category is calculated.

\section{A.2.3.2 Category Score}

The Category Score is determined as the percentage of total credit points a project has achieved out of the total points available in a category, as follows:

$$
\text { Category Score }=\frac{\text { Number of point s achieved }}{\text { Number of point s available }}
$$

For example, if twelve points are achieved out of a total of twenty-four in the Energy category then the category score is $50 \%$. Similarly, if two points are achieved out of a total of eight available in thr Land Use and Ecology category then the category score is 25\%.

\section{A.2.3.3 Weighted Category Score}

A Green Star NZ Environmental Weighting Factor is then applied to each of the project's category scores to give a Weighted Category Score.

The weighting factor (refer to Figure A-5) is applied to reflect the relative importance of each of the categories to New Zealand's unique environmental challenges.

Green Star NZ rating tools have the flexibility to allow for periodic updating of credits and weightings within the various tools. This is necessary to allow Green Star NZ to adapt to best practice and remain at the leading edge of industry practice. 


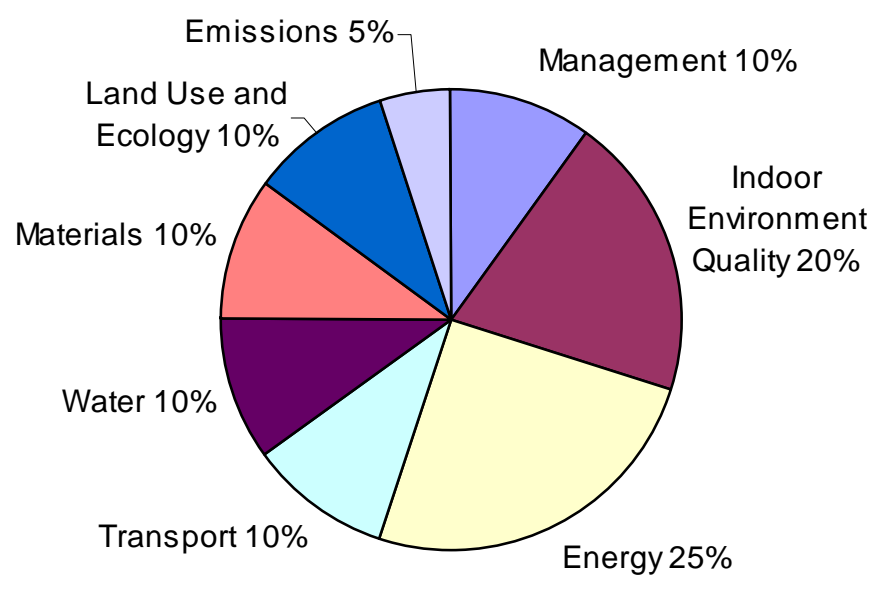

Figure A-5: Environmental weightings of the Green Star NZ categories

The innovation category is not subject to an Environmental Weighting Factor as the innovation could fall under any number of Green Star NZ categories.

Each Weighted category Score is calculated as follows:

Weighted Category Score = Category Score $(\%) \times$ Environmental Weighting Factor $(\%) \times 100$

Using the example provided in the Category Score section above, the Weighted Category Score for Energy is $0.5 \times 0.3 \times 100=15$. Similarly, the Weighted Category Score for Land Use and Ecology is $0.25 \times 0.05 \times 100=1.25$.

It is important to note that a Green Star NZ rating is based on Weighted Category Scores rather than the total number of points achieved.

\section{A.2.3.4 Single Score}

The single score - or overall score - of a building project is determined by adding together all the Weighed Category Scores plus the Innovation points. The maximum possible score for the weighted categories is 100, with an additional five points available for Innovation. 


\section{A.2.3.5 Ratings}

The rating scale for Green Star NZ is shown in Table A-10 below.

Table A-10: Green Star NZ rating tool scores \{New Zealand Green Building Council, Green Star NZ Office Design v1: Technical Manual $\}$

\begin{tabular}{|l|l|l|}
\hline Single Score (Overall) & Rating & Outcome \\
\hline $10-19$ & One Star & $\begin{array}{l}\text { Not eligible for formal certification, signifies 'Minimum } \\
\text { Practice' }\end{array}$ \\
\hline $20-29$ & Two Star & $\begin{array}{l}\text { Not eligible for formal certification, signifies 'Average } \\
\text { Practice' }\end{array}$ \\
\hline $30-44$ & Four Star & $\begin{array}{l}\text { Not eligible for formal certification, signifies 'Good } \\
\text { Practice' } \\
\text { signifies 'Best Practice' }\end{array}$ \\
\hline 60-74 & Five Star & $\begin{array}{l}\text { Eligible for Five Star Green Star NZ certification, } \\
\text { signifies New Zealand Excellence' }\end{array}$ \\
\hline $75+$ & Six Star & $\begin{array}{l}\text { Eligible for Six Star Green Star NZ certification, } \\
\text { signifies 'World Leader }\end{array}$ \\
\hline
\end{tabular}

The minimum Green Star NZ rating is One Star and the Maximum is Six Stars.

Green Star NZ recognises and rewards market leaders, so the NZGBC only formally certifies design, projects or buildings that achieve a rating of four, five or s[ix stars. However, building projects that do not qualify for certification are encouraged to use rating tools as a guide to track and improve their environmental initiatives.

\section{A.2.3.6 Green Star Certification}

A design, project or building cannot publicly claim a Green Star NZ rating unless the NZGBC has certified the rating. The NZGBC commissions one or more third-party Assessors to check and validate a project's self rating and recommend (or oppose) a Green Star Certified Rating.

Green Star NZ: Office design v1 certification identifies projects that have demonstrated a commitment to a specific level of environmental sustainability by informing the industry of the design performance of the project in terms that are widely understood and accepted.

The benefits of certification include:

- Having the competitive edge by promoting the building as environmentally friendly

- Gaining national and international market recognition as a leader in the green building industry

- Enjoying greater wellbeing and productivity of the building's occupants by providing a healthy environment 
- Establishing a competitive commercial advantage when seeking occupants or buyers for the building

- Validating the achievement through third party assessment

\section{A.2.3.7 Eligibility}

Green Star NZ: Office Design v1 all for certification of the design initiatives of new or refurbished Class 5 commercial office projects. At least $80 \%$ of the Gross Floor Area (GFA) must be classed as an office building.

Only designs that achieve a self-assessed weighted score of Four Starts or higher are eligible to apply for certification.

\section{A.2.3.8 Green Star NZ Office Design v1}

Table A-11: Credit summary table \{New Zealand Green Building Council, Green Star NZ Office Design v1: Technical Manual\}

\begin{tabular}{|c|c|c|c|}
\hline Category & Title & Credit No. & Points Available \\
\hline \multirow[t]{7}{*}{ Management } & Green Star Accredited Professional & Man-1 & 2 \\
\hline & Commissioning - Clauses & Man-2 & 2 \\
\hline & Commissioning - Building Tuning & Man-3 & 1 \\
\hline & $\begin{array}{l}\text { Commissioning }- \text { Commissioning } \\
\text { Agent }\end{array}$ & Man-4 & 1 \\
\hline & Building Users' Guide & Man-5 & 1 \\
\hline & Environmental Management & Man-6 & 3 \\
\hline & Waste Management & Man-7 & 3 \\
\hline \multicolumn{3}{|l|}{ Total } & 13 \\
\hline \multirow{15}{*}{$\begin{array}{l}\text { Indoor Environment } \\
\text { Quality }\end{array}$} & Base Ventilation Rates & IEQ-1 & Cond. Reqmt. \\
\hline & Ventilation Rates & IEQ-2 & 3 \\
\hline & Air Change Effectiveness & IEQ-3 & 2 \\
\hline & $\begin{array}{l}\text { Carbon Dioxide Monitoring and } \\
\text { Control }\end{array}$ & IEQ-4 & 1 \\
\hline & Daylight & IEQ-5 & 3 \\
\hline & Daylight Glare Control & IEQ-6 & 1 \\
\hline & High Frequency Ballasts & IEQ-7 & 1 \\
\hline & Electric Lighting Levels & IEQ-8 & 1 \\
\hline & External Views & IEQ-9 & 2 \\
\hline & Thermal Comfort & IEQ-10 & 3 \\
\hline & Individual Comfort Control & IEQ-11 & 2 \\
\hline & Internal Noise Levels & IEQ-12 & 2 \\
\hline & Volatile Organic Compounds & IEQ-13 & 3 \\
\hline & Formaldehyde Minimisation & IEQ-14 & 1 \\
\hline & Tenant Exhaust Riser & IEQ-15 & 1 \\
\hline \multicolumn{3}{|l|}{ Total } & 26 \\
\hline \multirow[t]{5}{*}{ Energy } & Energy & Ene-1 & Cond. Reqmt. \\
\hline & CO2 Emissions & Ene-2 & 15 \\
\hline & Electrical Sub-metering & Ene-3 & 1 \\
\hline & Tenancy Sub-metering & Ene-4 & 1 \\
\hline & Office Lighting Power Density & Ene-5 & 4 \\
\hline
\end{tabular}




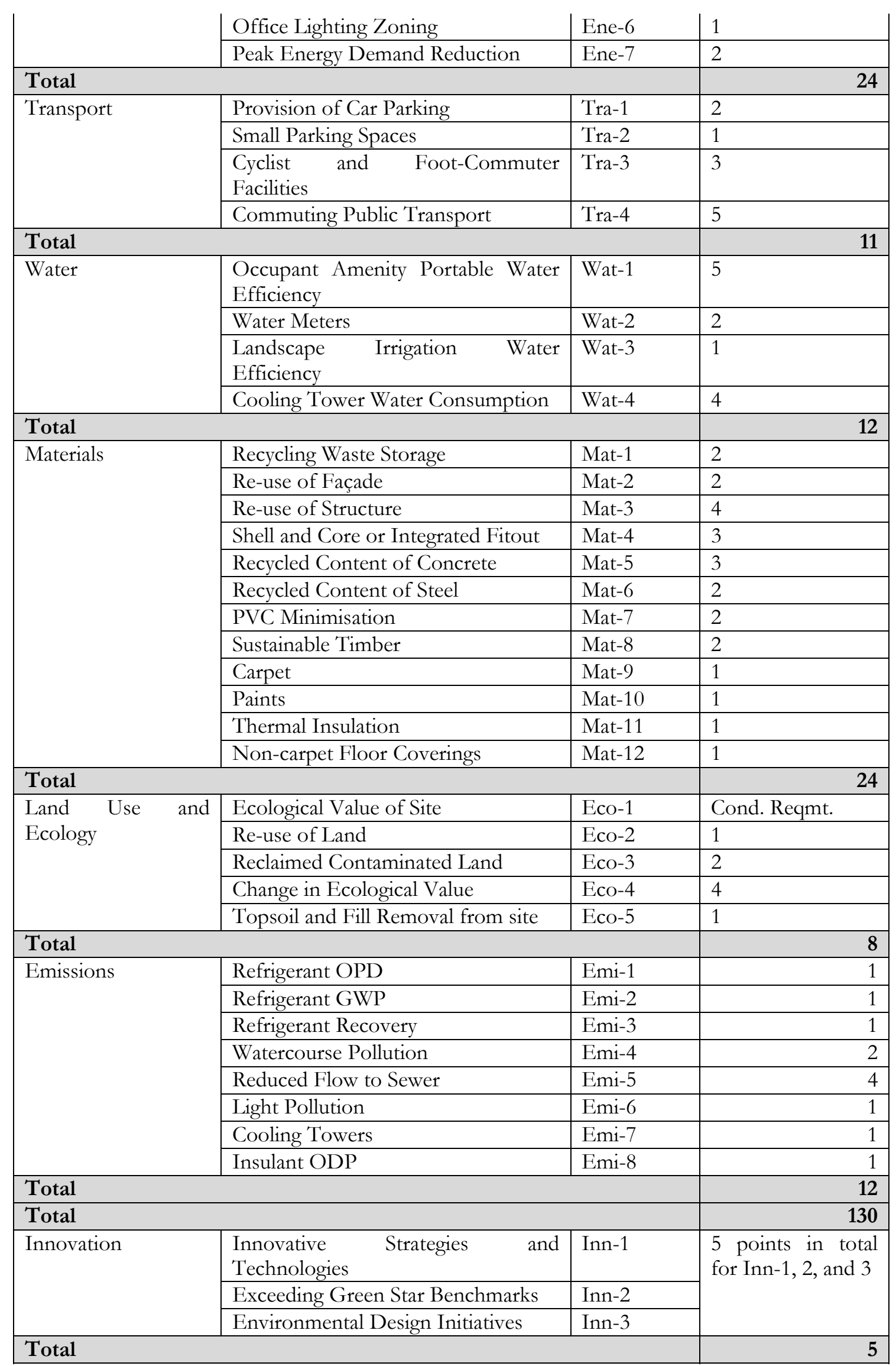




\section{Appendix B: Research Design}

\section{B.1 Sample Frame and Target Population}

\section{B.1.1 Contacted Building Industry professionals}

Table B-1: Number of professionals in each participating organisation ${ }^{9}$

\begin{tabular}{|l|r|}
\hline Name of Organisation & $\begin{array}{c}\text { Number of } \\
\text { contacts }\end{array}$ \\
\hline Cement and Concrete Association of New Zealand & 400 \\
\hline Design Institute of New Zealand & 900 \\
\hline Earth Building Association of New Zealand & 30 \\
\hline Illumination Engineering Society of Australia and New Zealand & 804 \\
\hline Institute of Professional Engineers New Zealand & 400 \\
\hline Institute of Refrigeration and Air Conditioning Engineers of New Zealand & 1000 \\
\hline New Zealand Green Building Council & 576 \\
\hline NZIA registered architects (from www.architecturenz.net) & 900 \\
\hline New Zealand Institute of Quantity Surveyors & 1 \\
\hline New Zealand Metal Roofing and Cladding Association & 800 \\
\hline New Zealand Planning Institute & 3000 \\
\hline New Zealand Property Institute & 4000 \\
\hline New Zealand Property Investors Federation & 300 \\
\hline New Zealand Timber Design Society & 30 \\
\hline New Zealand Building Subcontractors Federation Inc. & 1 \\
\hline Property Council of New Zealand & 1700 \\
\hline Registered Master Builders Federation & 1 \\
\hline Roofing Association of New Zealand & 5 \\
\hline Window Association of New Zealand & $\mathbf{2 2 2 0 8}$ \\
\hline Total & \\
\hline
\end{tabular}

\section{B.1.1.1 Conservative Population Estimate}

The conservative population estimate of those actually contacted was calculated on the basis of the respondents answer to their affiliations with building industry related organisations (refer to Table B-2). The result was proportionally weighted to the total building industry professionals contacted $(22,208)$, however due to $19 \%$ not being affiliated with any organisation this remainder was re-weighted and added to conservative population estimate. According to the method the 22,208 of professionals contacted, the figure was recalculated to be 17,350 (refer to Table B-3).

\footnotetext{
9 Those organisations with only one contact were organisations which participated on behalf of their organisations and did not forward the survey onto their respective databases.
} 
Appendix B

Table B-2: Respondents number of affiliations with building industry related organisations

\begin{tabular}{|l|r|c|}
\hline Number of organisations & Number & $\mathbf{0}$ \\
\hline 0 & 90 & $19 \%$ \\
\hline 1 & 243 & $51 \%$ \\
\hline 2 & 80 & $17 \%$ \\
\hline 3 & 37 & $8 \%$ \\
\hline 4 & 17 & $4 \%$ \\
\hline 5 & 7 & $1 \%$ \\
\hline 6 & 1 & $0 \%$ \\
\hline 7 & 1 & $0 \%$ \\
\hline Total & $\mathbf{4 7 6}$ & $\mathbf{1 0 0} \%$ \\
\hline
\end{tabular}


Table B-3: Conservative population estimate calculation

\begin{tabular}{|c|c|c|c|}
\hline Number of organisations & $\%$ & $\%$ of total & Number of professionals \\
\hline 0 & $19 \%$ & 4219.52 & - \\
\hline 1 & $51 \%$ & 11326.08 & 11326 \\
\hline 2 & $17 \%$ & 3775.36 & 1888 \\
\hline 3 & $8 \%$ & 1776.64 & 592 \\
\hline 4 & $4 \%$ & 888.32 & 222 \\
\hline 5 & $1 \%$ & 222.08 & 44 \\
\hline 6 & $0 \%$ & 0.00 & 0 \\
\hline 7 & $0 \%$ & 0.00 & 0 \\
\hline Total & & 22208 & 14072 \\
\hline Number of organisations & $\%$ & $\%$ of total & Number of professionals \\
\hline 0 & $19 \%$ & 801.71 & - \\
\hline 1 & $51 \%$ & 2151.96 & 2152 \\
\hline 2 & $17 \%$ & 717.32 & 359 \\
\hline 3 & $8 \%$ & 337.56 & 113 \\
\hline 4 & $4 \%$ & 168.78 & 42 \\
\hline 5 & $1 \%$ & 42.20 & 8 \\
\hline 6 & $0 \%$ & 0 & 0 \\
\hline 7 & $0 \%$ & 0 & 0 \\
\hline Total & & 4219.52 & 2674 \\
\hline Number of organisations & $\%$ & $\%$ of total & Number of professionals \\
\hline 0 & $19 \%$ & 152.32 & - \\
\hline 1 & $51 \%$ & 408.87 & 408.87 \\
\hline 2 & $17 \%$ & 136.29 & 68.15 \\
\hline 3 & $8 \%$ & 64.14 & 21.38 \\
\hline 4 & $4 \%$ & 32.07 & 8.02 \\
\hline 5 & $1 \%$ & 8.02 & 1.60 \\
\hline 6 & $0 \%$ & 0 & 0.00 \\
\hline 7 & $0 \%$ & 0 & 0.00 \\
\hline Total & & 801.7088 & 507 \\
\hline Number of organisations & $\%$ & $\%$ of total & Number of professionals \\
\hline 0 & $19 \%$ & 28.94 & - \\
\hline 1 & $51 \%$ & 77.69 & 77.69 \\
\hline 2 & $17 \%$ & 25.90 & 12.95 \\
\hline 3 & $8 \%$ & 12.19 & 4.06 \\
\hline 4 & $4 \%$ & 6.09 & 1.52 \\
\hline 5 & $1 \%$ & 1.52 & 0.30 \\
\hline 6 & $0 \%$ & 0 & 0.00 \\
\hline 7 & $0 \%$ & 0 & 0.00 \\
\hline Total & & 152.3247 & 97 \\
\hline \multicolumn{3}{|c|}{ Conservation Population Estimate } & 17350 \\
\hline
\end{tabular}




\section{B.1.2 Desired Sample Size}

$S S=\frac{Z^{2} \times p \times(1-p)}{c^{2}}$

Where:

ss $=$ actual sample size

$Z=z$ value (e.g. 1.96 for $95 \%$ confidence interval)

$\mathrm{p}=$ percentage picking a choice, expressed as a decimal (e.g. 0.5 is worst case scenario)

$\mathrm{c}=$ margin of error, expressed as a decimal (e.g. $0.05= \pm 5 \%$ )

ss $=\frac{\mathrm{Z}^{2} \times p \times(1-p)}{c^{2}}$

SS $=\frac{1.96^{2} \times 0.5 \times(1-0.5)}{0.05^{2}}$

ss $=384$

Therefore the desired sample size for a confidence interval of $95 \%$ and a margin of error of $\pm 5 \%$ is 384 .

\section{B.2 Questionnaire Design}

\section{B.2.1 Question List}

\section{Industry Information}

Which part of the building industry most represents you?

Please list your associated affiliations with building industry related organisations (IPENZ, NZIA, CCANZ, Property Council, NZGBC, etc) - If you are not associated with any organisation please write none.

\section{Section 1: Background (1/6)}

Question 1: To what extent would you describe your level of interest in?

Question 2: What best describes your level of involvement with? 


\section{Section 2: Building Sustainability Rating Tools (2/6)}

Question 3: What do you see as the purpose of a Building Sustainability Rating Tool?

Question 4: How important is it to have a New Zealand specific Building Sustainability Rating Tool?

Question 5: Of the current existing Building Sustainability Rating Tools which are you aware of (commercial or residential)?

Question 6: Of the current existing Building Sustainability Rating Tools which do you have experience with (commercial or residential)? Meaning that you have a very good understanding of how the rating tool works, either through application or through the involvement in the development process of creating the tool.

Question 7: In your experience with existing Building Sustainability Rating Tools what have been the highest achieved ratings/scores? 10

Question 8: Have you completed training to become an accredited professional for any existing Building Sustainability Rating Tool?

\section{Section 3: Green Star New Zealand (3/6)}

Question 9: Are you aware of Green Star New Zealand?

Question 10: How important is it for Green Star New Zealand to be a New Zealand equivalent of the Australian Green Star system?

Question 11: To what extent do you think Green Star New Zealand will influence the building industry in a shift towards more sustainable building development in New Zealand?

Question 12: How likely is it that you will use Green Star New Zealand once it is officially released?

Question 13: If you are likely to use Green Star New Zealand, how do you anticipate using it?

Question 14: How likely is it that you will seek training to become a Green Star New Zealand accredited professional?

Question 15: How important is it that New Zealand buildings seek full Green Star accreditation? Question 16: What would be your reasons for using Green Star New Zealand?

\section{Section 4: The New Zealand Green Building Council (4/6)}

Question 17: Are you aware of the New Zealand Green Building Council?

Question 18: How appropriate is the approach of the NZGBC in the establishment of a New Zealand specific Building Sustainability Rating Tool?

Question 19: Do you have any reason for your selection of the appropriateness of the New Zealand Green Building Council in the establishment of a New Zealand specific Buildings Sustainability Rating Tool? ${ }^{11}$

\footnotetext{
10 These results were not examined as part of thise thesis.
} 
Appendix B

Question 20: To what extent do you think the New Zealand Green Building Council will influence the building industry in a shift towards more sustainable building development?

\section{Section 5: Triggers, Drivers, Obstacles and Reasons for Sustainable Building (5/6)}

Question 21: In your experience who triggers sustainable building in the first place?

Question 22: In your opinion who should be the main driver for sustainable building?

Question 23: At what stage of the building process is sustainable building most likely triggered?

Question 24: What do you think are the main drivers for sustainable building?

Question 25: What are the obstacles to sustainable building?

Question 26: What are your reasons for being involved with sustainable building?

Question 27: What do you believe are the economic reasons/benefits of sustainable building?

Question 28: What do you believe are the environmental reasons/benefits of sustainable building?

Question 29: What do you believe are the social reasons/benefits of sustainable building?

\section{Section 6: Information requirements (6/6)}

Question 30: What information do you require in with regards to sustainable building?

Question 31: What is your level of satisfaction with the current information available about sustainable building?

11 These results were not examined as part of this thesis. 


\section{B.2.2 Web-survey Questionnaire}

\section{VICTORIA UNIVERSITY OF WELLINGTON \\ Te Whare Wananga o te Upoko o fe Ika a Maui

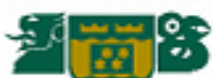 \\ SCHOOLOF ARCHITECTURE \\ Green Building Council}

Implementation of a New Zealand Building Sustainability Rating Too

Answers marked with $a *$ are required.

Information

The aim of this survey is to investigate the conditions needed for the successful implementation of a New Zealand Sustainability Rating Tool.

It investigates the building industry's understanding of Building Sustainability Rating Tools, Green Star New Zealand and sustainable building and should take no longer than 20 minutes to complete.

The information that is gathered from the survey will be used to complete the requirements of my Masters Thesis, and also by the New Zealand Green Building Council in their review processes, to help shape the design and delivery of Green Star New Zealand. Overall the research aims to assist the delivery of a more successful and New Zealand specific tool, and thus contribute to the development of more sustainable buildings in New Zealand.

Please be assured that the research is strictly confidential and has the approval of Victoria University of Wellington Human Ethics Committee.

A summary of the results will be available on request at the completion of the survey, with final results published in the Thesis.

If you have any queries about this research please do not hesitate to contact me. 
Thank you for your time and I look forward to your participation in this study.

Kind Regards

\section{Jono Smith}

Master of Building Science

Victoria University of Wellington

School of Architecture

Phone: +64 (04) 4636253

Mobile: +64 (0)21 1550517

Email: jonathan.ian.smith@gmail.com

Please click 'Next' to proceed. 


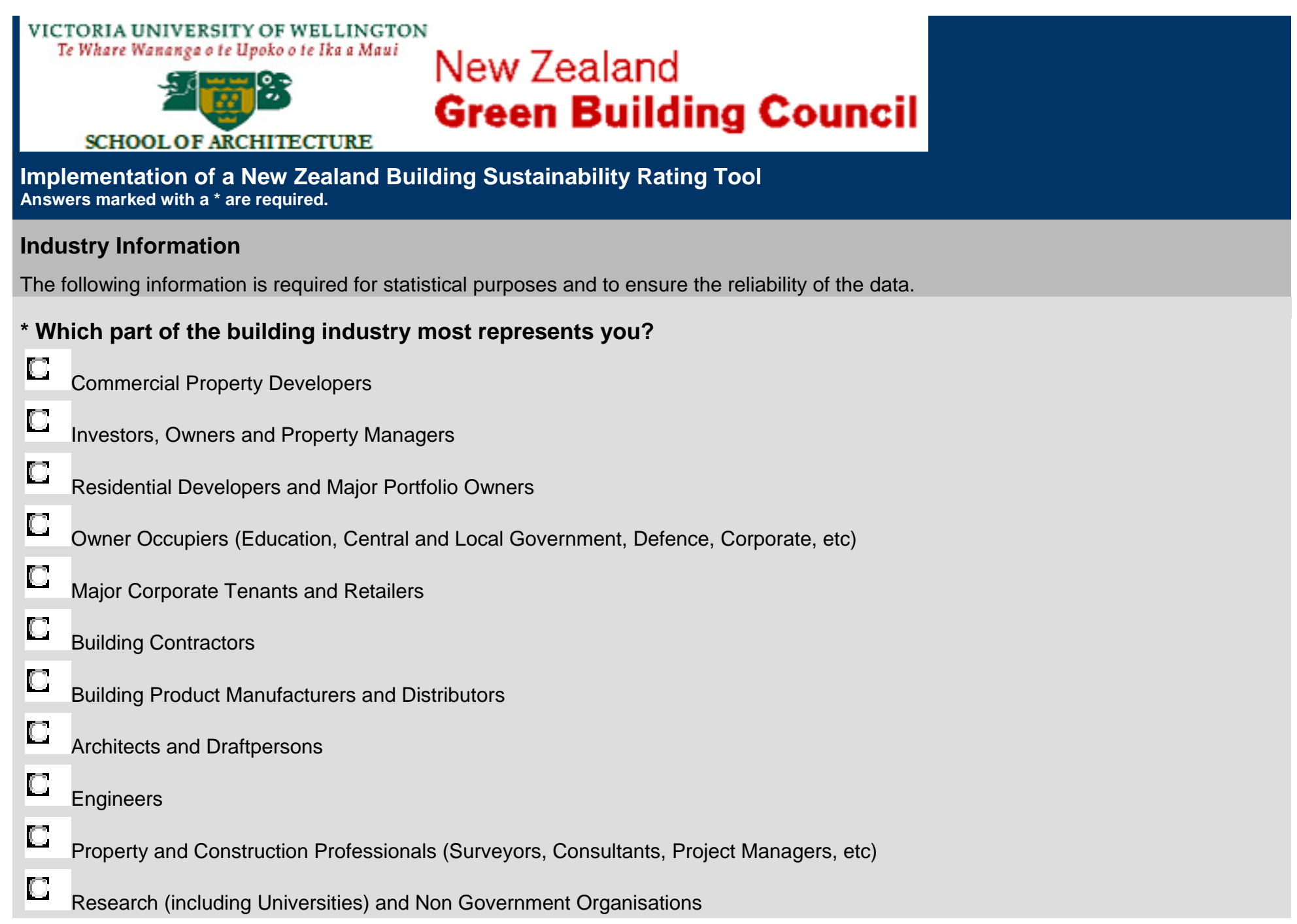


C Related Interests (Utilities, Financial, Insurance, Legal, etc)

* Please list your associated affiliations with building industry related organisations (IPENZ, NZIA, CCANZ, Property Council, NZGBC, etc) - If you are not associated with any organisation please write none.

Back Next




\section{VICTORIA UNIVERSITY OF WELLINGTON Te Whare Wananga o te Upoko o te Tha a Maui \\ SCHOOL OF ARCHITECTURE \\ New Zealand Green Building Council}

Implementation of a New Zealand Building Sustainability Rating Tool

Answers marked with $\mathbf{a}$ * are required.

Section 1: Background (1/6)

It is important to define sustainability and sustainable building in the context of this research.

Sustainability is defined as an idea of providing the best for human and the natural environment both now and in the future.

Sustainable building is defined as buildings which have been designed to minimize their impact on the environment, and that are economic to construct and operate over the whole lifetime of the building.

Question 1: To what extent would you describe your level of interest in?

\begin{tabular}{|c|c|c|c|c|c|c|c|}
\hline & $\begin{array}{c}\text { Not } \\
\text { interested }\end{array}$ & $\begin{array}{l}\text { Hardly } \\
\text { interested }\end{array}$ & $\begin{array}{l}\text { Slightly } \\
\text { interested }\end{array}$ & $\begin{array}{l}\text { Moderately } \\
\text { interested }\end{array}$ & $\begin{array}{l}\text { Considerably } \\
\text { interested }\end{array}$ & $\begin{array}{l}\text { Very } \\
\text { interested }\end{array}$ & $\begin{array}{l}\text { Extremely } \\
\text { interested }\end{array}$ \\
\hline Sustainability & $\mathbb{E}$ & $B$ & $\mathbb{E}$ & $\mathrm{C}$ & $\mathrm{C}$ & $\mathrm{C}$ & 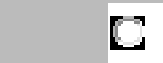 \\
\hline Sustainable building & $\mathrm{C}$ & $\mathrm{C}$ & $\mathrm{G}$ & $\mathbb{E}$ & $\mathrm{C}$ & $\mathrm{G}$ & $\mathrm{C}$ \\
\hline $\begin{array}{l}\text { Building Sustainability } \\
\text { Rating Tools }\end{array}$ & C & C & C & C & C & C & C \\
\hline
\end{tabular}

Question 2: What best describes your level of involvement with?

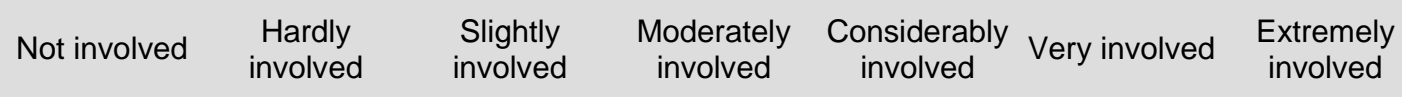




\begin{tabular}{l|lllllll}
\hline Sustainability & C & C & C & C & C & C & C \\
$\begin{array}{l}\text { Sustainable building } \\
\begin{array}{l}\text { Building Sustainability } \\
\text { Rating Tools }\end{array}\end{array}$ & C & C & C & C & C & C & C \\
\hline
\end{tabular}

Additional comments.

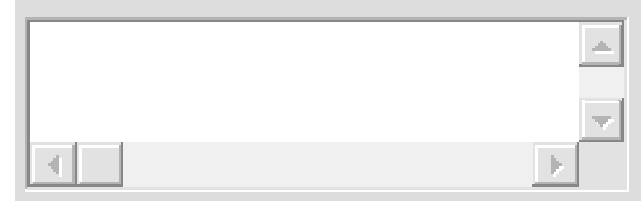




\section{VICTORIA UNIVERSITY OF WELLINGTON \\ Te Whare Wananga o te Upoko o te Tha a Maui

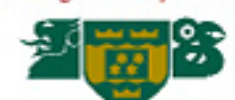 \\ SCHOOL OF ARCHITECTURE \\ New Zealand \\ Green Building Council}

Implementation of a New Zealand Building Sustainability Rating Tool

Answers marked with $\mathbf{a}^{*}$ are required.

Section 2: Building Sustainability Rating Tools (2/6)

Question 3: What do you see as the purpose of a Building Sustainability Rating Tool?

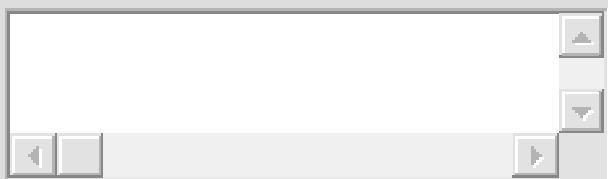

Question 4: How important is it to have a New Zealand specific Building Sustainability Rating Tool?

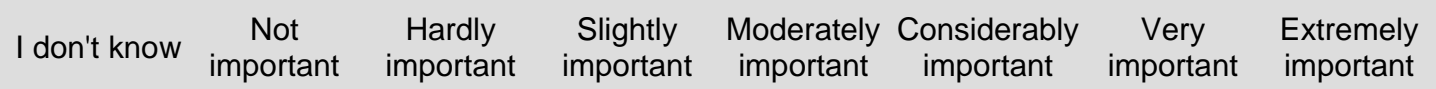

\begin{tabular}{|c|c|}
\hline Level of importance & $\mathbb{C}$ \\
\hline
\end{tabular}

Question 5: Of the current existing Building Sustainability Rating Tools which are you aware of (commercial or residential)?

Г I am not aware of any rating tools

- BASIX (Australia) 


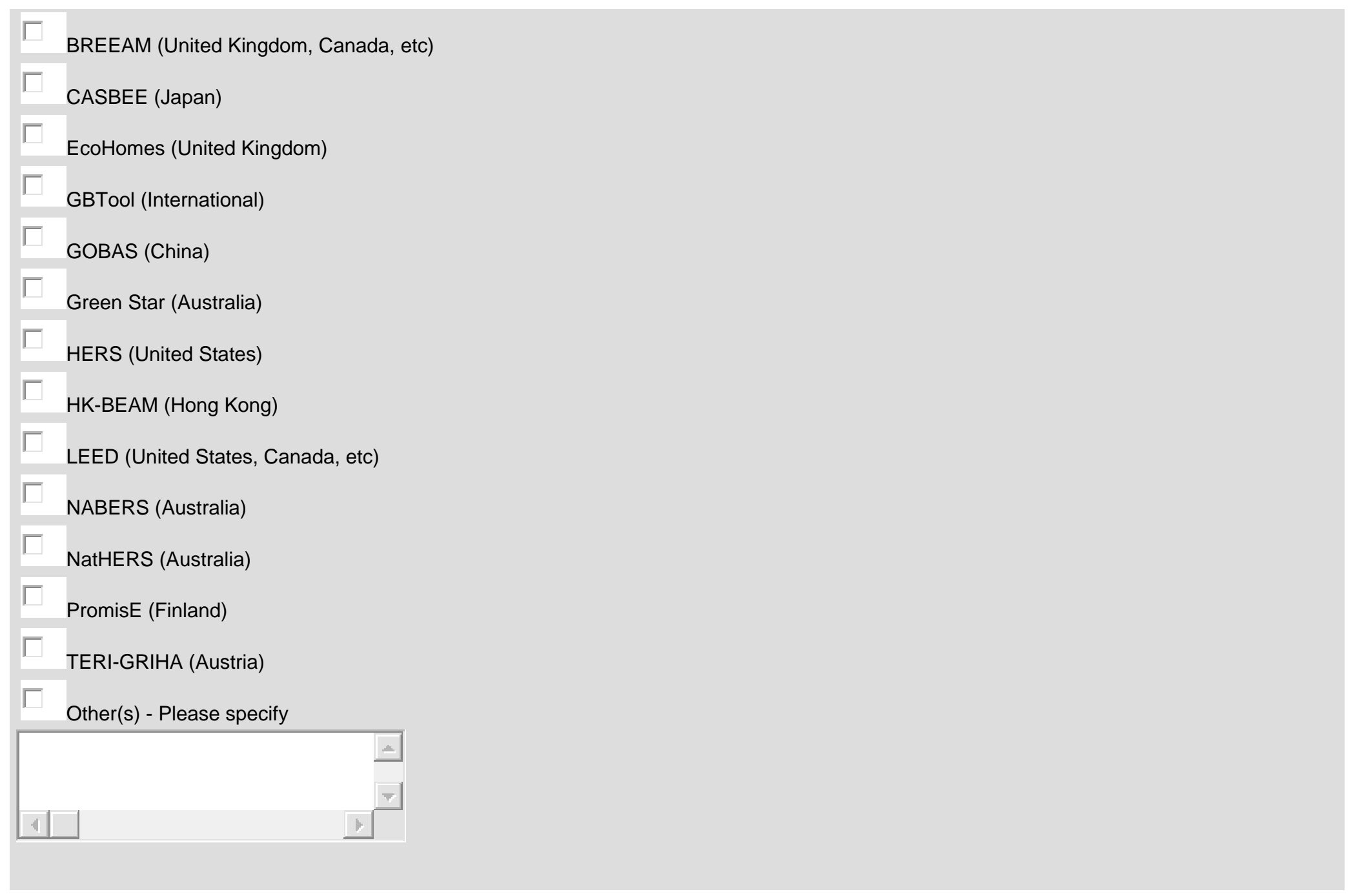


Question 6: Of the current existing Building Sustainability Rating Tools which do you have experience with (commercial or residential)? Meaning that you have a very good understanding of how the rating tool works, either through application or through the involvement in the development process of creating the tool.

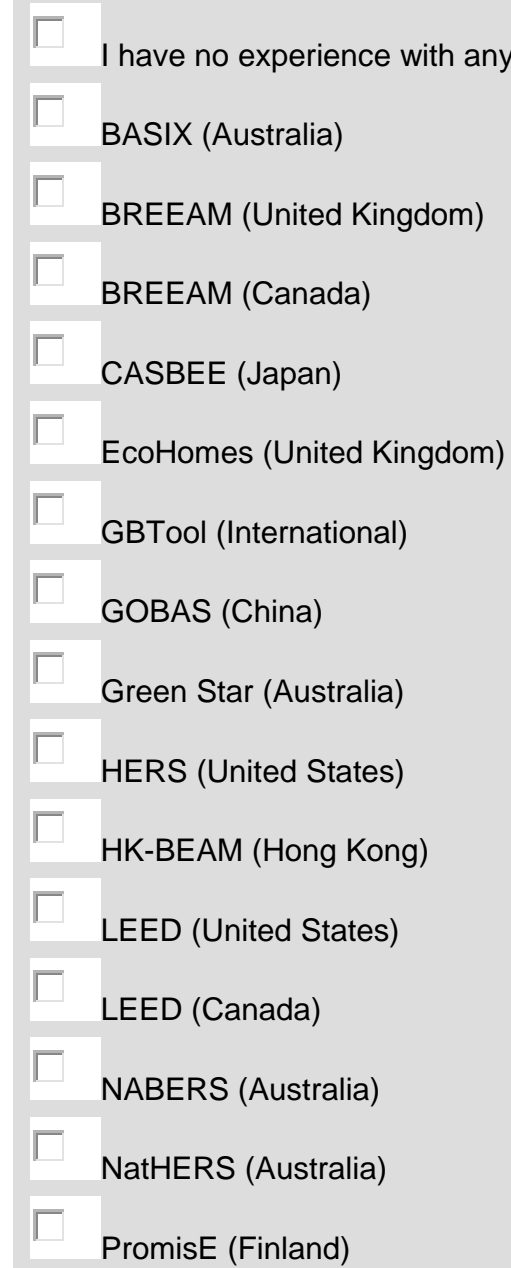


TERI-GRIHA (Austria)

$\square$ Other(s) - Please specify

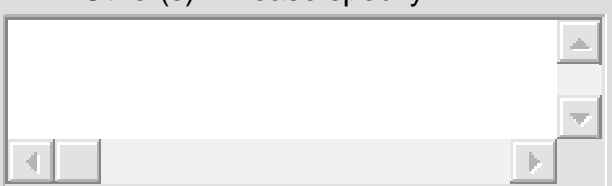

Question 7: In your experience with existing Building Sustainability Rating Tools what have been the highest achieved ratings/scores?

C Not applicable

C Please specify the details

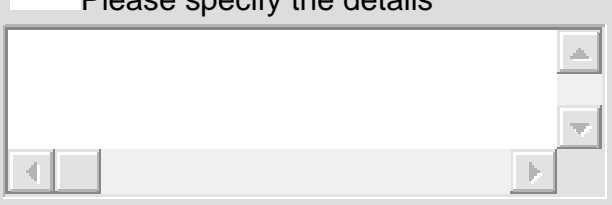

Question 8: Have you completed training to become an accredited professional for any existing Building Sustainability Rating Tool?

C No

C Yes, please specify the details

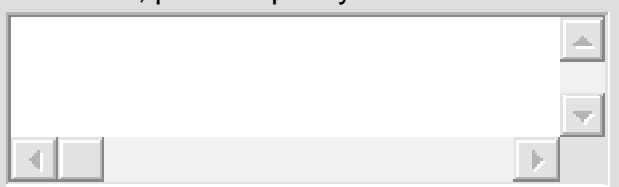


Additional comments.

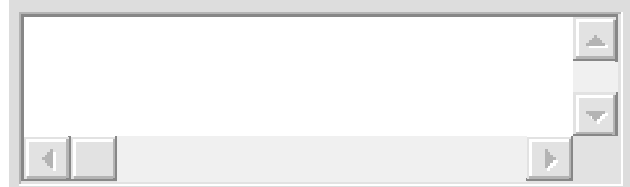




\section{VICTORIA UNIVERSITY OF WELLINGTON Te Whare Wananga o te Upoko o fe Ika a Maui SCHOOL OF ARCHITECTURE \\ New Zealand Green Building Council}

Implementation of a New Zealand Building Sustainability Rating Tool

Answers marked with $\mathbf{a}$ * are required.

Section 3: Green Star New Zealand (3/6)

Question 9: Are you aware of Green Star New Zealand?

C.

Yes

C No

Question 10: How important is it for Green Star New Zealand to be a New Zealand equivalent of the Australian Green Star system

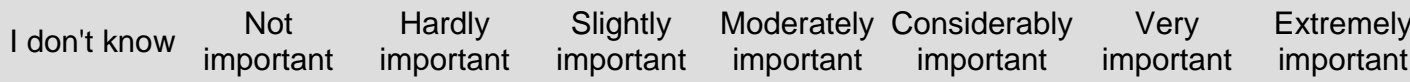

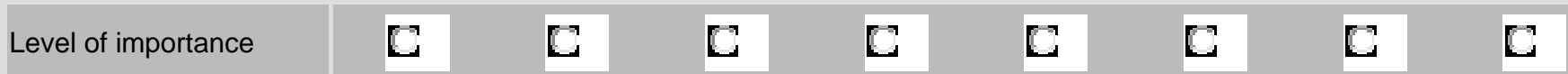

Question 11: To what extent do you think Green Star New Zealand will influence the building industry in a shift towards more sustainable building development in New Zealand?
I don't know
No Hardly any
A slight
A moderate$$
\text { A }
$$
A
A great
An extreme influence influence influence influence $\begin{gathered}\text { considerable } \\ \text { influence }\end{gathered}$
influence 


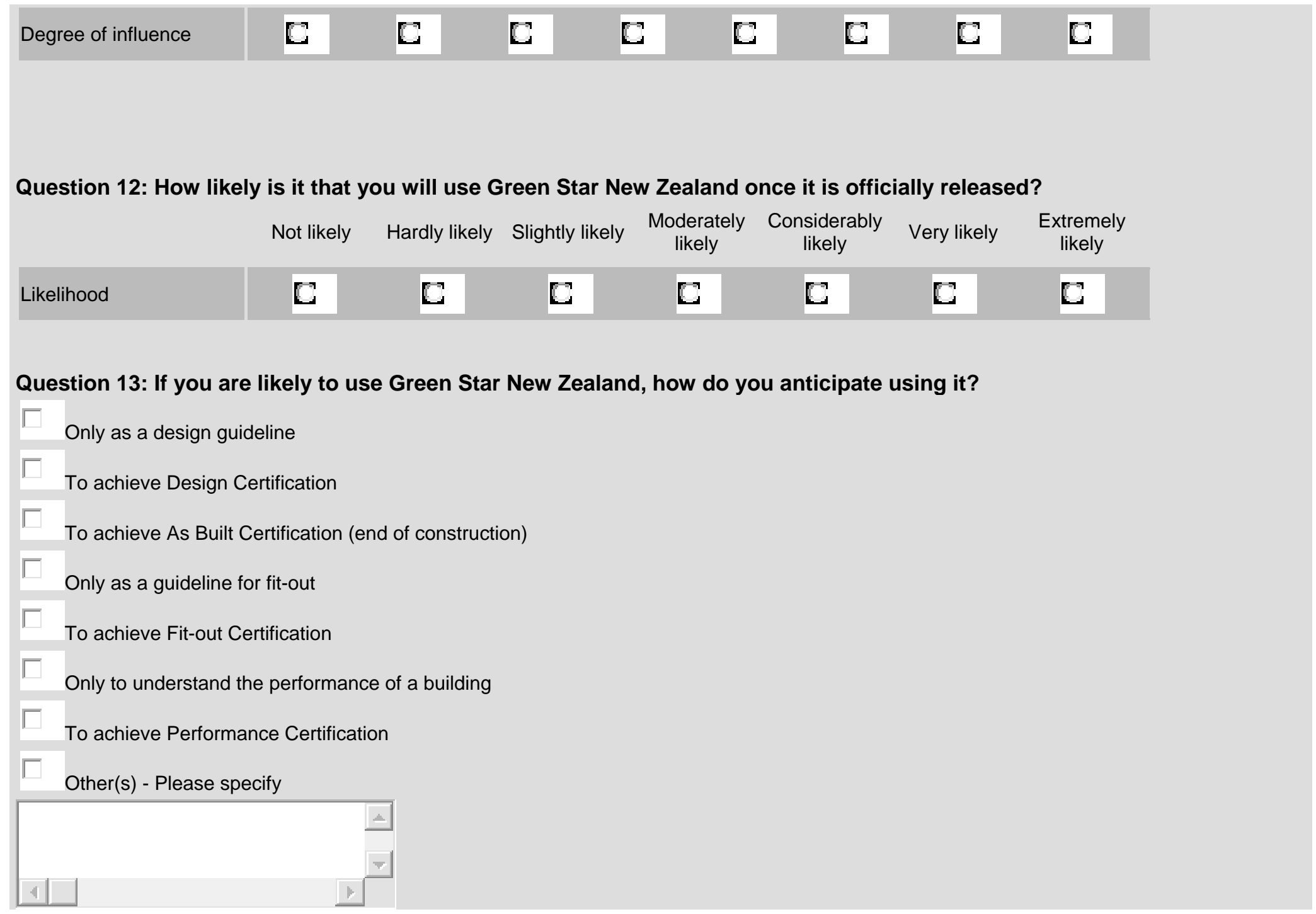




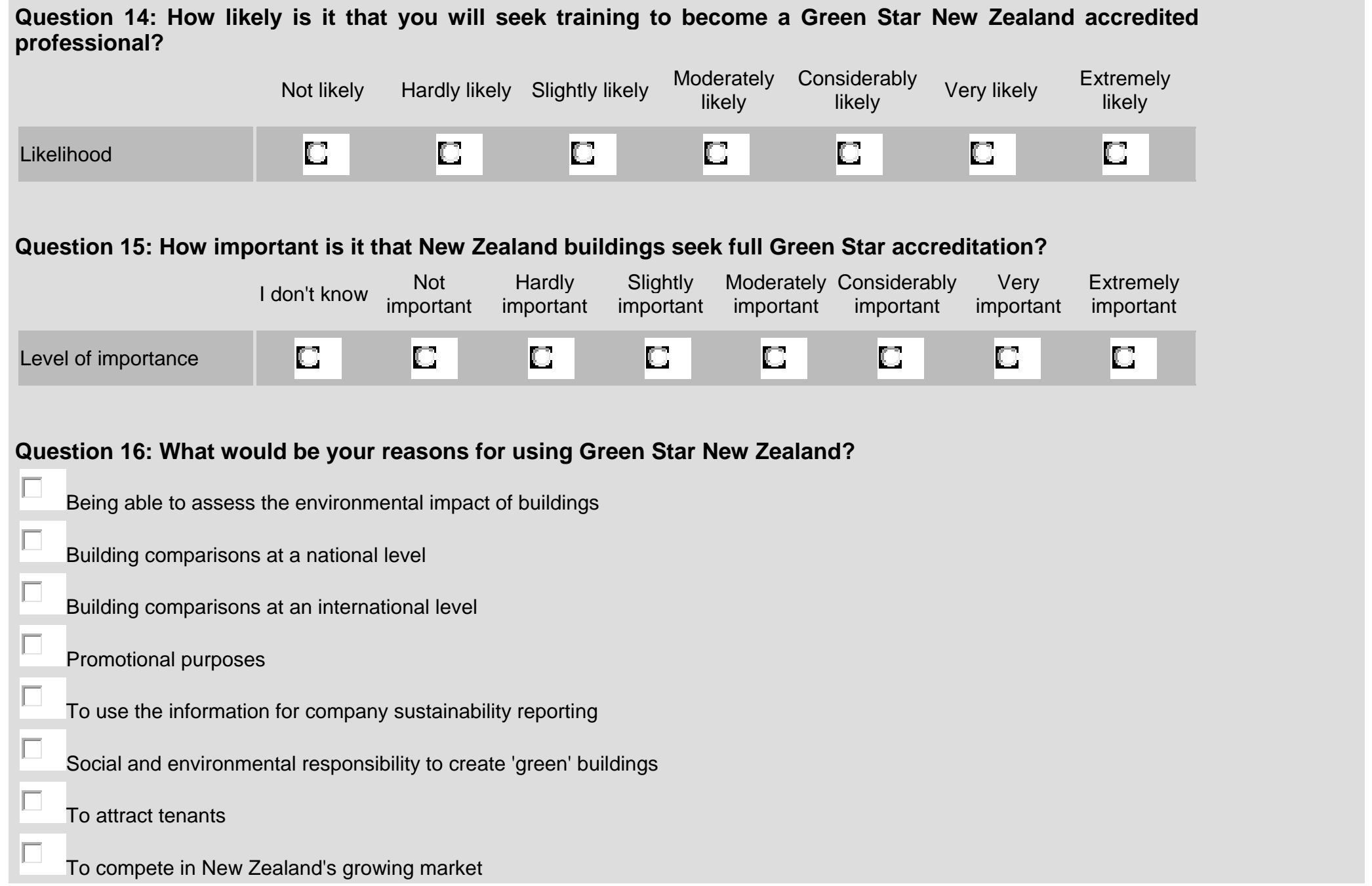


Other(s) - Please specify

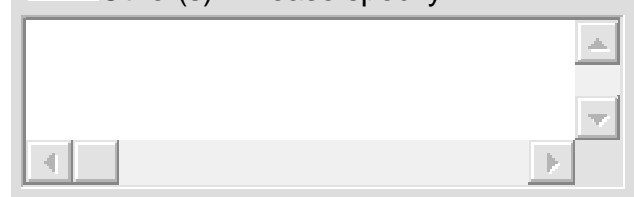

Additional comments.

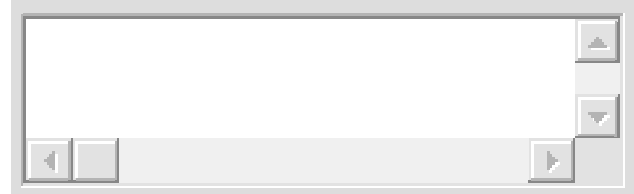




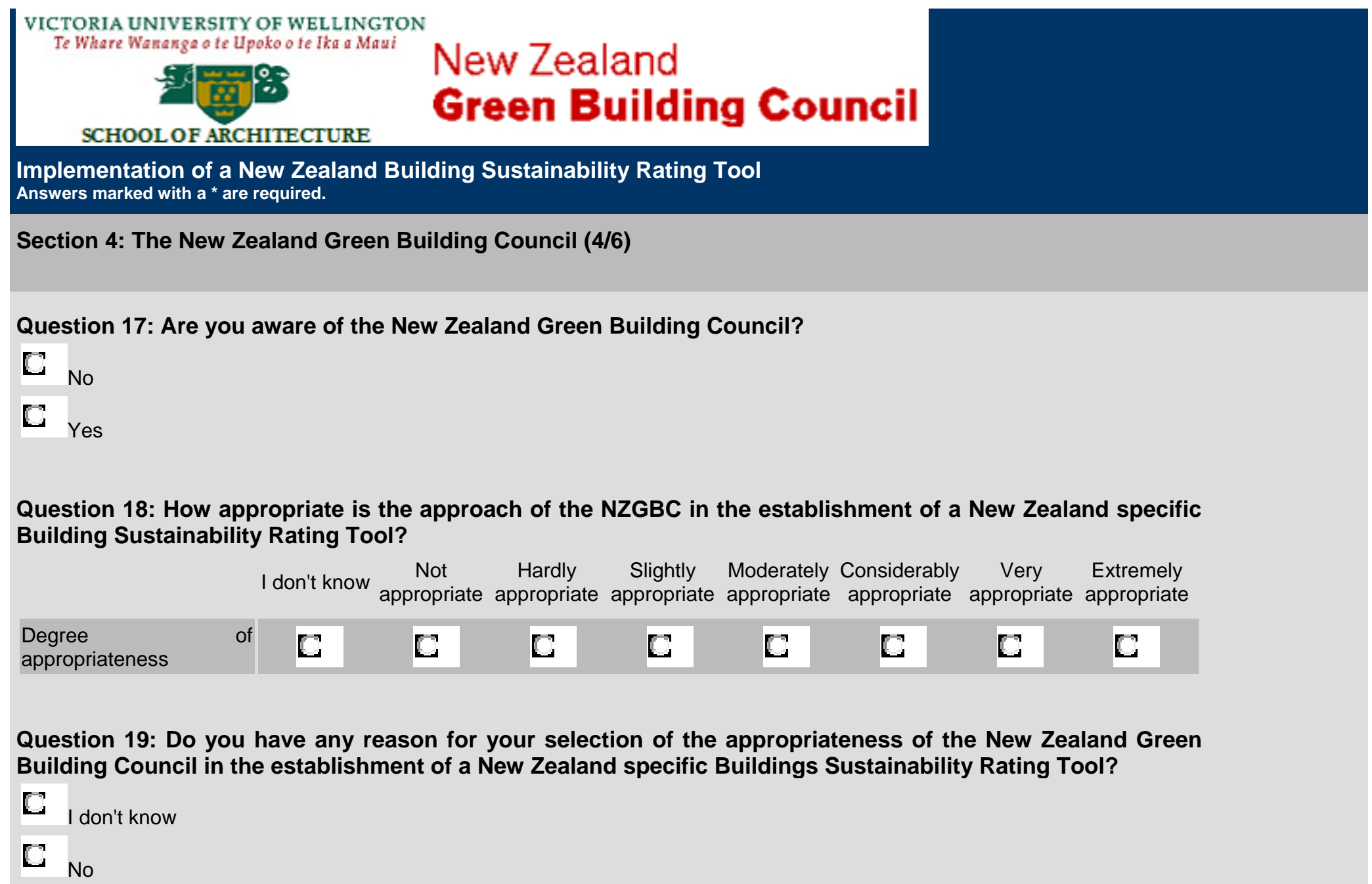




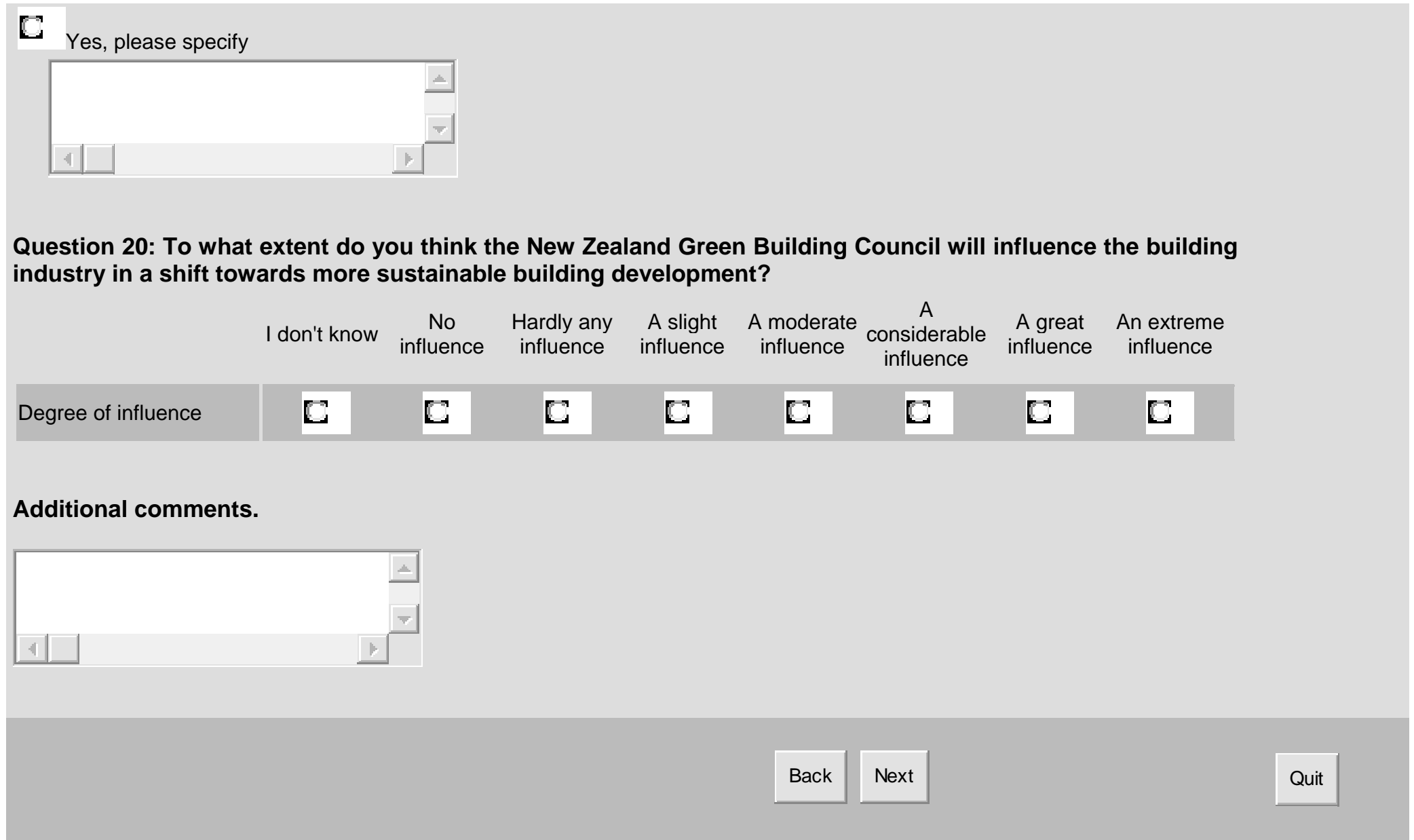


VICTORIA UNIVERSITY OF WELLINGTON Te Whare Wanange o te Upoko o te Ika a Maui

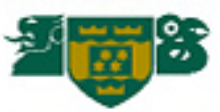

\section{New Zealand}

SCHOOL OF ARCHITECTURE

\section{Green Building Council}

Implementation of a New Zealand Building Sustainability Rating Tool

Answers marked with $\mathrm{a}$ * are required.

Section 5: Triggers, Drivers, Obstacles and Reasons for Sustainable Building (5/6)

The following questions relate to sustainable building and will allow some direct comparisons to be made to Australian and American research.

\section{Question 21: In your experience who triggers sustainable building in the first place?}

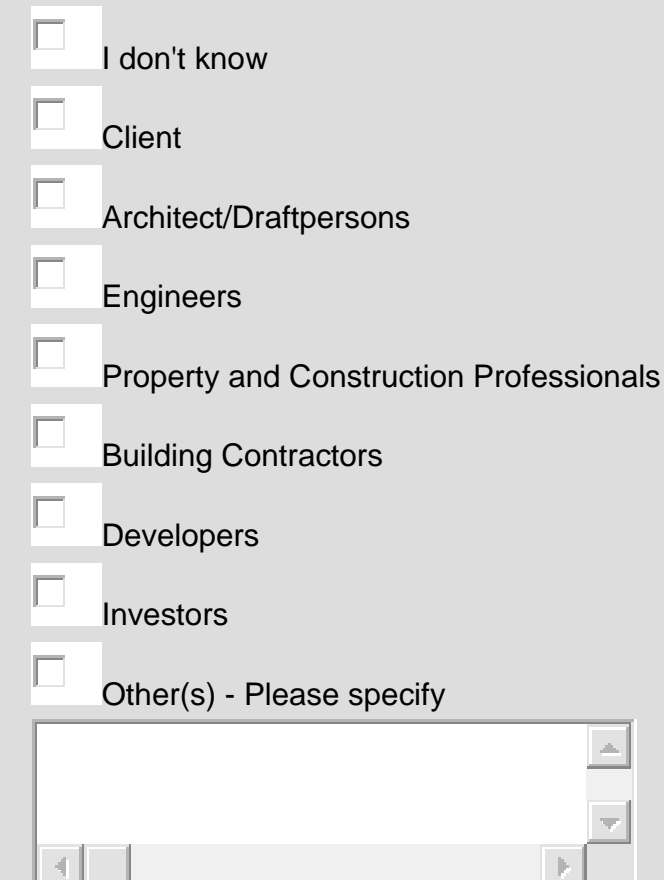




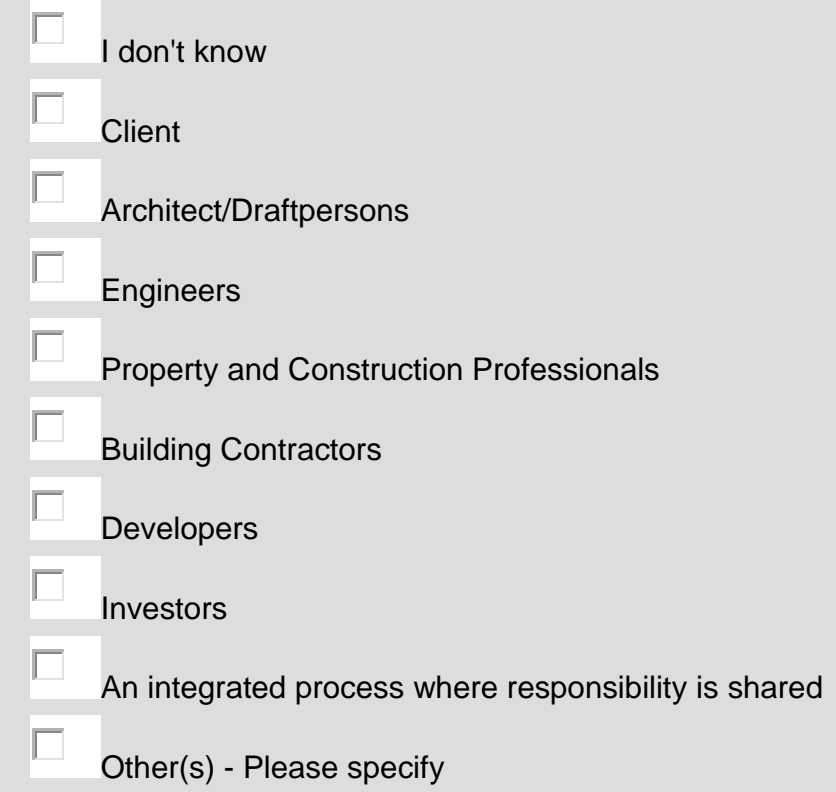

Question 23: At what stage of the building process is sustainable building most likley triggered?
$\ulcorner$ I don't know
$\Gamma$ Preliminary inquiries (meetings with client) 


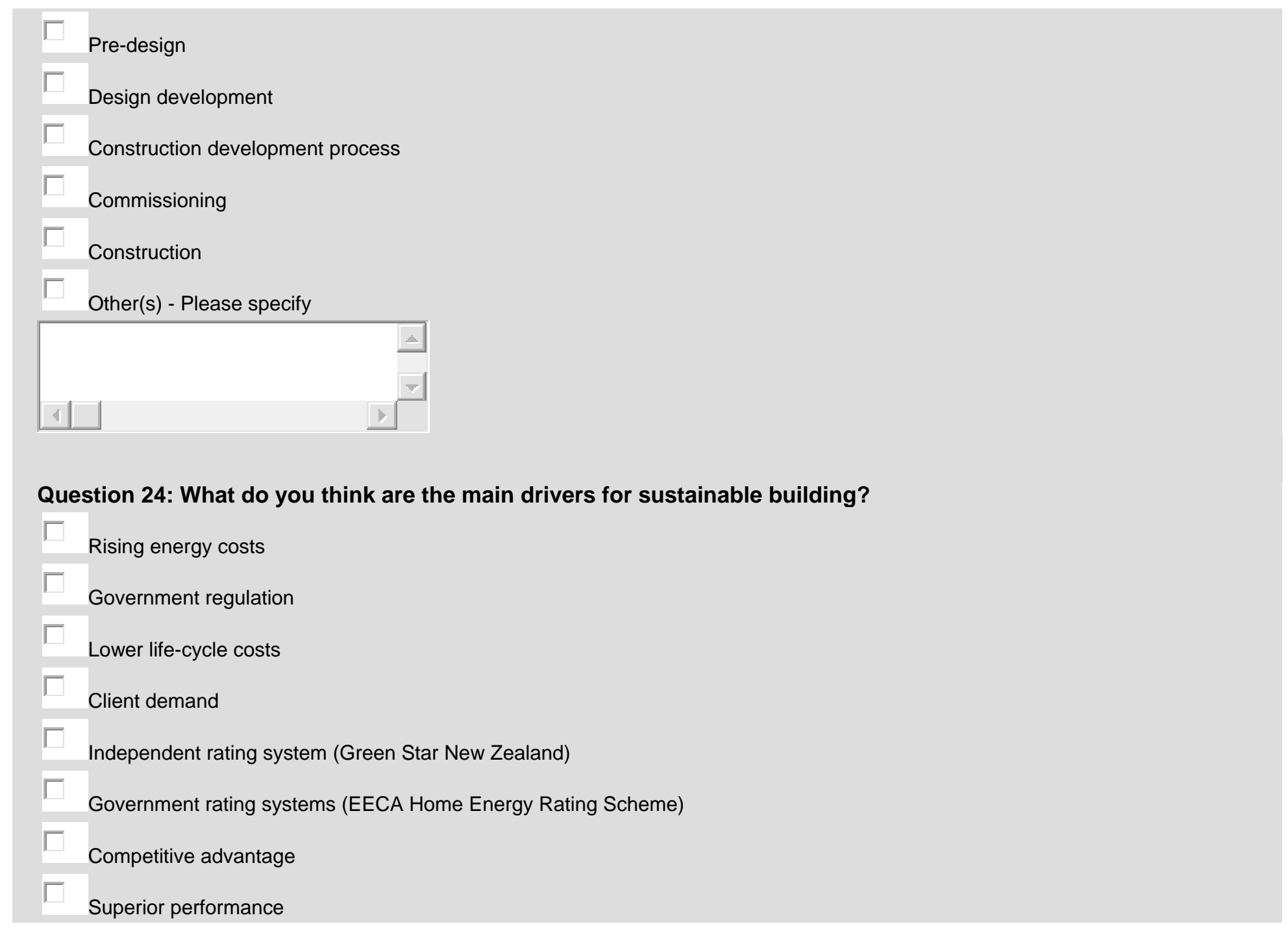




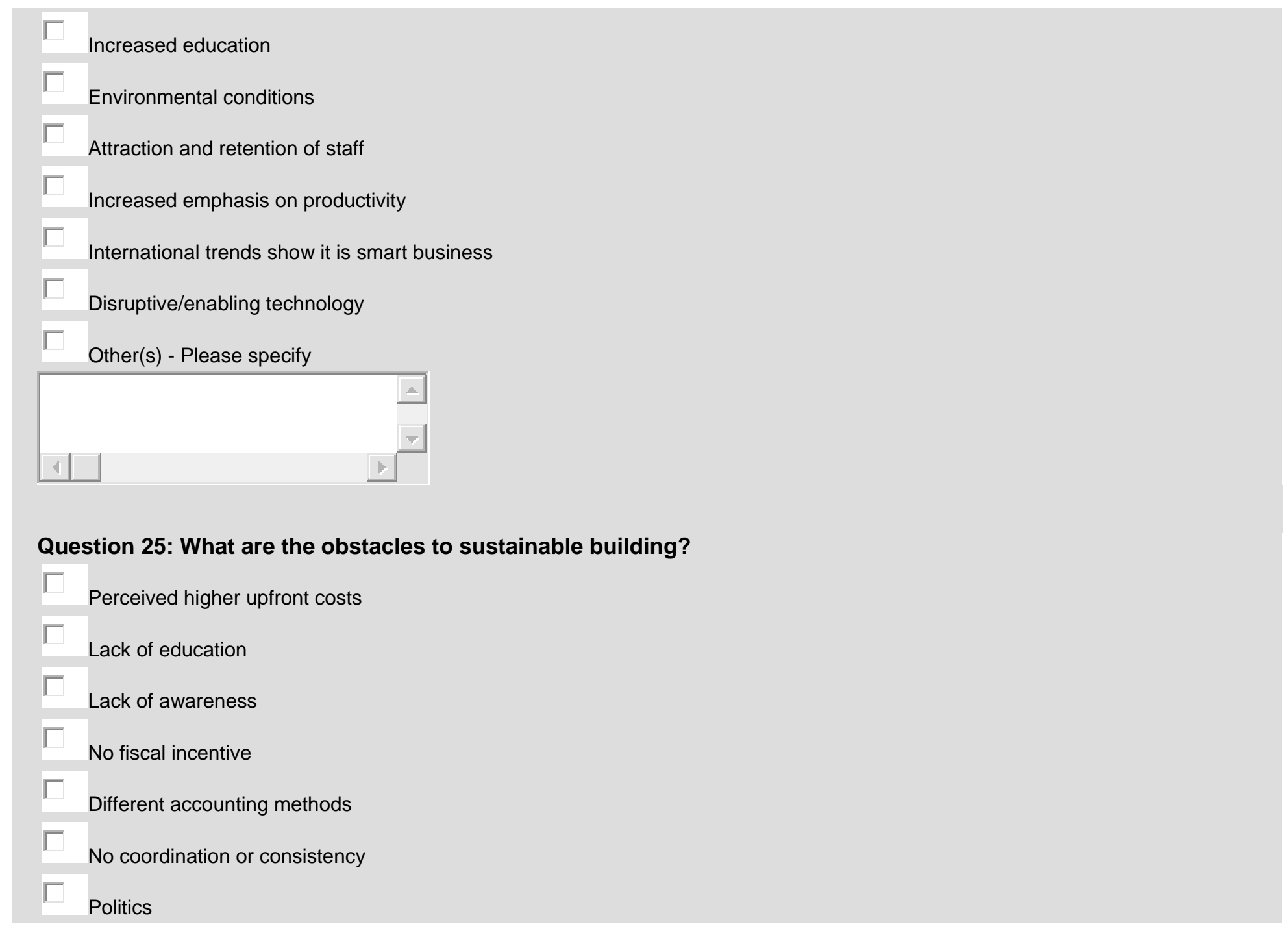




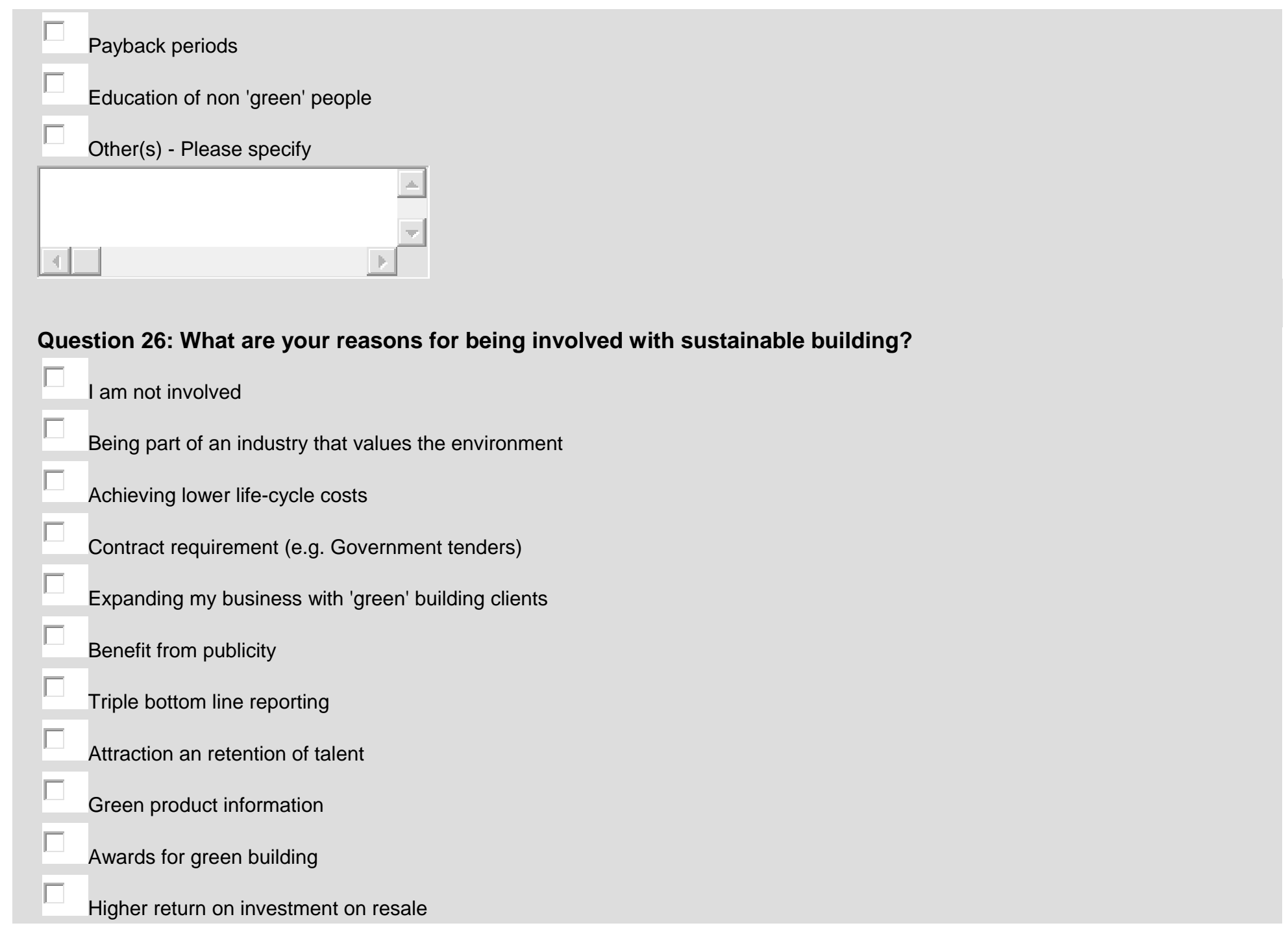




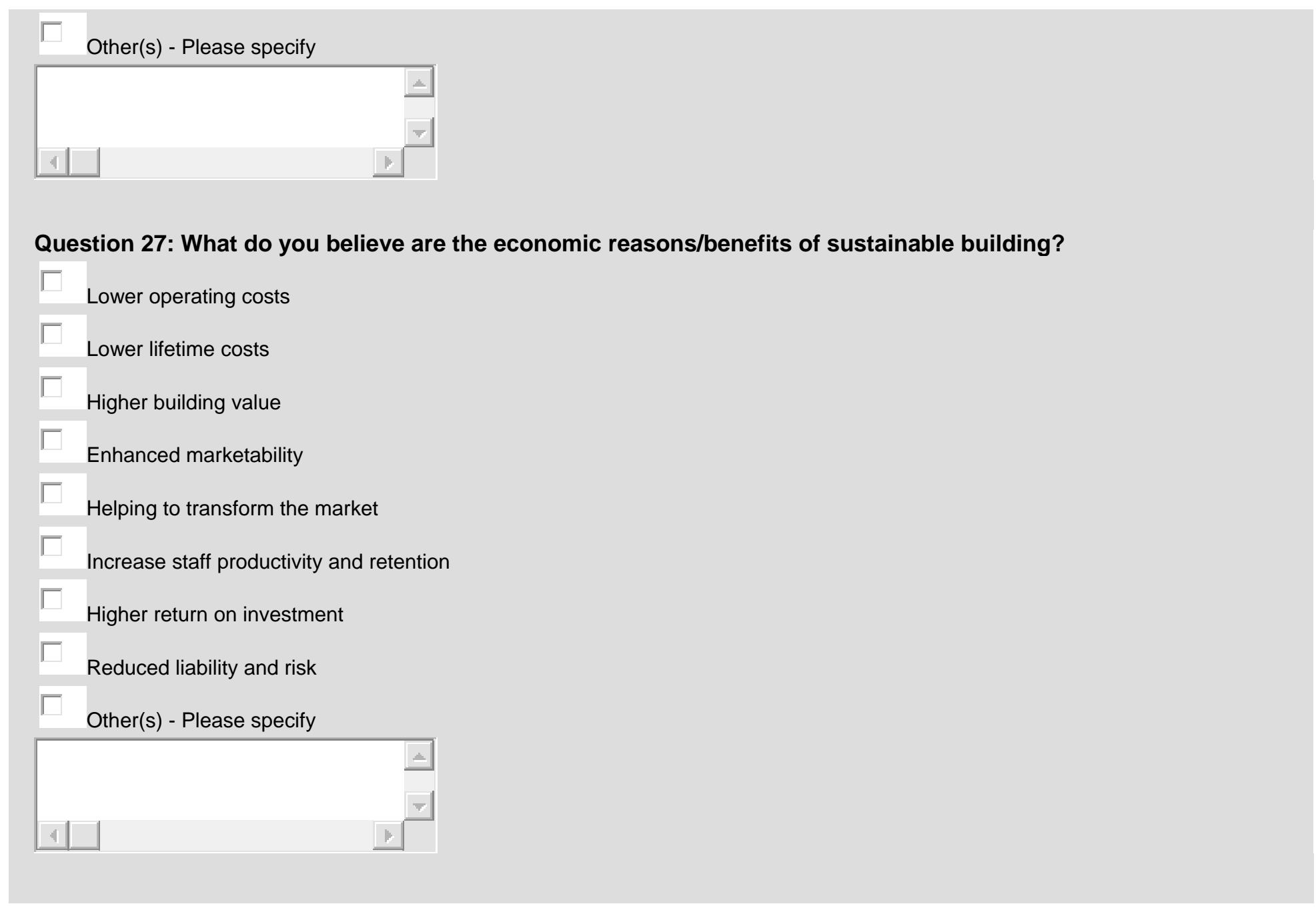


Question 28: What do you believe are the environmental reasons/benefits of sustainable building?

\section{building?}

Protection of the environment

Reducing climate change and emissions

- Minimising ecological impact of buildings

- Scarcity of natural resources

$\Gamma$

Improving indoor environment quality

एWaste reduction

T Other(s) - Please specify

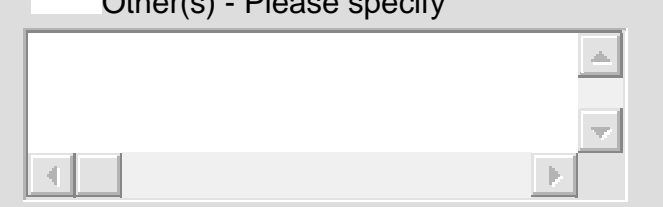

\section{Question 29: What do you believe are the social reasons/benefits of sustainable building?}

ए Greater health and well-being

Г Improved learning and healing environments

ГTenant productivity

Г Support for New Zealand economy

Г Moral imperative of being 'green'

— Aesthetically pleasing 


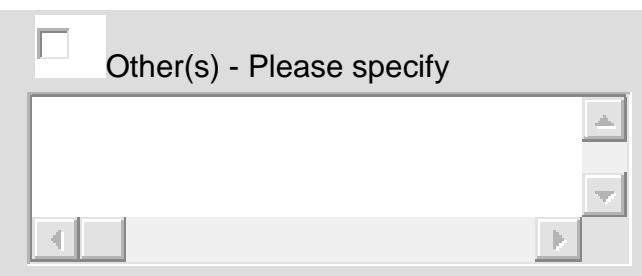

Additional comments.

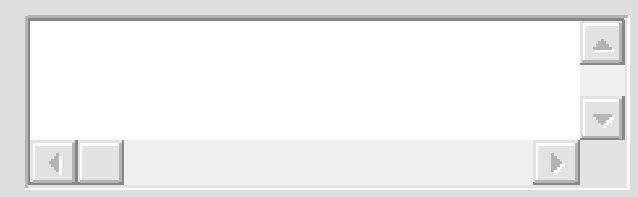




\section{VICTORIA UNIVERSITY OF WELLINGTON Te Whare Wananga o te Upoko o te Ika a Maui

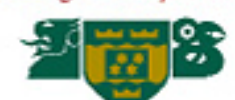 \\ New Zealand \\ SCHOOL OF ARCHITECTURE \\ Green Building Council}

Implementation of a New Zealand Building Sustainability Rating Tool

Answers marked with $a$ * are required.

Section 6: Information requirements (6/6)

\section{Question 30: What information do you require in regards to sustainable building?}

\section{Green products}

Environmental and economic cost benefit case studies

Green building emerging trends

Green projects

How-to design a 'green' building

Reviews and profiles of Green Star New Zealand buildings

下

Engineering or scientific information

How-to market a 'green' building

Green Star New Zealand accreditation course

How-to manage a 'green' building

'Green' players (services guide) 


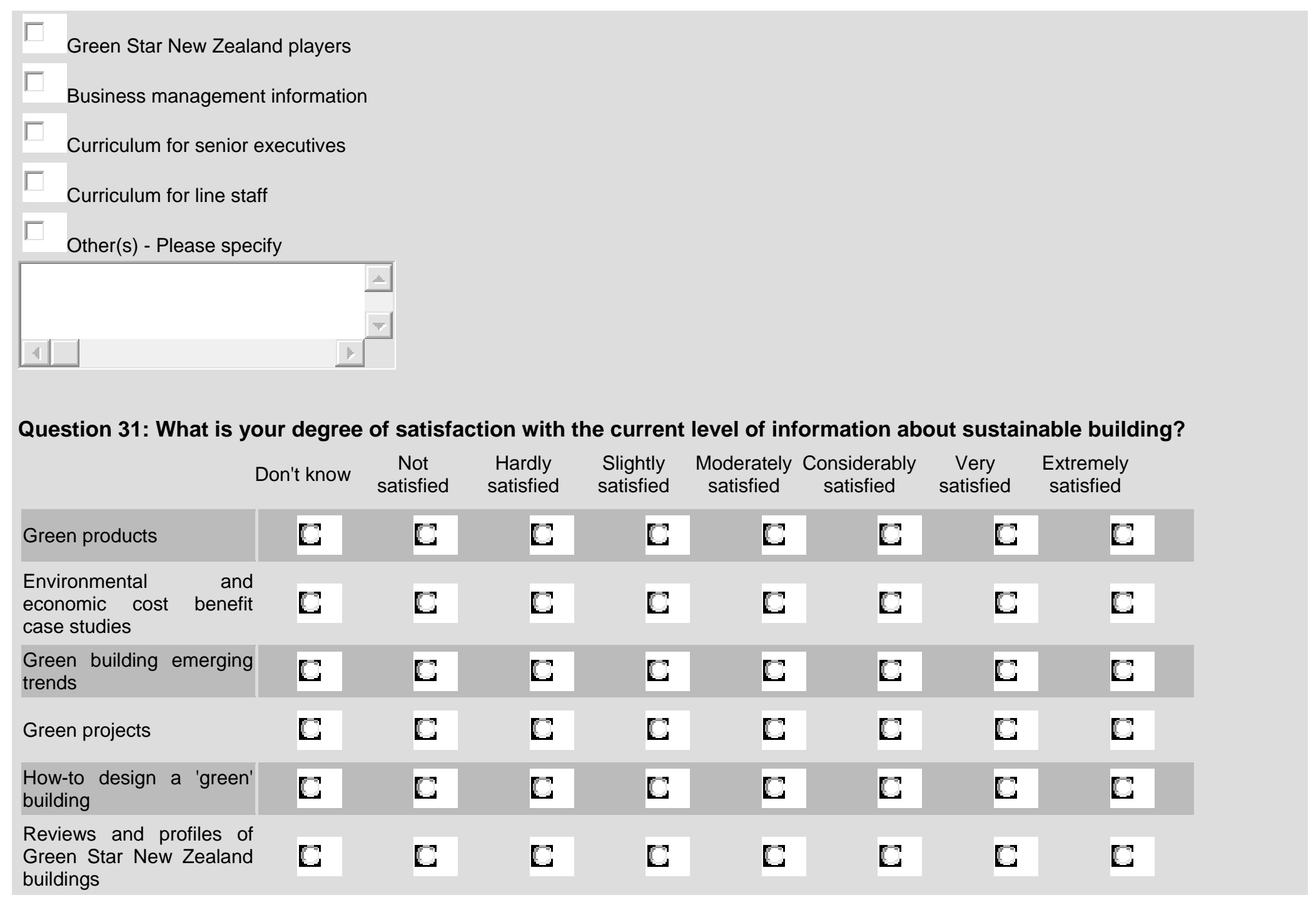




\begin{tabular}{|c|c|c|c|c|c|c|c|c|c|}
\hline $\begin{array}{l}\text { Engineering or scientific } \\
\text { information }\end{array}$ & C & $\mathrm{C}$ & $\mathrm{C}$ & $\mathrm{C}$ & $\mathrm{C}$ & $\mathbf{C}$ & $\mathrm{C}$ & $\mathrm{C}$ & \\
\hline $\begin{array}{l}\text { How-to market a 'green' } \\
\text { building }\end{array}$ & C & $\mathrm{C}$ & $\mathrm{C}$ & $\mathrm{C}$ & $\mathrm{C}$ & $\mathbf{C}$ & $\mathrm{C}$ & $\mathbf{C}$ & \\
\hline $\begin{array}{l}\text { Green Star New Zealand } \\
\text { accreditation course }\end{array}$ & $\mathbf{C}$ & $\mathrm{C}$ & $\mathrm{C}$ & $\mathbf{C}$ & $\mathrm{C}$ & C & $\mathrm{C}$ & $\mathrm{C}$ & \\
\hline $\begin{array}{l}\text { How-to manage a 'green' } \\
\text { building }\end{array}$ & $\mathbf{C}$ & $\mathbf{C}$ & $\mathrm{C}$ & $\mathrm{C}$ & $\mathrm{C}$ & C & $\mathrm{C}$ & $\mathrm{C}$ & \\
\hline $\begin{array}{l}\text { 'Green' players (services } \\
\text { guide) }\end{array}$ & C & $\mathbf{C}$ & $\mathrm{C}$ & $\mathrm{C}$ & $\mathrm{C}$ & C & $\mathrm{C}$ & $\mathrm{C}$ & \\
\hline $\begin{array}{l}\text { Green Star New Zealand } \\
\text { players }\end{array}$ & C & $\mathbf{C}$ & $\mathbf{C}$ & C & C & C & C & $\mathbf{C}$ & \\
\hline $\begin{array}{l}\text { Business management } \\
\text { information }\end{array}$ & C & $\mathrm{C}$ & $\mathrm{C}$ & $\mathrm{C}$ & C & C & $\mathrm{C}$ & $\mathrm{C}$ & \\
\hline $\begin{array}{l}\text { Curriculum for senior } \\
\text { executives }\end{array}$ & C & $\mathbf{C}$ & $\mathrm{C}$ & $\mathbf{C}$ & C & C & $\mathrm{C}$ & $\mathrm{C}$ & \\
\hline Curriculum for line staff & C & C & C & $\mathrm{C}$ & $\mathrm{C}$ & $\mathrm{C}$ & $\mathrm{C}$ & $\mathrm{C}$ & \\
\hline \multicolumn{10}{|l|}{ Additional comments. } \\
\hline 10 & & & & & & & & & \\
\hline & & & & & Back & Next & & & Quit \\
\hline
\end{tabular}


VICTORIA UNIVERSITY OF WELLINGTON Te Whare Wanange o te Upoko o te Ika a Maui

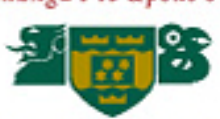

New Zealand

SCHOOL OF ARCHITECTURE

\section{Green Building Council}

Implementation of a New Zealand Building Sustainability Rating Tool

Answers marked with $\mathrm{a} *$ are required.

Preliminary results

If you wish to be sent the preliminary results at the conclusion of this survey, please provide your email address.

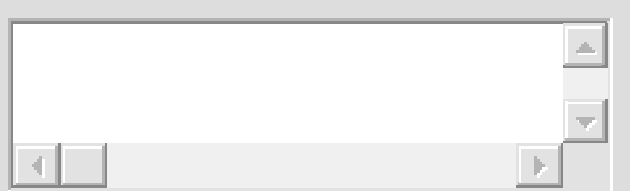

Thank you for participating in this study.

Please click 'Finished' to complete the survey.

$$
\text { Back Finished }
$$


Appendix B 


\section{Appendix C: Results}

\section{C.1 Statistical Significance}

\section{C.1.1 Actual Margin of Error}

actual ss $=\frac{Z^{2} \times p \times(1-p)}{c^{2}}$

Where:

actual ss $=$ actual sample size

$\mathrm{Z}=\mathrm{z}$ value (e.g. 1.96 for $95 \%$ confidence interval)

$\mathrm{p}=$ percentage picking a choice, expressed as a decimal (e.g. 0.5 is worst case scenario)

$\mathrm{c}=$ margin of error, expressed as a decimal (e.g. $0.05= \pm 5 \%$ )

Rearranged so the margin of error is the subject:

$c=\sqrt{\frac{Z^{2} \times p \times(1-p)}{\text { actual ss }}}$

$c=\sqrt{\frac{1.96^{2} \times 0.5 \times(1-0.5)}{476}}$

$c=0.044$

Therefore the actual margin of error for the survey was $\pm 4 \%$ with a desired confidence interval of $95 \%$. 


\section{C.1.2 Non-response}

Table C-1: Statistical information of survey questions

\begin{tabular}{|c|c|c|c|c|c|}
\hline Question: & $\begin{array}{l}\text { Early respondents versus } \\
\text { late respondents }\end{array}$ & Number & Mean & $\begin{array}{l}\text { Std. } \\
\text { Deviation }\end{array}$ & Std. Error Mean \\
\hline \multirow[b]{2}{*}{$\begin{array}{l}\text { Question 1: To what extent would you describe your level of } \\
\text { interest in sustainability? }\end{array}$} & Early & 335 & 6.0567 & 1.0888 & 0.0595 \\
\hline & Late & 100 & 6 & 1.0347 & 0.1035 \\
\hline \multirow[b]{2}{*}{$\begin{array}{l}\text { Question 1: To what extent would you describe your level of } \\
\text { interest in sustainable building? }\end{array}$} & Early & 336 & 6.0804 & 1.0774 & 0.0588 \\
\hline & Late & 97 & 6.1031 & 0.9734 & 0.0988 \\
\hline \multirow[b]{2}{*}{$\begin{array}{l}\text { Question 1: To what extent would you describe your level of } \\
\text { interest in BSRTs? }\end{array}$} & Early & 337 & 5.6706 & 1.2846 & 0.07 \\
\hline & Late & 100 & 5.71 & 1.1573 & 0.1157 \\
\hline \multirow[b]{2}{*}{$\begin{array}{l}\text { Question 2: What best describes your level of involvement with } \\
\text { sustainability? }\end{array}$} & Early & 335 & 4.7761 & 1.6141 & 0.0882 \\
\hline & Late & 100 & 4.59 & 1.6823 & 0.1682 \\
\hline \multirow[b]{2}{*}{$\begin{array}{l}\text { Question 2: What best describes your level of involvement with } \\
\text { sustainable building? }\end{array}$} & Early & 337 & 4.7359 & 1.5844 & 0.0863 \\
\hline & Late & 99 & 4.5657 & 1.6913 & 0.17 \\
\hline
\end{tabular}

Jonathan Smith 


\begin{tabular}{|c|c|c|c|c|c|}
\hline \multirow{2}{*}{$\begin{array}{l}\text { Question 2: What best describes your level of involvement with } \\
\text { BSRTs? }\end{array}$} & Early & 335 & 3.2985 & 1.9577 & 0.107 \\
\hline & Late & 100 & 3.24 & 1.9076 & 0.1908 \\
\hline \multirow{2}{*}{$\begin{array}{l}\text { Question 4: How important is it to have a New Zealand } \\
\text { specific Building Sustainability Rating Tool? }\end{array}$} & Early & 298 & 6.4329 & 1.6383 & 0.0949 \\
\hline & Late & 84 & 6.5595 & 1.3915 & 0.1518 \\
\hline \multirow{2}{*}{$\begin{array}{l}\text { Question 7: In your experience with existing Building } \\
\text { Sustainability Rating Tools what have been the highest achieved } \\
\text { ratings/scores? }\end{array}$} & Early & 364 & 1.3407 & 0.4746 & 0.0249 \\
\hline & Late & 111 & 1.3063 & 0.463 & 0.044 \\
\hline \multirow[b]{2}{*}{ Question 9: Are you aware of Green Star New Zealand? } & Early & 293 & 1.215 & 0.4115 & 0.024 \\
\hline & Late & 83 & 1.2651 & 0.444 & 0.0487 \\
\hline \multirow{2}{*}{$\begin{array}{l}\text { Question 10: How important is it for Green Star New Zealand } \\
\text { to be a New Zealand equivalent of the Australian Green Star } \\
\text { system }\end{array}$} & Early & 298 & 5.453 & 2.2307 & 0.1292 \\
\hline & Late & 87 & 5.2644 & 2.3941 & 0.2567 \\
\hline \multirow{2}{*}{$\begin{array}{l}\text { Question 11: To what extent do you think Green Star New } \\
\text { Zealand will influence the building industry in a shift towards } \\
\text { more sustainable building development in New Zealand? }\end{array}$} & Early & 298 & 5.3054 & 1.8938 & 0.1097 \\
\hline & Late & 86 & 5.0814 & 1.9049 & 0.2054 \\
\hline
\end{tabular}




\begin{tabular}{|c|c|c|c|c|c|}
\hline \multirow[b]{2}{*}{$\begin{array}{l}\text { Question 12: How likely is it that you will use Green Star New } \\
\text { Zealand once it is officially released? }\end{array}$} & Early & 289 & 5.3529 & 1.5321 & 0.0901 \\
\hline & Late & 84 & 5.2381 & 1.502 & 0.1639 \\
\hline \multirow{2}{*}{$\begin{array}{l}\text { Question 14: How likely is it that you will seek training to } \\
\text { become a Green Star New Zealand accredited professional? }\end{array}$} & Early & 294 & 3.7177 & 2.0166 & 0.1176 \\
\hline & Late & 86 & 3.8023 & 1.89 & 0.2038 \\
\hline \multirow{2}{*}{$\begin{array}{l}\text { Question 15: How important is it that New Zealand buildings } \\
\text { seek full Green Star accreditation? }\end{array}$} & Early & 294 & 5.8333 & 1.7651 & 0.1029 \\
\hline & Late & 87 & 5.6207 & 2.0923 & 0.2243 \\
\hline \multirow{2}{*}{$\begin{array}{l}\text { Question 17: Are you aware of the New Zealand Green } \\
\text { Building Council? }\end{array}$} & Early & 287 & 1.8258 & 0.38 & 0.0224 \\
\hline & Late & 83 & 1.7349 & 0.444 & 0.0487 \\
\hline \multirow{2}{*}{$\begin{array}{l}\text { Question 18: How appropriate is the approach of the NZGBC } \\
\text { in the establishment of a New Zealand specific Building } \\
\text { Sustainability Rating Tool? }\end{array}$} & Early & 286 & 4.9825 & 2.5621 & 0.1515 \\
\hline & Late & 83 & 4.3855 & 2.6997 & 0.2963 \\
\hline \multirow{2}{*}{$\begin{array}{l}\text { Question 19: Do you have any reason for your selection of the } \\
\text { appropriateness of the New Zealand Green Building Council in } \\
\text { the establishment of a New Zealand specific Buildings } \\
\text { Sustainability Rating Tool? }\end{array}$} & Early & 364 & 2.4093 & 0.8063 & 0.0423 \\
\hline & Late & 111 & 2.3153 & 0.9044 & 0.0858 \\
\hline
\end{tabular}




\begin{tabular}{|c|c|c|c|c|c|}
\hline \multirow{2}{*}{$\begin{array}{l}\text { Question 20: To what extent do you think the New Zealand } \\
\text { Green Building Council will influence the building industry in a } \\
\text { shift towards more sustainable building development? }\end{array}$} & Early & 286 & 5.3112 & 1.7605 & 0.1041 \\
\hline & Late & 84 & 4.9167 & 2.0192 & 0.2203 \\
\hline \multirow[b]{2}{*}{$\begin{array}{l}\text { Question 31: What is your degree of satisfaction with the } \\
\text { current level of information about 'green' products? }\end{array}$} & Early & 253 & 3.3715 & 1.3527 & 0.085 \\
\hline & Late & 77 & 3.4026 & 1.4802 & 0.1687 \\
\hline \multirow{2}{*}{$\begin{array}{l}\text { Question 31: What is your degree of satisfaction with the } \\
\text { current level of information about environmental and } \\
\text { economic cost benefit case studies? }\end{array}$} & Early & 252 & 2.9563 & 1.1951 & 0.0753 \\
\hline & Late & 76 & 2.8816 & 1.3949 & 0.16 \\
\hline \multirow{2}{*}{$\begin{array}{l}\text { Question 31: What is your degree of satisfaction with the } \\
\text { current level of information about 'green' building emerging } \\
\text { trends? }\end{array}$} & Early & 254 & 3.6969 & 1.3479 & 0.0846 \\
\hline & Late & 77 & 3.6234 & 1.4871 & 0.1695 \\
\hline \multirow[b]{2}{*}{$\begin{array}{l}\text { Question 31: What is your degree of satisfaction with the } \\
\text { current level of information about 'green' projects? }\end{array}$} & Early & 249 & 3.5984 & 1.3226 & 0.0838 \\
\hline & Late & 77 & 3.6364 & 1.486 & 0.1693 \\
\hline \multirow{2}{*}{$\begin{array}{l}\text { Question 31: What is your degree of satisfaction with the } \\
\text { current level of information about how-to design a 'green' } \\
\text { building? }\end{array}$} & Early & 249 & 3.3012 & 1.4514 & 0.092 \\
\hline & Late & 77 & 3.4156 & 1.5334 & 0.1747 \\
\hline
\end{tabular}




\begin{tabular}{|c|c|c|c|c|c|}
\hline \multirow{2}{*}{$\begin{array}{l}\text { Question 31: What is your degree of satisfaction with the } \\
\text { current level of information about reviews and profiles of } \\
\text { Green Star NZ buildings? }\end{array}$} & Early & 250 & 2.644 & 1.2472 & 0.0789 \\
\hline & Late & 76 & 2.5132 & 1.3416 & 0.1539 \\
\hline \multirow{2}{*}{$\begin{array}{l}\text { Question 31: What is your degree of satisfaction with the } \\
\text { current level of information about engineering or scientific } \\
\text { information? }\end{array}$} & Early & 248 & 2.9516 & 1.3815 & 0.0877 \\
\hline & Late & 76 & 2.8289 & 1.509 & 0.1731 \\
\hline \multirow{2}{*}{$\begin{array}{l}\text { Question 31: What is your degree of satisfaction with the } \\
\text { current level of information about how-to market a 'green' } \\
\text { building? }\end{array}$} & Early & 242 & 2.5207 & 1.4294 & 0.0919 \\
\hline & Late & 74 & 2.4865 & 1.4641 & 0.1702 \\
\hline \multirow{2}{*}{$\begin{array}{l}\text { Question 31: What is your degree of satisfaction with the } \\
\text { current level of information about Green Star NZ accreditation } \\
\text { course? }\end{array}$} & Early & 243 & 2.2593 & 1.4724 & 0.0945 \\
\hline & Late & 73 & 1.9041 & 1.1446 & 0.134 \\
\hline \multirow{2}{*}{$\begin{array}{l}\text { Question 31: What is your degree of satisfaction with the } \\
\text { current level of information about how-to manage a 'green' } \\
\text { building? }\end{array}$} & Early & 244 & 2.1434 & 1.2069 & 0.0773 \\
\hline & Late & 74 & 2.2162 & 1.3166 & 0.1531 \\
\hline \multirow[b]{2}{*}{$\begin{array}{l}\text { Question 31: What is your degree of satisfaction with the } \\
\text { current level of information about 'green' players? }\end{array}$} & Early & 245 & 2.2694 & 1.2646 & 0.0808 \\
\hline & Late & 72 & 2.0556 & 1.4031 & 0.1654 \\
\hline
\end{tabular}




\begin{tabular}{|c|c|c|c|c|c|}
\hline \multirow[b]{2}{*}{$\begin{array}{l}\text { Question 31: What is your degree of satisfaction with the } \\
\text { current level of information about Green Star NZ players? }\end{array}$} & Early & 238 & 2.2899 & 1.3917 & 0.0902 \\
\hline & Late & 70 & 2.3429 & 1.6496 & 0.1972 \\
\hline \multirow{2}{*}{$\begin{array}{l}\text { Question 31: What is your degree of satisfaction with the } \\
\text { current level of information about business management } \\
\text { information? }\end{array}$} & Early & 242 & 2.2066 & 1.265 & 0.0813 \\
\hline & Late & 70 & 2.0714 & 1.4776 & 0.1766 \\
\hline \multirow{2}{*}{$\begin{array}{l}\text { Question 31: What is your degree of satisfaction with the } \\
\text { current level of information about curriculum for senior } \\
\text { executives? }\end{array}$} & Early & 240 & 1.9 & 1.1743 & 0.0758 \\
\hline & Late & 68 & 1.9265 & 1.3856 & 0.168 \\
\hline \multirow[b]{2}{*}{$\begin{array}{l}\text { Question 31: What is your degree of satisfaction with the } \\
\text { current level of information about curriculum for line staff? }\end{array}$} & Early & 235 & 1.8851 & 1.1545 & 0.0753 \\
\hline & Late & 68 & 1.8676 & 1.2447 & 0.1509 \\
\hline
\end{tabular}


Table C-2: Results of the independent samples T-test procedure

\begin{tabular}{|c|c|c|c|c|c|c|c|c|c|c|}
\hline \multirow[t]{3}{*}{ Question } & \multirow[t]{3}{*}{$\begin{array}{l}\text { Equal or } \\
\text { unequal } \\
\text { variances }\end{array}$} & \multicolumn{2}{|c|}{$\begin{array}{l}\text { Levene's Test } \\
\text { for Equality of } \\
\text { Variances }\end{array}$} & \multicolumn{7}{|c|}{ t-test for Equality of Means } \\
\hline & & F & Sig. & $t$ & df & $\begin{array}{l}\text { Sig. } \\
(2- \\
\text { tailed })\end{array}$ & $\begin{array}{c}\text { Mean } \\
\text { Difference }\end{array}$ & $\begin{array}{l}\text { Std. Error } \\
\text { Difference }\end{array}$ & $\begin{array}{r}95 \% \text { Co } \\
\text { Interva } \\
\text { Diffe }\end{array}$ & $\begin{array}{l}\text { idence } \\
\text { of the } \\
\text { nce }\end{array}$ \\
\hline & & & & & & & & & Lower & Upper \\
\hline \multirow[b]{2}{*}{$\begin{array}{l}\text { Question 1: To what extent would } \\
\text { you describe your level of interest } \\
\text { in sustainability? }\end{array}$} & $\begin{array}{l}\text { Equal } \\
\text { variances } \\
\text { assumed }\end{array}$ & 0.6916 & 0.4061 & 0.4623 & 433 & 0.6441 & 0.0567 & 0.1227 & -0.1844 & 0.2979 \\
\hline & $\begin{array}{l}\text { Equal } \\
\text { variances not } \\
\text { assumed }\end{array}$ & & & 0.4752 & 169.7527 & 0.6353 & 0.0567 & 0.1194 & -0.1789 & 0.2923 \\
\hline \multirow[b]{2}{*}{$\begin{array}{l}\text { Question 1: To what extent would } \\
\text { you describe your level of interest } \\
\text { in sustainable building? }\end{array}$} & $\begin{array}{l}\text { Equal } \\
\text { variances } \\
\text { assumed }\end{array}$ & 0.2487 & 0.6183 & -0.187 & 431 & 0.8518 & -0.0227 & 0.1216 & -0.2618 & 0.2163 \\
\hline & $\begin{array}{l}\text { Equal } \\
\text { variances not } \\
\text { assumed }\end{array}$ & & & -0.1977 & 169.8123 & 0.8435 & -0.0227 & 0.115 & -0.2497 & 0.2043 \\
\hline \multirow{3}{*}{$\begin{array}{l}\text { Question 1: To what extent would } \\
\text { you describe your level of interest } \\
\text { in BSRTs? }\end{array}$} & $\begin{array}{l}\text { Equal } \\
\text { variances } \\
\text { assumed }\end{array}$ & 1.8917 & 0.1697 & -0.2752 & 435 & 0.7833 & -0.0394 & 0.1431 & -0.3206 & 0.2419 \\
\hline & $\begin{array}{l}\text { Equal } \\
\text { variances not } \\
\text { assumed }\end{array}$ & & & -0.2912 & 177.6266 & 0.7713 & -0.0394 & 0.1352 & -0.3063 & 0.2275 \\
\hline & & & & & & & & & & \\
\hline
\end{tabular}


Question 2: What best describes your level of involvement with sustainability?

\begin{tabular}{|c|c|c|c|c|c|c|c|c|c|}
\hline $\begin{array}{l}\text { Equal } \\
\text { variances } \\
\text { assumed }\end{array}$ & 0.1686 & 0.6815 & 1.002 & 433 & 0.3169 & 0.1861 & 0.1857 & -0.1789 & 0.5512 \\
\hline $\begin{array}{l}\text { Equal } \\
\text { variances not } \\
\text { assumed }\end{array}$ & & & 0.9799 & 157.3638 & 0.3287 & 0.1861 & 0.1899 & -0.1891 & 0.5613 \\
\hline $\begin{array}{l}\text { Equal } \\
\text { variances } \\
\text { assumed } \\
\end{array}$ & 0.2415 & 0.6234 & 0.9255 & 434 & 0.3552 & 0.1702 & 0.184 & -0.1913 & 0.5318 \\
\hline $\begin{array}{l}\text { Equal } \\
\text { variances not } \\
\text { assumed }\end{array}$ & & & 0.893 & 152.098 & 0.3732 & 0.1702 & 0.1906 & -0.2064 & 0.5469 \\
\hline $\begin{array}{l}\text { Equal } \\
\text { variances } \\
\text { assumed } \\
\end{array}$ & 0.1995 & 0.6554 & 0.2638 & 433 & 0.7921 & 0.0585 & 0.2218 & -0.3774 & 0.4944 \\
\hline $\begin{array}{l}\text { Equal } \\
\text { variances not } \\
\text { assumed }\end{array}$ & & & 0.2675 & 166.1734 & 0.7894 & 0.0585 & 0.2187 & -0.3733 & 0.4903 \\
\hline $\begin{array}{l}\text { Equal } \\
\text { variances } \\
\text { assumed }\end{array}$ & 2.1793 & 0.1407 & -0.6457 & 380 & 0.5189 & -0.1266 & 0.1961 & -0.5123 & 0.259 \\
\hline $\begin{array}{l}\text { Equal } \\
\text { variances not } \\
\text { assumed }\end{array}$ & & & -0.7073 & 153.9689 & 0.4804 & -0.1266 & 0.179 & -0.4803 & 0.2271 \\
\hline $\begin{array}{l}\text { Equal } \\
\text { variances } \\
\text { assumed } \\
\end{array}$ & 1.9988 & 0.1581 & 0.6714 & 473 & 0.5023 & 0.0344 & 0.0512 & -0.0662 & 0.1349 \\
\hline $\begin{array}{l}\text { Equal } \\
\text { variances not } \\
\text { assumed } \\
\end{array}$ & & & 0.6802 & 185.9761 & 0.4972 & 0.0344 & 0.0505 & -0.0653 & 0.134 \\
\hline
\end{tabular}

Question 2: What best describes your level of involvement with BSRTs?

Question 4: How important is it to have a New Zealand specific

Building Sustainability Rating Tool?

Question 7: In your experience with existing Building

Sustainability Rating Tools what have been the highest achieved ratings/scores? 


\begin{tabular}{|c|c|c|c|c|c|c|c|c|c|c|}
\hline & $\begin{array}{l}\text { Equal } \\
\text { variances } \\
\text { assumed }\end{array}$ & 3.3359 & 0.0686 & -0.9608 & 374 & 0.3373 & -0.05 & 0.0521 & -0.1525 & 0.0524 \\
\hline $\begin{array}{l}\text { Question 9: Are you aware of } \\
\text { Green Star New Zealand? }\end{array}$ & $\begin{array}{l}\text { Equal } \\
\text { variances not } \\
\text { assumed } \\
\end{array}$ & & & -0.9208 & 124.6852 & 0.3589 & -0.05 & 0.0543 & -0.1576 & 0.0575 \\
\hline \multirow{2}{*}{$\begin{array}{l}\text { Question 10: How important is it } \\
\text { for Green Star New Zealand to be } \\
\text { a New Zealand equivalent of the } \\
\text { Australian Green Star system }\end{array}$} & $\begin{array}{l}\text { Equal } \\
\text { variances } \\
\text { assumed }\end{array}$ & 1.2258 & 0.2689 & 0.6825 & 383 & 0.4954 & 0.1887 & 0.2764 & -0.3549 & 0.7322 \\
\hline & $\begin{array}{l}\text { Equal } \\
\text { variances not } \\
\text { assumed }\end{array}$ & & & 0.6565 & 132.6509 & 0.5126 & 0.1887 & 0.2874 & -0.3798 & 0.7571 \\
\hline \multirow{2}{*}{$\begin{array}{l}\text { Question 11: To what extent do } \\
\text { you think Green Star New } \\
\text { Zealand will influence the building } \\
\text { industry in a shift towards more } \\
\text { sustainable building development } \\
\text { in New Zealand? }\end{array}$} & $\begin{array}{l}\text { Equal } \\
\text { variances } \\
\text { assumed }\end{array}$ & 0.0642 & 0.8001 & 0.9649 & 382 & 0.3352 & 0.224 & 0.2321 & -0.2324 & 0.6804 \\
\hline & $\begin{array}{l}\text { Equal } \\
\text { variances not } \\
\text { assumed }\end{array}$ & & & 0.9618 & 137.2132 & 0.3378 & 0.224 & 0.2329 & -0.2365 & 0.6845 \\
\hline \multirow{2}{*}{$\begin{array}{l}\text { Question 12: How likely is it that } \\
\text { you will use Green Star New } \\
\text { Zealand once it is officially } \\
\text { released? }\end{array}$} & $\begin{array}{l}\text { Equal } \\
\text { variances } \\
\text { assumed }\end{array}$ & 0.0215 & 0.8836 & 0.6074 & 371 & 0.544 & 0.1148 & 0.1891 & -0.257 & 0.4866 \\
\hline & $\begin{array}{l}\text { Equal } \\
\text { variances not } \\
\text { assumed }\end{array}$ & & & 0.6141 & 137.1782 & 0.5402 & 0.1148 & 0.187 & -0.255 & 0.4847 \\
\hline \multirow{2}{*}{$\begin{array}{l}\text { Question 14: How likely is it that } \\
\text { you will seek training to become a } \\
\text { Green Star New Zealand } \\
\text { accredited professional? }\end{array}$} & $\begin{array}{l}\text { Equal } \\
\text { variances } \\
\text { assumed } \\
\end{array}$ & 1.1462 & 0.285 & -0.3471 & 378 & 0.7287 & -0.0846 & 0.2438 & -0.5641 & 0.3948 \\
\hline & $\begin{array}{l}\text { Equal } \\
\text { variances not }\end{array}$ & & & -0.3597 & 146.3311 & 0.7196 & -0.0846 & 0.2353 & -0.5497 & 0.3804 \\
\hline
\end{tabular}

Jonathan Smith 


\begin{tabular}{|c|c|c|c|c|c|c|c|c|c|c|}
\hline & assumed & & & & & & & & & \\
\hline & & & & & & & & & & \\
\hline \multirow[b]{2}{*}{$\begin{array}{l}\text { Question 15: How important is it } \\
\text { that New Zealand buildings seek } \\
\text { full Green Star accreditation? }\end{array}$} & $\begin{array}{l}\text { Equal } \\
\text { variances } \\
\text { assumed }\end{array}$ & 3.2934 & 0.0703 & 0.9446 & 379 & 0.3454 & 0.2126 & 0.2251 & -0.23 & 0.6553 \\
\hline & $\begin{array}{l}\text { Equal } \\
\text { variances not } \\
\text { assumed } \\
\end{array}$ & & & 0.8616 & 124.417 & 0.3906 & 0.2126 & 0.2468 & -0.2758 & 0.7011 \\
\hline \multirow[b]{2}{*}{$\begin{array}{l}\text { Question 17: Are you aware of the } \\
\text { New Zealand Green Building } \\
\text { Council? }\end{array}$} & $\begin{array}{l}\text { Equal } \\
\text { variances } \\
\text { assumed }\end{array}$ & $\begin{array}{r}11.654 \\
7\end{array}$ & 0.0007 & 1.8447 & 368 & 0.0659 & 0.0908 & 0.0492 & -0.006 & 0.1877 \\
\hline & $\begin{array}{l}\text { Equal } \\
\text { variances not } \\
\text { assumed }\end{array}$ & & & 1.6932 & 118.874 & 0.093 & 0.0908 & 0.0537 & -0.0154 & 0.1971 \\
\hline \multirow{2}{*}{$\begin{array}{l}\text { Question 18: How appropriate is } \\
\text { the approach of the NZGBC in } \\
\text { the establishment of a New } \\
\text { Zealand specific Building } \\
\text { Sustainability Rating Tool? }\end{array}$} & $\begin{array}{l}\text { Equal } \\
\text { variances } \\
\text { assumed }\end{array}$ & 2.973 & 0.0855 & 1.8462 & 367 & 0.0657 & 0.597 & 0.3234 & -0.0389 & 1.2328 \\
\hline & $\begin{array}{l}\text { Equal } \\
\text { variances not } \\
\text { assumed } \\
\end{array}$ & & & 1.7937 & 127.954 & 0.0752 & 0.597 & 0.3328 & -0.0616 & 1.2555 \\
\hline \multirow{2}{*}{$\begin{array}{l}\text { Question 19: Do you have any } \\
\text { reason for your selection of the } \\
\text { appropriateness of the New } \\
\text { Zealand Green Building Council } \\
\text { in the establishment of a New } \\
\text { Zealand specific Buildings } \\
\text { Sustainability Rating Tool? }\end{array}$} & $\begin{array}{l}\text { Equal } \\
\text { variances } \\
\text { assumed }\end{array}$ & 9.3296 & 0.0024 & 1.0446 & 473 & 0.2967 & 0.094 & 0.09 & -0.0828 & 0.2709 \\
\hline & $\begin{array}{l}\text { Equal } \\
\text { variances not } \\
\text { assumed }\end{array}$ & & & 0.9827 & 166.8256 & 0.3272 & 0.094 & 0.0957 & -0.0949 & 0.2829 \\
\hline $\begin{array}{l}\text { Question 20: To what extent do } \\
\text { you think the New Zealand Green }\end{array}$ & $\begin{array}{l}\text { Equal } \\
\text { variances }\end{array}$ & 2.0333 & 0.1547 & 1.7447 & 368 & 0.0819 & 0.3945 & 0.2261 & -0.0501 & 0.8392 \\
\hline
\end{tabular}

Jonathan Smith 


\begin{tabular}{|c|c|c|c|c|c|c|c|c|c|c|}
\hline \multirow{2}{*}{$\begin{array}{l}\text { Building Council will influence the } \\
\text { building industry in a shift } \\
\text { towards more sustainable building } \\
\text { development? }\end{array}$} & assumed & & & & & & & & & \\
\hline & $\begin{array}{l}\text { Equal } \\
\text { variances not } \\
\text { assumed }\end{array}$ & & & 1.6191 & 122.4206 & 0.108 & 0.3945 & 0.2437 & -0.0878 & 0.8769 \\
\hline \multirow{2}{*}{$\begin{array}{l}\text { Question 31: What is your degree } \\
\text { of satisfaction with the current } \\
\text { level of information about 'green' } \\
\text { products? }\end{array}$} & $\begin{array}{l}\text { Equal } \\
\text { variances } \\
\text { assumed }\end{array}$ & 0.5019 & 0.4792 & -0.1725 & 328 & 0.8632 & -0.0311 & 0.18 & -0.3852 & 0.3231 \\
\hline & $\begin{array}{l}\text { Equal } \\
\text { variances not } \\
\text { assumed }\end{array}$ & & & -0.1644 & 117.2556 & 0.8697 & -0.0311 & 0.1889 & -0.4052 & 0.3431 \\
\hline \multirow{2}{*}{$\begin{array}{l}\text { Question 31: What is your degree } \\
\text { of satisfaction with the current } \\
\text { level of information about } \\
\text { environmental and economic cost } \\
\text { benefit case studies? }\end{array}$} & $\begin{array}{l}\text { Equal } \\
\text { variances } \\
\text { assumed } \\
\end{array}$ & 4.6396 & 0.032 & 0.4593 & 326 & 0.6463 & 0.0748 & 0.1628 & -0.2455 & 0.395 \\
\hline & \begin{tabular}{|l|} 
Equal \\
variances not \\
assumed
\end{tabular} & & & 0.4228 & 110.2695 & 0.6732 & 0.0748 & 0.1768 & -0.2757 & 0.4252 \\
\hline \multirow{2}{*}{$\begin{array}{l}\text { Question 31: What is your degree } \\
\text { of satisfaction with the current } \\
\text { level of information about 'green' } \\
\text { building emerging trends? }\end{array}$} & \begin{tabular}{|l} 
Equal \\
variances \\
assumed
\end{tabular} & 3.4337 & 0.0648 & 0.4089 & 329 & 0.6829 & 0.0735 & 0.1797 & -0.28 & 0.427 \\
\hline & $\begin{array}{l}\text { Equal } \\
\text { variances not } \\
\text { assumed }\end{array}$ & & & 0.3879 & 116.3995 & 0.6988 & 0.0735 & 0.1894 & -0.3017 & 0.4486 \\
\hline \multirow{2}{*}{$\begin{array}{l}\text { Question 31: What is your degree } \\
\text { of satisfaction with the current } \\
\text { level of information about 'green' } \\
\text { projects? }\end{array}$} & \begin{tabular}{|l} 
Equal \\
variances \\
assumed
\end{tabular} & 2.8901 & 0.0901 & -0.2137 & 324 & 0.8309 & -0.038 & 0.1777 & -0.3875 & 0.3116 \\
\hline & $\begin{array}{l}\text { Equal } \\
\text { variances not } \\
\text { assumed }\end{array}$ & & & -0.201 & 115.6719 & 0.8411 & -0.038 & 0.189 & -0.4122 & 0.3363 \\
\hline
\end{tabular}


Question 31: What is your degree of satisfaction with the current level of information about how-to design a 'green' building?

\begin{tabular}{|c|c|c|c|c|c|c|c|c|c|}
\hline $\begin{array}{l}\text { Equal } \\
\text { variances } \\
\text { assumed }\end{array}$ & 0.8351 & 0.3615 & -0.5963 & 324 & 0.5514 & -0.1144 & 0.1918 & -0.4917 & 0.263 \\
\hline $\begin{array}{l}\text { Equal } \\
\text { variances not } \\
\text { assumed } \\
\end{array}$ & & & -0.5792 & 121.0943 & 0.5635 & -0.1144 & 0.1975 & -0.5053 & 0.2766 \\
\hline $\begin{array}{l}\text { Equal } \\
\text { variances } \\
\text { assumed } \\
\end{array}$ & 1.4428 & 0.2306 & 0.7867 & 324 & 0.432 & 0.1308 & 0.1663 & -0.1963 & 0.458 \\
\hline $\begin{array}{l}\text { Equal } \\
\text { variances not } \\
\text { assumed }\end{array}$ & & & 0.7566 & 117.1508 & 0.4508 & 0.1308 & 0.1729 & -0.2116 & 0.4733 \\
\hline $\begin{array}{l}\text { Equal } \\
\text { variances } \\
\text { assumed }\end{array}$ & 2.0751 & 0.1507 & 0.6625 & 322 & 0.5081 & 0.1227 & 0.1852 & -0.2416 & 0.4869 \\
\hline $\begin{array}{l}\text { Equal } \\
\text { variances not } \\
\text { assumed }\end{array}$ & & & 0.6321 & 116.1513 & 0.5285 & 0.1227 & 0.1941 & -0.2617 & 0.507 \\
\hline $\begin{array}{l}\text { Equal } \\
\text { variances } \\
\text { assumed }\end{array}$ & 0.2046 & 0.6514 & 0.179 & 314 & 0.8581 & 0.0342 & 0.191 & -0.3415 & 0.4099 \\
\hline $\begin{array}{l}\text { Equal } \\
\text { variances not } \\
\text { assumed }\end{array}$ & & & 0.1767 & 118.6981 & 0.8601 & 0.0342 & 0.1934 & -0.3488 & 0.4172 \\
\hline $\begin{array}{l}\text { Equal } \\
\text { variances } \\
\text { assumed } \\
\end{array}$ & 4.6588 & 0.0317 & 1.8952 & 314 & 0.059 & 0.3551 & 0.1874 & -0.0136 & 0.7239 \\
\hline $\begin{array}{l}\text { Equal } \\
\text { variances not } \\
\text { assumed } \\
\end{array}$ & & & 2.1666 & 150.3279 & 0.0318 & 0.3551 & 0.1639 & 0.0313 & 0.679 \\
\hline
\end{tabular}

Question 31: What is your degree of satisfaction with the current level of information about Green

Star NZ accreditation course?

Question 31: What is your degree of satisfaction with the current level of information about reviews and profiles of Green Star NZ buildings?

Question 31: What is your degree of satisfaction with the current level of information about engineering or scientific information?

Question 31: What is your degree of satisfaction with the current level of information about how-to market a 'green' building?

assumed 


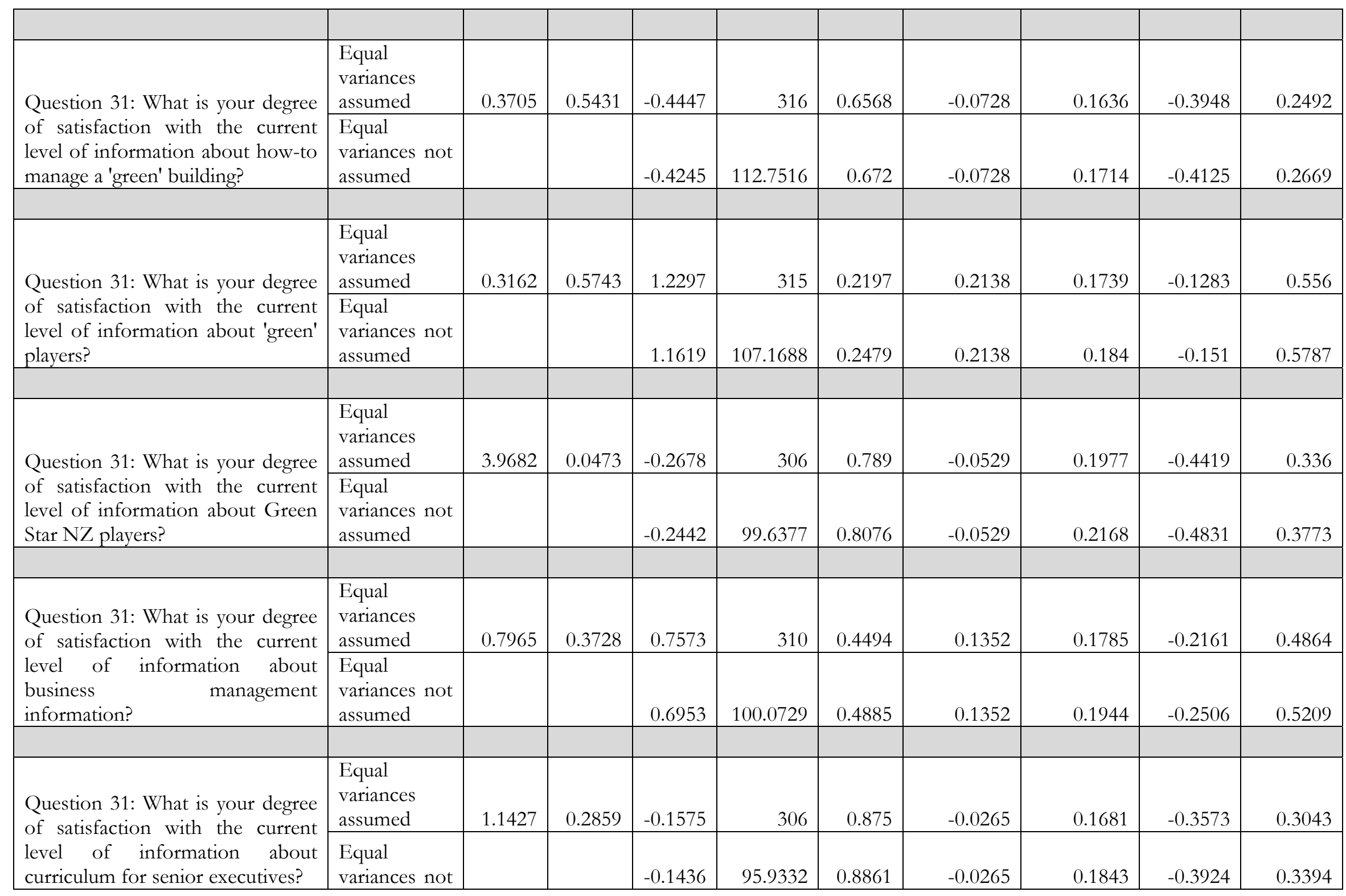




\begin{tabular}{|c|c|c|c|c|c|c|c|c|c|c|}
\hline & assumed & & & & & & & & & \\
\hline & & & & & & & & & & \\
\hline \multirow{2}{*}{$\begin{array}{l}\text { Question 31: What is your degree } \\
\text { of satisfaction with the current } \\
\text { level of information about } \\
\text { curriculum for line staff? }\end{array}$} & $\begin{array}{l}\text { Equal } \\
\text { variances } \\
\text { assumed }\end{array}$ & 0.1974 & 0.6572 & 0.1079 & 301 & 0.9142 & 0.0175 & 0.1618 & -0.301 & 0.3359 \\
\hline & $\begin{array}{l}\text { Equal } \\
\text { variances not } \\
\text { assumed }\end{array}$ & & & 0.1035 & 102.6865 & 0.9178 & 0.0175 & 0.1687 & -0.3171 & 0.352 \\
\hline & & & & & & & & & & \\
\hline
\end{tabular}




\section{C.2 Survey Results}

\section{C.2.1 Background}

\section{C.2.1.1 Level of Interest}

Question: To what extent would you describe your level of interest in?

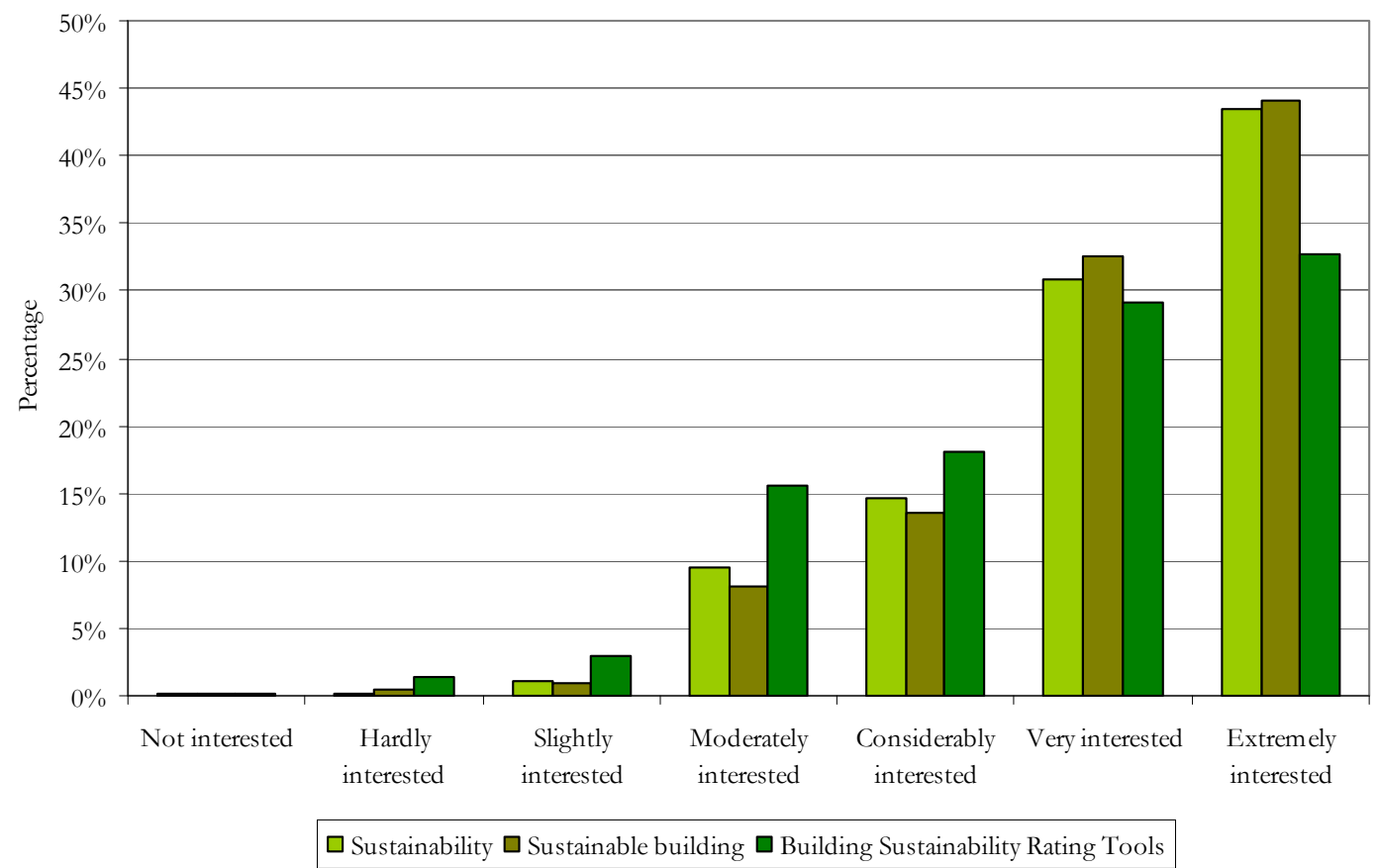

Figure C-1: Overall participant interest in sustainability, sustainable building and BSRTs 


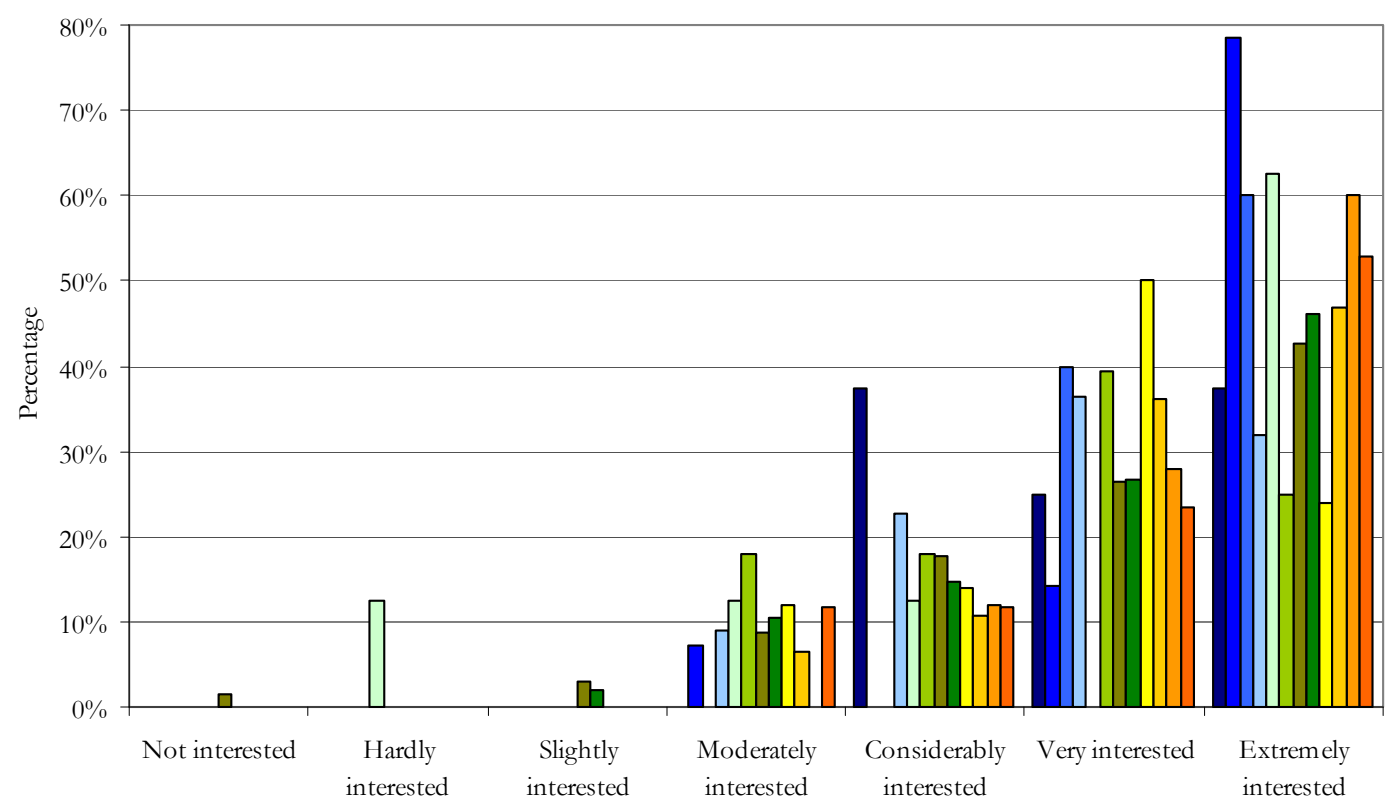

—CPD $\square$ IO\&PM $\square$ RD\&MPO $\square$ OO $\square$ MCT\&R $\square$ BC $\square$ BPM\&D $\square$ A\&D $\square$ E $\square$ P\&CP $\square$ R\&NGO $\square$ RI

Figure C-2: Overall interest in sustainability by industry sector

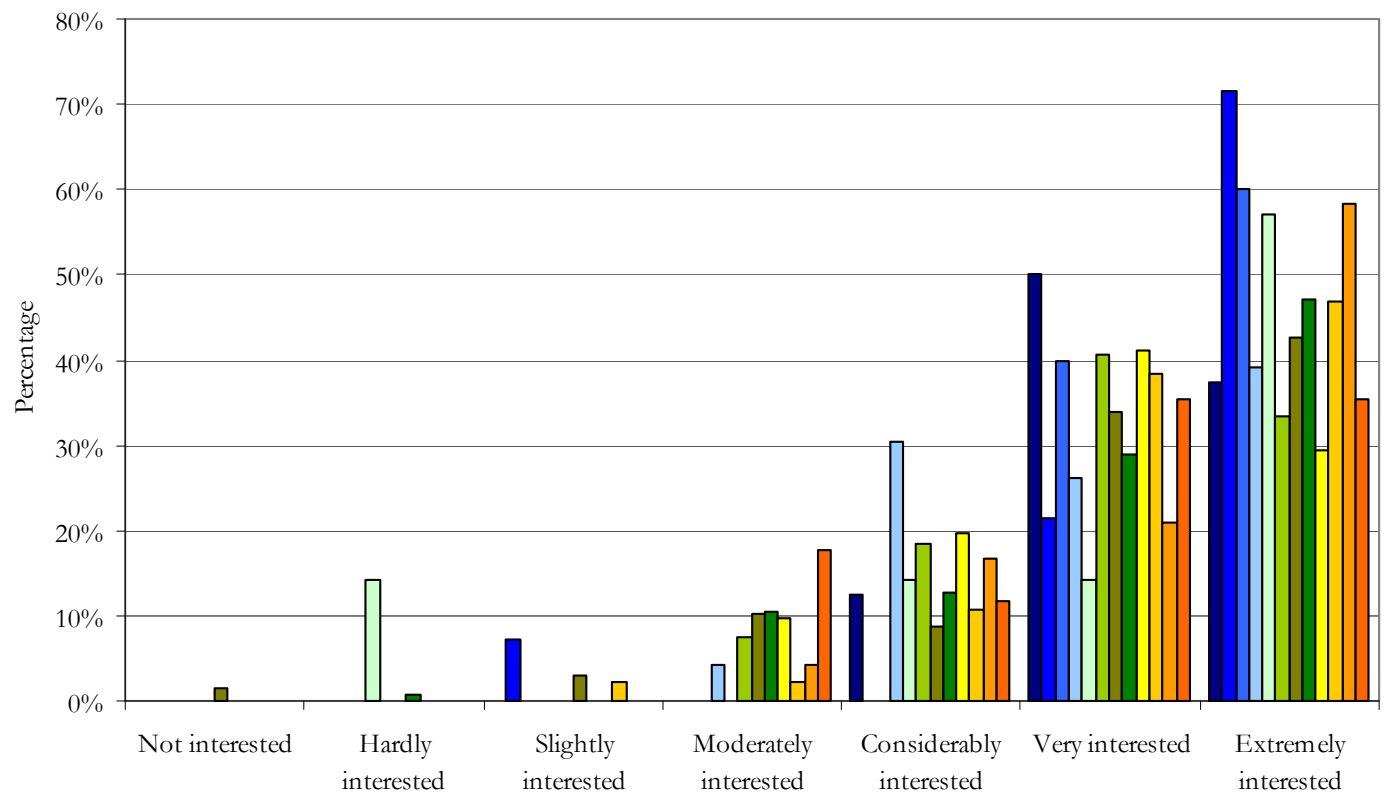

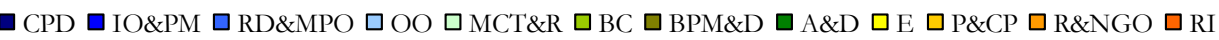

Figure C-3: Overall interest in sustainable building by industry sector 


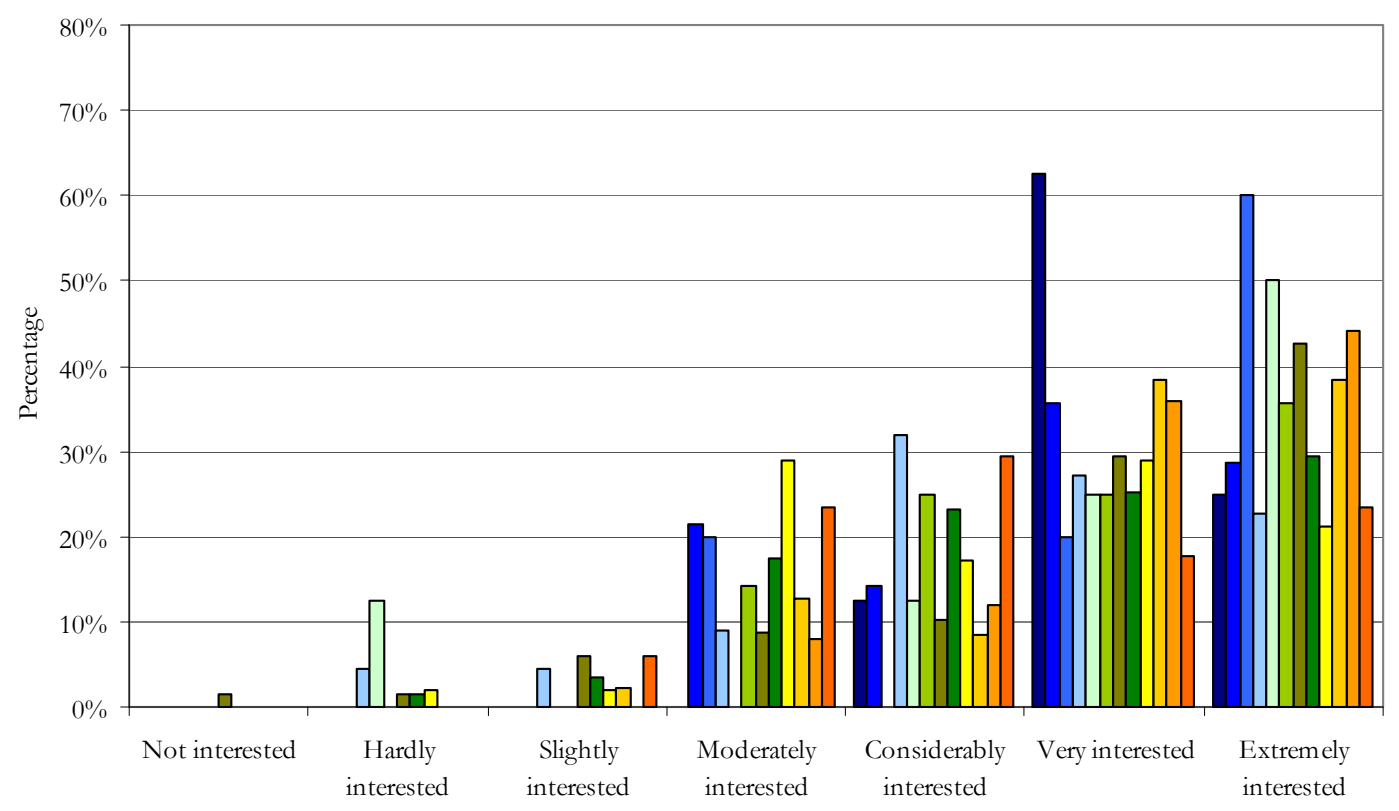

$\square$ CPD $\square$ IO\&PM $\square$ RD\&MPO $\square$ OO $\square$ MCT\&R $\square$ BC $\square$ BPM\&D $\square$ A\&D $\square$ E P\&CP $\square$ R\&NGO $\square$ RI

Figure C-4: Overall interest in BSRTs by industry sector

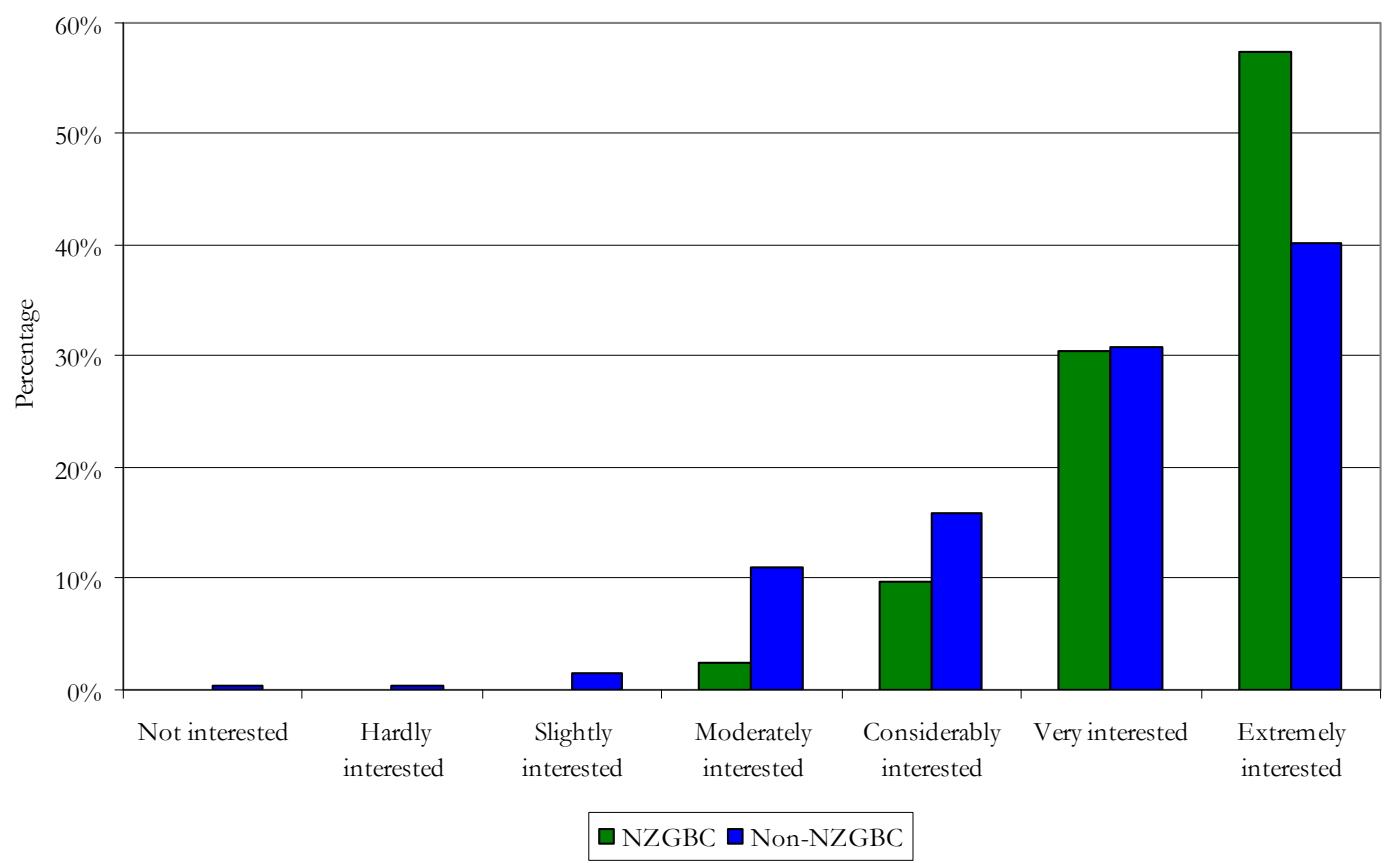

Figure C-5: Overall interest in sustainability by NZGBC vs. non-NZGBC 
Appendix C

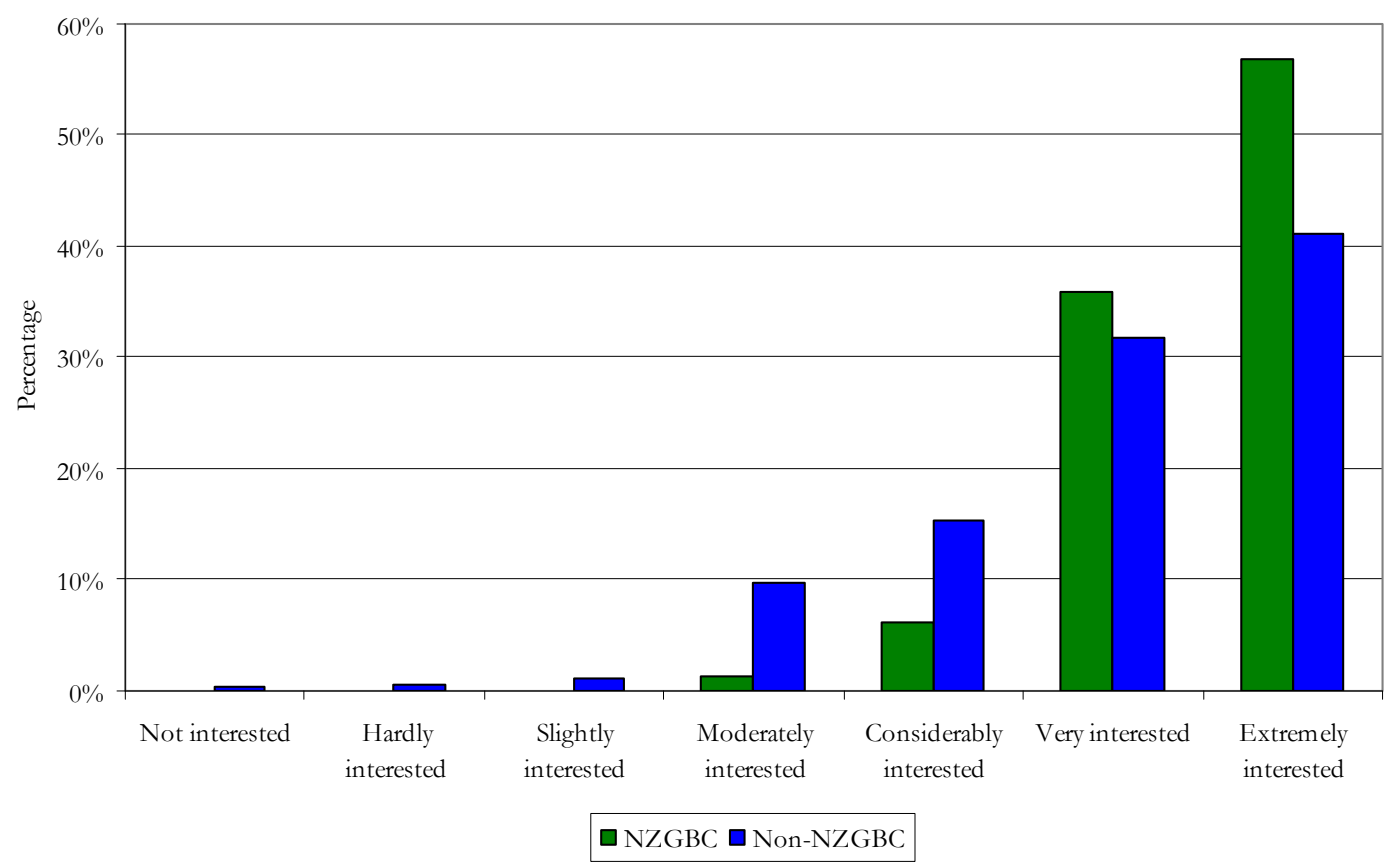

Figure C-6: Overall interest in sustainable buildings by NZGBC vs. non-NZGBC

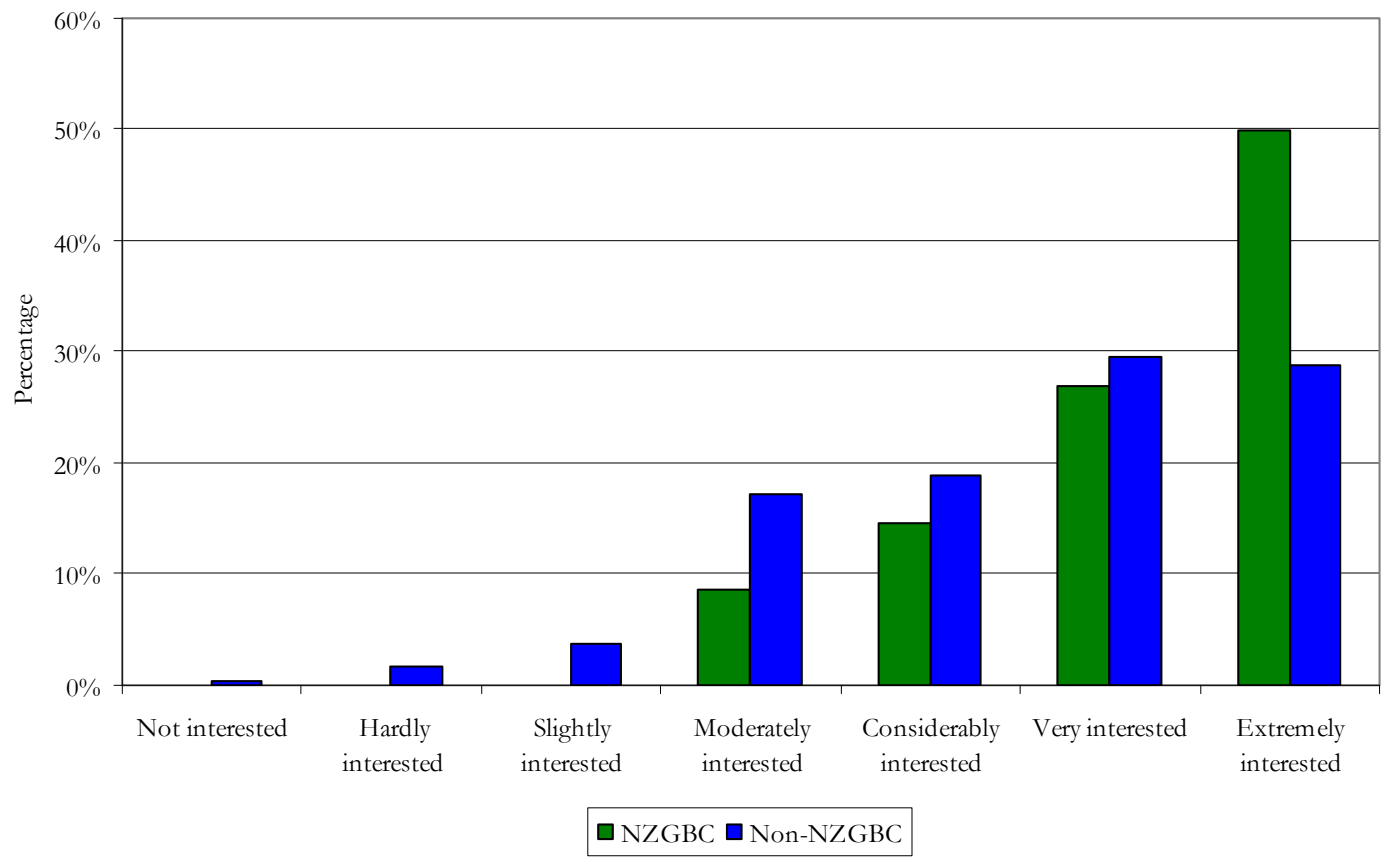

Figure C-7: Overall interest in BSRTs by NZGBC vs. non-NZGBC 


\section{C.2.1.2 Level of Involvement}

Question: What best describes your level of involvement?

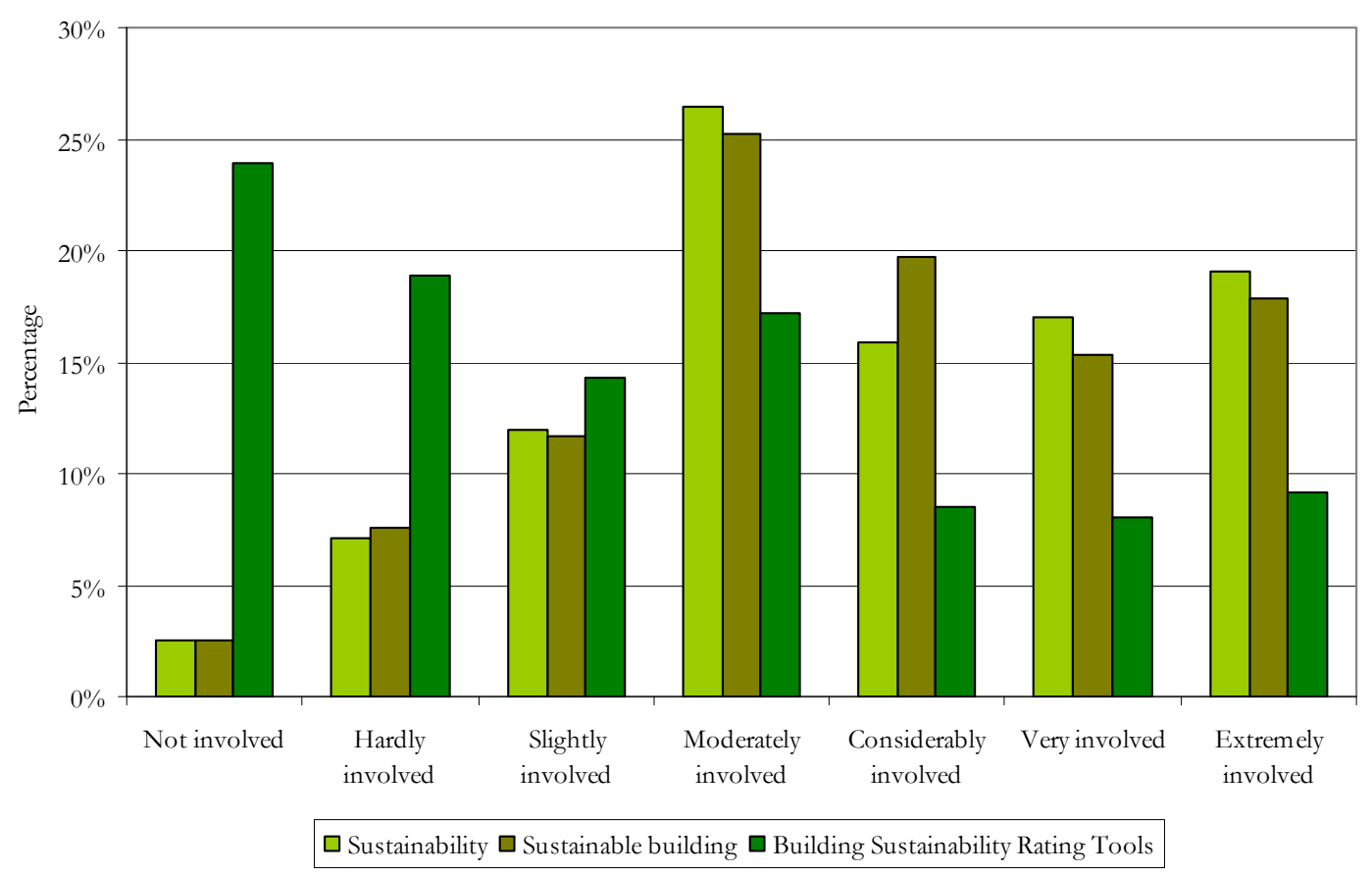

Figure C-8: Overall participant involvement in sustainability, sustainable building and BSRTs

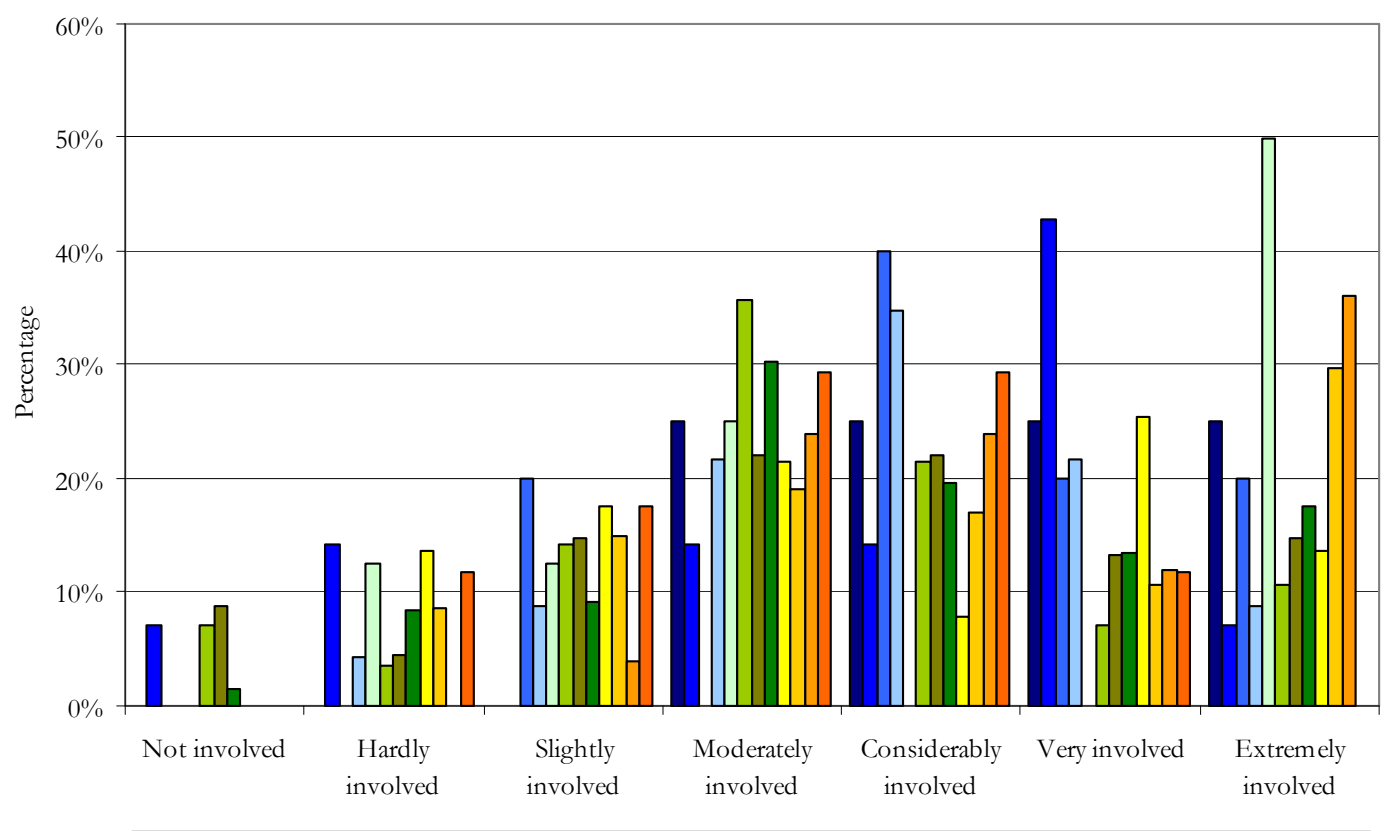

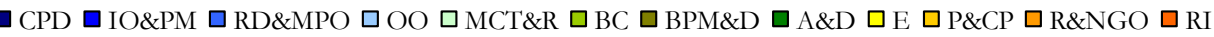

Figure C-9: Overall involvement in sustainable buildings by industry sector 


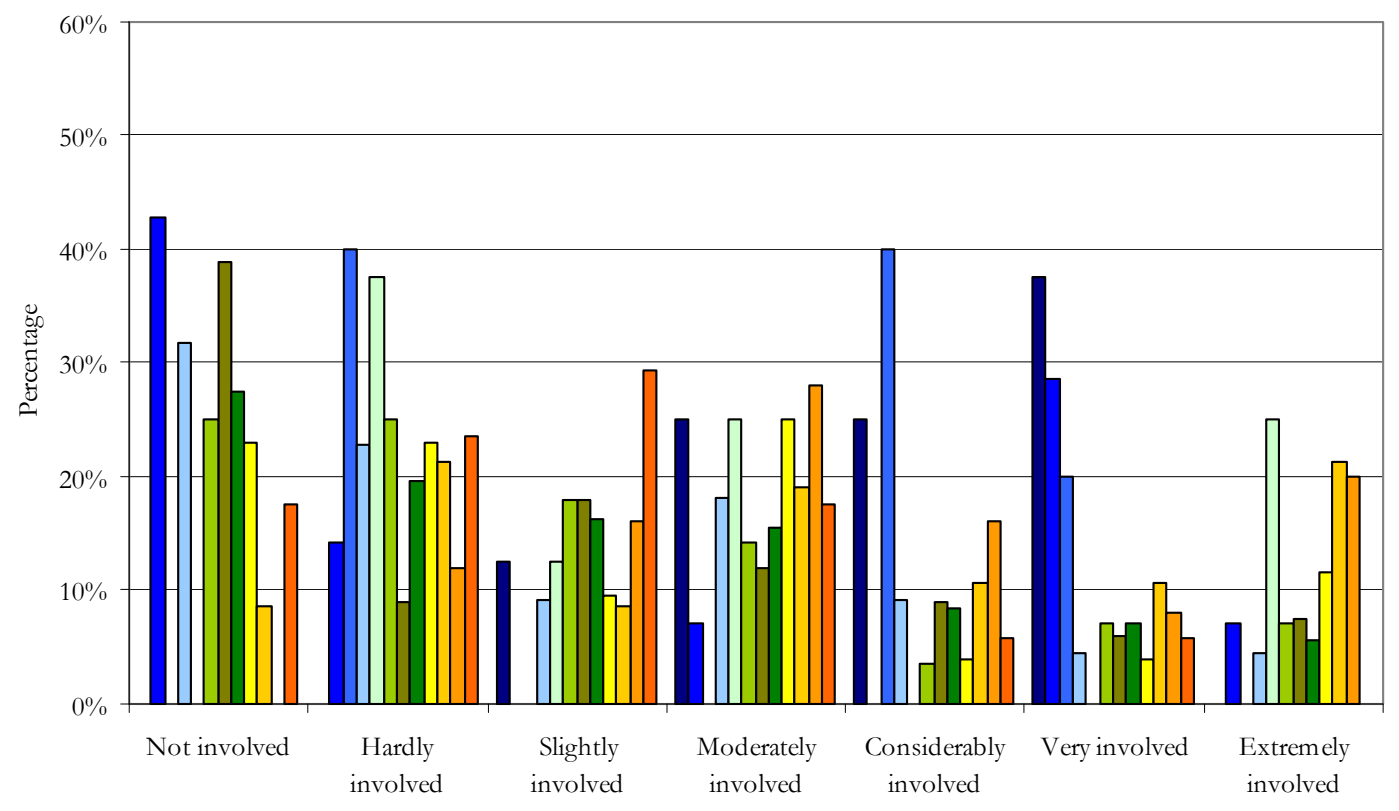

$\square$ CPD $\square$ IO\&PM $\square$ RD\&MPO $\square$ OO $\square$ MCT\&R $\square$ BC $\square$ BPM\&D $\square$ A\&D $\square$ E P\&CP $\square$ R\&NGO $\square$ RI

Figure C-10: Overall involvement in BSRTs by industry sector

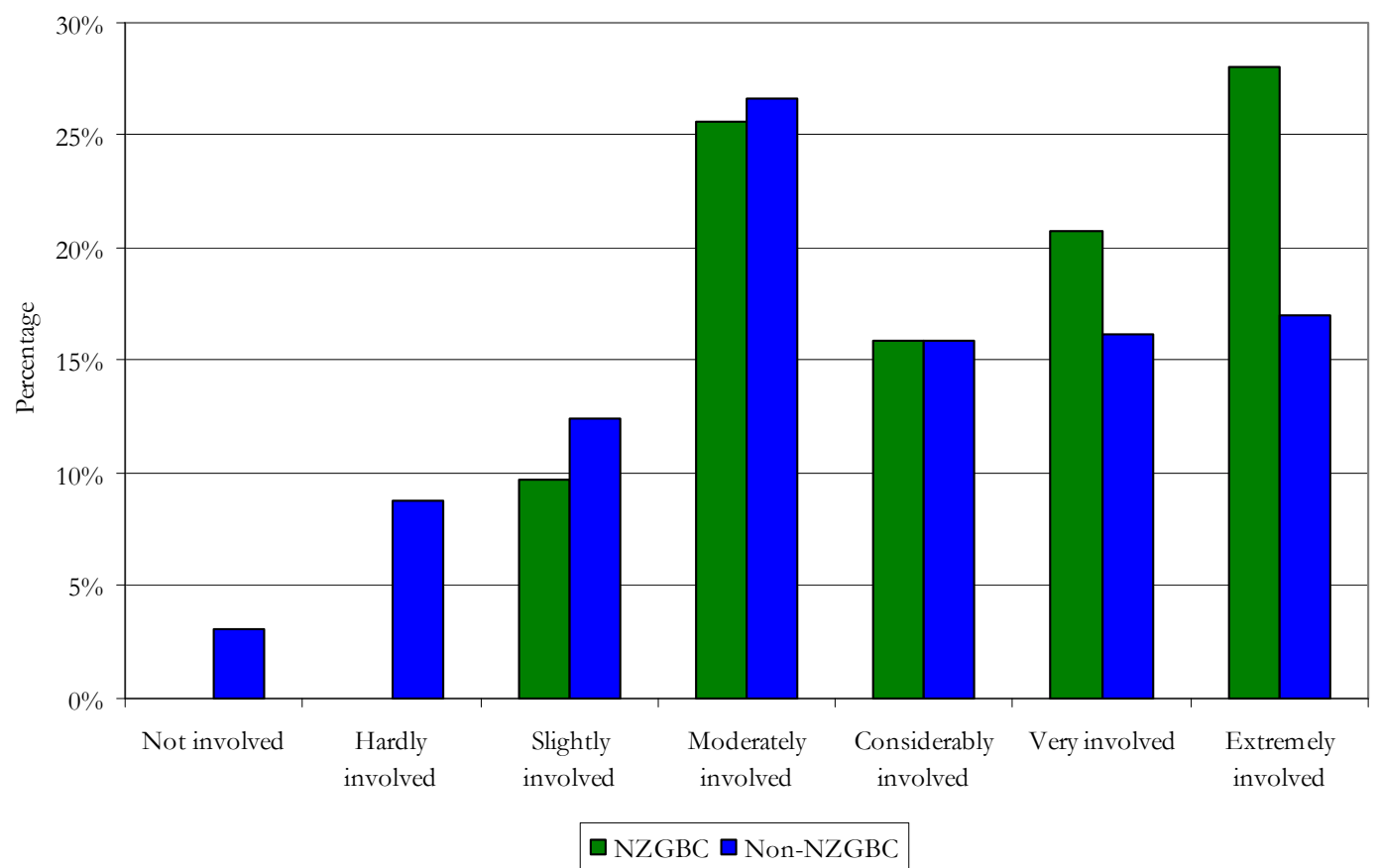

Figure C-11: Overall involvement in sustainability by NZGBC vs. non-NZGBC 


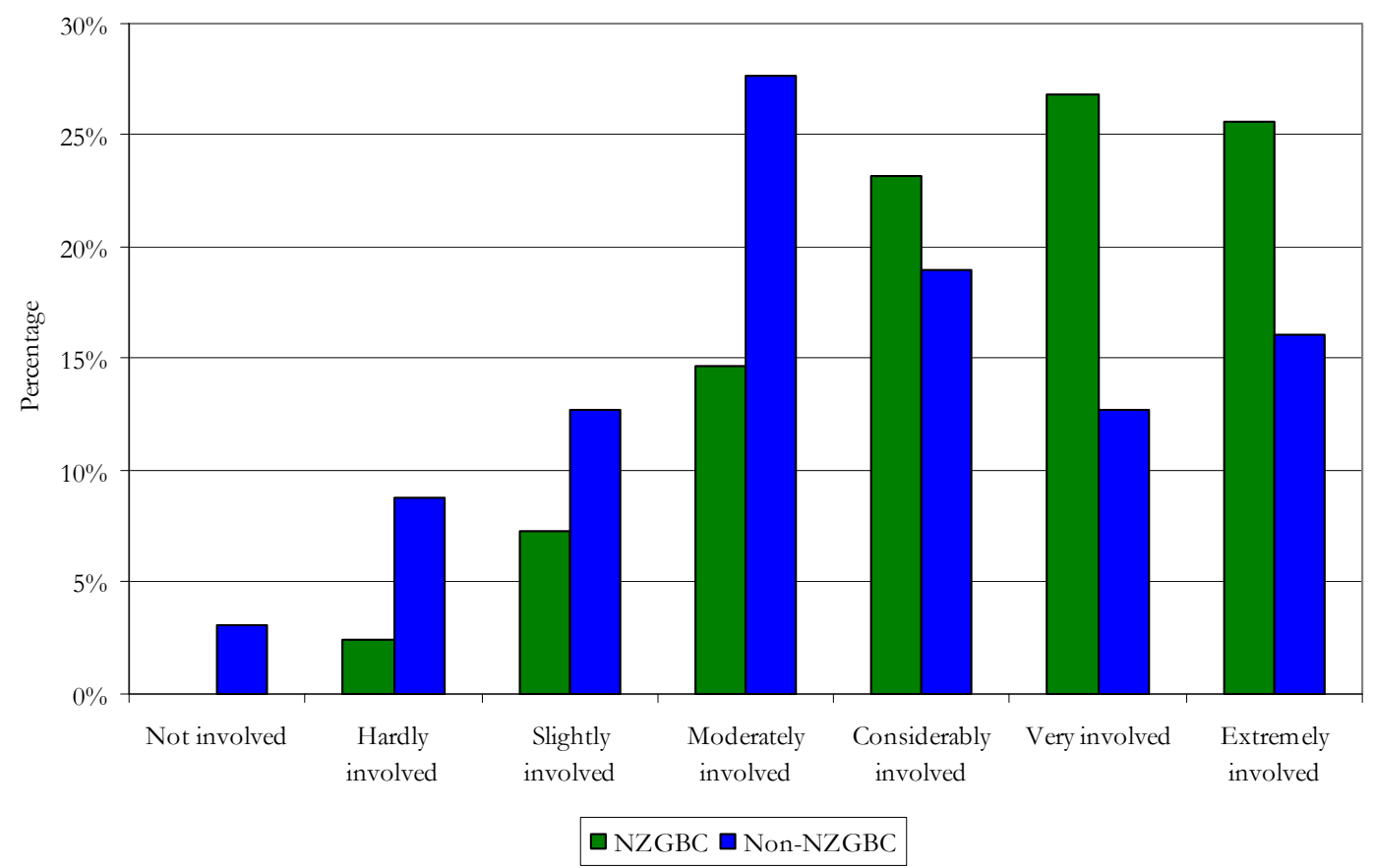

Figure C-12: Overall involvement in sustainable buildings by NZGBC vs. non-NZGBC

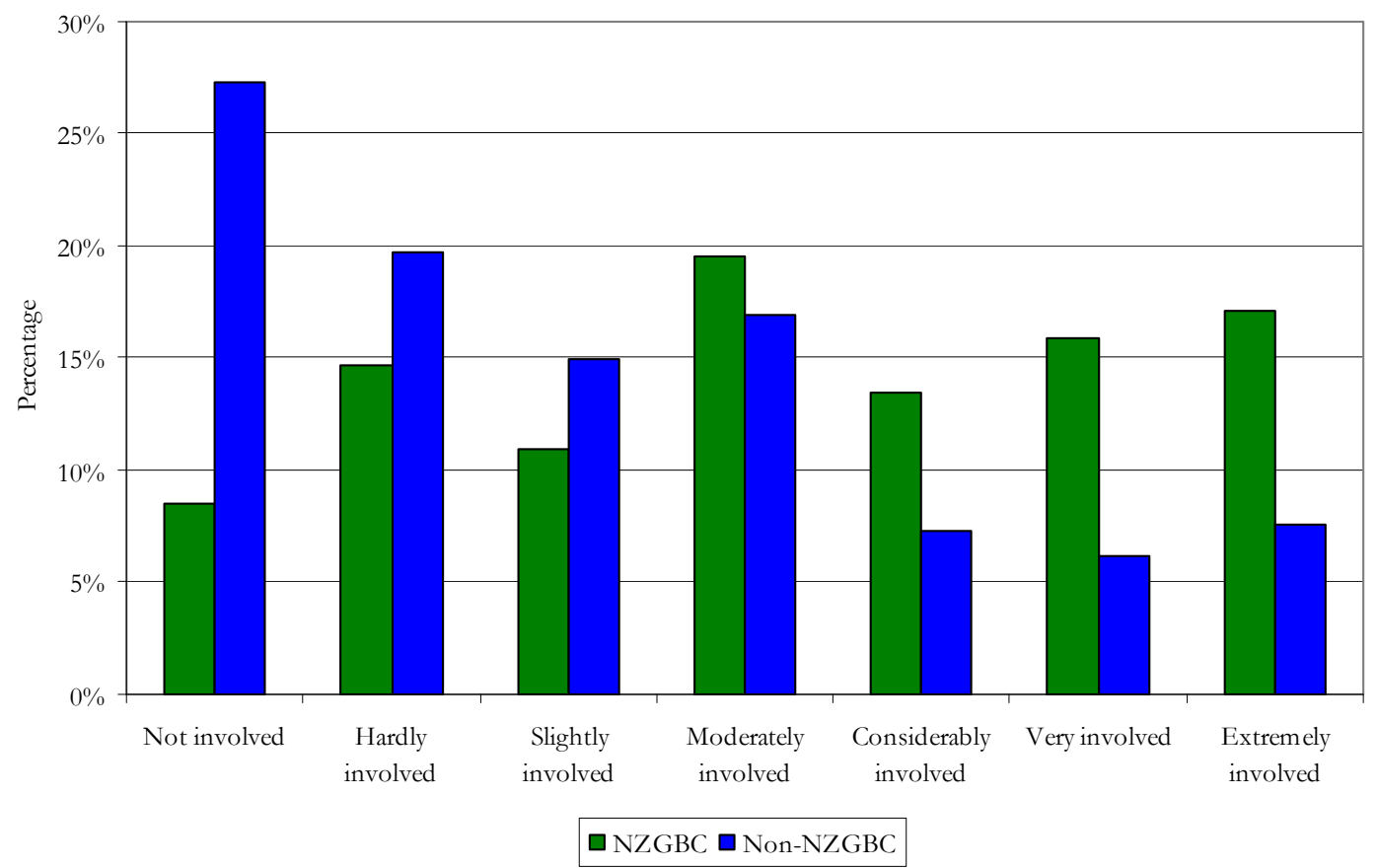

Figure C-13: Overall involvement in BSRTs by NZGBC vs. non-NZGBC 


\section{C.2.1.3 Interest versus Involvement}

Table C-3: Key of options choices for difference between level of interest and level of involvement

\begin{tabular}{|l|l|}
\hline Number & Definition \\
\hline 1 & Not interested and not involved \\
\hline 2 & Hardly interested and hardly involved \\
\hline 3 & Slightly interested and slightly involved \\
\hline 4 & Moderately interested and moderately involved \\
\hline 5 & Considerably interested and considerably involved \\
\hline 6 & Very interested and very involved \\
\hline 7 & Extremely interested and extremely involved \\
\hline
\end{tabular}

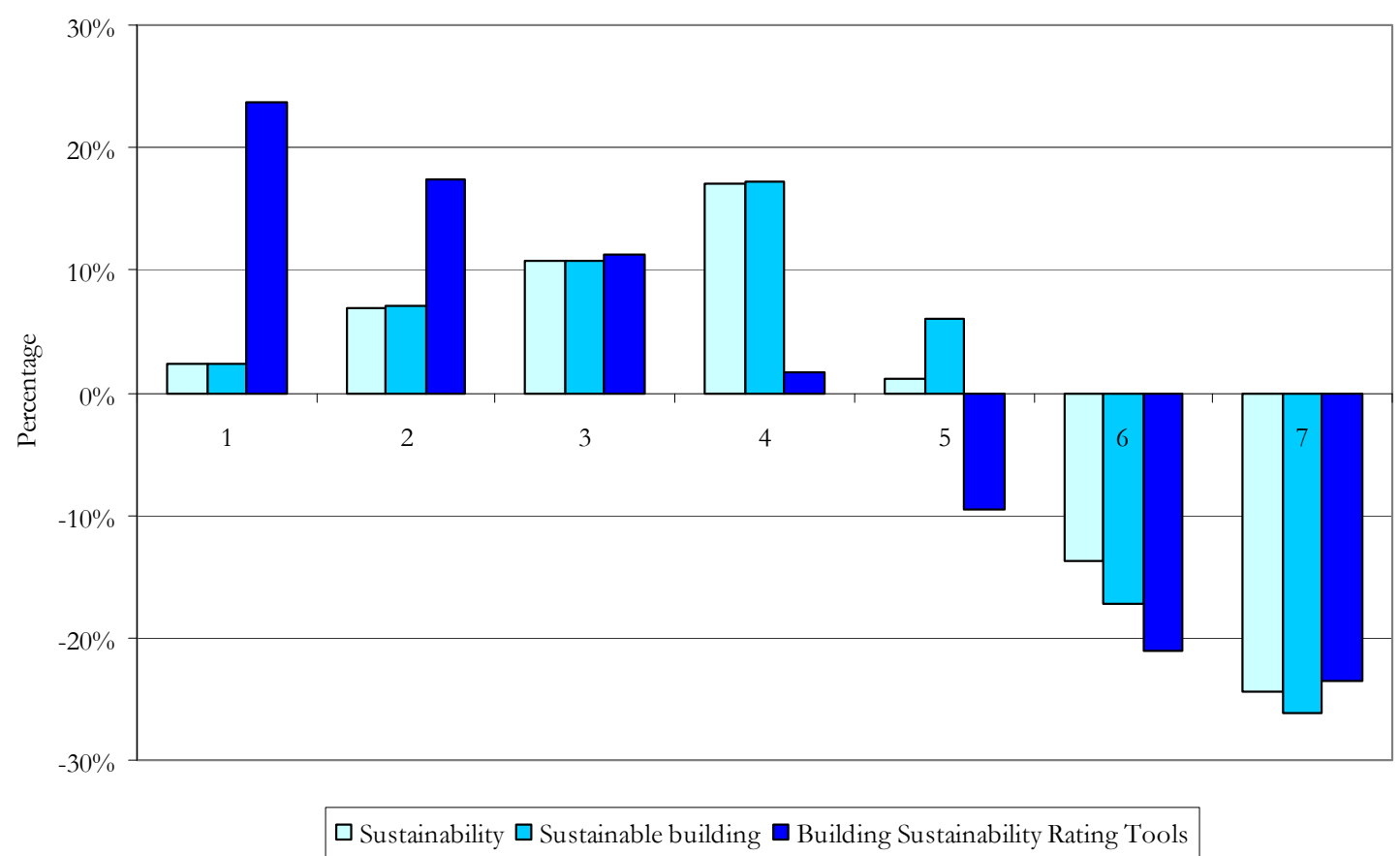

Figure C-14: Overall difference between level of interest and level of involvement 


\section{C.2.2 Building Sustainability Rating Tools}

\section{C.2.2.1 Purpose of a Building Sustainability Rating Tool}

Question: What do you see as the purpose of a Building Sustainability Rating Tool?

Table C-4: Participant interpretations to the purpose of a BSRT

\begin{tabular}{|c|c|}
\hline Purpose & Number \\
\hline To standardize/set benchmarks & 59 \\
\hline To assist in the decision making process & 31 \\
\hline To enable comparisons & 30 \\
\hline To assist with education and creating better awareness & 23 \\
\hline To quantify the sustainability of buildings & 20 \\
\hline To protect the environment/reduce building environmental impact & 20 \\
\hline As a guide or checklist & 16 \\
\hline To aid in marketing and promotion of sustainable buildings & 13 \\
\hline To encourage sustainable building & 11 \\
\hline To allow credible third party assessment & 10 \\
\hline To quantify and raise building performance & 7 \\
\hline To create best practice & 6 \\
\hline To add more bureaucracy and government interference & 5 \\
\hline To confirm that a building is sustainable & 5 \\
\hline To create change & 4 \\
\hline To drive sustainable development & 4 \\
\hline To create market demand & 3 \\
\hline To reward sustainable practice & 2 \\
\hline To prevent green-washing & 2 \\
\hline To simplify a complex issue & 2 \\
\hline To create a better future & 2 \\
\hline As a long term measure & 1 \\
\hline To foster competition & 1 \\
\hline To eliminate bad practice & 1 \\
\hline To add value & 1 \\
\hline To create investment & 1 \\
\hline To increase property values & 1 \\
\hline To identify/create new sustainable technology and products & 1 \\
\hline To create a competitive edge & 1 \\
\hline To provide sustainable solutions & 1 \\
\hline To provide targets & 1 \\
\hline To put sustainable building into the mainstream & 1 \\
\hline To create impetus at the design stage & 1 \\
\hline
\end{tabular}




\section{C.2.2.2 New Zealand Specific Building Sustainability Rating Tool}

Question: How important is it to have a New Zealand specific Building Sustainability Rating Tool?

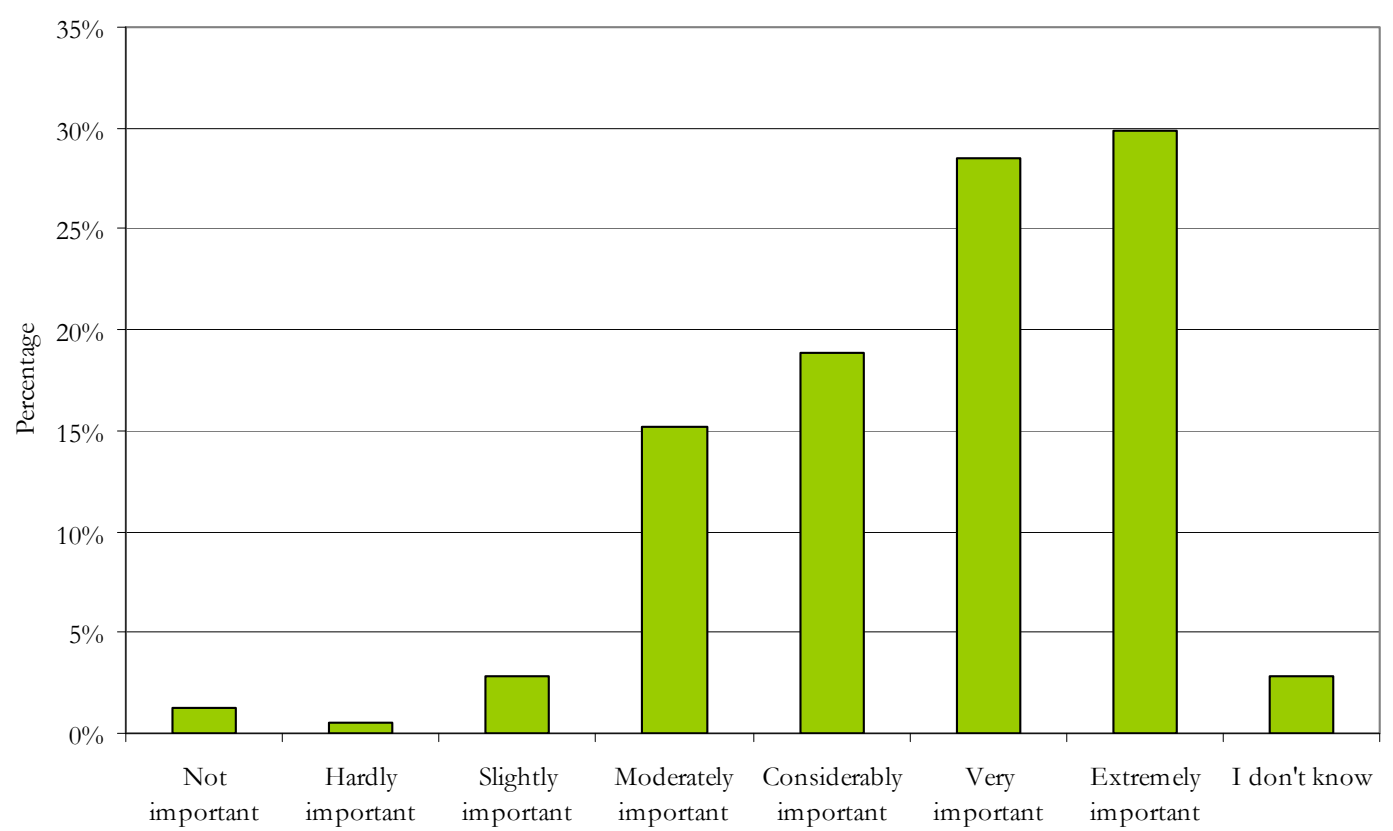

Figure C-15: Overall importance for New Zealand to have a specific BSRT

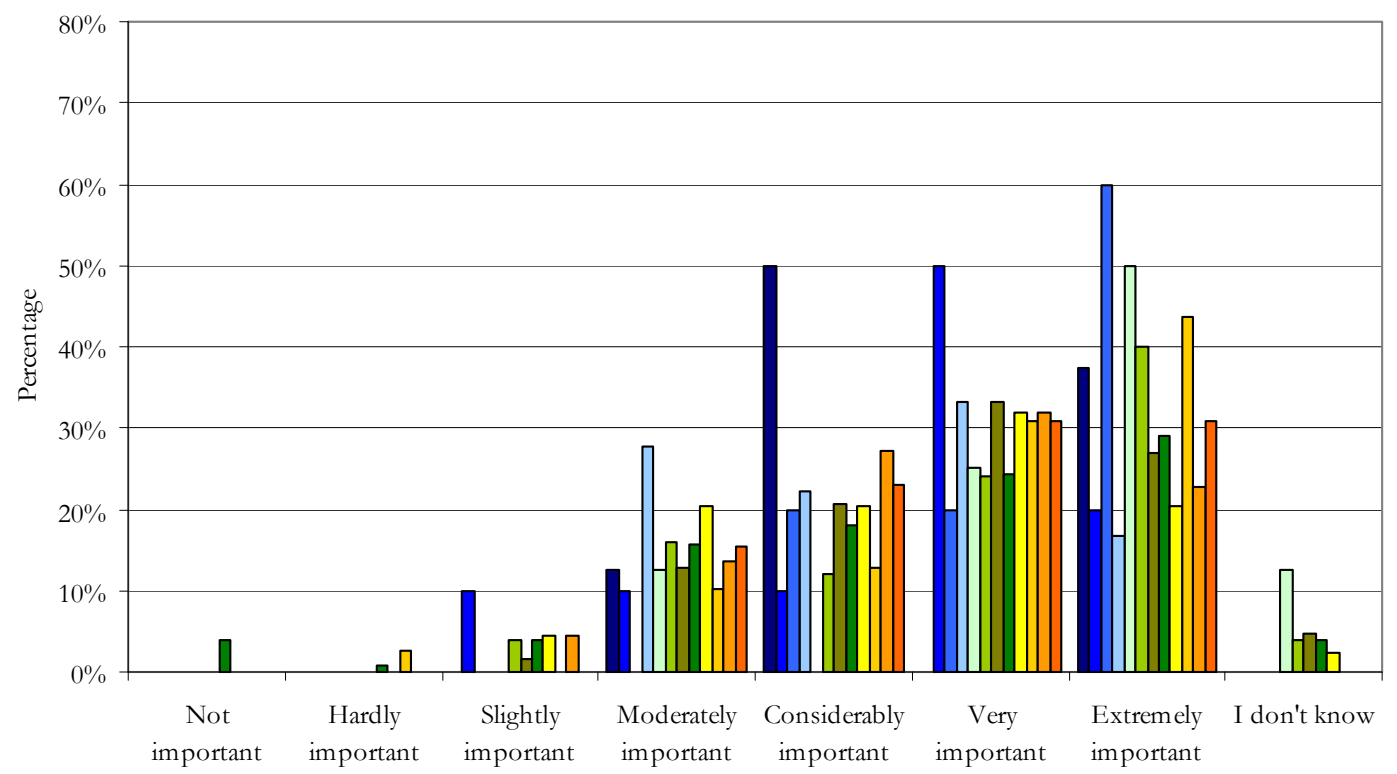

CPD $\square$ IO\&PM $\square$ RD\&MPO $\square$ OO $\square$ MCT\&R $\square$ BC $\square$ BPM\&D $\square$ A\&D $\square$ E $\square$ P\&P $\square$ R\&NGO $\square$ RI

Figure C-16: Overall importance for New Zealand to have a specific BSRT by industry sector 


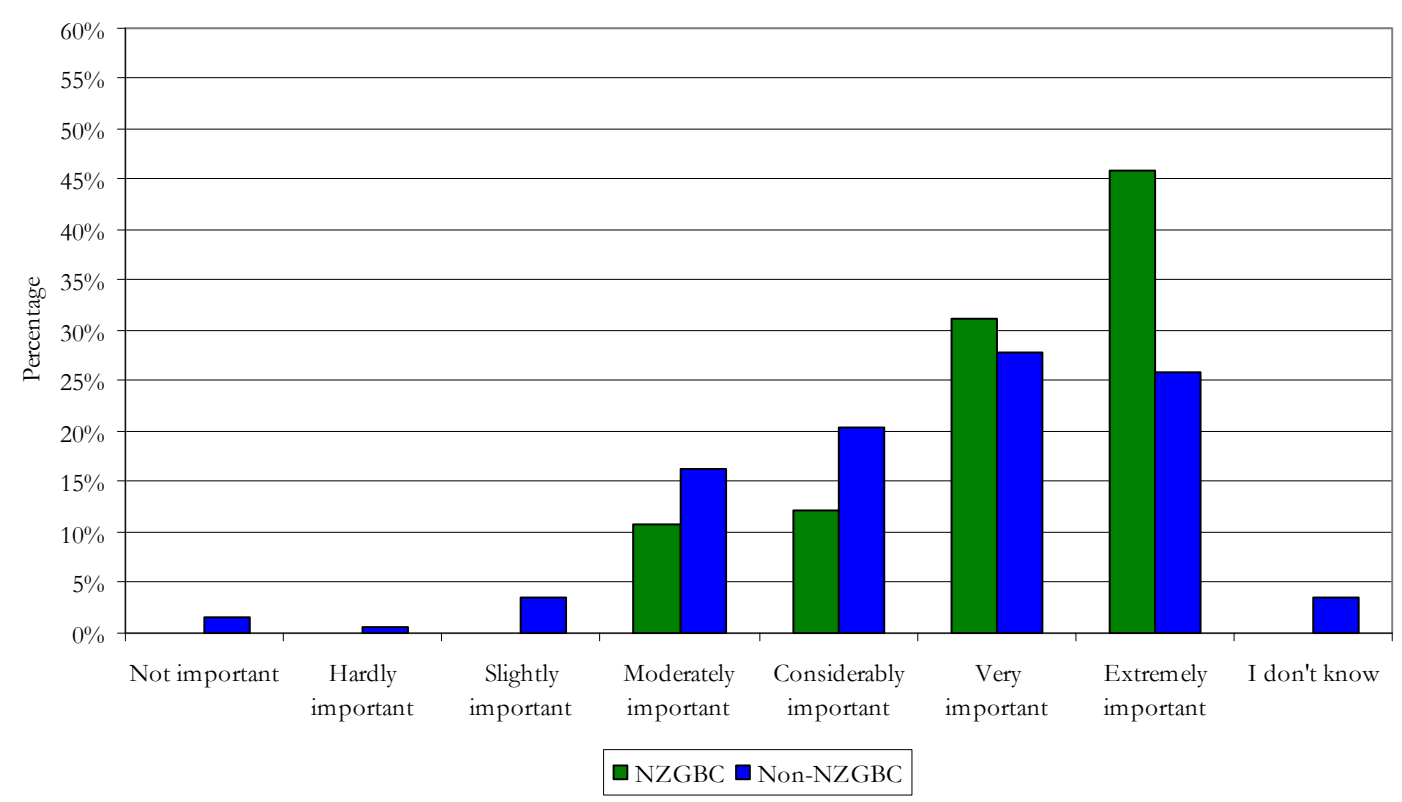

Figure C-17: Overall importance for New Zealand to have a specific BSRT by NZGBC vs. nonNZGBC

\section{C.2.2.3 Awareness of Existing Building Sustainability Rating Tools}

Question: Of the current existing Building Sustainability Rating Tools which are you aware of?

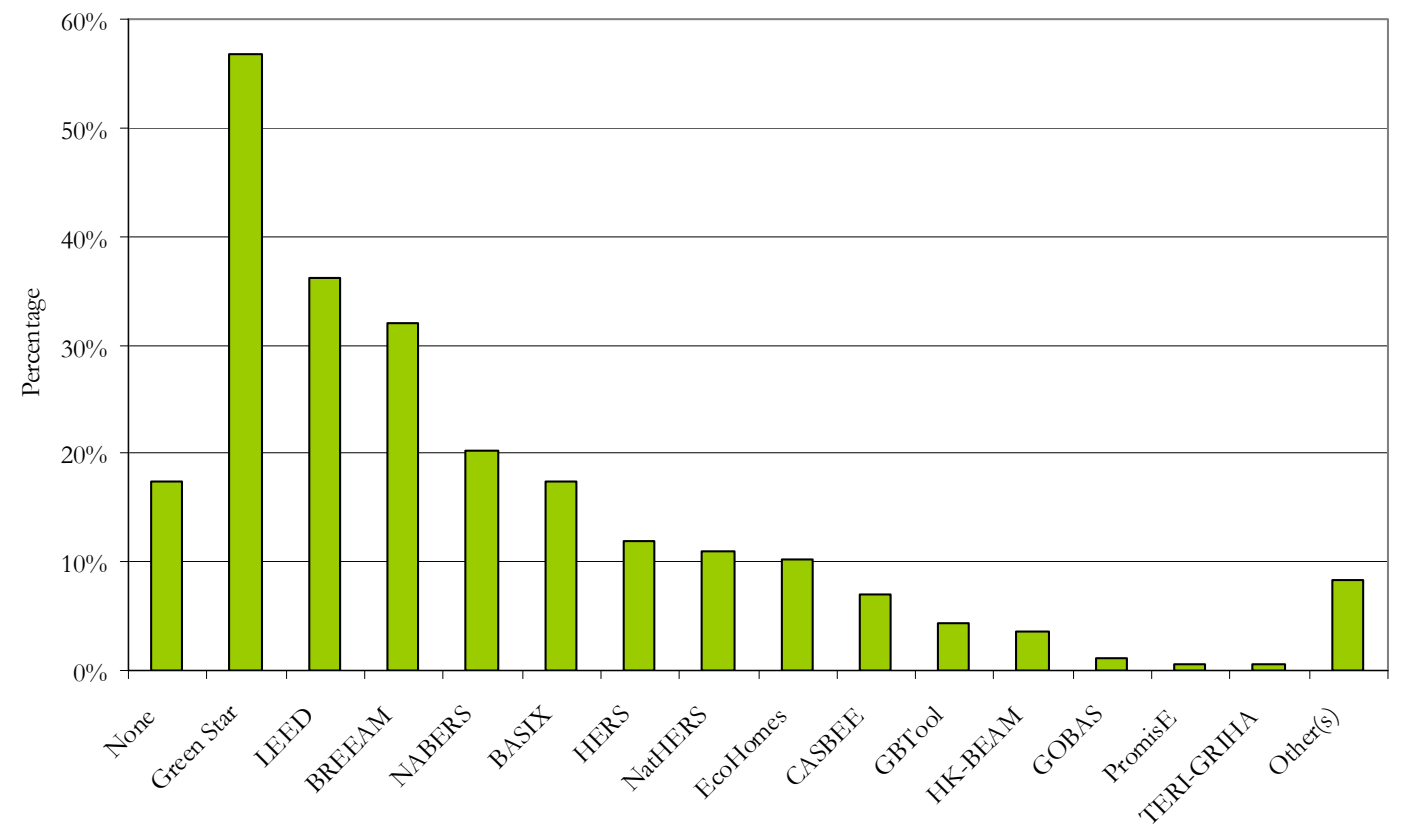

Figure C-18: Overall awareness of the current existing BSRTs (in order of highest to lowest) 


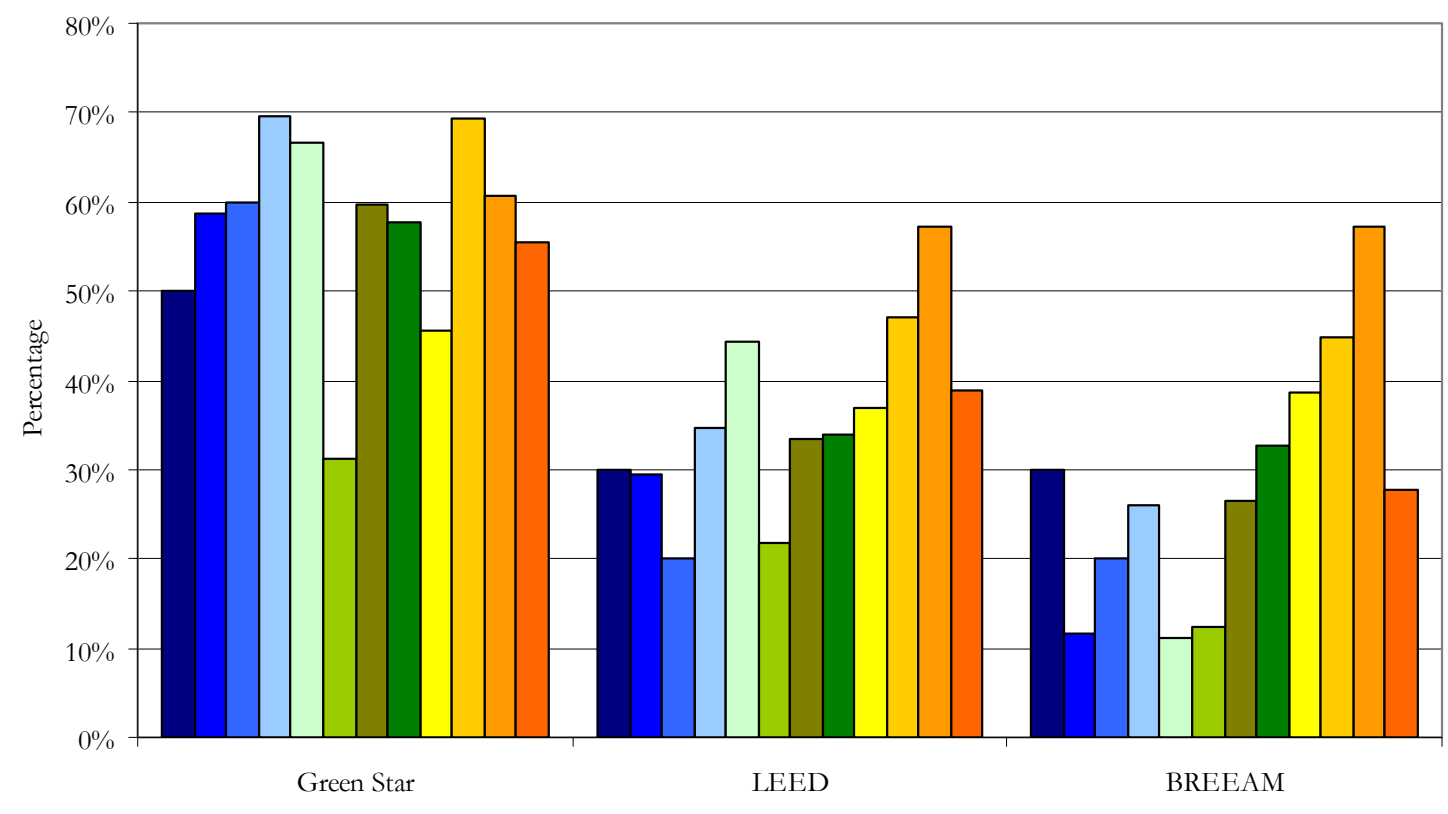

$\square$ CPD $\square$ IO\&PM $\square$ RD\&MPO $\square$ OO $\square$ MCT\&R $\square$ BC $\square$ BPM\&D $\square$ A\&D $\square$ E P\&CP $\square$ R\&NGO $\square$ RI

Figure C-19: Overall awareness of the current existing BSRTs by industry sector (top three results)

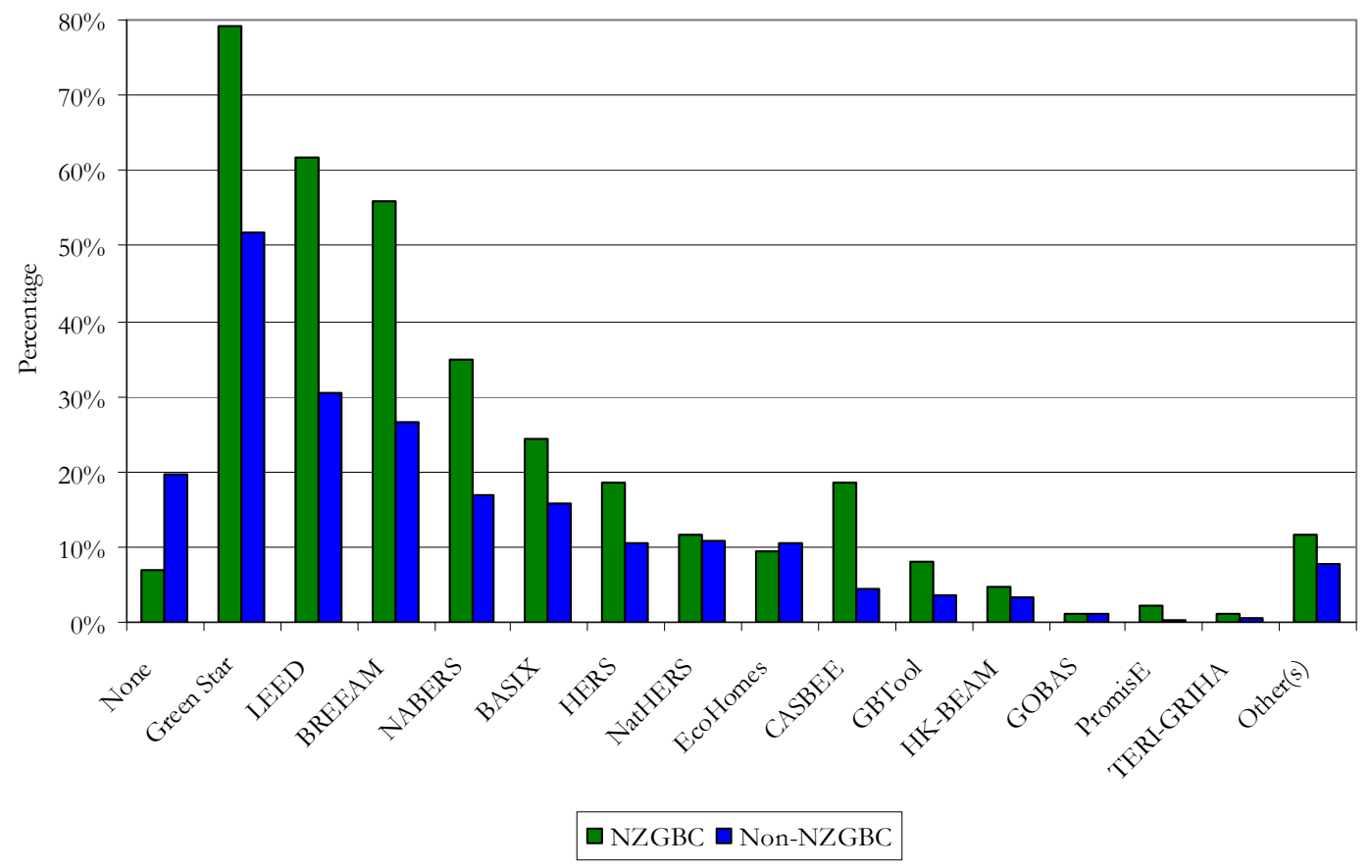

Figure C-20: Overall awareness of the current existing BSRTs by NZGBC vs. non-NZGBC 


\section{C.2.2.4 Experience with Existing Building Sustainability Rating Tools}

Question: Of the current existing Building Sustainability Rating Tools with do you have experience with?

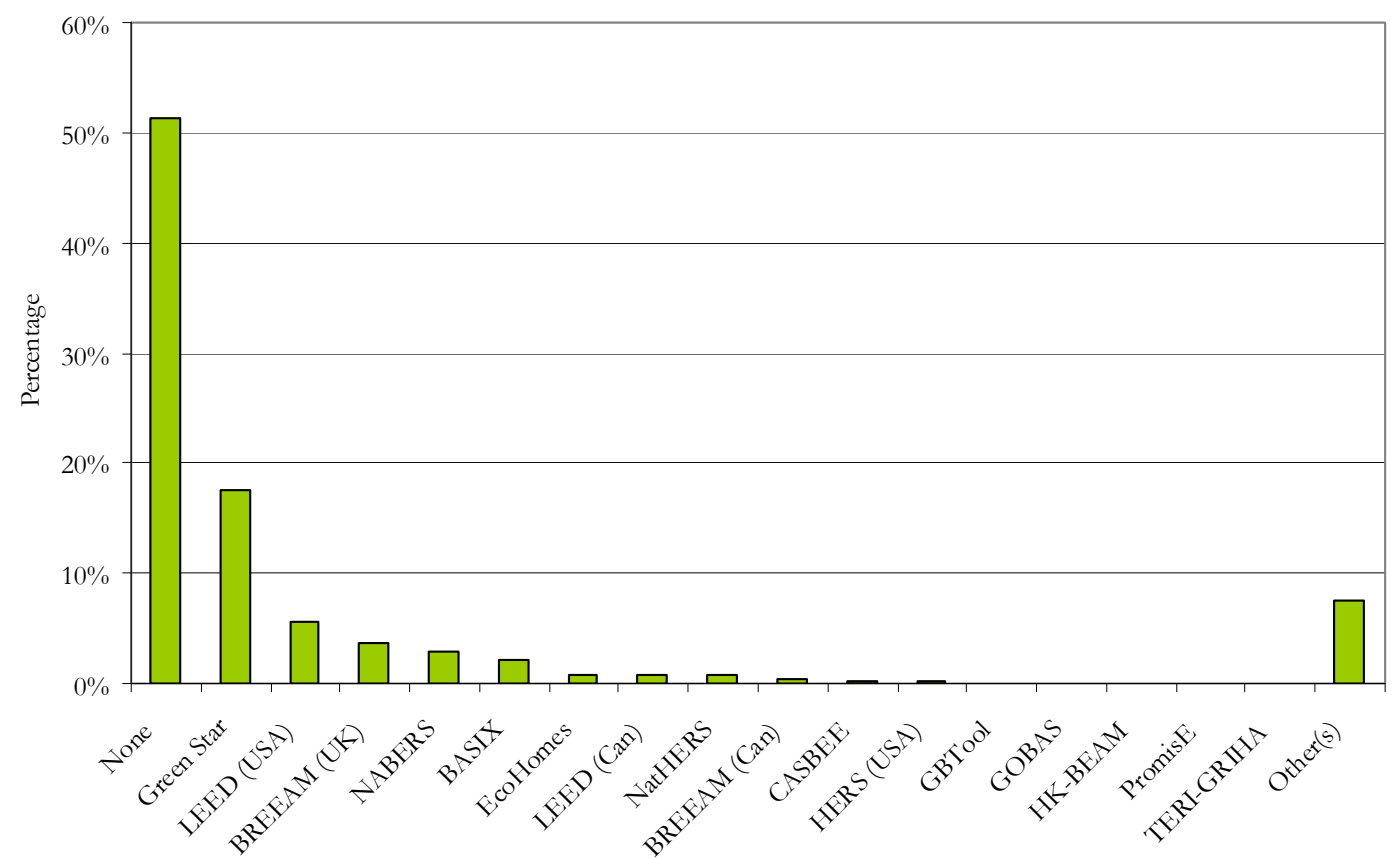

Figure C-21: Overall current experience with existing BSRTs (in order from highest to lowest)

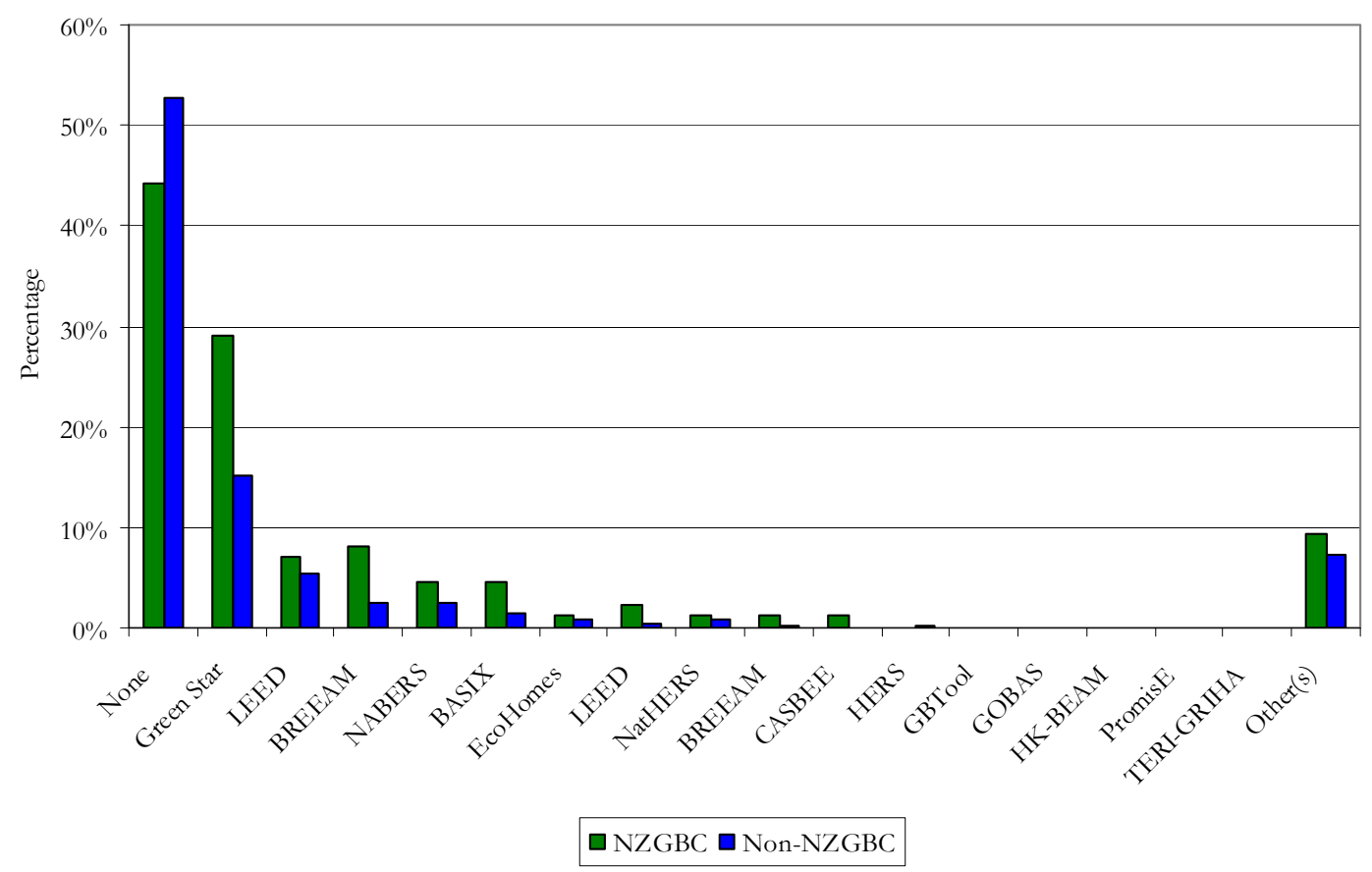

Figure C-22: Overall current experience with existing BSRTs by NZGBC vs. non-NZGBC 


\section{C.2.2.5 Existing Accreditation}

Question: Have you completed training to become an accredited professional for any existing Building Sustainability Rating Tool?

Table C-5: Overall participant level of professional accreditation for existing BSRTs

\begin{tabular}{|l|r|}
\hline Accredited Professional & Percentage \\
\hline Yes & $8 \%$ \\
\hline No & $92 \%$ \\
\hline Total & $100 \%$ \\
\hline
\end{tabular}




\section{C.2.3 Green Star New Zealand}

\section{C.2.3.1 Green Star New Zealand Awareness}

Question 9: Are you aware of Green Star New Zealand?

Table C-6: Overall awareness of Green Star NZ

\begin{tabular}{|l|r|}
\hline Level of awareness & Percentage \\
\hline Yes & $78 \%$ \\
\hline No & $22 \%$ \\
\hline Total & $100 \%$ \\
\hline
\end{tabular}

\section{C.2.3.2 New Zealand Equivalent of Green Star}

Question: How important is it for Green Star New Zealand to be an equivalent of the Australian Green Star system?

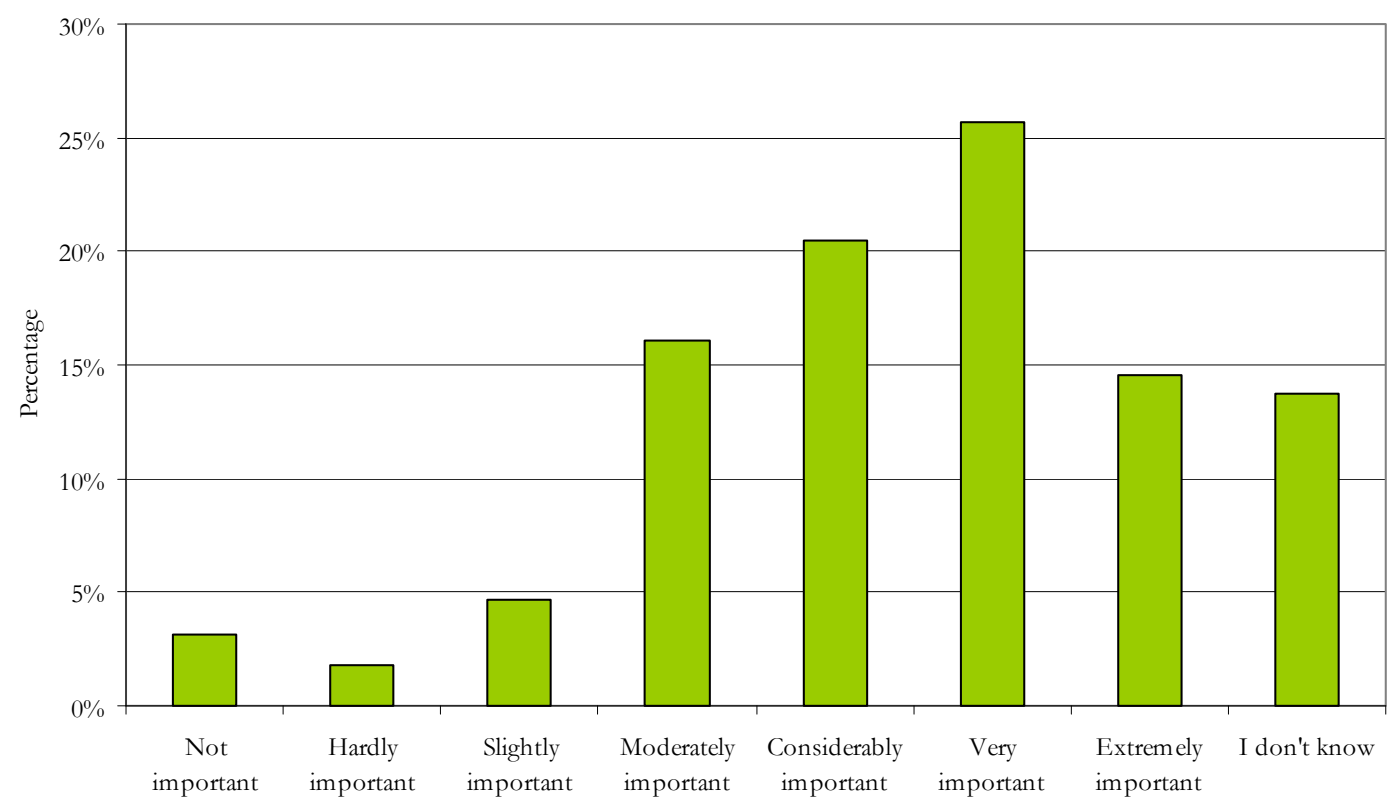

Figure C-23: Overall importance for Green Star NZ to be a New Zealand equivalent of the Australian Green Star system 


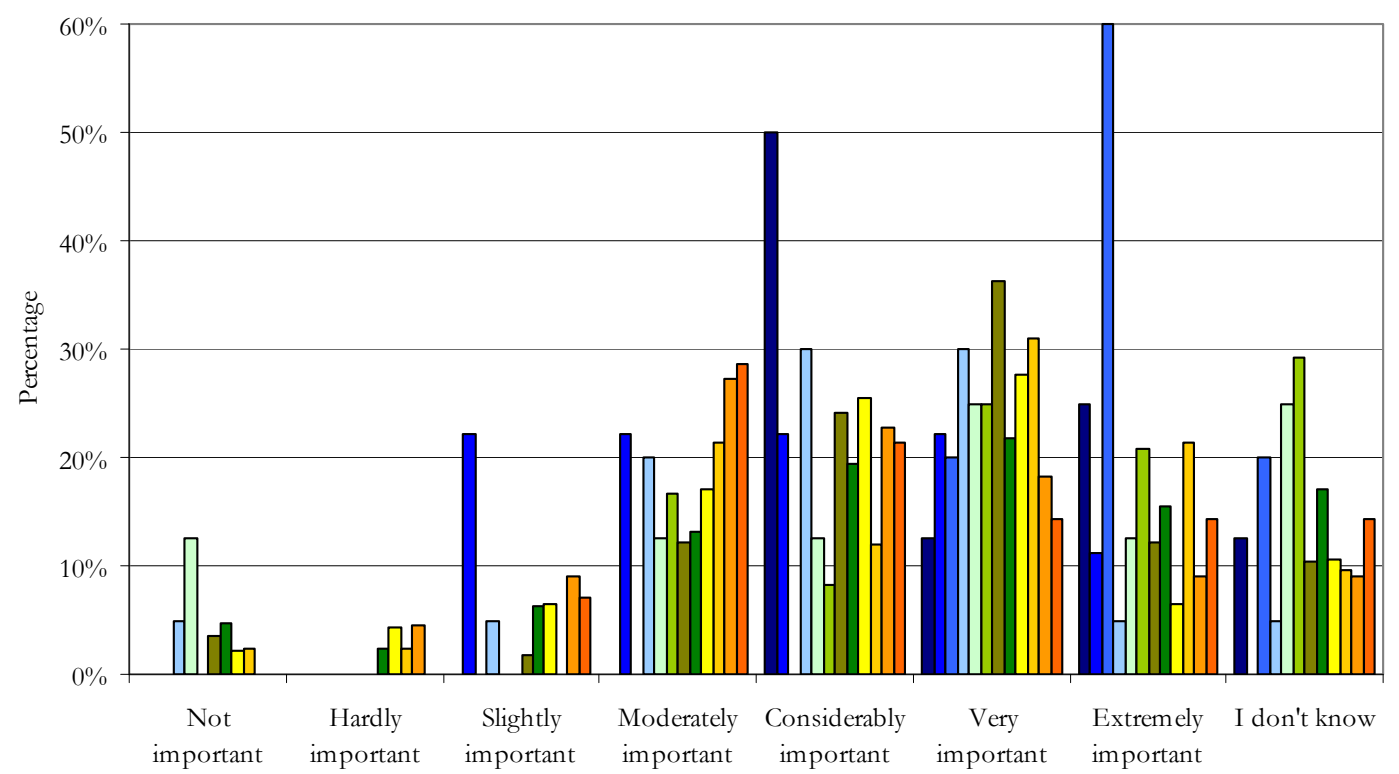

$\square \mathrm{CPD} \square \mathrm{IO \& PM} \square \mathrm{RD \& MPO} \square \mathrm{OO} \square \mathrm{MCT \& R} \square \mathrm{BC} \square \mathrm{BPM} \& \mathrm{D} \square \mathrm{A} \& \mathrm{D} \square \square \mathrm{P} \& \mathrm{CP} \square \mathrm{R} \& N G O \square \mathrm{RI}$

Figure C-24: Overall importance for Green Star NZ to be a New Zealand equivalent of the Australian Green Star system by industry sector

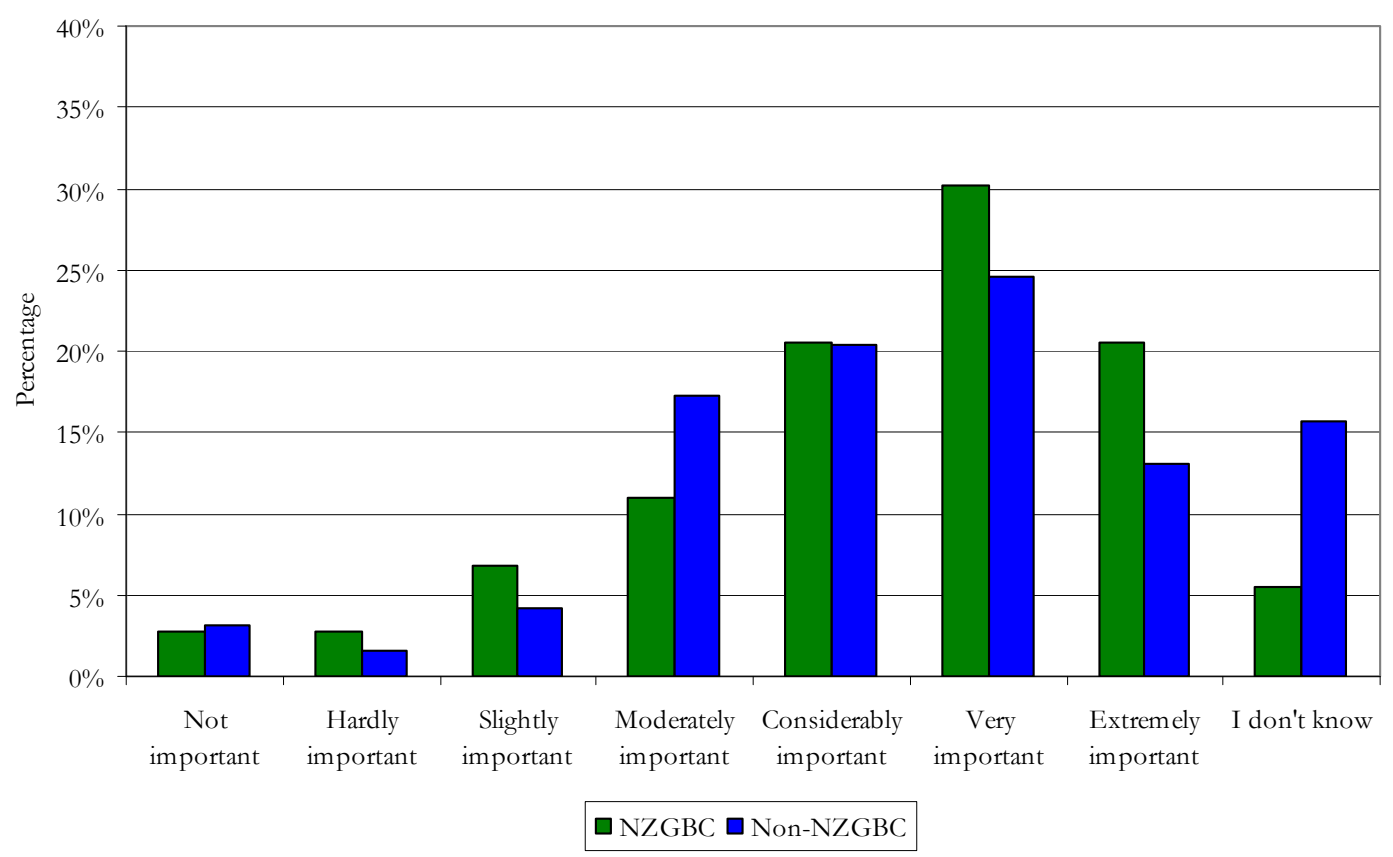

Figure C-25: Overall importance for Green Star NZ to be a New Zealand equivalent of the Australian Green Star system by NZGBC vs. non-NZGBC 


\section{C.2.3.3 Green Star New Zealand Influence}

To what extent do you think Green Star New Zealand will influence the building industry in a shift towards more sustainable building development in New Zealand?

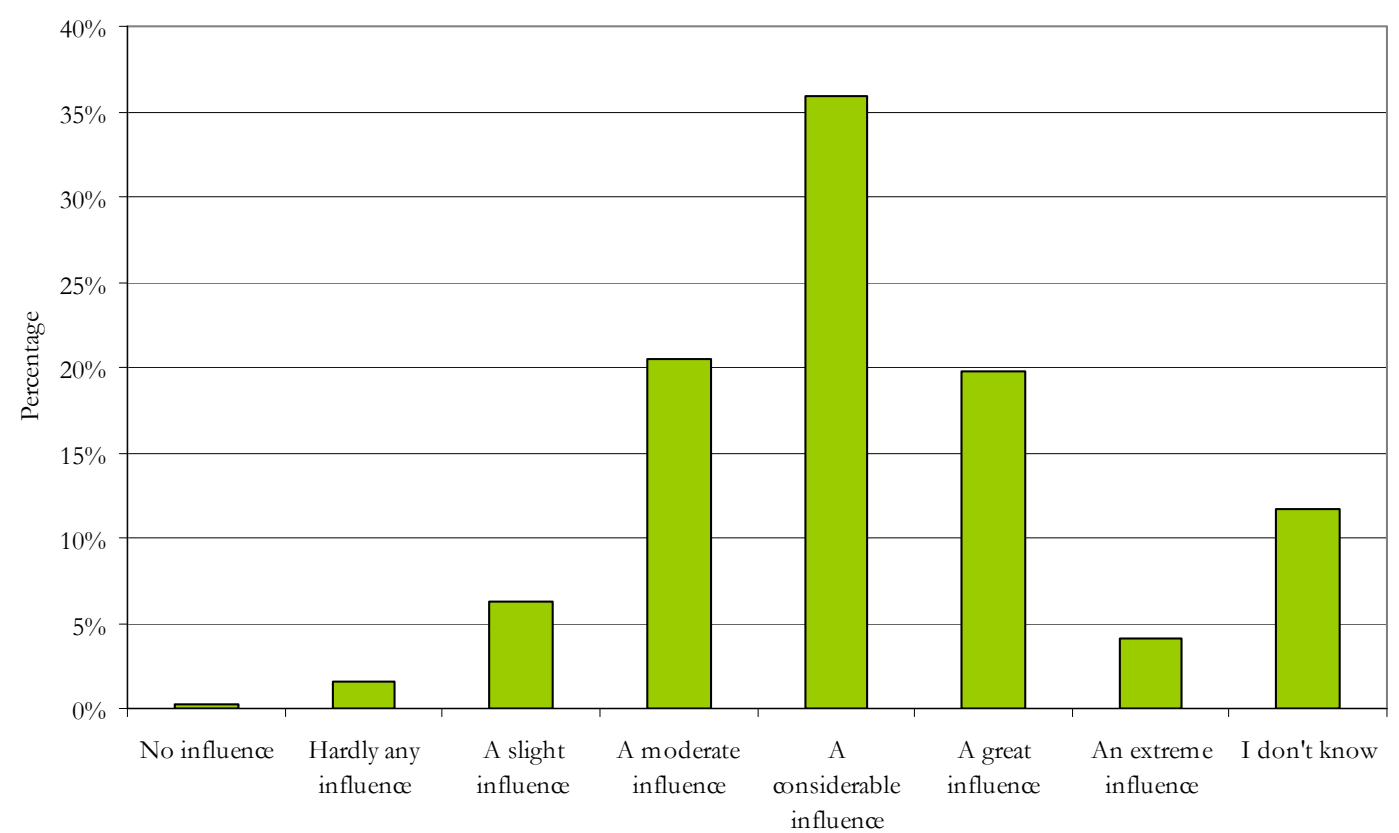

Figure C-26: Overall perceived extent that Green Star NZ will influence the building industry in a shift towards more sustainable building development in New Zealand

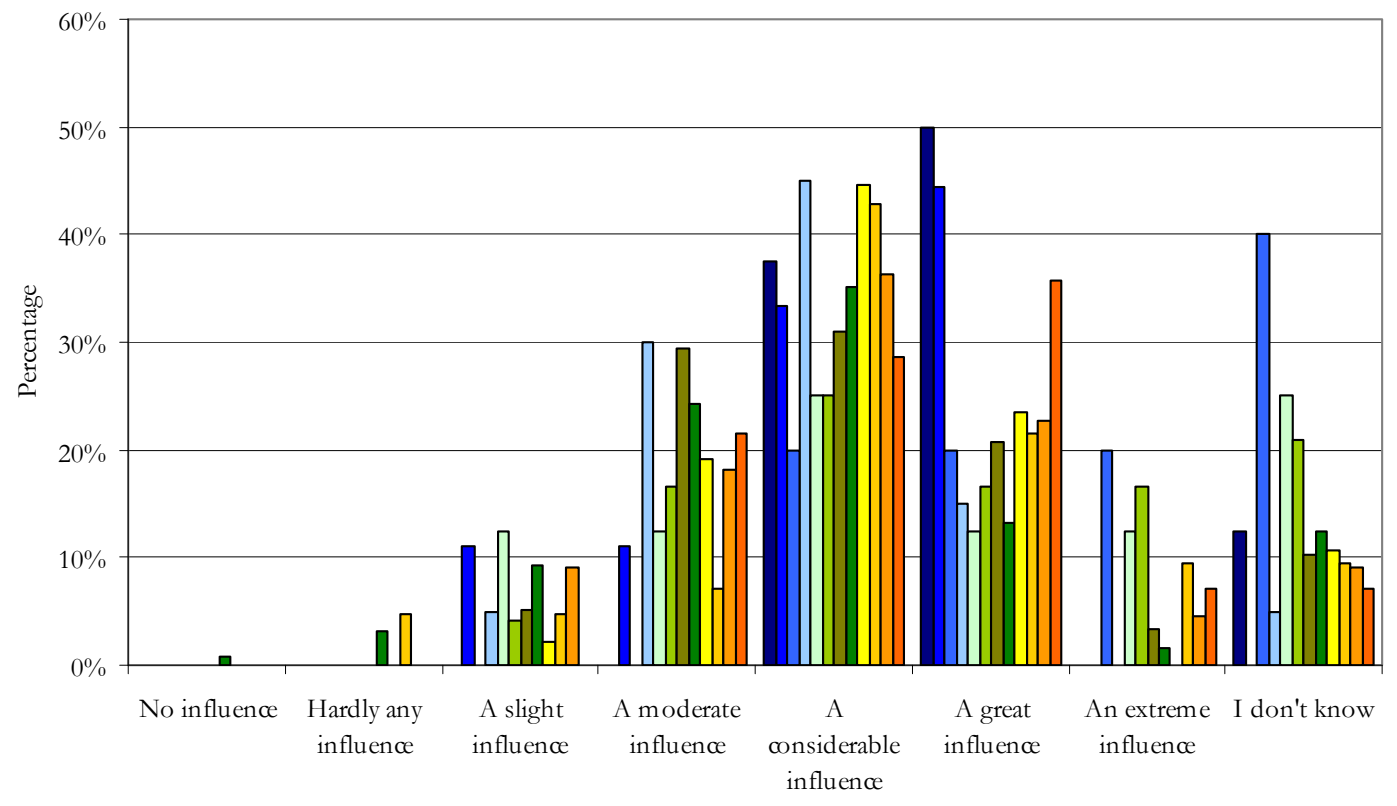

$\square$ CPD $\square$ IO\&PM $\square$ RD\&MPO $\square$ OO $\square$ MCT\&R $\square$ BC $\square$ BPM\&D $\square$ A\&D $\square$ E $\square$ P\&C $\square$ R\&NGO $\square$ RI

Figure C-27: Overall perceived extent that Green Star NZ will influence the building industry in a shift towards more sustainable building development in New Zealand by industry sector 


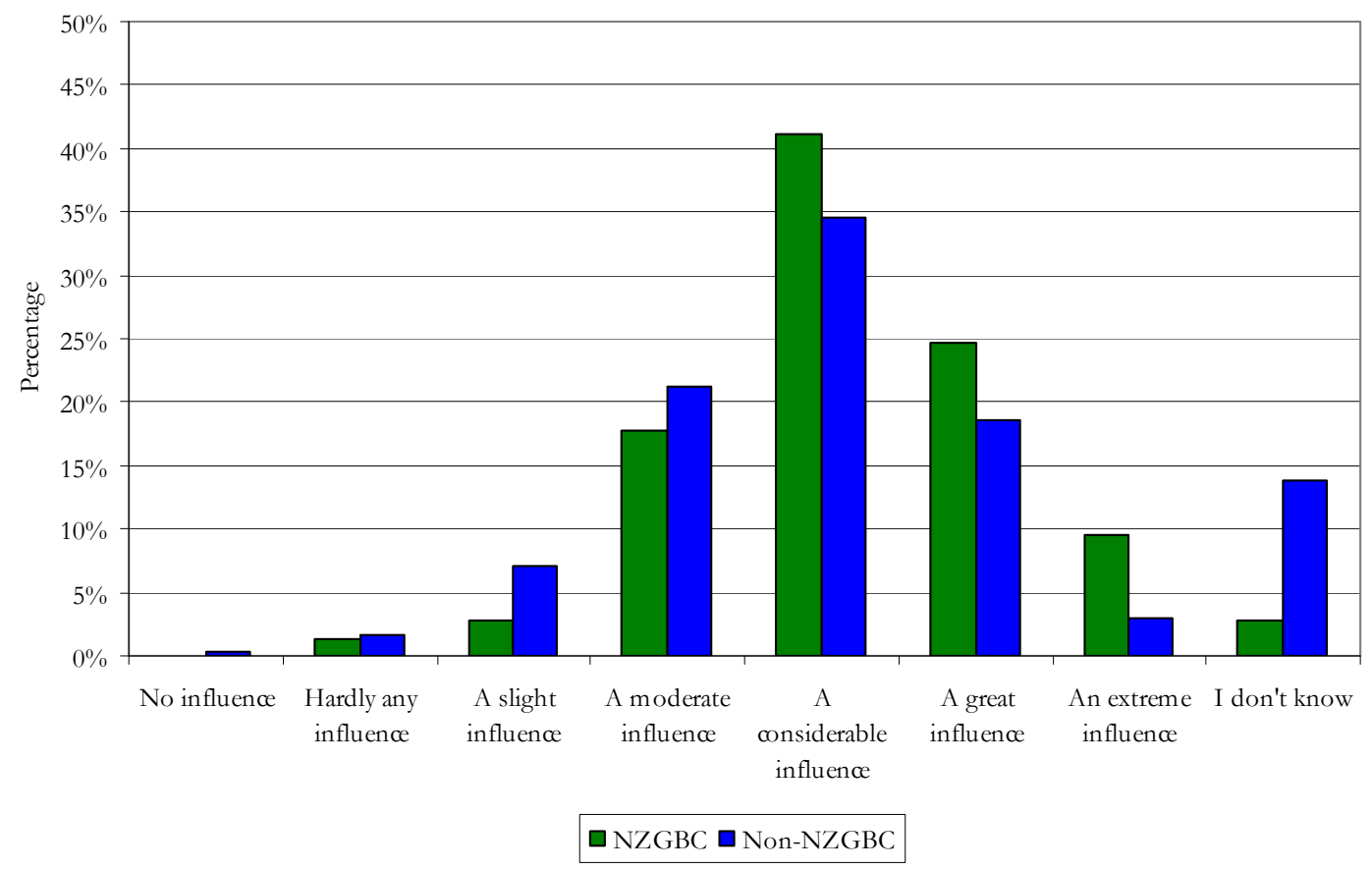

Figure C-28: Overall perceived extent that Green Star NZ will influence the building industry in a shift towards more sustainable building development in New Zealand by NZGBC vs. nonNZGBC

\section{C.2.3.4 Use of Green Star New Zealand}

Question: How likely is it that you will use Green Star New Zealand once it is officially released?

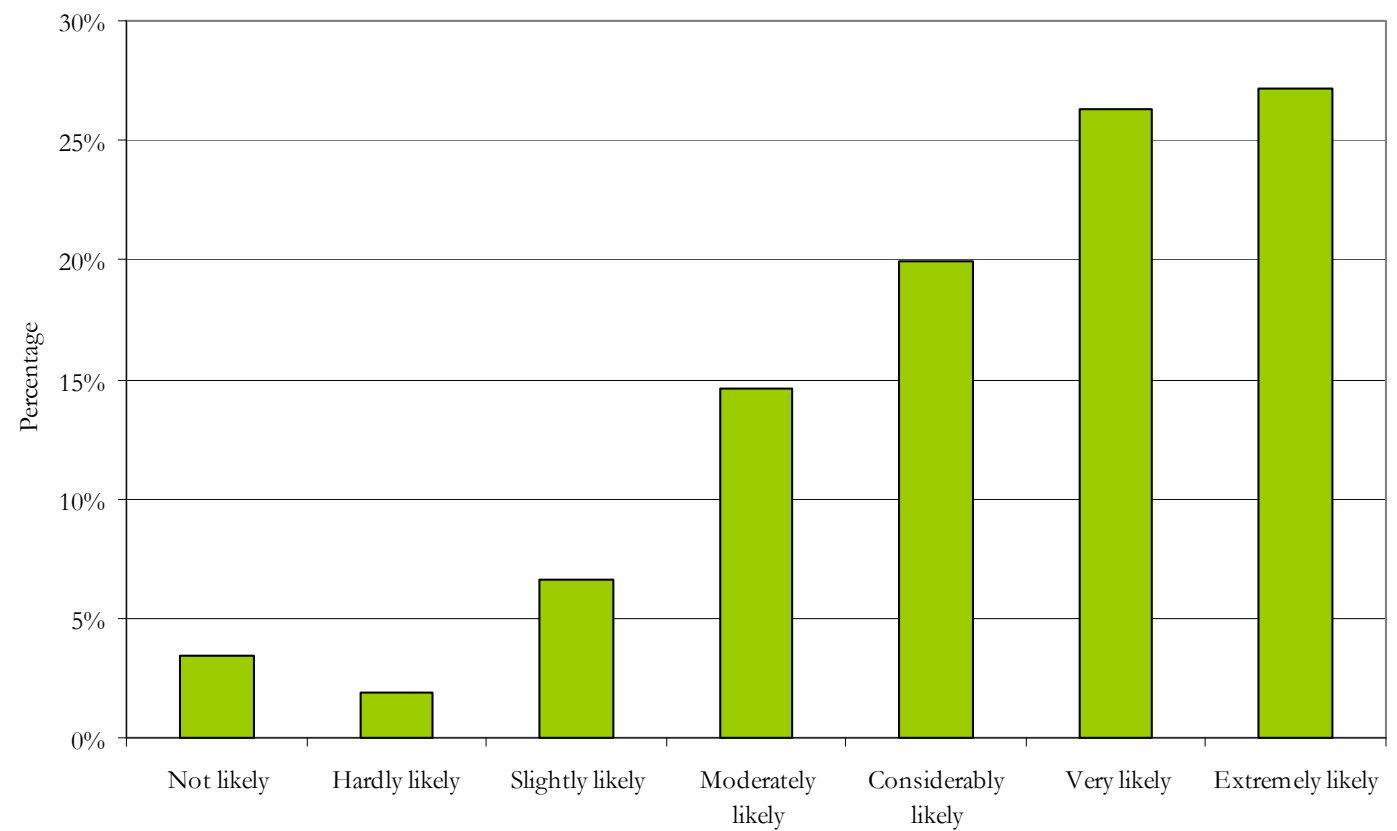

Figure C-29: Overall likelihood that participants will use Green Star NZ once it is officially released 


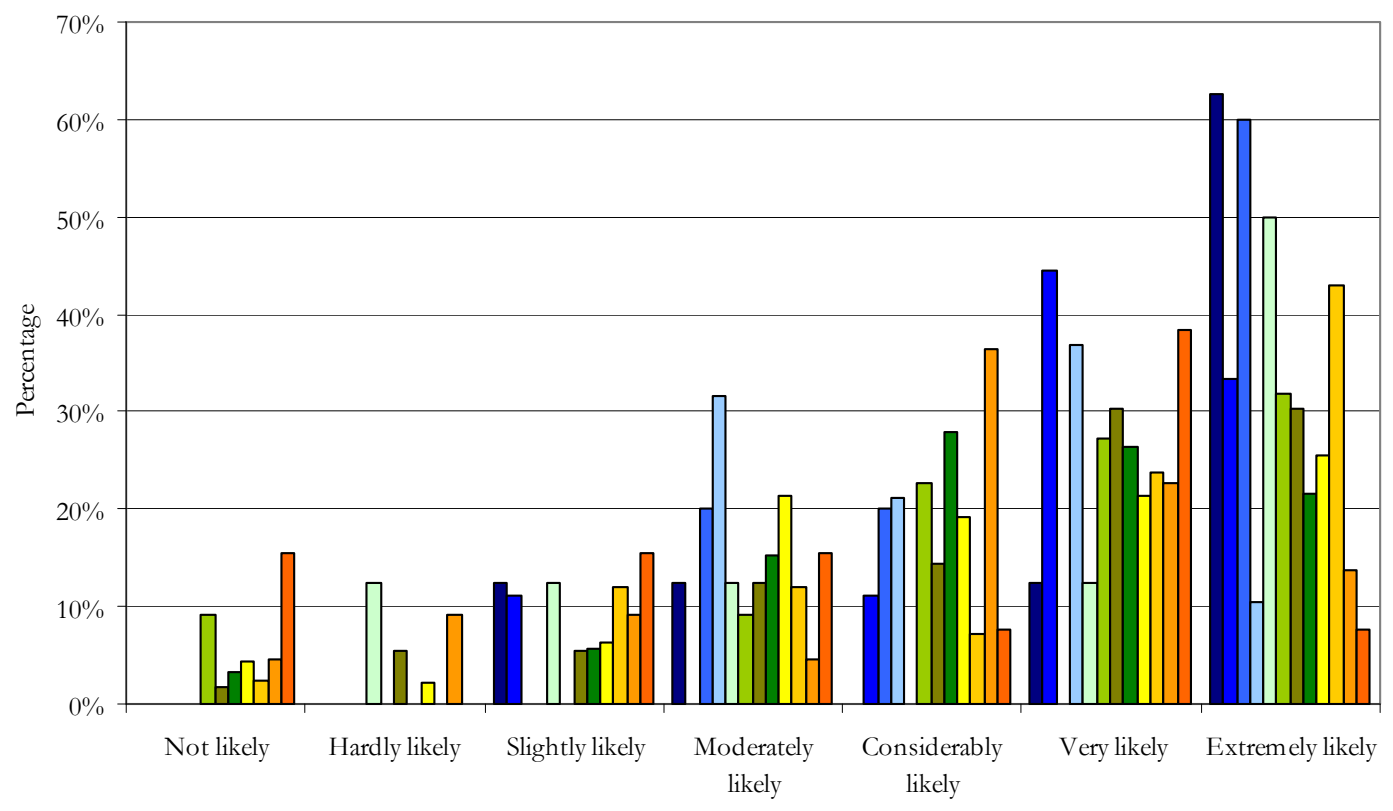

$\square$ CPD $\square$ IO\&PM $\square$ RD\&MPO $\square$ OO $\square$ MCT\&R $\square$ BC $\square$ BPM\&D $\square$ A\&D $\square$ E P\&CP $\square$ R\&NGO $\square$ RI

Figure C-30: Overall likelihood that participants will use Green Star NZ once it is officially released by industry sector

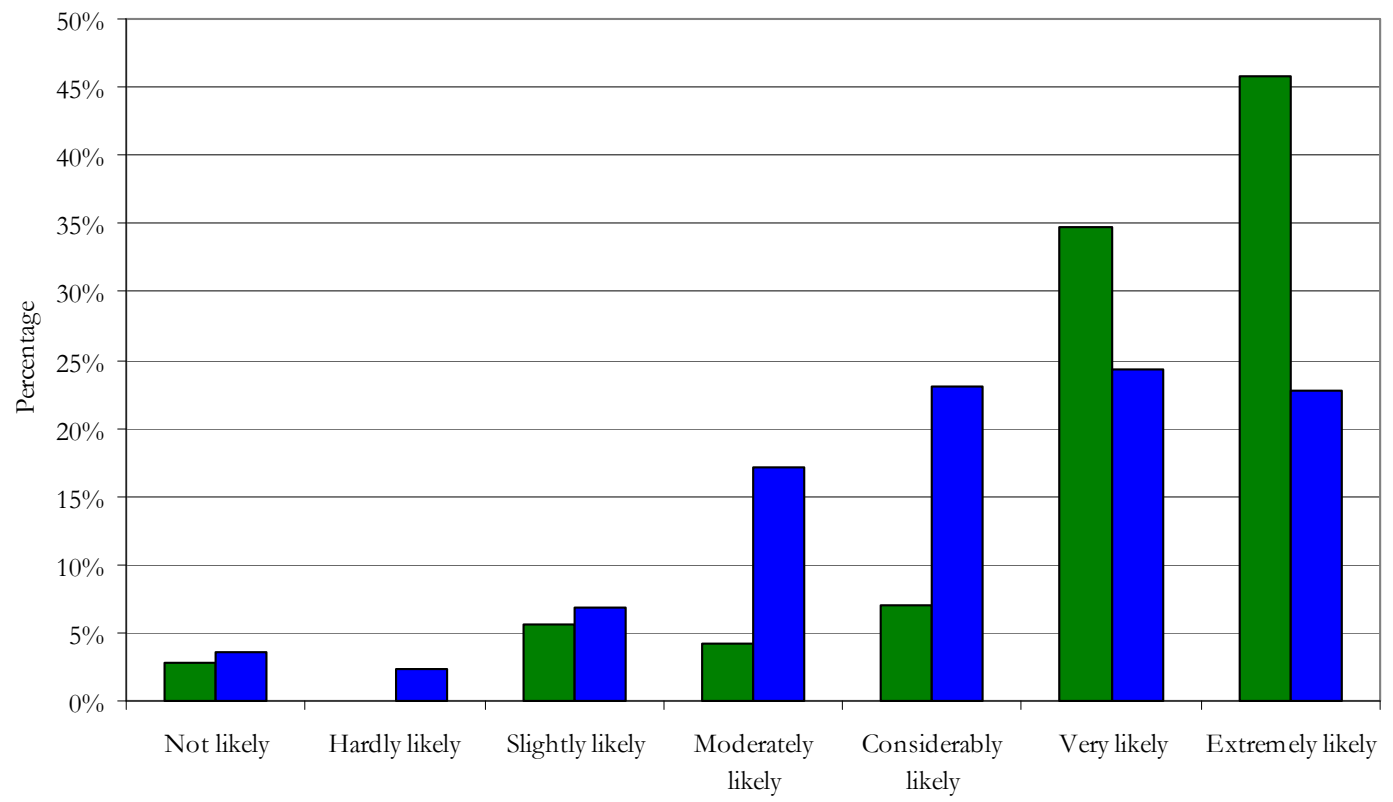

$\square$ NZGBC $\square$ Non-NZGBC

Figure C-31: Overall likelihood that participants will use Green Star NZ once it is officially released by NZGBC vs. non-NZGBC 


\section{C.2.3.5 Intended Use of Green Star New Zealand}

Question: If you are likely to use Green Star New Zealand, how do you anticipate using it?

Table C-7: Definitions of option choices for how Green Star NZ is likely to be used (in order asked in survey)

\begin{tabular}{|l|l|}
\hline Option & Definition \\
\hline Option A & Design guideline \\
\hline Option B & Design Certification \\
\hline Option C & As Built Certification \\
\hline Option D & Guideline for fit-out \\
\hline Option E & Fit-out Certification \\
\hline Option F & Understanding building performance \\
\hline Option G & Performance Certification \\
\hline Option H & Other(s) \\
\hline
\end{tabular}

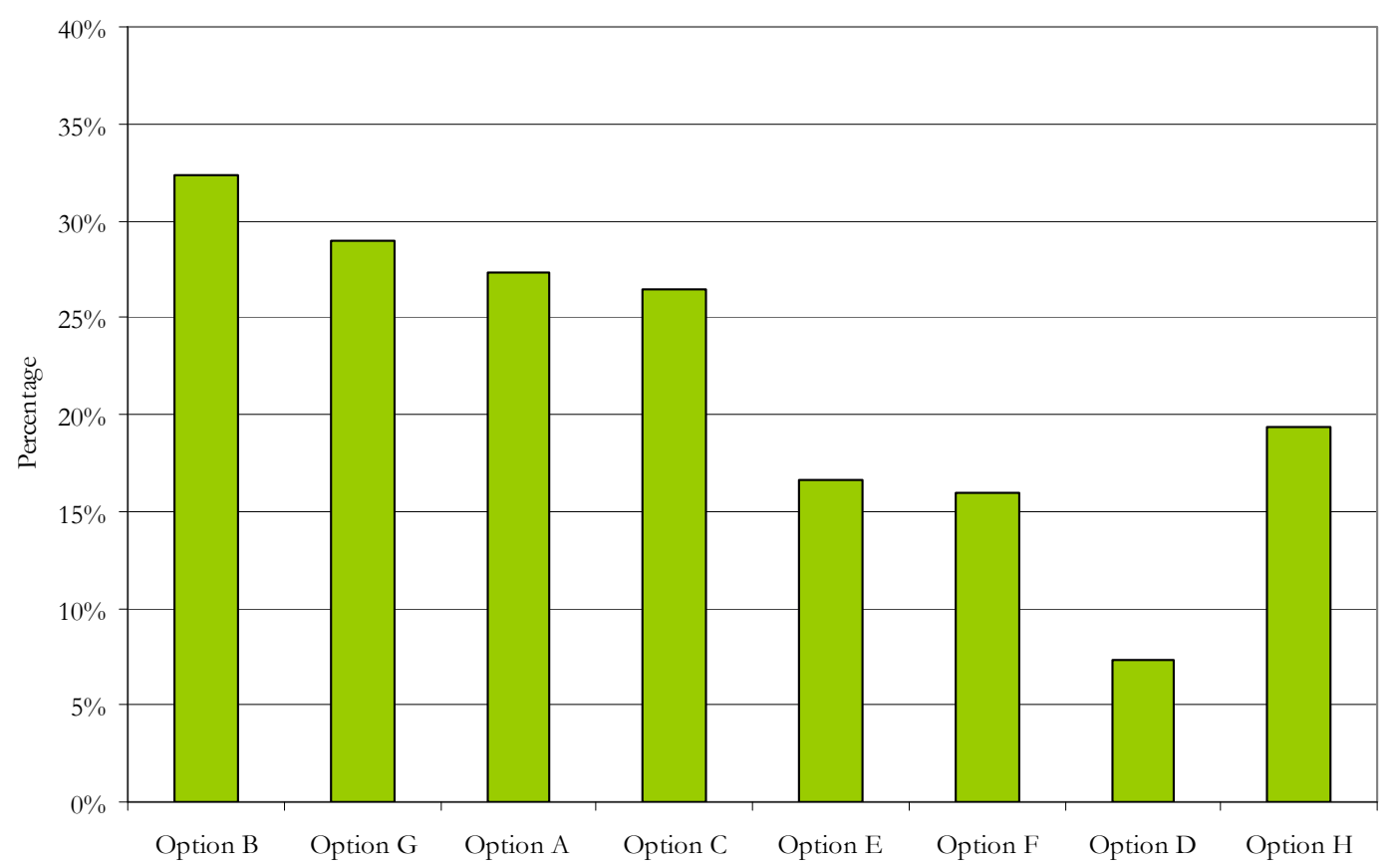

Figure C-32: Overall anticipation how Green Star NZ will be used, if participants are likely to use it (in order from highest to lowest) 


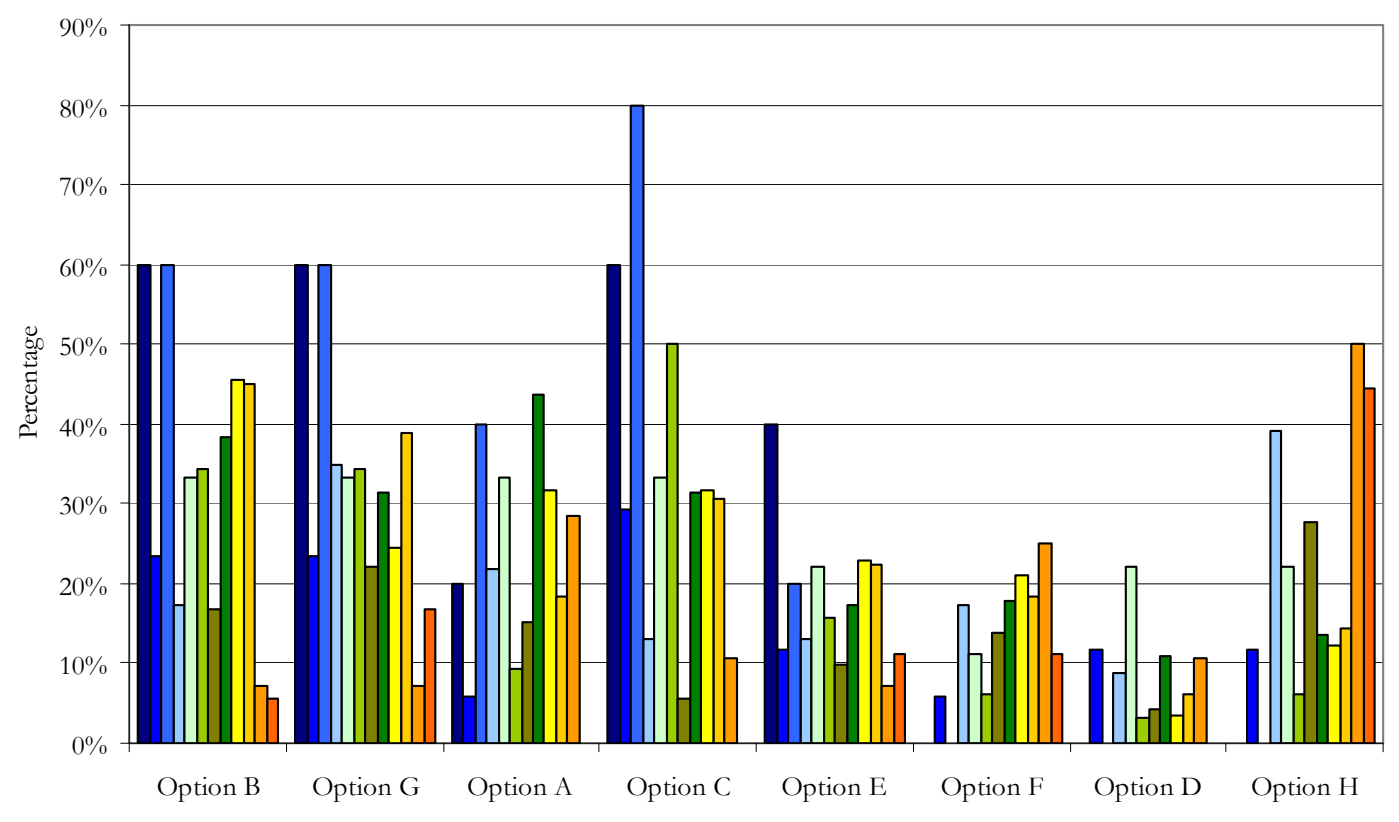

$\square$ CPD $\square$ IO\&PM $\square$ RD\&MPO $\square$ OO $\square$ MCT\&R $\square$ BC $\square$ BPM\&D $\square$ A\&D $\square$ E $\square$ PCP $\square$ R\&NGO $\square$ RI

Figure C-33: Overall anticipation how Green Star NZ will be used, if participants are likely to use it by industry sector

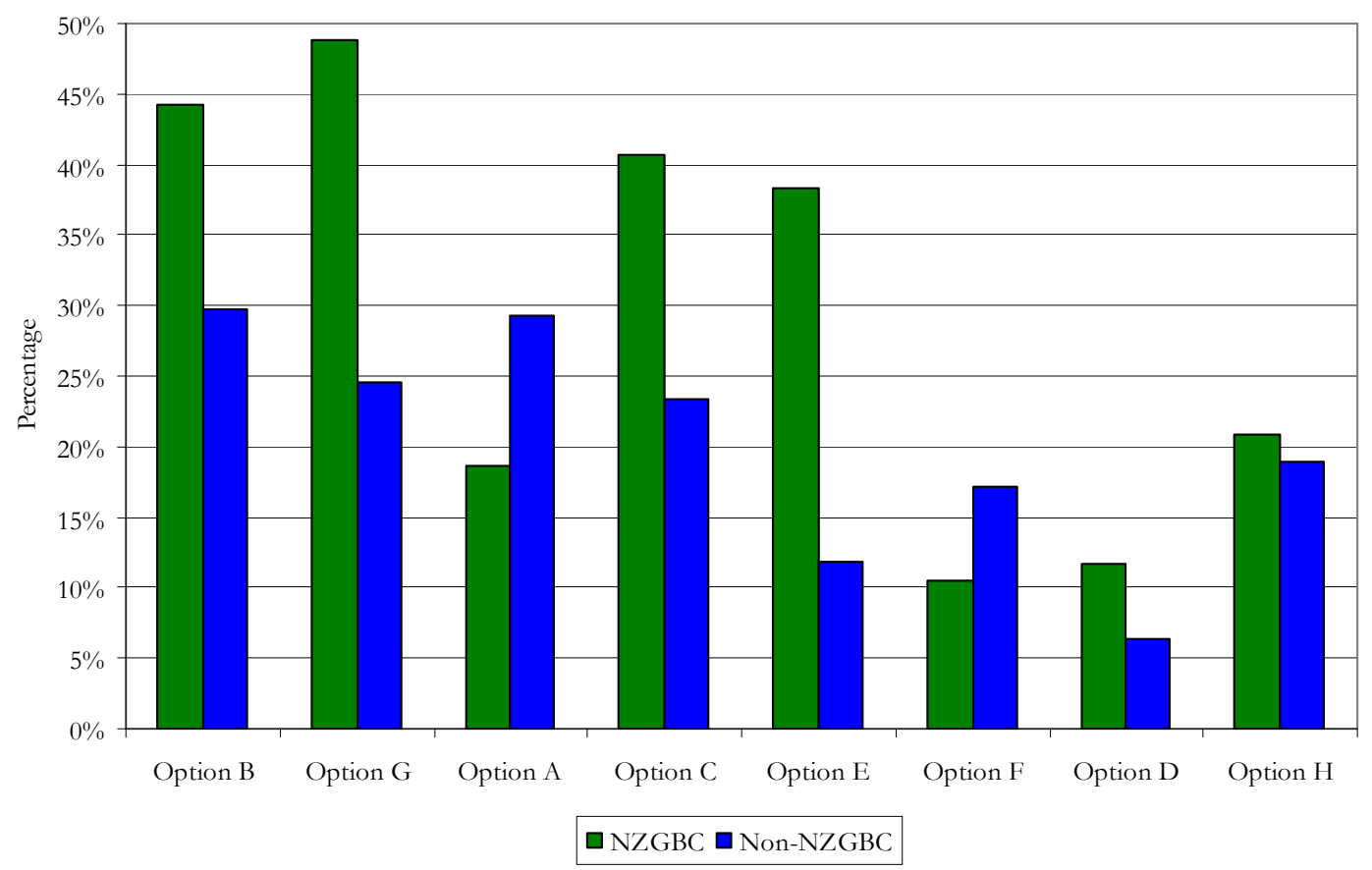

Figure C-34: Overall anticipation how Green Star NZ will be used, if participants are likely to use it by NZGBC vs. non-NZGBC 


\section{C.2.3.6 Green Star New Zealand Training}

Question: How likely is it that you will seek training to become a Green Star New Zealand accredited professional?

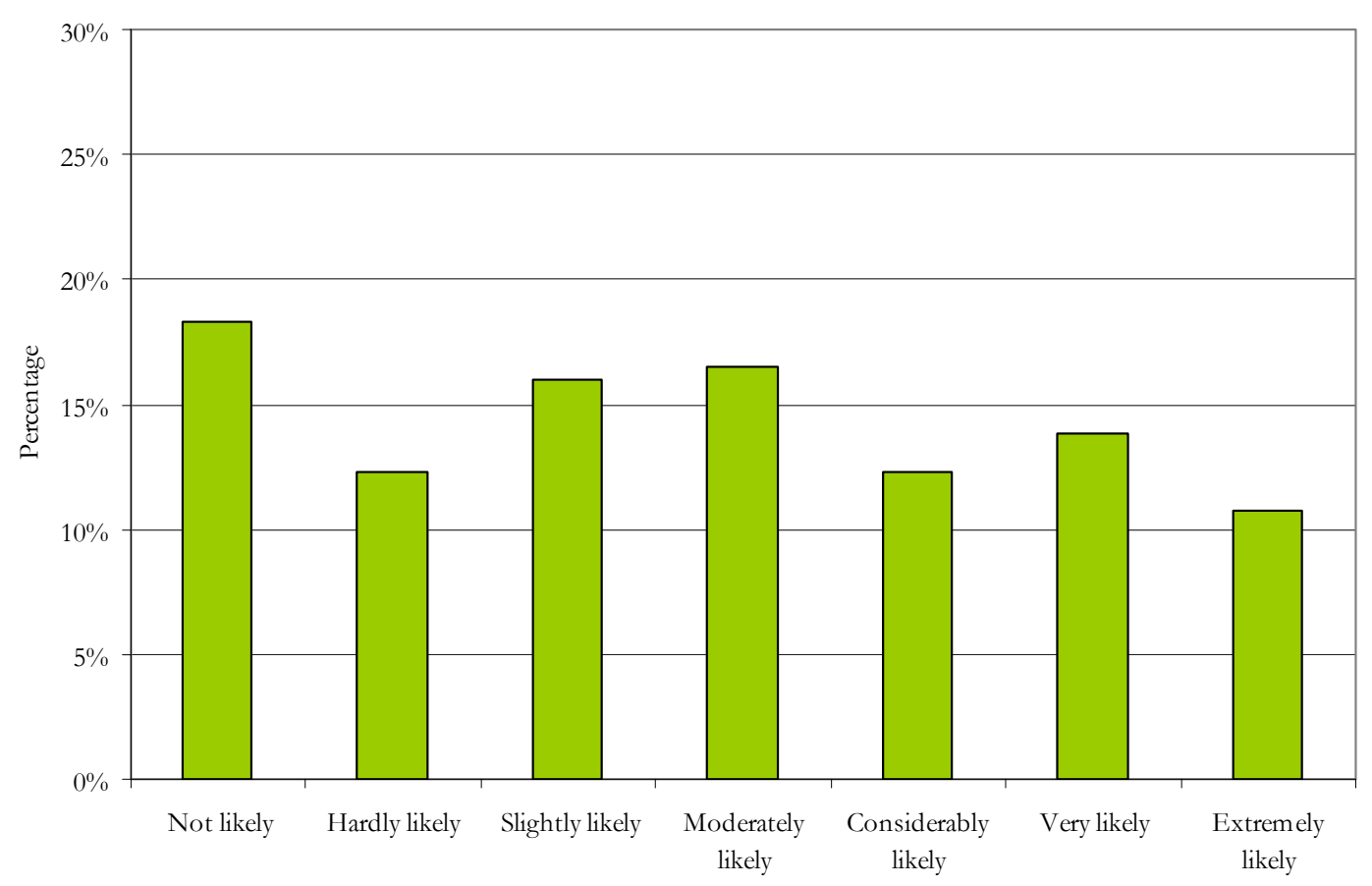

Figure C-35: Overall likelihood that participants will seek training to become a Green Star NZ accredited professional

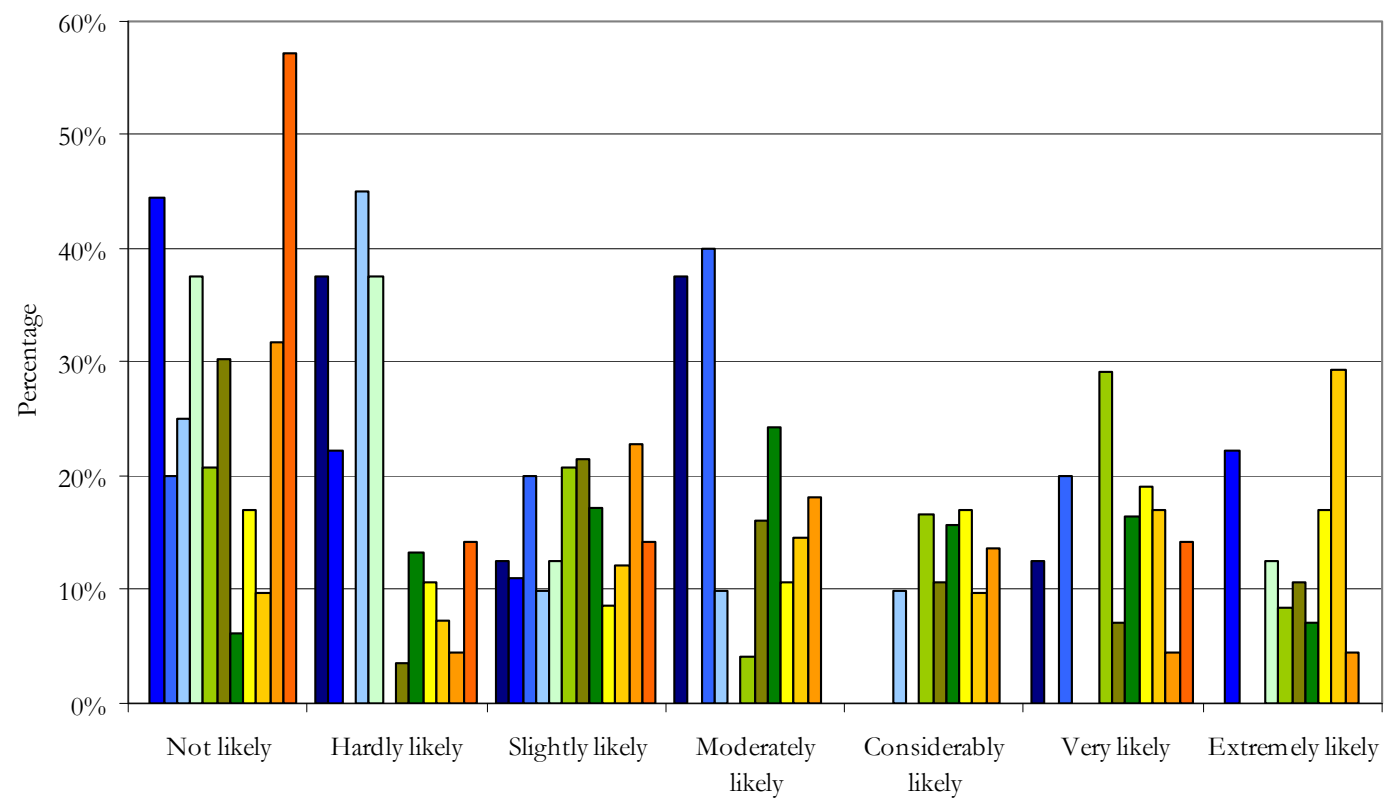

$\square$ CPD $\square$ IO\&PM $\square$ RD\&MPO $\square$ OO $\square$ MCT\&R $\square$ BC $\square$ BPM\&D $\square$ A\&D $\square$ E P\&CP $\square$ R\&NGO $\square$ RI

Figure C-36: Overall likelihood that participants will seek training to become a Green Star NZ accredited professional by industry sector

Jonathan Smith 


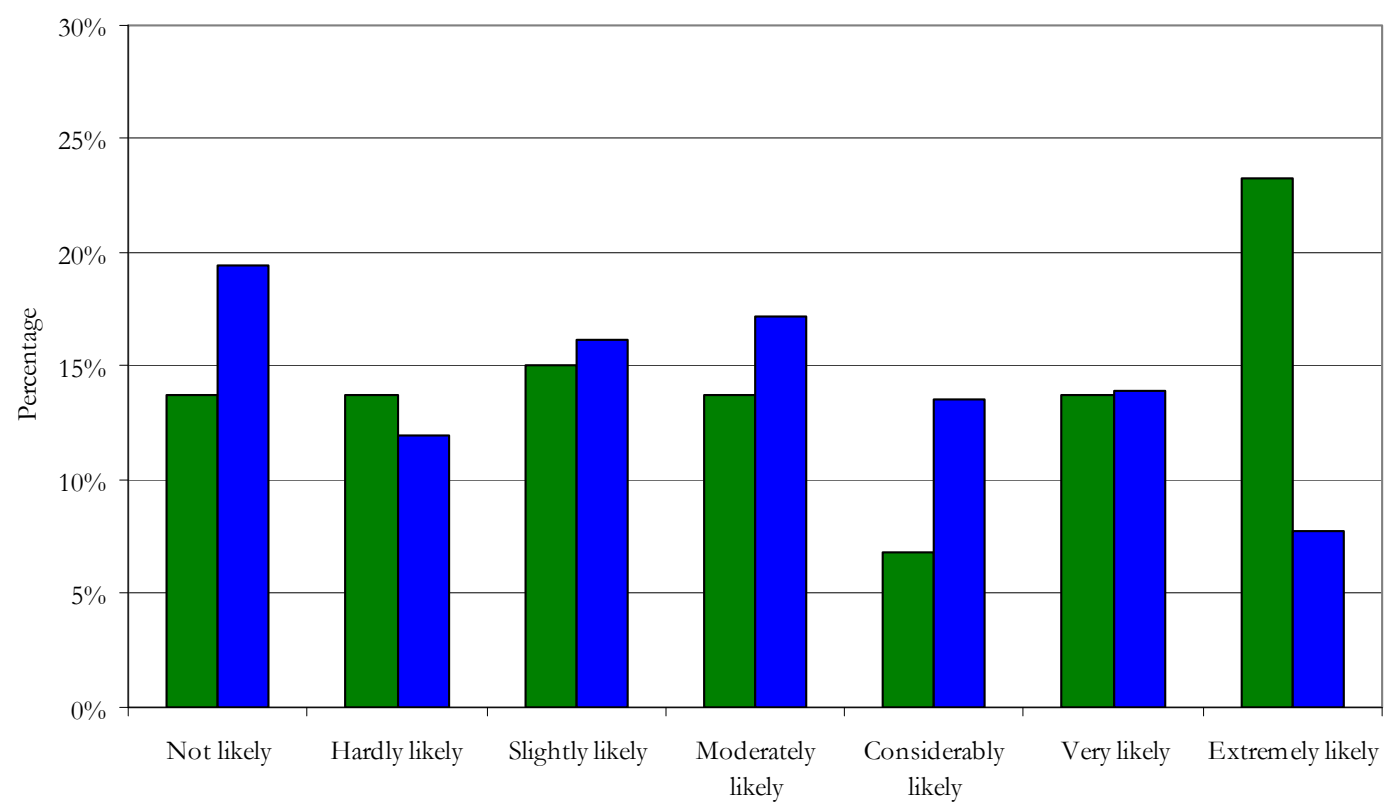

$\square$ NZGBC $\square$ Non-NZGBC

Figure C-37: Overall likelihood that participants will seek training to become a Green Star NZ accredited professional by NZGBC vs. non-NZGBC

\section{C.2.3.7 Green Star New Zealand Certification}

Question: How important is it that New Zealand buildings seek Green Star New Zealand certification?

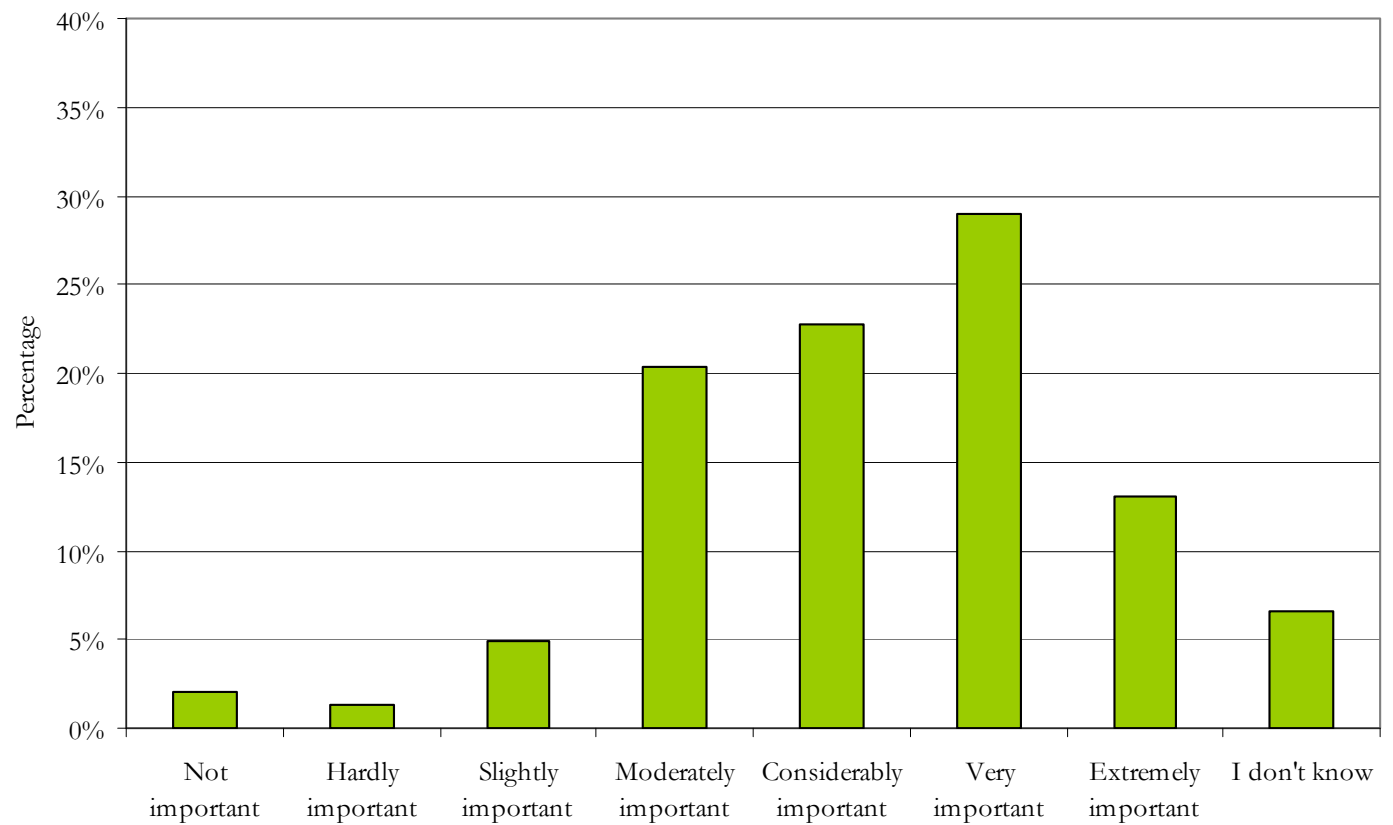

Figure C-38: Overall importance that New Zealand buildings seek full Green Star NZ accreditation 


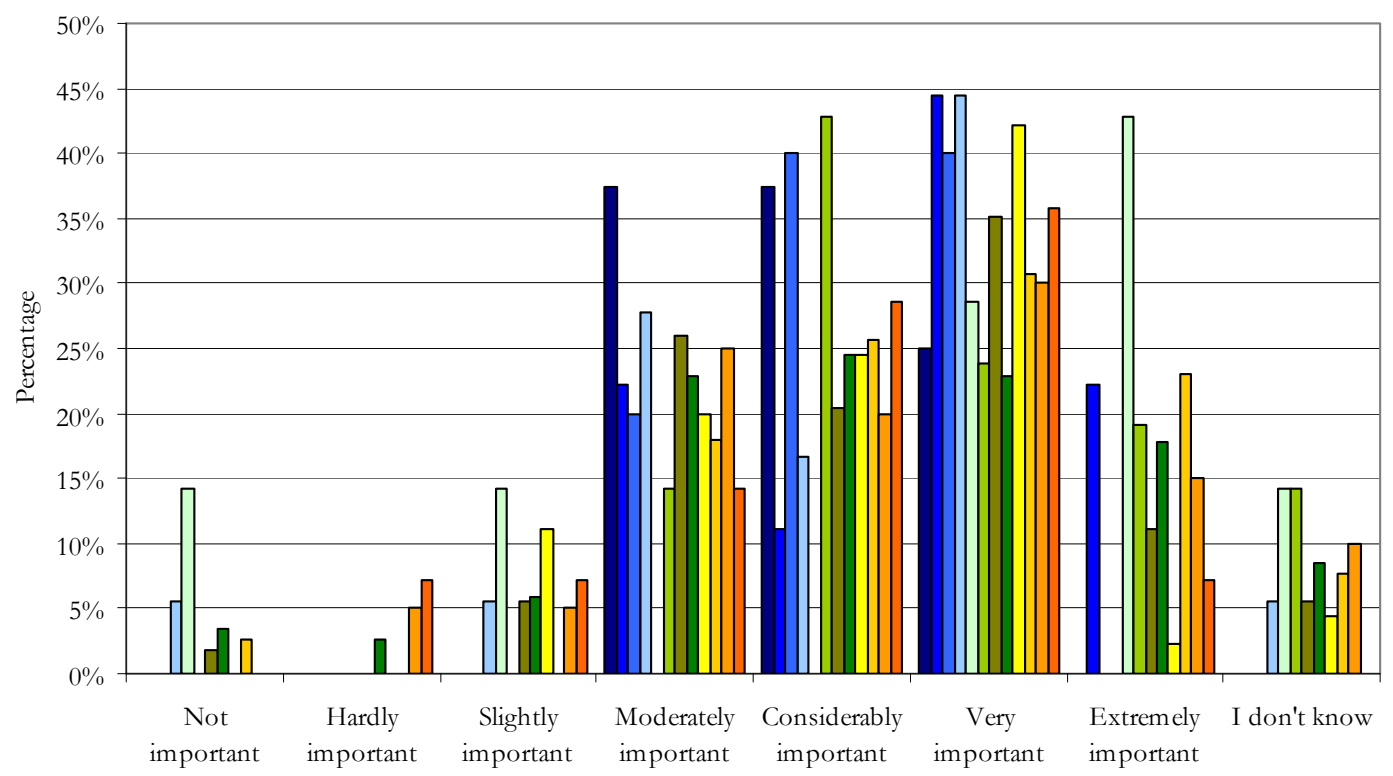

—CPD $\square$ IO\&PM $\square$ RD\&MPO $\square$ OO $\square$ MCT\&R $\square$ BC $\square$ BPM\&D $\square$ A\&D $\square$ E P\&CP $\square$ R\&NG $\square$ RI

Figure C-39: Overall importance that New Zealand buildings seek full Green Star NZ accreditation by industry sector

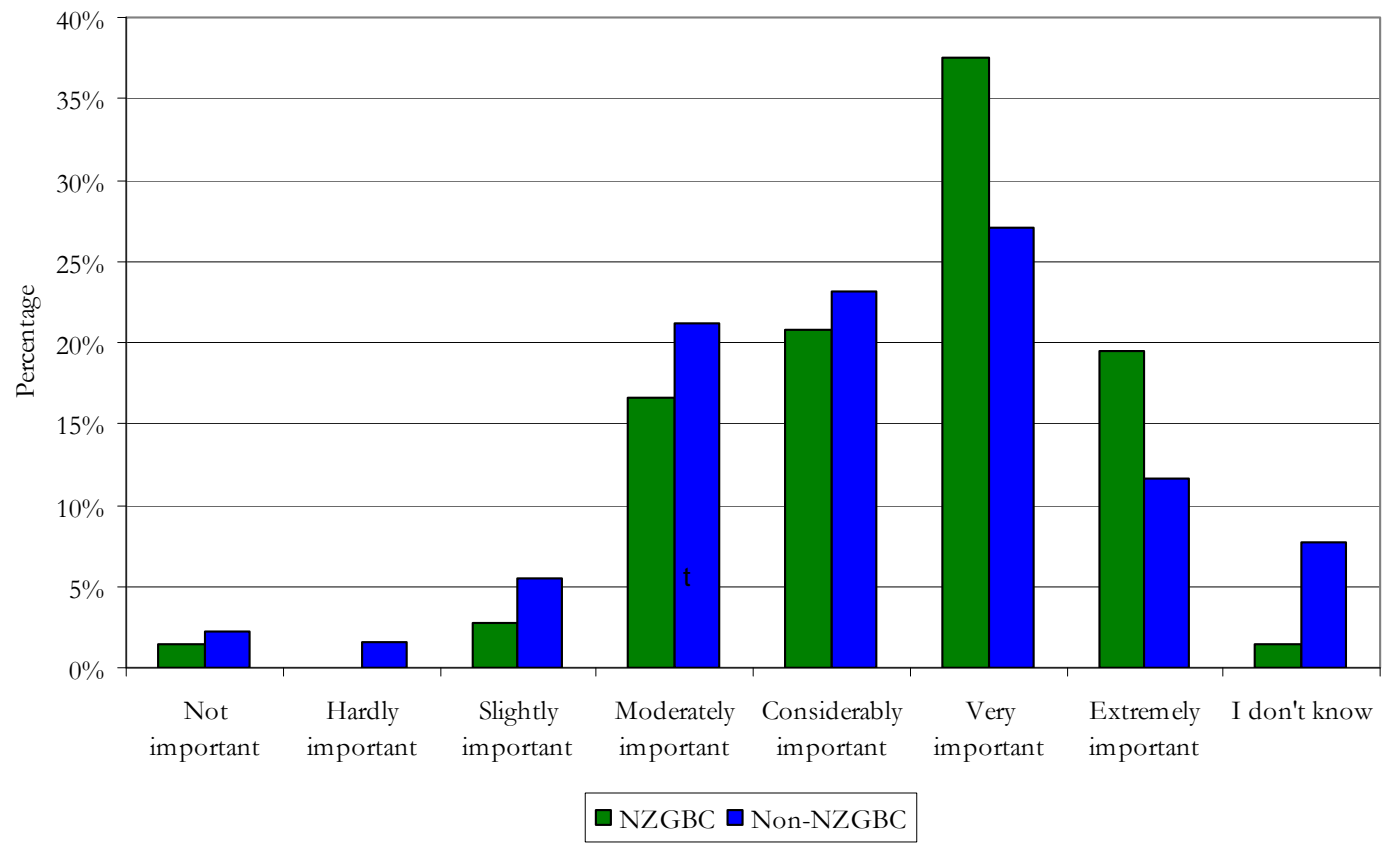

Figure C-40: Overall importance that New Zealand buildings seek full Green Star NZ accreditation by NZGBC vs. non NZGBC 


\section{C.2.3.8 Reasons for Using Green Star New Zealand}

Question: What would be your reasons for using Green Star New Zealand?

Table C-8: Definitions of option choices to reasons for using Green Star NZ (in order asked in

\begin{tabular}{|l|l|}
\hline Option & Definition \\
\hline Option A & Being able to assess the environmental impact of buildings \\
\hline Option B & Building comparisons at a national level \\
\hline Option C & Building comparisons at an international level \\
\hline Option D & Promotional purposes \\
\hline Option E & To use the information for company sustainability reporting \\
\hline Option F & Social and environmental responsibility to create 'green' buildings \\
\hline Option G & To attract tenants \\
\hline Option H & To compete in New Zealand's growing market \\
\hline Option I & Other(s) - Please specify \\
\hline
\end{tabular}

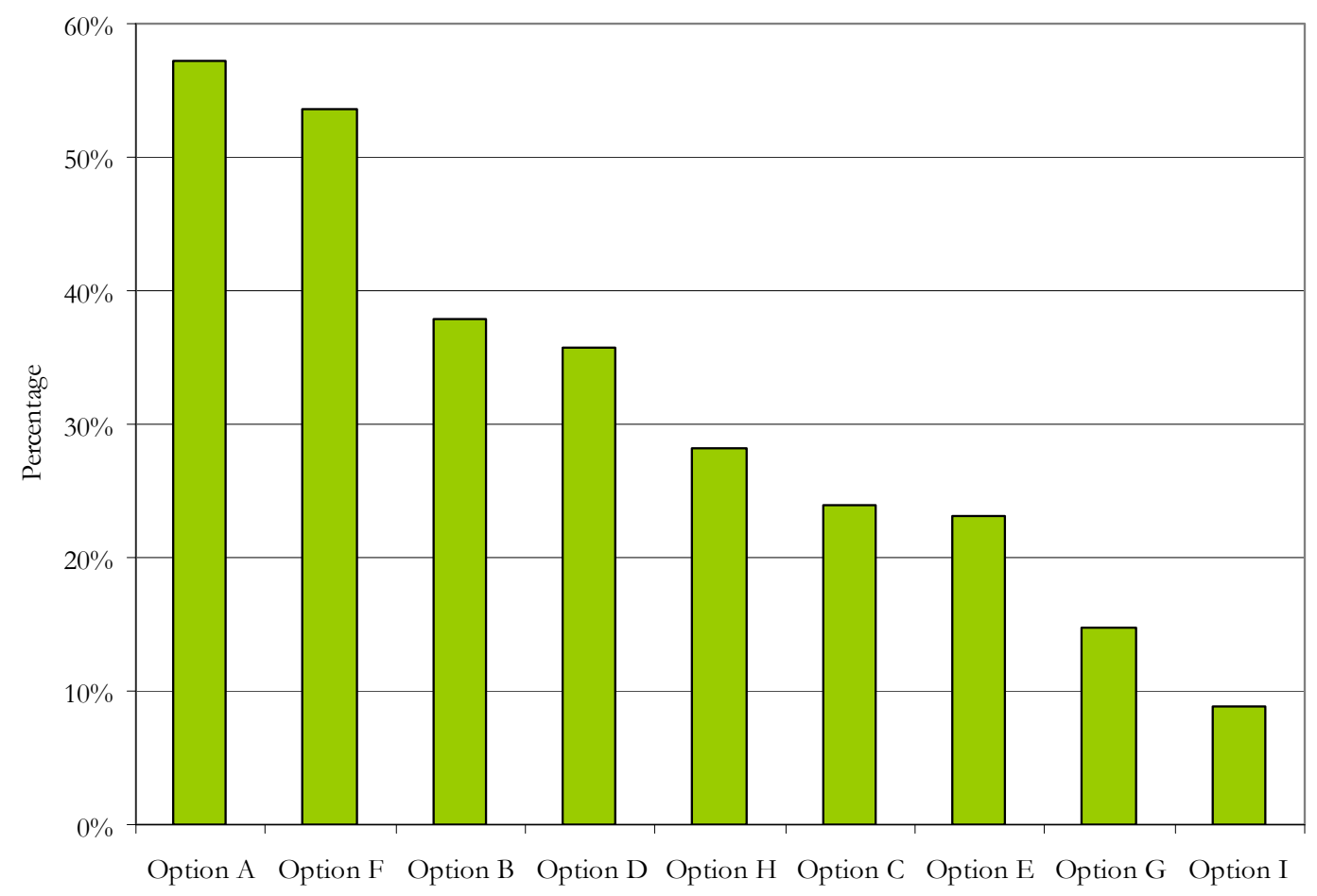

Figure C-41: Overall reasons for using Green Star NZ (in order from highest to lowest) 


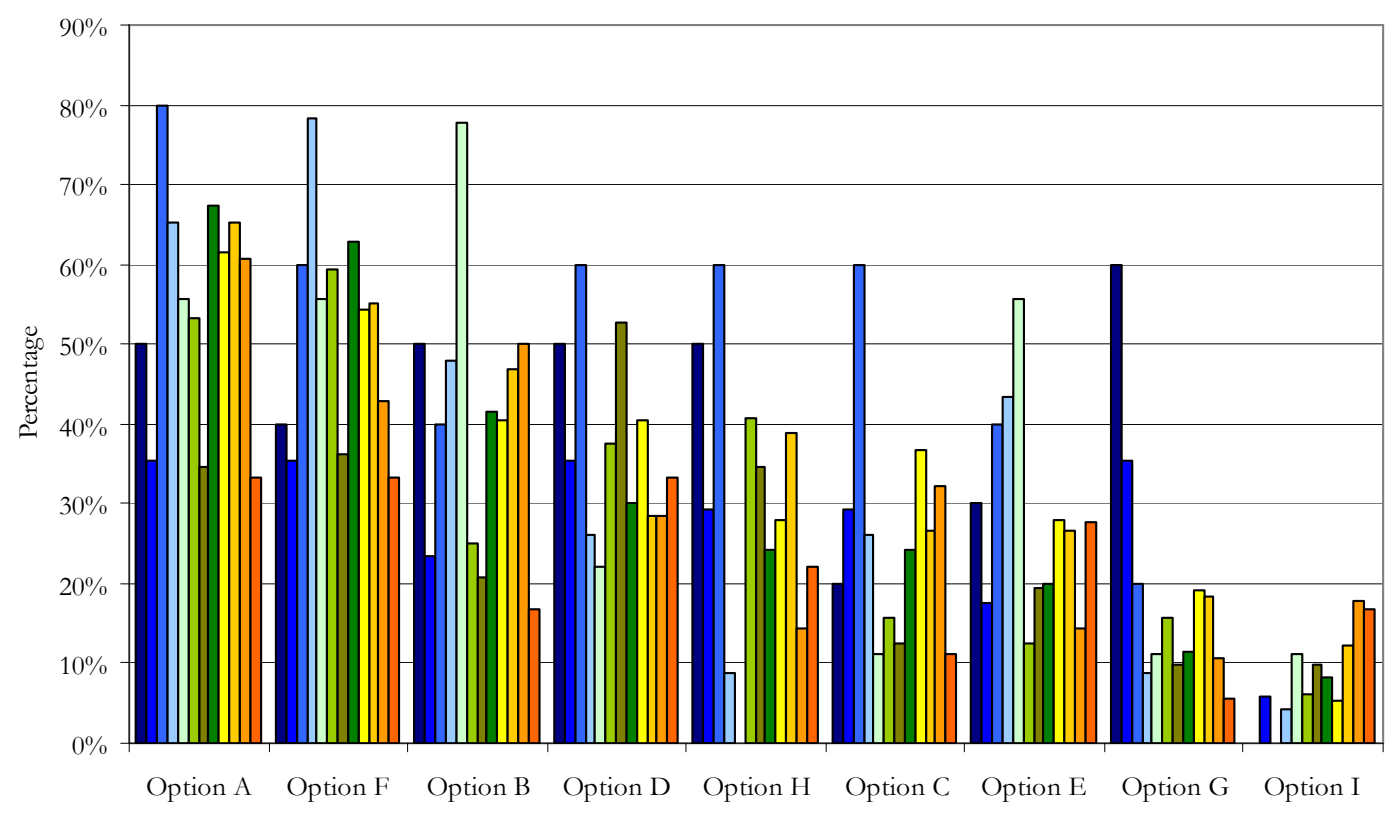

$\square$ CPD $\square$ IO\&PM $\square$ RD\&MPO $\square$ OO $\square$ MCT\&R $\square$ BC $\square$ BPM\&D $\square$ A\&D $\square$ E P\&CP $\square$ R\&NGO $\square$ RI

Figure C-42: Overall reasons for using Green Star NZ by industry sector

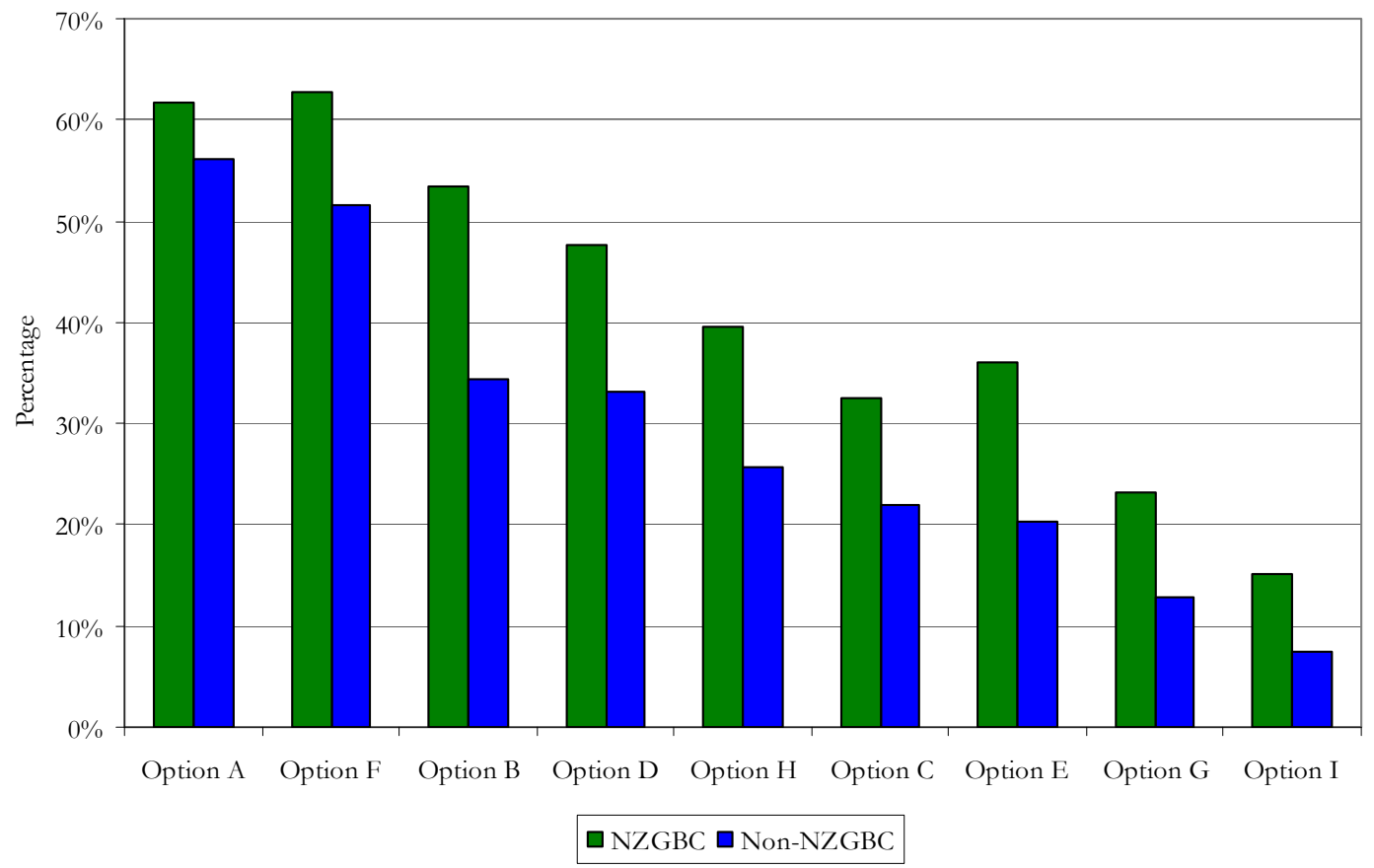

Figure C-43: Overall reasons for using Green Star NZ by NZGBC vs. non-NZGBC 


\section{C.2.4 The New Zealand Green Building Council}

\section{C.2.4.1 New Zealand Green Building Council Awareness}

Question 17: Are you aware of the New Zealand Green Building Council?

Table C-9: Overall awareness of the NZGBC

\begin{tabular}{|l|r|}
\hline Awareness & Percentage \\
\hline Yes & $82 \%$ \\
\hline No & $18 \%$ \\
\hline Total & $100 \%$ \\
\hline
\end{tabular}

\section{C.2.4.2 New Zealand Green Building Council Approach}

Question: How appropriate is the approach of the New Zealand Green Building Council in the establishment of a New Zealand specific Building Sustainability Rating Tool?

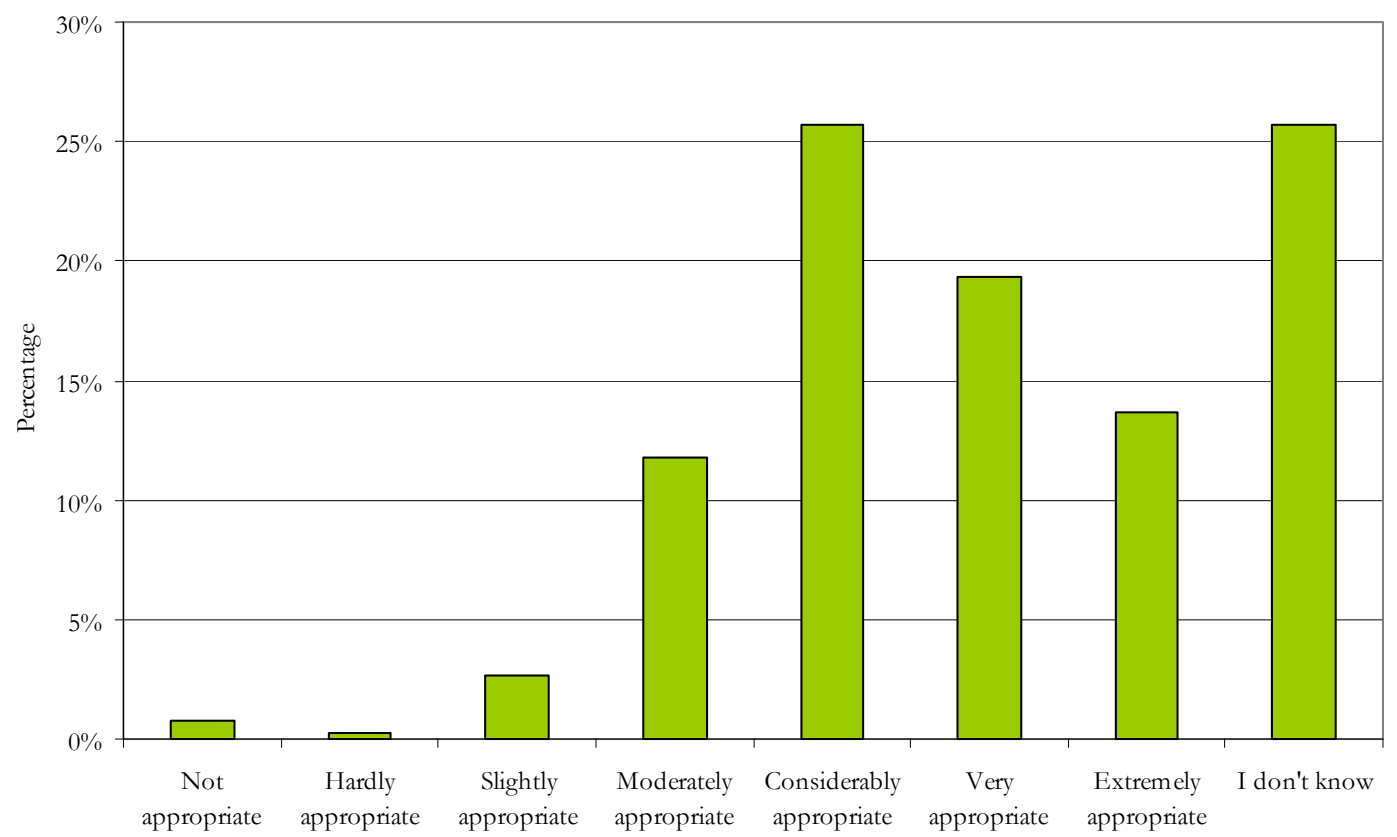

Figure C-44: Overall appropriateness of the approach of the NZGBC in the establishment of a New Zealand specific BSRT 


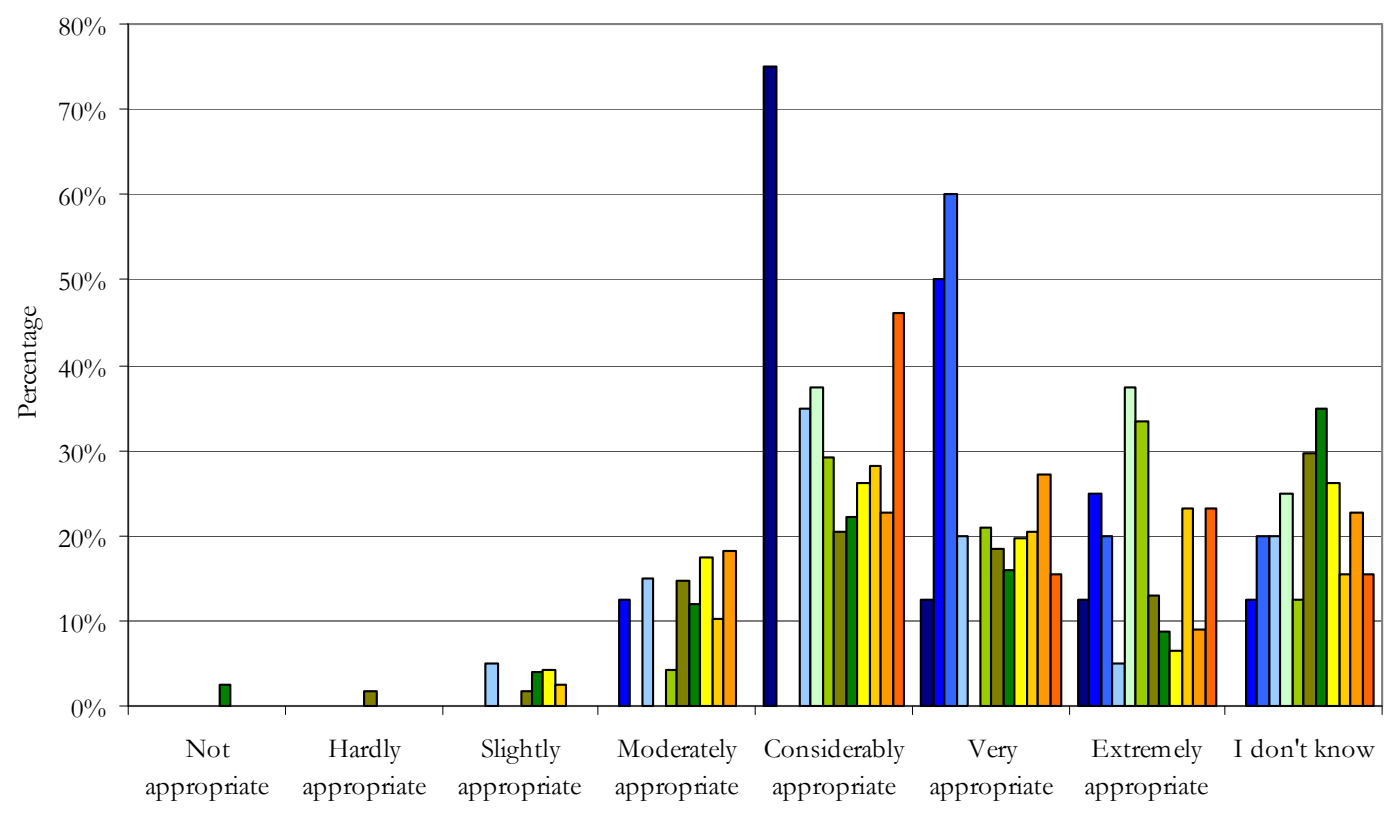

$\square$ CPD $\square$ IO\&PM $\square$ RD\&MPO $\square$ OO $\square$ MCT\&R $\square$ BC $\square$ BPM\&D $\square$ A\&D $\square$ E P\&CP $\square$ R\&NGO $\square$ RI

Figure C-45: Overall appropriateness of the approach of the NZGBC in the establishment of a New Zealand specific BSRT by industry sector

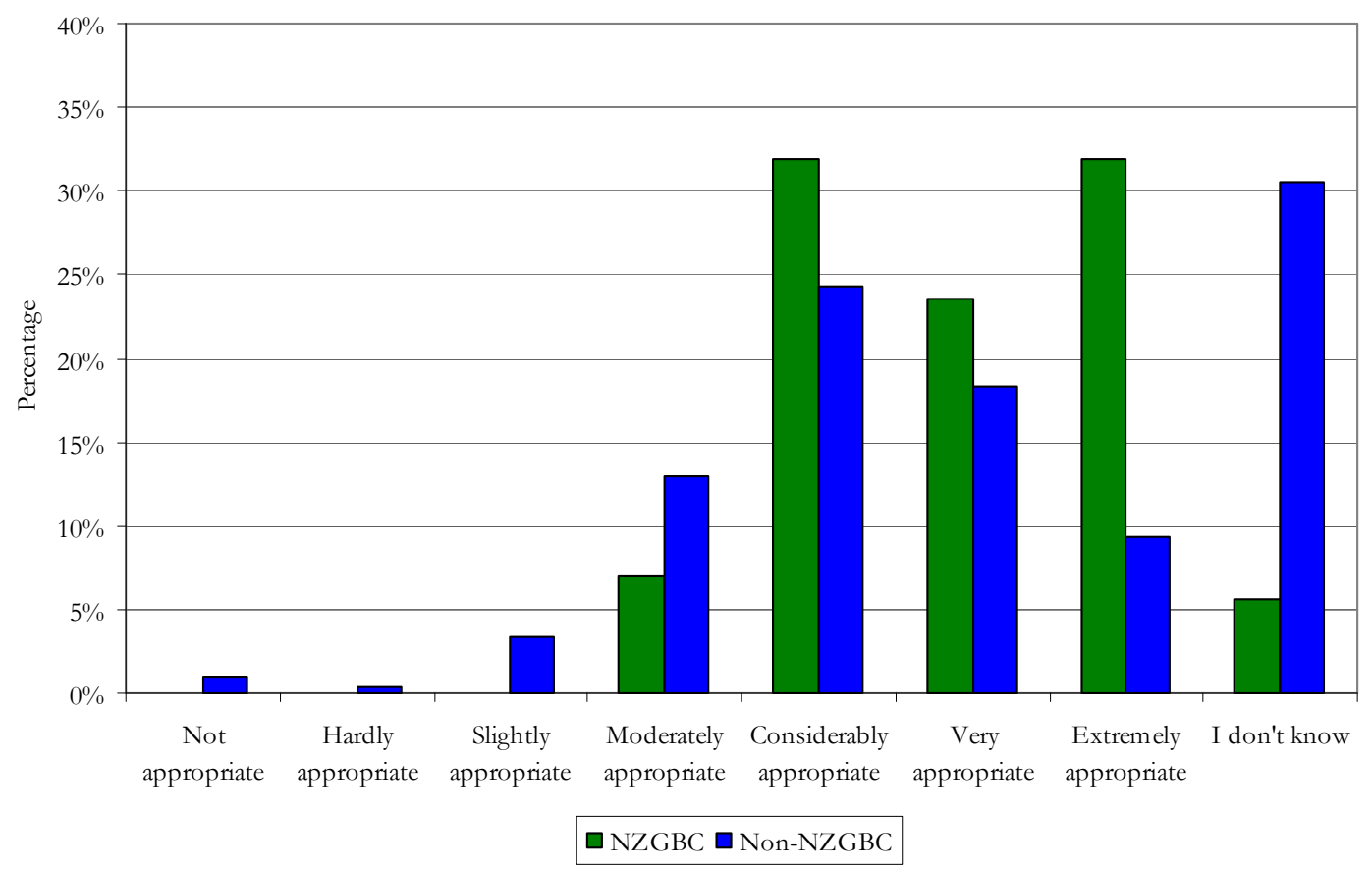

Figure C-46: Overall appropriateness of the approach of the NZGBC in the establishment of a New Zealand specific BSRT by NZGBC vs. non-NZGBC 


\section{C.2.4.3 New Zealand Green Building Council Influence}

Question: To what extent do you think the New Zealand Green Building Council will influence the building industry in a shift towards more sustainable building development?

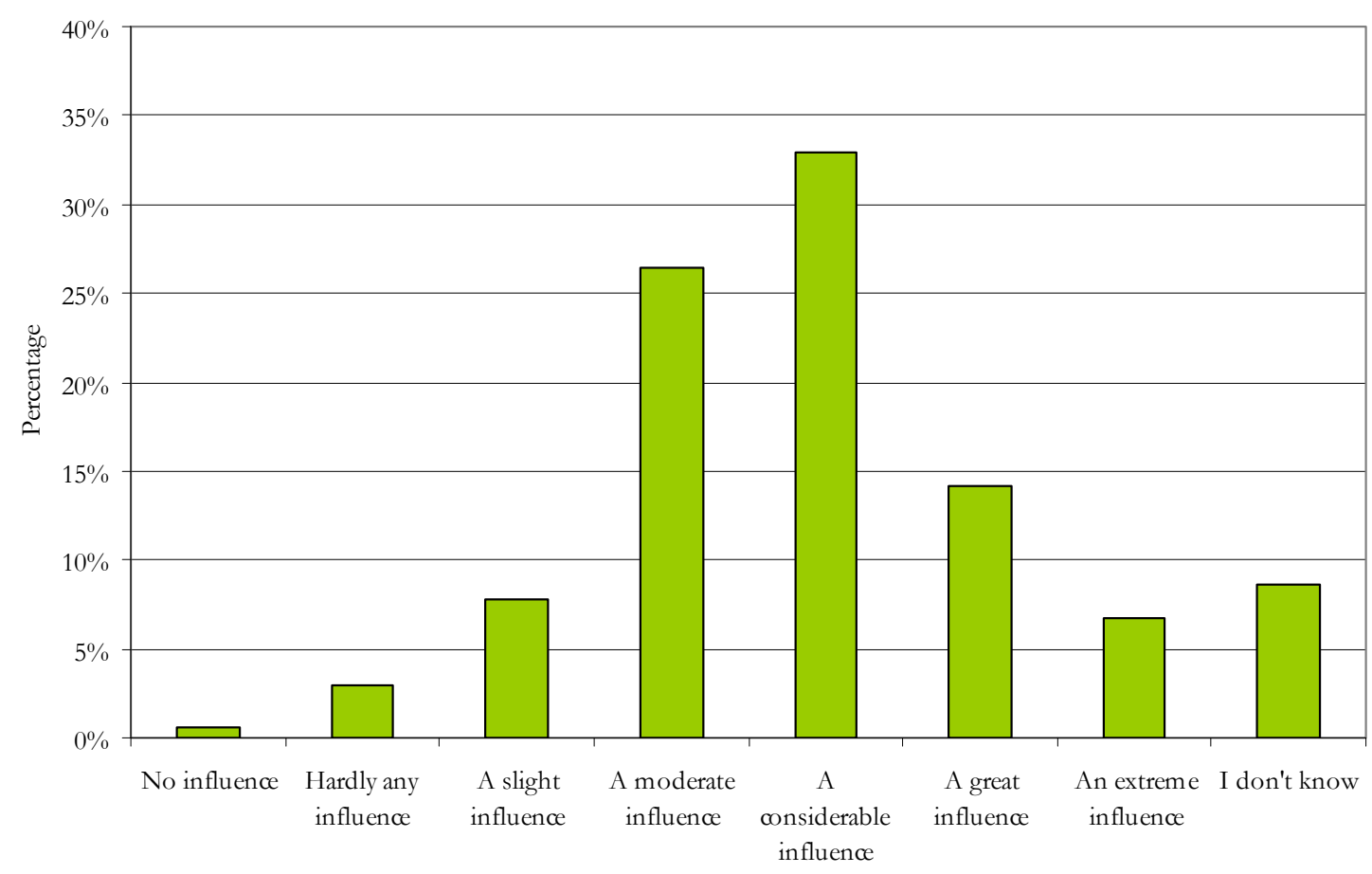

Figure C-47: Overall perceived extent that the NZGBC will influence the building industry in a shift towards more sustainable building development 


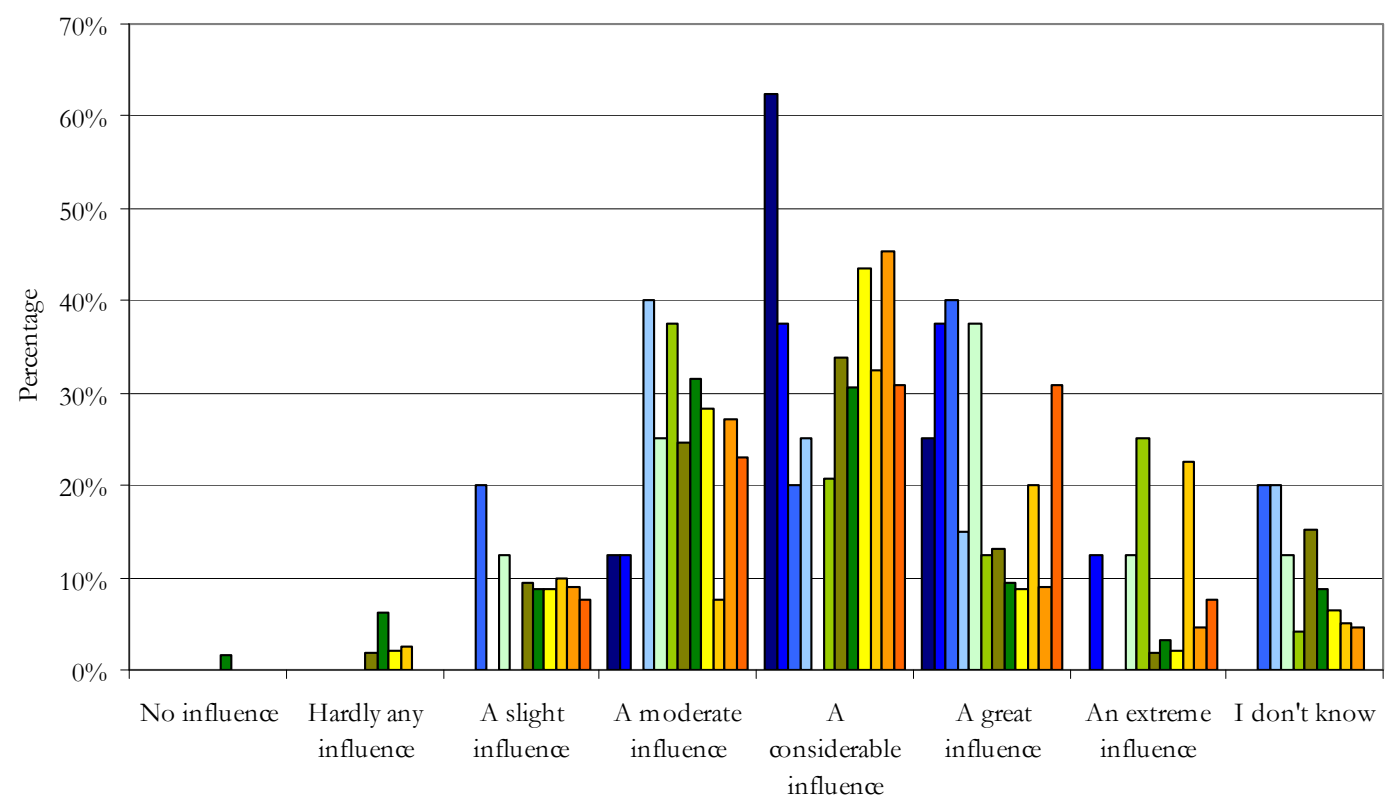

$\square$ CPD $\square$ IO\&PM $\square$ RD\&MPO $\square$ OO $\square$ MCT\&R $\square$ BC $\square$ BPM\&D $\square$ A\&D $\square$ E $\square \& C P \square$ R\&NGO $\square$ RI

Figure C-48: Overall perceived extent that the NZGBC will influence the building industry in a shift towards more sustainable building development by industry sector

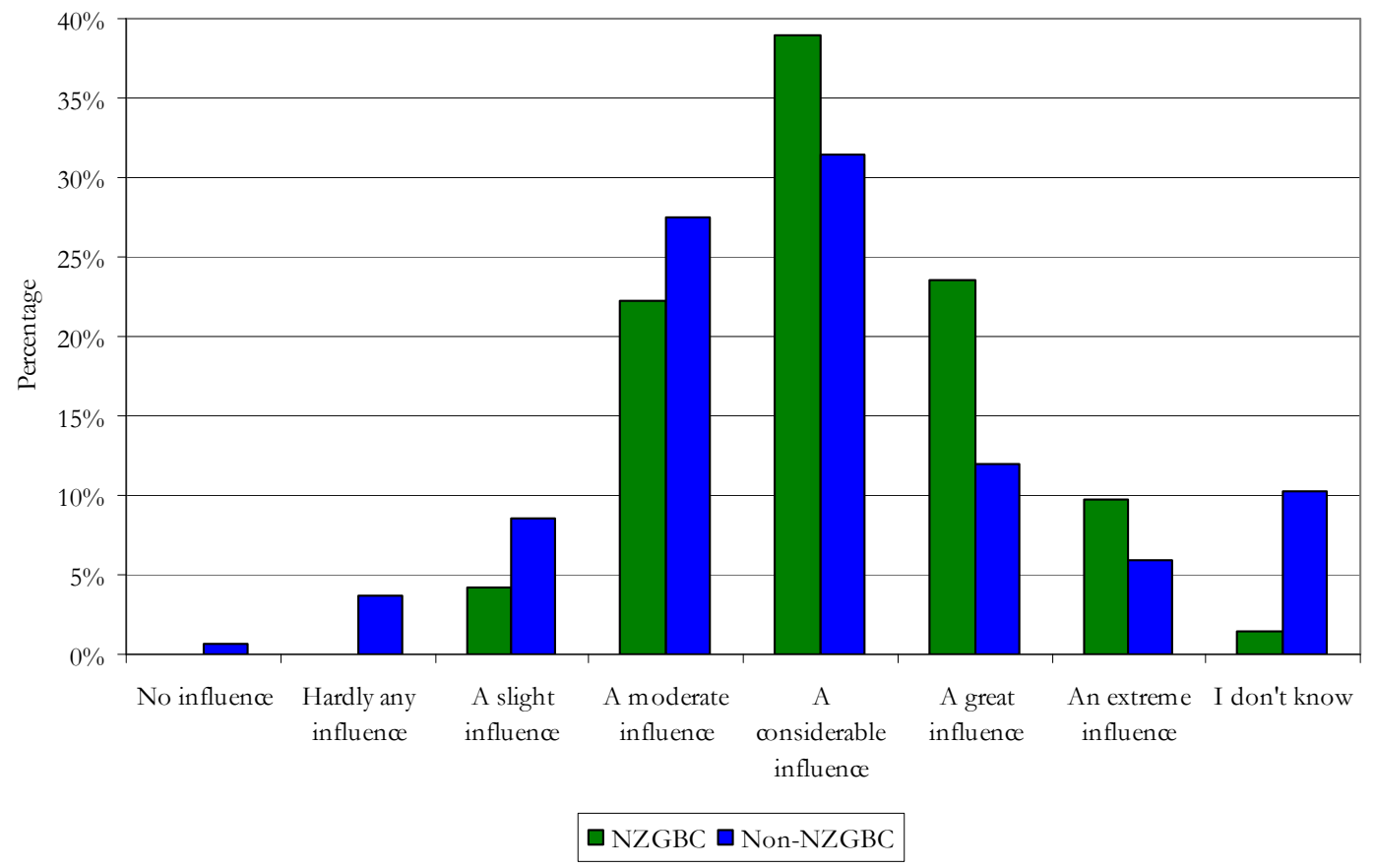

Figure C-49: Overall perceived extent that the NZGBC will influence the building industry in a shift towards more sustainable building development by NZGBC vs. non-NZGBC 


\section{C.2.5 Drivers, Triggers, Obstacles and Reasons for Sustainable Building}

\section{C.2.5.1 Trigger Person of Sustainable Building}

Question: In your experience who triggers sustainable building in the first place?

Table C-10: Definitions of option choices to who triggers sustainable building (in order asked in survey)

\begin{tabular}{|l|l|}
\hline Option & Definition \\
\hline Option A & I don't know \\
\hline Option B & Client \\
\hline Option C & Architect/Draftpersons \\
\hline Option D & Engineers \\
\hline Option E & Property and Construction Professionals \\
\hline Option F & Building Contractors \\
\hline Option G & Developers \\
\hline Option H & Investors \\
\hline Option I & Other(s) \\
\hline
\end{tabular}

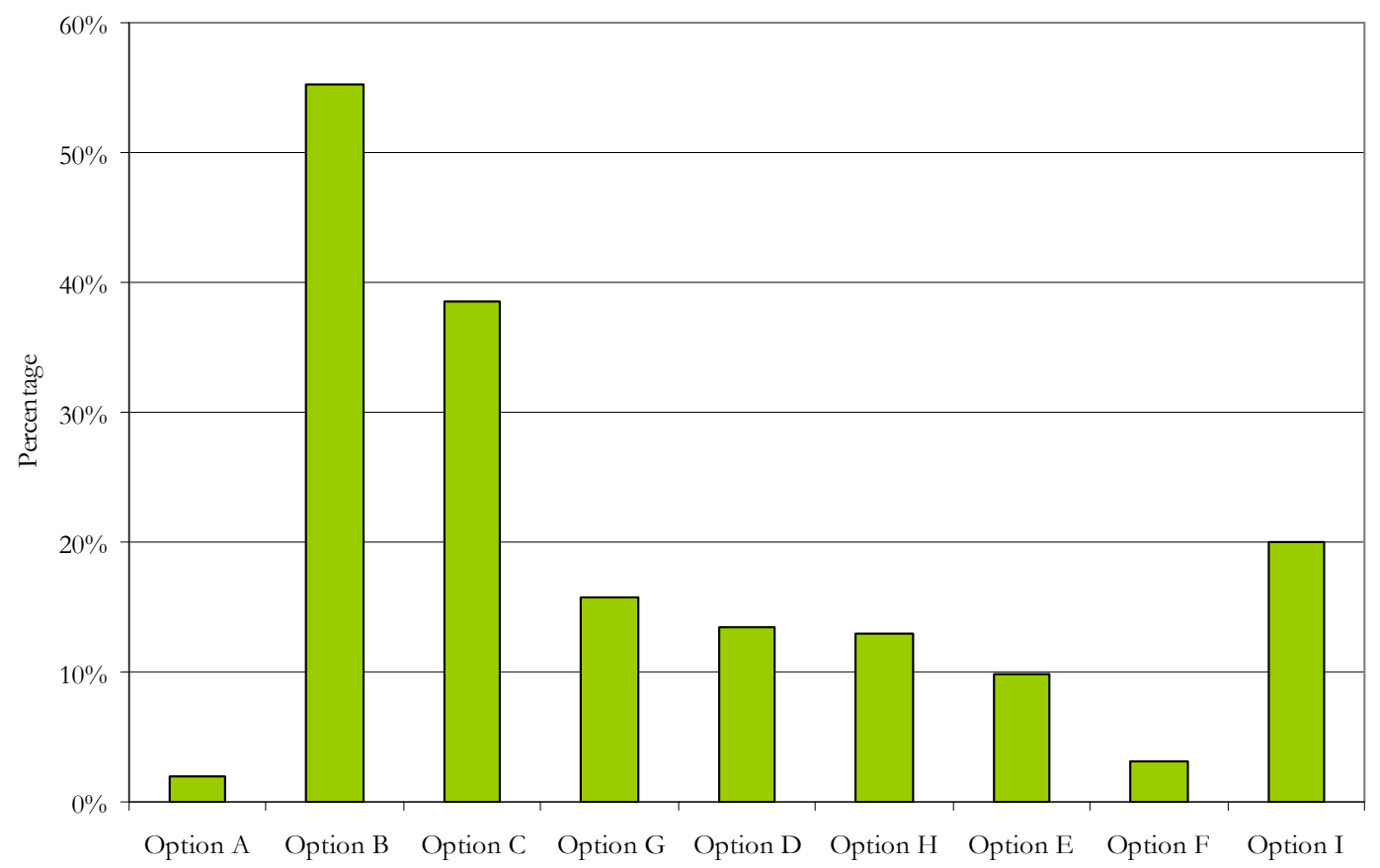

Figure C-50: Overall participant experience of who triggers sustainable building in the first place (in order from highest to lowest 


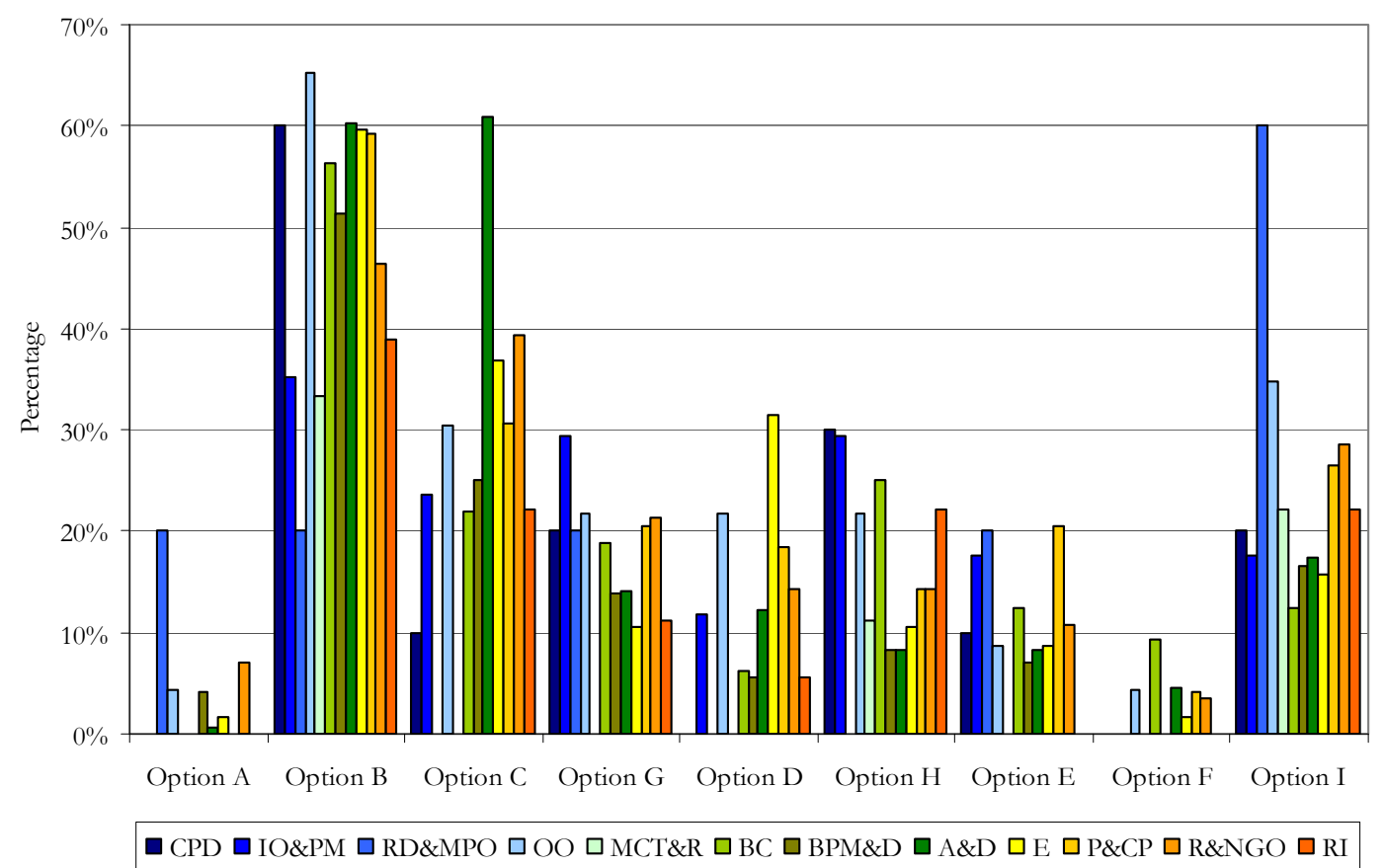

Figure C-51: Overall participant experience of who triggers sustainable building in the first place by industry sector

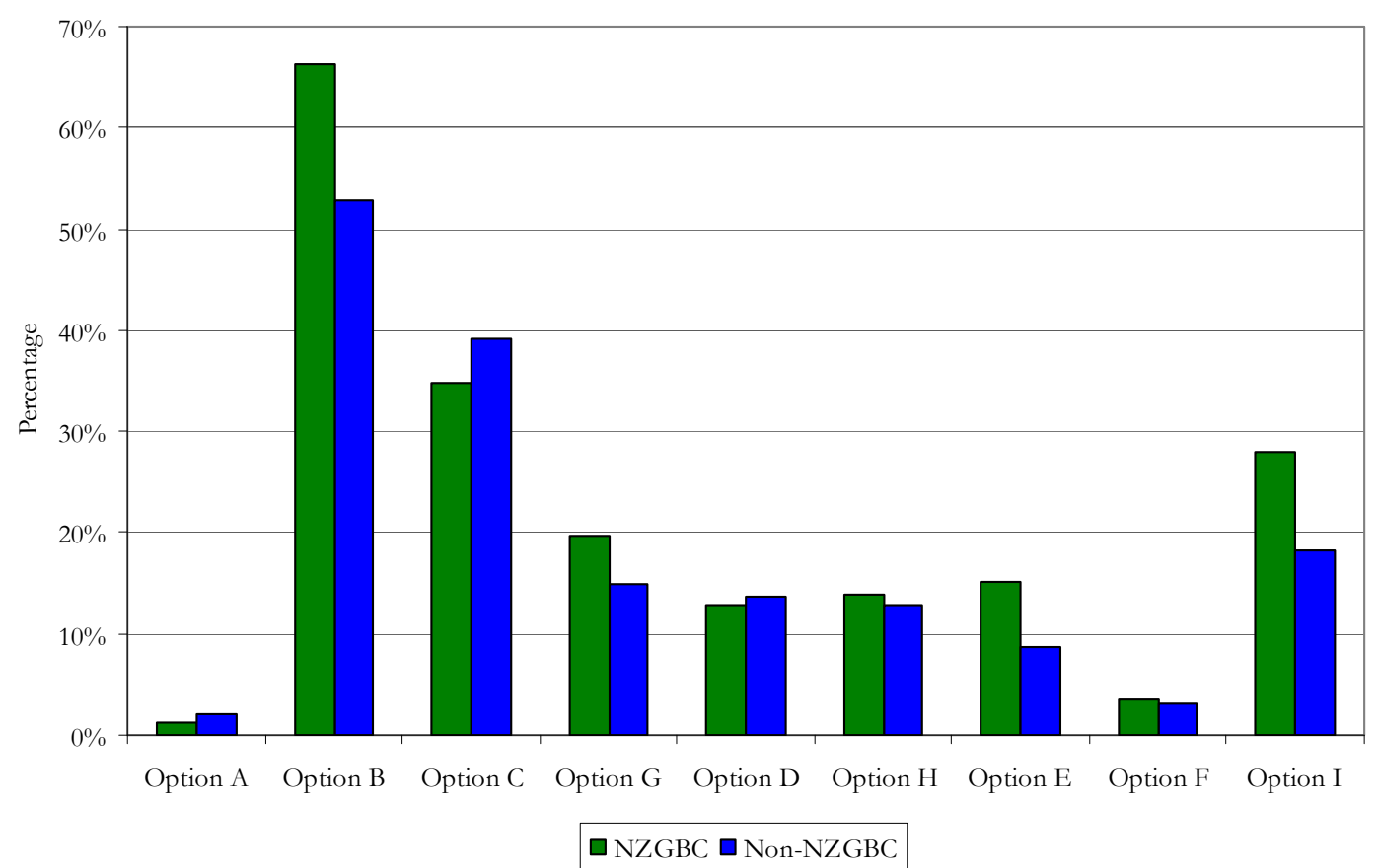

Figure C-52: Overall participant experience of who triggers sustainable building in the first place by NZGBC vs. non-NZGBC 


\section{C.2.5.2 Main Driver of Sustainable Building}

Question: In your opinion who should be the main driver for sustainable building?

Table C-11: Definitions of option choices to who should drive sustainable building (in order asked in survey)

\begin{tabular}{|l|l|}
\hline Option & Definition \\
\hline Option A & I don't know \\
\hline Option B & Client \\
\hline Option C & Architect/Draftpersons \\
\hline Option D & Engineers \\
\hline Option E & Property and Construction Professionals \\
\hline Option F & Building Contractors \\
\hline Option G & Developers \\
\hline Option H & Investors \\
\hline Option I & An integrated process where responsibility is shared \\
\hline Option J & Other(s) \\
\hline
\end{tabular}

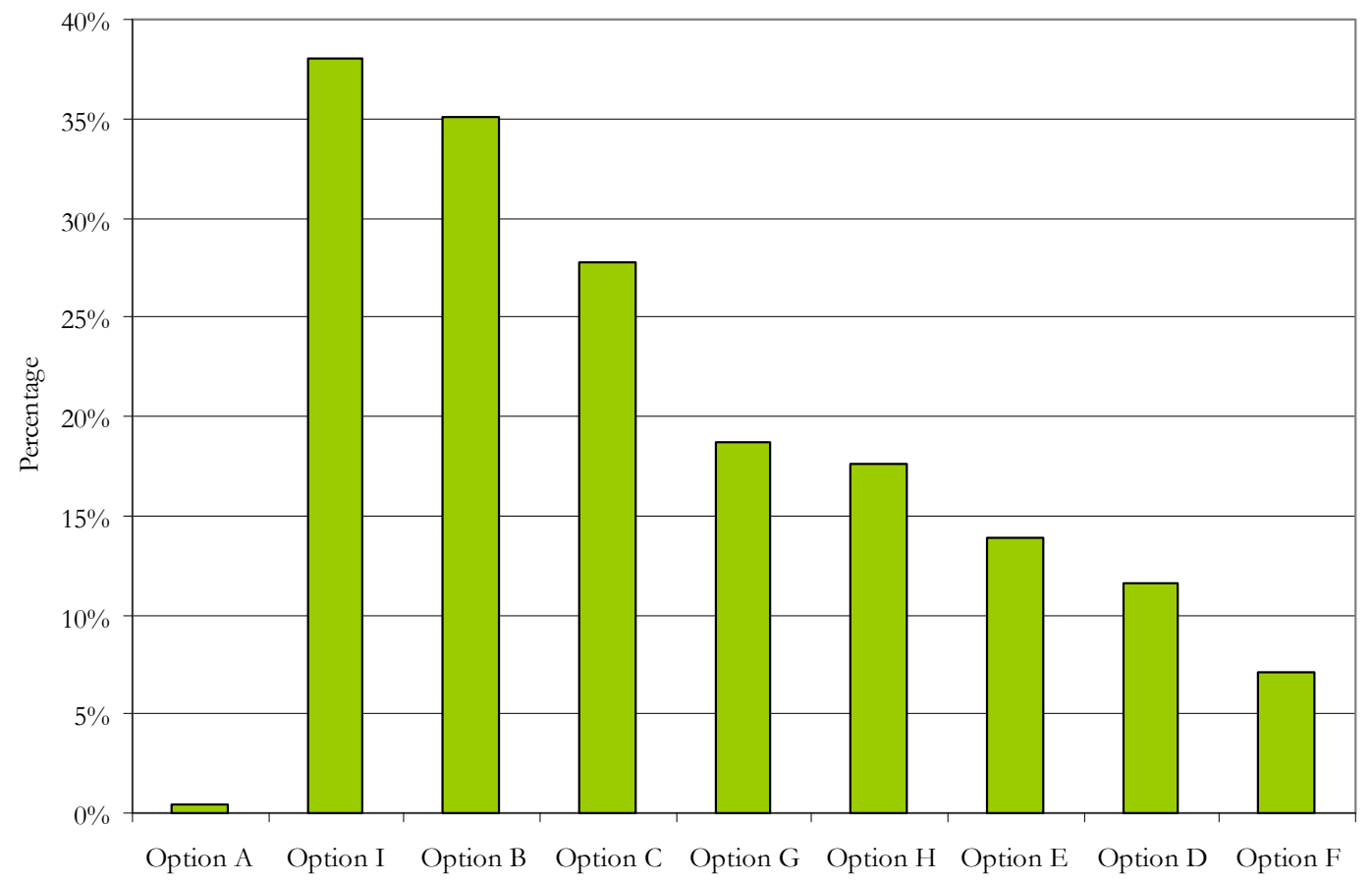

Figure C-53: Overall opinion of who should be the main driver for sustainable building (in order from highest to lowest) 


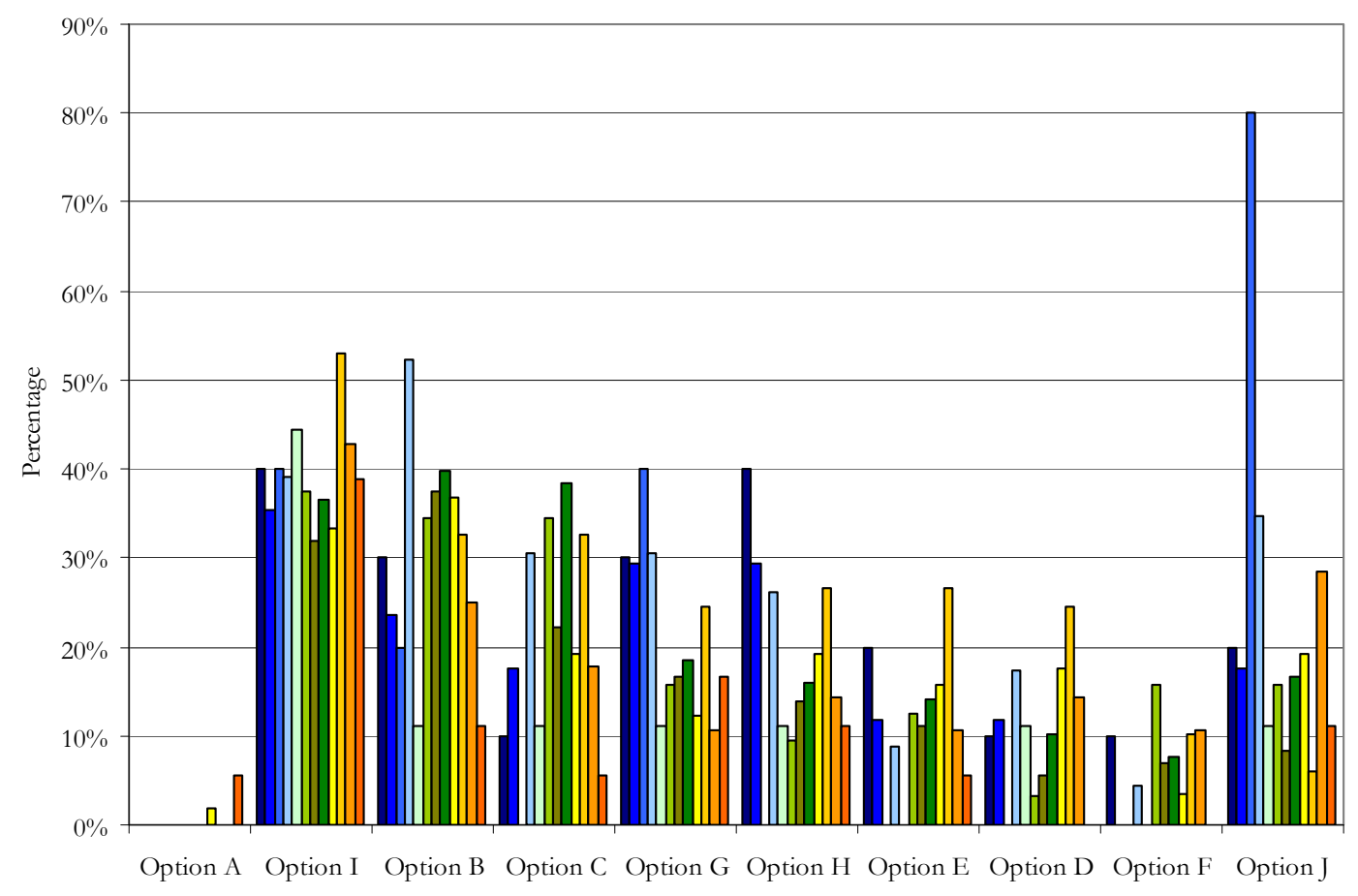

$\square$ CPD $\square$ IO\&PM $\square$ RD\&MPO $\square$ OO $\square$ MCT\&R $\square$ BC $\square$ BPM\&D $\square$ A\&D $\square$ E $\square$ P\&CP $\square$ R\&NGO $\square$ RI

Figure C-54: Overall opinion of who should be the main driver for sustainable building by industry sector

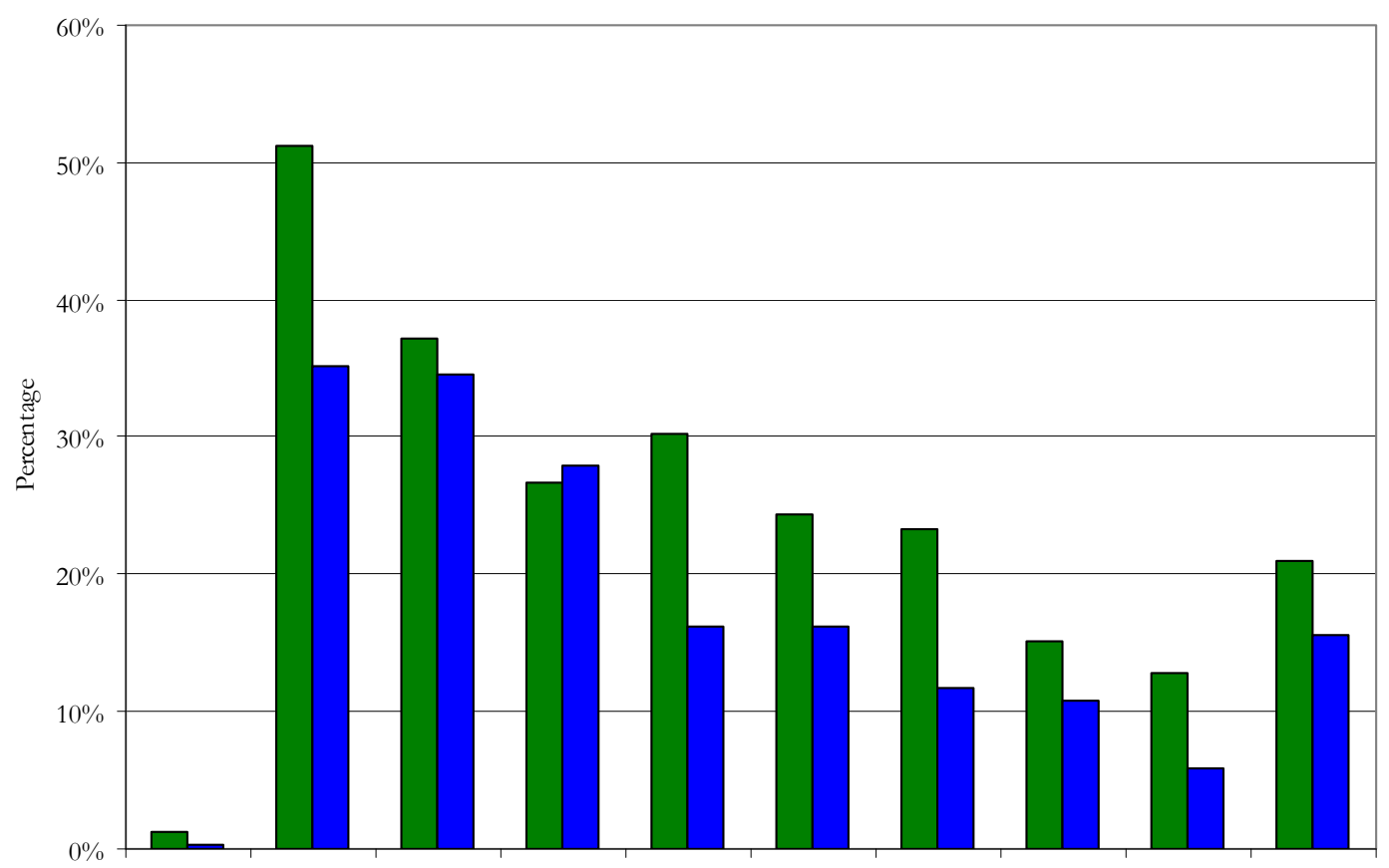

Option A Option I Option B Option C Option G Option H Option E Option D Option F Option J

$\square$ NZGBC $\square$ Non-NZGBC

Figure C-55: Overall opinion of who should be the main driver for sustainable building by NZGBC vs. non-NZGBC 


\section{C.2.5.3 Trigger Stage for Sustainable Building}

Question: At what stage of the building process is sustainable building most likely triggered?

Table C-12: Definitions of option choices to when sustainable building is most likely triggered (in order asked in survey)

\begin{tabular}{|l|l|}
\hline Option & Definition \\
\hline Option A & I don't know \\
\hline Option B & Preliminary inquiries \\
\hline Option C & Pre-design \\
\hline Option D & Design development \\
\hline Option E & Construction development process \\
\hline Option F & Commissioning \\
\hline Option G & Construction \\
\hline Option H & Other(s) \\
\hline
\end{tabular}

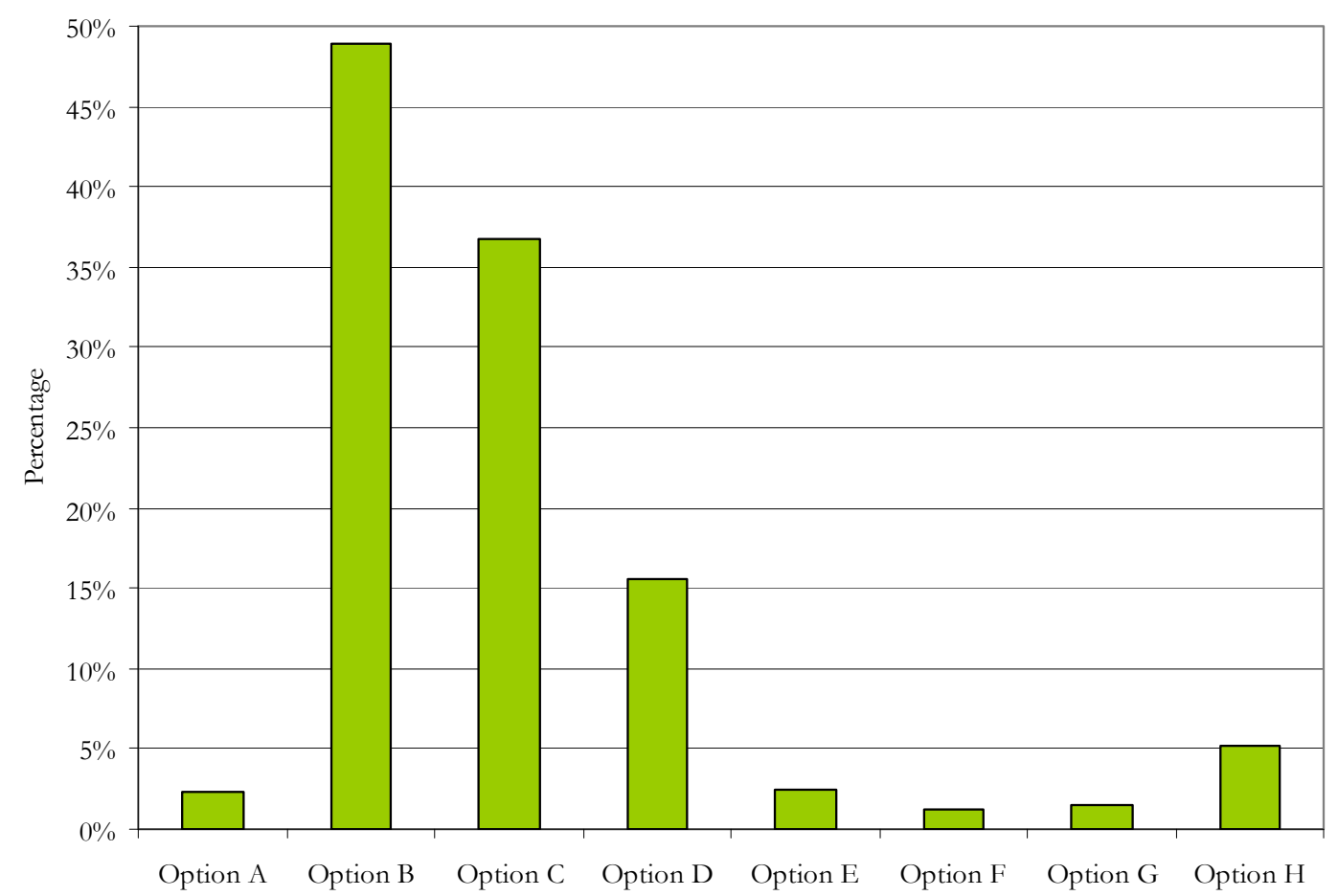

Figure C-56: Overall stage of the building process that sustainable building most likely triggered (in order from highest to lowest) 


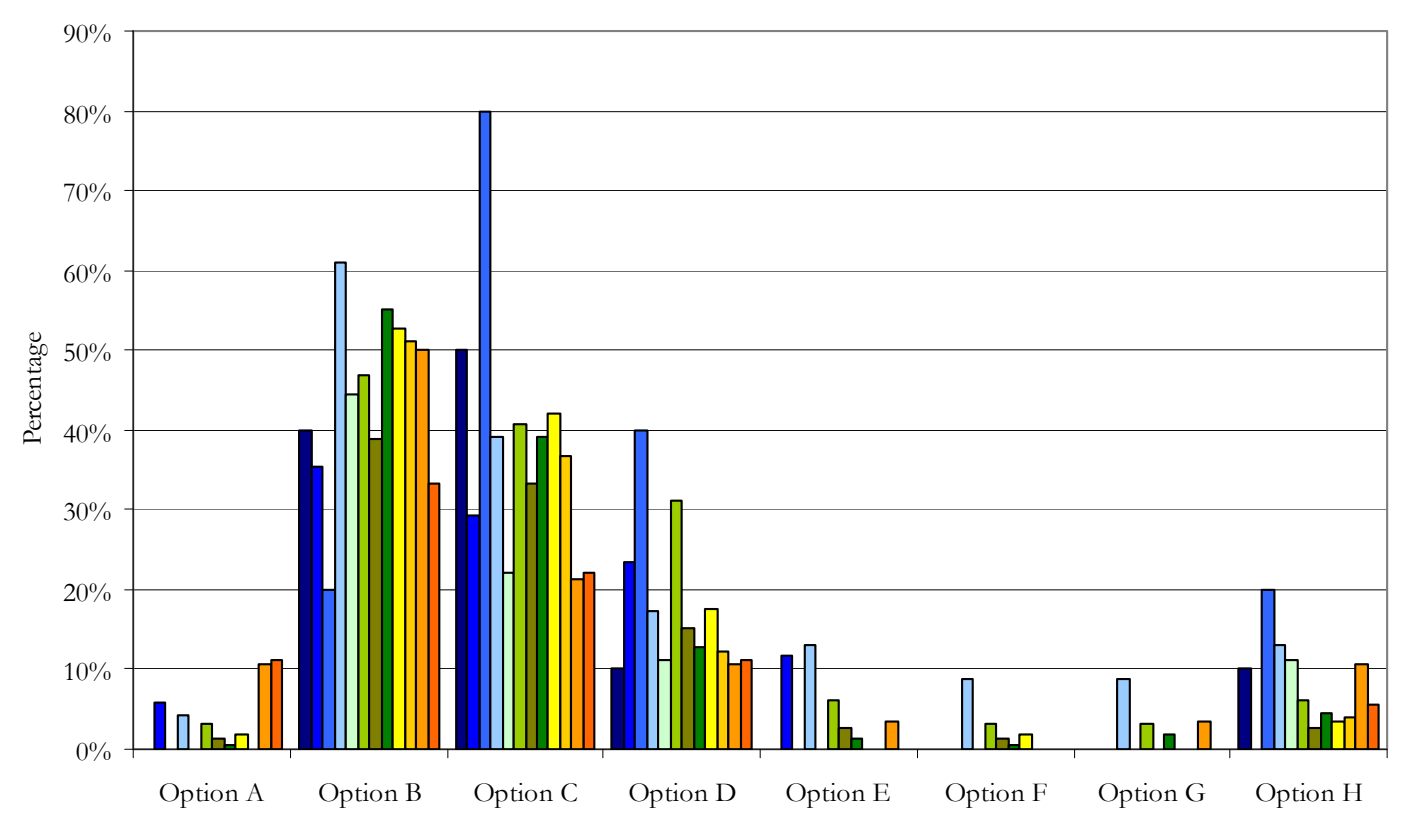

$\square$ CPD $\square$ IO\&PM $\square$ RD\&MPO $\square$ OO $\square$ MCT\&R $\square$ BC $\square$ BPM\&D $\square$ A\&D $\square$ E P\&CP $\square$ R\&NGO $\square$ RI

Figure C-57: Overall stage of the building process that sustainable building most likely triggered by industry sector

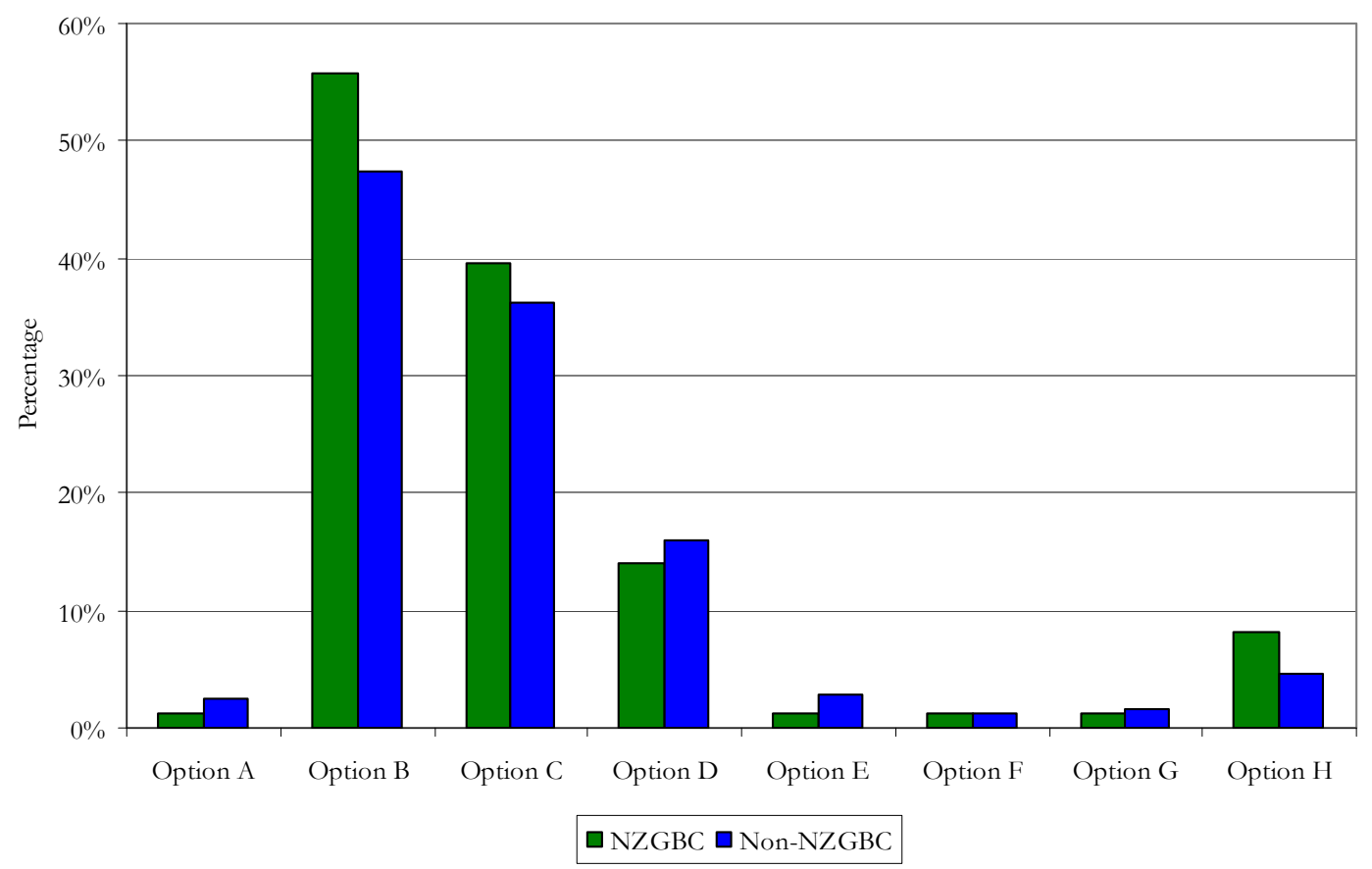

Figure C-58: Overall stage of the building process that sustainable building most likely triggered by NZGBC and non-NZGBC 


\section{C.2.5.4 Drivers for Sustainable Building}

Question: What do you think are the main drivers for sustainable building?

Table C-13: Definitions of option choices to drivers for sustainable buildings (in order asked in survey)

\begin{tabular}{|l|l|}
\hline Option & Definition \\
\hline Option A & Rising energy costs \\
\hline Option B & Government regulation \\
\hline Option C & Lower life-cycle costs \\
\hline Option D & Client demand \\
\hline Option E & Independent rating system \\
\hline Option F & Government rating systems \\
\hline Option G & Competitive advantage \\
\hline Option H & Superior performance \\
\hline Option I & Increased education \\
\hline Option J & Environmental conditions \\
\hline Option K & Attraction and retention of staff \\
\hline Option L & Increased emphasis on productivity \\
\hline Option M & International trends show it is smart business \\
\hline Option N & Disruptive/enabling technology \\
\hline Option O & Other(s) \\
\hline
\end{tabular}

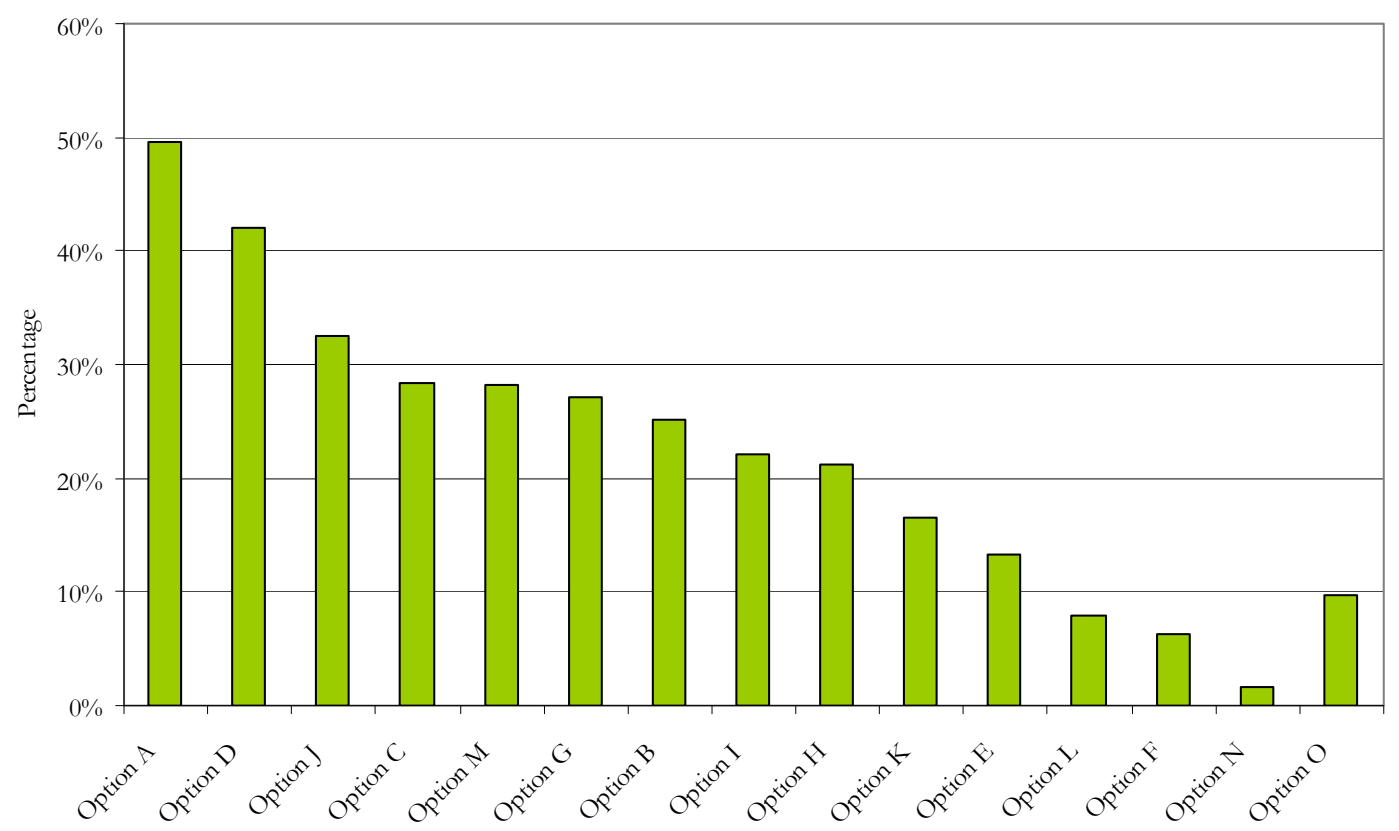

Figure C-59: Overall drivers for sustainable building (in order from highest to lowest) 


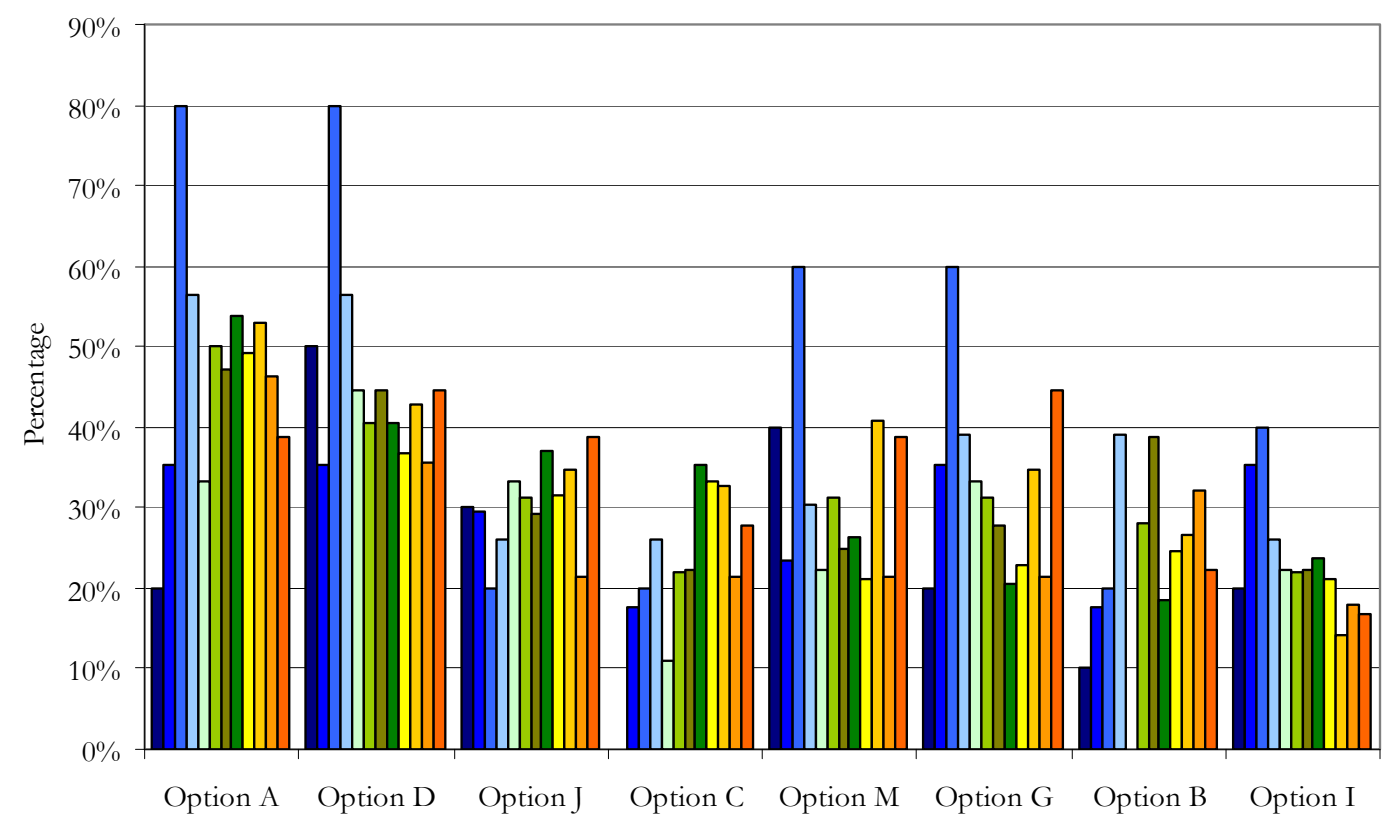

$\square$ CPD $\square$ IO\&PM $\square$ RD\&MPO $\square$ OO $\square$ MCT\&R $\square$ BC $\square$ BPM\&D $\square$ A\&D $\square$ E $\square$ P\&CP $\square$ R\&NGO $\square$ RI

Figure C-60: Overall drivers for sustainable building by industry sectors (top eight choices)

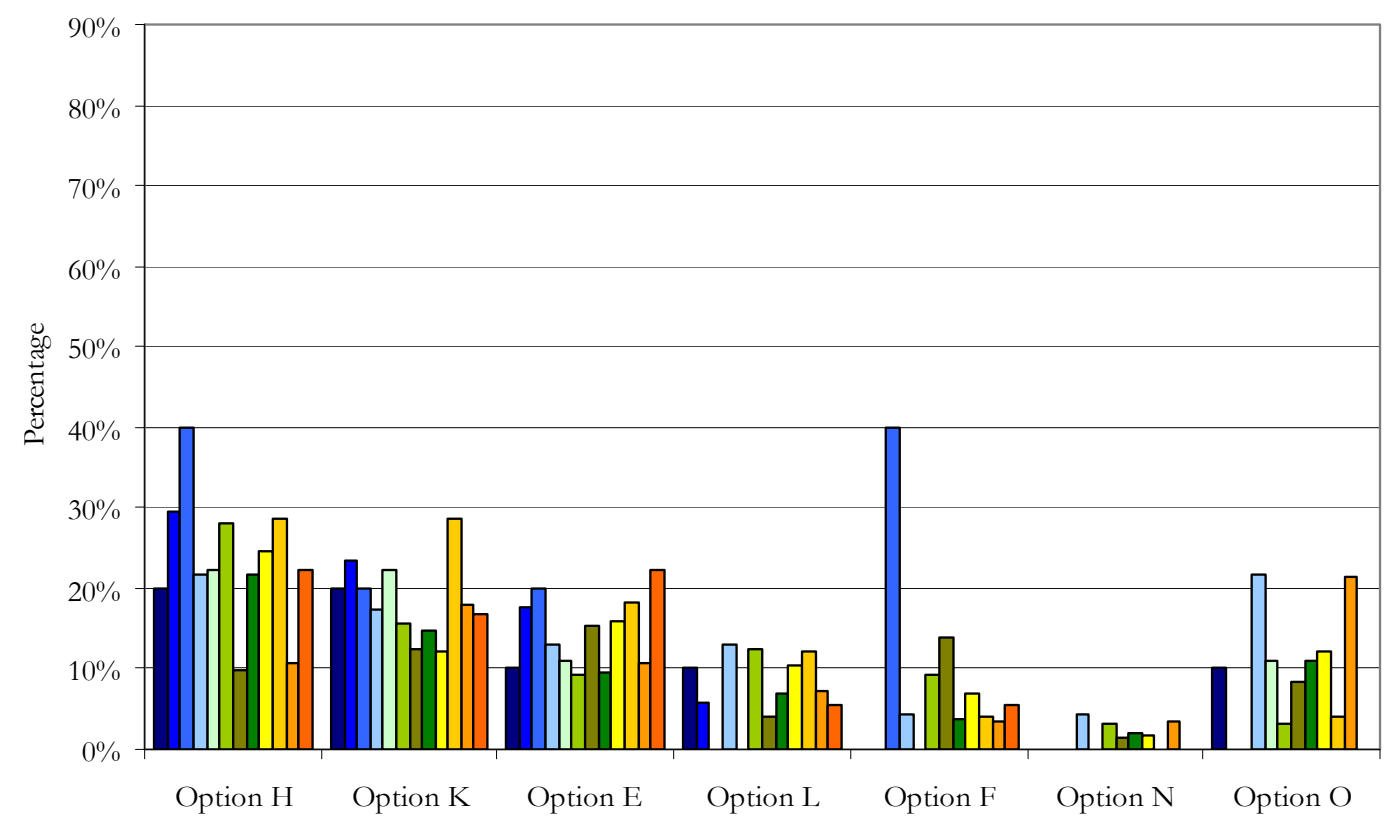

$\square$ CPD $\square$ IO\&PM $\square$ RD\&MPO $\square$ OO $\square$ MCT\&R $\square$ BC $\square$ BPM\&D $\square$ A\&D $\square$ E $\square$ P\&CP $\square$ R\&NGO $\square$ RI

Figure C-61: Overall drivers for sustainable building by industry sector (bottom eight choices) 


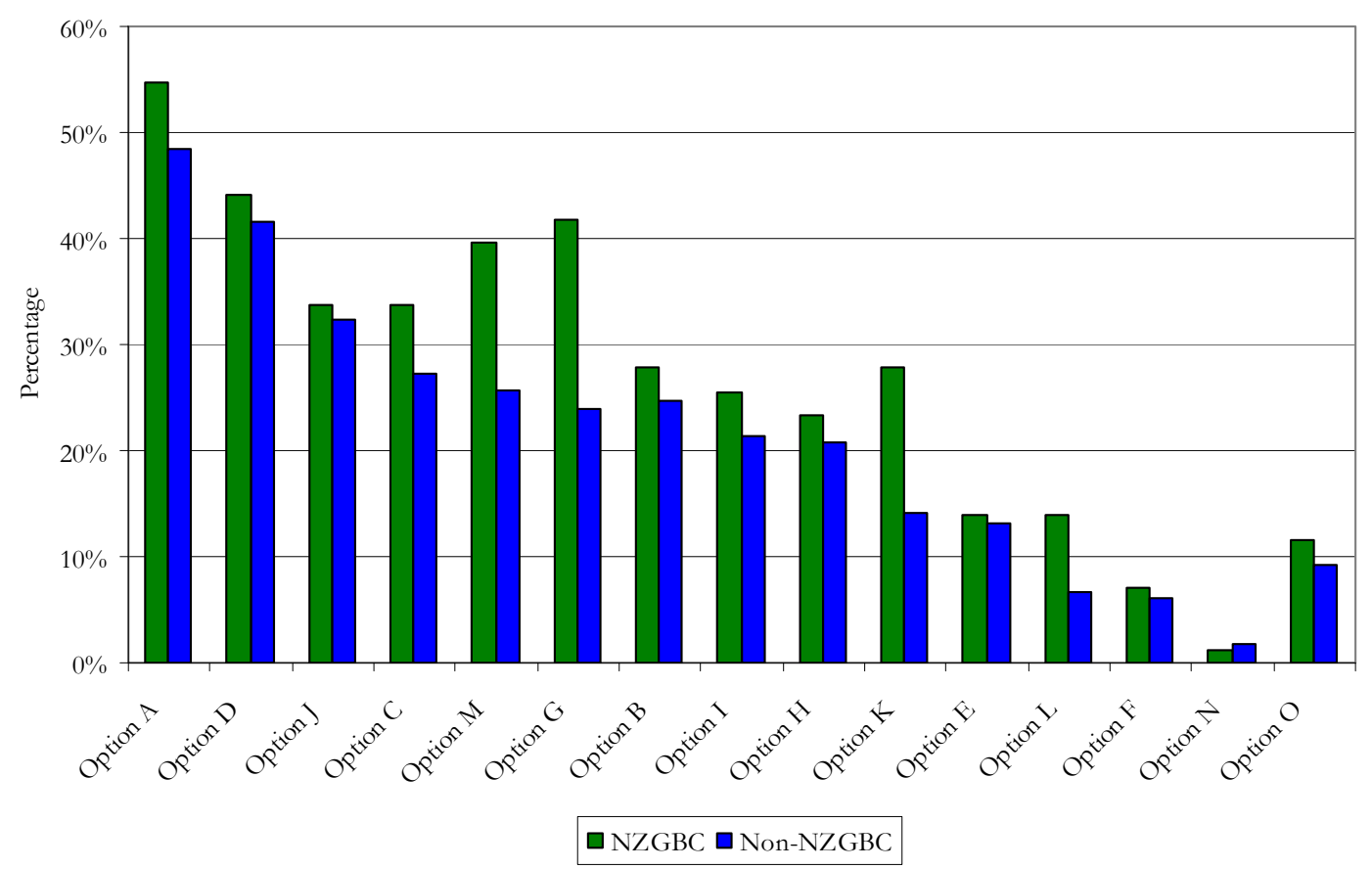

Figure C-62: Overall drivers for sustainable building by NZGBC vs. non-NZGBC 


\section{C.2.5.5 Obstacles for Sustainable Building}

Question: What are the obstacles to sustainable building?

Table C-14: Definitions of option choices to obstacles for sustainable building (in order asked in survey)

\begin{tabular}{|l|l|}
\hline Option & Definition \\
\hline Option A & Perceived higher upfront costs \\
\hline Option B & Lack of education \\
\hline Option C & Lack of awareness \\
\hline Option D & No fiscal incentive \\
\hline Option E & Different accounting methods \\
\hline Option F & No coordination or consistency \\
\hline Option G & Politics \\
\hline Option H & Payback periods \\
\hline Option I & Education of non 'green' people \\
\hline Option J & Other(s) \\
\hline
\end{tabular}

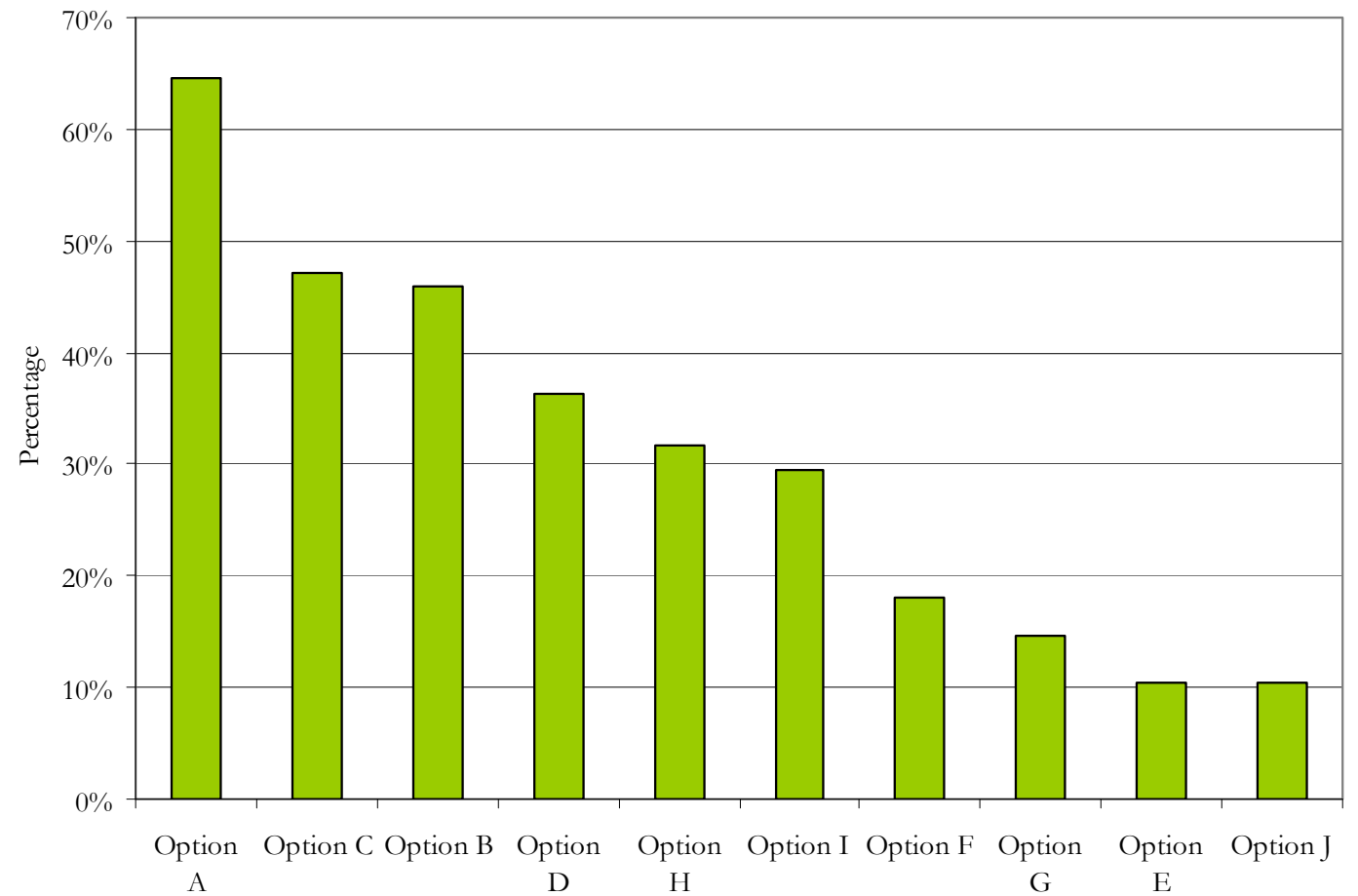

Figure C-63: Overall obstacles to sustainable buildings (in order from highest to lowest) 


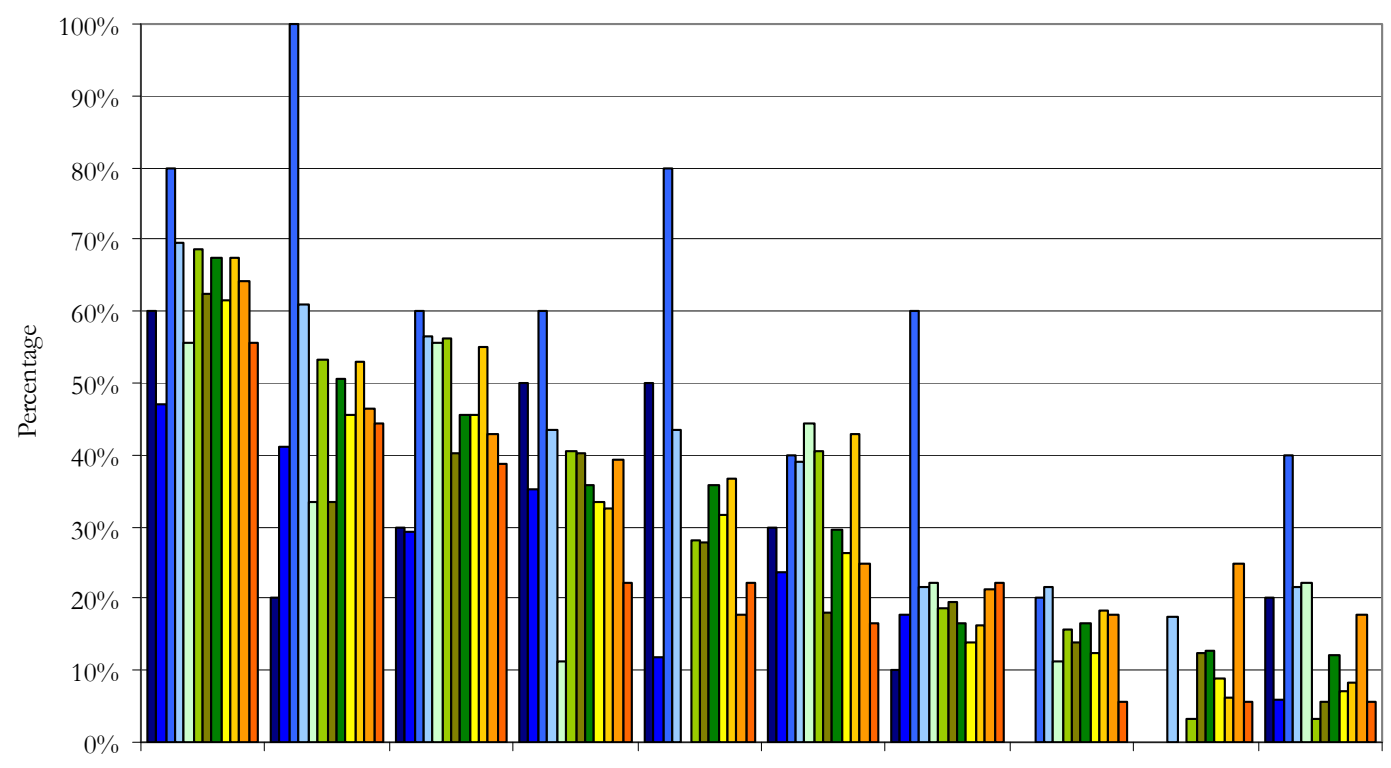

Option A Option C Option B Option D Option H Option I Option F Option G Option E Option J - CPD $\square$ IO\&PM $\square$ RD\&MPO $\square$ OO $\square$ MCT\&R $\square$ BC $\square$ BPM\&D $\square$ A\&D $\square$ E $\square$ P\&CP $\square$ R\&NGO $\square$ RI

Figure C-64: Overall obstacles to sustainable buildings by industry sector

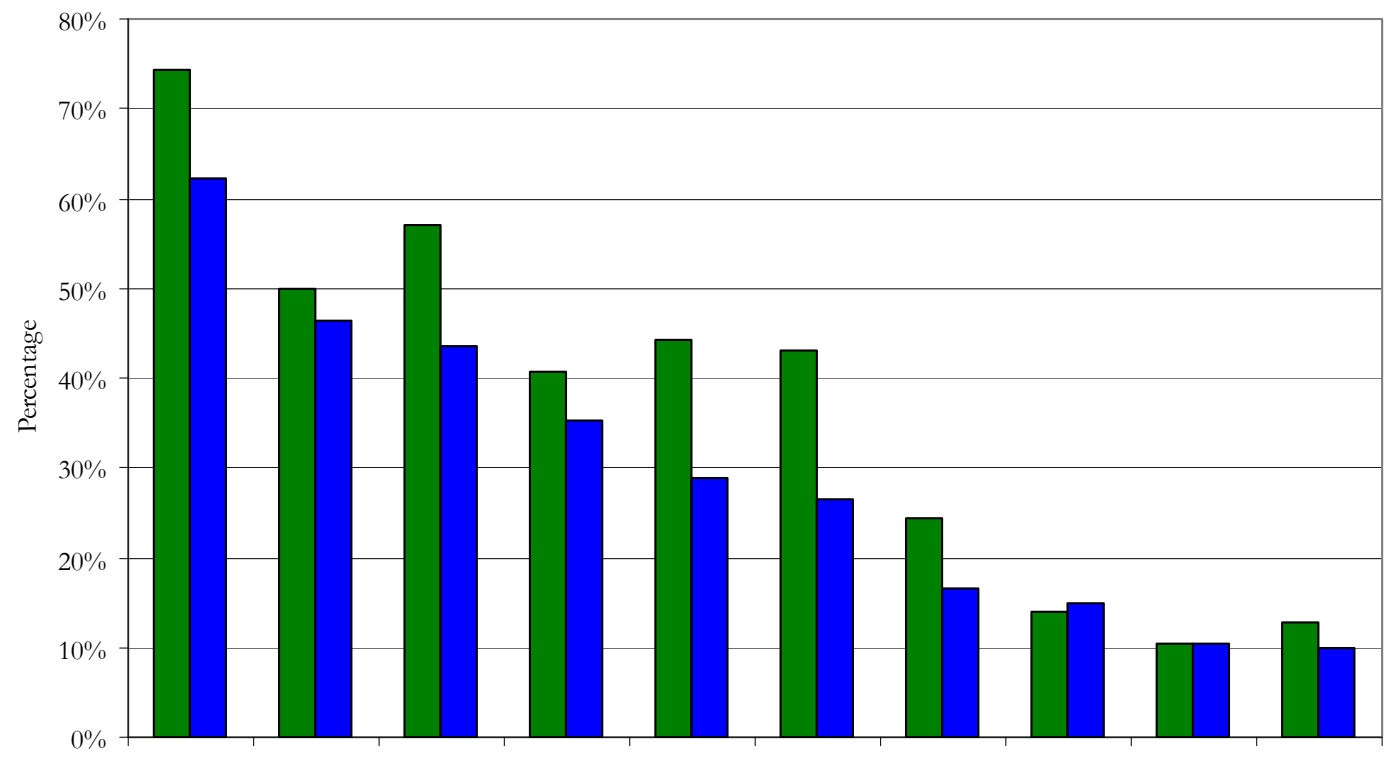

Option A Option C Option B Option D Option H Option I Option F Option G Option E Option J

$\square$ NZGBC $\square$ Non-NZGBC

Figure C-65: Overall obstacles to sustainable buildings by NZGBC vs. non-NZGBC 


\section{C.2.5.6 Reasons for Involvement in Sustainable Building}

Question: What are your reasons for being involved in sustainable building?

Table C-15: Definitions of option choices to reasons for being involved in sustainable building (in order asked in survey)

\begin{tabular}{|l|l|}
\hline Option & Definition \\
\hline Option A & I am not involved \\
\hline Option B & Being part of an industry that values the environment \\
\hline Option C & Achieving lower life-cycle costs \\
\hline Option D & Contract requirement (e.g. Government tenders) \\
\hline Option E & Expanding my business with 'green' building clients \\
\hline Option F & Benefit from publicity \\
\hline Option G & Triple bottom line reporting \\
\hline Option H & Attraction an retention of talent \\
\hline Option I & Green product information \\
\hline Option J & Awards for green building \\
\hline Option K & Higher return on investment on resale \\
\hline Option L & Other(s) \\
\hline
\end{tabular}

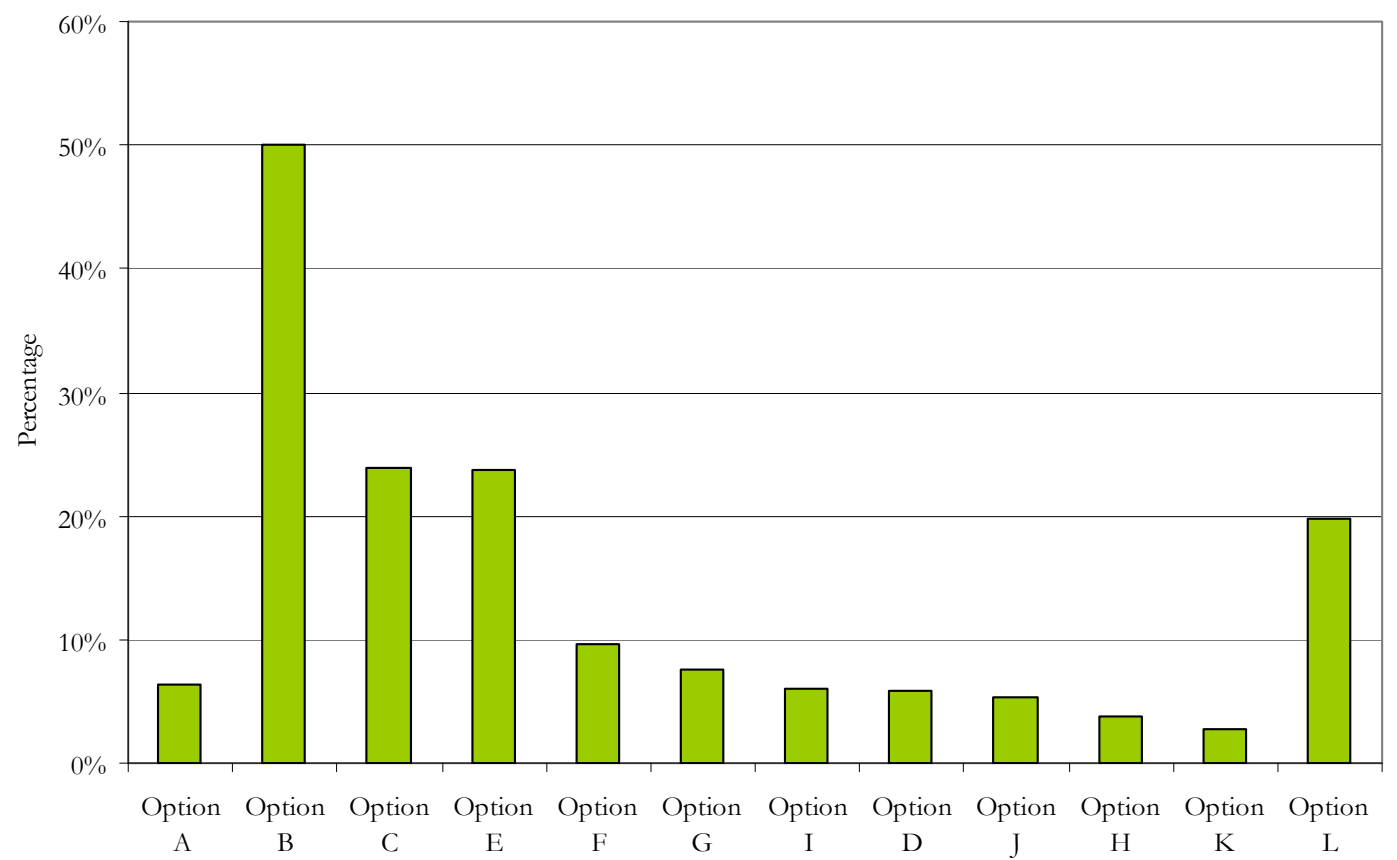

Figure C-66: Overall reasons for being involved with sustainable building (in order from highest to lowest) 


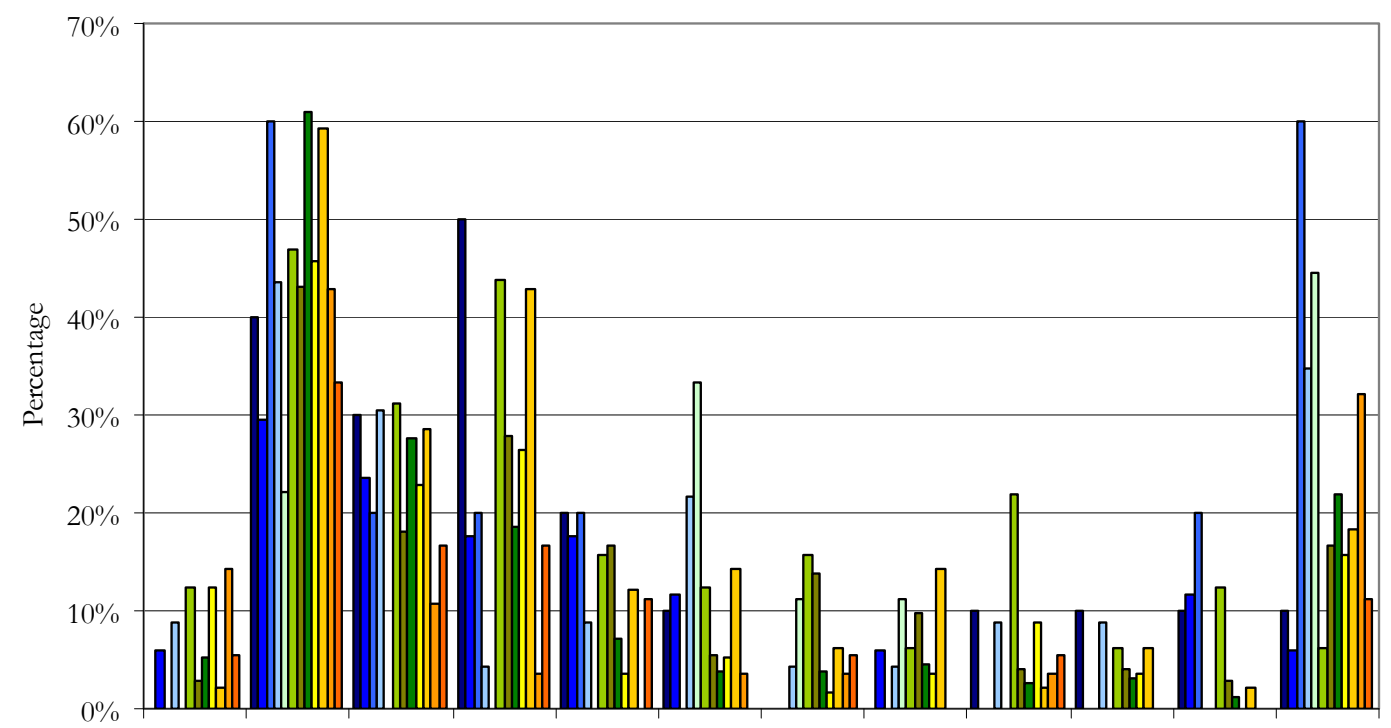

Option Option Option Option Option Option Option Option Option Option Option Option $\begin{array}{llllllllllll}\text { A } & \text { B } & \text { C } & \text { E } & \text { F } & \text { G } & \text { I } & \text { D } & \text { J } & \text { H } & \text { K } & \text { L }\end{array}$

$\square$ CPD $\square$ IO\&PM $\square$ RD\&MPO $\square$ OO $\square$ MCT\&R $\square$ BC $\square$ BPM\&D $\square$ A\&D $\square$ E $\square$ P\&CP $\square$ R\&NGO $\square$ RI

Figure C-67: Overall reasons for being involved with sustainable building by industry sector

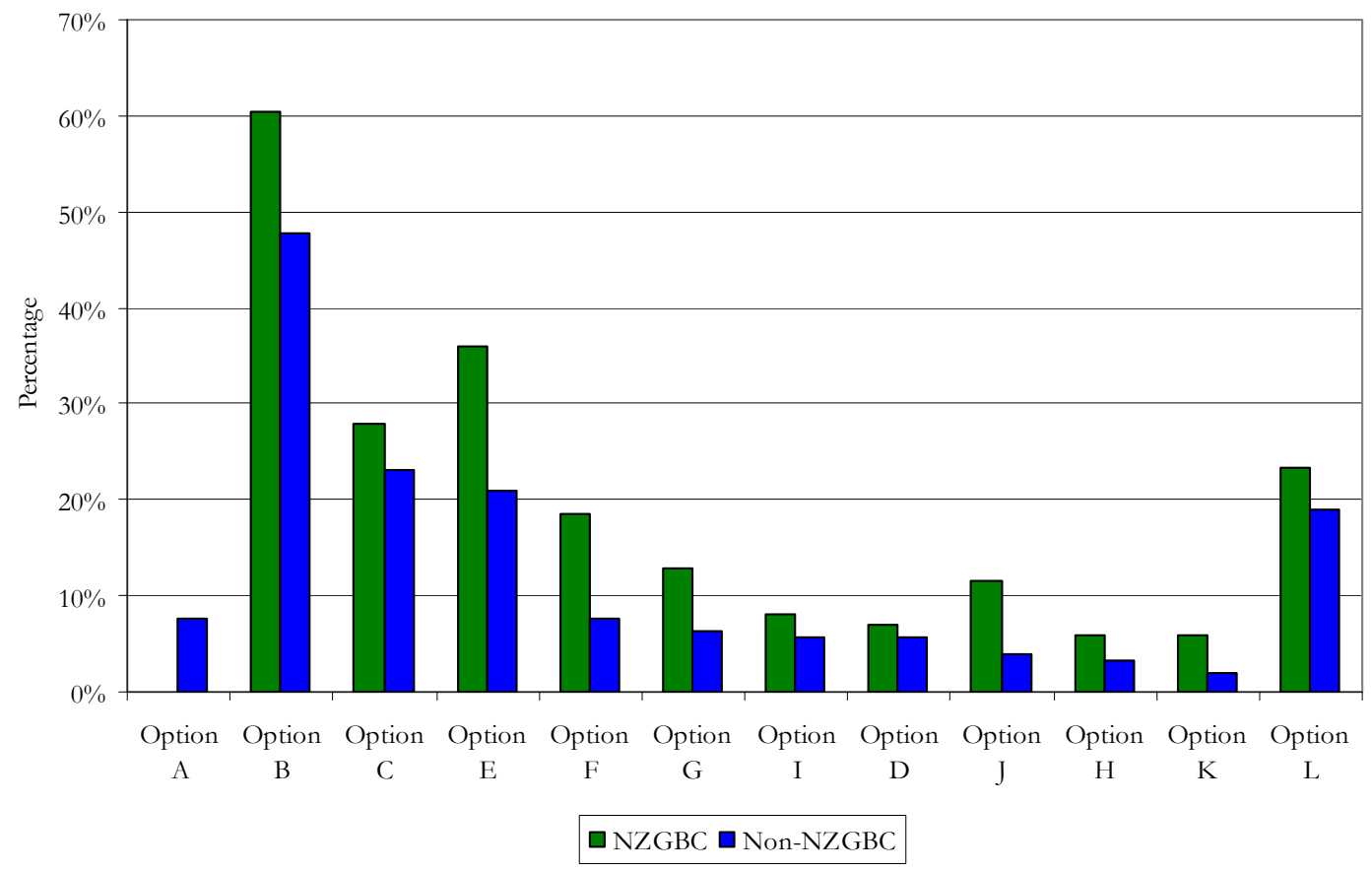

Figure C-68: Overall reasons for being involved with sustainable building by NZGBC vs. nonNZGBC 


\section{C.2.5.7 Economic Reasons for Sustainable Building}

Question: What do you believe are the economic reasons/benefits of sustainable building?

Table C-16: Definitions of option choices to economic reasons/benefits for sustainable building (in order asked in survey)

\begin{tabular}{|l|l|}
\hline Option & Definition \\
\hline Option A & Lower operating costs \\
\hline Option B & Lower lifetime costs \\
\hline Option C & Higher building value \\
\hline Option D & Enhanced marketability \\
\hline Option E & Helping to transform the market \\
\hline Option F & Increase staff productivity and retention \\
\hline Option G & Higher return on investment \\
\hline Option H & Reduced liability and risk \\
\hline Option I & Other(s) \\
\hline
\end{tabular}

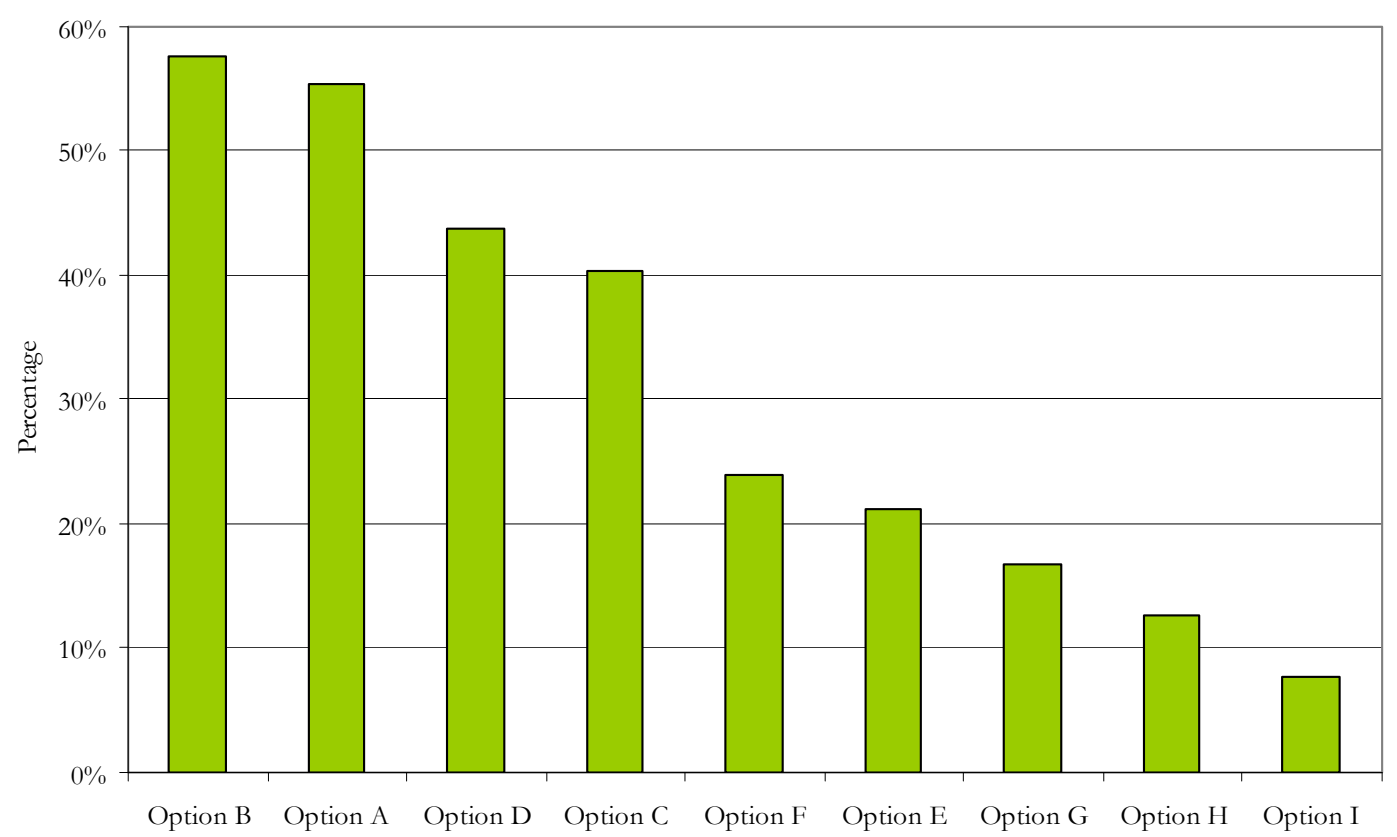

Figure C-69: Overall economic reasons/benefits of sustainable building (in order from highest to lowest) 


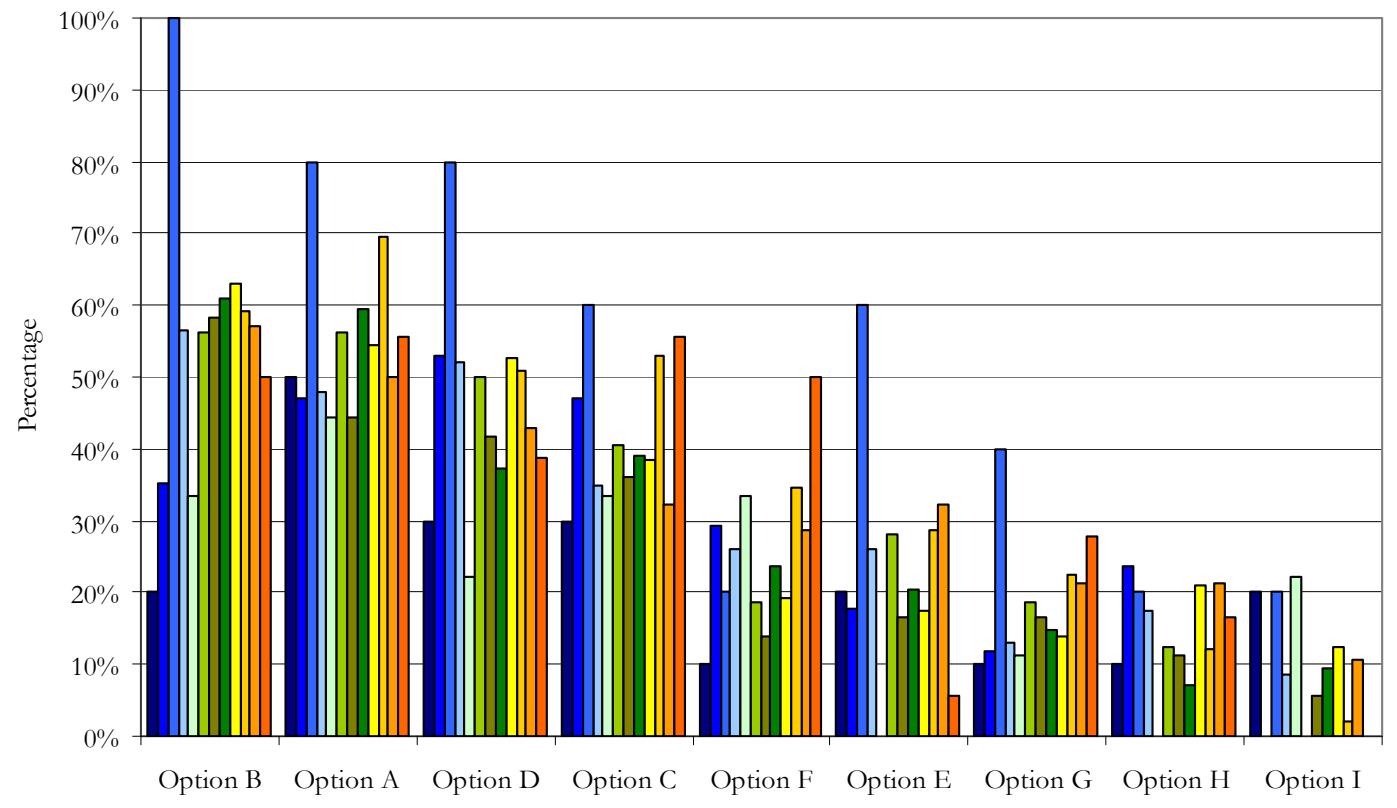

- CPD $\square$ IO\&PM $\square$ RD\&MPO $\square$ OO $\square$ MCT\&R $\square$ BC $\square$ BPM\&D $\square$ A\&D $\square$ E $\square$ P\&CP $\square$ R\&NGO $\square$ RI

Figure C-70: Overall economic reasons/benefits of sustainable building by industry sector

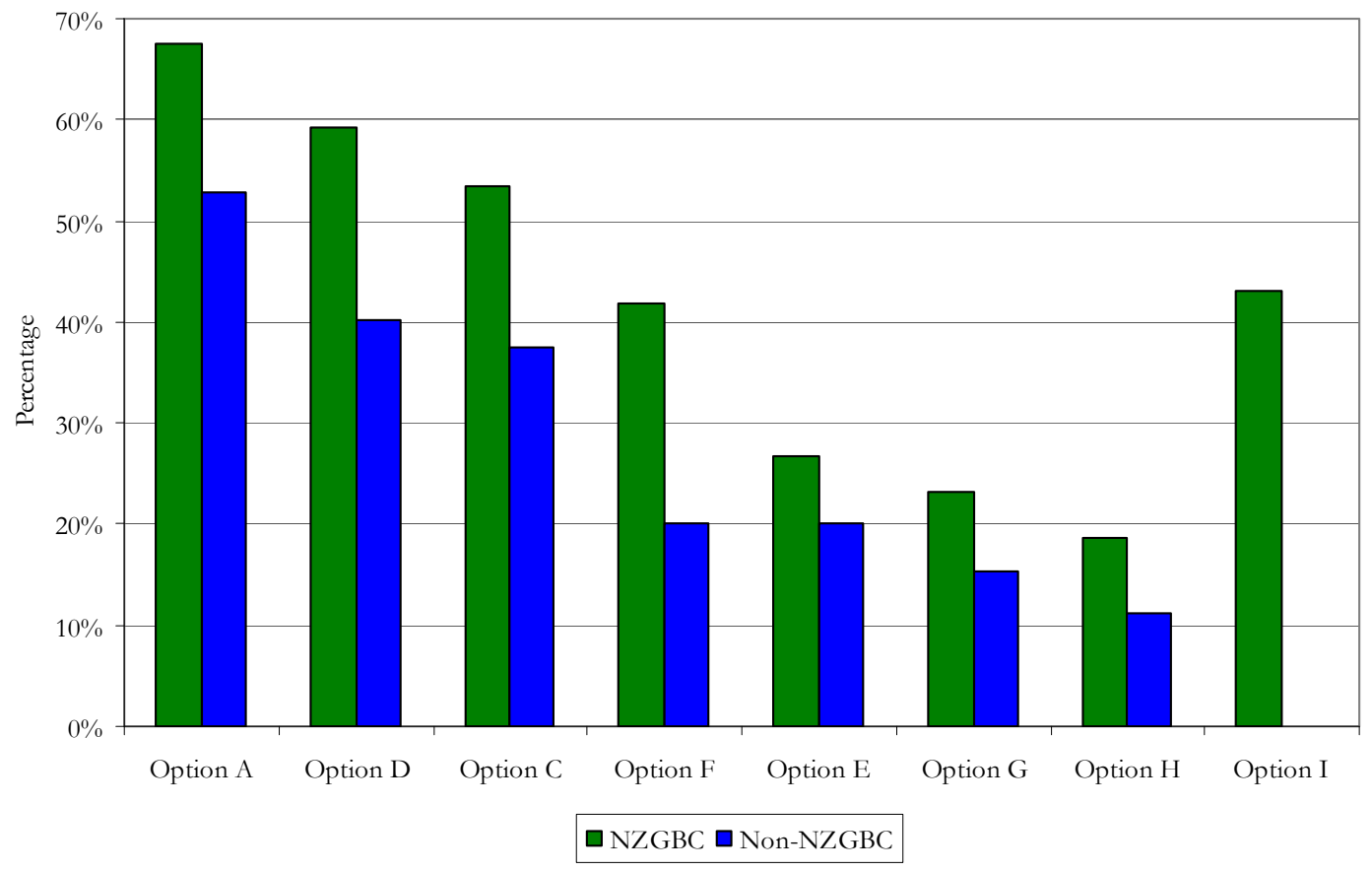

Figure C-71: Overall economic reasons/benefits of sustainable building by NZGBC vs. nonNZGBC 


\section{C.2.5.8 Environmental Reasons for Sustainable Building}

Question: What do you believe are the environmental reasons/benefits of sustainable building?

Table C-17: Definitions of option choices to environmental reasons/benefits for sustainable building (in order asked in survey)

\begin{tabular}{|l|l|}
\hline Option & Definition \\
\hline Option A & Protection of the environment \\
\hline Option B & Reducing climate change and emissions \\
\hline Option C & Minimising ecological impact of buildings \\
\hline Option D & Scarcity of natural resources \\
\hline Option E & Improving indoor environment quality \\
\hline Option F & Waste reduction \\
\hline Option G & Other(s) \\
\hline
\end{tabular}

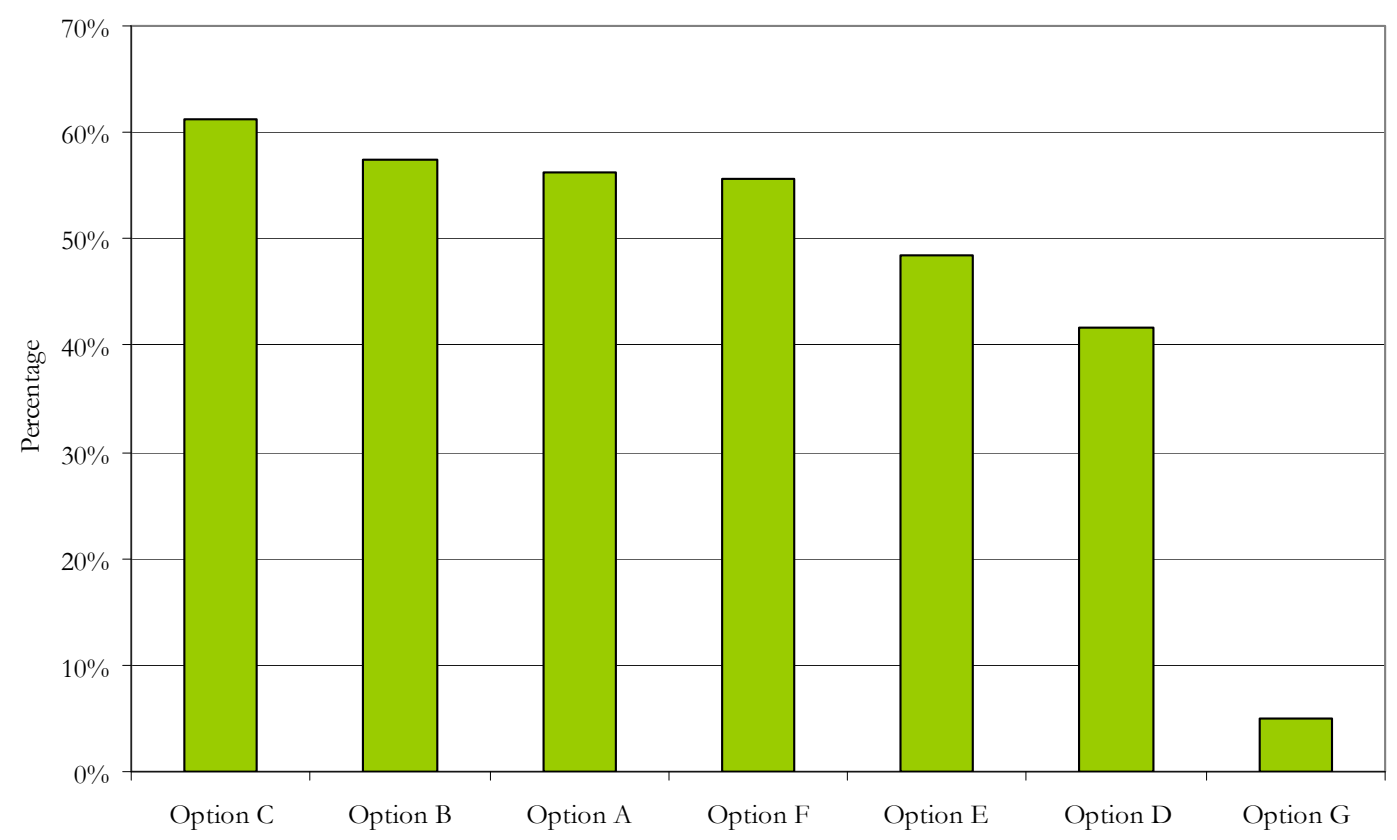

Figure C-72: Overall perceived of the environmental reasons/benefits of sustainable building (in order from highest to lowest) 


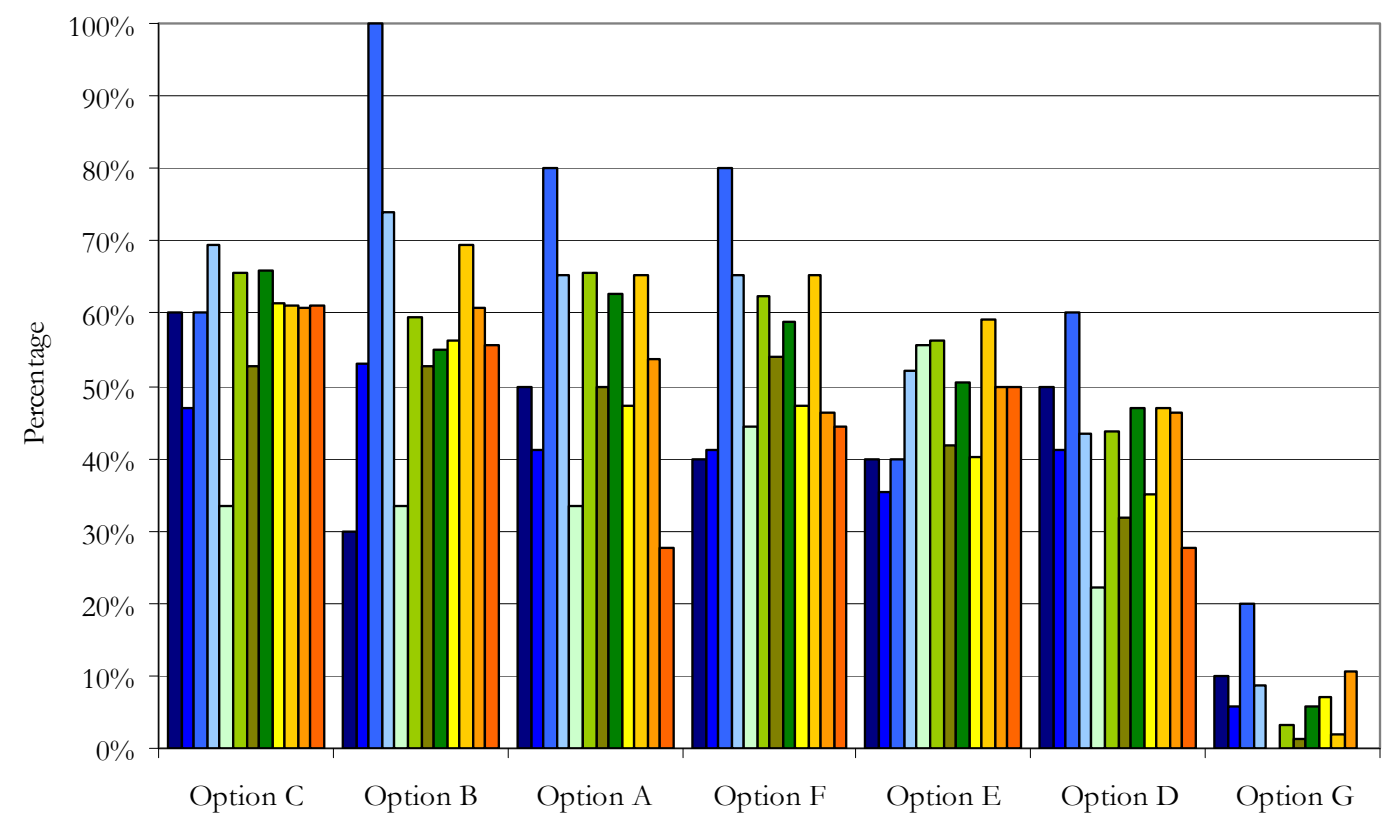

$\square \mathrm{CPD} \square \mathrm{IO \& PM} \square \mathrm{RD \& MPO} \square \mathrm{OO} \square \mathrm{MCT} \& \mathrm{R} \square \mathrm{BC} \square \mathrm{BPM} \& \mathrm{D} \square \mathrm{A} \& \mathrm{D} \square \mathrm{E} \square \mathrm{P} \& \mathrm{CP} \square \mathrm{R} \& \mathrm{NGO} \square \mathrm{RI}$

Figure C-73: Overall perceived of the environmental reasons/benefits of sustainable building by industry sector

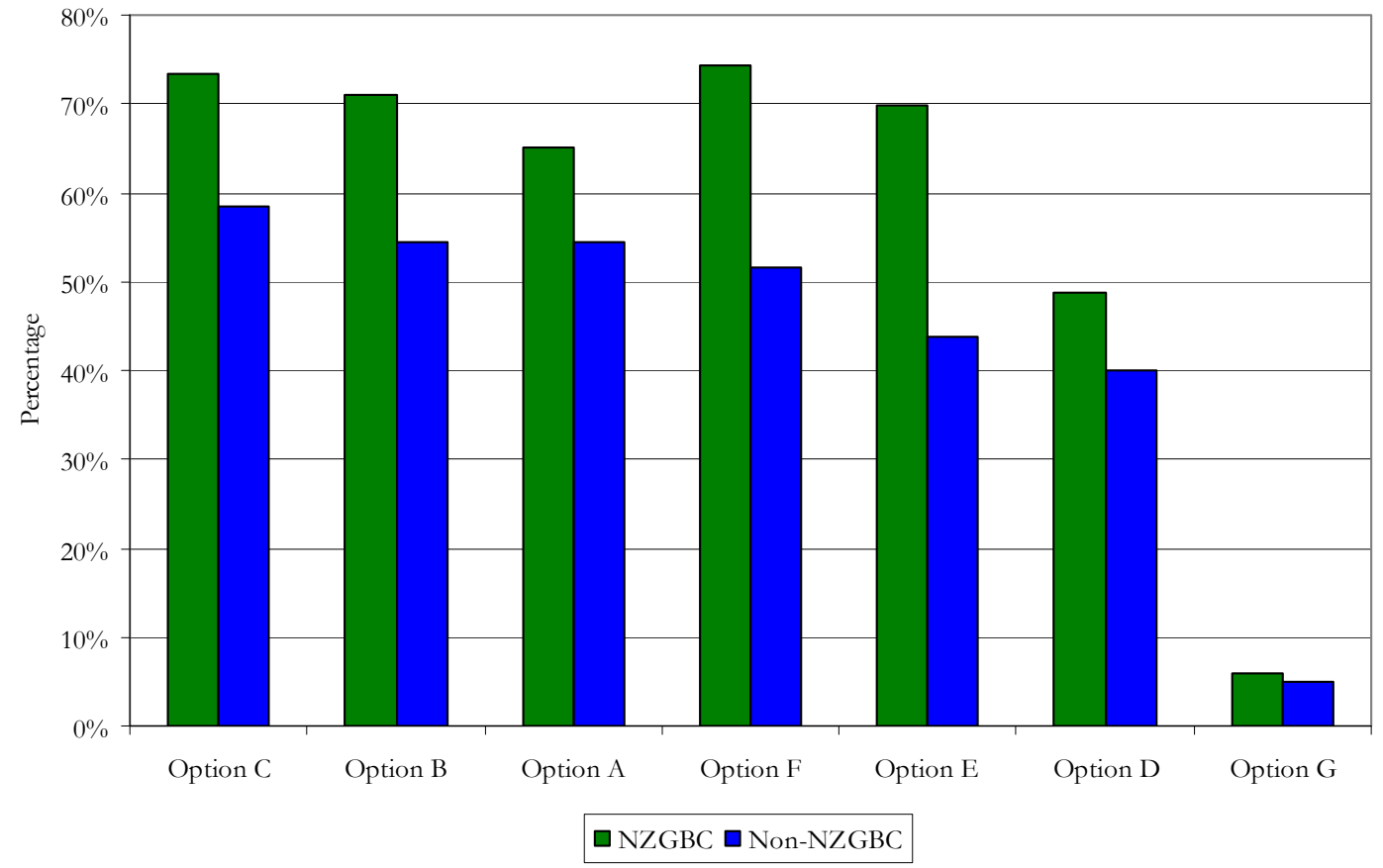

Figure C-74: Overall perceived of the environmental reasons/benefits of sustainable building by NZGBC vs. non-NZGBC 


\section{C.2.5.9 Social Reasons for Sustainable Building}

Question: What do you believe are the social reasons/benefits of sustainable building?

Table C-18: Definitions of option choices to social reasons/benefits for sustainable building (in order asked in survey)

\begin{tabular}{|l|l|}
\hline Option & Definition \\
\hline Option A & Greater health and well-being \\
\hline Option B & Improved learning and healing environments \\
\hline Option C & Tenant productivity \\
\hline Option D & Support for New Zealand economy \\
\hline Option E & Moral imperative of being 'green' \\
\hline Option F & Aesthetically pleasing \\
\hline Option G & Other(s) \\
\hline
\end{tabular}

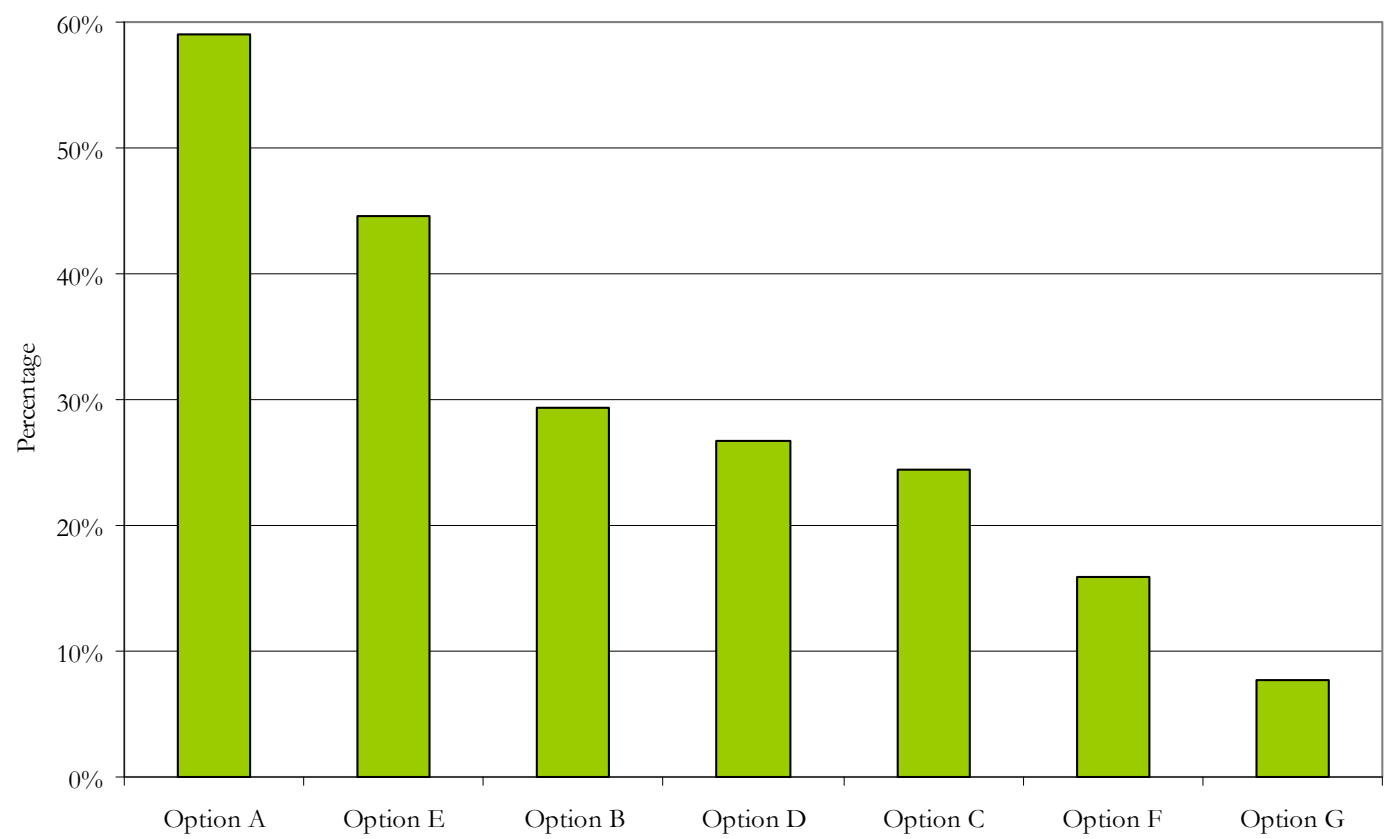

Figure C-75: Overall perceived social reasons/benefits of sustainable building (in order from highest to lowest) 


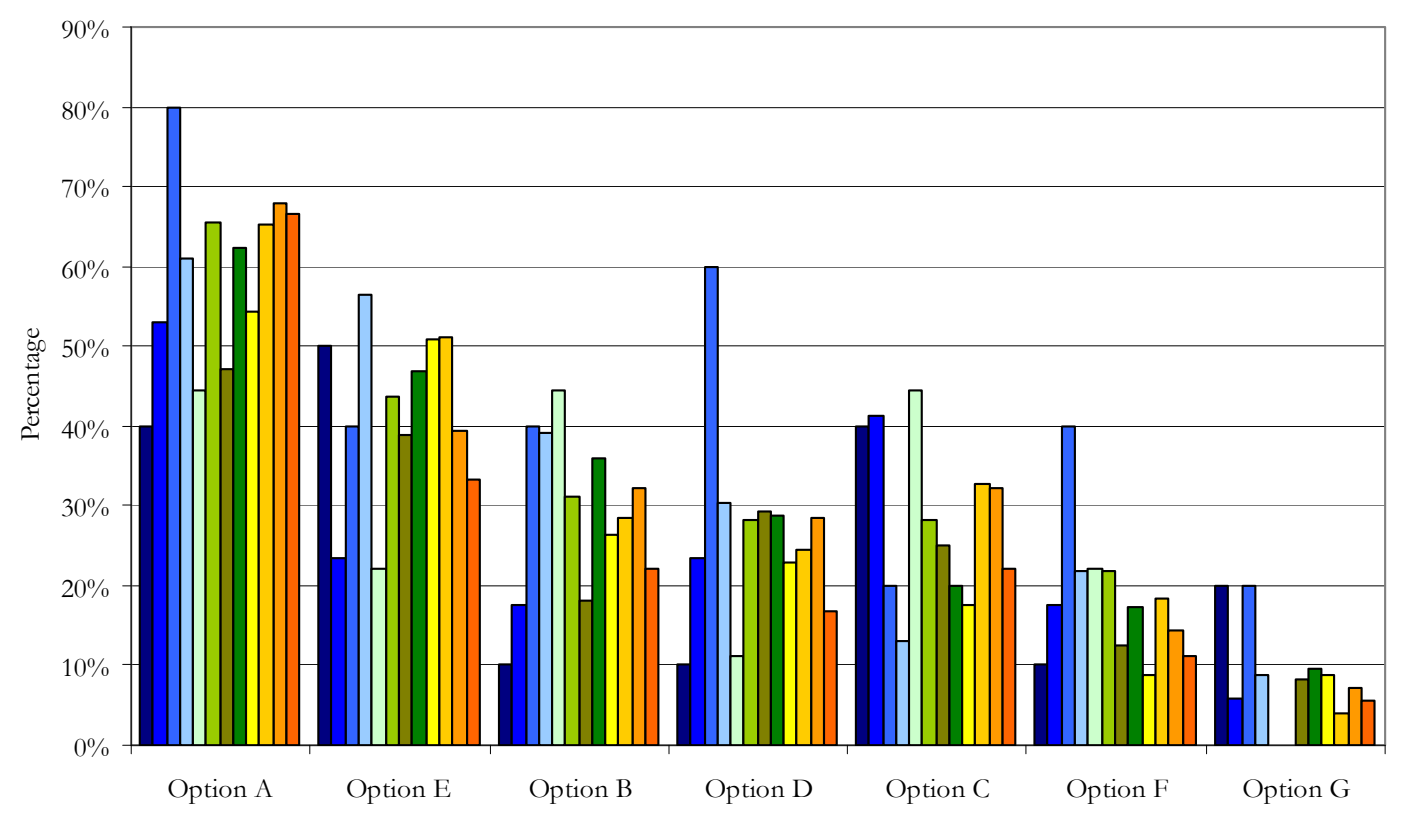

$\square$ CPD $\square$ IO\&PM $\square$ RD\&MPO $\square$ OO $\square$ MCT\&R $\square$ BC $\square$ BPM\&D $\square$ A\&D $\square$ E P\&CP $\square$ R\&NGO $\square$ RI

Figure C-76: Overall perceived social reasons/benefits of sustainable building by industry sector

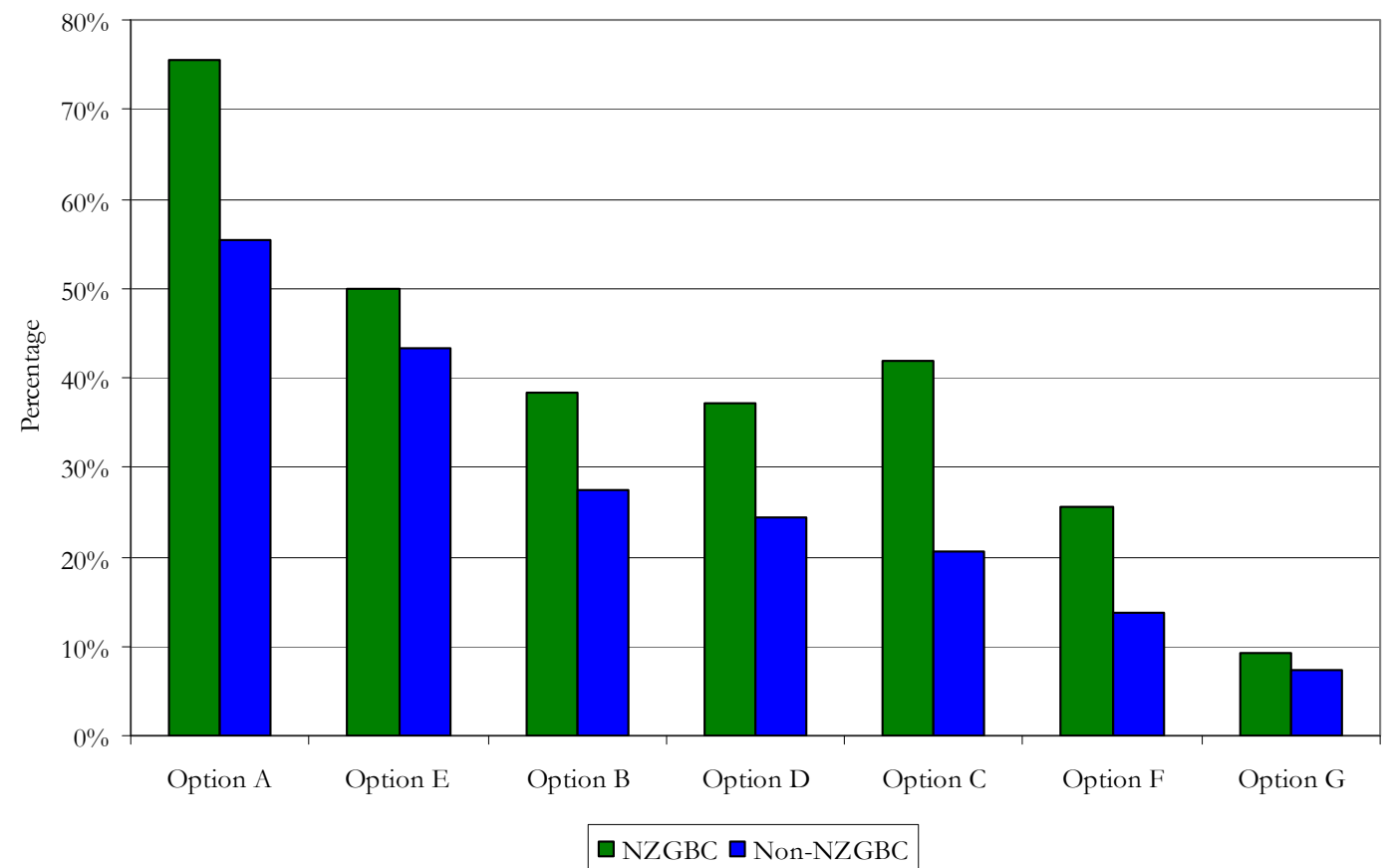

Figure C-77: Overall perceived social reasons/benefits of sustainable building by NZGBC vs. nonNZGBC 


\section{C.2.6 Sustainable Building Information}

\section{C.2.6.1 Sustainable Building Information Requirements}

Question: What information do you require in regards to sustainable building?

Table C-19: Definitions of option choices to information requirements (in order asked in survey)

\begin{tabular}{|l|l|}
\hline Option & Definition \\
\hline Option A & Green products \\
\hline Option B & Environmental and economic cost benefit case studies \\
\hline Option C & Green building emerging trends \\
\hline Option D & Green projects \\
\hline Option E & How-to design a 'green' building \\
\hline Option F & Reviews and profiles of Green Star New Zealand buildings \\
\hline Option G & Engineering or scientific information \\
\hline Option H & How-to market a 'green' building \\
\hline Option I & Green Star New Zealand accreditation course \\
\hline Option J & How-to manage a 'green' building \\
\hline Option K & 'Green' players (services guide) \\
\hline Option L & Green Star New Zealand players \\
\hline Option M & Business management information \\
\hline Option N & Curriculum for senior executives \\
\hline Option O & Curriculum for line staff \\
\hline Option P & Other(s) \\
\hline
\end{tabular}

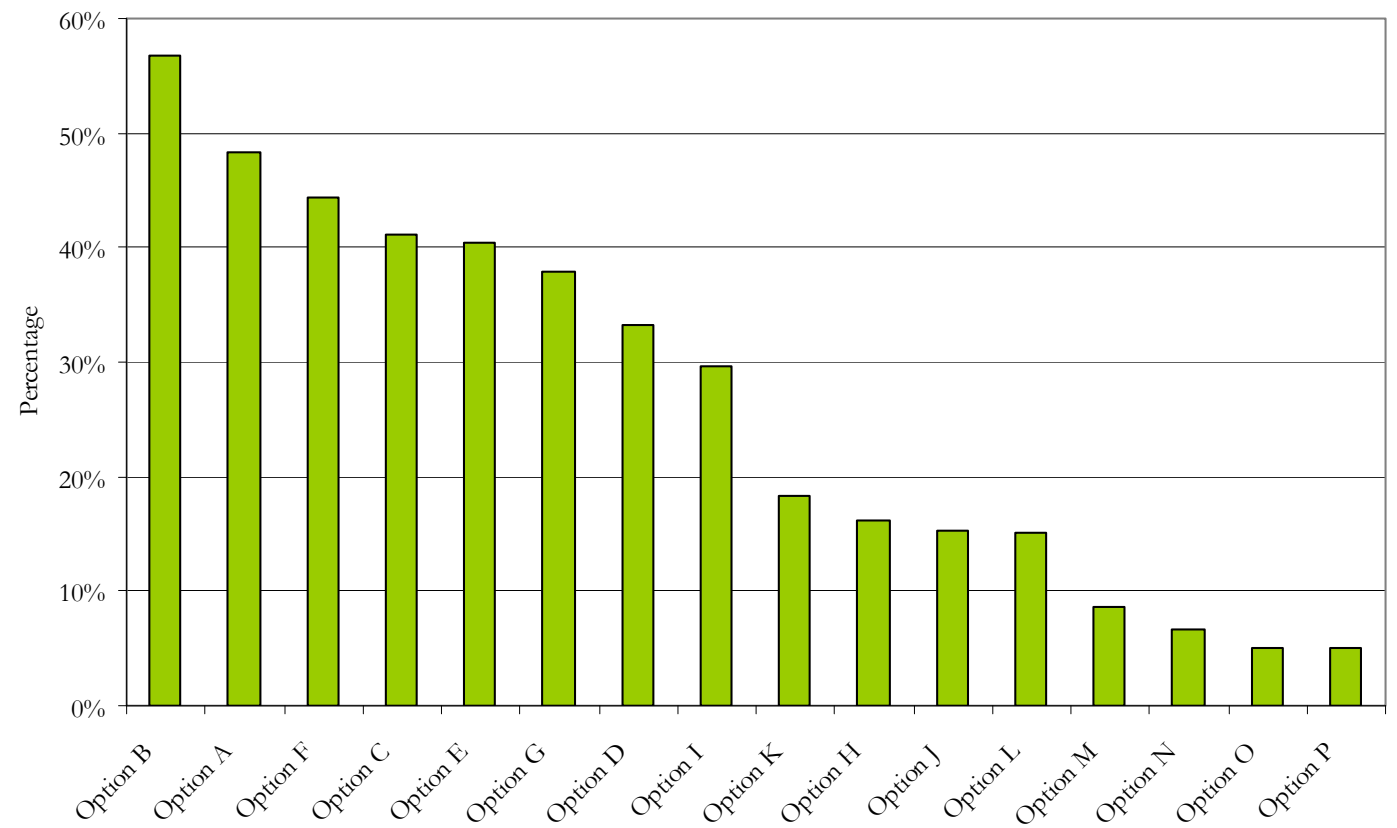

Figure C-78: Overall requirements for information about sustainable building (in order from highest to lowest) 


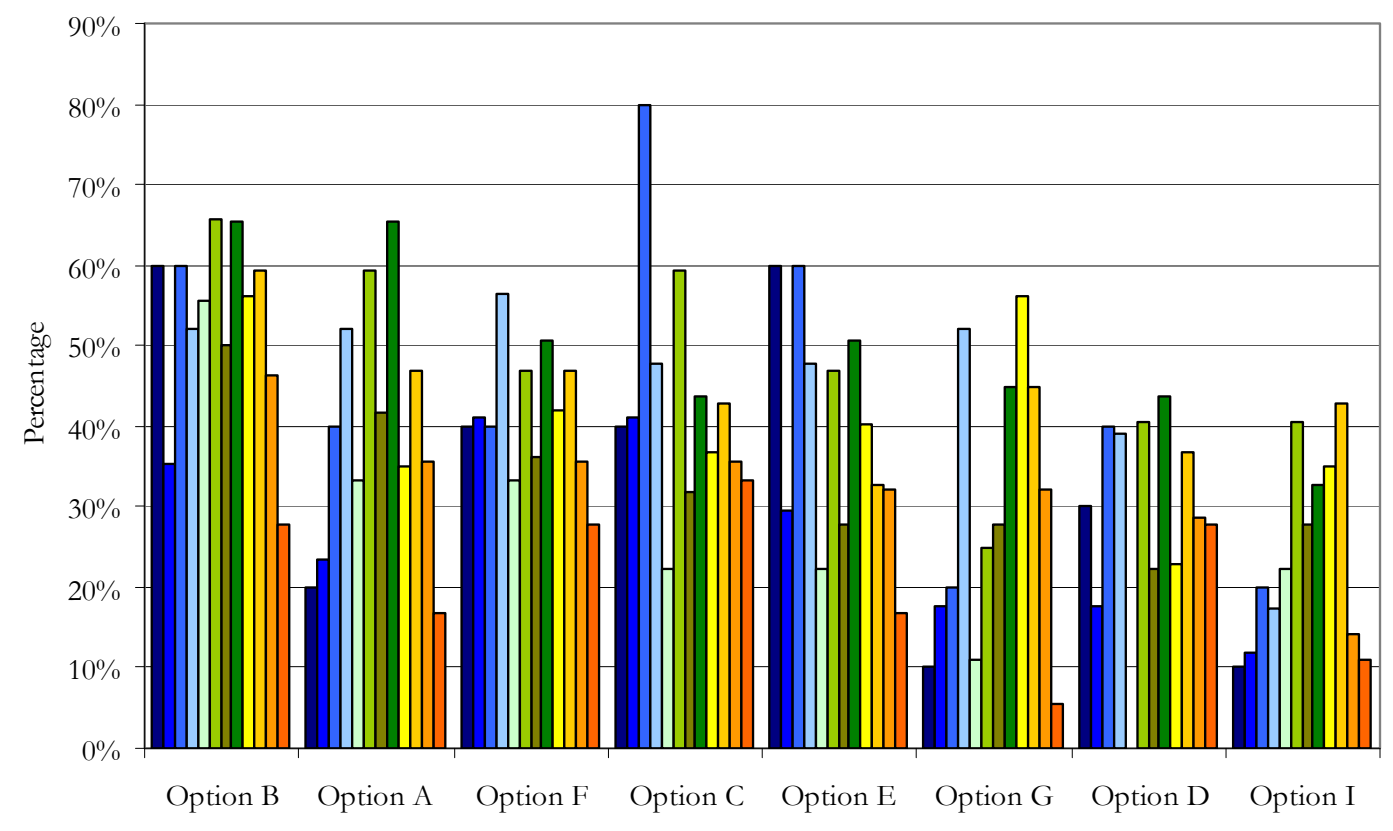

$\square$ CPD $\square$ IO\&PM $\square$ RD\&MPO $\square$ OO $\square$ MCT\&R $\square$ BC $\square$ BPM\&D $\square$ A\&D $\square$ E $\square$ P\&CP $\square$ R\&NGO $\square$ RI

Figure C-79: Overall requirements for information about sustainable building by industry sector (top eight options)

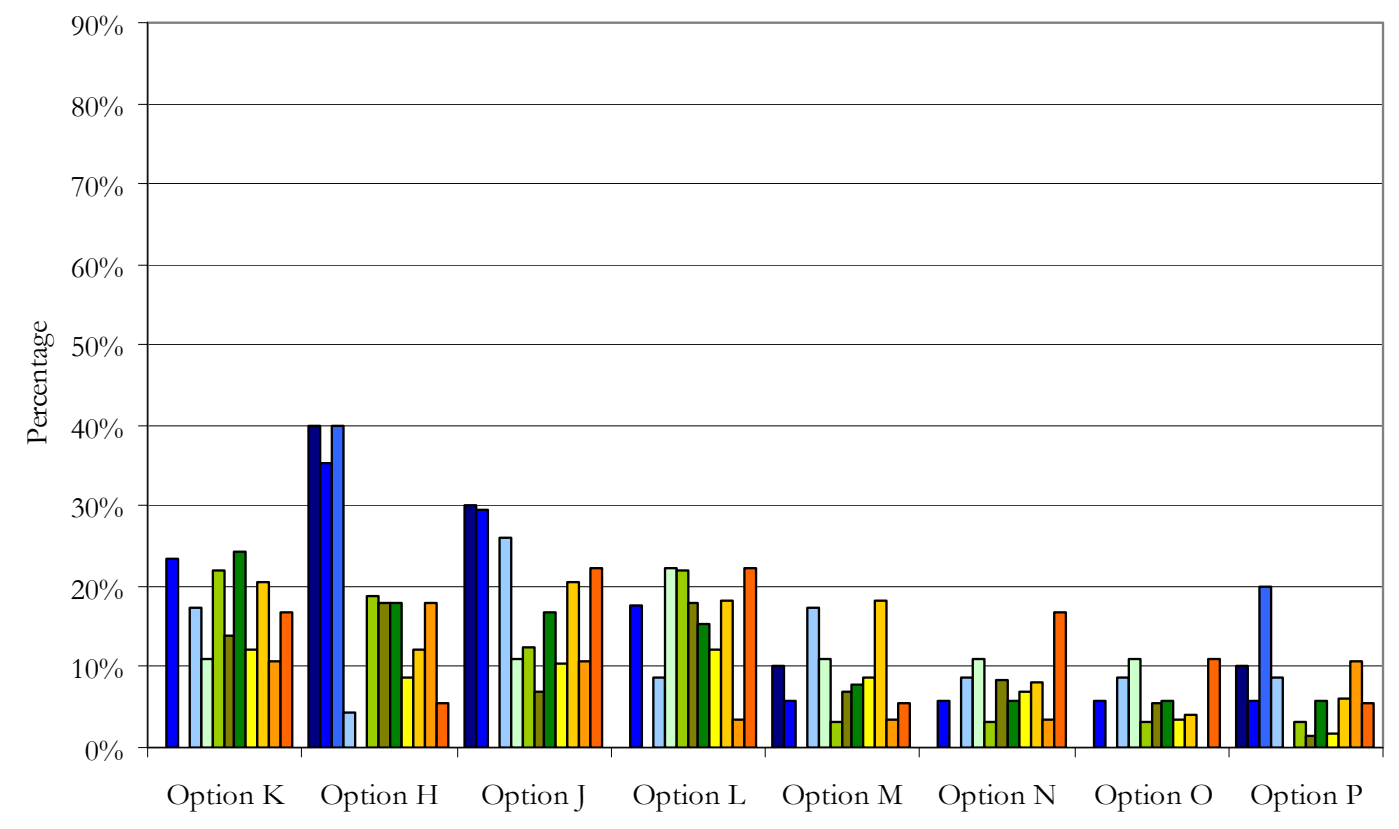

$\square$ CPD $\square$ IO\&PM $\square$ RD\&MPO $\square$ OO $\square$ MCT\&R $\square$ BC $\square$ BPM\&D $\square$ A\&D $\square$ E P\&CP $\square$ R\&NGO $\square$ RI

Figure C-80: Overall requirements for information about sustainable building by industry sector (bottom eight options) 
Appendix C

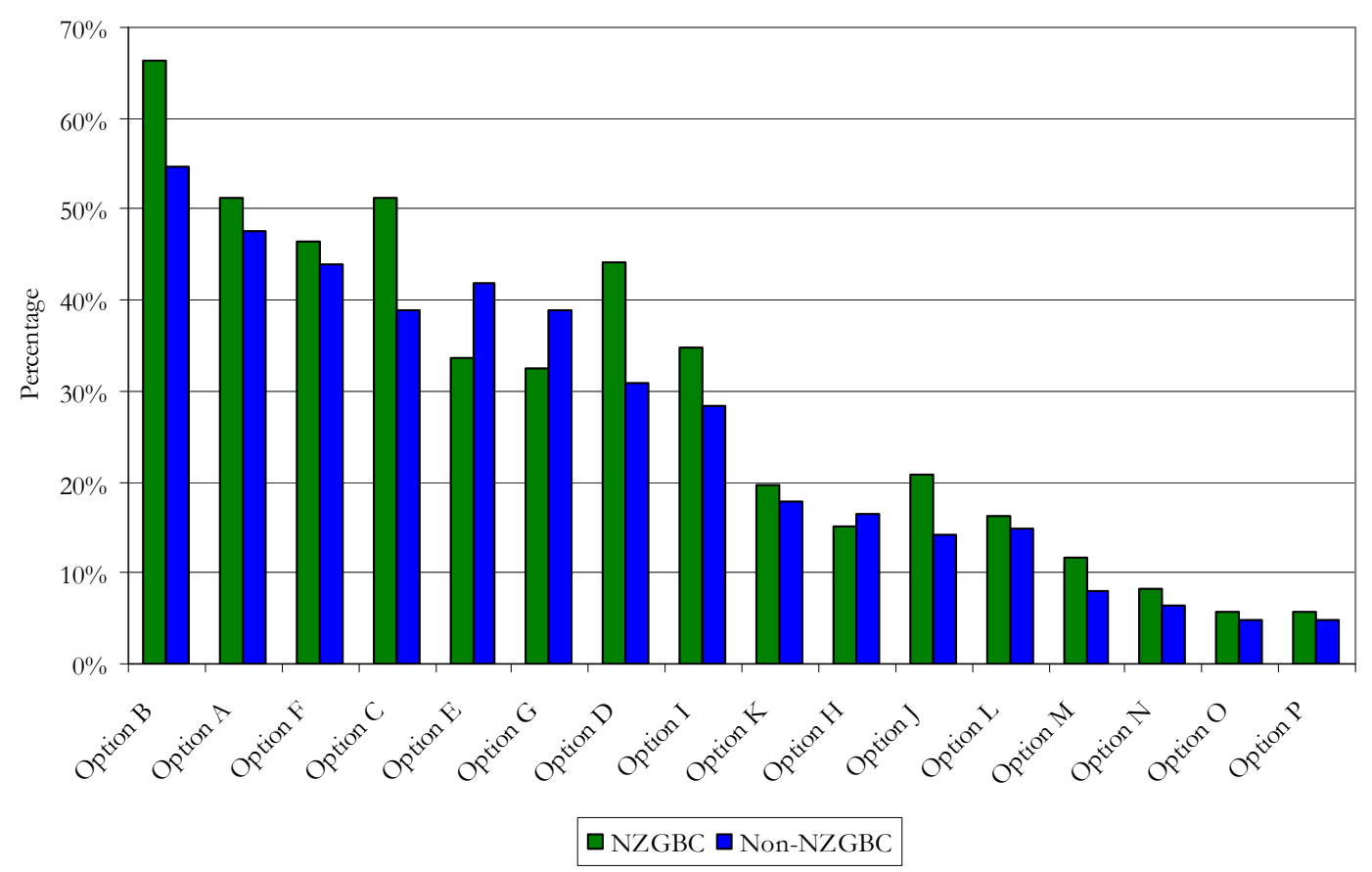

Figure C-81: Overall requirements for information about sustainable building by NZGBC vs. nonNZGBC 


\section{C.2.6.2 Sustainable Building Information Satisfaction}

Question: What is your level of satisfaction with current information about sustainable building?

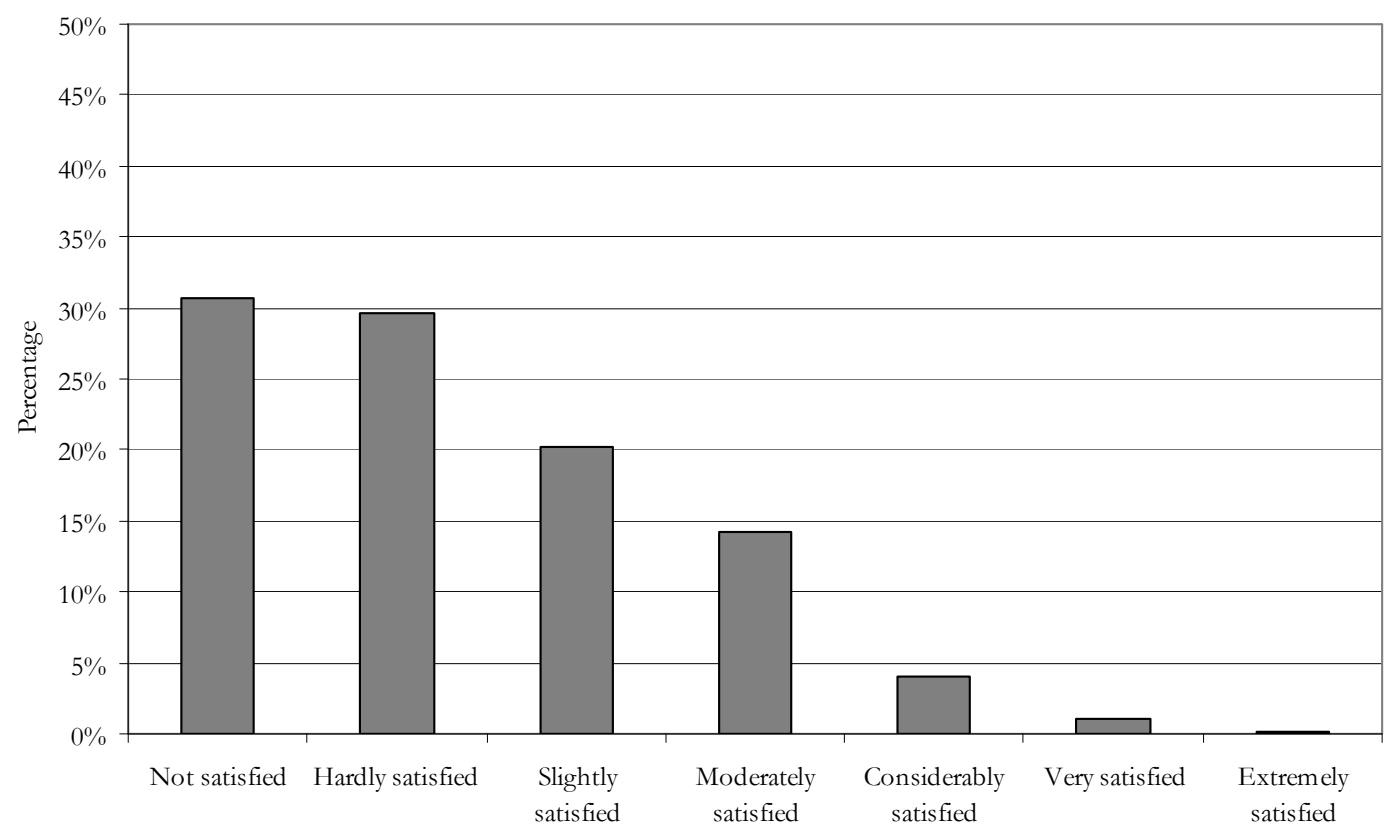

Figure C-82: Overall level of satisfaction with the current information available about sustainable building 
Table C-20: Definitions of option choices to information requirements with colour key

\begin{tabular}{|l|l|l|}
\hline Answer Choice & Definition & Key \\
\hline Option A & Green products & \\
\hline Option B & Environmental and economic cost benefit case studies & \\
\hline Option C & Green building emerging trends & \\
\hline Option D & Green projects & \\
\hline Option E & How-to design a 'green' building & \\
\hline Option F & Reviews and profiles of Green Star New Zealand buildings & \\
\hline Option G & Engineering or scientific information & \\
\hline Option H & How-to market a 'green' building & \\
\hline Option I & Green Star New Zealand accreditation course & \\
\hline Option J & How-to manage a 'green' building & \\
\hline Option K & 'Green' players (services guide) & \\
\hline Option L & Green Star New Zealand players & \\
\hline Option M & Business management information & \\
\hline Option N & Curriculum for senior executives & \\
\hline Option O & Curriculum for line staff & \\
\hline
\end{tabular}

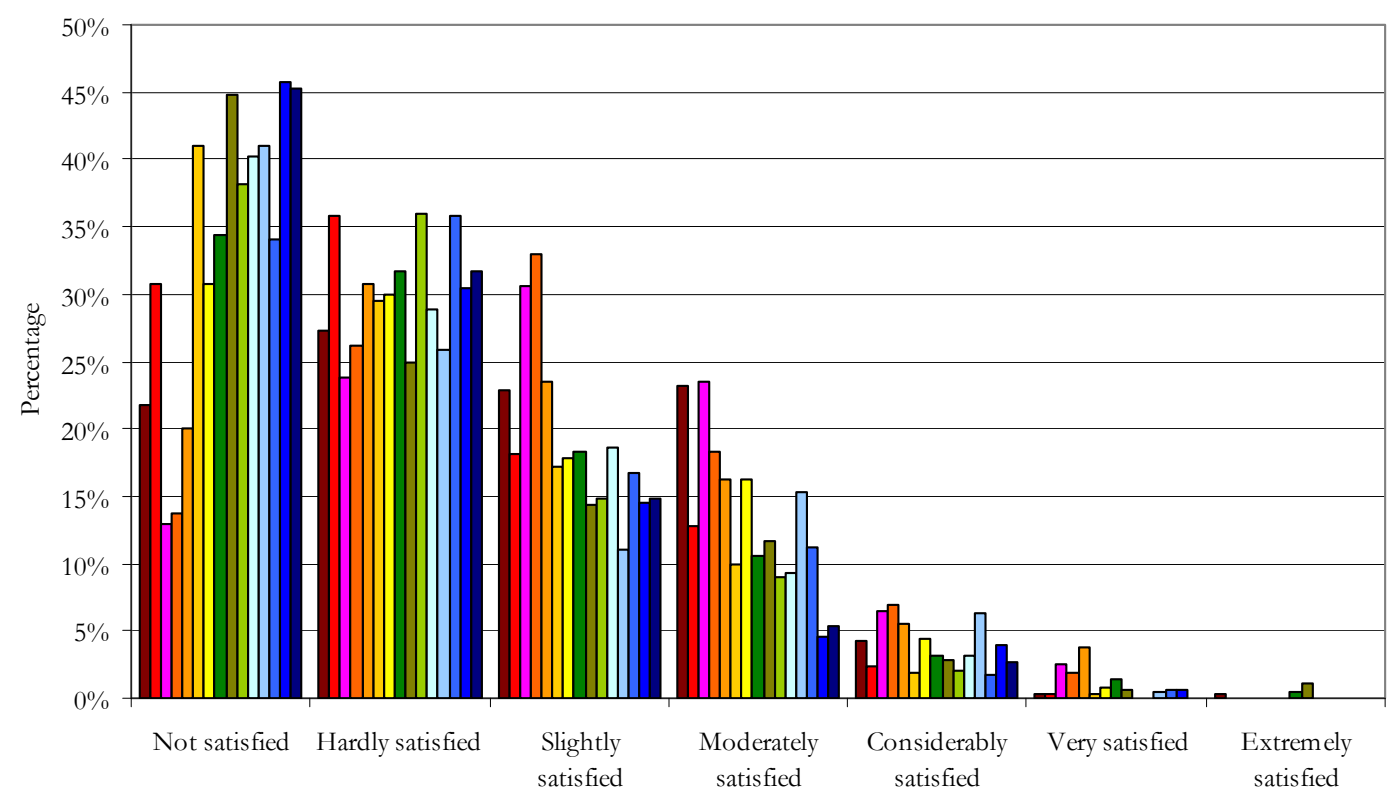

$\square$ Option A $\square$ Option B $\square$ Option C $\square$ Option D $\square$ Option E $\square$ Option F $\square$ Option G $\square$ Option H

$\square$ Option I $\quad \square$ Option J $\quad \square$ Option K $\square$ Option L $\quad \square$ Option M $\square$ Option N $\square$ Option O

Figure C-83: Overall level of satisfaction with the current information available about sustainable building according to option choices 


\section{C.2.6.2.1 Green Products}

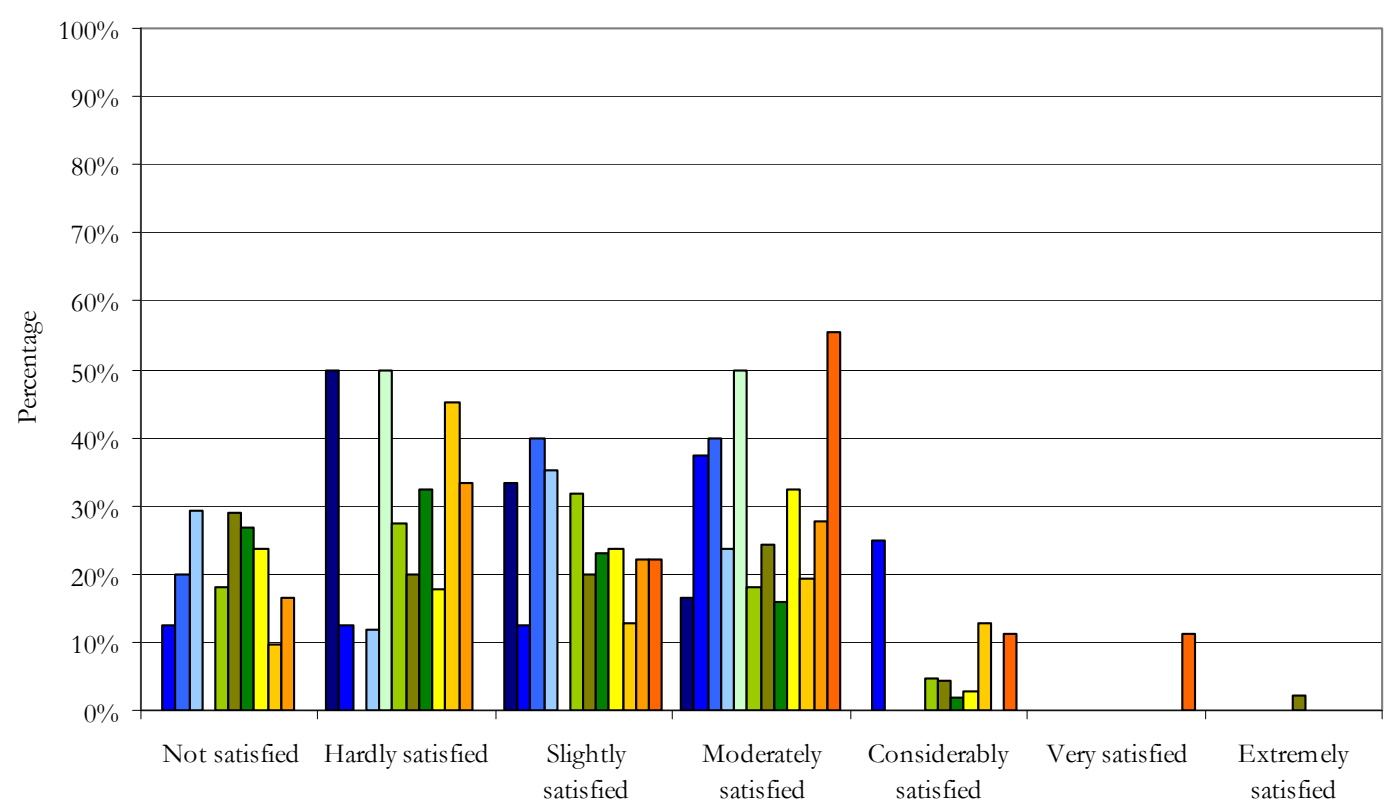

$\square$ CPD $\square$ IO\&PM $\square$ RD\&MPO $\square$ OO $\square$ MCT\&R $\square$ BC $\square$ BPM\&D $\square$ A\&D $\square$ E $\square$ P\&CP $\square$ R\&NGO $\square$ RI

Figure C-84: Overall level of satisfaction with the current information available about green products by industry sector

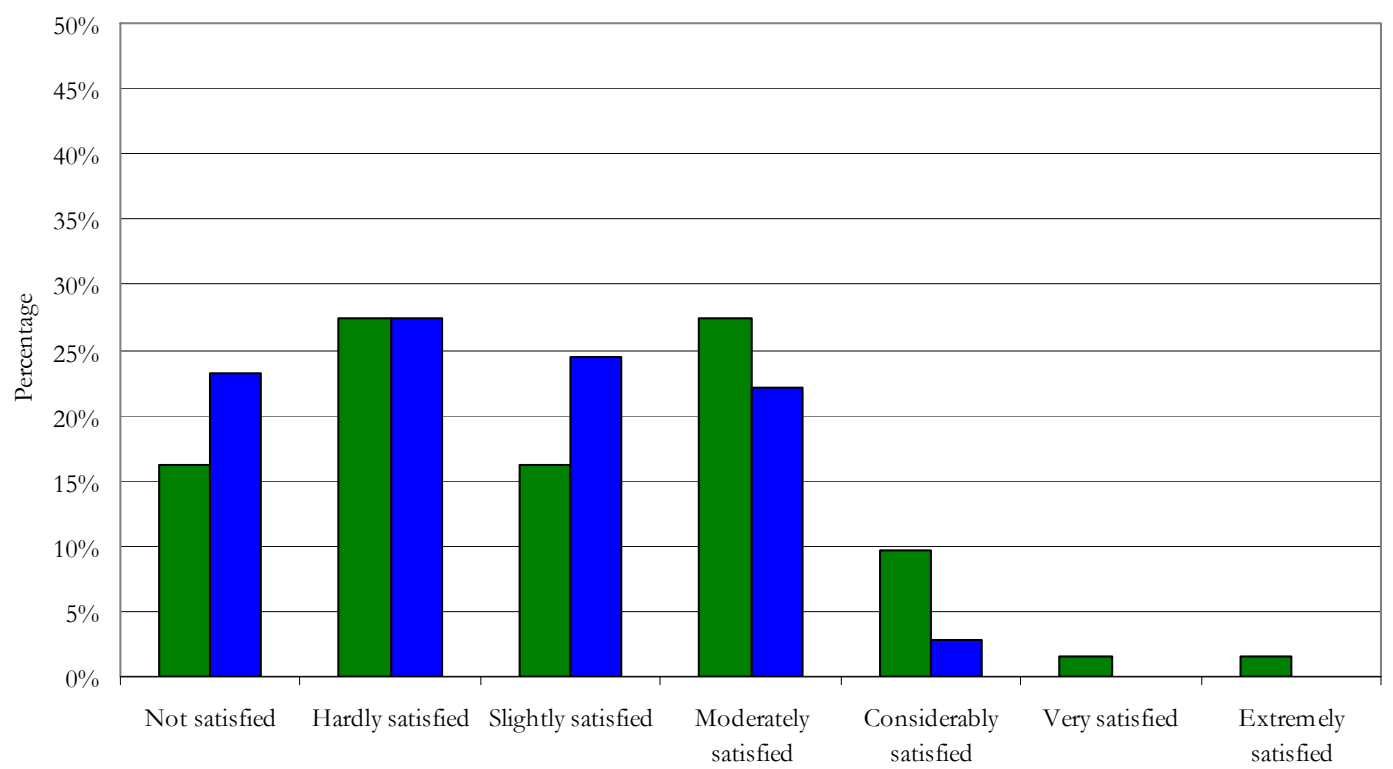

$\square$ NZGBC $\square$ Non-NZGBC

Figure C-85: Overall level of satisfaction with the current information available about green products by NZGBC vs. non-NZGBC 


\section{C.2.6.2.2 Environmental and Economic Cost Benefit Case Studies}

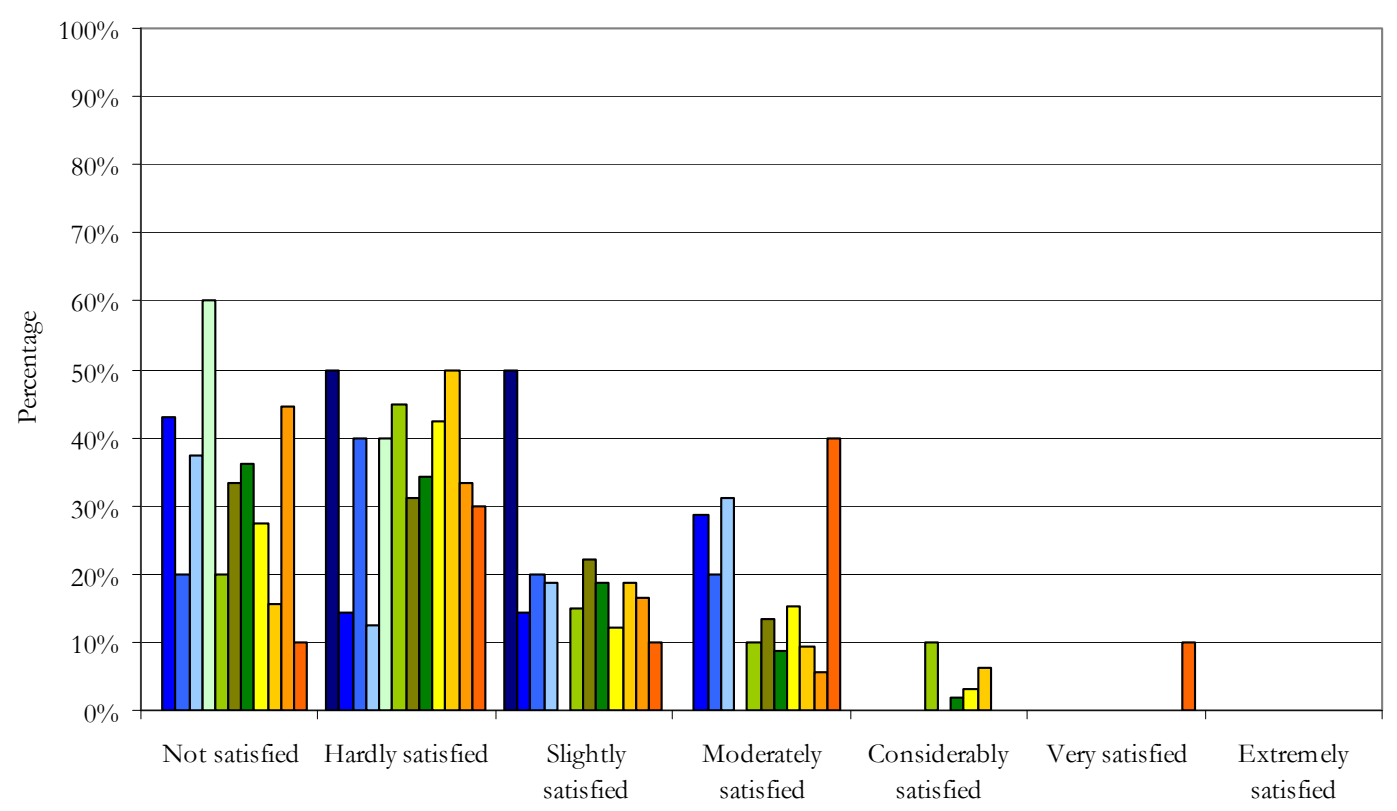

$\square$ CPD $\square$ IO\&PM $\square$ RD\&MPO $\square$ OO $\square$ MCT\&R $\square$ BC $\square$ BPM\&D $\square$ A\&D $\square$ E $\square$ P\&CP $\square$ R\&NGO $\square$ RI

Figure C-86: Overall level of satisfaction with the current information available about environmental and economic cost benefit case studies by industry sector

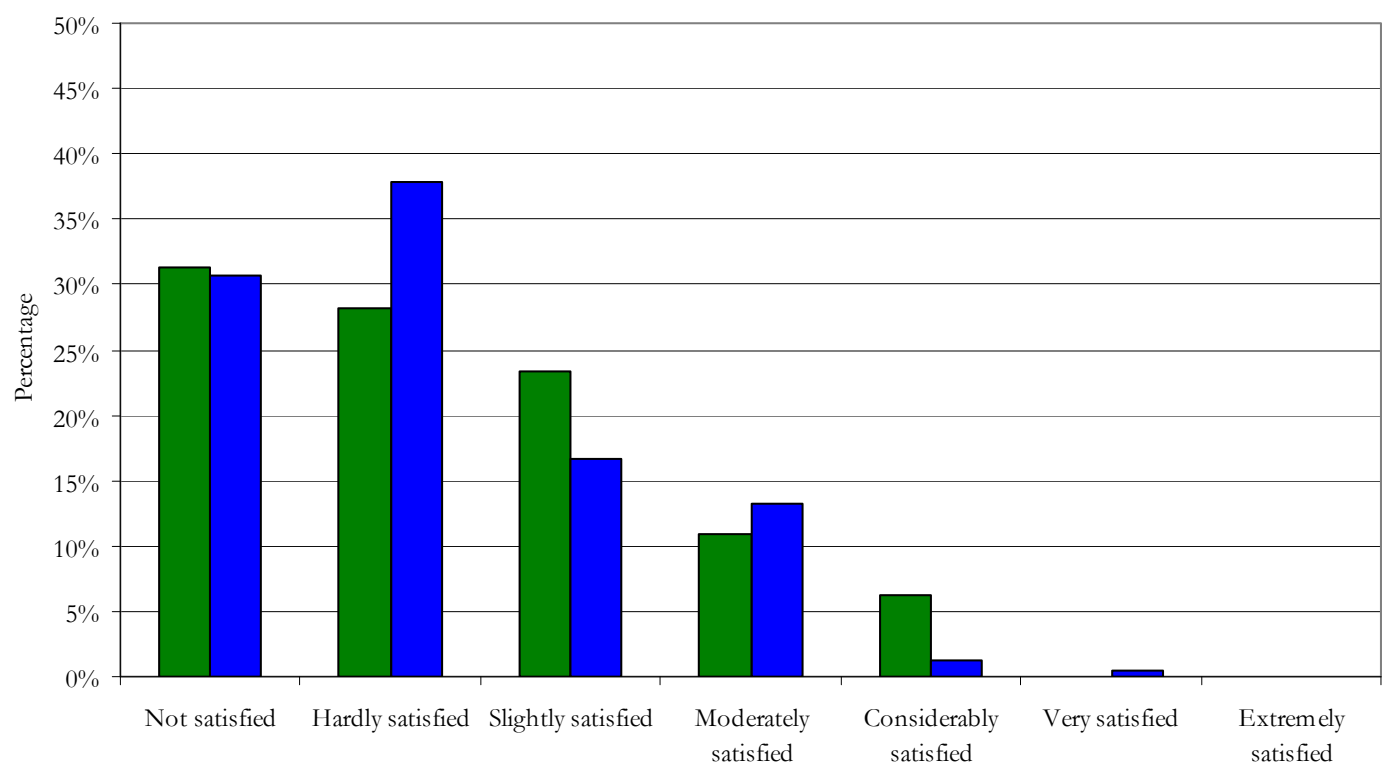

$\square$ NZGBC $\square$ Non-NZGBC

Figure C-87: Overall level of satisfaction with the current information available about environmental and economic cost benefit case studies by NZGBC vs. non-NZGBC 


\section{C.2.6.2.3 Green Building Emerging Trends}

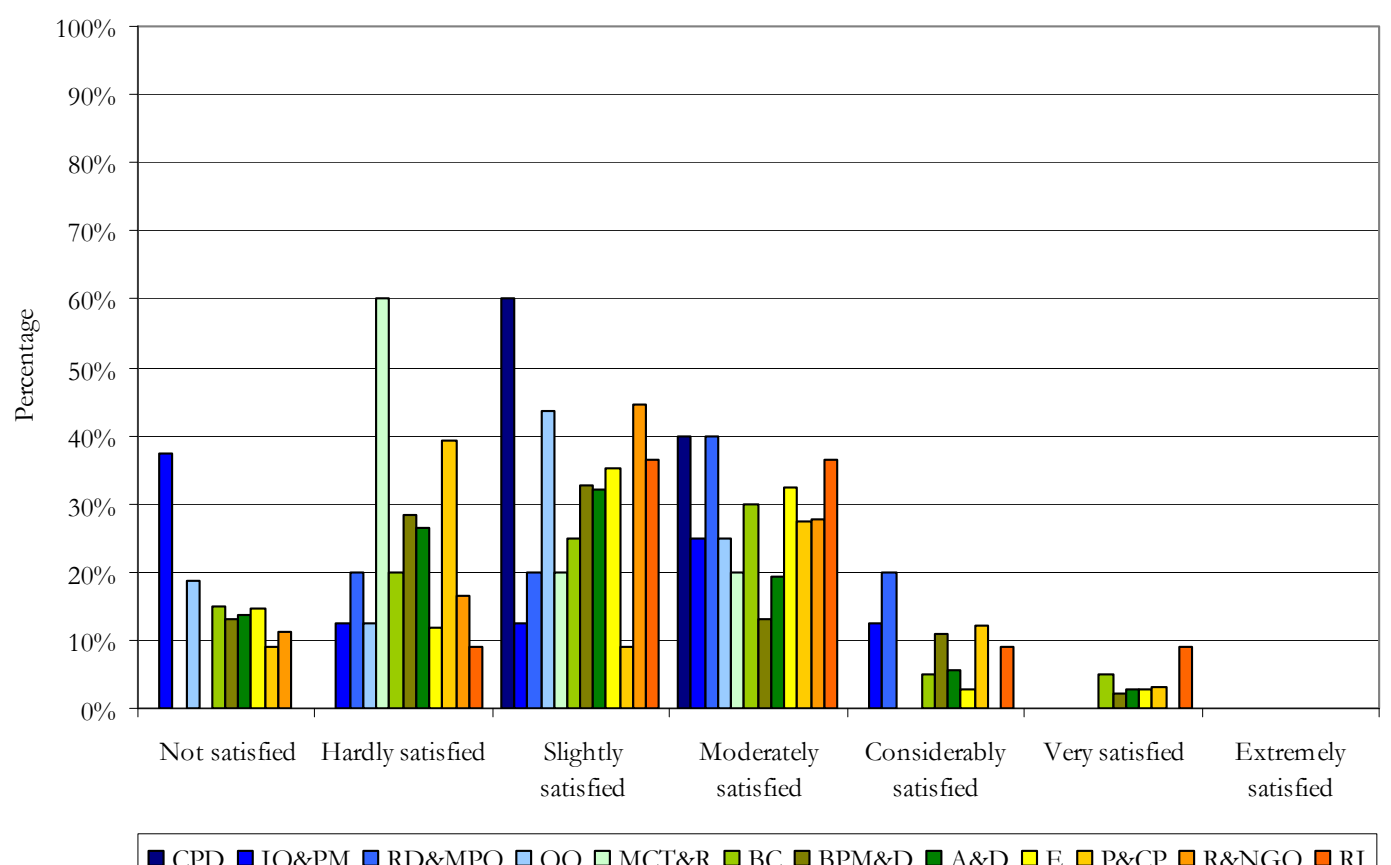

Figure C-88: Overall level of satisfaction with the current information available about green building emerging trends by industry sector

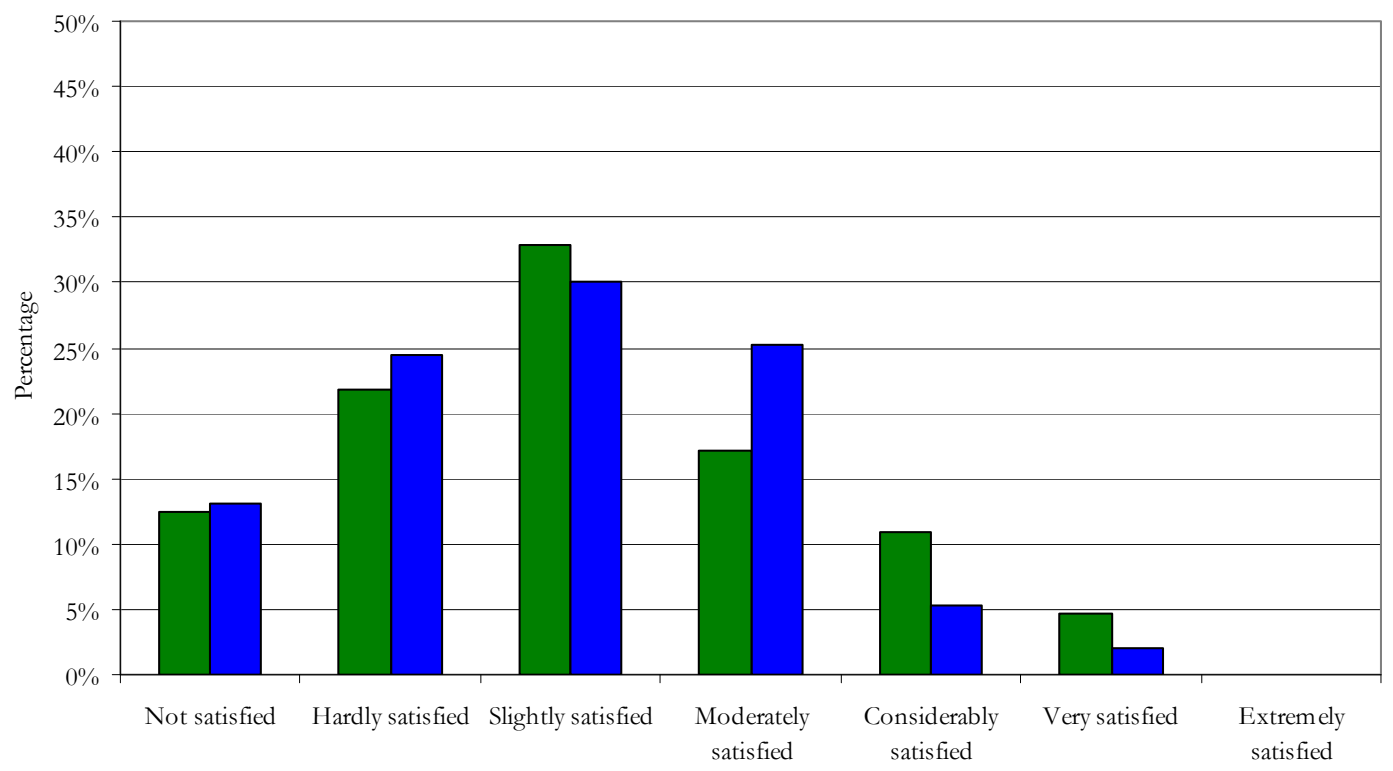

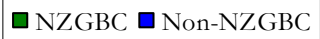

Figure C-89: Overall level of satisfaction with the current information available about green building emerging trends by NZGBC vs. non-NZGBC 


\section{C.2.6.2.4 Green Projects}

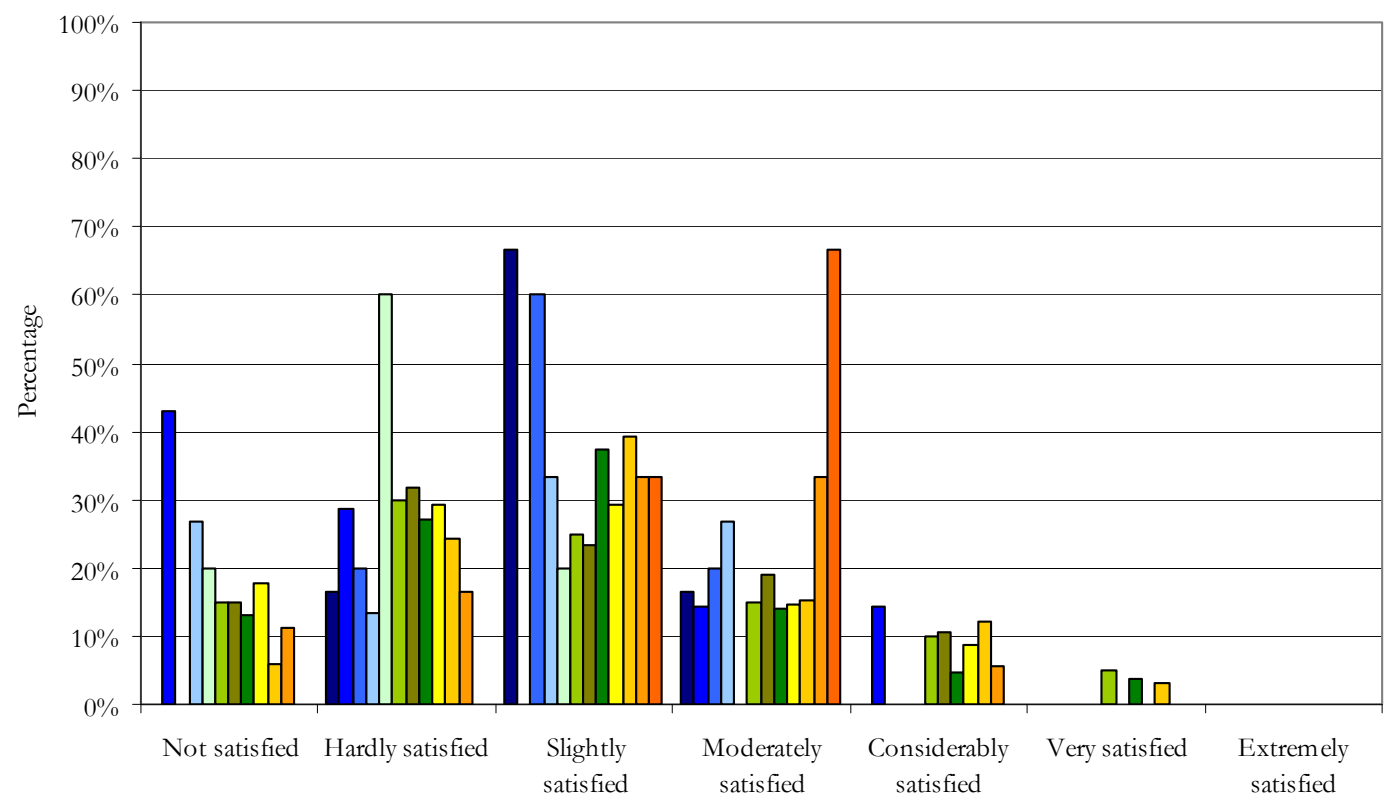

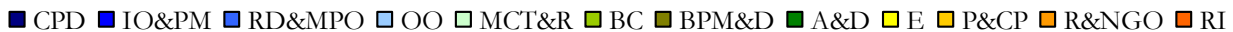

Figure C-90: Overall level of satisfaction with the current information available about green projects by industry sector

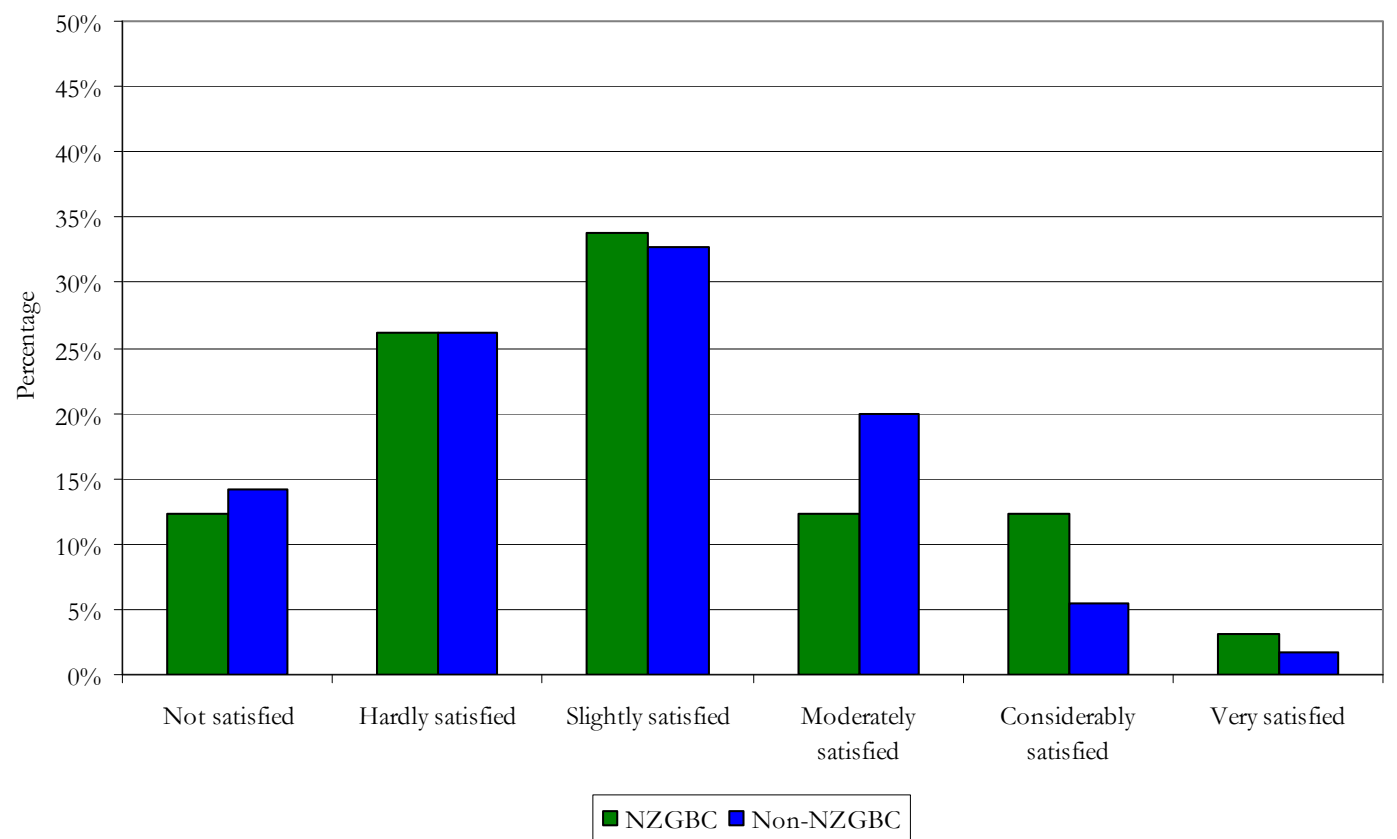

Figure C-91: Overall level of satisfaction with the current information available about green projects NZGBC vs. non-NZGBC 


\section{C.2.6.2.5 How-to Design a Green Building}

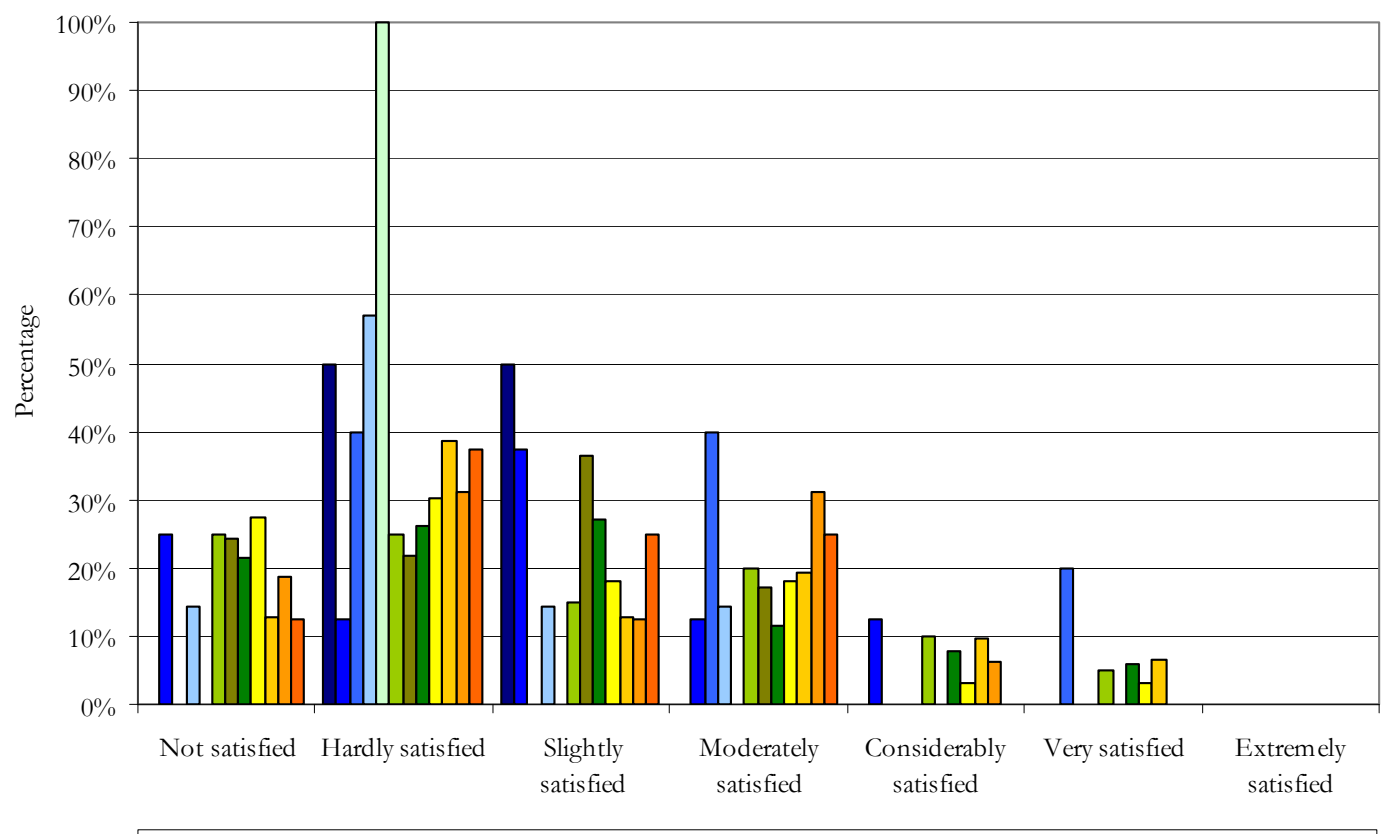

$\square$ CPD $\square$ IO\&PM $\square$ RD\&MPO $\square$ OO $\square$ MCT\&R $\square$ BC $\square$ BPM\&D $\square$ A\&D $\square$ E $\square$ P\&CP $\square$ R\&NGO $\square$ RI

Figure C-92: Overall level of satisfaction with the current information available about how-to design a 'green' building by industry sector

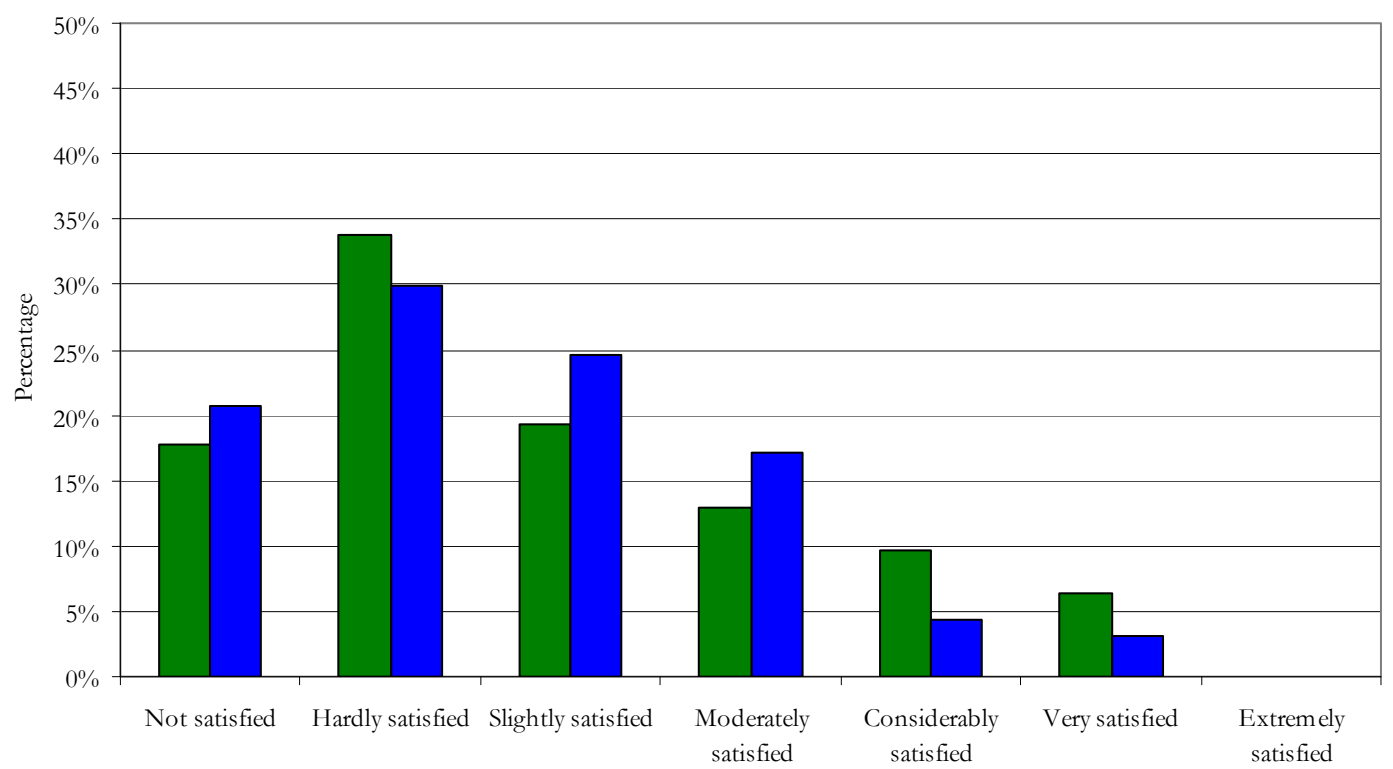

$\square \mathrm{NZGBC} \square$ Non-NZGBC

Figure C-93: Overall level of satisfaction with the current information available about how-to design a 'green' building by NZGBC vs. non-NZGBC 


\section{C.2.6.2.6 Reviews and Profiles of Green Star New Zealand Buildings}

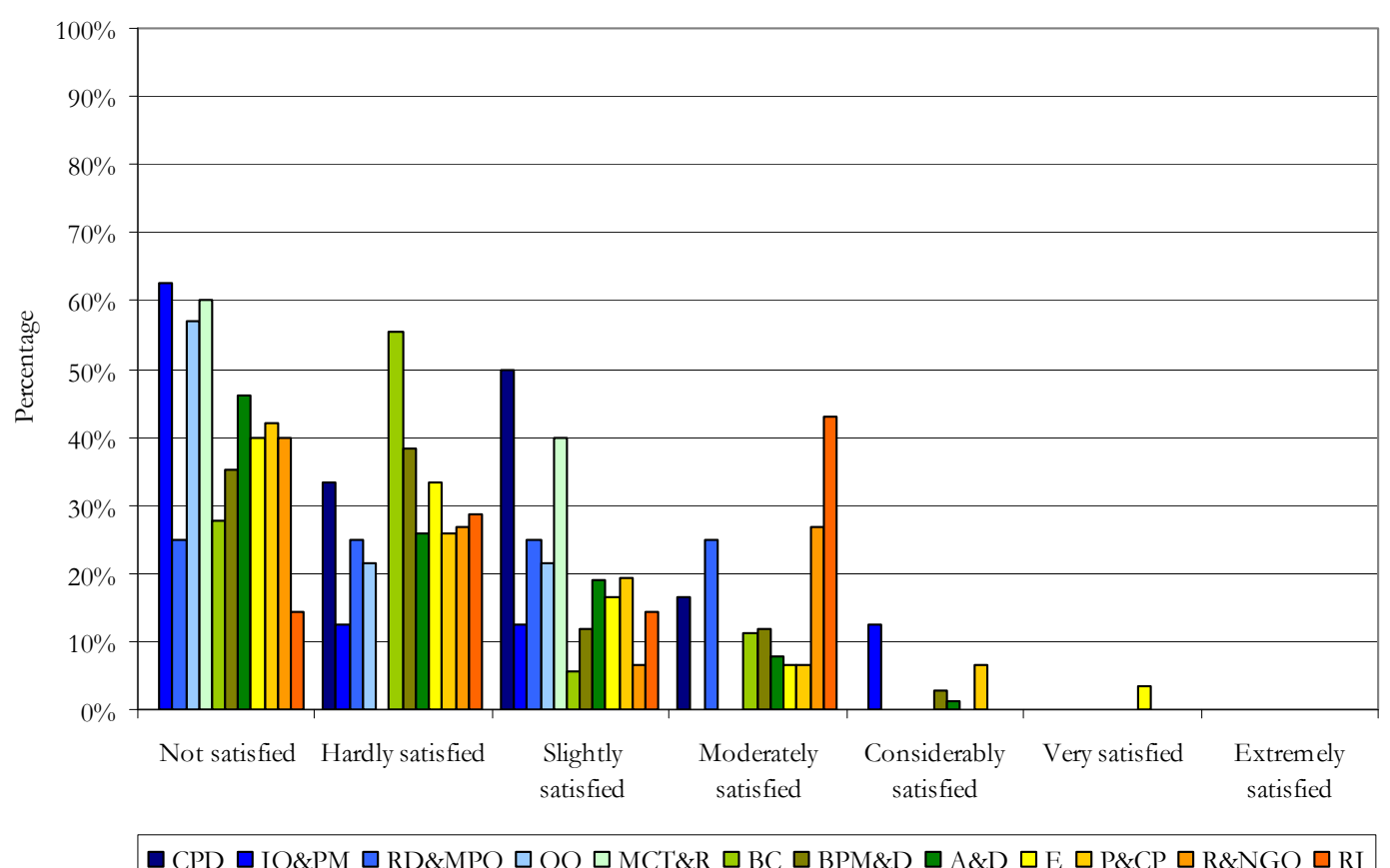

Figure C-94: Overall level of satisfaction with the current information available about reviews and profiles of Green Star NZ buildings by industry sector

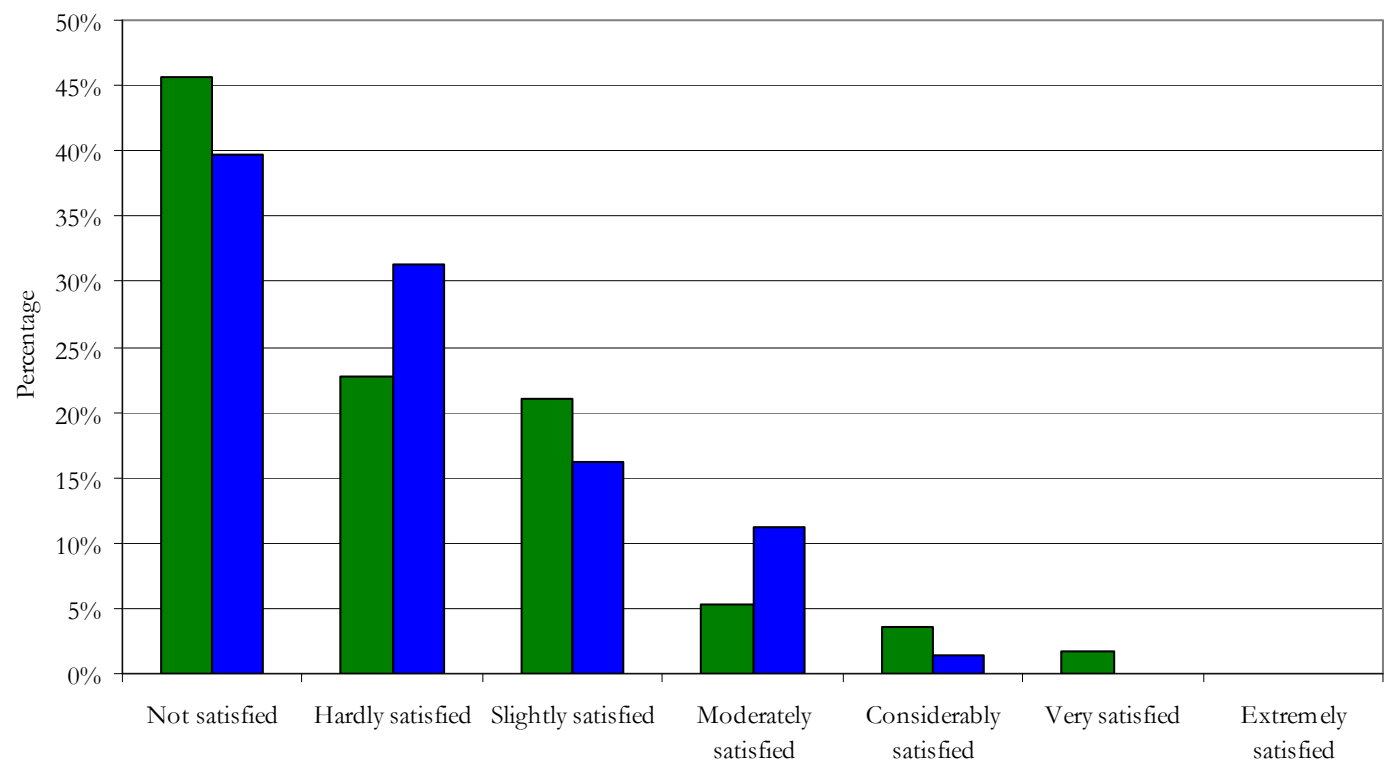

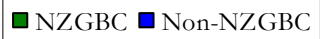

Figure C-95: Overall level of satisfaction with the current information available about reviews and profiles of Green Star NZ buildings by NZGBC vs. non-NZGBC 


\section{C.2.6.2.7 How-to Market a Green Building}

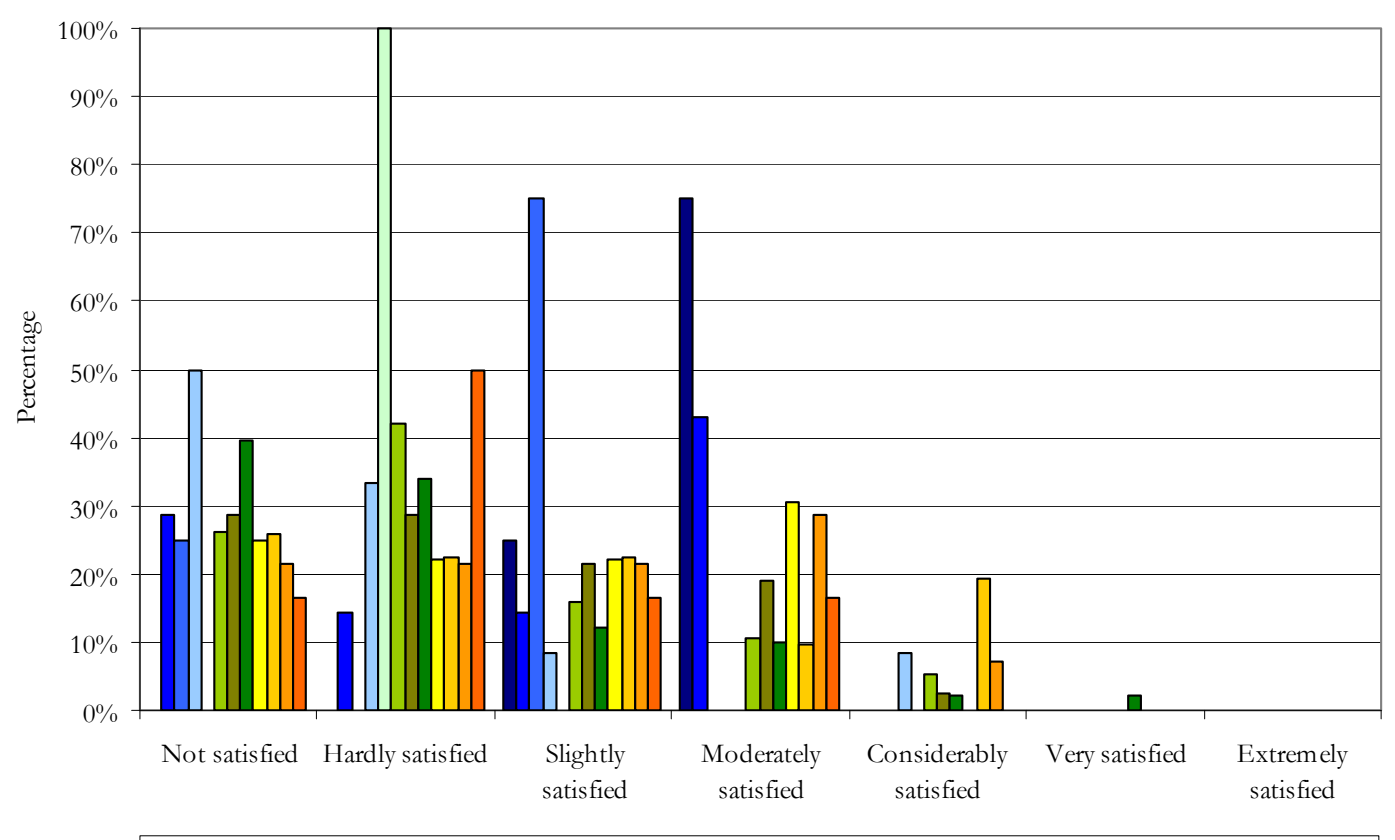

$\square \mathrm{CPD} \square \mathrm{IO \& PM} \square \mathrm{RD \& MPO} \square \mathrm{OO} \square \mathrm{MCT \& R} \square \mathrm{BC} \square \mathrm{BPM} \& \mathrm{D} \square \mathrm{A} \& \mathrm{D} \square \mathrm{E} \square \mathrm{P \& CP} \square \mathrm{R} \& \mathrm{NGO} \square \mathrm{RI}$

Figure C-96: Overall level of satisfaction with the current information available about how-to market a 'green' building by industry sector

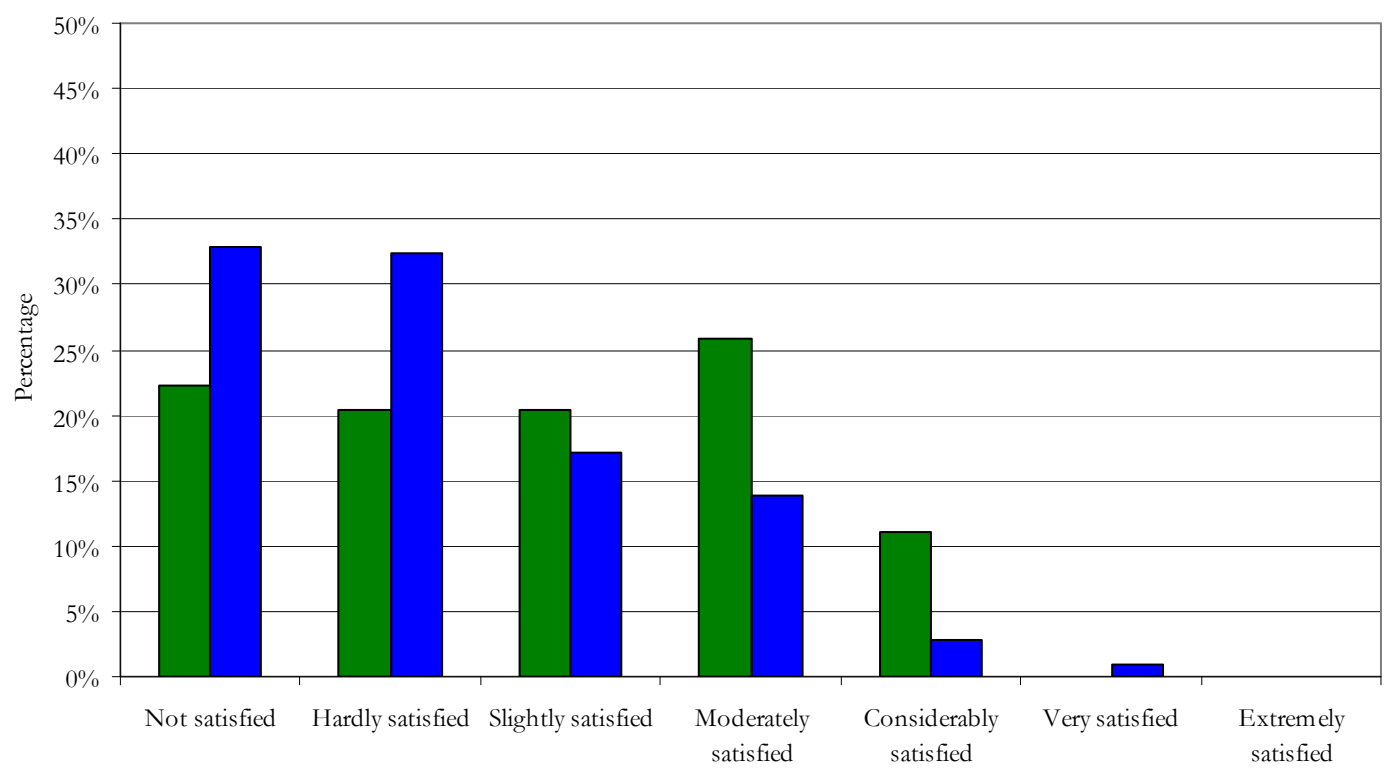

$\square \mathrm{NZGBC} \square$ Non-NZGBC

Figure C-97: Overall level of satisfaction with the current information available about how-to market a 'green' building by NZGBC vs. non-NZGBC 


\section{C.2.6.2.8 Engineering or Scientific Information}

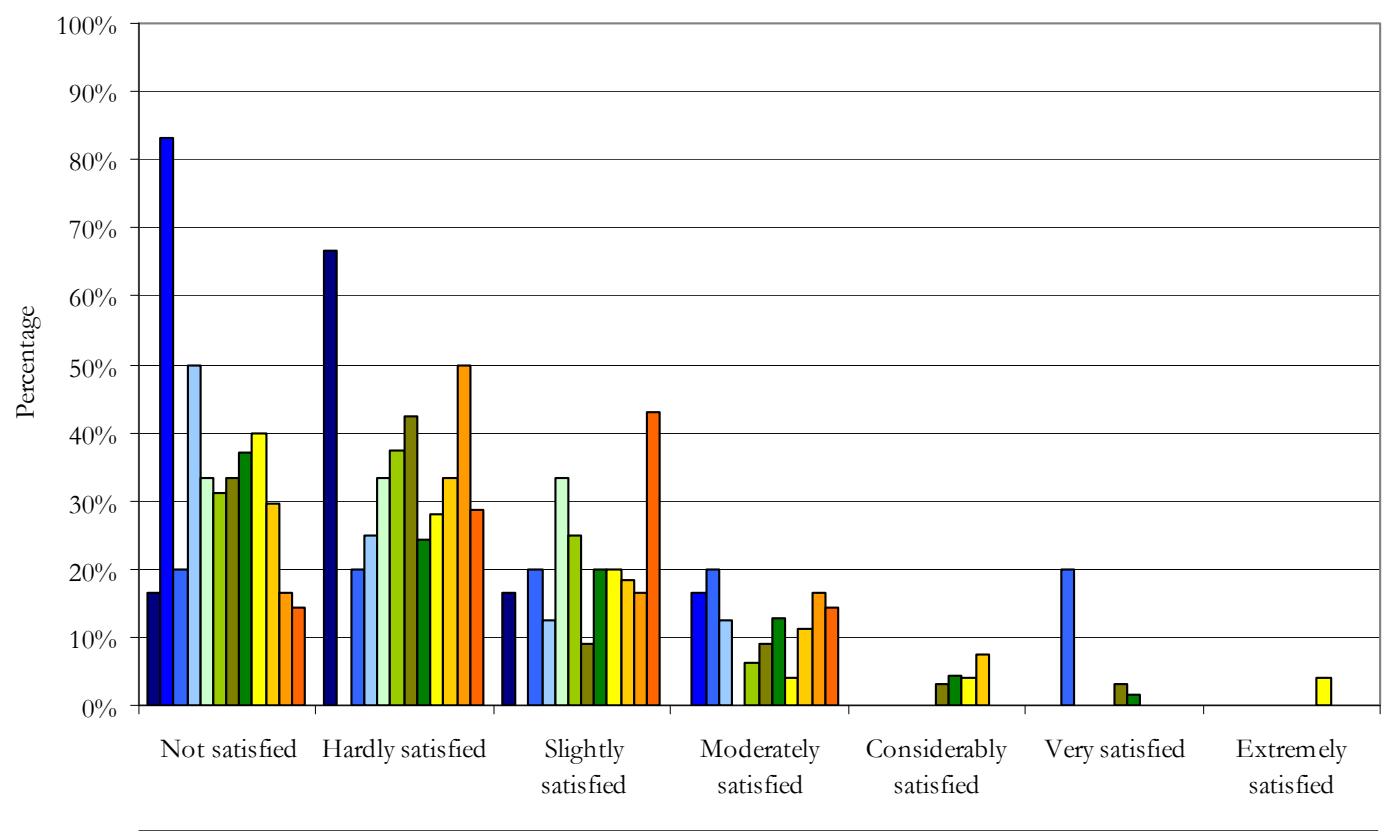

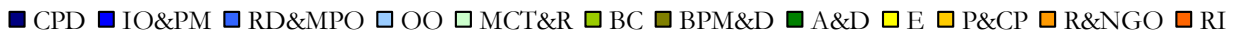

Figure C-98: Overall level of satisfaction with the current information available about engineering or scientific information by industry sector

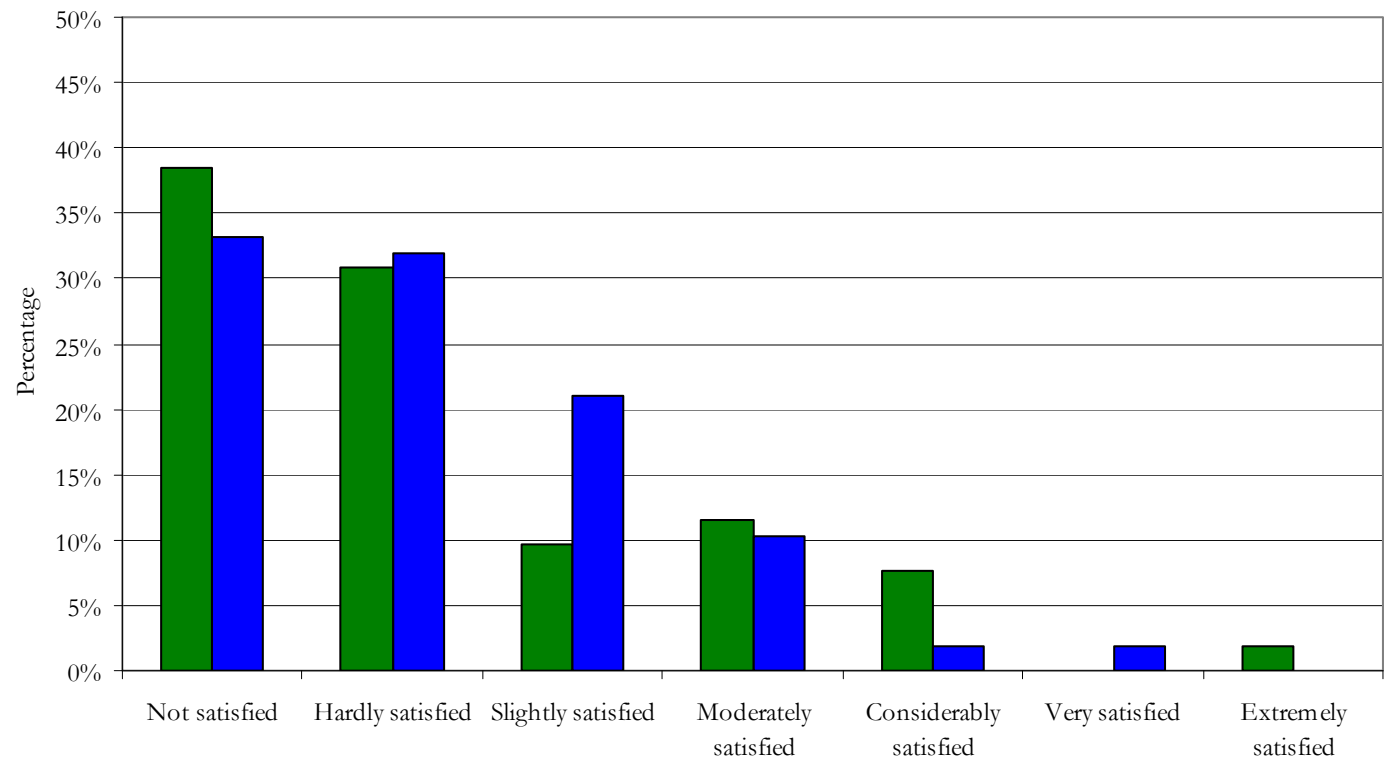

$\square$ NZGBC $\square$ Non-NZGBC

Figure C-99: Overall level of satisfaction with the current information available about engineering or scientific information by NZGBZ vs. non-NZGBC 


\section{C.2.6.2.9 Green Star New Zealand Accreditation Course}

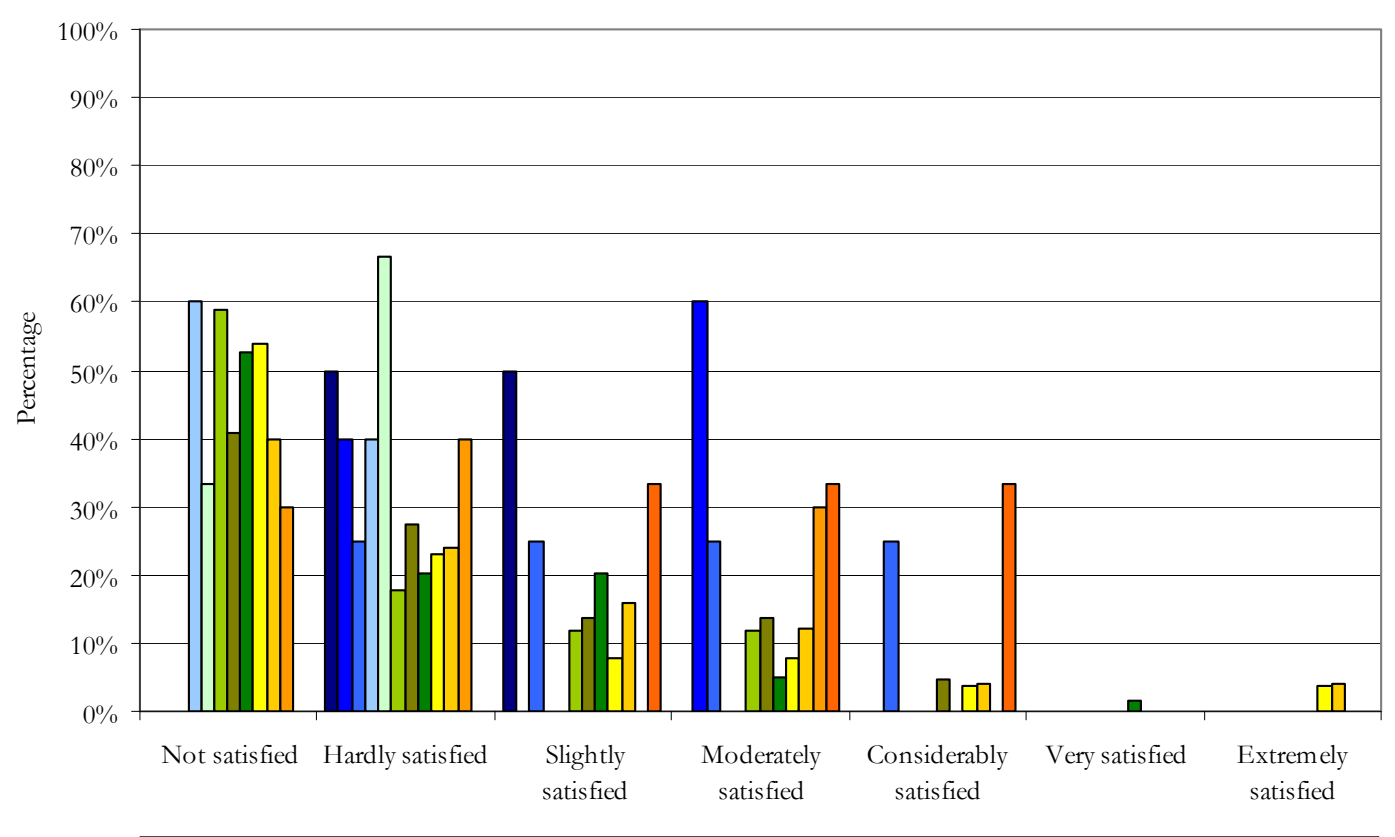

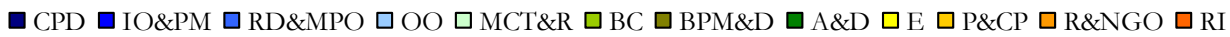

Figure C-100: Overall level of satisfaction with the current information available about Green Star NZ accreditation course by industry sector

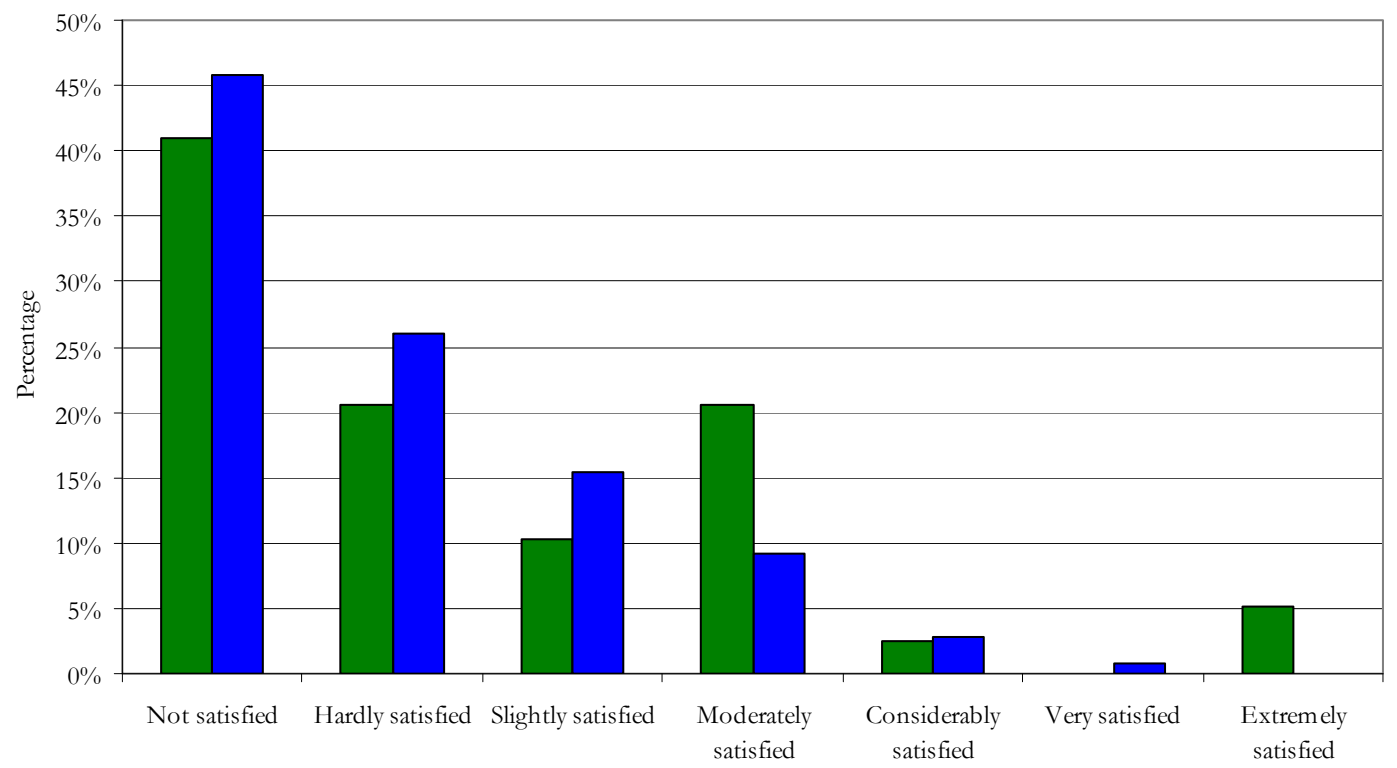

$\square$ NZGBC $\square$ Non-NZGBC

Figure C-101: Overall level of satisfaction with the current information available about Green Star NZ accreditation course by NZGBC vs. non-NZGBC 


\section{C.2.6.2.10 How-to Manage a Green Building}

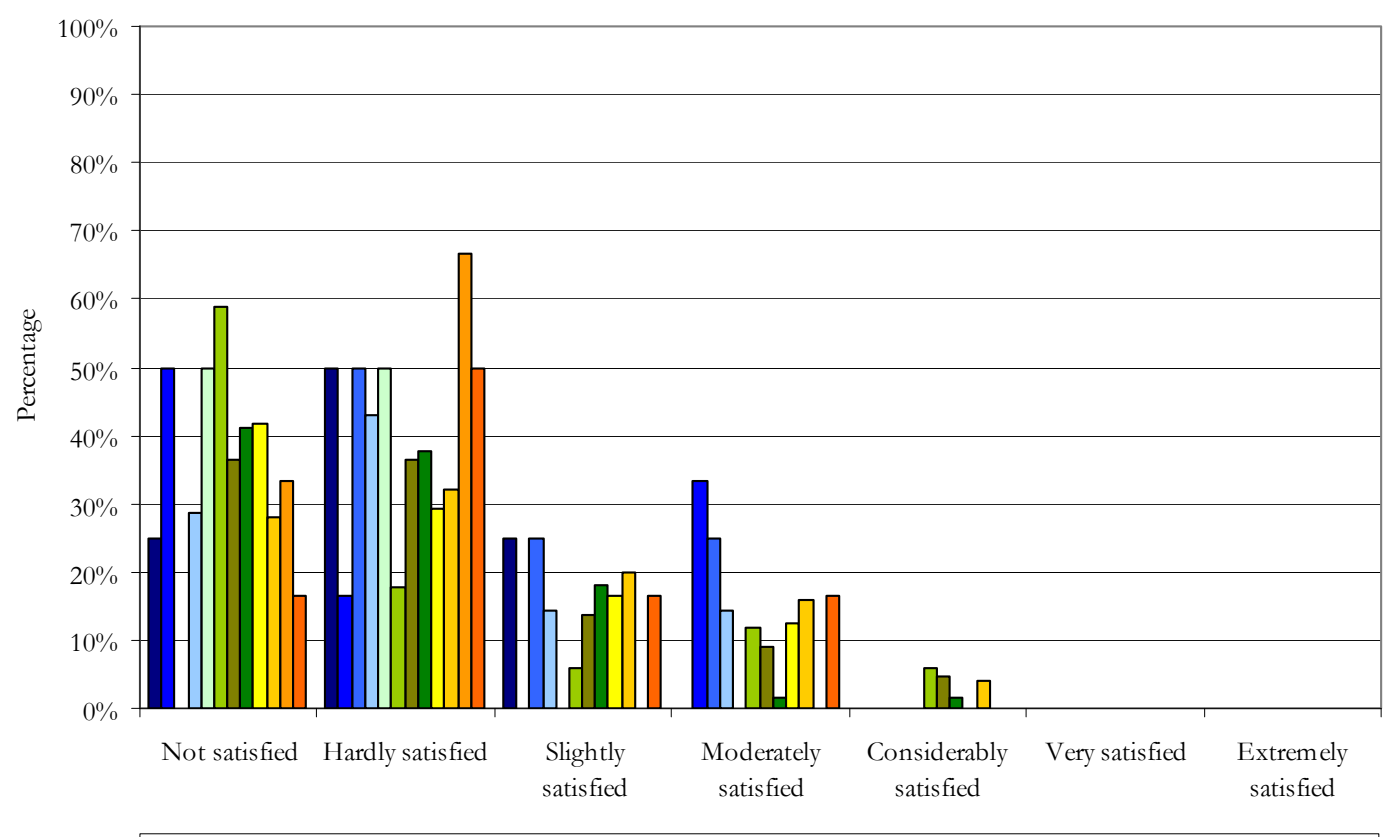

$\square \mathrm{CPD} \square \mathrm{IO \& PM} \square \mathrm{RD \& MPO} \square \mathrm{OO} \square \mathrm{MCT \& R} \square \mathrm{BC} \square \mathrm{BPM} \& \mathrm{D} \square \mathrm{A} \& \mathrm{D} \square \square \mathrm{P} \& \mathrm{CP} \square \mathrm{R} \& \mathrm{NGO} \square \mathrm{RI}$

Figure C-102: Overall level of satisfaction with the current information available about how-to manage a 'green' building by industry sector

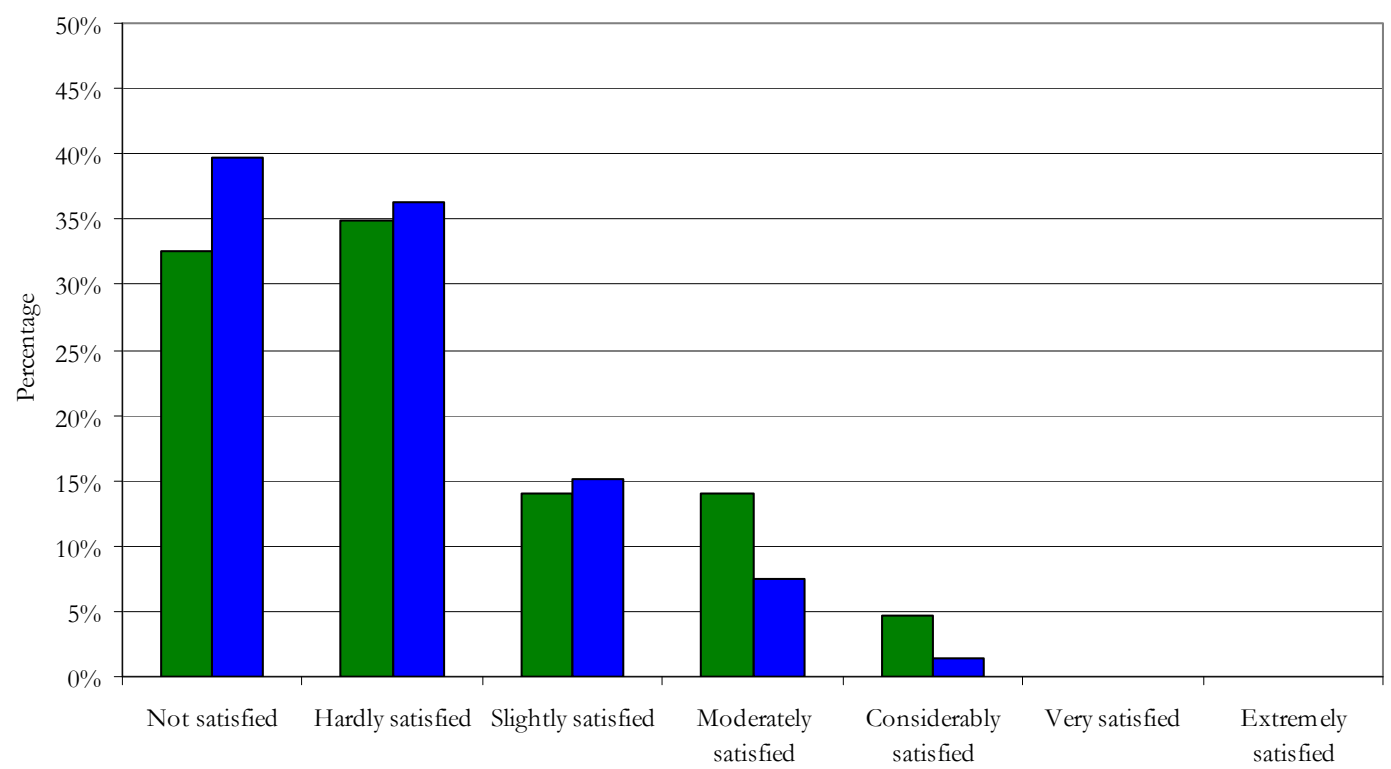

$\square$ NZGBC $\square$ Non-NZGBC

Figure C-103: Overall level of satisfaction with the current information available about how-to manage a 'green' building by NZGBC vs. non-NZGBC 


\section{C.2.6.2.11 Green Players}

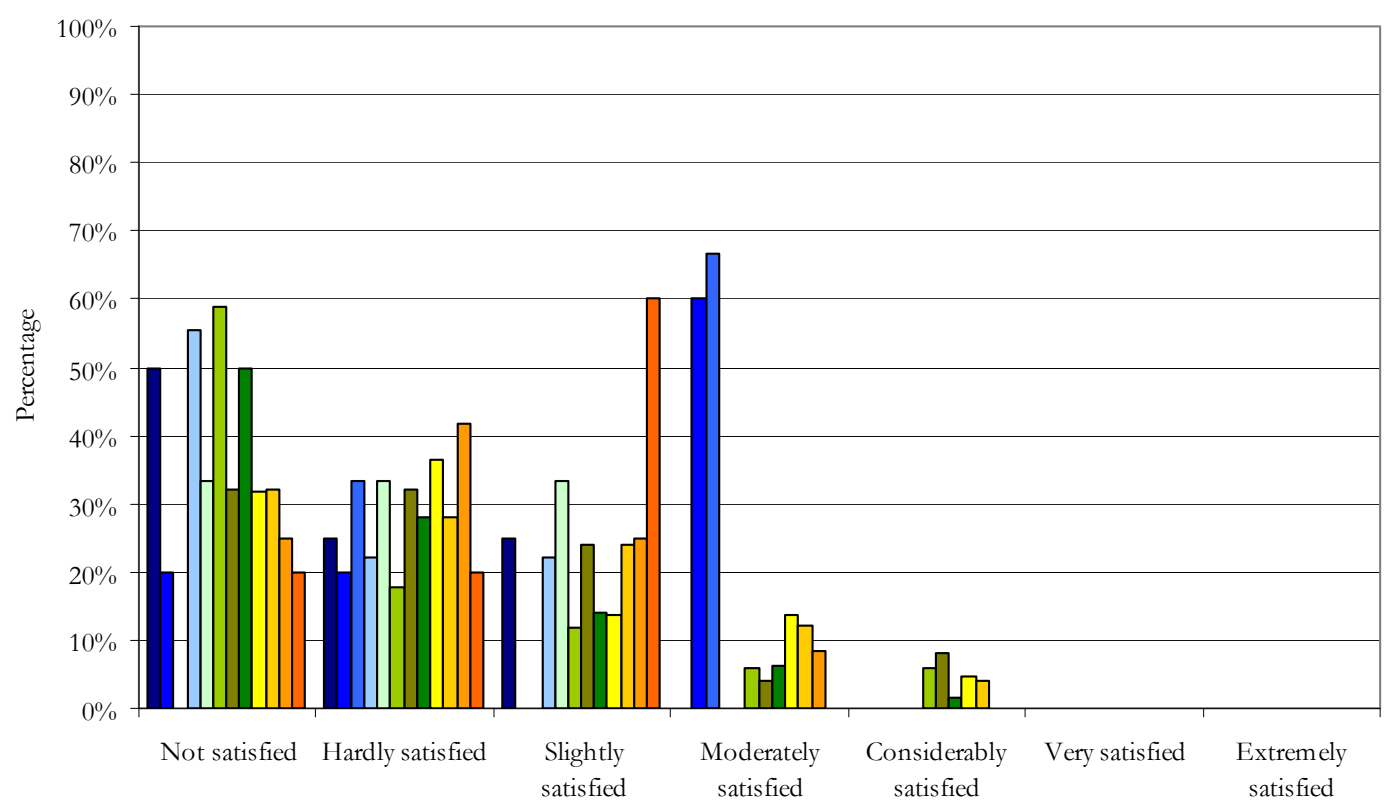

$\square$ CPD $\square$ IO\&PM $\square$ RD\&MPO $\square$ OO $\square$ MCT\&R $\square$ BC $\square$ BPM\&D $\square$ A\&D $\square$ E $\square$ P\&CP $\square$ R\&NGO $\square$ RI

Figure C-104: Overall level of satisfaction with the current information available about green players by industry sector

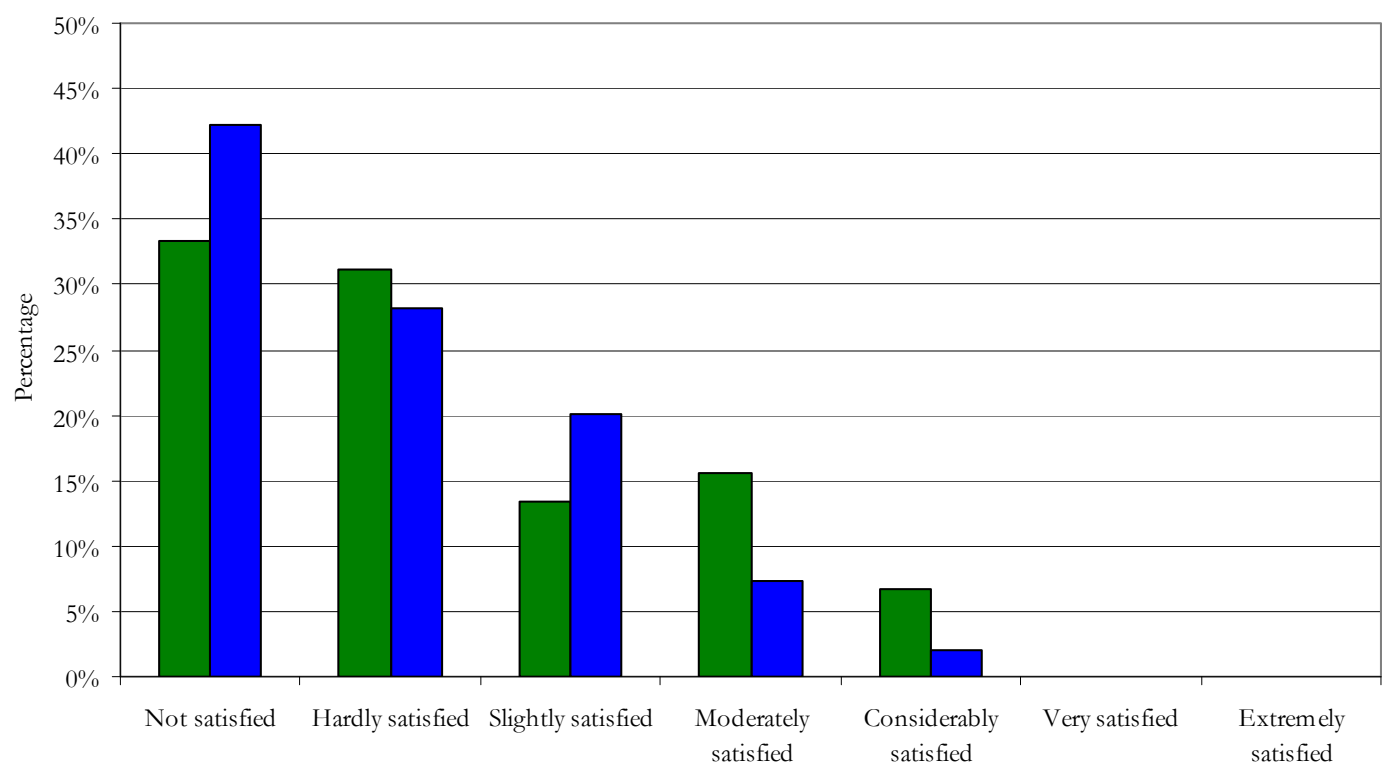

$\square$ NZGBC $\square$ Non-NZGBC

Figure C-105: Overall level of satisfaction with the current information available about green players NZGBC vs. non-NZGBC 


\section{C.2.6.2.12 Green Star New Zealand Players}

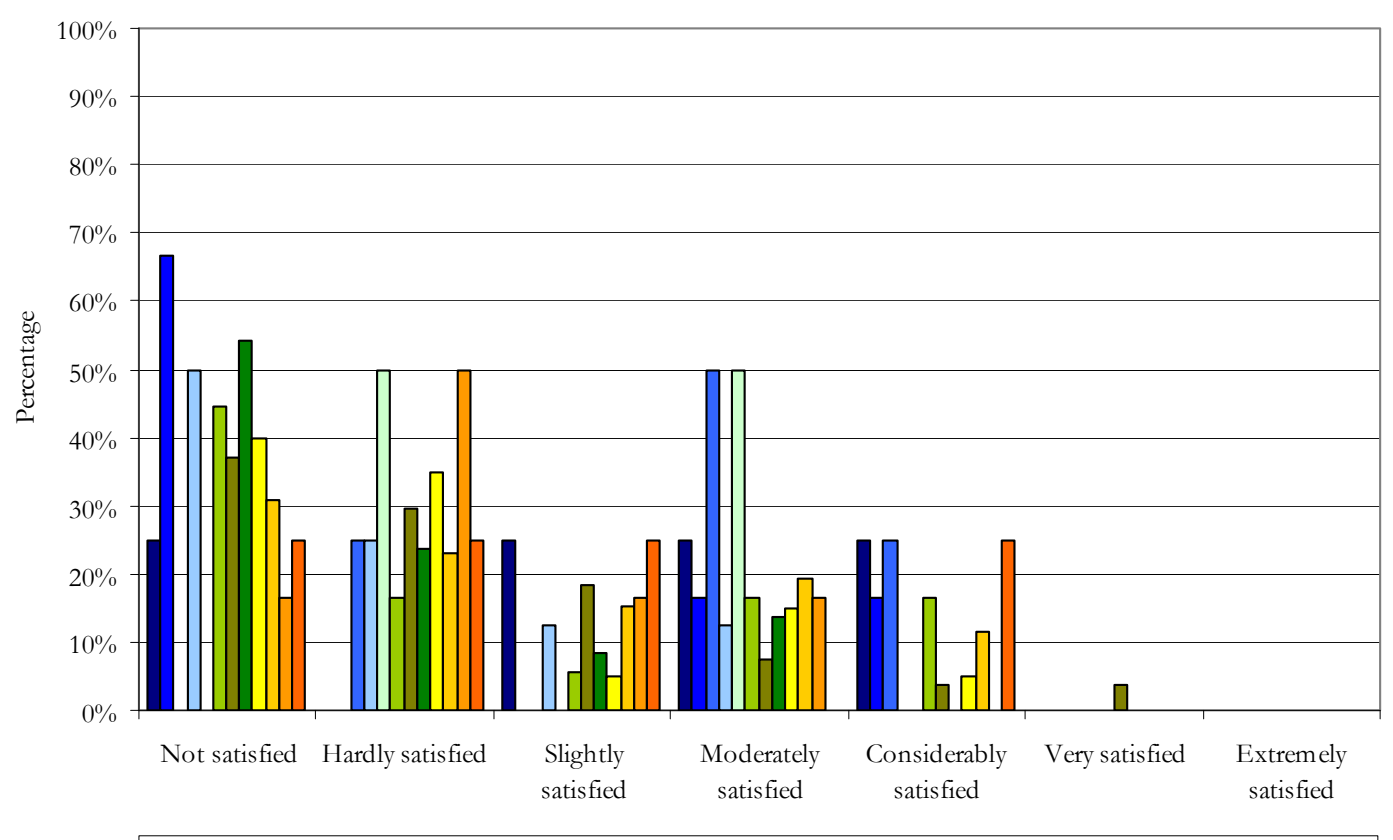

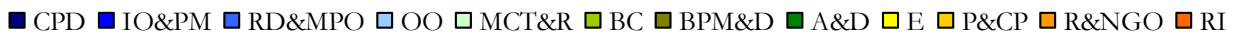

Figure C-106: Overall level of satisfaction with the current information available about Green Star NZ players by industry sector

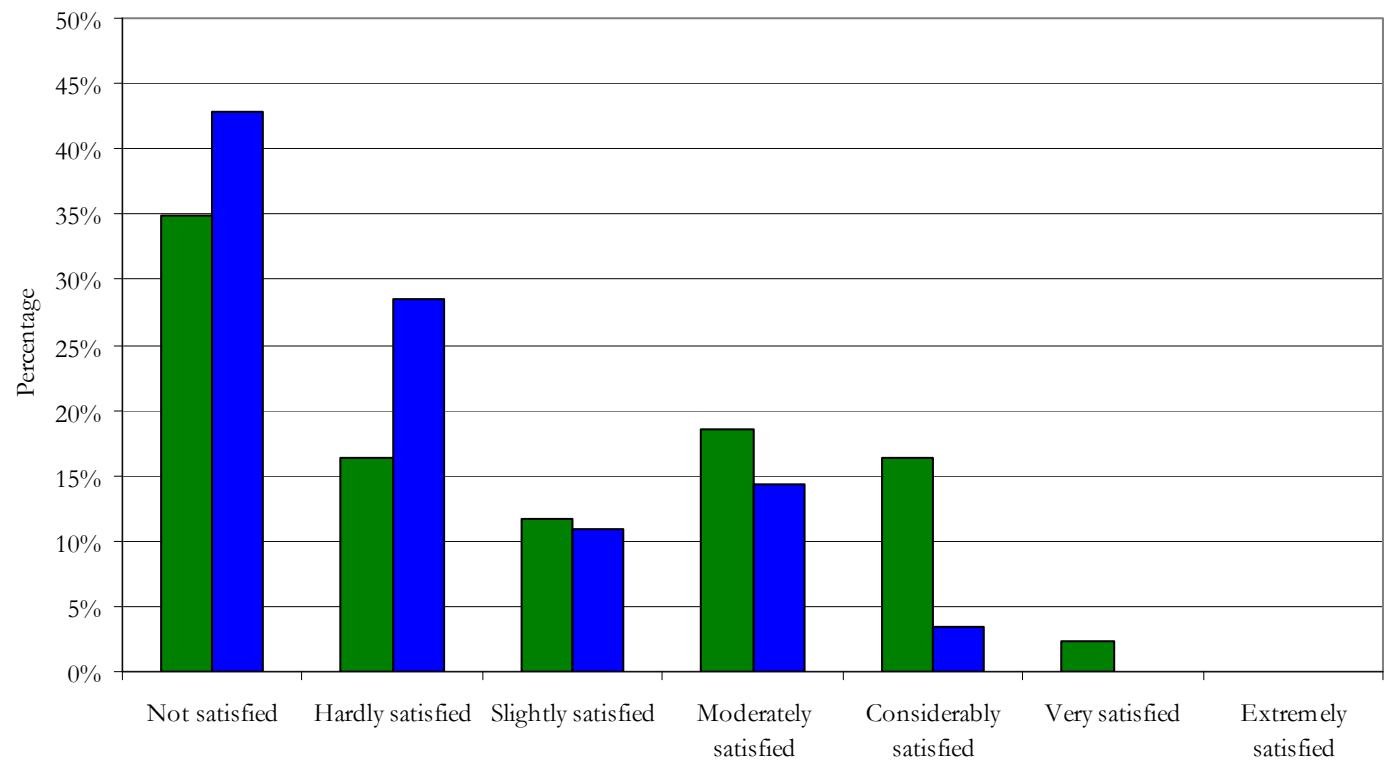

$\square$ NZGBC $\square$ Non-NZGBC

Figure C-107: Overall level of satisfaction with the current information available about Green Star NZ players by NZGBC vs. non-NZGBC 


\section{C.2.6.2.13 Business Management Information}

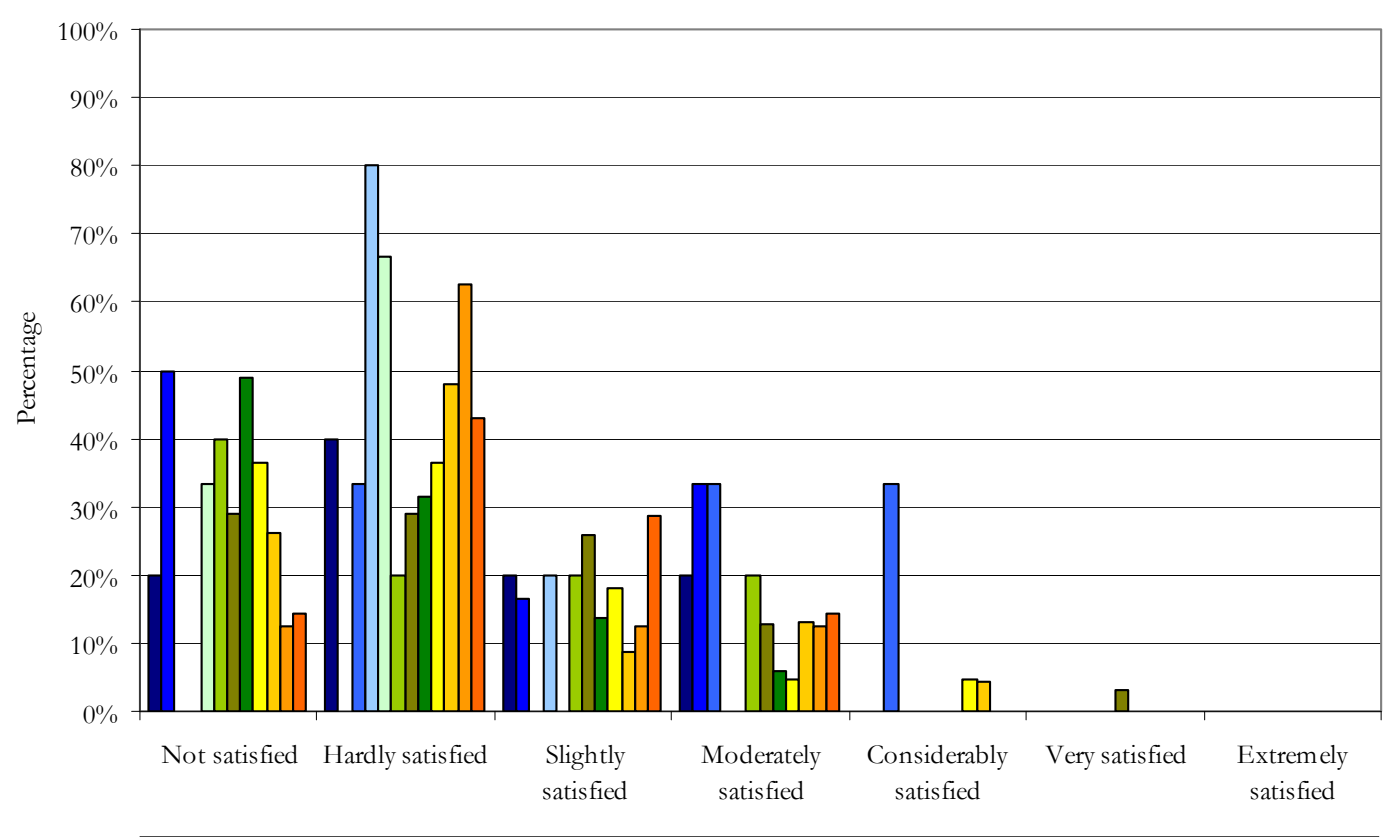

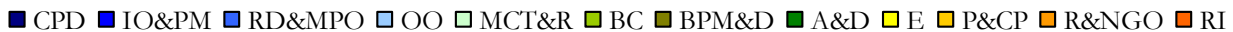

Figure C-108: Overall level of satisfaction with the current information available about business management information by industry sector

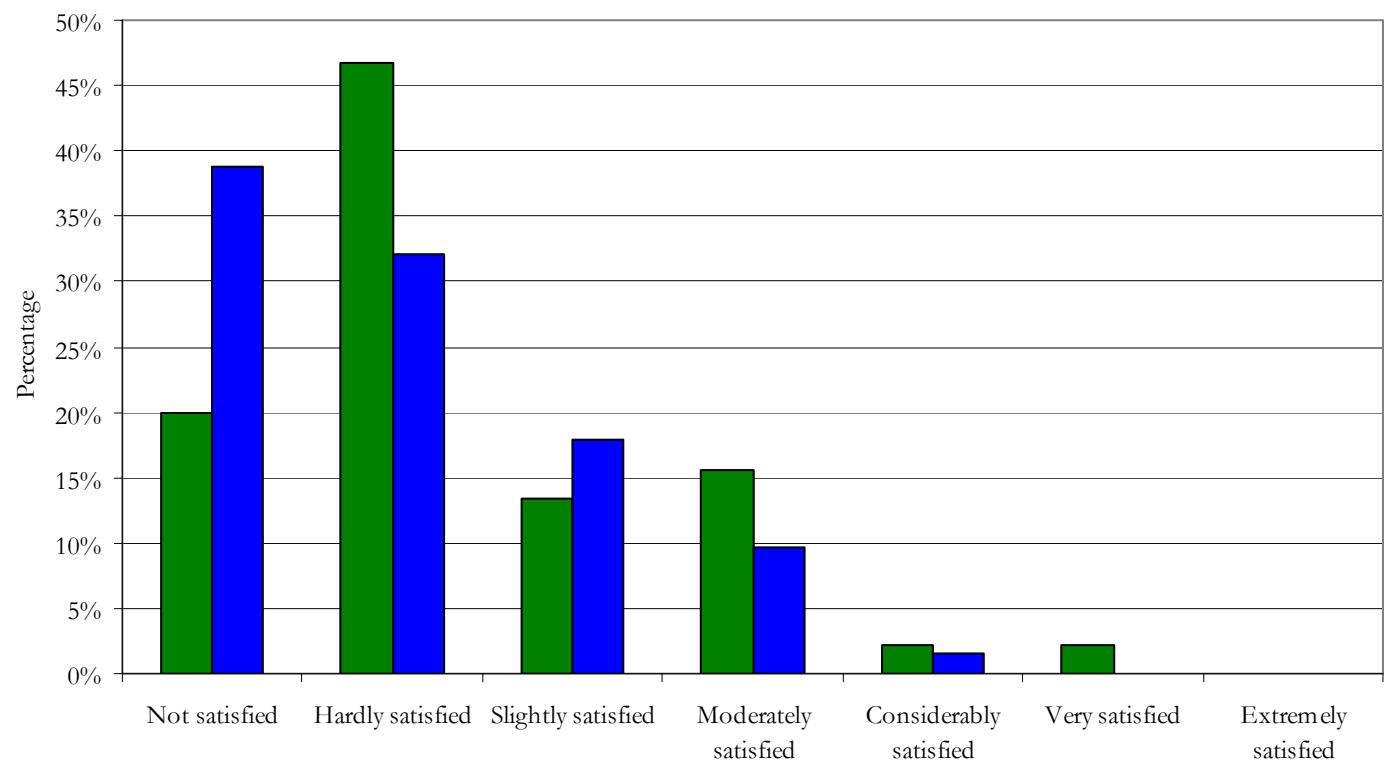

$\square$ NZGBC $\square$ Non-NZGBC

Figure C-109: Overall level of satisfaction with the current information available about business management by NZGBC vs. non-NZGBC 


\section{C.2.6.2.14 Curriculum for Senior Executives}

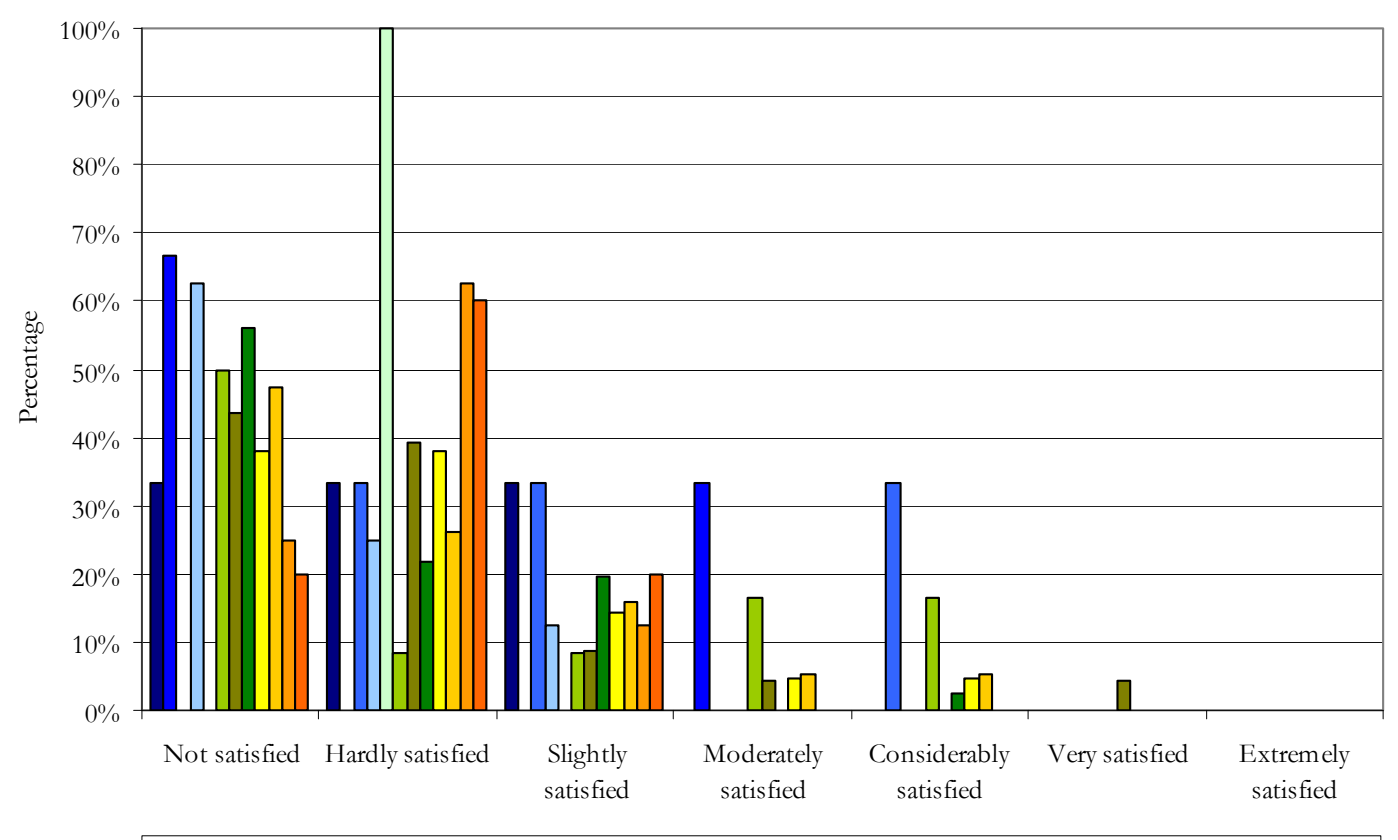

• CPD $\square$ IO\&PM $\square$ RD\&MPO $\square$ OO $\square$ MCT\&R $\square$ BC $\square$ BPM\&D $\square$ A\&D $\square$ E P\&CP $\square$ R\&NGO $\square$ RI

Figure C-110: Overall level of satisfaction with the current information available about curriculum for senior executives by industry sector

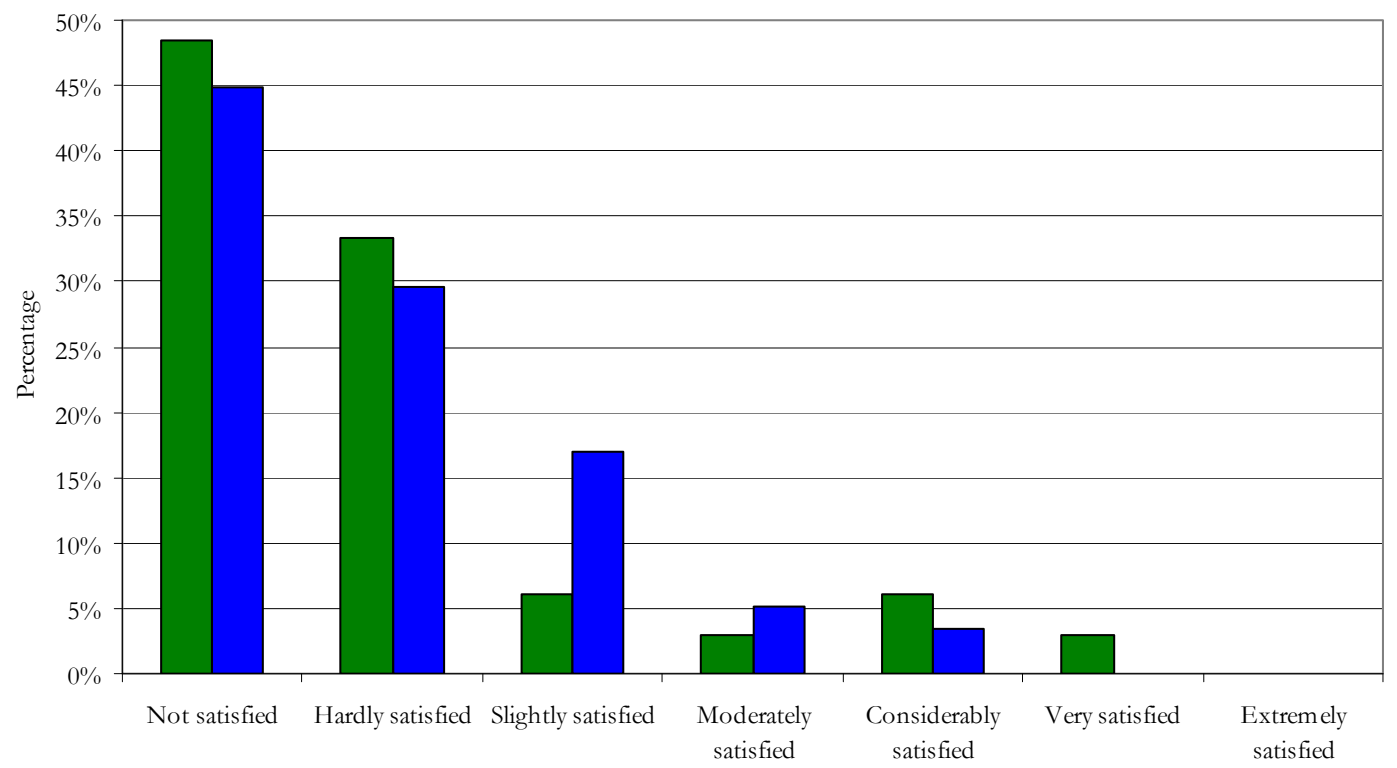

$\square \mathrm{NZGBC} \square$ Non-NZGBC

Figure C-111: Overall level of satisfaction with the current information available about curriculum for senior executives by NZGBC vs. non-NZGBC 


\section{C.2.6.2.15 Curriculum for Line Staff}

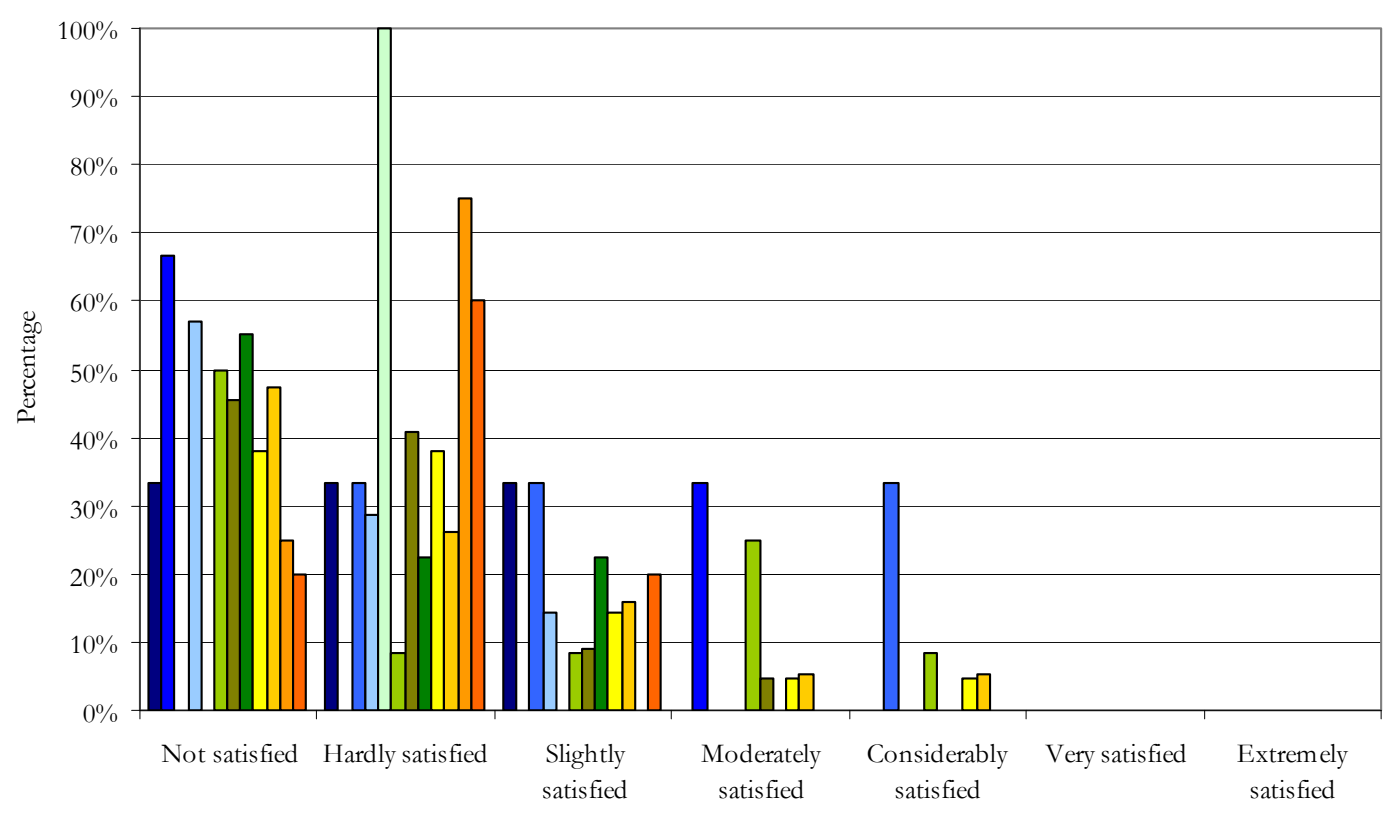

ⒸPD $\square$ IO\&PM $\square$ RD\&MPO $\square$ OO $\square$ MCT\&R $\square$ BC $\square$ BPM\&D $\square$ A\&D $\square$ E P\&CP $\square$ R\&NGO $\square$ RI

Figure C-112: Overall level of satisfaction with the current information available about curriculum for line staff by industry sector

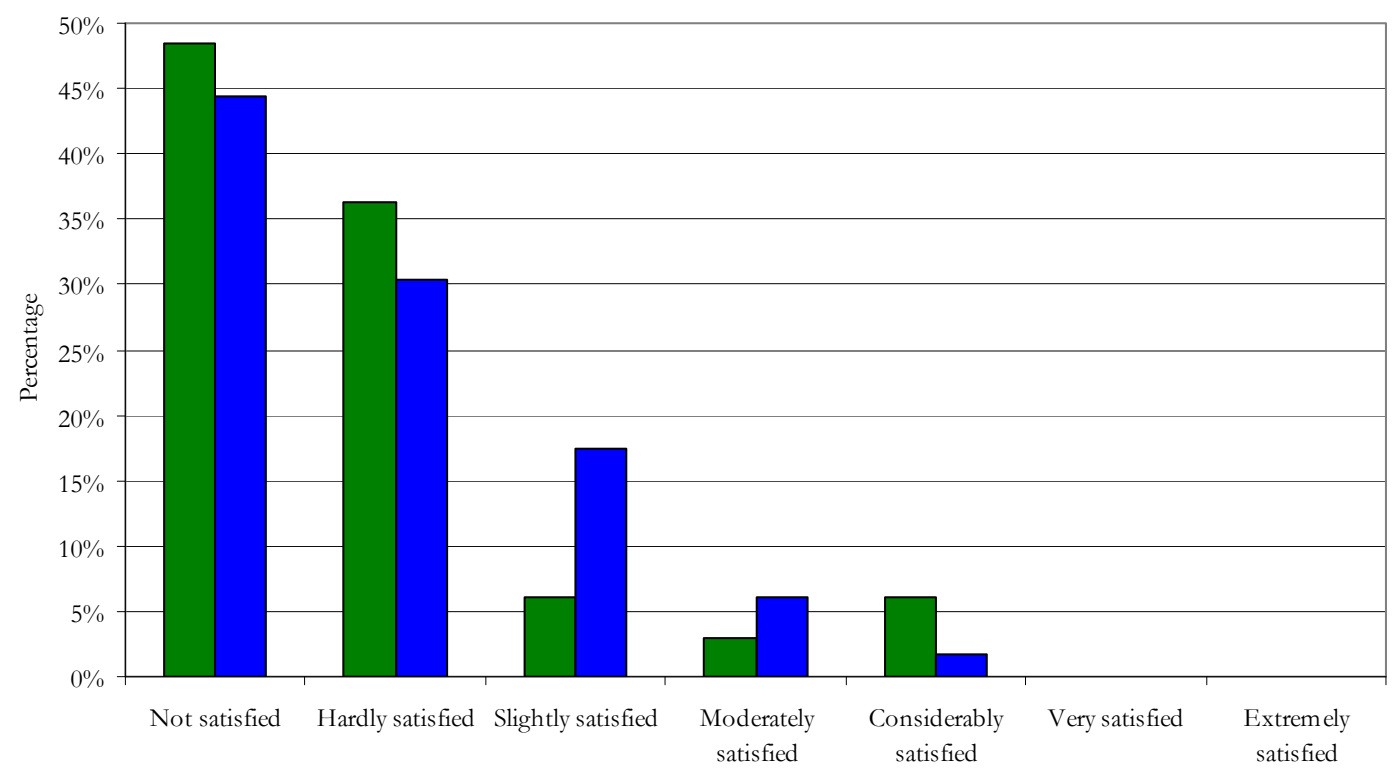

$\square$ NZGBC $\square$ Non-NZGBC

Figure C-113: Overall level of satisfaction with the current information available about curriculum for line staff by NZGBC vs. non-NZGBC 
Appendix C

\section{C.3 Collated Data}

For Appendix C.3 please contact the author. 
Appendix C 


\section{Appendix D: Comparative Analyses and Results}

\section{D.1 International Comparison}

\section{D.1.1 Trigger Stage for Sustainable Building}

Table D-1: Definition of answer choices to reasons to when sustainable is most likely triggered (in order asked in New Zealand survey)

\begin{tabular}{|l|l|}
\hline Option & Definition \\
\hline Option A & I don't know \\
\hline Option B & Preliminary inquiries \\
\hline Option C & Pre-design \\
\hline Option D & Design development \\
\hline Option E & Construction development process \\
\hline Option F & Commissioning \\
\hline Option G & Construction \\
\hline
\end{tabular}

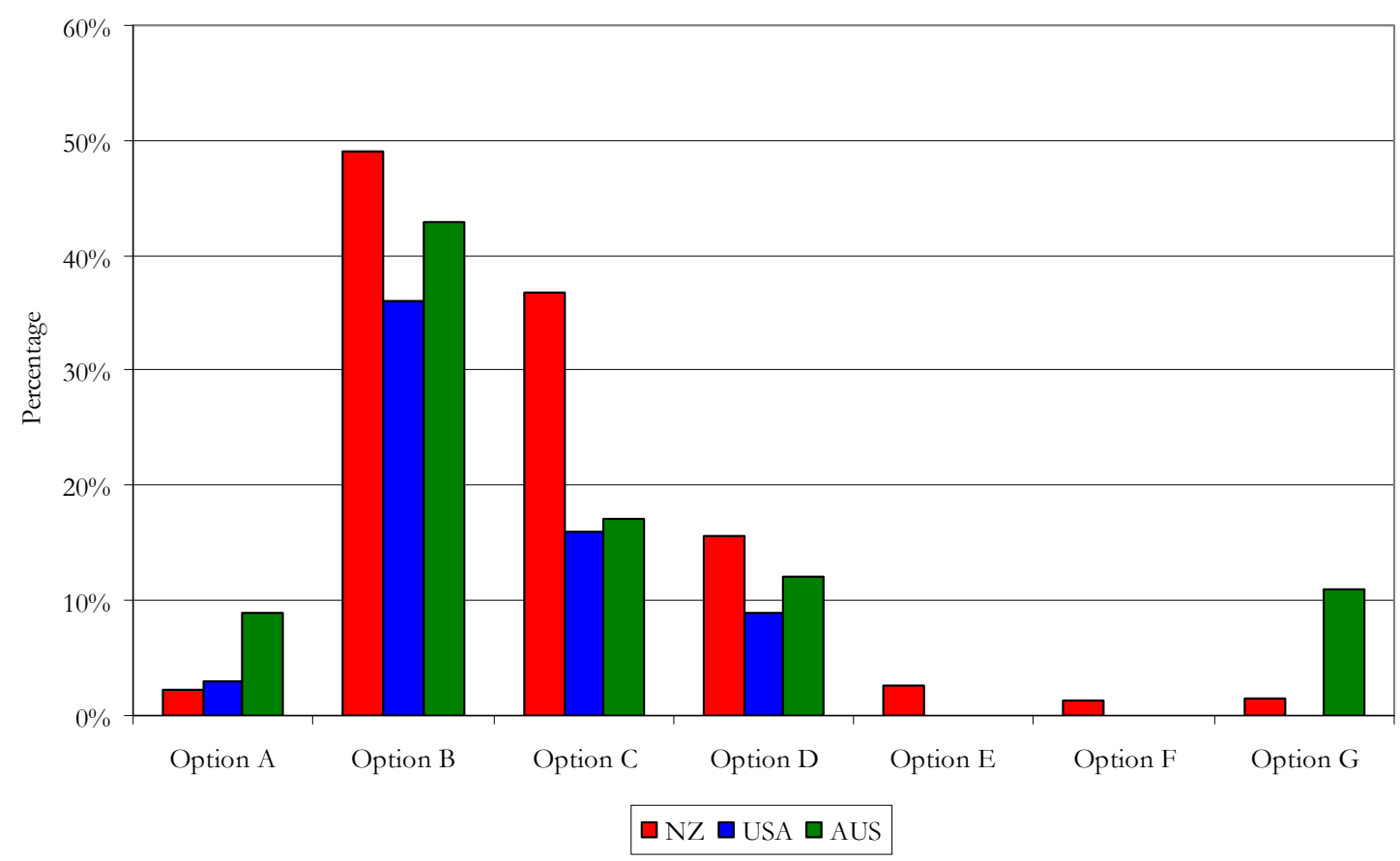

Figure D-1: Overall international comparison of when sustainable building is most likely triggered (in order of highest to lowest in New Zealand) 


\section{D.1.1.1 United States Results}

Table D-2: Definition of answer choices to reasons to when sustainable is most likely triggered in the United States

\begin{tabular}{|l|l|}
\hline Option & Definition \\
\hline Option A & I don't know \\
\hline Option B & Client request \\
\hline Option C & Design team recommendation \\
\hline Option D & Program development \\
\hline Option E & Conceptual Design \\
\hline Option F & Design development \\
\hline Option G & Production of construction documents \\
\hline
\end{tabular}

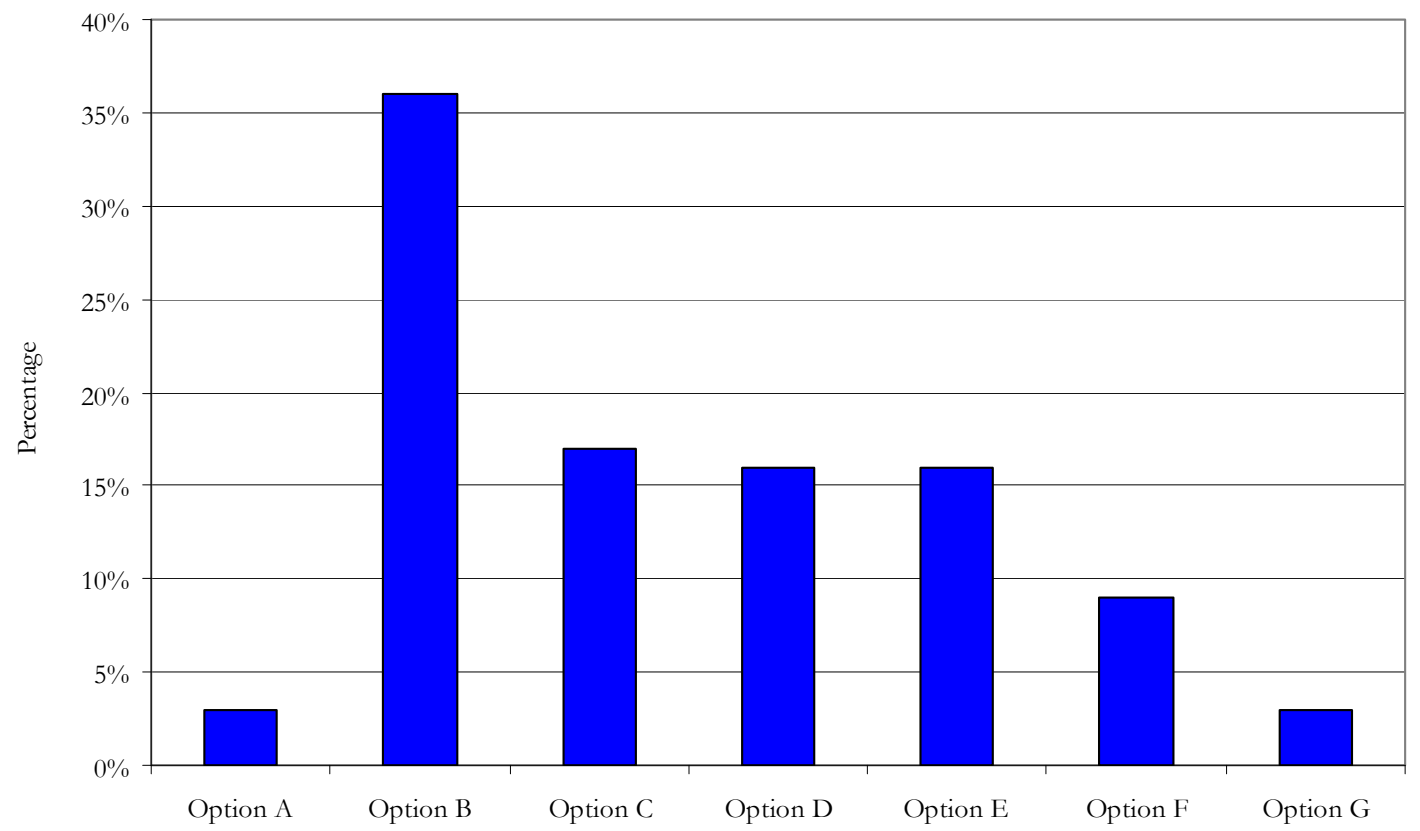

Figure D-2: When sustainable building is most likely triggered in the United States 


\section{D.1.1.2 Australian Results}

Table D-3: Definition of answer choices to reasons to when sustainable is most likely triggered in Australia

\begin{tabular}{|l|l|}
\hline Option & Definition \\
\hline Option A & Client briefing \\
\hline Option B & Conceptual design \\
\hline Option C & Design development \\
\hline Option D & Construction \\
\hline Option E & I don't know \\
\hline Option F & Design team recommendation \\
\hline Option G & Program development \\
\hline Option H & Production of construction documents \\
\hline
\end{tabular}

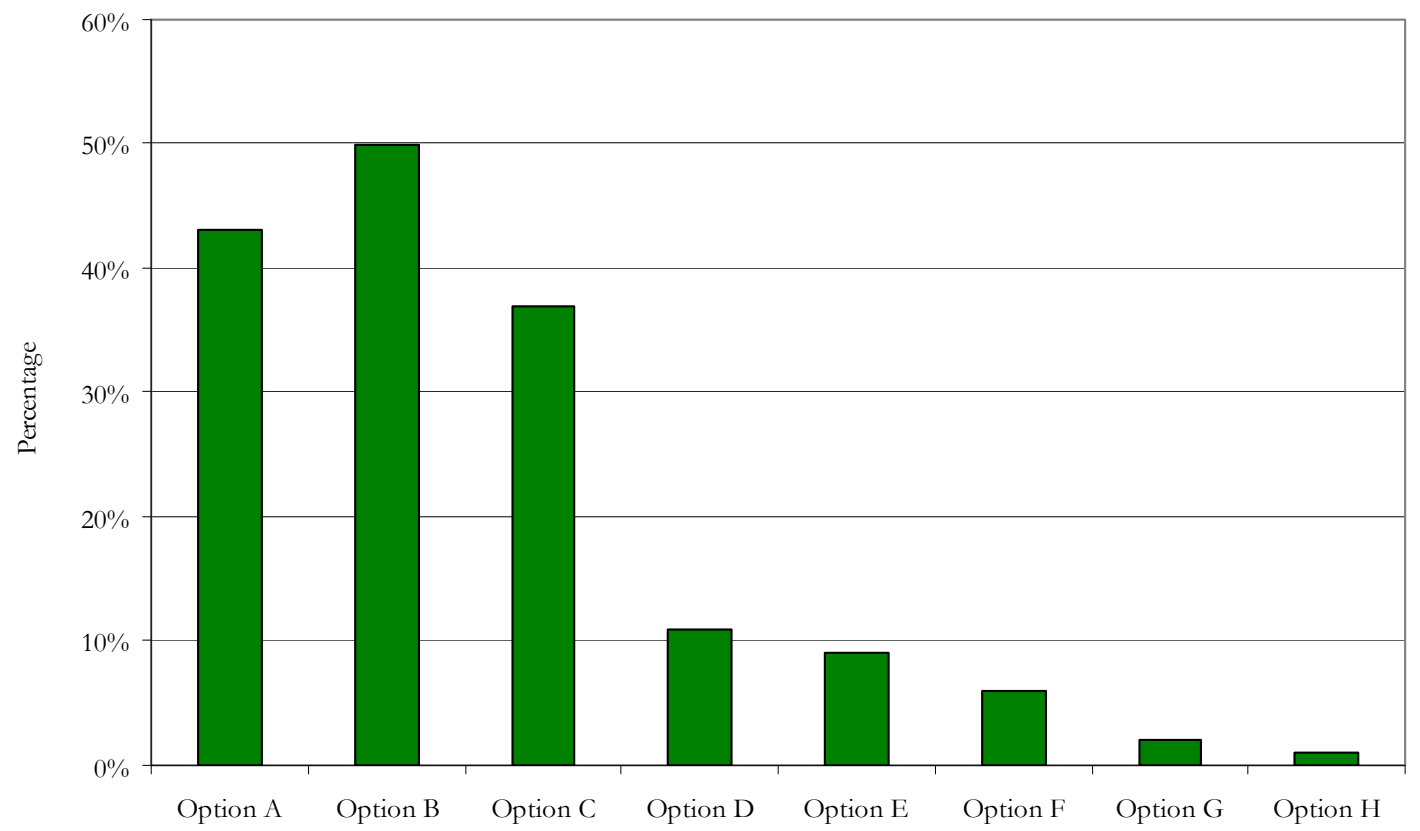

Figure D-3: When sustainable building is most likely triggered in Australia 


\section{D.1.2 Drivers for Sustainable Building}

Table D-4: Definition of answer choices to drivers for sustainable building (in order asked in New Zealand survey)

\begin{tabular}{|l|l|}
\hline Option & Definition \\
\hline Option A & Rising energy costs \\
\hline Option B & Government regulation \\
\hline Option C & Lower life-cycle costs \\
\hline Option D & Client demand \\
\hline Option E & Independent rating system \\
\hline Option F & Government rating systems \\
\hline Option G & Competitive advantage \\
\hline Option H & Superior performance \\
\hline Option I & Increased education \\
\hline Option J & Environmental conditions \\
\hline Option K & Attraction and retention of staff \\
\hline Option L & Increased emphasis on productivity \\
\hline Option M & International trends show it is smart business \\
\hline Option N & Disruptive/enabling technology \\
\hline
\end{tabular}

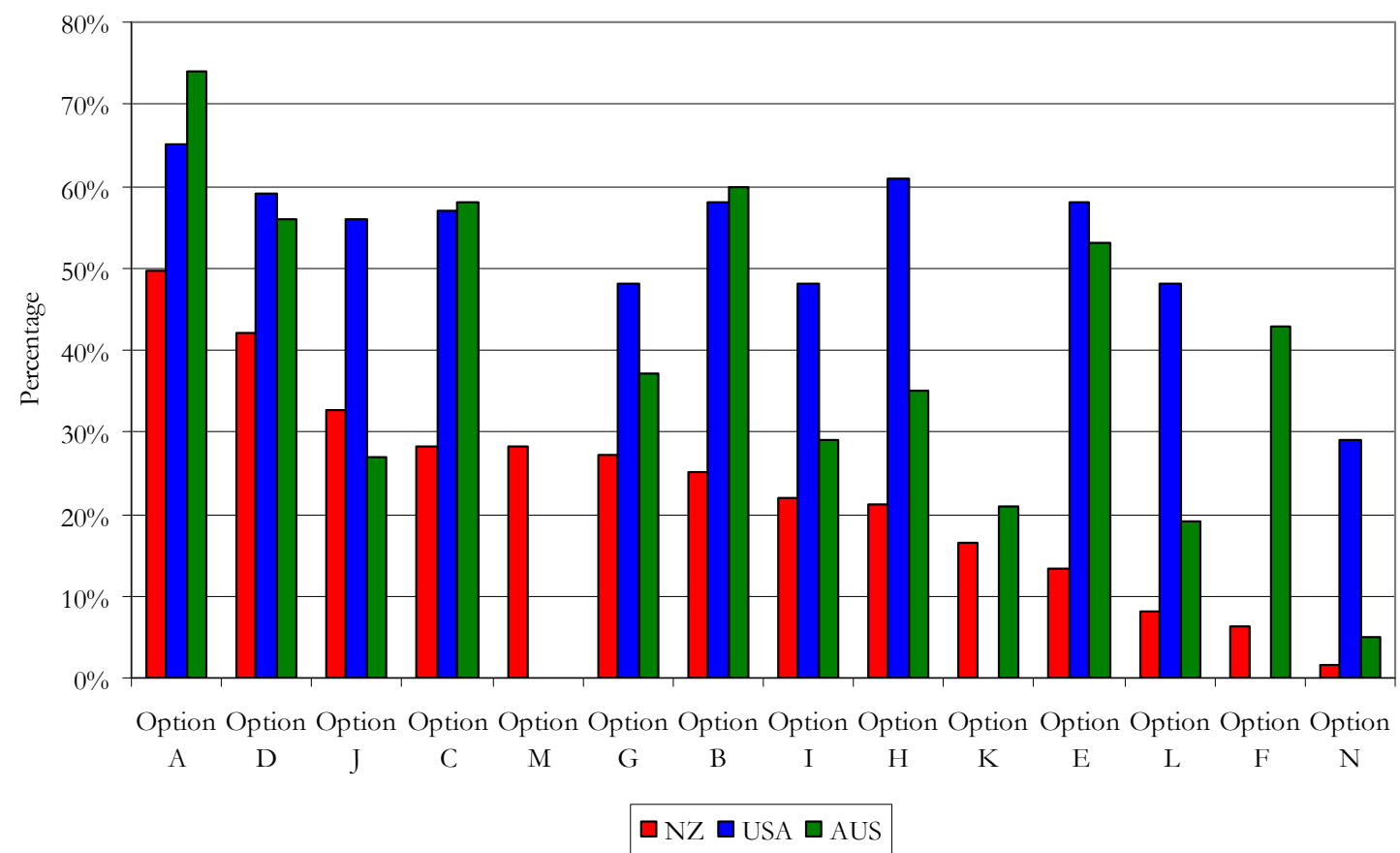

Figure D-4: Overall international comparison of drivers for sustainable building (in order from highest to lowest in New Zealand) 


\section{D.1.2.1 United States Results}

Table D-5: Definition of answer choices to drivers for sustainable building in the United States

\begin{tabular}{|l|l|}
\hline Option & Definition \\
\hline Option A & Energy costs increases and utility rebates \\
\hline Option B & Superior performance \\
\hline Option C & Client demand \\
\hline Option D & Simplified LEED documentation process \\
\hline Option E & Government regulations \\
\hline Option F & Lower life-cycle costs \\
\hline Option G & Environmental conditions with industry impact \\
\hline Option H & Emphasis on productivity \\
\hline Option I & Increased education \\
\hline Option J & Competitive advantage \\
\hline Option K & Disruptive/enabling technology \\
\hline
\end{tabular}

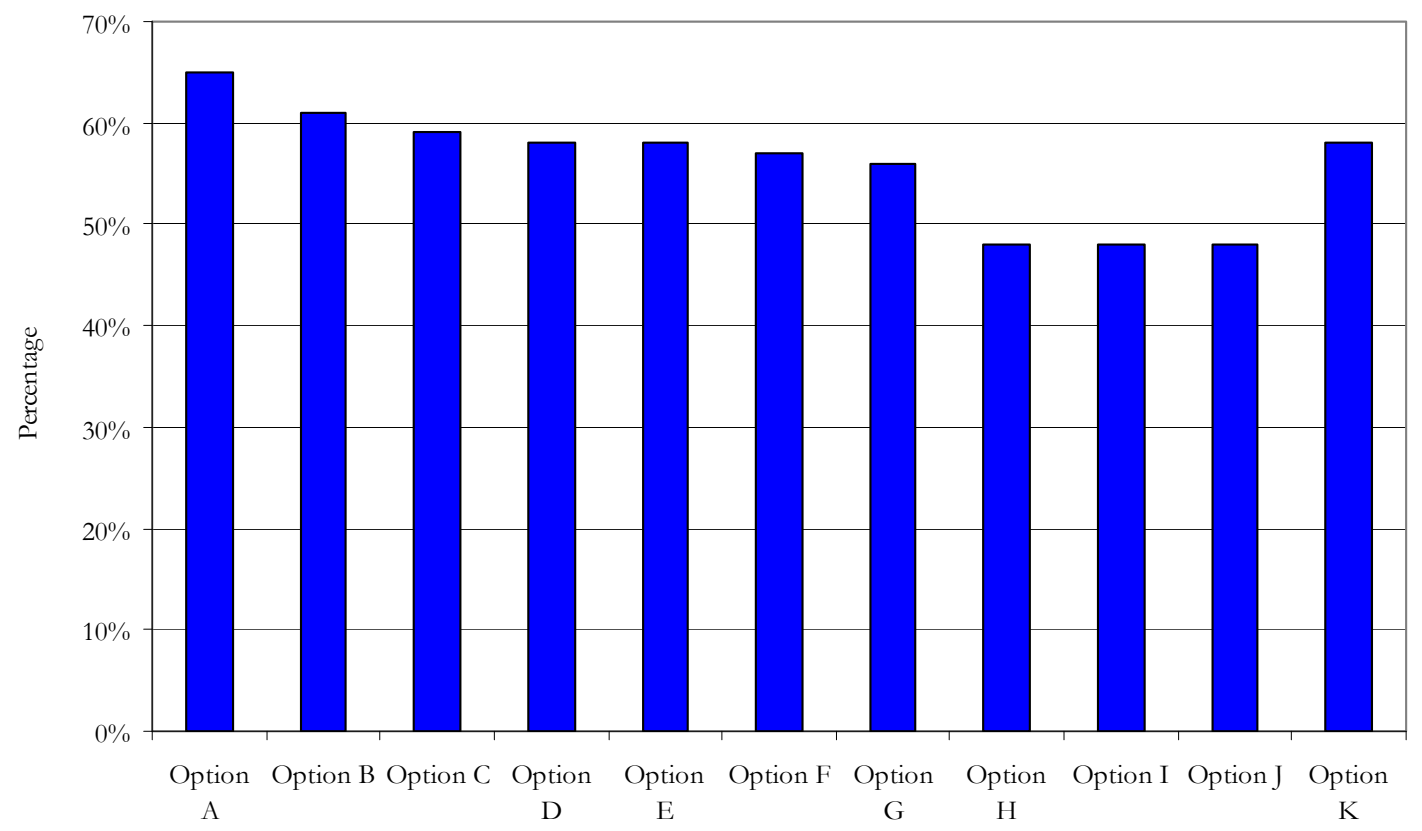

Figure D-5: Drivers for sustainable building in the United States 


\section{D.1.2.2 Australian Results}

Table D-6: Definition of answer choices to drivers for sustainable building in Australia

\begin{tabular}{|l|l|}
\hline Option & Definition \\
\hline Option A & Rising energy costs \\
\hline Option B & Government regulation \\
\hline Option C & Lower life-cycle costs \\
\hline Option D & Client demand \\
\hline Option E & Independent rating system \\
\hline Option F & Government rating systems \\
\hline Option G & Competitive advantage \\
\hline Option H & Superior performance \\
\hline Option I & Increased education \\
\hline Option J & Environmental conditions \\
\hline Option K & Attraction and retention of staff \\
\hline Option L & Increased emphasis on productivity \\
\hline Option N & Disruptive/enabling technology \\
\hline
\end{tabular}

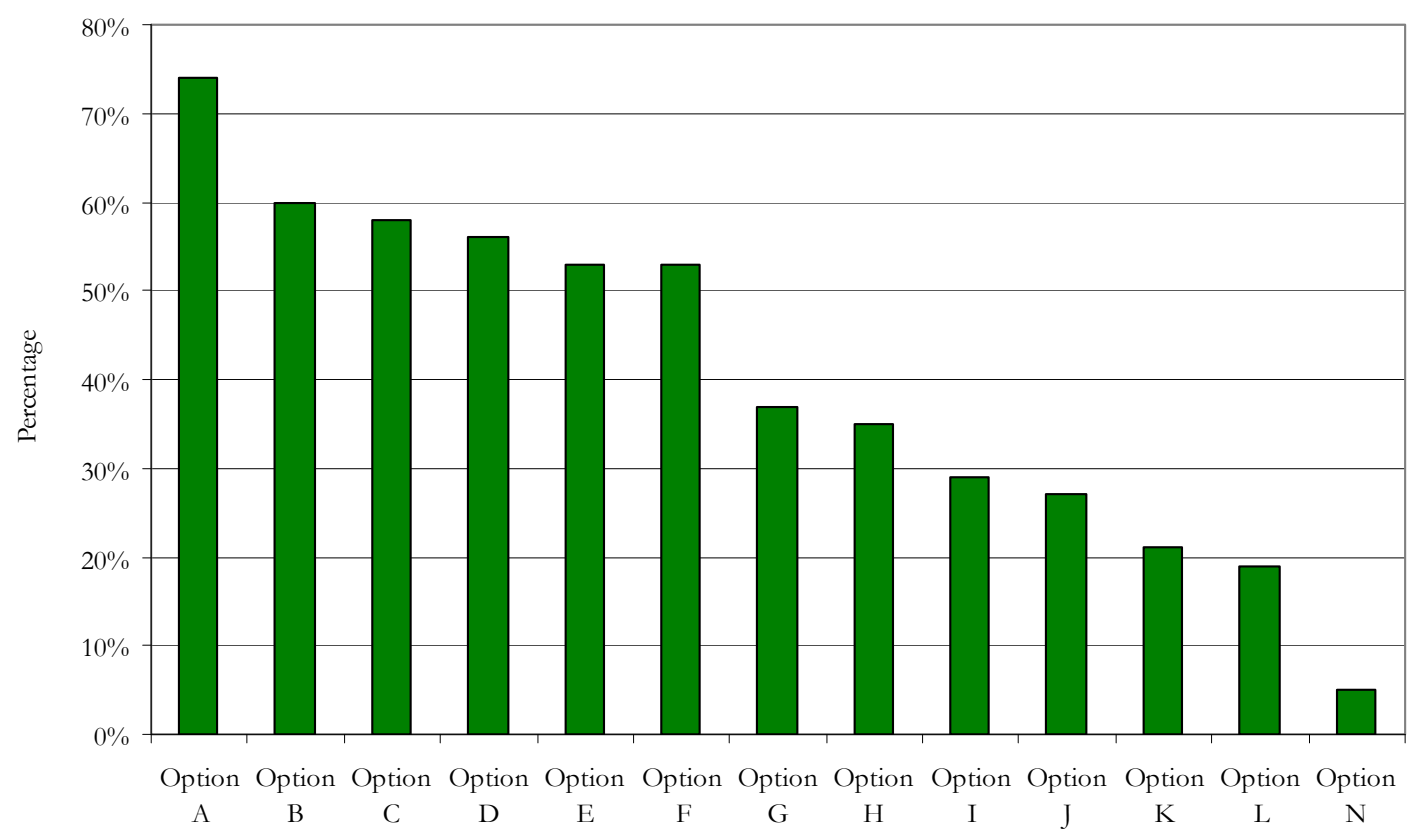

Figure D-6: Drivers for sustainable building in Australia 


\section{D.1.3 Obstacles for Sustainable Building}

Table D-7: Definition of answer choices to obstacles for sustainable building (in order in New Zealand survey)

\begin{tabular}{|l|l|}
\hline Option & Definition \\
\hline Option A & Perceived higher upfront costs \\
\hline Option B & Lack of education \\
\hline Option C & Lack of awareness \\
\hline Option D & No fiscal incentive \\
\hline Option E & Different accounting methods \\
\hline Option F & No coordination or consistency \\
\hline Option G & Politics \\
\hline Option H & Payback periods \\
\hline Option I & Education of non 'green' people \\
\hline
\end{tabular}

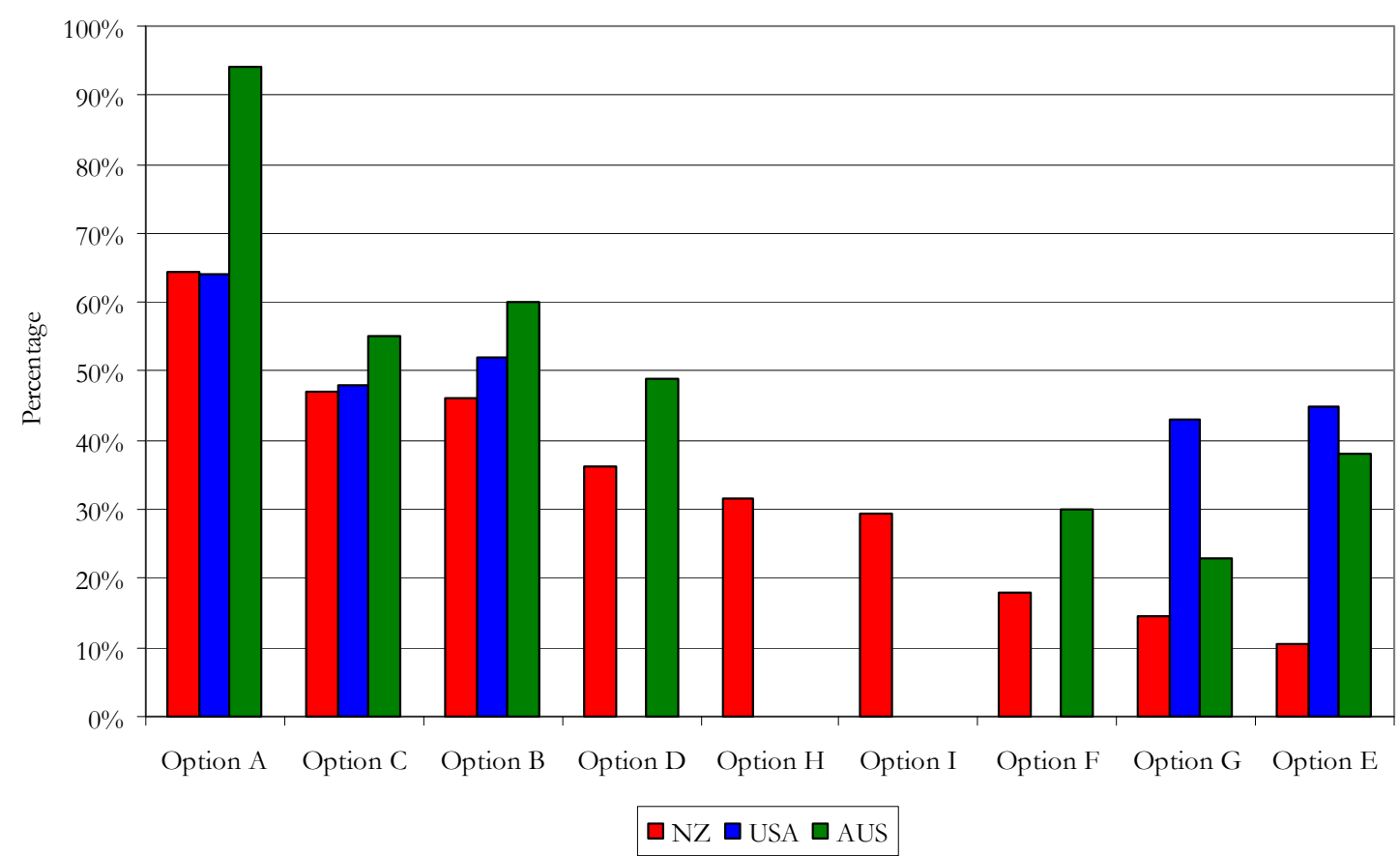

Figure D-7: Overall international comparison of obstacles for sustainable building (in order from highest to lowest in New Zealand) 


\section{D.1.3.1 United States Results}

Table D-8: Definition of answer choices to obstacles for sustainable building in the United States

\begin{tabular}{|l|l|}
\hline Option & Definition \\
\hline Option A & Higher first costs \\
\hline Option B & Lack of education \\
\hline Option C & Lack of awareness \\
\hline Option D & Different budget accounting \\
\hline Option E & Politics \\
\hline Option F & Green building perceived as a fad \\
\hline Option G & Greenwashing \\
\hline
\end{tabular}

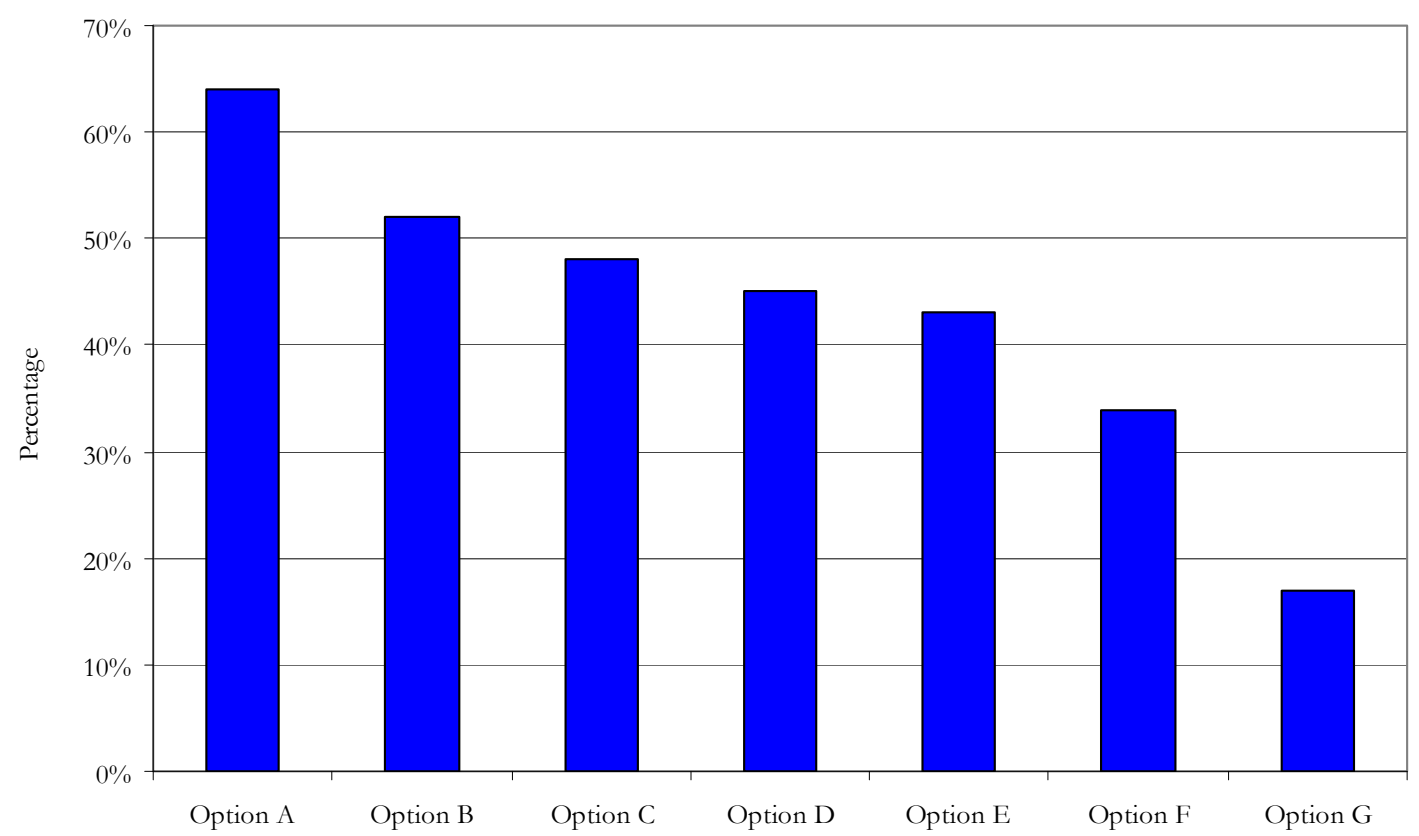

Figure D-8: Obstacles for sustainable building in the United States 


\section{D.1.3.2 Australian Results}

Table D-9: Definition of answer choices to obstacles for sustainable building in Australia

\begin{tabular}{|l|l|}
\hline Option & Definition \\
\hline Option A & Perceived higher upfront costs \\
\hline Option B & Lack of education \\
\hline Option C & Lack of awareness \\
\hline Option D & No fiscal incentive \\
\hline Option E & Different accounting methods \\
\hline Option F & No coordination or consistency \\
\hline Option G & Lack of research/case studies \\
\hline Option H & Unrecognised eco labelling \\
\hline Option I & Politics \\
\hline Option J & Green building is a fad \\
\hline
\end{tabular}

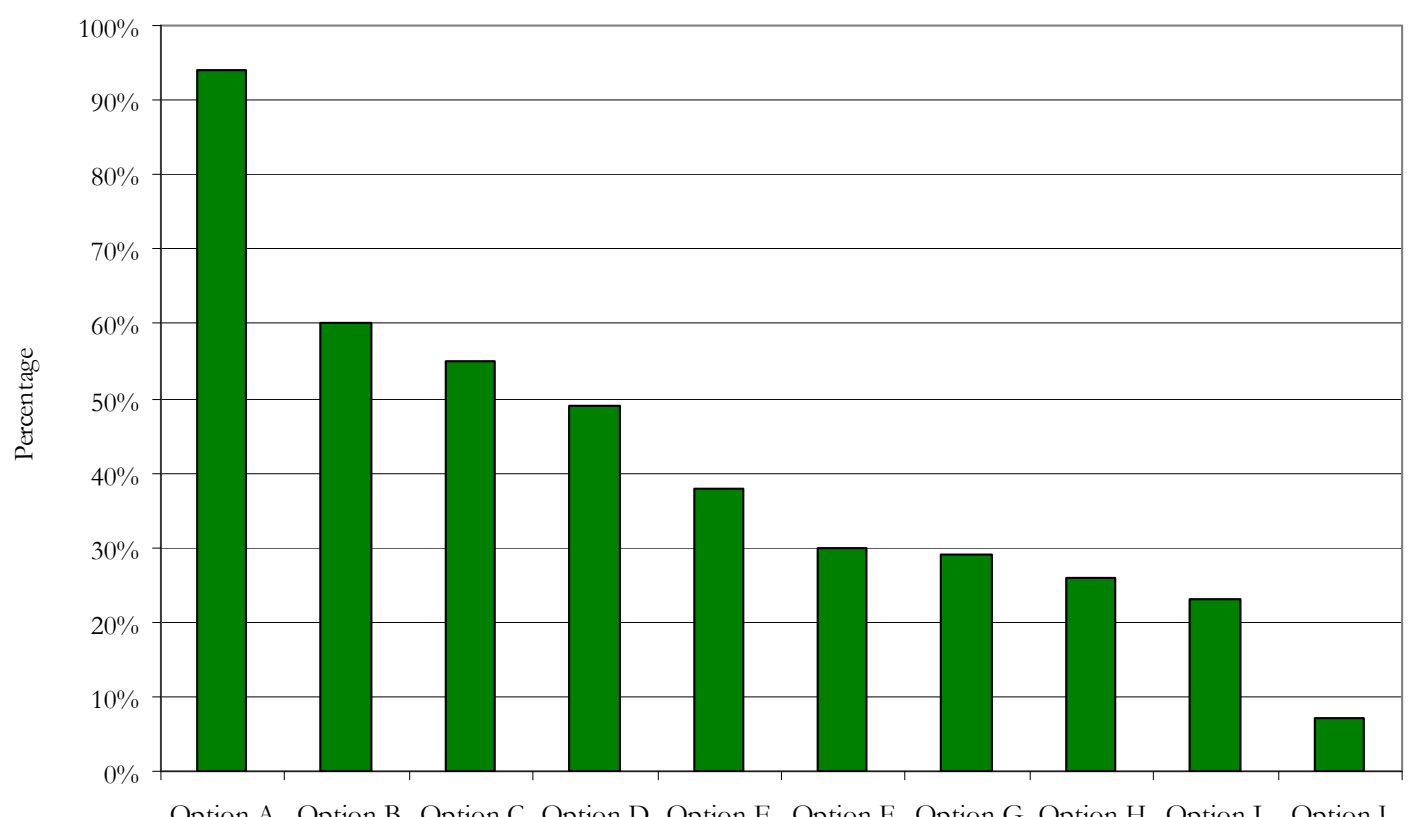

Figure D-9: Obstacles for sustainable building in Australia 


\section{D.1.4 Reasons for Involvement in Sustainable Building}

Table D-10: Definition of answer choices to reasons for involvement in sustainable building (in order asked in New Zealand survey)

\begin{tabular}{|l|l|}
\hline Option & Definition \\
\hline Option A & I am not involved \\
\hline Option B & Being part of an industry that values the environment \\
\hline Option C & Achieving lower life-cycle costs \\
\hline Option D & Contract requirement (e.g. Government tenders) \\
\hline Option E & Expanding my business with 'green' building clients \\
\hline Option F & Benefit from publicity \\
\hline Option G & Triple bottom line reporting \\
\hline Option H & Attraction and retention of talent \\
\hline Option I & Green product information \\
\hline Option J & Awards for green building \\
\hline Option K & Higher return on investment on resale \\
\hline
\end{tabular}

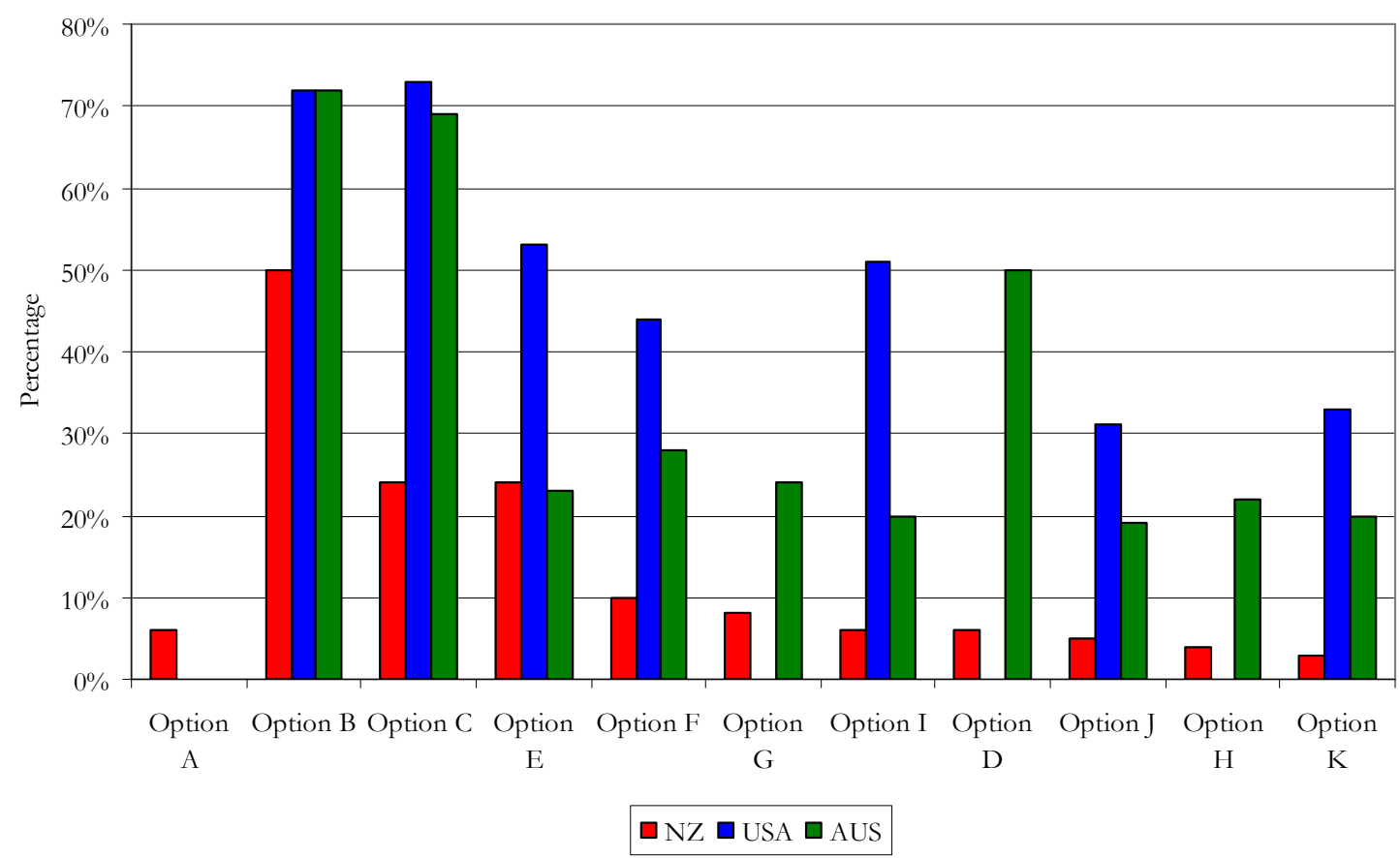

Figure D-10: Overall international comparison of reasons for involvement in sustainable building (in order from highest to lowest in New Zealand) 


\section{D.1.4.1 United States Results}

Table D-11: Definition of answer choices to reasons for involvement in sustainable building in the \begin{tabular}{|l|l|}
\hline Option & Definition \\
\hline Option A & Loweting life-
\end{tabular}

\begin{tabular}{l|l} 
Option A & Lowering life-cycle costs, such as energy efficiencies and productivity increases \\
\hline
\end{tabular}

Option B $\quad$ Being part of an industry that values the environment

\begin{tabular}{l|l}
\hline Option C & Expanding my business with 'green' building clients \\
\hline
\end{tabular}

$\begin{array}{ll}\text { Option D } & \text { Means for staying informed about LEED }\end{array}$

\begin{tabular}{|l|l}
\hline Option E & Green product information \\
\hline
\end{tabular}

\begin{tabular}{|l|l|}
\hline Option F & Benefit from publicity \\
\hline
\end{tabular}

\begin{tabular}{ll} 
Option G & Higher return on investment on resale \\
\hline
\end{tabular}

\begin{tabular}{|l|l|}
\hline Option $\mathrm{H}$ & Awards for green building \\
\hline
\end{tabular}

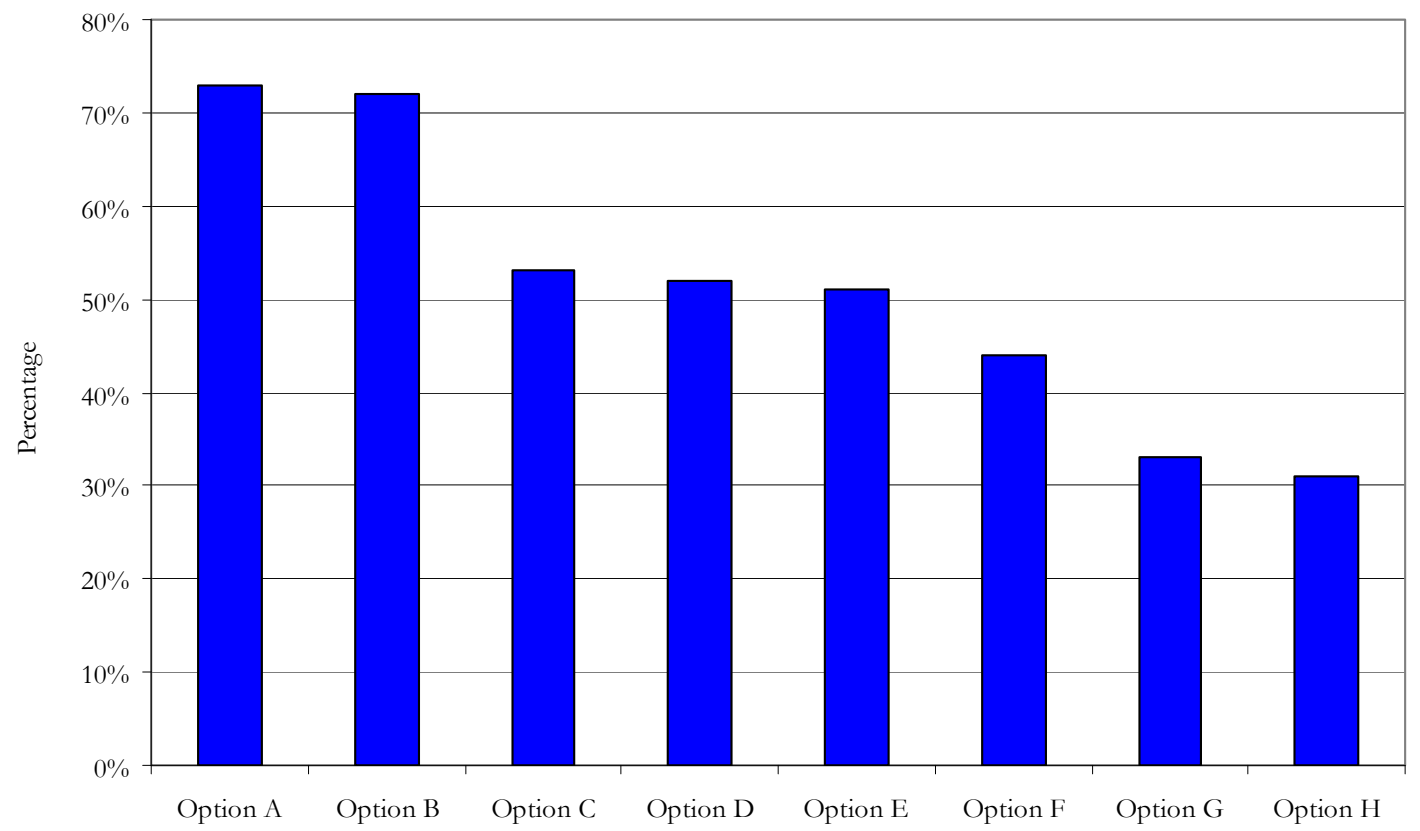

Figure D-11: Reasons for involvement in sustainable building in the United States 


\section{D.1.4.2 Australian Results}

Table D-12: Definition of answer choices to reasons for involvement in sustainable building in

\begin{tabular}{|l|l|}
\hline Option & Definition \\
\hline Option A & Being part of an industry that values the environment \\
\hline Option B & Achieving lower life-cycle costs \\
\hline Option C & Contract requirement (e.g. Government tenders) \\
\hline Option D & Expanding my business with 'green' building clients \\
\hline Option E & Benefit from publicity \\
\hline Option F & Triple bottom line reporting \\
\hline Option G & Attraction an retention of talent \\
\hline Option H & Green product information \\
\hline Option I & Awards for green building \\
\hline Option J & Higher return on investment on resale \\
\hline
\end{tabular}

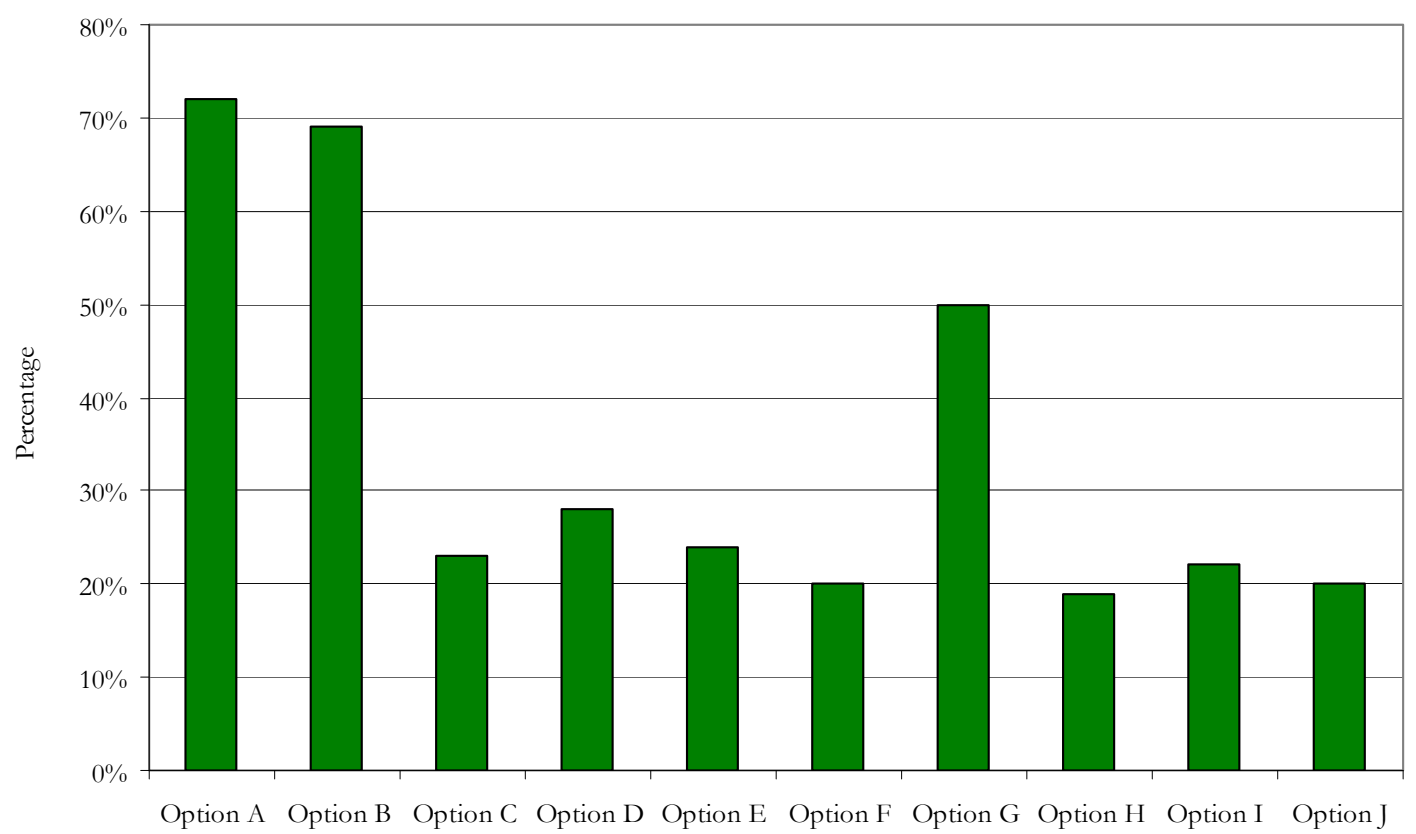

Figure D-12: Reasons for involvement in sustainable building in Australia 


\section{D.1.5 Economic Reasons for Sustainable Building}

Table D-13: Definition of answer choices to economic reasons/benefits for sustainable building (in order asked in New Zealand survey)

\begin{tabular}{|l|l|}
\hline Option & Definition \\
\hline Option A & Lower operating costs \\
\hline Option B & Lower lifetime costs \\
\hline Option C & Higher building value \\
\hline Option D & Enhanced marketability \\
\hline Option E & Helping to transform the market \\
\hline Option F & Increase staff productivity and retention \\
\hline Option G & Higher return on investment \\
\hline Option H & Reduced liability and risk \\
\hline
\end{tabular}

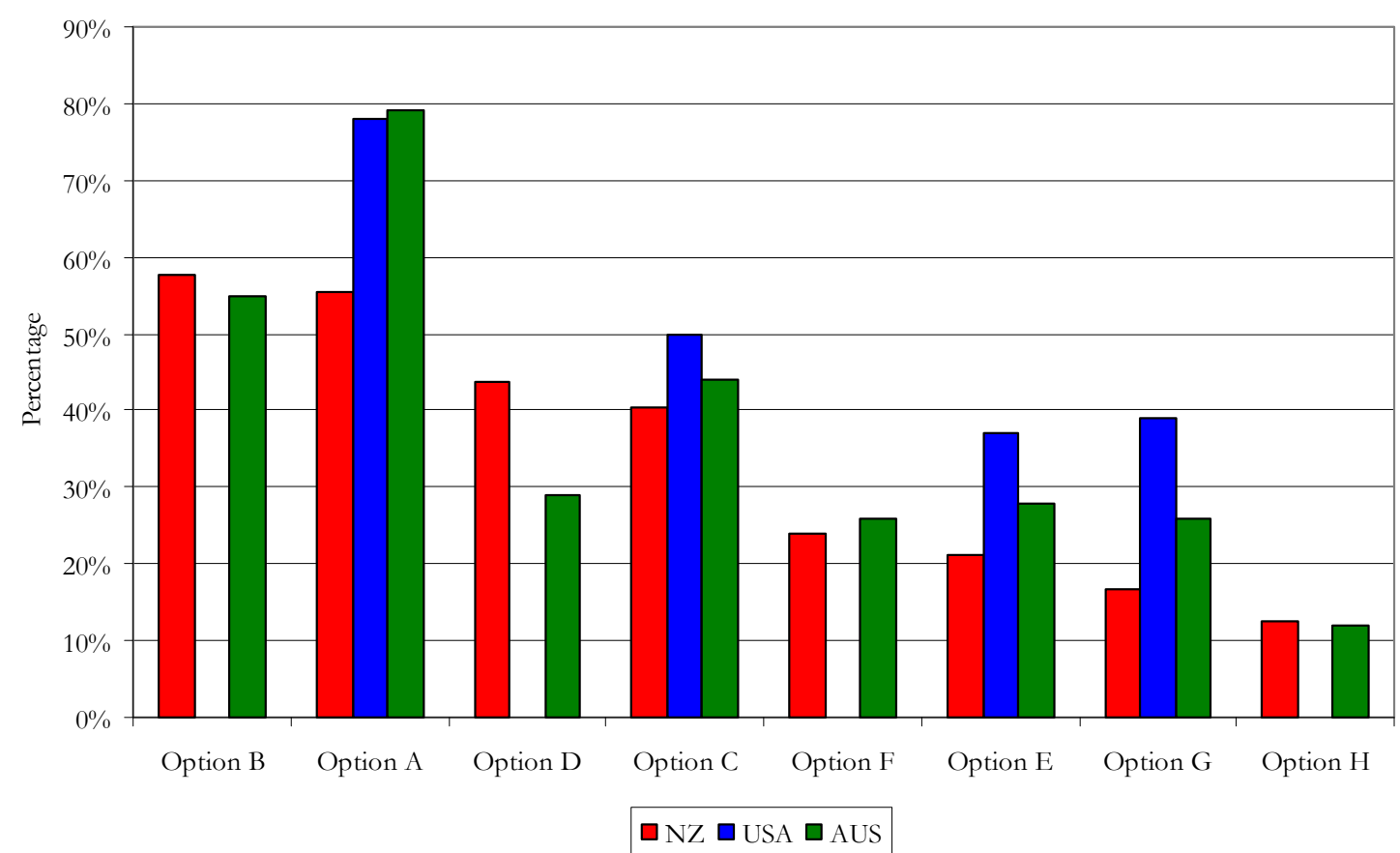

Figure D-13: Overall international comparison of the economic reasons/benefits of sustainable building (in order from highest to lowest in New Zealand) 


\section{D.1.5.1 United States Results}

Table D-14: Definition of answer choices to economic reasons/benefits for sustainable building in the United States

\begin{tabular}{|l|l|}
\hline Option & Definition \\
\hline Option A & Lower operating costs \\
\hline Option B & Higher building value \\
\hline Option C & 10-year costs better \\
\hline Option D & Higher return on investment \\
\hline Option E & Helping to transform the market \\
\hline Option F & Occupancy rates \\
\hline Option G & Improve rents \\
\hline
\end{tabular}

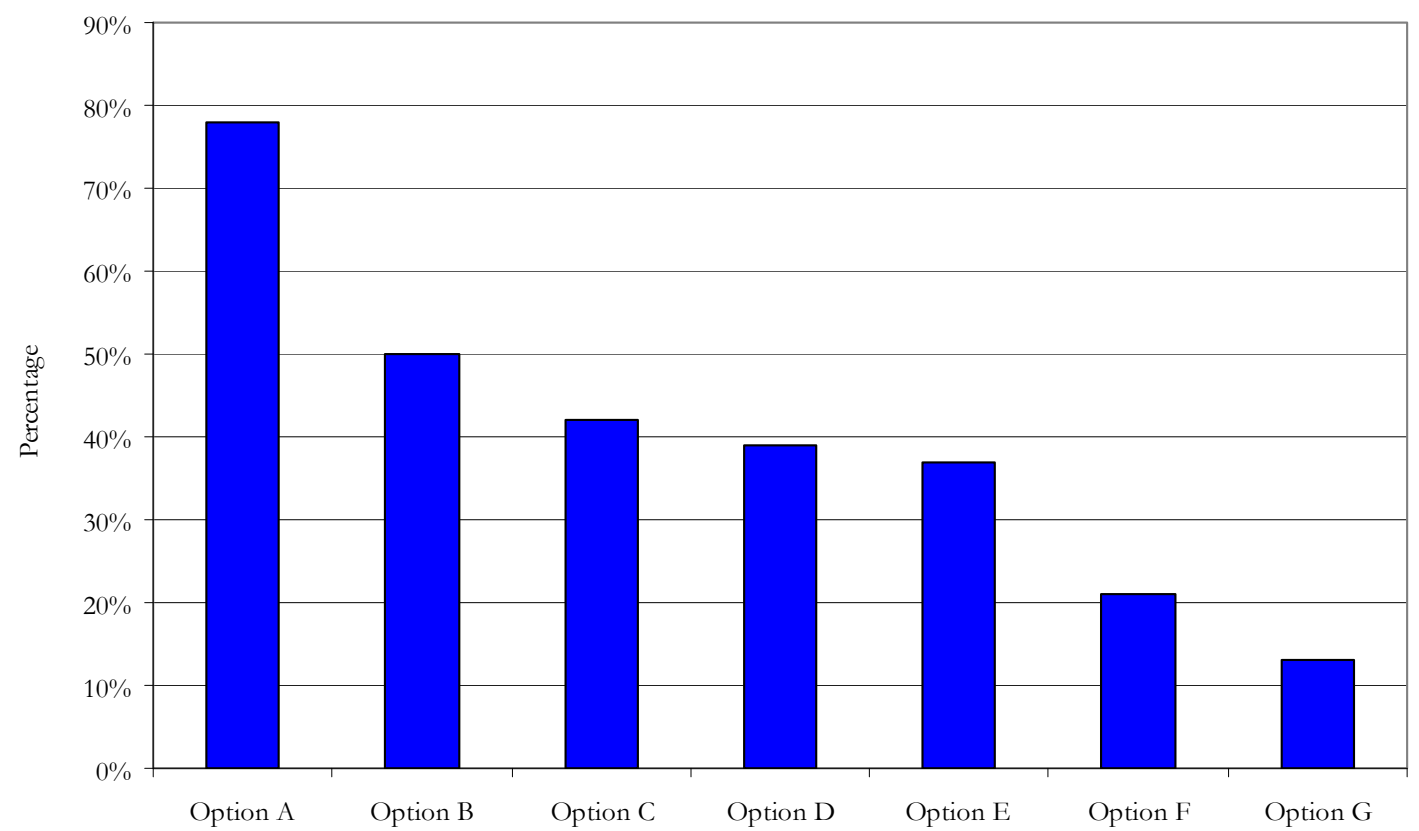

Figure D-14: Economic reasons/benefits for sustainable building in the United States 


\section{D.1.5.2 Australian Results}

Table D-15: Definition of answer choices to economic reasons/benefits for sustainable building in Australia

\begin{tabular}{|l|l|}
\hline Option & Definition \\
\hline Option A & Lower operating costs \\
\hline Option B & Lower lifetime costs \\
\hline Option C & Higher building value \\
\hline Option D & Enhanced marketability \\
\hline Option E & Helping to transform the market \\
\hline Option F & Increase staff productivity and retention \\
\hline Option G & Higher return on investment \\
\hline Option H & Reduced liability and risk \\
\hline
\end{tabular}

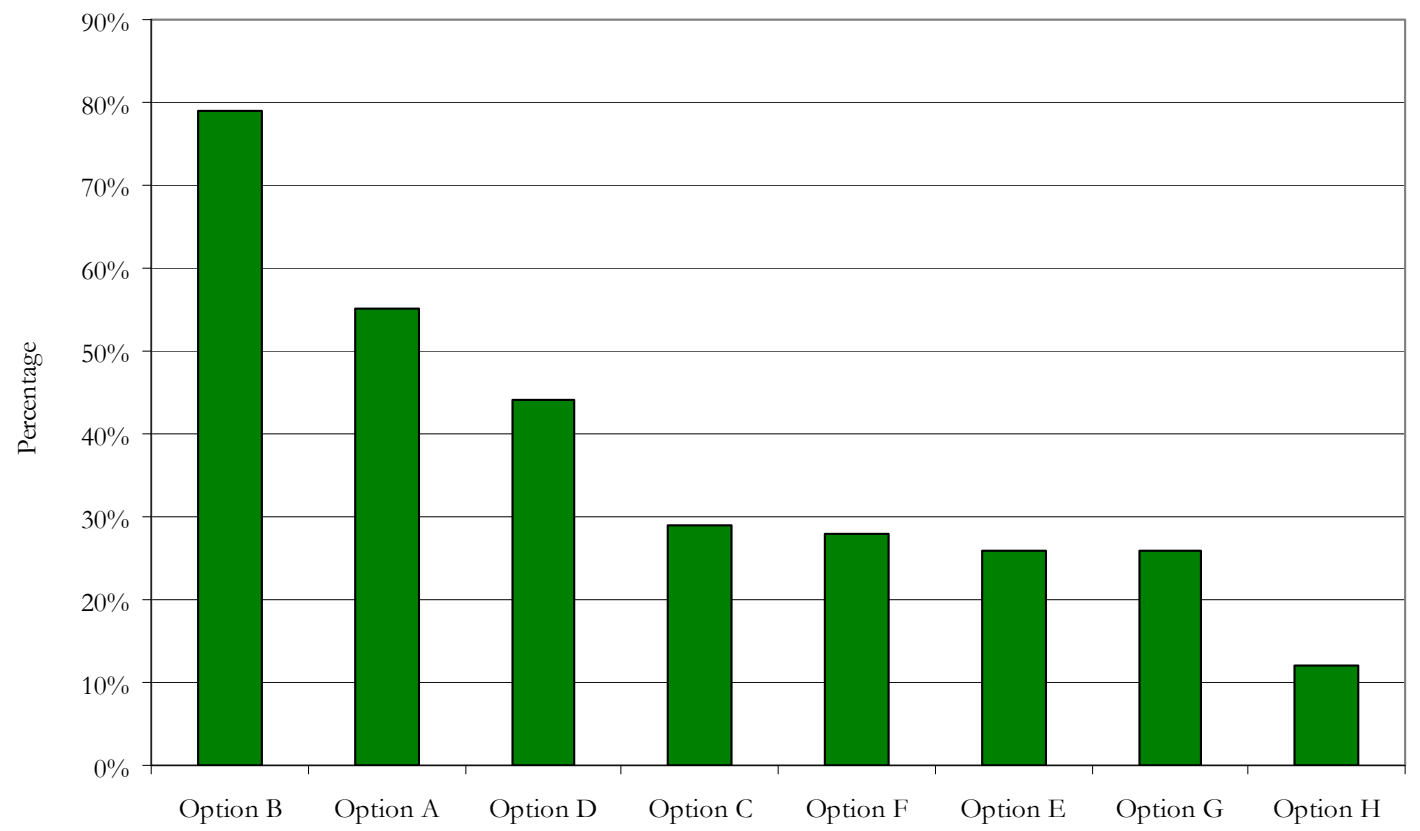

Figure D-15: Economic reasons/benefits for sustainable building in Australia 


\section{D.1.6 Environmental Reasons for Sustainable Building}

Table D-16: Definition of answer choices to environmental reasons/benefits for sustainable buildings (in order asked in New Zealand survey)

\begin{tabular}{|l|l|}
\hline Option & Definition \\
\hline Option A & Protection of the environment \\
\hline Option B & Reducing climate change and emissions \\
\hline Option C & Minimising ecological impact of buildings \\
\hline Option D & Scarcity of natural resources \\
\hline Option E & Improving indoor environment quality \\
\hline Option F & Waste reduction \\
\hline
\end{tabular}

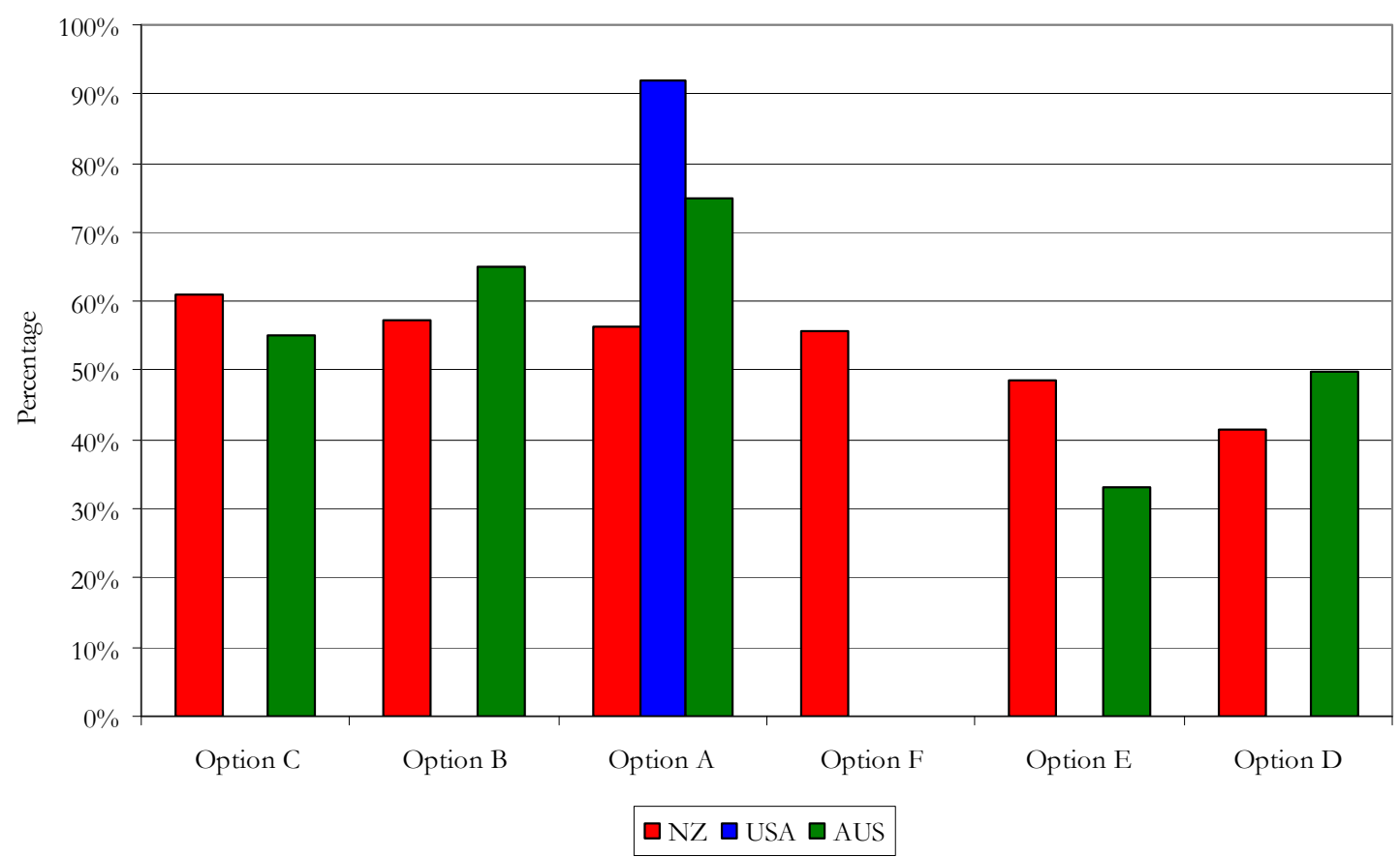

Figure D-16: Overall international comparison of the environmental reasons/benefits of sustainable building (in order from highest to lowest in New Zealand) 


\section{D.1.6.1 United States Results}

Table D-17: Definition of answer choices to environmental reasons/benefits for sustainable buildings in the United States

\begin{tabular}{|l|l|}
\hline Option & Definition \\
\hline Option A & Energy costs \\
\hline Option B & Value the environment \\
\hline Option C & Support LEED \\
\hline Option D & Moral imperative of being green \\
\hline
\end{tabular}

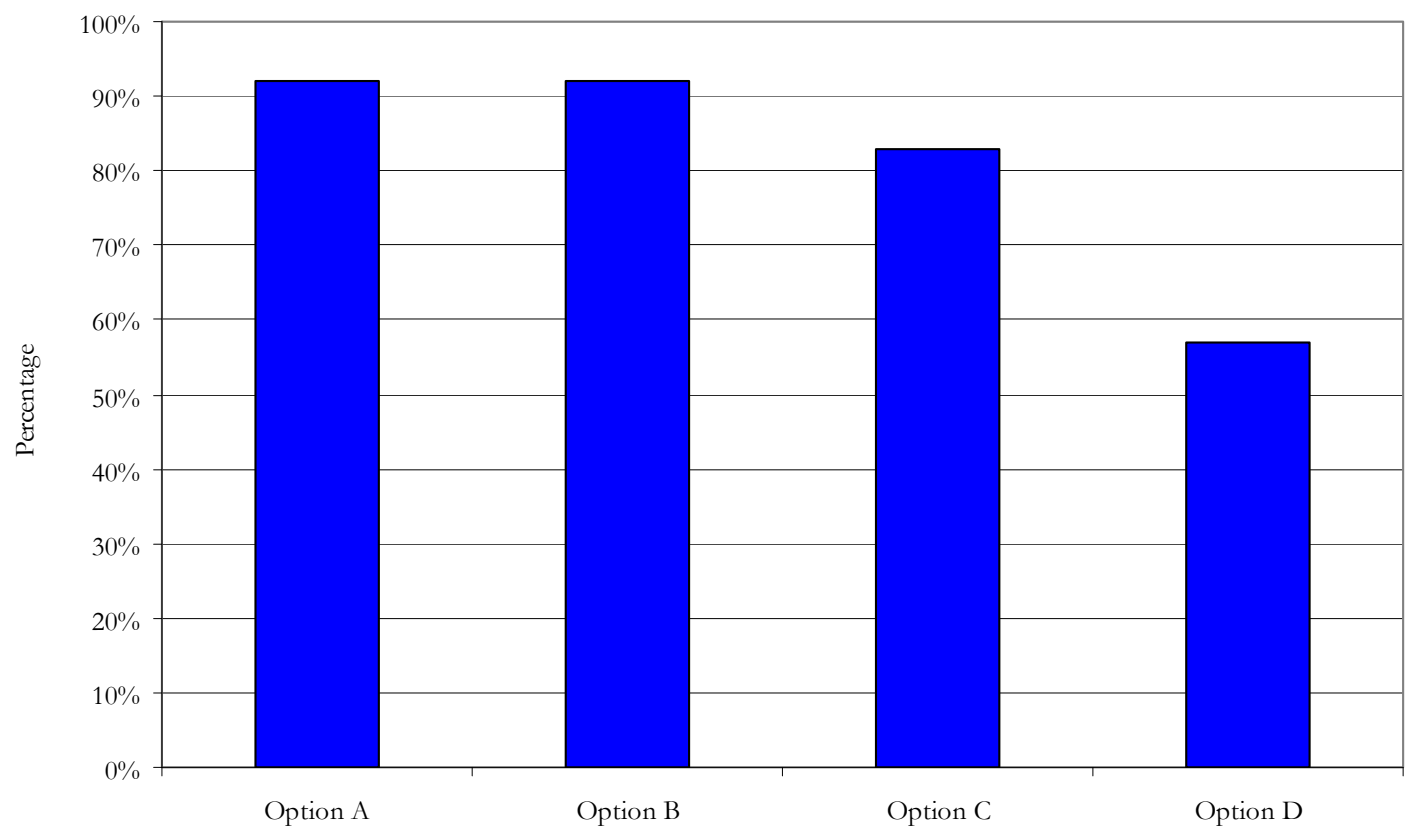

Figure D-17: Environmental reasons/benefits for sustainable buildings in the United States 


\section{D.1.6.2 Australian Results}

Table D-18: Definition of answer choices to environmental reasons/benefits for sustainable buildings in Australia

\begin{tabular}{|l|l|}
\hline Option & Definition \\
\hline Option A & Protection of the environment \\
\hline Option B & Reducing climate change and emissions \\
\hline Option C & Minimising ecological impact of buildings \\
\hline Option D & Scarcity of natural resources \\
\hline Option E & Improving indoor environment quality \\
\hline Option F & Moral imperative of being 'green' \\
\hline
\end{tabular}

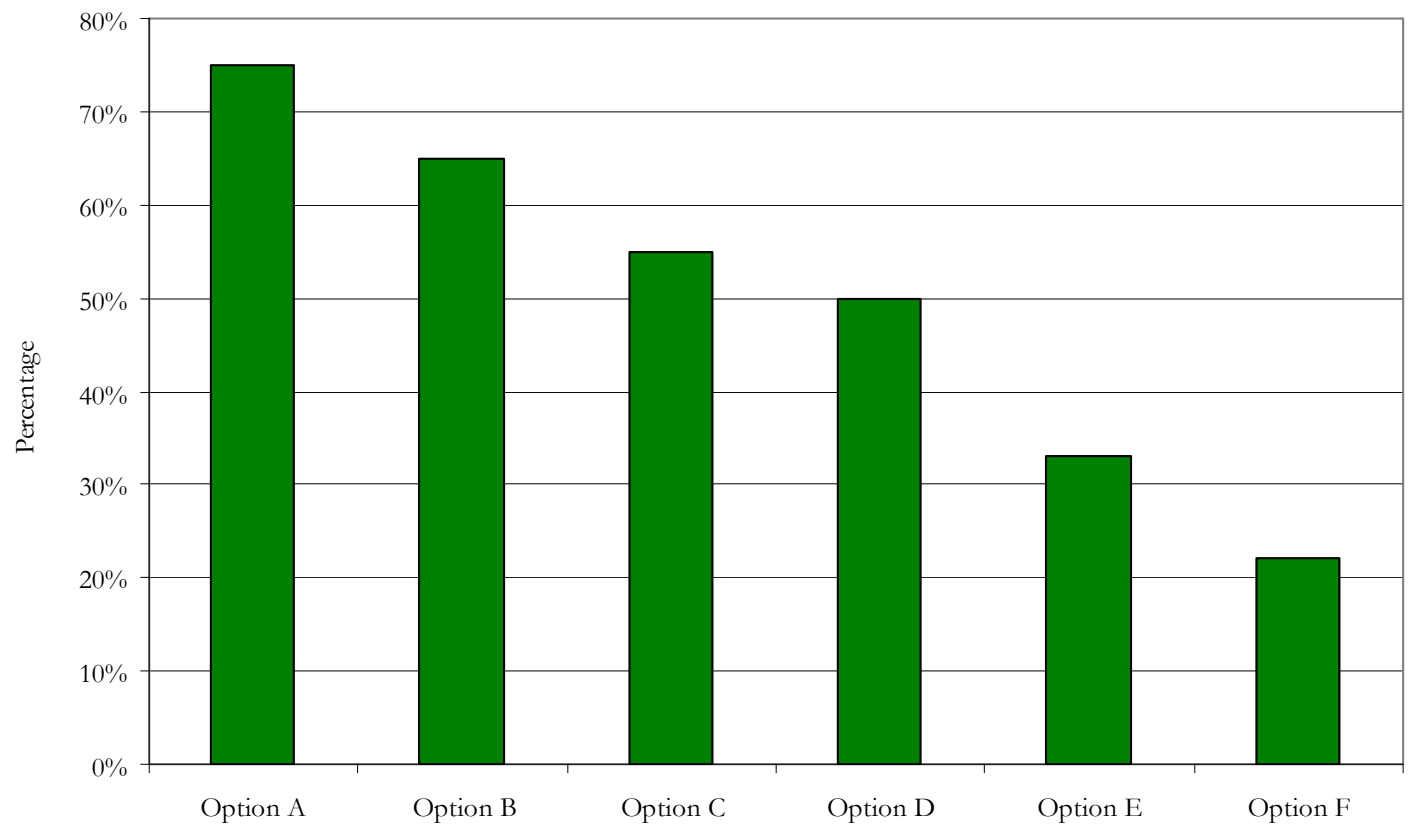

Figure D-18: Environmental reasons/benefits for sustainable buildings in Australia 


\section{D.1.7 Social Reasons for Sustainable Building}

Table D-19: Definition of answer choices to social reasons/benefits for sustainable buildings (in order asked in New Zealand survey)

\begin{tabular}{|l|l|}
\hline Option & Definition \\
\hline Option A & Greater health and well-being \\
\hline Option B & Improved learning and healing environments \\
\hline Option C & Tenant productivity \\
\hline Option D & Support for applicable economy (NZ, USA, AUS) \\
\hline Option E & Moral imperative of being 'green' \\
\hline Option F & Aesthetically pleasing \\
\hline
\end{tabular}

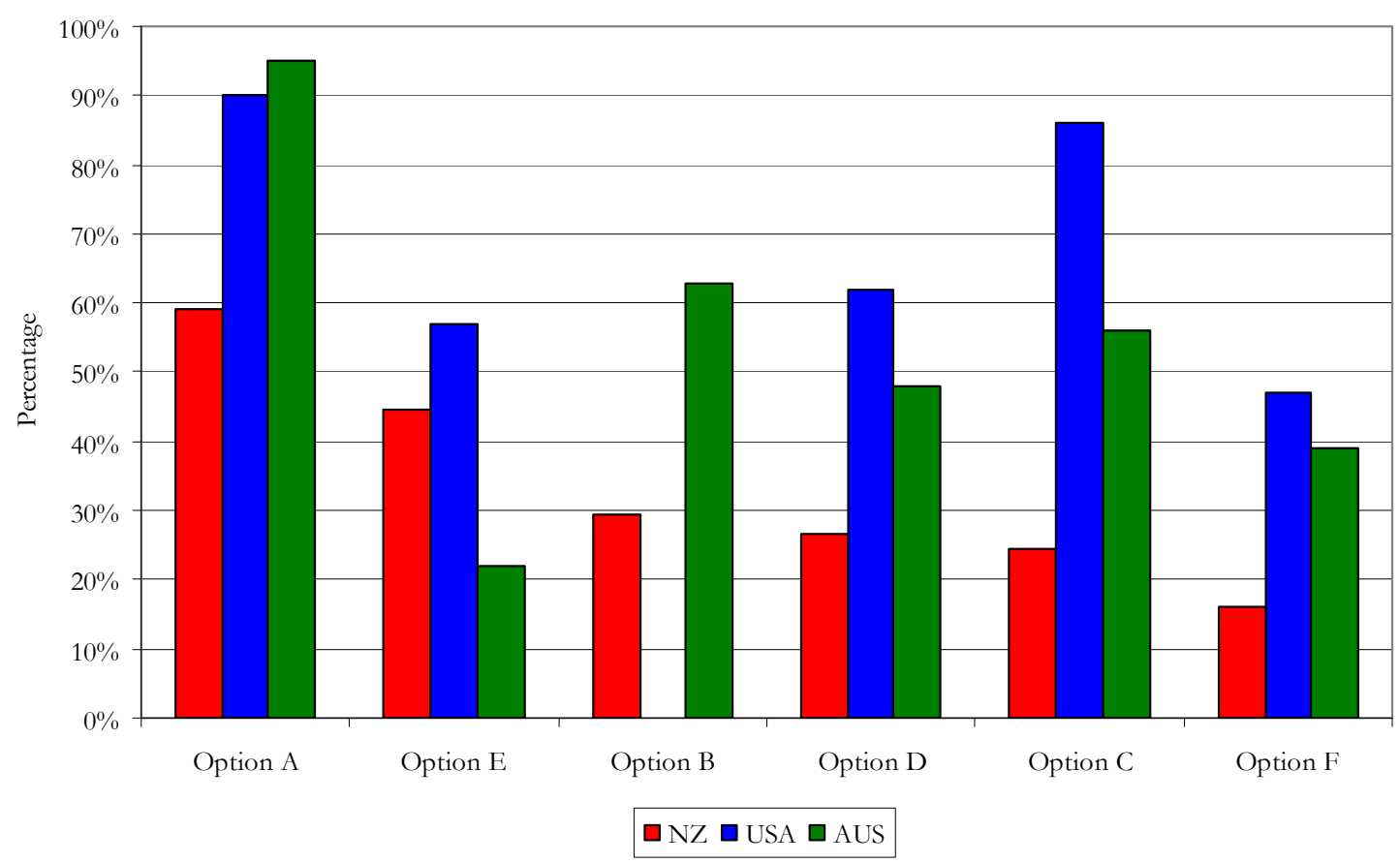

Figure D-19: Overall international comparison of the social reasons/benefits for sustainable building (in order from highest to lowest in New Zealand) 


\section{D.1.7.1 United States Results}

Table D-20: Definition of answer choices to social reasons/benefits for sustainable buildings in the United States

\begin{tabular}{|l|l|}
\hline Option & Definition \\
\hline Option A & Greater health and well-being \\
\hline Option B & Worker productivity \\
\hline Option C & Support the domestic US economy \\
\hline Option D & Aesthetically pleasing \\
\hline
\end{tabular}

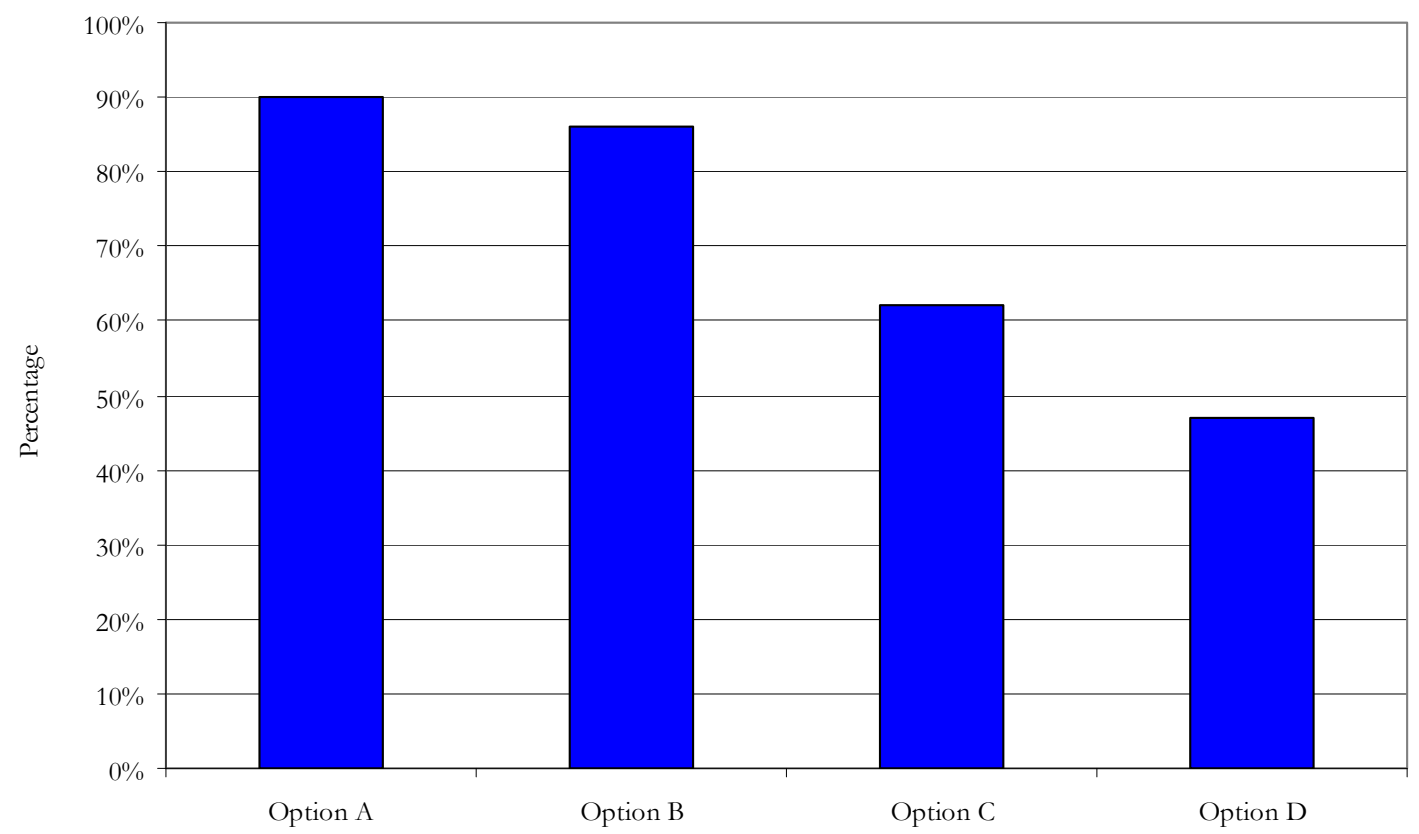

Figure D-20: social reasons/benefits for sustainable buildings in the United States 


\section{D.1.7.2 Australian Results}

Table D-21: Definition of answer choices to social reasons/benefits for sustainable buildings in Australia

\begin{tabular}{|l|l|}
\hline Option & Definition \\
\hline Option A & Greater health and well-being \\
\hline Option B & Improved learning and healing environments \\
\hline Option C & Tenant productivity \\
\hline Option D & Support for Australian economy \\
\hline Option E & Aesthetically pleasing \\
\hline
\end{tabular}

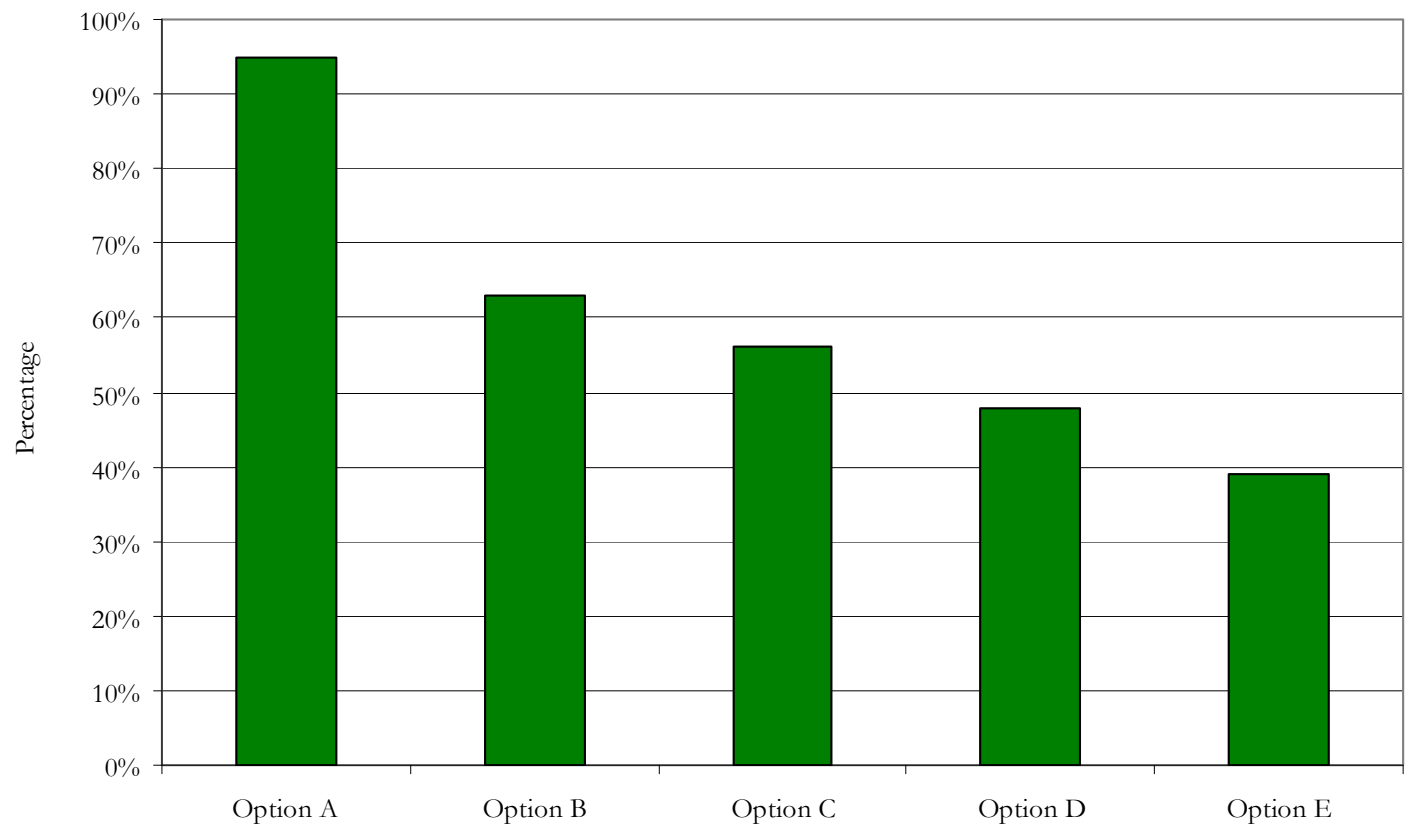

Figure D-21: Social reasons/benefits for sustainable buildings in Australia 


\section{D.1.8 Sustainable Building Information}

Table D-22: Definition of answer choices to information requirements regarding sustainable buildings (in order asked in New Zealand survey)

\begin{tabular}{|l|l|}
\hline Option & Definition \\
\hline Option A & Green products \\
\hline Option B & Environmental and economic cost benefit case studies \\
\hline Option C & Green building emerging trends \\
\hline Option D & Green projects \\
\hline Option E & How-to design a 'green' building \\
\hline Option F & Reviews and profiles of applicable BSRT buildings \\
\hline Option G & Engineering or scientific information \\
\hline Option H & How-to market a 'green' building \\
\hline Option I & Applicable BSRT accreditation course \\
\hline Option J & How-to manage a 'green' building \\
\hline Option K & 'Green' players (services guide) \\
\hline Option L & Applicable BSRT players \\
\hline Option M & Business management information \\
\hline Option N & Curriculum for senior executives \\
\hline Option O & Curriculum for line staff \\
\hline
\end{tabular}

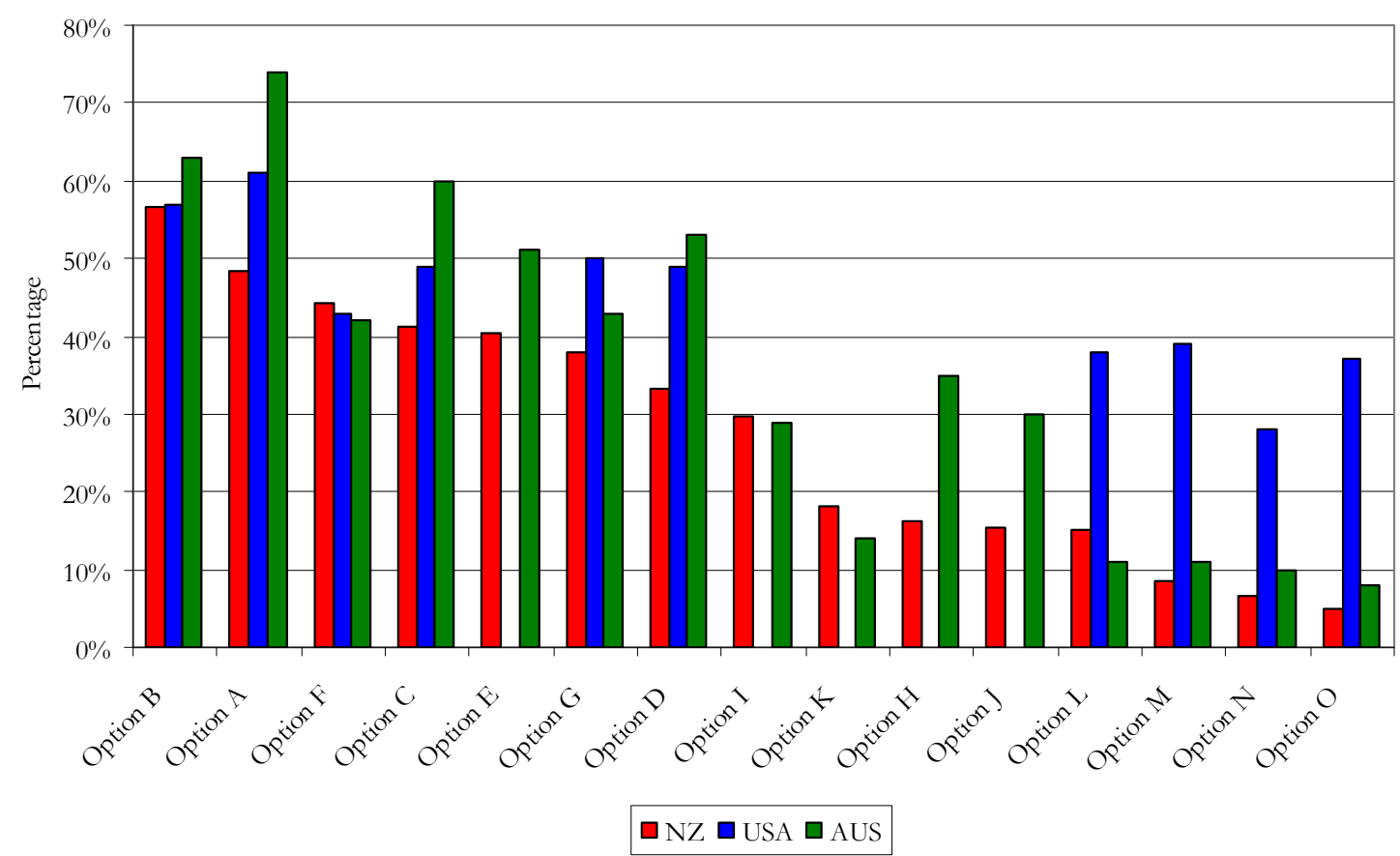

Figure D-22: Overall international comparison of information requirements regarding sustainable building (in order from highest to lowest in New Zealand) 


\section{D.1.8.1 United States Results}

Table D-23: Definition of answer choices to information requirements regarding sustainable buildings in the United States

\begin{tabular}{|l|l|}
\hline Option & Definition \\
\hline Option A & Green products \\
\hline Option B & Environmental and economic information \\
\hline Option C & Engineering or scientific information \\
\hline Option D & Green building emerging trends \\
\hline Option E & Green projects \\
\hline Option F & LEED process details \\
\hline Option G & Reviews and showcasing of LEED buildings \\
\hline Option H & Business management information \\
\hline Option I & LEED players \\
\hline Option J & Green players \\
\hline Option K & Curriculum for senior executives \\
\hline Option L & Curriculum for line staff \\
\hline
\end{tabular}

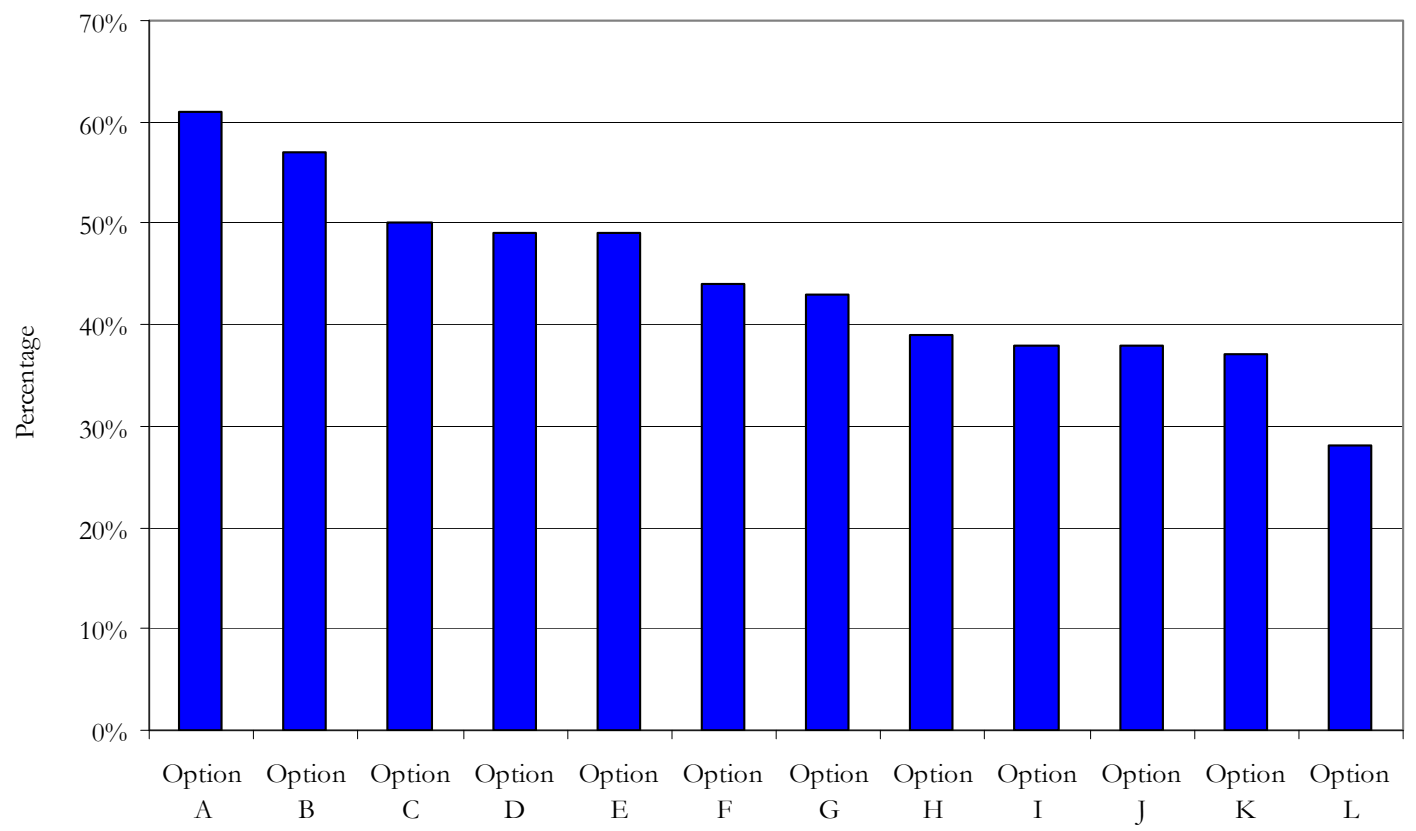

Figure D-23: Information requirements regarding sustainable buildings in the United States 


\section{D.1.8.2 Australian Results}

Table D-24: Definition of answer choices to information requirements regarding sustainable buildings in Australia

\begin{tabular}{|l|l|}
\hline Option & Definition \\
\hline Option A & Green products \\
\hline Option B & Environment and economics \\
\hline Option C & Green building emerging trends \\
\hline Option D & Green projects \\
\hline Option E & How to design a green building \\
\hline Option F & Reviews and profiles of Green Star buildings \\
\hline Option G & Engineering or scientific information \\
\hline Option H & How to market a green building \\
\hline Option I & How to manage a green building \\
\hline Option J & Green Star accreditation course \\
\hline Option K & Green players \\
\hline Option L & Green Star players \\
\hline Option M & Business management information \\
\hline Option N & Curriculum for senior executives \\
\hline Option O & Curriculum for line staff \\
\hline
\end{tabular}

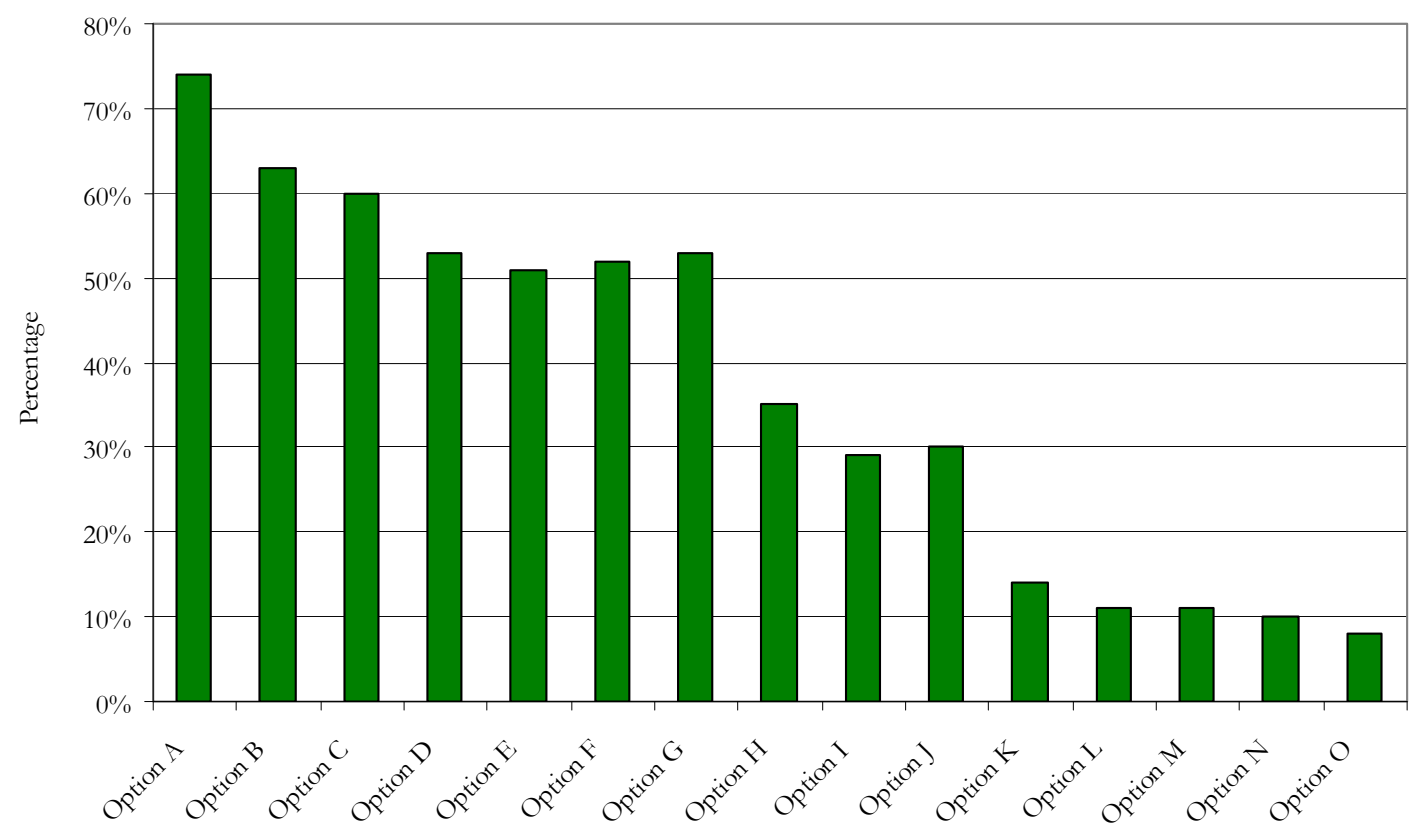

Figure D-24: Information requirements regarding sustainable buildings in Australia 